\title{
Sam $\mathfrak{m} \mathfrak{4} \mathfrak{n g}$

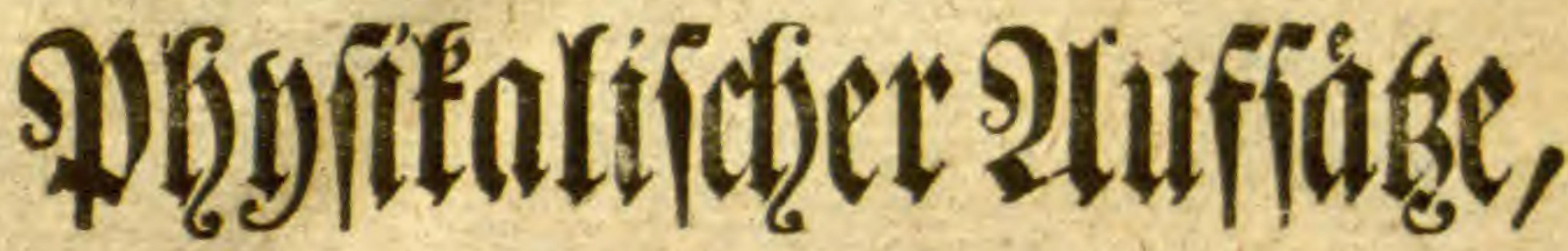 befonders
}

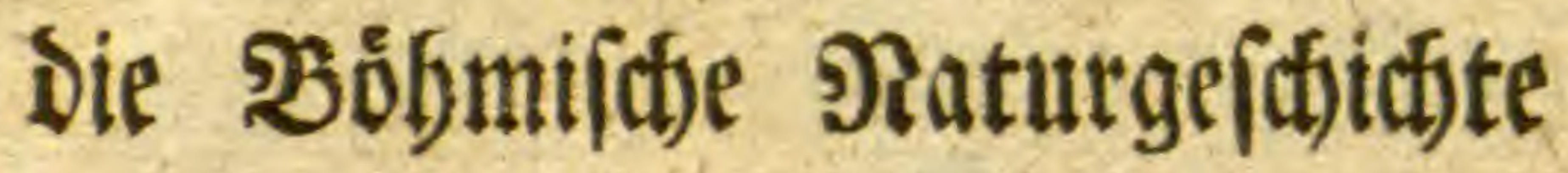

betreffent,

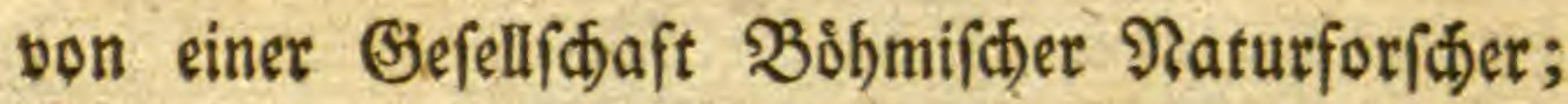

berauzgegeben bon

\section{Dr. Johann Mayer,}

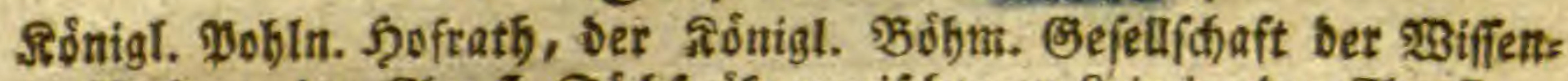

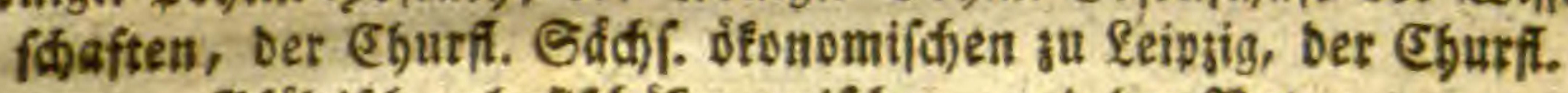

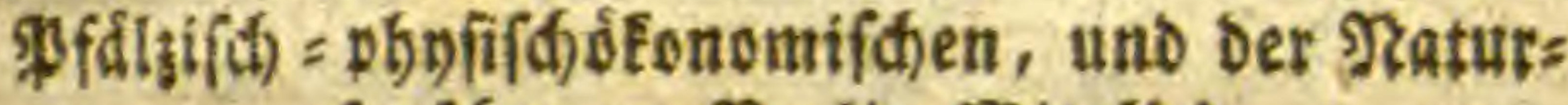

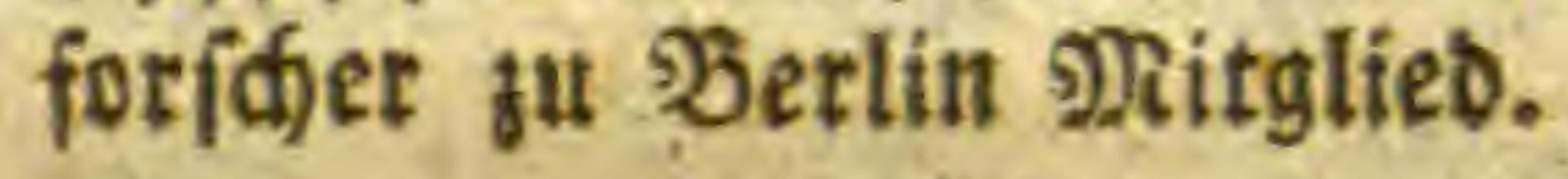

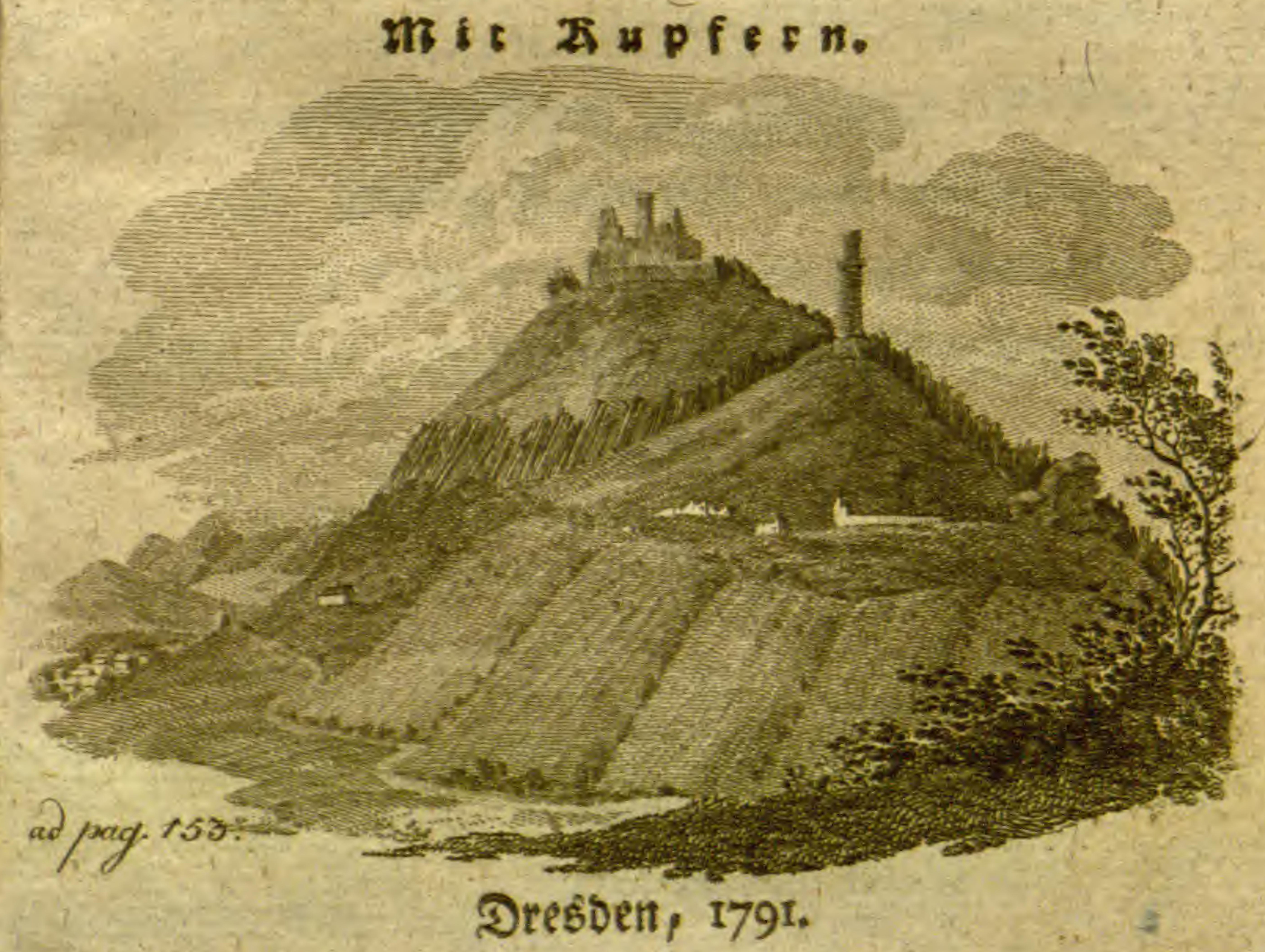

In ber 23 altherifhen Şofbudgganblung. 
Deg Serauggebers.

Gen Die 2 (bfiditen uno Der alwect, weldje Die ebemaligen গnitglieber ber Sóbmifhen gelebr:

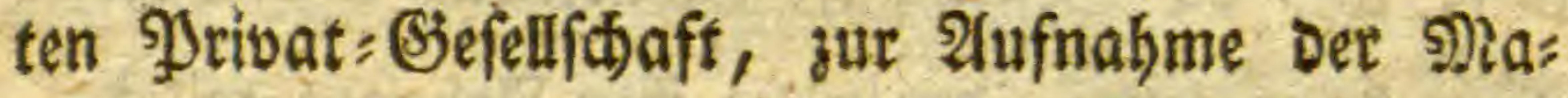

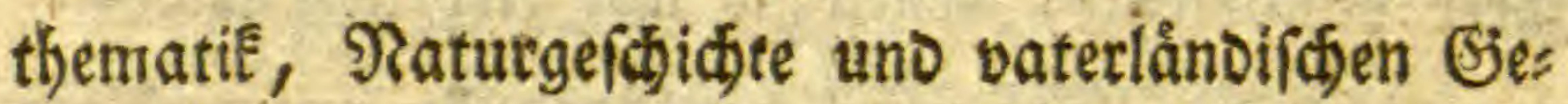

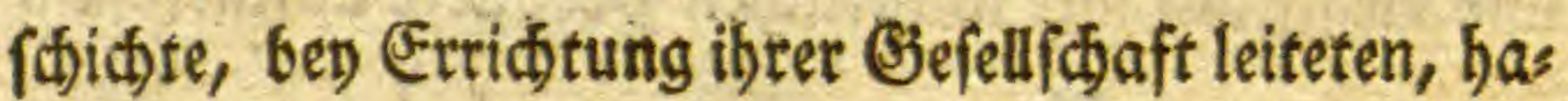

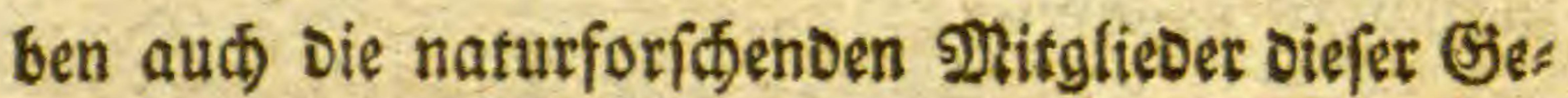
fellf(b)aft unter fin vereiniget.

Bòbmen, Oas in Der Bahl feiner naturlicten Эrooufte io unermeflic) als mannichfaltig ift, bes Darf nod) einer langen Эeíhe bon Sabren, uno Die Mitwirtung einer grògern $\mathfrak{A n}_{3} a b l$ von Naturfor: fatern, um fie nur grógtentbeils aufzufudien uno 


\section{Botrede.}

beẼannt zu mad)en. Indetien haben Die Sitglie Der siebe genung; folwohl für Das Waterlano; als

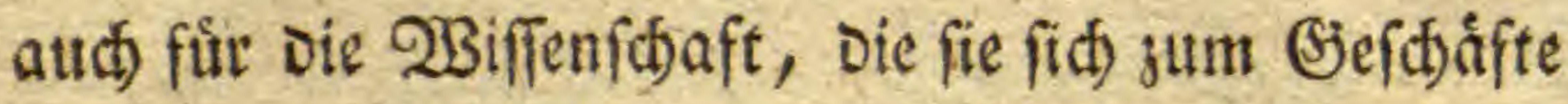
gemad)t, um nad) ihren Rråften Diefes Biel gu erreis ben, uno diefe berrliden ஒrooufte aufzufudjen, ofne Deren Renntniß́ Eein Sano feinen 2fferbau, Sinfte, Generbe und Jandlung, zu einem Girad von Dolleommenbet bringen wiro.' Das Refultat ifhrer Bemuீbungen, wovon oiefer Eleine Bano Der Infang ift, wiro von 3eit fu Bcit im Drucf erfheis nen, und Die (Gefellifhaft rechnet auf Den Bervfall iffer Eandsleute, Denen fie ihre 2trbeiten wiomet, uno oie fie auf thre natúrlid)en গुrooukte aufmerEfan jull madjen minfist.

Quodfi deficiant vires, audacia certe laus erit, in magnis, et voluiffe fat ef -

Propert.

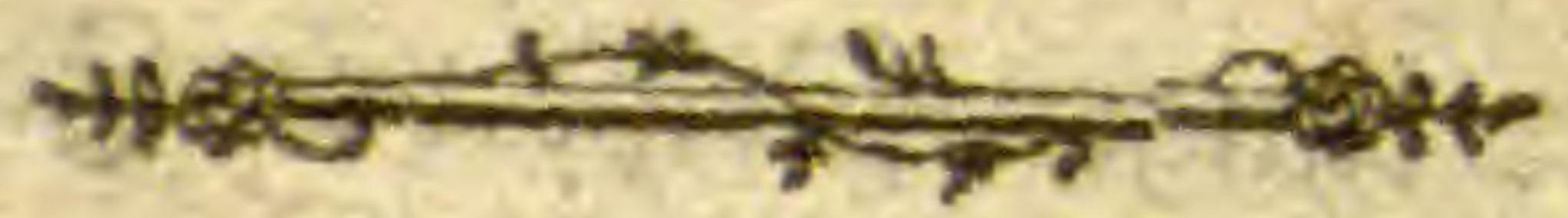

I. ஒ[yุs 


\section{1.}

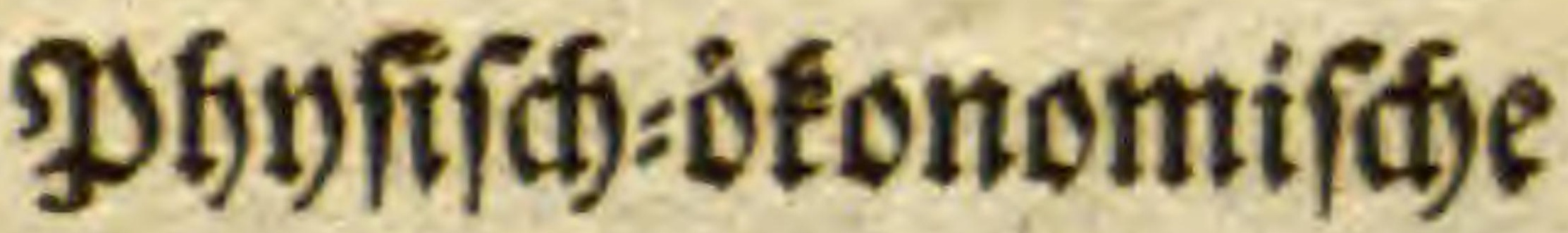

$\mathfrak{V} \mathfrak{e} \mathfrak{e} \mathfrak{r} \mathfrak{f} \mathfrak{n} \mathfrak{g}$

uีber bie

atmojpbårifó)en Cinmuirfungen auf ben Erofforper, in Nituffidt Der Rultur;

2on

Э. Gr. v. St. 


$$
\begin{aligned}
& \text { ? }
\end{aligned}
$$

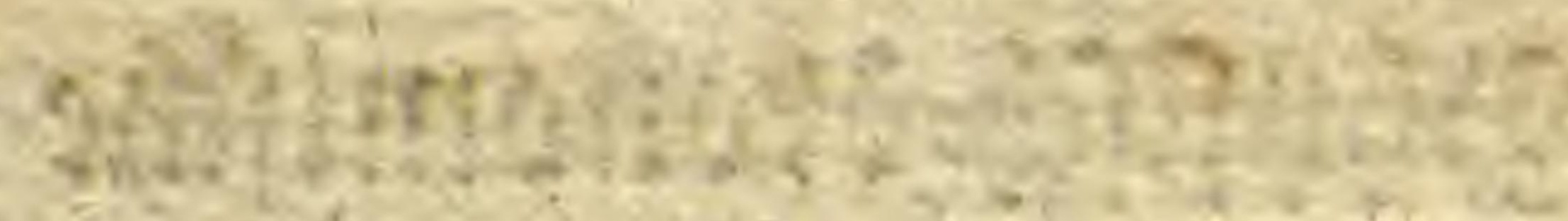

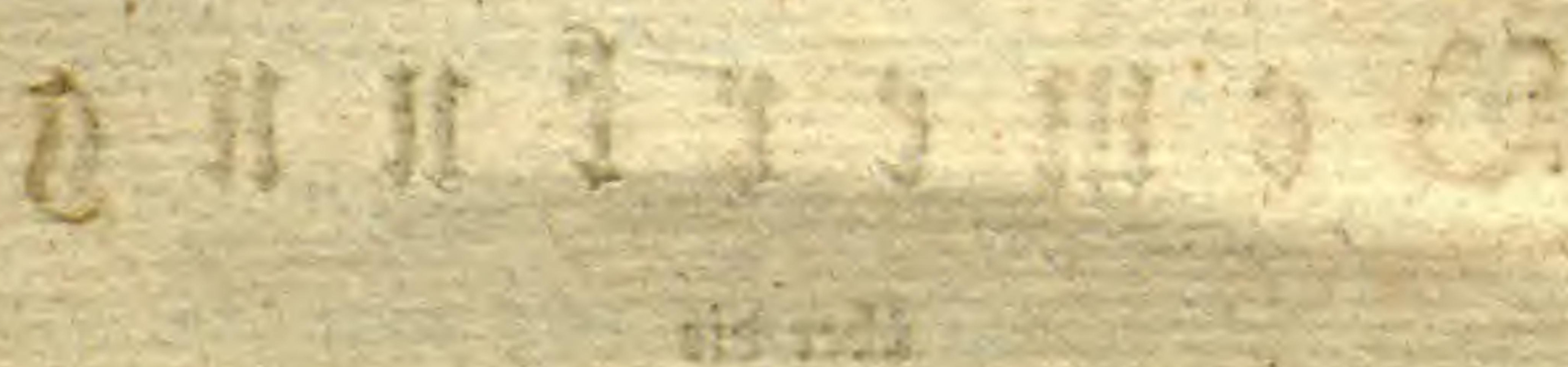

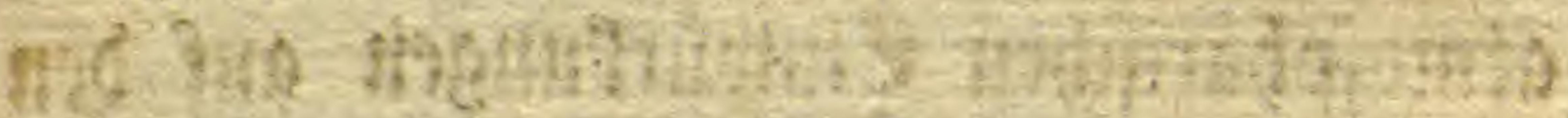
ctrithe ate

$$
43.12, x^{3}+3
$$



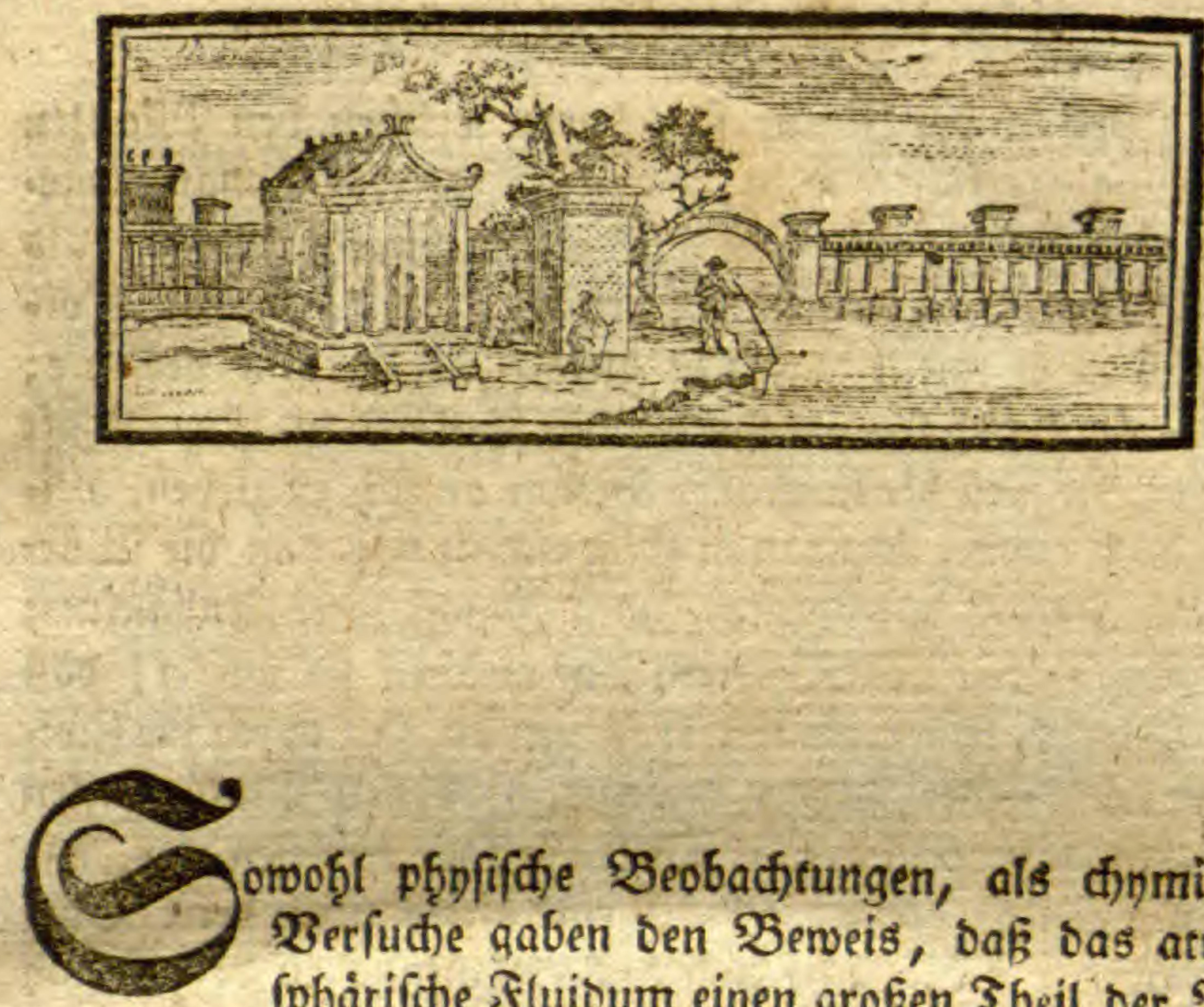

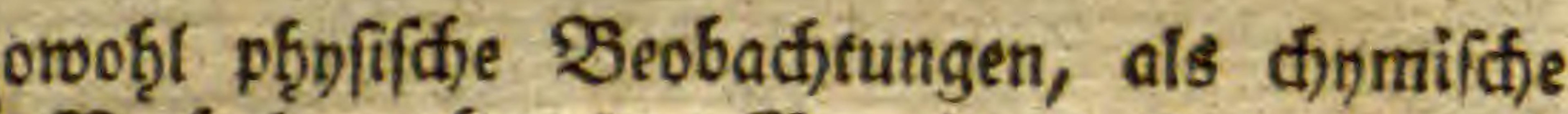
Berfuche gaben ben Serweis, Daf bas atmos

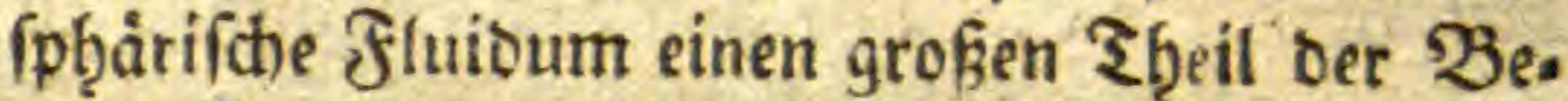
fantbeile benen PFlanjen jufühwe, uno felbigen mittbeile, ourch metches ibe Sachsthum befortert wiro; felbft bie Berlegunz cines Fichenbaums giebt uns an Eroe uno feuer. beftanoigen 23 ftanbtheilen nid)t mebgr als ein $\frac{1}{1} \div$. Die Serlegung oes Silees, nach Wefirumbs Erfab̨rungen, zei=

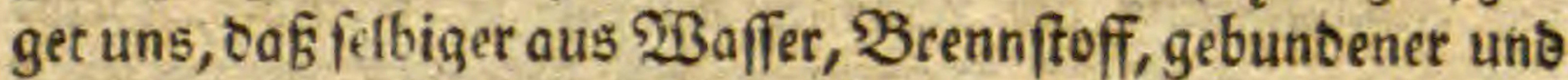
ungebunbener $2 B$ einfteinfäure, freyen uno gebunbenen \{aus genfalze, frener uno gebunbener Ralcjerbe, vitriolifitten 2Geinftein, Digeftiofalz, Riefeteroe, ร̧̧onetbe uno Eifen beftefo, ferner aus brantigtem Dele uno flühtigem Salje uno Bucferfáure, uno zmar lieferten 2 Pfuno frifther grüs ner Filee an $\mathfrak{B a f f e r} 20$ Unjen, branbigten Dele 3 Unjin, 6 Quentchen, so Gran; am Rob̨le 5 Utnzen, 4 Quentchen, am falzigten Sublimat 7 (Sran, an entroictiener suft 2 Un. zen, 5 Quentchen, 3 Sran: ba faum ein Eđheibefunftler jemals aus ber Eroe, fo zur f̧ervorbringung 2 Pf. Rilees

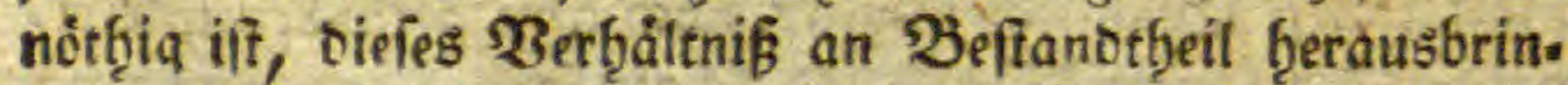
gen wiro, oa wenigftens id nad meiner Erfaḩrung, fo id mit Serlegung ber Felderte unt benen barauf erzeugten (Servad)=

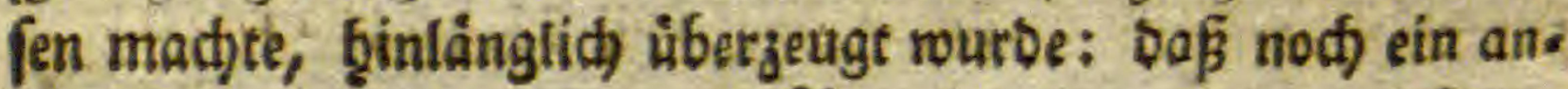




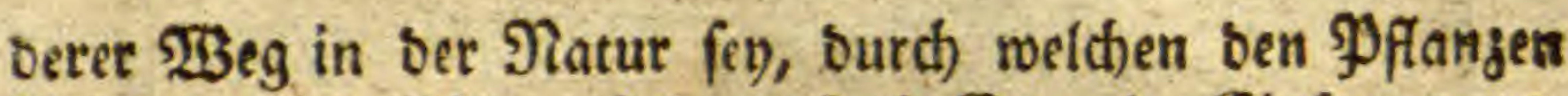
Nab̧rung jugefüg̨ret wiro; onß̧ oie Eroe eine Einfaugungs.

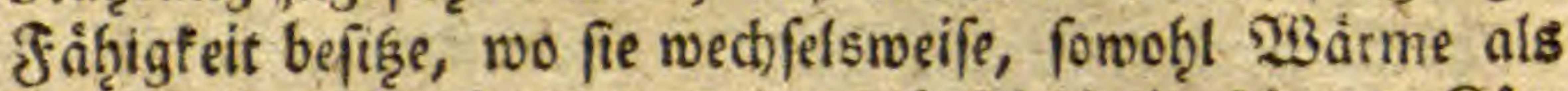

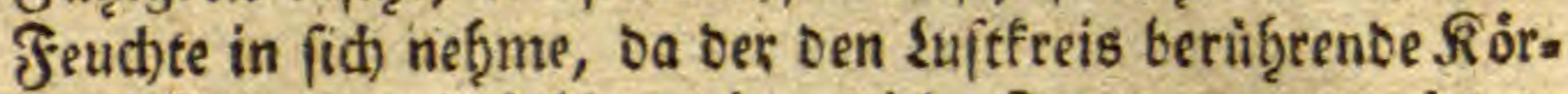
pe: fich aud) mit feibigem in gleidhe Temperafur berieçit; Iaß̧ unter benen fünf Erbarten Die Rallet De tie Eigenfthaft

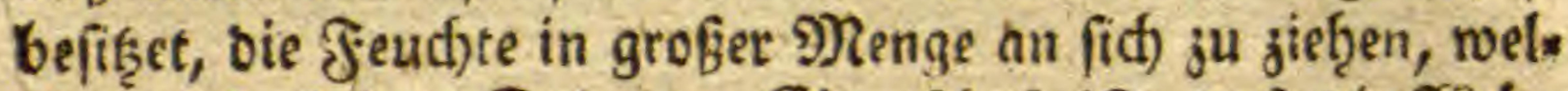

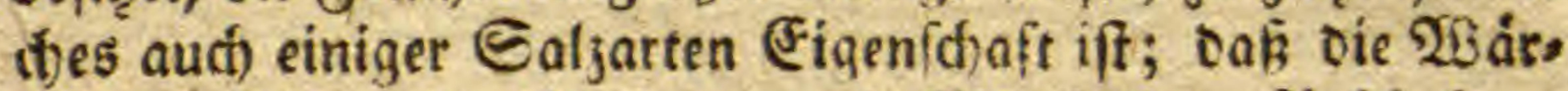

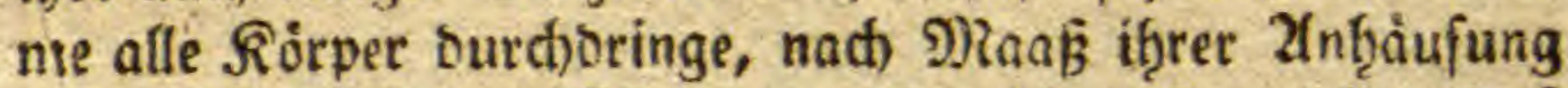
uab Did)tigfeit Des Rơrpers, auf welchen fie mitfet; $\mathrm{DaB}$

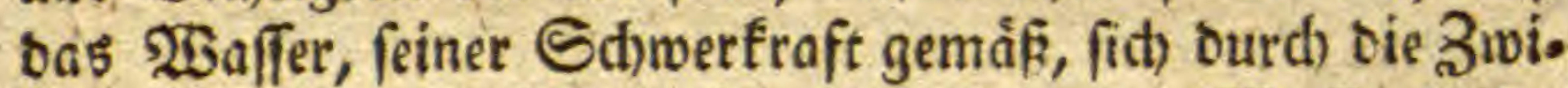
fchenráume jener Rörper berweget, fo oenen 2 Baffertygeilen ben Eingang verftatten. Diefe Grủnbe erwiefen mix, wie wichtig es fen, bie (Frbe burch) eine ofters verainberte Dat: bietung ber Deerfladioe und Eocfererbaltung in ben Stano ju fegen, benen atmufpţärifthen 23 itrfungen ben Eingang ju geftatten; Dod war mir nod) nótbig zu miffen, bie vers

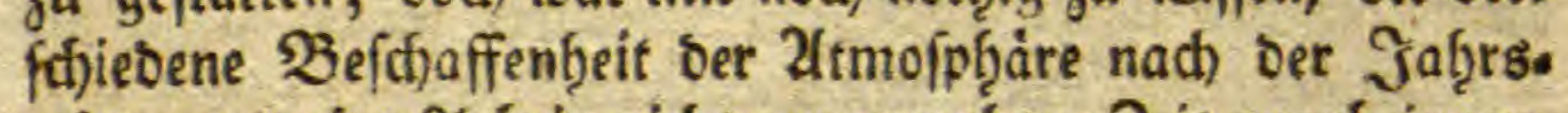
jeit, um meine 2frbeit nidht zur unrectten Beit anjubringen.

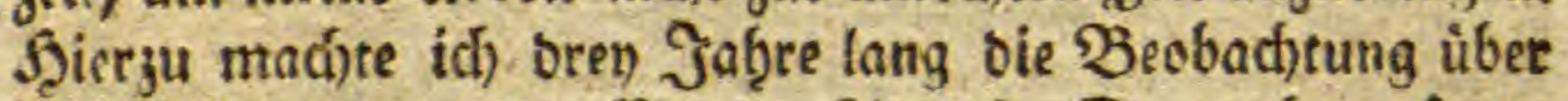
bic 2(usbuinffung ber Monate 2luguft, Eeptember, Dcto. ber uno November; bie zroen erften $\mathfrak{M}$ onate, im $\mathfrak{B}$ eriauf Diefer orel) Jafgre, verbielten fidh wie $23^{\prime} \cdot 4^{\prime \prime} .3^{\prime \prime \prime}$, bie

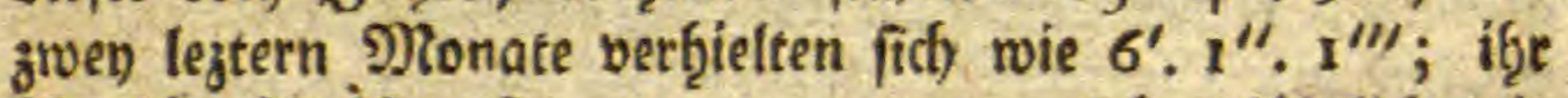

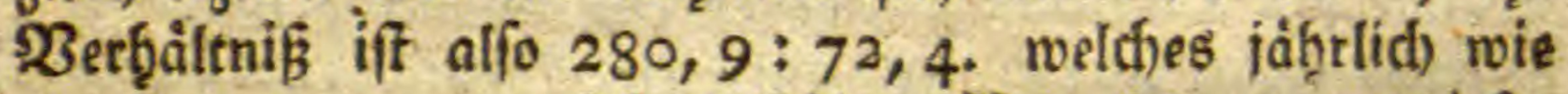
$93,07: 24$, 015. fich) verthâlt. Nun folget aus biefer

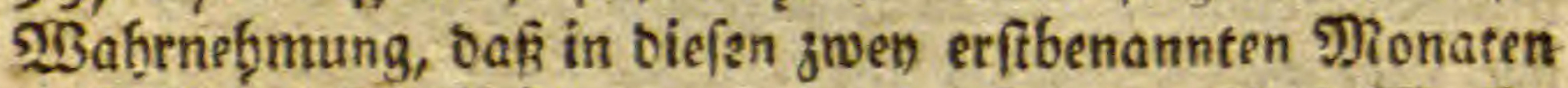

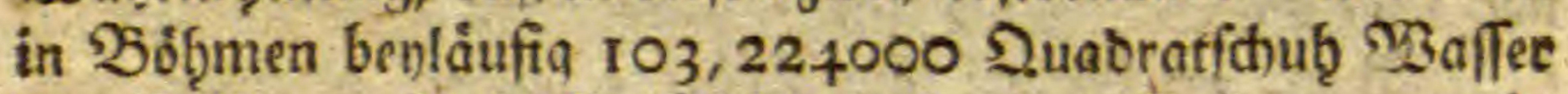
ausoúnften, weil bie Brobadtung in einer (Begent gemad)t

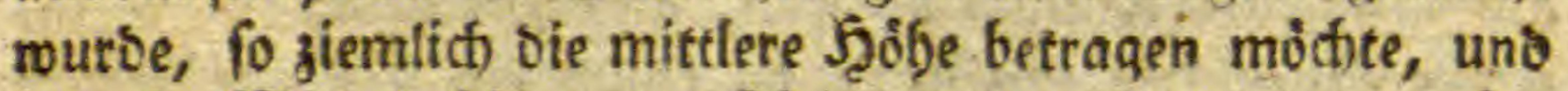
als ein Mittelgebirge angefefenen werben fann: nun aber

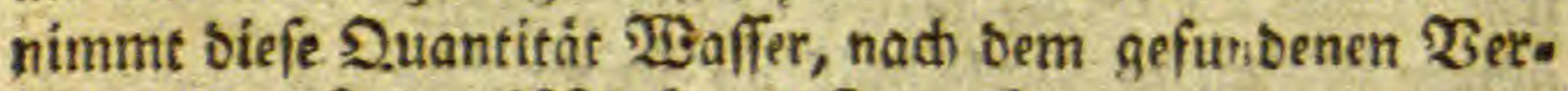
ḩältni b ber f̧erren Wo atb uno (raw fort, 1599 972,000 an $2 B$ àrmeftoff in iffer $\mathfrak{B}$ erbinbung auf, fo in einer conts

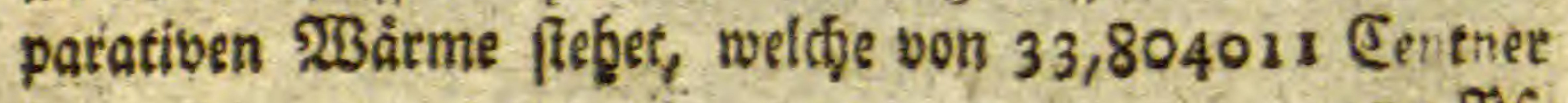




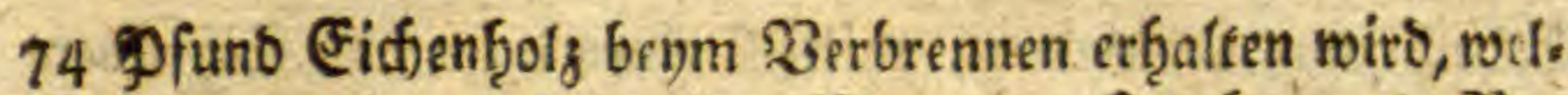
d)es in benen zwer folgenben Mionaten, Dctober uno Nio=

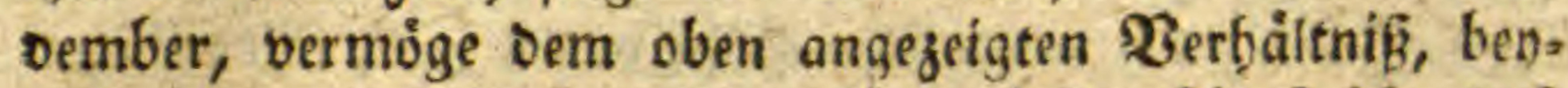
naf̧e viermal geringer wirb. Zfus oiefem faflopi id), Dab man tradten muife, in jenen Ronaten, fo wie es nach) $\mathfrak{B} e=$ fchaffentzeit oer frùbeen ober fpátern Ernote tḩuntich) wers Den fann, bie Erbe locfer zu machen, die Stoppeln umjtt* ftưrzen, uno bie Erbe fo viel wie móglid) ber Eintoirtung

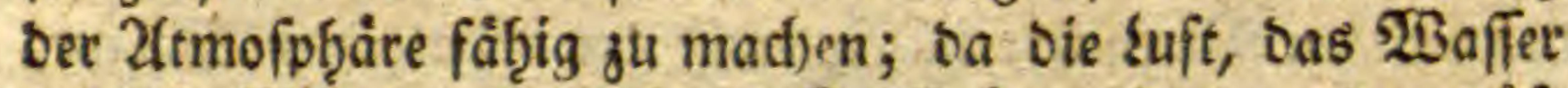
uno bie $\mathfrak{B}$ ărme als wirfende Stoffe betract)tet werten mifo

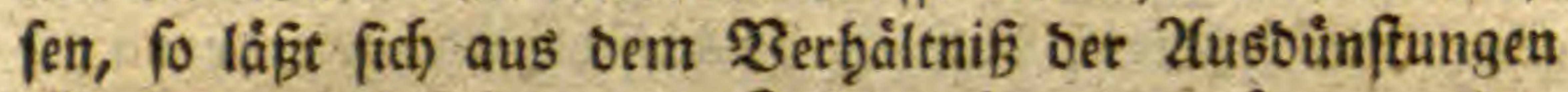
abneḩmen, wie viel an ber Jaf̨reszeit gelegen fer, um ben Eroboben tragbar zu erḩalten, uno jene ib̧m fo nugilicten Deftanotḩeile aus ber 2temofph̨arre annebmbar ju macten; aud) fino biefe Einwirtungen als 2uflơfungsmittel ju be. trac)ten, woourch oie Eroe in fo zarte Theile gefdieben wiro, baß̧ fie benen Iffanjen juträglid) werben fann. Itm aber aud) beftimmen ju fỏnnen, in weldhem Berb̨álteniß̧ ber zu biefer Seit bearbeitete Soben mit Dem unbearbeiteten,

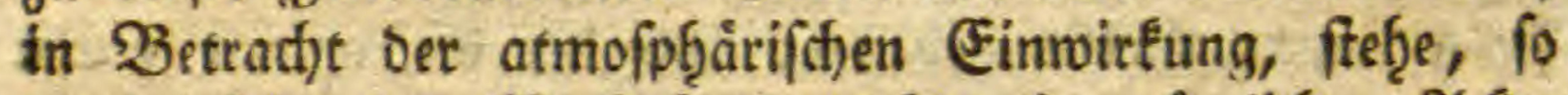
surbe folgenber $\mathfrak{B e r f u d}$ gematht: im naimlidien 2lder wurben zmen Beete zu biefem Enbjwed beftimmt; bas eine Beet blieb ungeppliget, forvob̧l in Diefes als bas bars

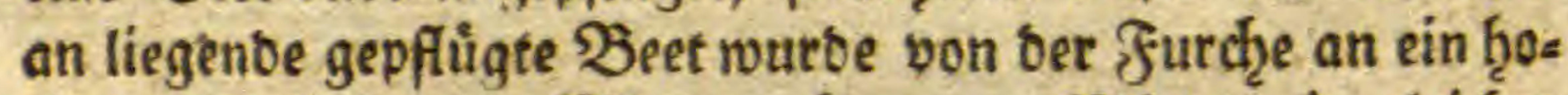
rizontales \{ocf, von Mitternad)t gegen Mittag, in gleicher Siefe, mittelft eines runben eifernen Stabes, gebobret: jwey

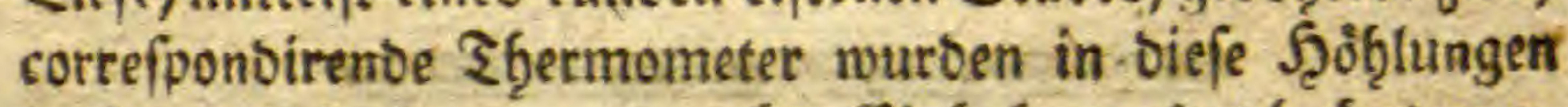
borizontal bineingeleget, uno ber) (Finbohrung bes foc)es wute be barauf gefégen, bas obere (Froreid) nid)t ju erf(huttern; if. re Differenz wurbe tågliđ) bemerfet, woraus fid) ber beträchte liche Unterf́djies ber (Finwirfung ber 23 ärme in ben gepfligge ten gegen bas ungepfligte $\$$ geil ergab, oer im $\mathfrak{B e r l a u f}$ oiefer jwer) Nonate wie $73,6: 19,7$ war. Ltm bie Einwirfung ber Menge ber ffeud)te ju erforidjen, murbe immer nach einer res genb̧aften 


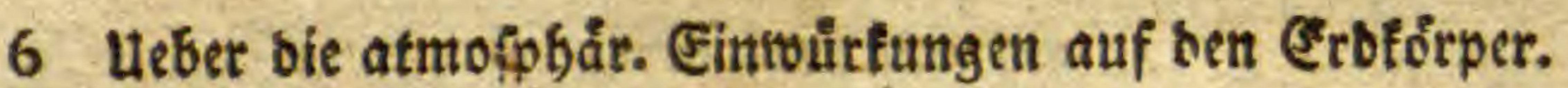

Erbe bृeraus genommen, mittelf eines baju bon Eifen ver. fertigten $2 B e r f$ zeuges, weldhes in bie Eroe getrieben wirb, uno fid), bis jur angemertten f̧obte von 8 . Soll, mit felbiger anfüllet; bende Theile Erben wurben gewogen, bann ber Deffillation unterworfen, bie erf̧altene freuchtigfeit, forwoht oem Maake als bem (Serwid)te nach, angemerfet, Die jus rùcf gebliebene Erbe gewogen uno mit if̧rem $\mathfrak{B}$ erluft ber. glidfen: woraus fich) bas gange $\mathfrak{B}$ erḩáltniß, als auch jenes bes vorigen $\mathfrak{B}$ erfucbs, in Betradt ber erb̧altenen $\mathfrak{B}$ årme, beftimmen ließ̧. Da micb ber betráctitliche Unterifthieo gánglid) ủberzeugte, baßß ein zu biefer Jaந̨rszeit benen ate mofphảirif(h)en Einmuirfungen vorgerid)teter 2(cfer fruch)to baree gemadt) merben fann, fo fdritt id) zum Berfuct):

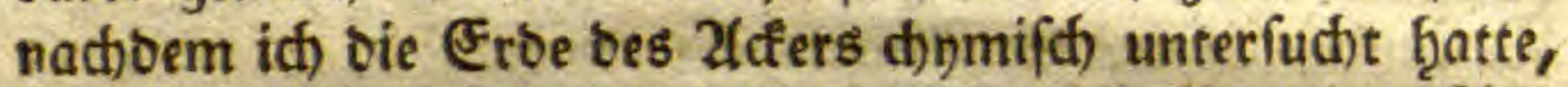
fo wåb̨lte id) eines ber guten uno eines ber fdilechten $2(\mathrm{rt}$, bie pine f̧allfte jebes biefer jwen 2lfer murbe nach meiner 2(bfid)t bebanbelt, bie anoere f̧ålfte blieb bey ber fonft üblt. den Searbeitung, wo bie Etoppeln ben ganjen Jjerbft ab: gefgutet, unb fooann erft gepfluget werben; in biefe benben 2lefer wurbe Berffe gebauet, uno ber Ertrag im guten war $11 \frac{1}{4}$ ju 7 , im fiblect)en $5 \frac{3}{4}$ zu $3 \frac{1}{2}$. Der Erfolg bie.

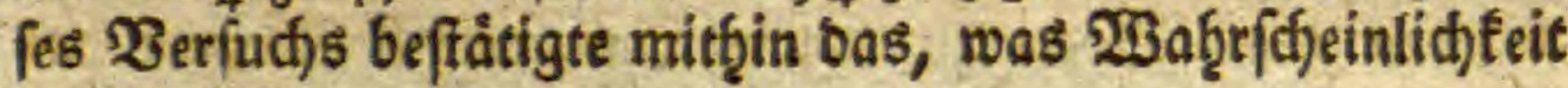
bृoffen liefs. 


\section{II. \\ Beobadtung \\ นี่อะ}

einige Steinfoblen=Ragen Deร \$illänet

\section{Sireifę,}

bon

Johann ThadDåub \{indacfer. 

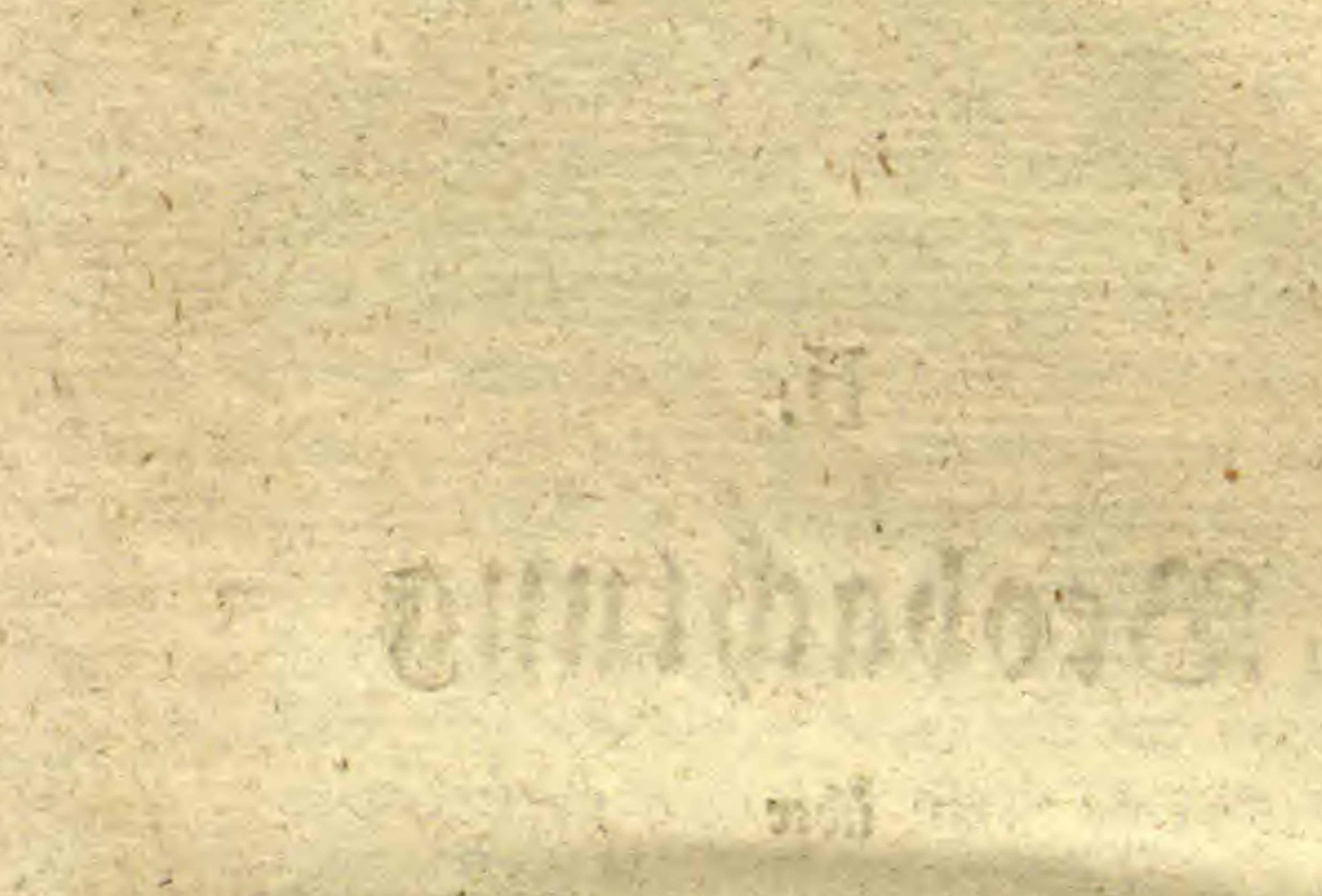

t.

W.

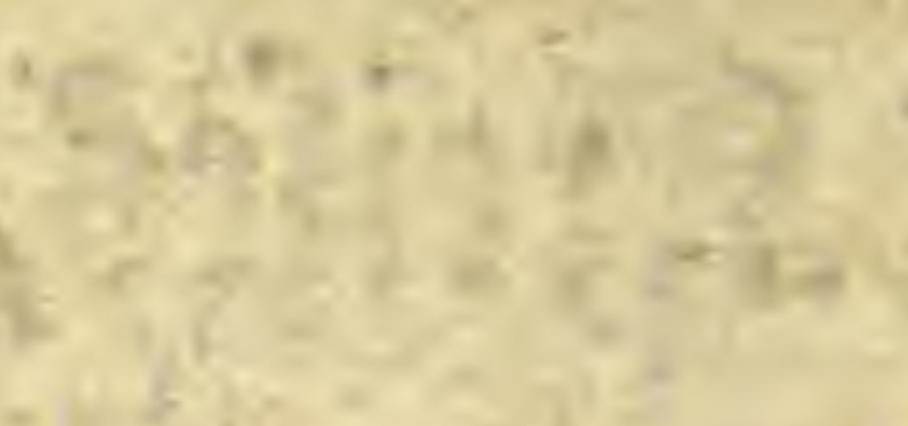

$$
\begin{aligned}
& \text { wat }
\end{aligned}
$$

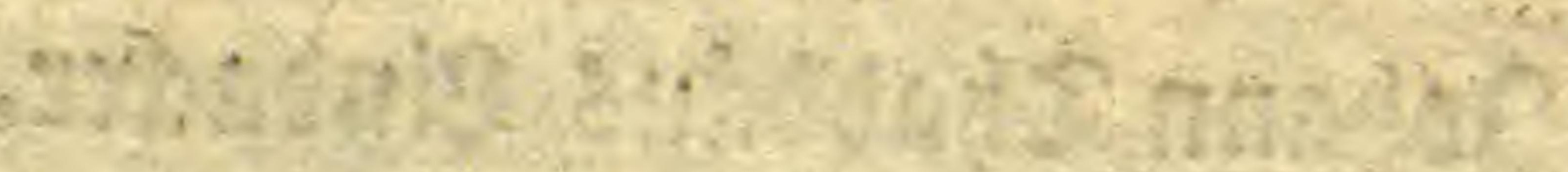

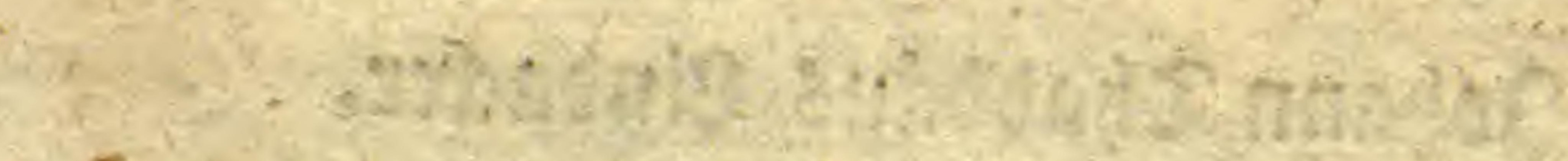




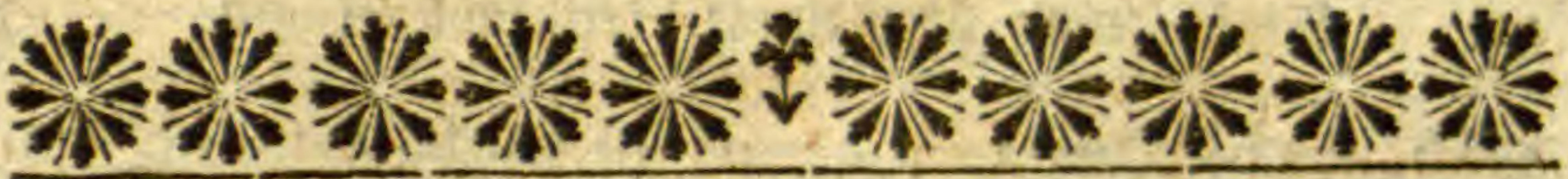

Derr Mrofeffor Serbet hat in feinen Benträgen jur Mi.

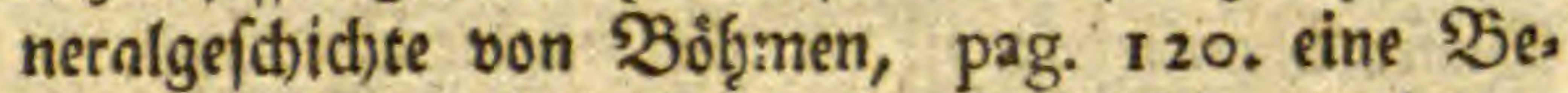

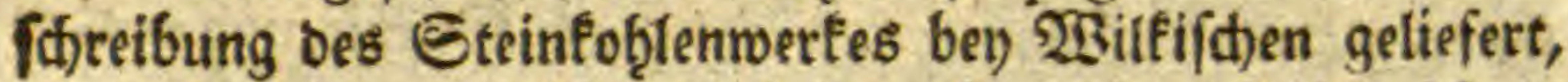
wo er felbiges mit vielen Groủnben für mef̧r urfprùnglich) ju erflären fucht, unb groar für eine mit Fettheildjen ourch)=

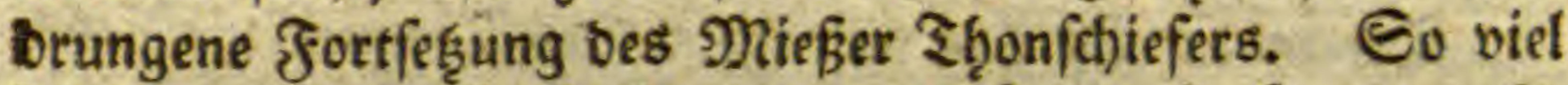
id) audh immer Jjodfact)tung gegen Şetrn Serbers großje (Einfichten unb unetmúbeten (Eifer hege, fo mu(B id) tods einige Beobachtungen liefetn, bie vielmeţr bas Begentḩeil 3u betweifen ffeinen.

Sowofil in bem Ecfiefer, als felbft aud) in ben Stein. foblen fann man nod) ziemlich) beutlid) vegetabilif(d) Heber. bleibfel roabrnefgemen, bie id mir nie in einem urfprünglis

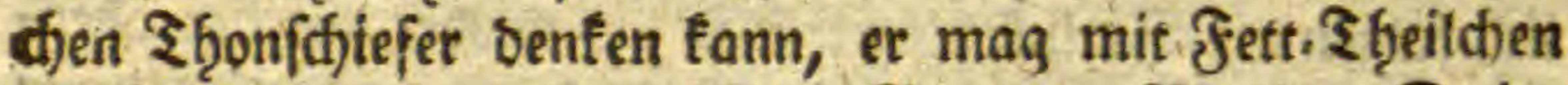

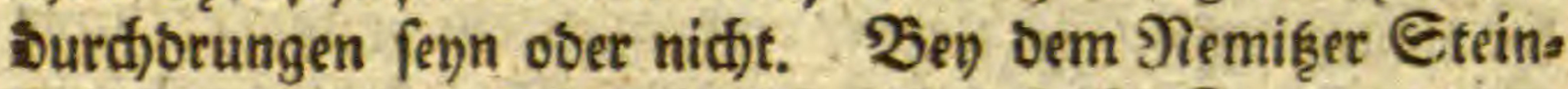
Fof̧lenwerf, bas boch nut eine fleine Galbe Stunbe tavon entfernt ift, unb auf ber námlid)en Steinfof̧lenlage betries ben wirt, Eann man fich noch) beutlicher überzeugen. Die Decfe bes Steinfob̨lenfdiefers ift hier viel mädtiger, uno Die barinn entbaltenen 9 Planzenaborúdfe jiemlich beutlich), uno bie ḩåufigften fino Fatrentråuter, ઉ̧räfer, viel feltener Ballienarten; eben fo verb̧ălt es fidh mit bem Eḩotiefdhauer uno bem ben Merflin, fo wie ben ber $\mathcal{Z}$ fdiminer Biegent; two ebenfalls Eteinfob̨len, unb zwar in meģrern abwed)= felnben über einanber liegenben sagen finb. $D_{a}$ ic) nun einmal von Eteinfoḅlen fiprect)e, fo wifl idh bie Eagen des Ieztbenannten Drtes etroas beutiidjer befffreiben. Die gana

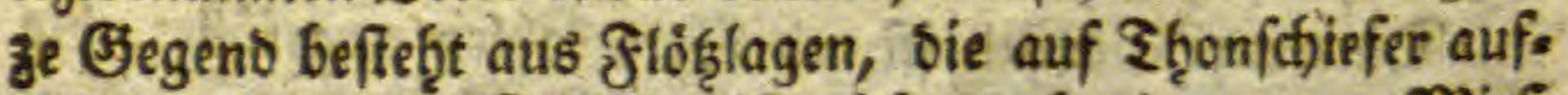
sefegt finb; ber Sddiefer ift nidjt meḩe jenem zu Nieß 
gleidf, wo ber Duarg nur abernmeife ourdigezegen iff, fons bern f̧ier ift er mebgr innigit mit felbigem vermifd)t, feine Eagen fino aud nidit mebre fo geraofiactsid)t, fie fint vielo melge erwas fenfrecht, ober mie oer ßergmann (prid)t: fie ftehen auf Dem $\Re$ isf; er raget feltner nadeno hervor. $\mathfrak{B}$ ey Defel, einem Dorfe, ftreict)t mitfen ourch) Den $\mathfrak{B a d}$ ein fd)warzer Ëtirefergang, ber wie Gteinfobten ausfieb̨t. Diefer ₹honfdriefer ift vermutb̧lid Die Unterlage ber aufges fezren fpatern Flöglager, obftion auch) (Sranit uno anbere Eteinarten felbft mit jur Utnterlage bienen fönnten, wo Derfelbe ofne Besecfung bes ₹Gonfhiefers herborragte.

Die sagen von ₹ag nieber fino ben ₹̧̨emnin: erffens, Dammerbe; gleich) unter biefer ift an manchen Drten eine Forferbe, bie id vielmebre unvollfommene Eteinfob̨len nens nen mo̊d)te; bann formmt cine 2(rt von פergel; auf biefen folgt ein Ganoffein, ber an mandhen Drten mit (Fifen burd): orungen ift; oann folgt wieser Mergel; Dann ein etwas grōberer Sanbfrein, unter bem bie gemodhrliche fofiefrige ¿bonbecfe von Eteinfoblen liegt; (bort Soich) genannt) ento lid) folgen bie Eteintohlen felbit, bie wieber auf ber obene benannten Ş̧onlage liegen. (Enolich) ein etwas gro̊beree Eantffein, uno nun fommen mieber Strinfof̧len mit beya ben tḩonigten \{agen, fowoh̨t ober als unter Denfelben; Dann

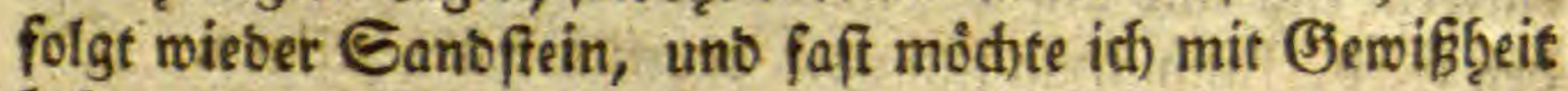

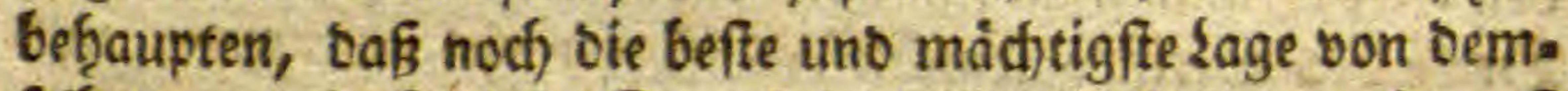
felben unterf̧alb biefes Sanofteines liegen buirfte; nod) mus id) anmerfen, baß̧ ourd) bie erfte Nergellage, bann ben mik Eifen burdforungenen Sanbftein, unb bie zwote Mergella.

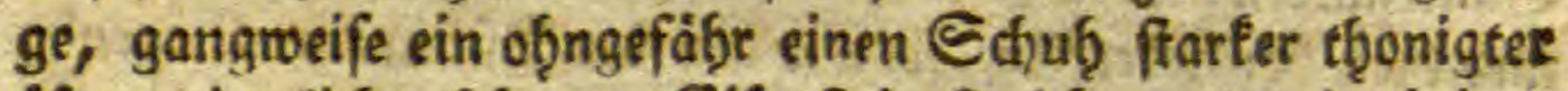
ôfters jiemlita) erb̧ärteter Eifenftein ftreicht, uno mit einiger. Berflád)ung oie eben benannten sagen ourch)(d)eint; ob ee aber auch) burd) bie ribrigen tiefen sagen gebet, tann ia nidbe bę̧aupten.

Die gange Begent ift mit Steinfoḩten angefüllet, bie aber immer bie Spuren einer fpátern Entfitebung verratben. 
Die Pfanjenaborticfe fino bie unwiberiegbarfen 5 Bemeife Davon, oie ein jeber ob̨ne viel Mithe am Drte felbft fam. meln fanu.

Die gange (J)egent fdeint einft eine See gebilbet zu thas: ben, wo fich nach uno nad) bie Steinfoblenmaffe abgefejt bzat, es mỏgen nut eine ober mef̧rere bergleid)en sagen gee wefen fenn. Diefe wurben entich mit ร̧gon uno Sanb ùberbect. Sene Gegent, bie ein Branitgebirge in ber פiad)barfd)aft batte, musite nod) mit einem foldsen Eanbe bebectet werben, ber wegen feiner geringen. Entfermung fri. nesweges noch) fo zerftoret werben fonnte, bak man frine Beftanotbeile nicht b̧ätte exfennen tỏnnen. Diefe See Durfte enolich, ourch was immer für Utrachen, ib̨ren Damm,

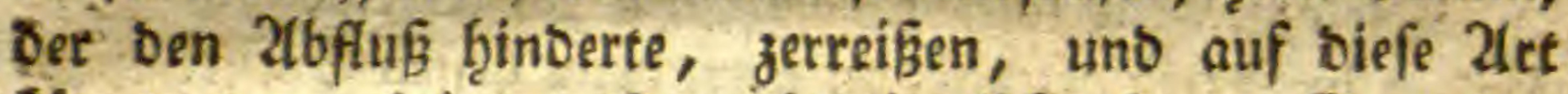
fönnte man einigermaßien bie jiemlich ebenen Gegenben erflären.

\section{Uteber Die Solzfteine in Der $\mathbf{3}$ (f)iminer Gegent.}

Diefe Gegenb entḩàlt eine Menge bet fófoinften berfteis therten f̧ölzet, uno fie fino nicht nur feb̨r fobỏn gejeidinet, fonbern aud) von verfditetenen f̧olzarten: unter aflen aber zeidjnet fid) bas (Eid)enţolz mit feiner nod) jurùcf gebliebe. nen Porofitåt aus; menn baffefbe braun, unb eine borns

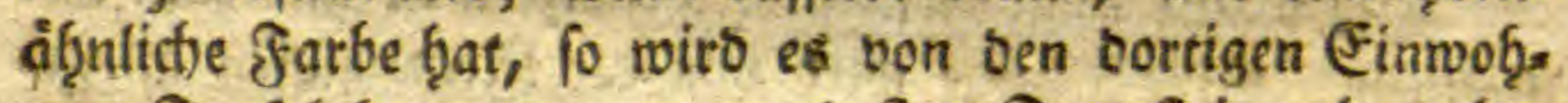
nern ₹eufelsborth genannt, uno fatt Jeuerftein gebraud)t; man finbet aud) ein im vegetabilif(ben (Gewebe, noch rid)e teres Şolz, Das balo bas 2lnfebeen von Birfen, Fuuchen uno anbern Saubb̧ofzarten ḩat: id babe ein Stricf, bas gleich) fam wie gani bon 23 ưrmern auf ber innern Geite zu angefreffen if, bann ein Etùct, beffen Rern ausgeboilt, unb bafür mit bem fhjonften fówarzen ₹ropfeifenffein übers zogen ift, unb ein Gtùd, bas mefermal zerbrochen, aber bod) fo, baf es nie gang getrennet wurbe; vorjüglich) abec

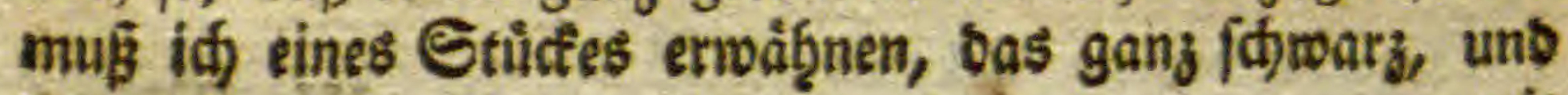




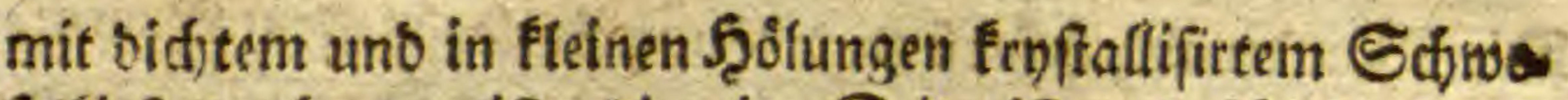
felfief ourd)jegen ift; bie eine Geite ift nod) überbiés mit Dem ftjonften Duarjernftalle verfefgen, two hingegen bie entgegengefezte Seite toabre im freuer brennenbe Scolgfohle iff, an ber nod) ganj bas (J)ewebe bes J̧oljes zu fehen ift.

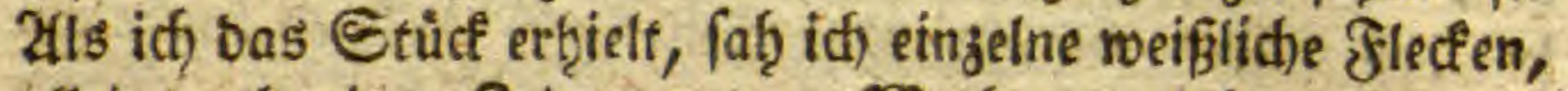

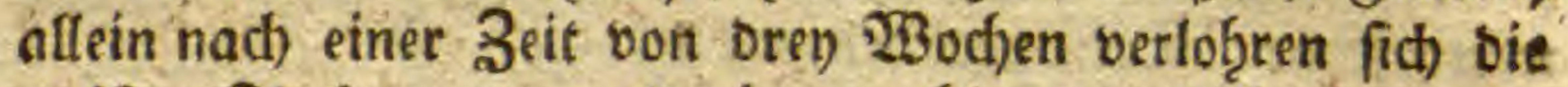
weifien Jledfen, es wurbe immer blauer uno blauer, unb jezt fino fie faft ganz Berlinerblau: ich) bielt fie juerft für Supfer, allein ben ber Unterfu(f)ung berrietben fie nicht bie geringfte Epur babon, fonbern'zeigten, bafi fie wab̨res (Fi. fen, uno folglic) naturlid)es Serlinerblau waren.

Diefe (Segeno fdeint vorjüglich zur Berwanblung bes Şolges in Etein gefficft zu fern, benn beffen Entftef̧unqs. art ift in bem Eanbftein ju fuchen; bier ift es vor bem 3u.

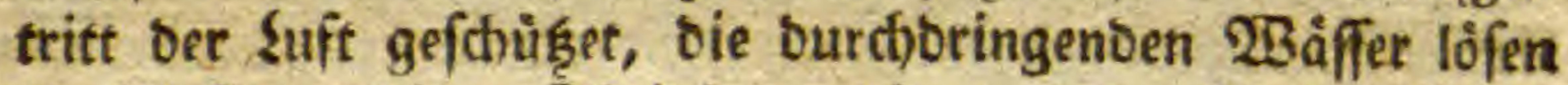
Die feinften erbigen Fyeild)en auf, und burchoringen bas vorfindente 5018 , bier finten fie einigen 2 Biberftant, lafs fen einen ₹beil bes exbiaten Etoffes zuriff, uno loofen ver. muthlith roiecer im B̈egentheil etros f̧olzmaffe auf, uns biefes 3ubringen bes erbigten Ettoffes uno 2luswafthen bes begetabilifdien bauert fo lange, bis es entweder Unftanbe binbern, ober bas f̧olj ganz in Stein ungewanbelt ift.

Die Menge von verffeinerten Şölzern ift bier zum $\mathrm{F}_{\text {r. }}$ ftaunen. Fine Menge wirb von ten Regenguifien ausges raichen und bem vorbenfliegenten Mi no fie bann bis Spilien uno nod) weiter fortgef hilemmt wet: ben, uno man findet fie ưberall an ben Utern beffelben; bie bortiae Sthäferen entb̧ălt über ein Drittbeil verfteinerte Scilzer in iffrer Mauer, wenn id) bie ganze Mauer in brey इ̧̧eile zertḩeile. 


\section{III.}

Mineralogiface

כ̧emerfungen

นี่อย

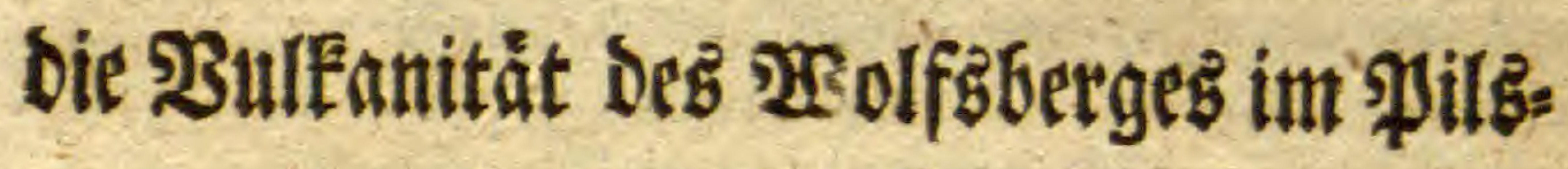
ner Siteife.

2on Cాbendemfelben. 


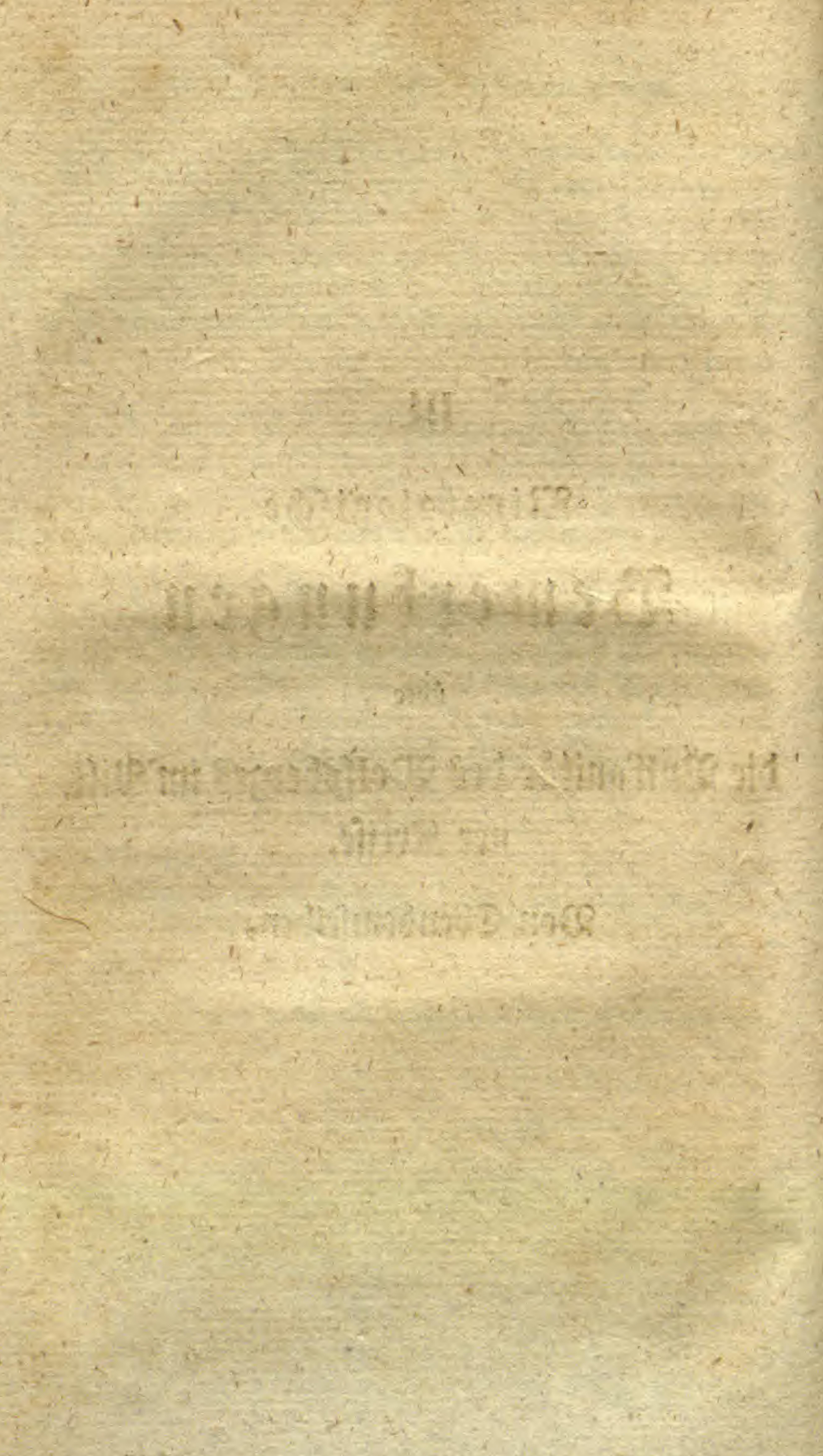




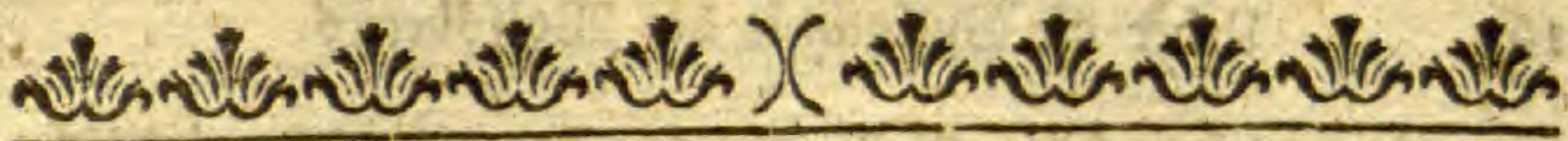

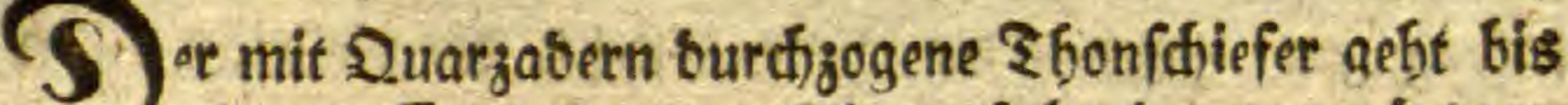
Ginter $\mathcal{E}_{\text {ijerlefin, wo fid }}$ terfectbe in etwas ánsert,

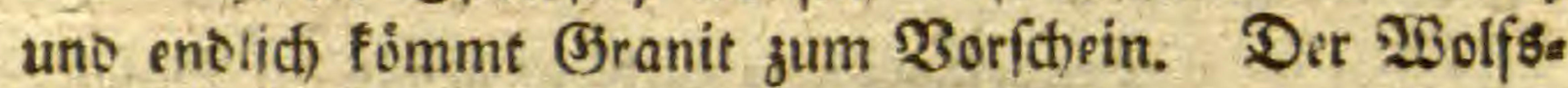
berg ift ebenfalls auf ₹̧̧onfthiefer aufgefegt.

Err ift ein einzelner jiemlid frener $\mathfrak{B e r g , ~ u n b ~ i f t ~ i n ~ b i e a ~}$

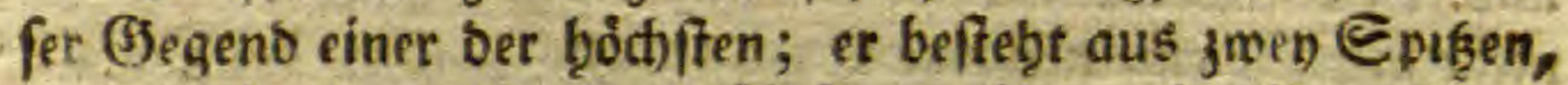
webon sie eine mefor gegen 2lufgang liegt, nieoriger ift unb ganz aus $\mathfrak{B}$ afalt beftebet; ebeorm frano ein शeufere Ed) log Da, uno oie alten Ueberbleibfel fann fóreibung Defe man nodh fergen; fiton von ferne zeidinet fid Telben.

Der ziemlich) bobe uno zugleich runo gebaute Tुurm aus. Die anoere Epişe ift viel ţơber, unb faft aang mit Kava angeḩåuft. Dann bitter er eine fleine Ebene, aber einen

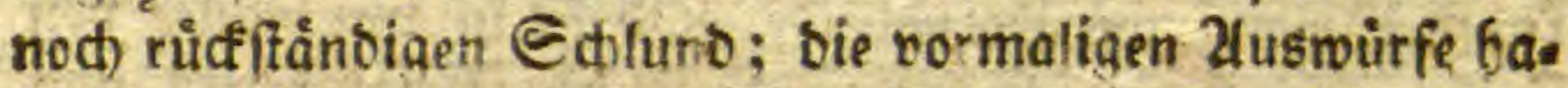
be id) nod nidte mit (Semikheit beffimmen fónnen. (See gen Mittag láuft von ber aro̊sern Erb̧abenbeit ein etmas langer ziemlid) niebrizer $\mathfrak{B}$ ergricfen fort; alle biefe 2 fnb̧o. Gen uno $\mathfrak{B}$ erge fint mit $\mathfrak{B}$ altung bewachfen, unb nur am Jufie finbet man feltobau.

Gegen 2lufgang fteigt er in etwas fanfter, qegen Uno tergang if er aber ziemlich freil, intem bier ber llusfus gemefen zu fonn fdeint. (Geaen Mitternact)t ift er aud) an mefrern Dtten fteil, wo er aber gegen פRittag es viel wea niger iff.

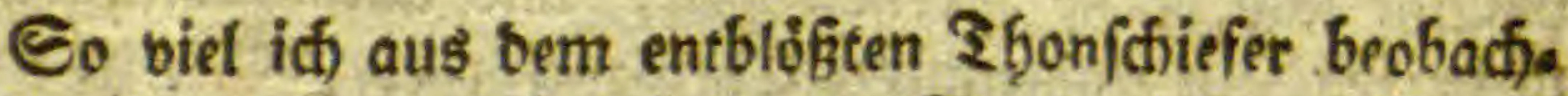
ten fonnte, aeb̧t berfeltbe unter bem $\mathfrak{B}$ erg, unt es iff alfo ber $\mathfrak{B} a$ falt unb bie saba auf felbigen aufgefezt. Ith fanb in ber Gegeno gegen Mittag einen fpannebicen feinen Eanbe

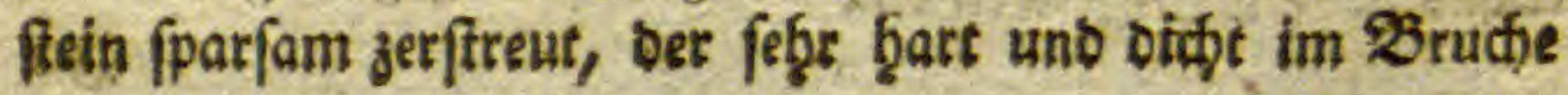


war, ber mid, auf ben (Jebanfen bradjte, ob nidft bielleidst berfelbe eine sage zmiftien bem క̧̧onfthiefer uub bem $\mathfrak{B a}$

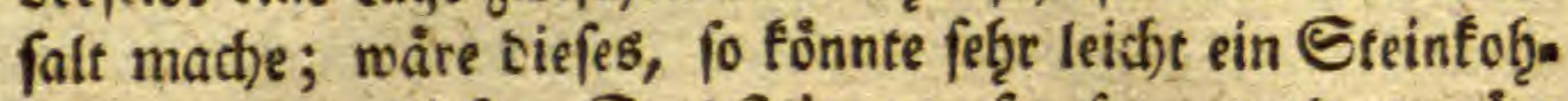
lenlager unter biefem Sandftein gewefen fenn, uno es wäre aud) fdion oie Urfache biefes $\mathfrak{B}$ ulfans erflärt, allein bevor

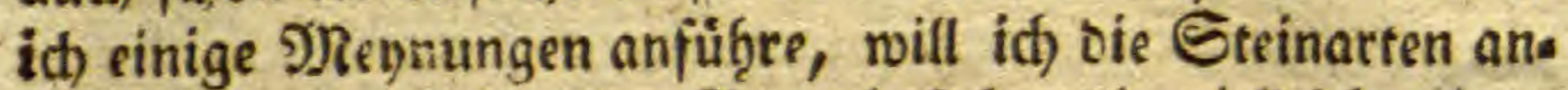
fübren, aus weld)en ber Berg bafteht, bie viefleid)t einen beffern 2uffohlus geben werben.

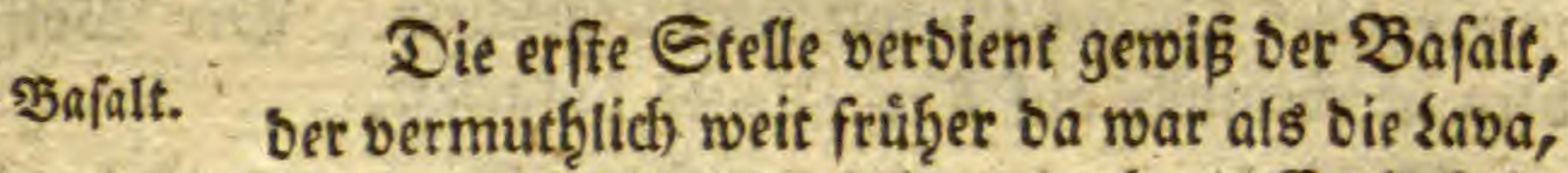
unb ex fat fidjer ben Stoff ju Derfelben gegeben. Es beftebte nicht nur ber eine niebrige $\mathfrak{B} e r g$ baraus, fonbern ber $\mathfrak{B}$ alalt umgiebt an mef̧rern Drten senfelben, befonters gegen Mit. ternacht. Er beftebt aus einer fofwarzgrauen, etrwas in bas blaue fallenben Srunbmaffe, fie liefert ḩier oren Epielo arten, Dem Bruche uno (Bewebe nach).

Die erfte Epielart ift im $B$ rudfe förnigt.' Das Siange beffebt aus bुanfforngropen Studfdien; id fanb in biefer faum Epuren von Sornblenbe, uno fie ift viel bläfer von

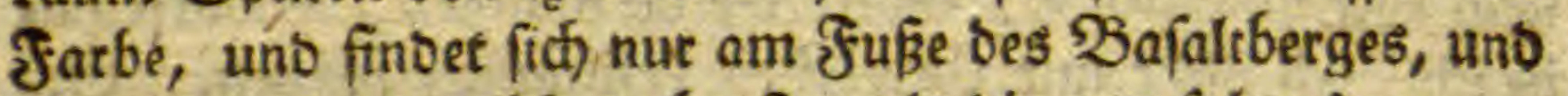
ift mehe unorbentlic) jerborften als bie zwo folgenden.

Die zwote Spielart ift, bem Sruche nach), ebenfalls föt: nig, aber babey viel bidjtet uno bunfler, enthaàlt fttion meţr, obgleid) noch) (parfam, eingemifchte J̧ornblenbe uno (E)gry= folifförner in פounten, uno fómmt in Cåulen jerborften sor.

Die britke Epielart if giemlich bict)t unb gleichartig im

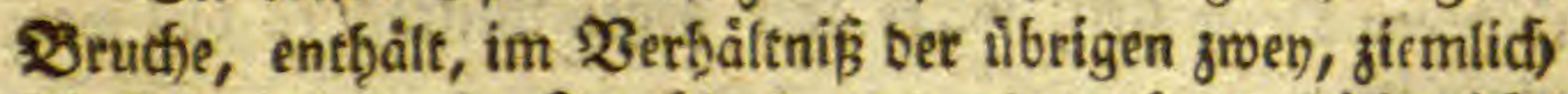
Gáufige uno groß̧e f̧ornblenten, uno audh zuqleid) nidjt

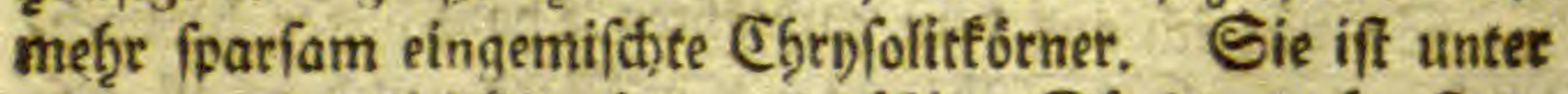
allen am beutlichiten in regeimápige Eåulen jerborften, yon bren, vier uno meţretn Eeitenfläđen, unb nimmt bie etwas bृớgern Giegenben ein 
In biefen $\mathfrak{B a f a l t e n , ~ b e f o n b e r s ~ i n ~ b e r ~ l e z t e n ~ c h r n f o l i t f i : s ~}$ Epielart, finbet man eine grủne butchfichtige ner.

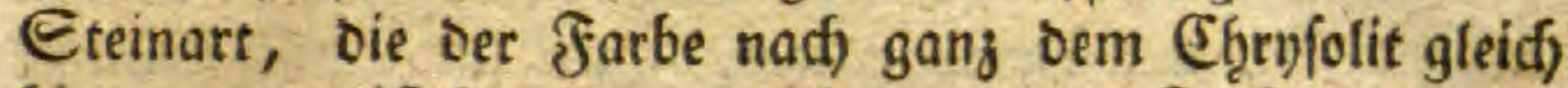
fommt, nur ift fie etwas raud)grauer von Jarbe, unb ge. fd)liffen fann man fie feinesweges von bem (Ģrnfolit unter. f(thetoen, aufer ourd) ole etwas minber angenebme farbe. Man finbet fie meiftens zerfprungen; id) roar nie fo glücf. lich), eine Rriftallifations, (S) ffalt maf̧rzunef̧men, benn fie Gaben vielmef̧r sine runbe Gieftalt; tḩre Groke if von ben fleinften Dunften bis ju einem Durd)meffer von einem 3oll. Man finbet fie efters in einem vollfommen braunen Ddfee aufgelófet, uno man erfennt fie nur nod) aus oen Sprim. gen, unb aus einem ftufenweifen Utebergang aus bem (Ȩry)e folit in benfelben; und Dann fann man fie ofters mit bem Jinger zerreiben.

Man finbet biefe Ef̧rufolitförner ebenfalls in ber Saba, wo fie aber in unenolich feine SBlättchen zerfprungen fino, uno einen ben gruntid)en Ra(zenaugen gleidfenden Sd)ein von fich werfen; fie entḩalten aud) noch) òfters beutlid) 2 las fen: mandie fino fier oft ganj zerftòrt, fo baß aud) nur of o ters noch) ein Ddfer ùbrig iff.

Der Ç̧ryfolit fofeint bier unter biefe Sava feinesweges zu geb̧ơren, fonbern ift vielmef̧r als ein jerftörter frember Rơrper anjufeb̨en, Der fein Dafein bem $\mathfrak{B}$ afalt zu betbant fen bुat.

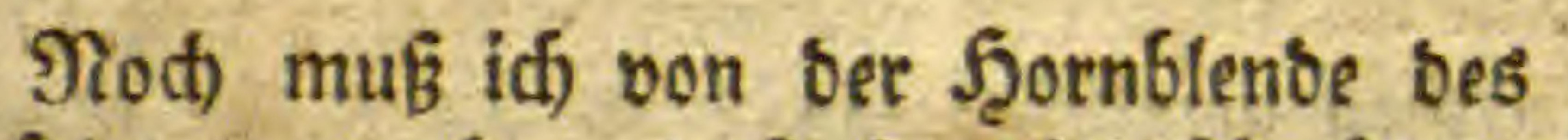
Bafalts anmerfen, Daß̧ fie viel fofwairzer, bict)er, uno jugleid) b̧arter ift, als bie ber Lava; bem Strich nact) zief̨t fid) bie in ber Eaba enthaltene meţr in bas rotg̨braune.

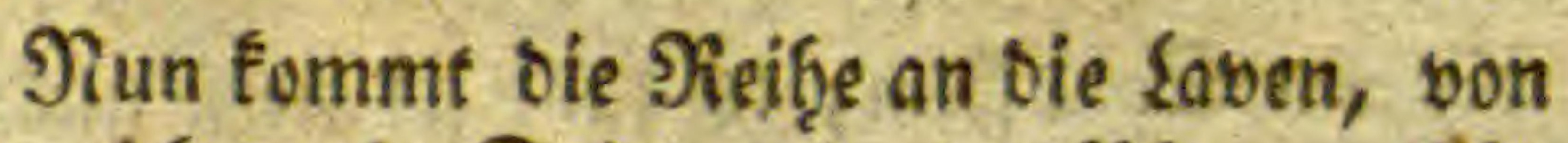
benen ich meb̨r Spielarten anjufüf̨ren, níb) \&aven. uิberfů. 
1.) Sava yon einet blaugrauen Srunsfarbe, mit baiufi= gen nur Punftgrofen, uno eingelnen erwas grókern $B$ lafen untermifd)t, uno etwas f(f)wer, Эa) fübre oiejes Stûd an, weil es burch) ben enthattenen erbairteten eroigten siale

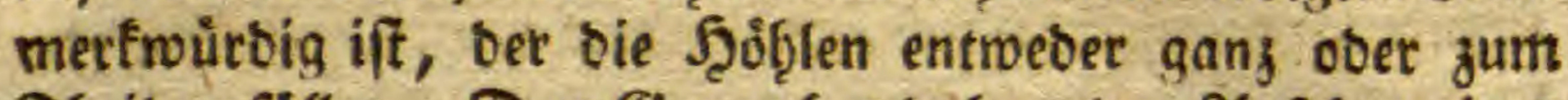
Sbeil anfüllet. Das Banje hat babero das 2Anfeţen eines

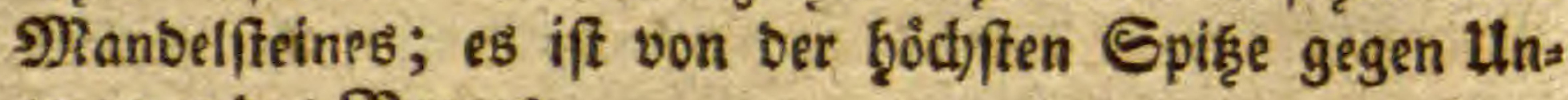
tergang bes Berges.

2.) Blaugraue \{ava, bie son ber Menge in ibre entfiala tener SBlafen,ziemlich) leich)t ift. Das (5anze bat tas 2(n=

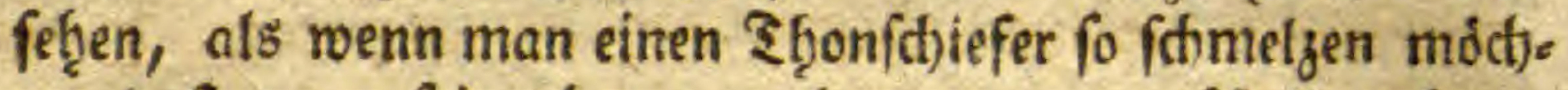
te, Daßs man feine sagen noch) etroas unterf(heiben fann, uno fie entḩålt feine Jornblente. Jah) fano meţrere Etù. cfe ganj los, meb̧r an dem fuß̧ bes Berges.

3.) (Graue Lava mit faff gleid) grofien SBlafen; sie

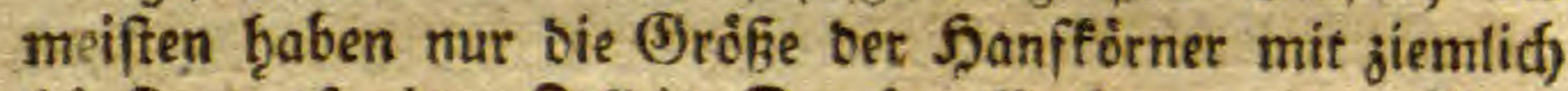
båufigen, oft einen Boll im Durd)meffer betragenten f̧orns blenbe=-Rriftaflen eingeftreur, bie bier nidft in Blafen gebit. bet liegen, fonbern mit ber Maffe feibft verbunben find, uno oaburd) eine gleichjeitige (Entffebung verrathen; es fin. ben fich nod) einzelne einem roth gebrannten ₹bqon gleiden. De Etùde eingeftreut, bie nidjt im geringften ein blafigtes

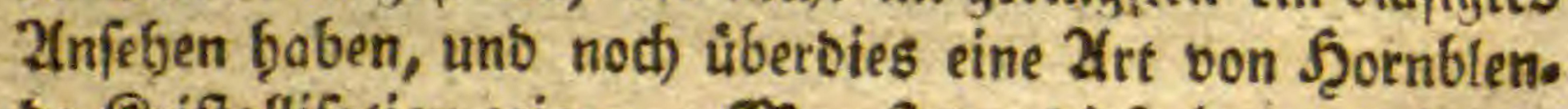
be Rriffallifation jeigen. Man findet biefe Laba meḩr gee. gen Nittag ju.

4.) Sraue gelbfiche mit braunen Punften unb Dacer. färbigen Jlecfd)en gemifhte saba; fie if etwas fotweres als bie vorbergehenten, unb mit faum ju unterfderibenden Dlafen verfę̧en; fie enthălt eine Nenge feiner eingeftreu. ter glänzenber פunfte, Die Blimmertbeild)en ober Sporn. blenve Rriffallen fenn butrften. Das (Jange gleid)t eineth etwas gefdmolzenen Sanoftein; id) fano fie mef̧r nad) bet פitte bes ßerges zุ.

5.) Rommt श゚. 3. ziemlid) nab̧e, nur mit båufigern Blafen verfeben, worunter fich) auch jiemlich großje befinben, Die 
Die entrveber gum ₹̧beil, ober faft gang mit Jjornblenbe. Rriffallen angefúllt fino; uno nić)t nur oie \$̨̊̊)lungen, fonbern aud) bie Shornblenten fino mit einem viel lid)tern

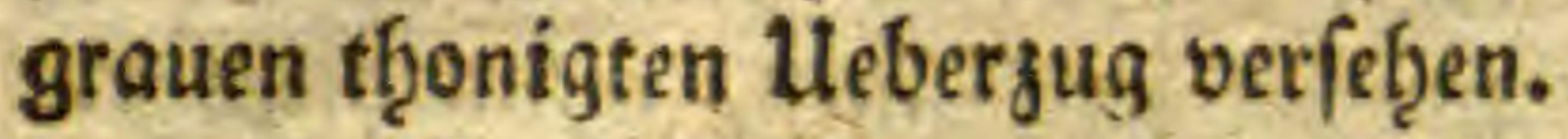

6.) Rommt No. 5. feb̧r nabe; nur ift bie Maffe viel gleichartiger gef(d)moljen, uno ḩier uno ba fino rotḩ gea brannte fleine ₹ b̧onftưcfe eingeffreut.

7.) Saba von einem leberfarbenen (Grunb, ber fich eto was in bas fdimargbraune zieft, mit bajuftaen fowobl flei nern als grỏgern SBlafen verfehen, mit einzelnen zerfprunge. nen, wie Rafenaugen ipielenden (Ebrnfolitfómern, uno nod) ziemlid) fparfam rotbggebrannten Şbonftucten eingeftreut. Die grơkern \$ojblen finb entweder faft ganj ober nur jum

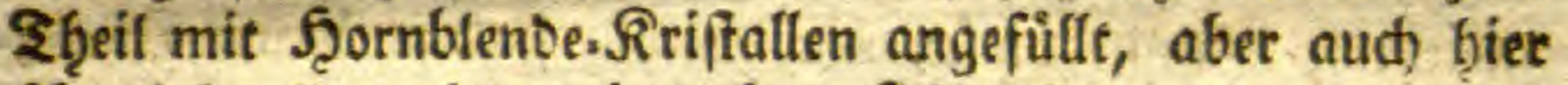
u̇bergieb̨t alles wieber eine ounne Stgonrinoe, bie eine etwas

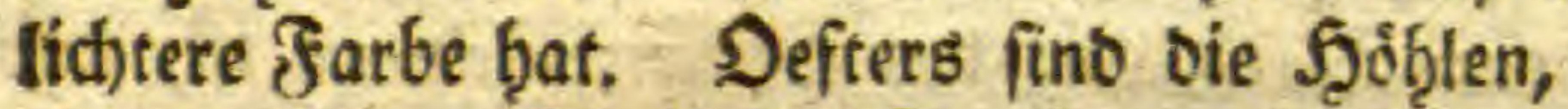
ober aud) jum Tyeil Die f̧ornblenben mit eis 3eolit.

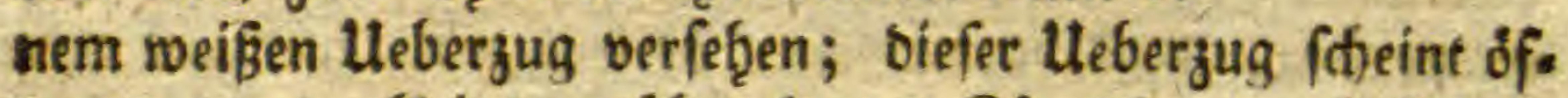
ters aus ganz fleinen geidhmolzenen Rügeld)en zu beffeţen, ober er gleidjt nur einem Etaub, ober if friftaffifirt. Sprengt man eine fold)e গinbe los, befonbers von ben friftallifirter, fo fdeint er, vermittelft bes 2 ergròfierungsglafes, aus

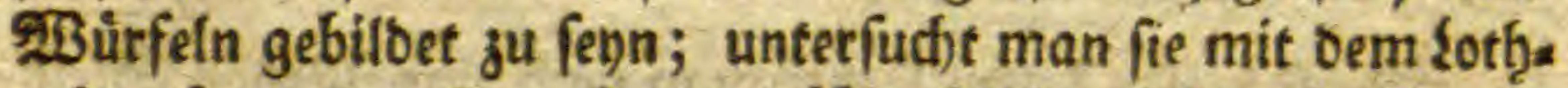
rof̧t, to werben fie anfangs trübe, bläheen fich) auf, bergla. fen auf ber Dberflád)e, uno werben enolich fo leidct, baß fie bavon fliegen, inbem fie oann nich) meb̧e ben suftfteom vertragen. Jof b̧abe fie aus biefer Urfache nut vermittelf ber Bebecfung mit einer fleinen Rob̨le, zu einer unvollfom menen Rugelgeffalt bringen fónnen: in Saiuren werben fie aufgelópt, aber viel langfamer als Zeolit, fie bleiben offers an bem Olafe fleben, uno erb̧alten ein Sallertartiges 21nje: bzen; id werbe fie unterbeffen aeolit nennen, bis id) Geles genfeit ḩaben werbe, fie genauer zu unterfudisen.

Diefe jezt befdyriebene Sava ift bie fiảufigfte; es befteh̨t faft ganj ber obere mittlere ŞGeil bes 2 Berges aus ber. 
felben, unb ba fie nidjt fonberlid fojwer ift, fo wirb fie sf? ters weit ven felbigem burd) bas $\mathfrak{W}$ affer weggeführt.

8.) Dunfelleberfarbige, im $\mathfrak{B r u c h}$ ziemlich) bict)te \&as va; man muirbe fie nie für Saba erfennen, wenn nicht bas gewaffnete 2(uge bie feinften $\mathfrak{B l a ̊ s c h e n ~ i n ~ b e r ~ f o n f t ~ b i d ) t e n ~}$ Naffe verrathen mòthte, aber ganj augzeid)neno fino bie in

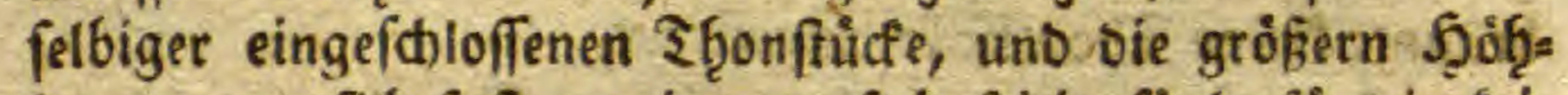
lungen, wo fich faft nur immer fechsfeitig fàulenfơrmig frí.

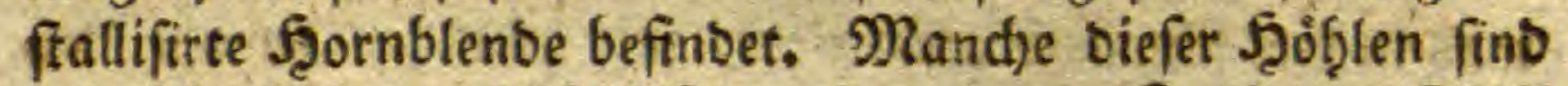
mit febr fthỏnem friftallifirten fogenannten Xeolit zum ₹ angefült, ber baben noch jiemlidfe Durdffict)tigfeit befiztDie bier eingeids)loffenen Sbonftucfe fint entroeber mit fleis nen Blafen berfegen, ober fo bidft, bafi fie einem Jafpis

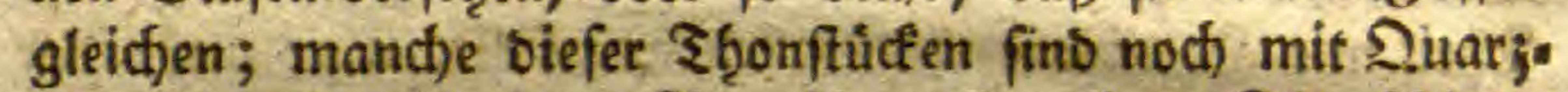
abern burd)jogen, zum Beweiß, baßß es jener ₹ţonidhiefer

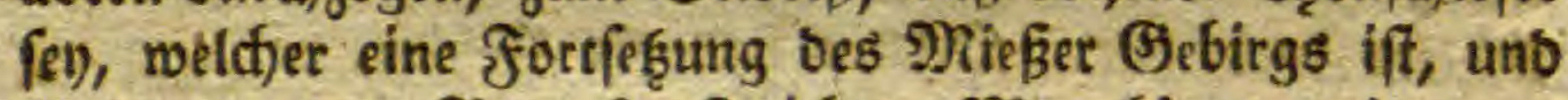
hier unter bem $\mathfrak{B e r g}$ fortftreidft. Mian fónnte mir gmas einmenben, $\mathrm{ba \beta}$ es bielleid)t berjenige ₹bonfdhiefer feun fónnte, welcher hier bie oben vermutţete Steinfoblenlage bebect, allein bisber habe id) noch nie Edfiefer gefunben,

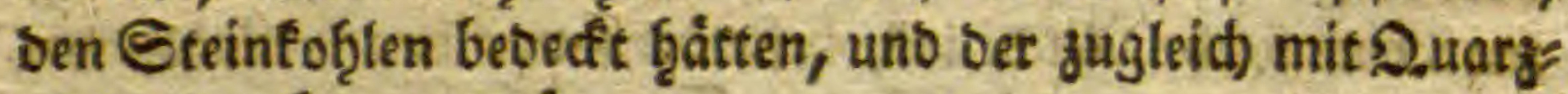
abern burdfjogen wáre.

Nebft biefen Saben finbet man noh) eine Nenge Etein= arten, bie id) nod) anfübৃren muß.

Berfificte inebr ange= băufte Qava. gleidhenber Eteinart:

1.) Nothbraune Sbongrünbe, in weldien eingetne sbonftùcfe jerftreut liegen, mit noch eingefthlofferer, einem gebrannten felofpath

2.) Fine angefialufte $2 a b a$, bie aus No. I. befffriebe. nen SGongrunb befteft, oer nod mit eingelnen Quarzfth den, ganjer uno zerftúdter Sjornblente, uno nod) ganz une beránberten offters fopfarofien $B$ afalt angehăuft iff. Ste

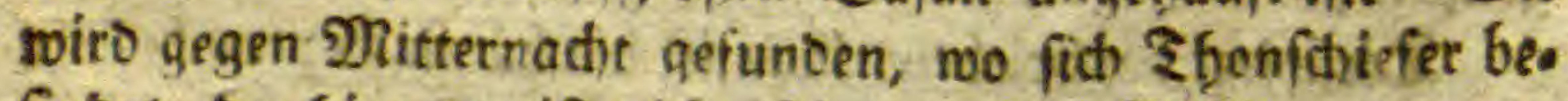
finbet, ber hier gewiß nidjt feinen exfen $\mathfrak{\text { Beftimmungsort }}$ 
Sat, fonbern burd) eine (b) walt emporgetgoben unb burch Lava uno 3 afalt ourd)gebrochen ift. Diefem gewaltfamen Durdbred)en baben vermutb̨lidf) oie eben benannten ange. Gุảuften Stùcfe if̧r Dafenn ju verbanfen. Id) jerfd)lug mehrere Stưcfe, um bie entḩaltenen Siòrper genauer unter. fudben gu foinnen, uno id) fano einen bem gemeinen weigen

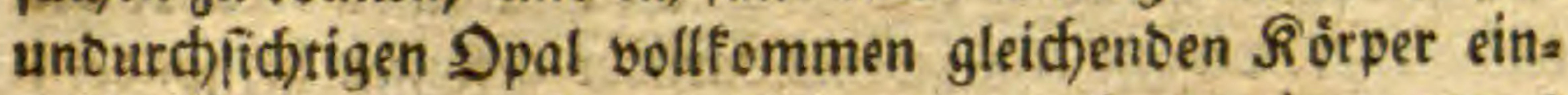
gefd)loffen, er war aber viel baarter, uno bৃatte einen etroas mufdlidten 3 rud blattridhten gu haben fóten; er war nur fo grof als eine Sucfererbfe; follte es vielleid)t gefdimolzener feltopatbig gea

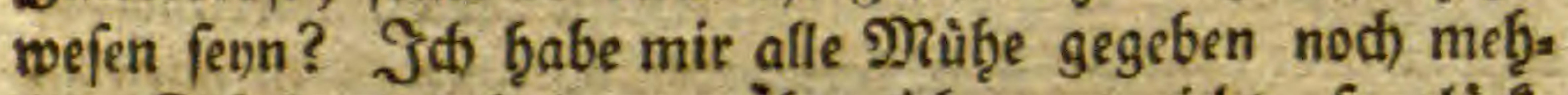
rere Stưce zu erḩalten, àber ich) war nid)t fo glücf. (id aud) nur bas geringfte mef̧r ju finben. $\mathfrak{B}$ en bem burd)gebrodtenen Shonf(hiefer findet fid) ein

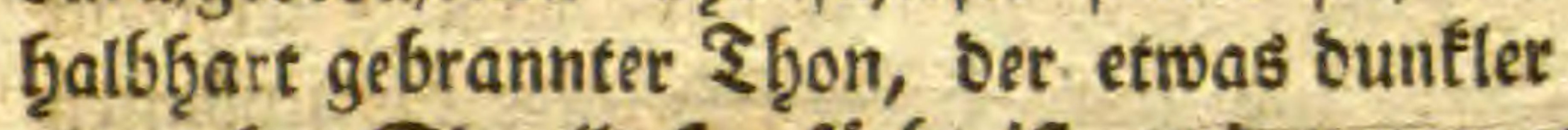
als rothes Siegellact gefärbt ift, uno nur mand)mal finbet fich weißser ober etwas ffeiff)rotber mit eingemifít)t; id wat noc) nidit im Etanbe mit biefem క̧̧on Berfud)e anju. ftellen.

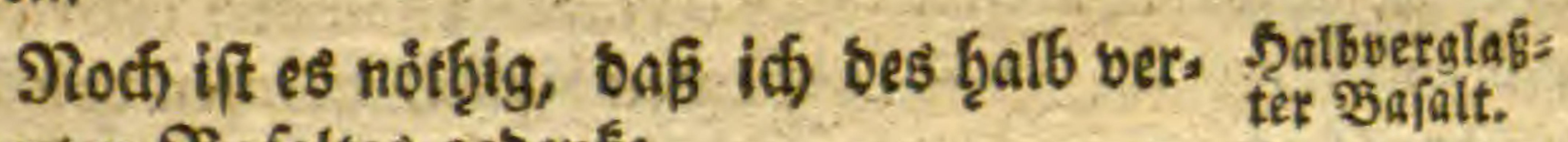
anberten Bafaltes gebenfe.

Er gleid)t meiffens bem vollfommenen $\mathfrak{B}$ afalt gang, entḩălt feine eingefd)loffenen Ş̧onftücfe uno bergleid)en, uno ḩat nur mand)mal ein etroas blafigtes Infȩ̣en; allein oie jeriprungene Jeornblende uno Ş̧ryfolittörner, weldje lejtere nod öfters am গianbe ober in ber Mitte einige $\mathfrak{B l a A}$ fen jeigen, beweifen eine balbe Berglafung, wenn idf fo fagen barf, bollfommen, fie fino aud) nod) úberbies rơther an Farbe, vermutblich, waren fie in ber 9(ac)barffiaft bee flügigen saven, uns rourben, nacfibem fie nàber ober ento fernter bon ber Feuersgewalt entfernt, mebpe ober weniger

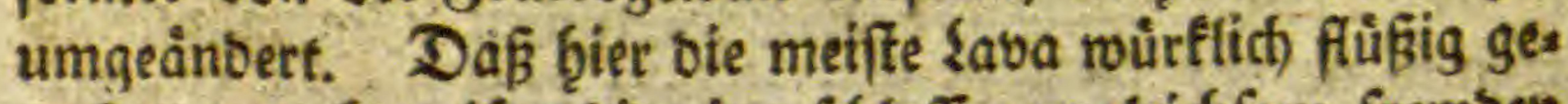
wejen war, beweifen bie eingefdilofienen gleidffam fremben

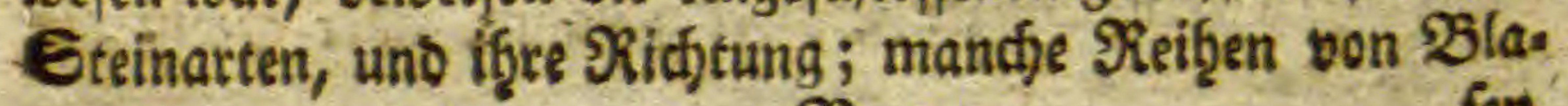


fén, bie entweber in geraben ober trummen sinien nod) gu

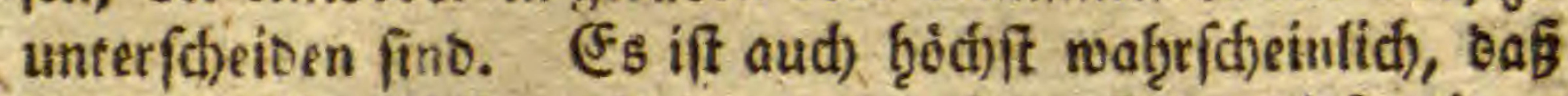
megrere 2fusfurffe auf einanber gefolgt fino; diefes fann id) nidje nur burd) Stüdfe von groen berfdiebenen überein: ariber gefitteten Sabaichid)ten beweifen, wovon bie eine Edicht fthon gebiloet, uno vielleid)t aud) fidion erfaltet ge. wefen war, ba erft eine zwente bariber geflefien if, fonbern es beftátigen es aud) Die Menge ber verf(diebenen Laven felbft, sie fid) nicht nur ber Jarbe nat), fonsern aud ourd Die in ihnen enthaltenen Rörper genugfam unterffteiben.

Berfallen ber Dieje Lava miberffeht ber Einwirfung bet Sava in Erbe. Suft u. D. g. feineglweges, fonbern fie roirb an

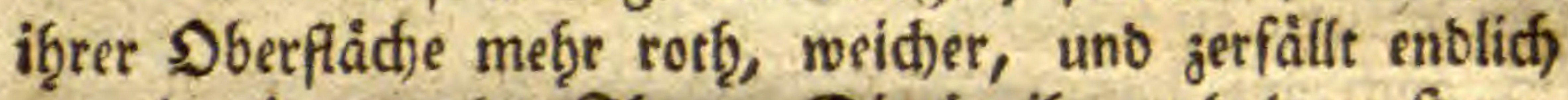

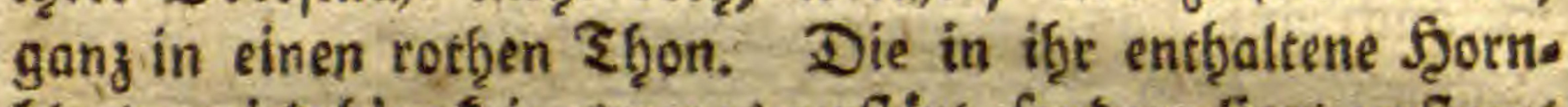
blende wirb bier feinesweges zerftort, fondern liegt zerftreut in biefem ?Ggon, uno man farn fich Gier bie fhoonften Rriftafle auslefen, beren Rriftallifation id) am Enbe bes fofreiben werbe: an einigen Drten ift felbbau angelegt, und bie felber beftefgen blos aus folcher zerftorten Sava, auth bie aange $23 a t b u n g$ jiebt ibre Nabrung aus berfelben, unb bie Eteflen, roo fie nicht bewadffen, glànzen von bet untermifduten Sjornblente. Die Saba ift an einigen Drten in Jgaufen zufammengelegt, bie fichon gang in einen rotb. braunen, erbigten Thyon aufgelöf fino, gråbe man aber nach), fo fintet man nod meiftens ganje, aber fofon weidfe sava, bie man öfters jwifthen ben fingern zerreiben fann.

Sortublente Die in biefen Saven enthaltenen J̧ornblen. Det Eava. ben fino ju ausgezeicinet, als baji fie nicht bere bienten genau befdrieben gu werben.

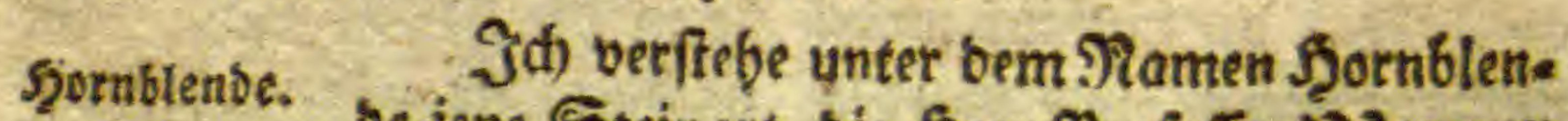
be jene Eteinart, bie feerr Profeffor Wetner in feiner Ueberfeşung bes Rronftadotifden. Mineralfyftems eben fo nennt; fie wito von einigen friftallifitter $\mathfrak{B}$ afalf, von antern friftallifirter Edjeirl genannt, aber gewiß̄ nie mit æectjte. 
Sie fommt meiftens, uno am ḩăufigften in ben gróe fern Slafen, uno faft immer friffallifirt vor; feltener ift fie in ben fleinen, nod) feltener iff fie in ber Maffe ferbit gleichfam eingeroad) fen, uno wo fie bann, wie id) f(t)on oben etinnerte, eine gleidf)eitige Entftef̧ung mit ber Maffe felbft

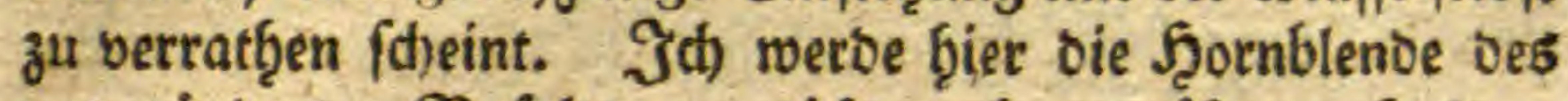
unberainberten $\mathfrak{B}$ afalts gar nid)t meb̨r erwåg̨nen, fonbern nur jener, bie in ber Lava enthalten ift.

Der Şauptcharafter ift, oaf fie fich in Blenbente Blatter tḩeilt, uno fie theilt fich zroar fo, Daf fie bie Saule ver (ánge nad) (paltet, fie läst fich) rísen, ift etroas weld)er als bie in bem Bafalt enţ̧altene Blende, uno giebt ein etroas rótb̨lid) graues Pulver.

Er ift faft immer friftalfifite, unb grate in einer acfic uno fect)sfeitigen Såule. Die adtrfeitlge Såule brat ente neber ziemlich gleichbreite Eeitenflächen, ober, meldhes weit ḩaufiger iff, es fino jwen berfélben, uns zwar bie fich.

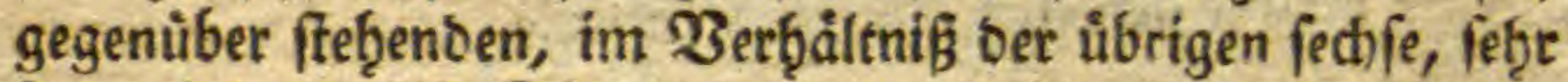

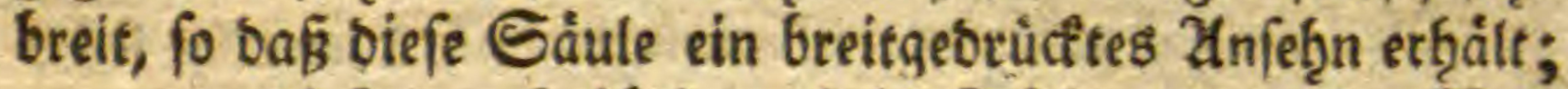
green von biefen noch) úbrigen fech) fläd)en fino, im $\mathfrak{B e c}$

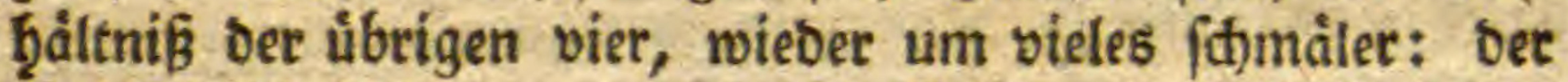
Rriftall ift faft immer an beiben Enoen zugefpizt, (eigents lidh foltte es beifien jugefd)airft) uno zwar an jebent Ente

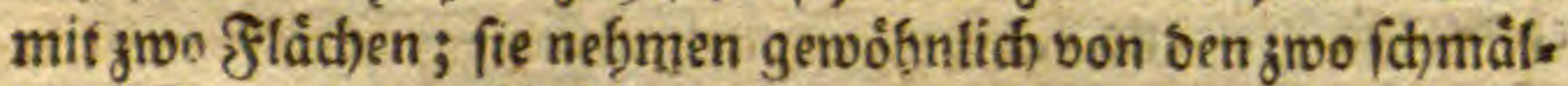
ften Geiten ib̧en 21nfang, uno fommen ob̧ngefähre in oet Mitte ber breiten Geitenffádjen zufammen, uno biloen ba sine ziemlid) ftumpfe Ed)àrfe.

Der sängeourd)meffer verbålt fich zu bem ßreiteburd;o

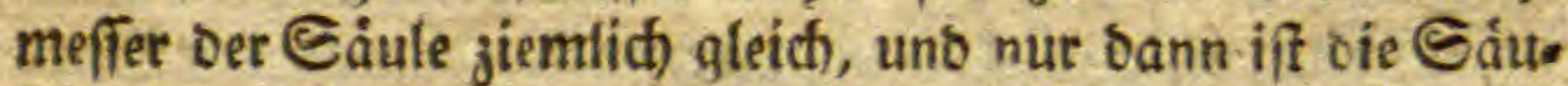
le etroas lánger, wenn bie Seitenflád)en unter einanber meg̨e vollfommen gleich) breit fint.

Diefer Rriftall ift ber ḩáuftafte, uno es aiebt zmo Spiel. arten, in Betreff ber $\mathfrak{B}$ erwachfuna, benn es fino entweber mefgrere auf einanber, ober neben einanber gewadfen. 
Bey bem 2fufeinanberwachfen pflegt immer ein fleiner Rriftall mit bem einem Enbe auf bem Enbe eines gröfiern aufgefegt zu fenn, uno jwar fo, baßj fie mit ibren Enden innigft mit einanber verwadffen fino; mand)mat figt pin britter nod) fleinerer auf, woburd) ber Rriftall oas Infeb̧n einer Etiege erḩălt; biejer Rriftall ift ber feltenfte bon oer ad)treitigen Såule.

Die neben einanber verwad)fene adfitfeitige Säule freflt. jwo verbriberte Eàulen vor, Die meiftens nur eine volls frảnbige adjtreitige Såule bilben, auf benoen Seiten fino fie mit vier fläbjen verfegen, uno nur ouf ber einen ftellen

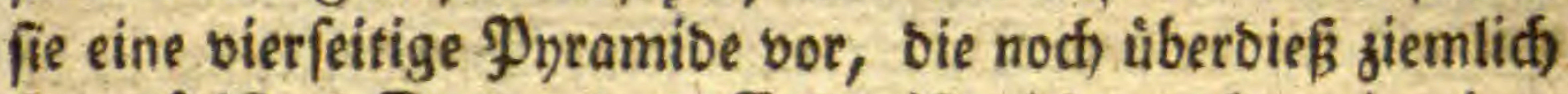
ftumpf iff. Das andere Enbe ift nicht mef̧r mit einer Pyramibe verfẹen, fonbern mit vier fläd)en einmårts ver= tieft, ooer gleidffam eingefd)nitten, uno fo oft ich ben Rriftall fah, fo wat bas eine Enbe mit bier fläd)en jugefpizt, uno bas anbere immer bertieft zugefpizt; biefer Rriftall ift fettener als bie gemeine ad)rfeitige Gaule.

Die fect)sfeitige Gaule ift entweber mit bren ober fechs flächen jugefpizt. Die fectisfeitige Salule fo mit oren Fläctien jugefpijt ift, bzat meiftens ein etroas beditgebruicf:

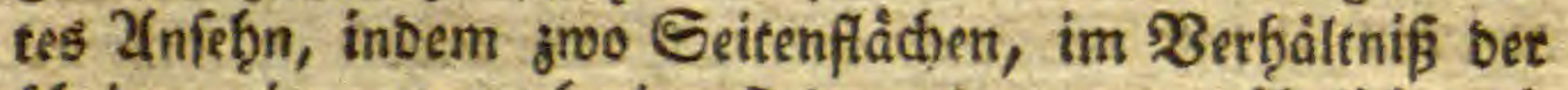
übrigen vier, etwas breiter fino, uno jwar gewoôţnlid) noch) einmal fo breit als ein 23 reitesurchmeffer von ber fómåletn Seite beträgt. Die oren Bufpişungsflätien fino \$ibonts boiben, uno zwar jwo grổere unb ein fleinerer, uno fie bilben nur eine fege frumpfe Pytamibe.

Diefer Rriffalf fiefert wieber groo Spielarten, eine wo ber Gäulenturdmeffer viel Eleiner im ßetbältniß bes \$ret. teburd)meffers ift; bie antere, too ber Eaulenourd)meffer Den Breiteburchmeffer um vielmal uibertrifft. Dbfhion bie. fer Rriftall viel feltener iff, fo ift et boch ber grökte, benn if fano nicht nur fingerslange uno eben fo bicfe Rriffalle, fonbern auch banolange uno oren 2uerfinger breite Eau. 


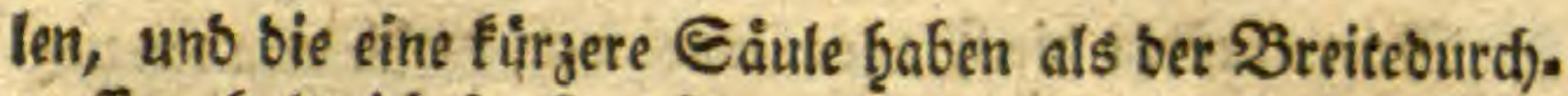
meffer, ḩalte id fauftgroß.

In $\mathfrak{B e t t e f f ~ b e r ~} \mathfrak{B}$ erwadffung babe idf nie etwas merf. wuirbiges angettroffen, aufer baßs mandbmal eine Eaule auf ber anbern ber ¿uere aufgewadfen ift.

Die fect)sfeitige Sáule mit ped)e fläđten zugefpizt; bie. fer $\checkmark$ riftall ift unter allen oer feltenffe, uno id habe if̧n

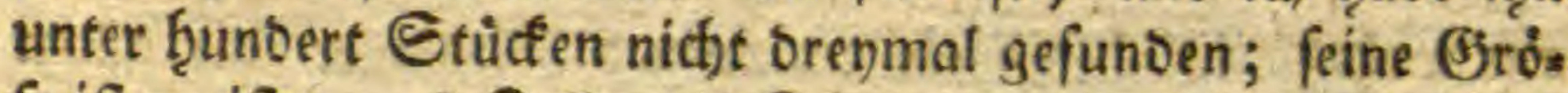
fe ift meiftens I $\frac{1}{2}$ Boll; bie Saiule hat ebenfalls jwo etwas breitere Seitenflámen, uno ber sángeburdfmeffer betrògt ofjngefäbr bie Şâlfte meģr als Der Duerburchmeffer; bie fect)s 3ufpisungsflächen fino ouf ben Seitenfláden cufge. fejt, unb bilten ebenfalls eine ziemlid) fumpfe gyramibe, Die aber oben wieber etwas abgeftumpft ift.

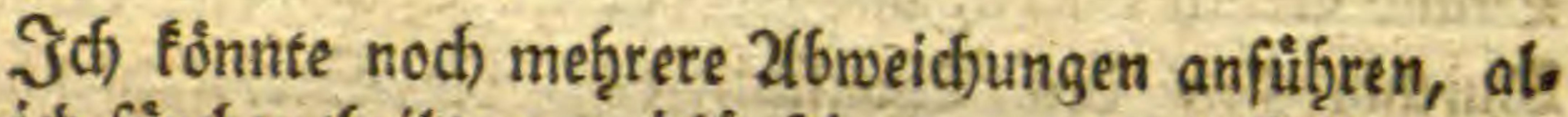
lein id) fürchre theils gu weitláftig ju werben, theils laffen

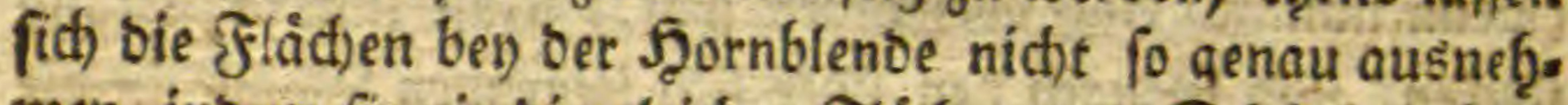
men, inoem fie nie bie gleichen fläd)en uno Edbärfe ḩaben,

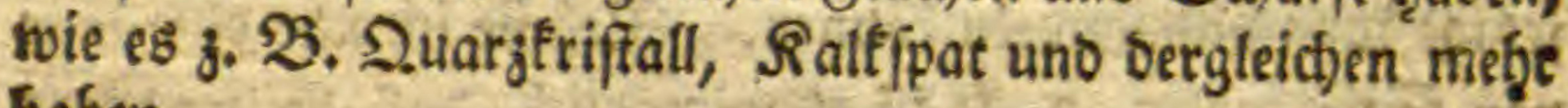
bुaben.

Ueberf̧aupt muß idf nocf) anmerfen, baß manche siefer Rriftalle gleidffam an ben $\Re$ anten runs gefdimoljen bor: fommen, fo dák fie nur einen Sropfen bilben, an bem faum noc) Die Rriffallifation zu erfénnen ift. Daß̧ hier ein mirf. lidbes feuter an bem Siunbfomelgen utrfache fen, ift mit unwabrifheinlich, id glaube vielmefge baßs bie meiften

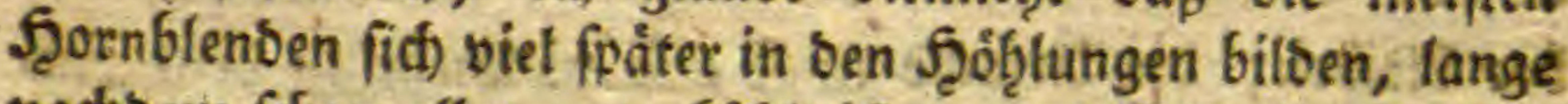
nadjoem fdion alles ausgefúblt ift: unD bak fie if̧r Dafenn Den burdibringenten $\mathfrak{B a}$ affern zu verbanfen baben, wo es alfo mo̊glid mar, daßz eine Blafe fo angefültt mutbe, baß Der R̂riffall, wegen oem ḩåufigen Etoff, bie șôthlung gang ausfutlte. 
Nun entffef̧t bie Jrage: was war woḩl sou ben tít: bie Urfad)e biefes Bulfans, uno too lag bie fadben des felbe:

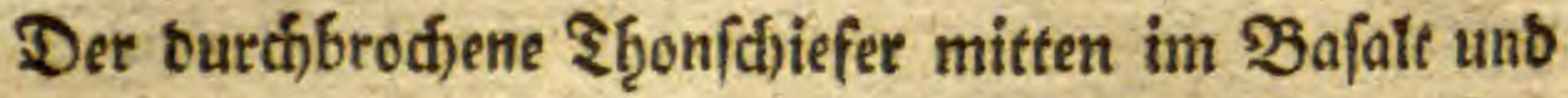

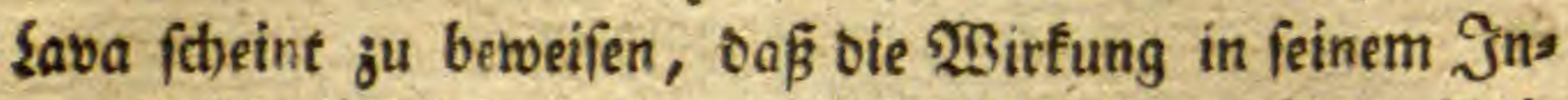
nern felbff zu fuct)en, oder bielleid)t felbit in oer (Strenzidheioung bes Granits mit bem Shonichiefer, uno bann b̧atte am wahtrfheintichften ein maid)siges Rieslaget bie ganje Ummanblung in sava ferborbringen foinnen. Daß̧ bers. gleicten Rieslager mirflich vorbzanben finb, beweife ich bas burch, baßz noch einige (bie glcich)/am Stocfwerfe bilben) im Shonfftiefer bes gifsner Rreifes gefunben werben; biefer Ries mag nun burd) was immer für eine Utrfache in Branb gerathen (eyn, und ḩat bann audf) zugleich) ben bem

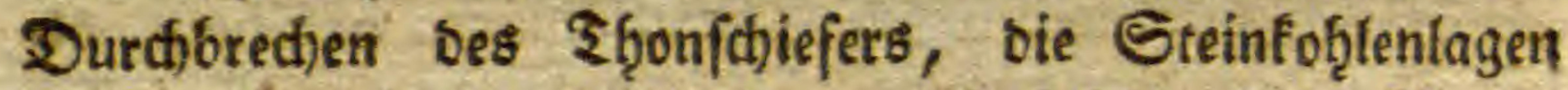
(wenn námfid) eine vorb̧anben war, ) felbft mit in \$rano ftecten, uno ḩernach ben über fich) liegenten $\mathfrak{B}$ afalt in bie

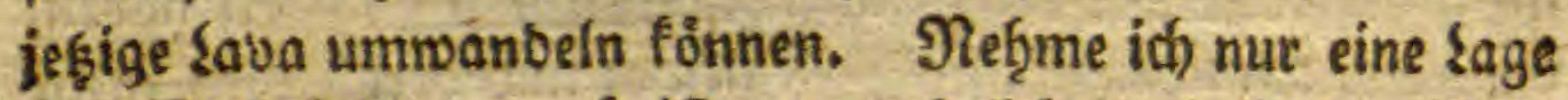
von Steinfob̧len an, fo ift es unmogglich, baß̧, ba ber Berg

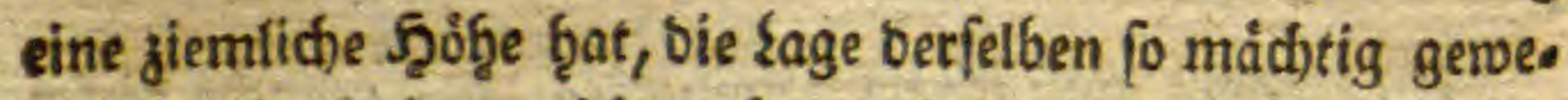
fen fenn fann (wenn id) aud) annef̧me, baß̧ bey) Entfteḩung uns 216 fégung berfelben fiter eine Bertiefung gewefen, wo (id) folglich meģe anf̧äufen fonnte $)_{2}$ dafi fie fo eine unge. ḩeuere 2 Birfung ţervorbringen fonnte, uno ùberoies wưr. be Das Durchbred)en bes ₹Ģon(chiefers baburd) unerflär bar bleiben; bie Urfacte muf alfo vielmeh̨r in bem Snr nern bes S bonfdjiefers felbft gelegen haben, weldhe mit grofs

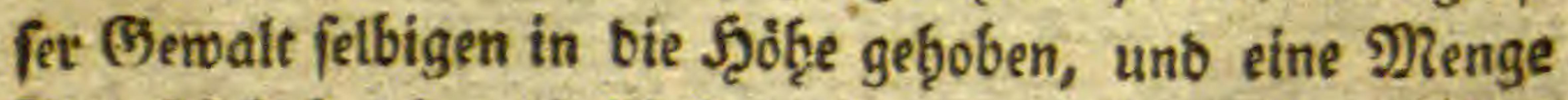

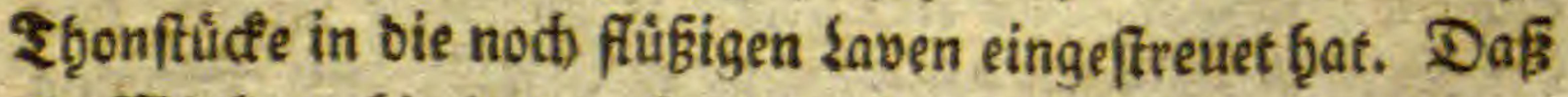
bie Wirfuna bis in ben (Sranit, ober beffen Grenzicheibung mit Dem Shonfdiefer eingeorungen fenn mag, fdjeinen bie einges 
eingefofloffenen Rörper zu beweifen, bie cin vollfommenes Selbfpatţ:2 2 nfę̣en ţaben.

Fine greente Frage foinnte biefe feyn: ob

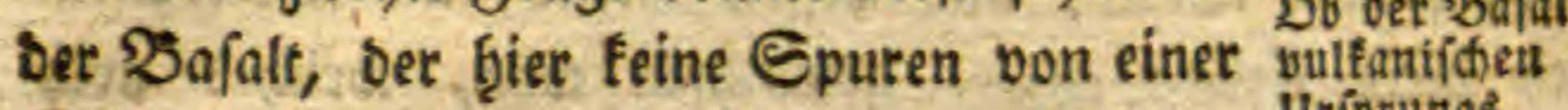
Edfmeljung zeigt, bem fouer fein Dafenn utiptutigs zu verbanten f̧at? ober aber, ob er frúf̧er ba gewefen, bevor Der $\mathfrak{B}$ ulfan feine $\mathfrak{B}$ irtung äußern founte?

Daß̧ ber $\mathfrak{B}$ afalt früber ba gewefen fern muß̧, if

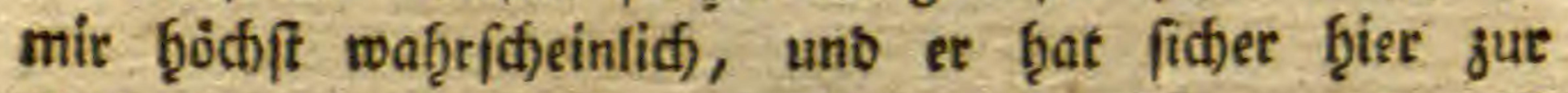
Silbung ber sava feinen Etoff Gergegeben, ober ift vielmeţe in felbige umgewanbelt; benn ba et viel leidj. ter fd)molz, fo that er weniger $\mathfrak{B}$ iberftano: am beute lichften fofeint mir ber ftufenweife llebergang aus ber Sava in ben bqaibverglaften $\mathfrak{B} a f a l t$, uno von biefem in ben unberånberten, je nadjoem er meb̧r ober weniget Dem feuer auggefezt gervefen. Die Çrnfolittörner be weifen nod) meø̨r meine Seb̧auptung; in bem $\mathfrak{B}$ afalt fommen fie zroar aud) öfters zerfucteft vor, allein fie fino immer meb̨r zerpprungen, jemę̧r ber $\mathfrak{B} a f a l t$ in Saba umgeanbert ift, unb fie finb bann meiftens nod)

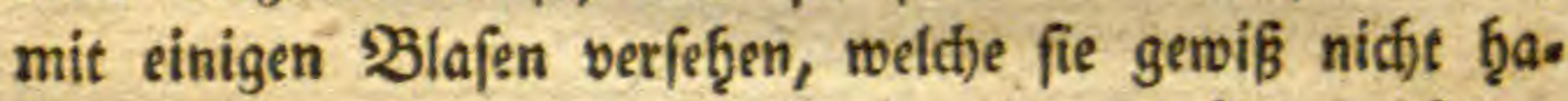
ben wùrben, wenn fie fich) in ber Saba gebilbet beátten, wie 3. 2 . bie f̧ornblenbe; ib̨re etwas gròjfere Etreng. fiúbigleit ift Urfact)e saran, $\mathrm{ba \beta}$ fie länger ber fómels zenben Sava troşte, uno es lápit fiid) vermuthen, bafi ber Ç̧rnfolit bem ungead)tet in einiger fef̧e flüfigen Sava ganj zerfdfmolzen feyn bưrfte.

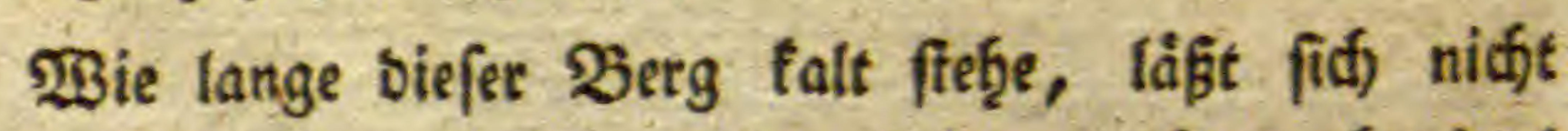
genau beftimmen; es werben fífjer mef̧rere bunbert Gab̧re 


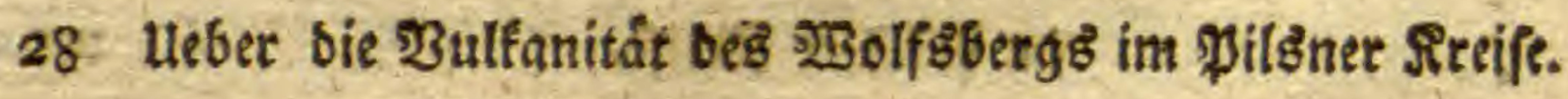
Jaf̧re erforbert, bevor fid) bie Sava wieber in ₹g̨on jerlegen fann, uno faft eben fo lange, um mit $\mathfrak{W a l s}$ bebeft zu reerben. Jid) fano einen ziemlich bicfen fichon ganz faulen Stod, aus beffen Mitte eine fiton ziem: lid) bicfe fid)te empor gewadffen war, meldhes nod) mef̧e beffen alteter erbृoţt.

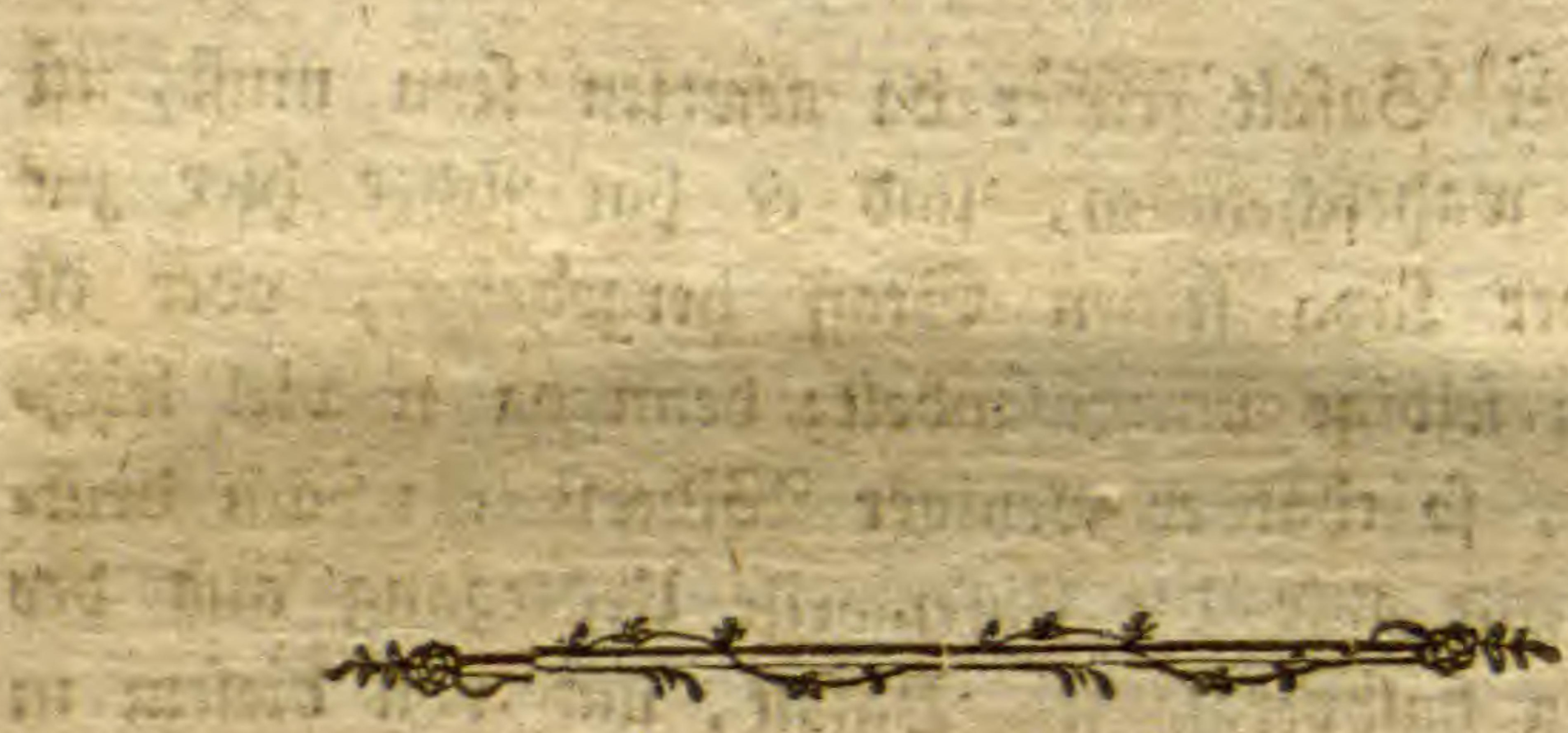


IV.

\section{Ueber Dic (Gefurtsorter}

\section{einiger \\ SBobmifichen Calcedone uno Der} in ifnen eingefthloffenen Roirper. Zon E:bendemfetben. 


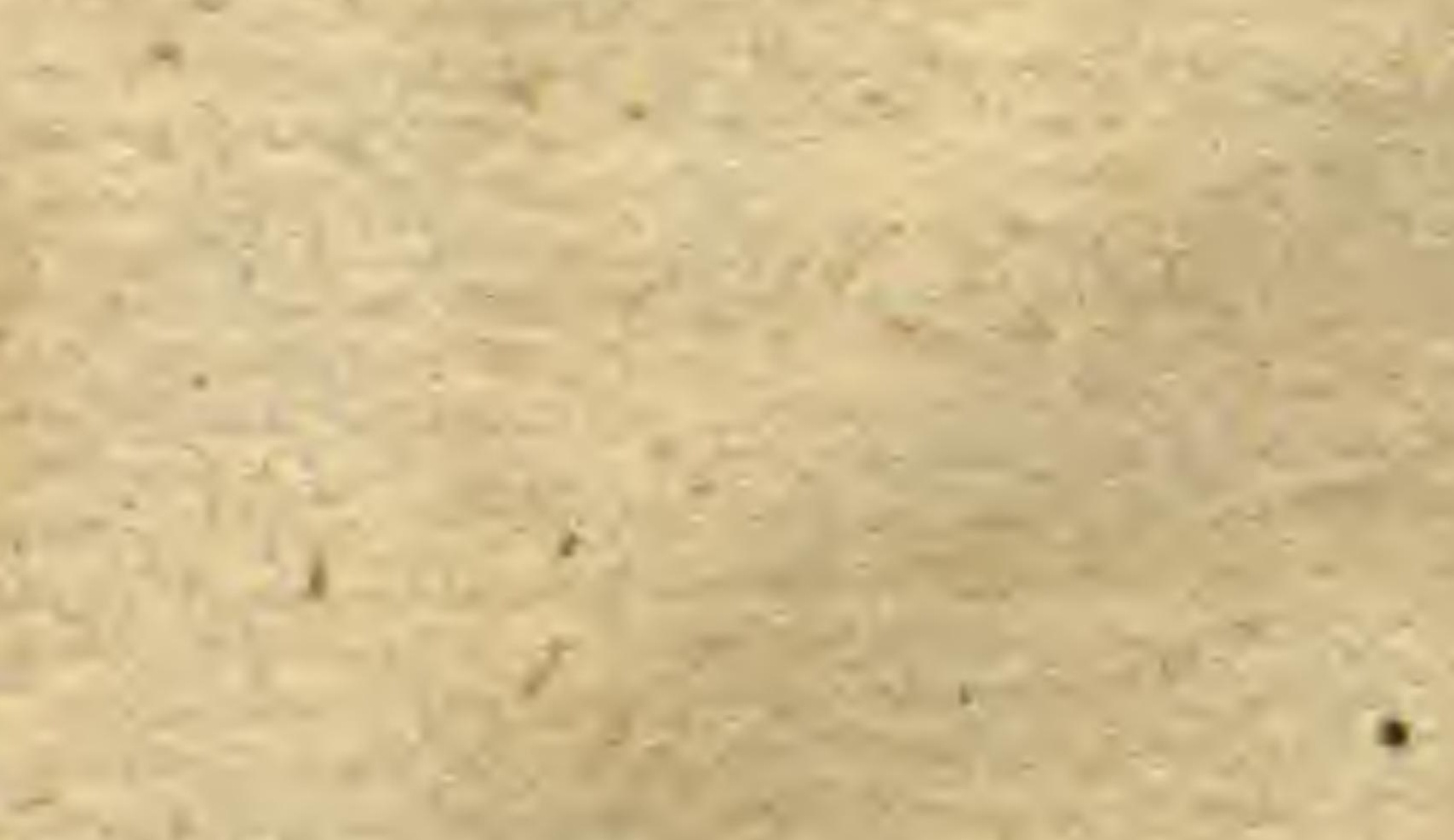

nit

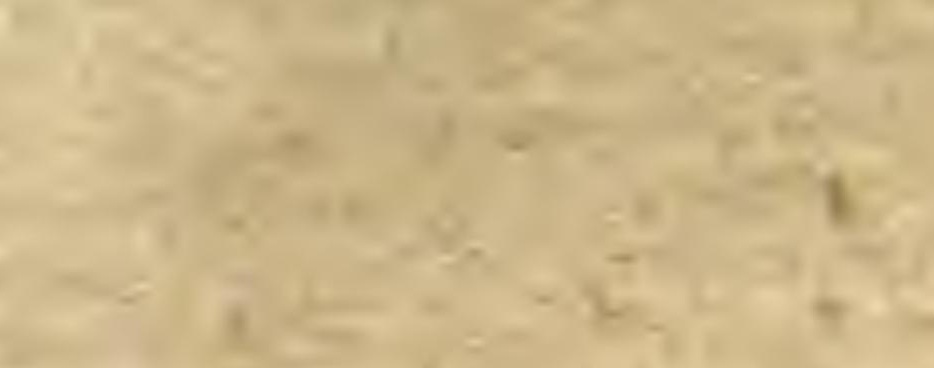

Th:

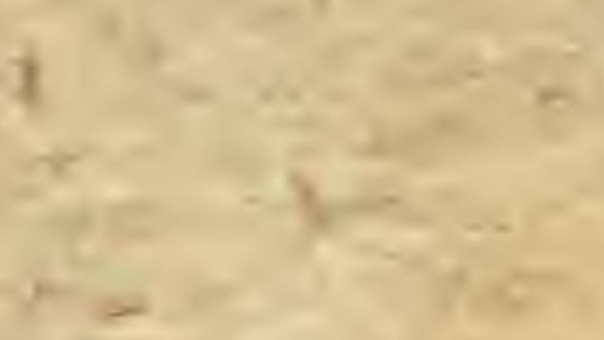

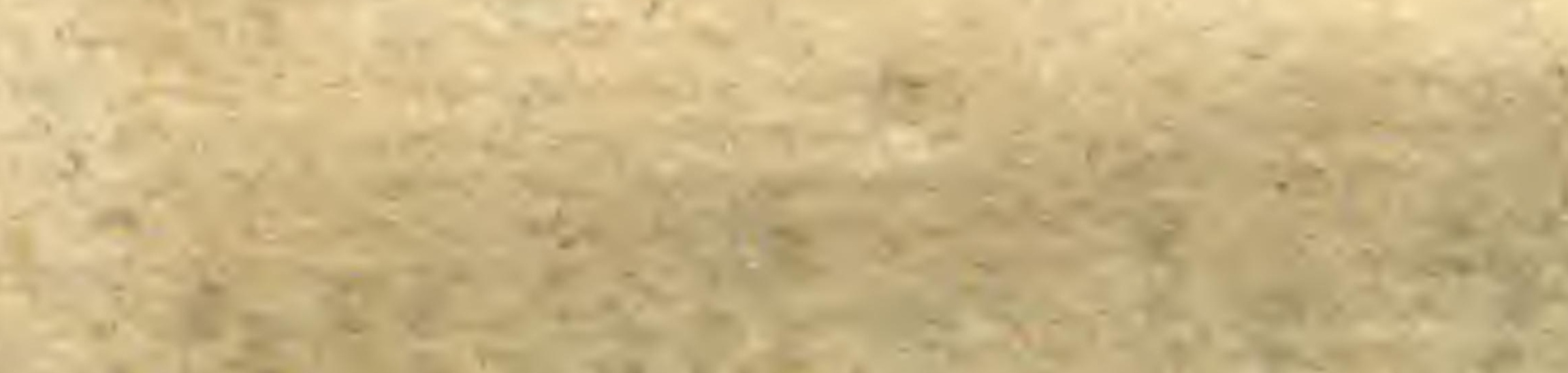

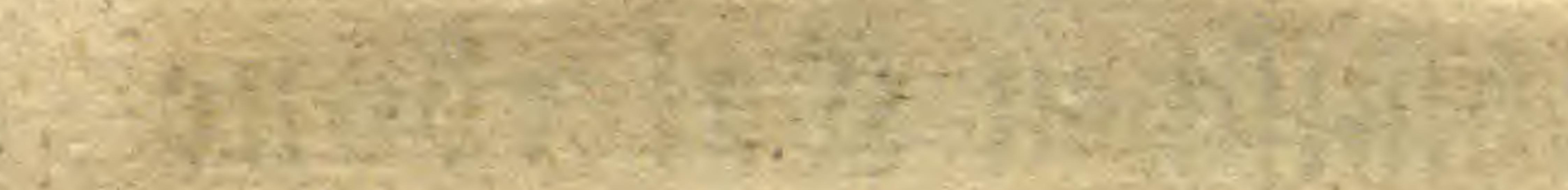
$+2=$

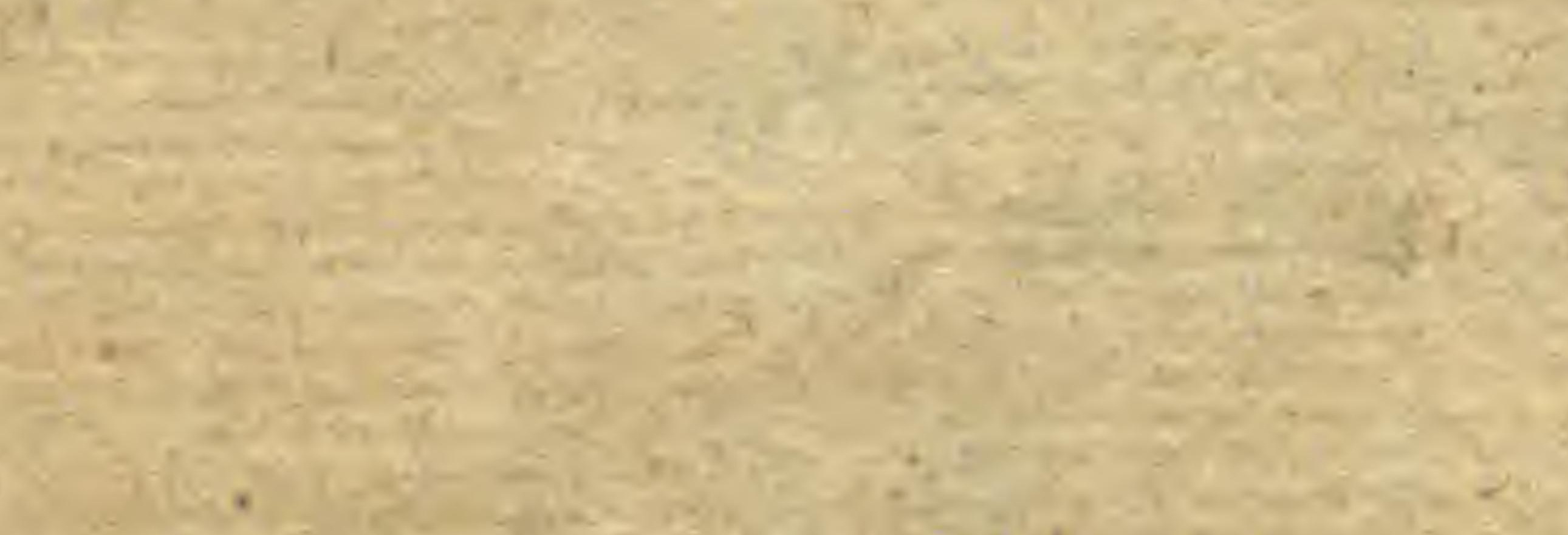

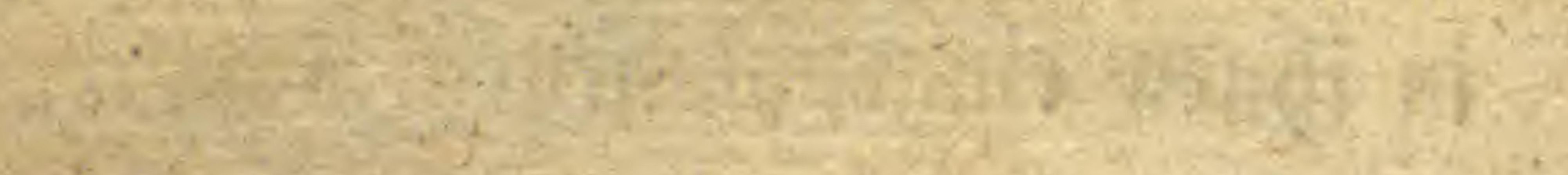

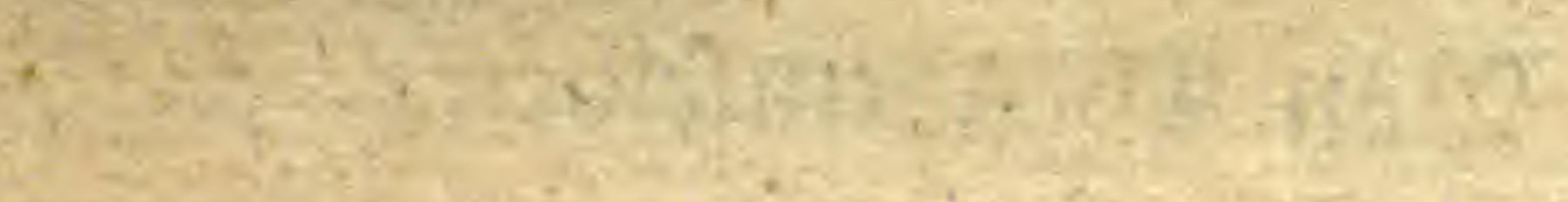

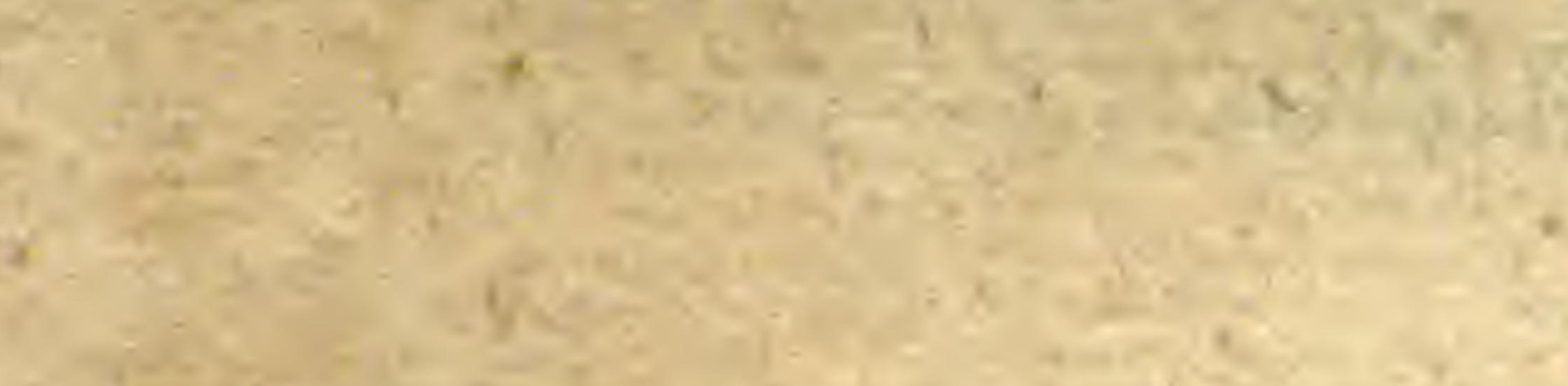

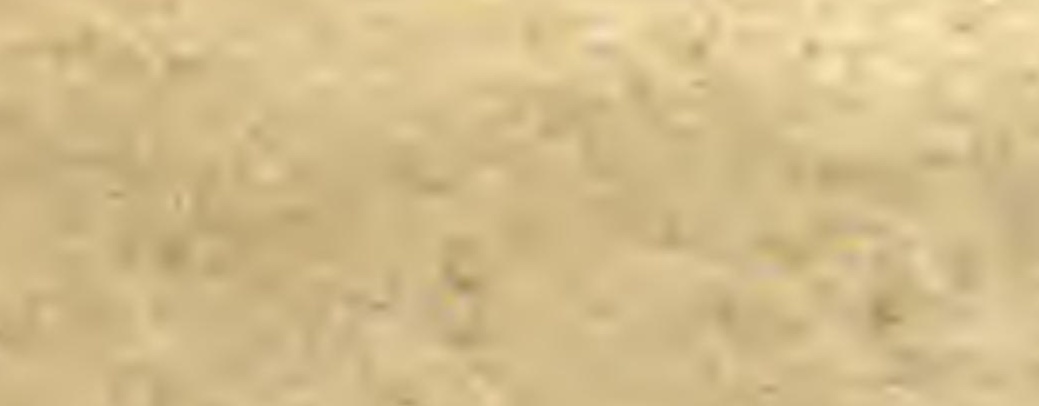

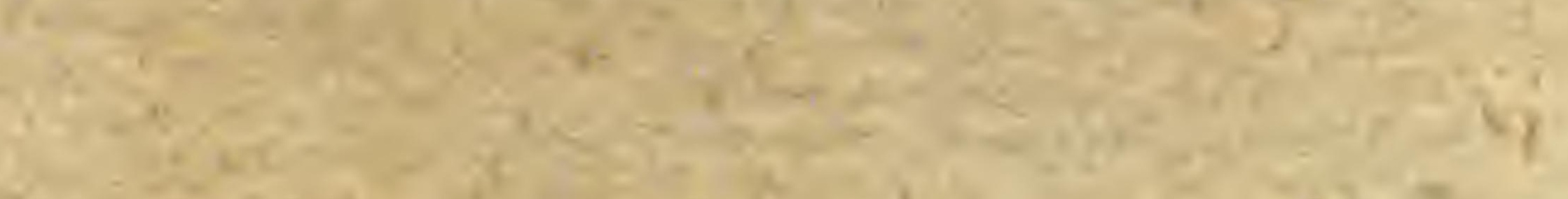

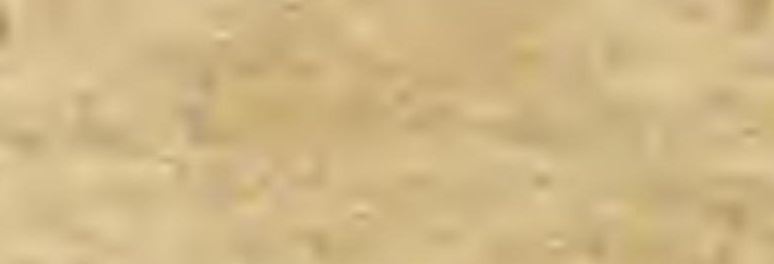$$
\text { ter } 10 m
$$ 


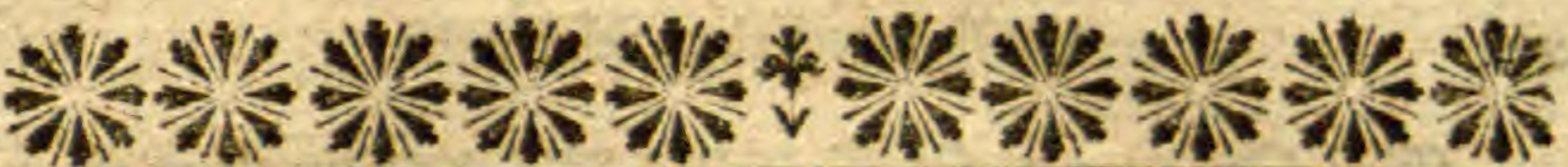

(S) Fenge Calcebons.Rugeln, bie man in Böb̨men auf Felbern uno an Lfern einiger flüffe finbet, ver. sienen gewiß unfere 2lufmerffamfeit. WBenn man ùber if̧re (Geburtsơrter nad) Denft, fann man gleid) benm er= fien 2rnblicfe vermuthen, baß̧ fie iţr Dafenn bem naffen 25 ege zu verbanfen haben, uno bie in felbigen eingefdhlof. fenen fremben Rörper beftátigen es noch mètj. Zllein, baß̧ fie auf frenem folbe ober an tlfern entffeben follen, (wie einige befjaupten) ift mir ḩỏd)ft unwab̧rffheinlid); fie machen vielmef̧r ein eigenes Struff (jebirge aus, unb zwar

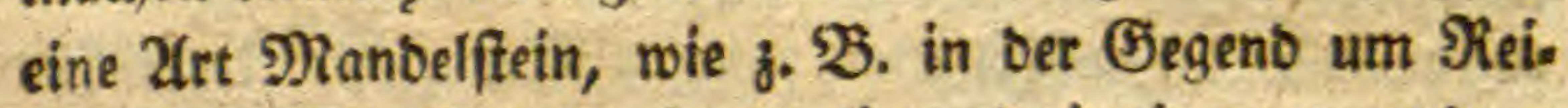
d)enberg. Die Calcebonfugeln liegen ba in einem etroas bume fel leberfarbenen, balo meb̨r ober weniger erb̧ärteten Ş̧on. grunbe, uno bie Ealceion. Rugeln vertreten gleidfam bie Etefle bes im शanbelffein gewöbnhlict)en Ralffpates, benn Diefer feb̆lt b̧ier. Miandjer bon biefen fogenannten Ealces bon-פ) Ranbelfteinen ift fệt zetreiblich), uno mit etwas grò fern Rugeln angefúttt, unb bie Tafpis= ober Grunbmaffe

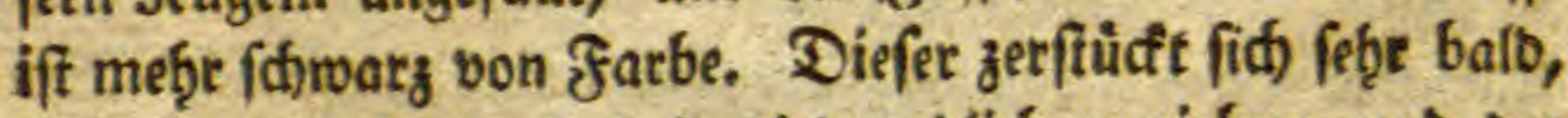
bet tḩonigte Beftanotheil mitb enolich) zerrieben, unb oer bártere Calcebon wiberftebet, uno wirb entrveber vom ${ }^{2} B$ af: fer auf bie Jelber gefübrt, ober an bis Lfer Der Bache gea collet. 
Eine Epielart biefes Calcebon, Mandelffeins bृat einen giemlid) b̧arten, faft bolffommenen Jafpisgrunb, ber les berfarbig ift, bie SBruchflächen fino giemlich eben, aber man fann bod) (efor beutlid) oen erbigeen SBrud abnebmen, in biefem finb bie Ealcebon- Rugeln feber fein, of faum fo grok als Punfte, ober f̧irfefơrner, obfchon auch) gro̊kere, ie. bod) jiemlich felten, untermifdft finb. Diefe Epielatt if mandimal roieber etwas zertrúmmert, uno if̧re Smif̧chen. rảume finb bann wieber mit Ealcebonmaffen ausgefüllet, entweber mit ganj gleicjartigen, ober es iff jene Epielart

- von fhaligt abgefonberten Etůden, (Onyx) meiftens mit mildfärbigen Streifen. Mand)mal ift ber mittelfte Theil reiner Suarz, ber bann, wenn er Raum ḩat, friftal, lifirt ift.

Die in biefem Calcebon-शanbelftein entḩaltenen Ru. geln fino mef̧r ober weniger runb, ober anbers geffaltet, einige fino faft volleommen rumb, uno auf ber Dberfladese

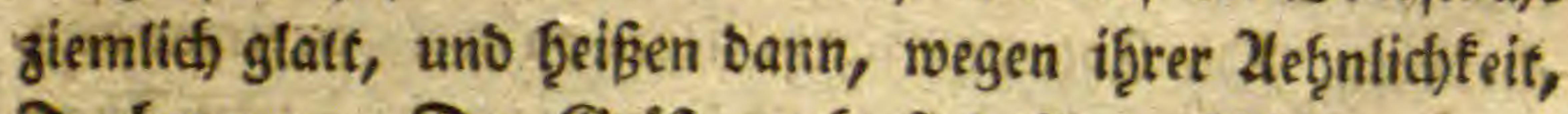
Taubeneyer. Der (Sirófe nach finb fie berfdieben, von ben fleinften झunften an, bis in meb̨rere fauftgroßje Etüt. fe : bie Rugeln fint entweber ḩob̨l ober bicht; menn fie ḩoh̨l fino, fo pflegen fie oann meiftens mit 2uarjfriftallen tiber: zogen zu fenn, unb bie jumal am gewoothnlidaften von wei. fer Jatbe, feltener bon raudjgrauer (Rauct)topas) am feitenften bon violetblauer farbe (2) fino bie innern J̧öhlen mit etwas Ralffpatḩ angefitlet, uno am wenigften ganj frey, uno gleid)fam tropffteina fơrmig. 
Der Jarbe nach fino fie gewơh̨nlid) Rerlgrau, weikk(f), boniggelb uno in ben meiften gerwóbnlicten Jarben bes Calcebons. Der 3eicf)nung nach), einfärbig, geflectt, geftreift.

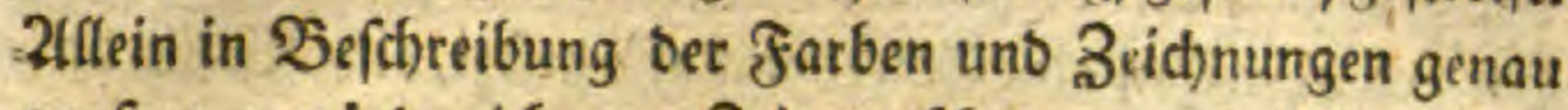
zu feyn, wübe id nur Beit verfofwenben beifen. Die beridfiebenen, gleichfom fremben eingefdiloffenen Siorper fann id nid)t of̧ne Gtillif)meigen übergeben, als: weis= lichter, grauer, gleichförmig balbourdffict)tiger Calceoon,

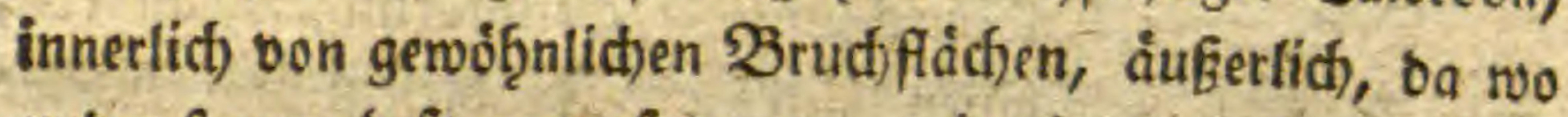
er ber frenen suft ausgefezt war, mit einer weislidjen uns Durchfichtigen milchigten J̧aut übergogen.

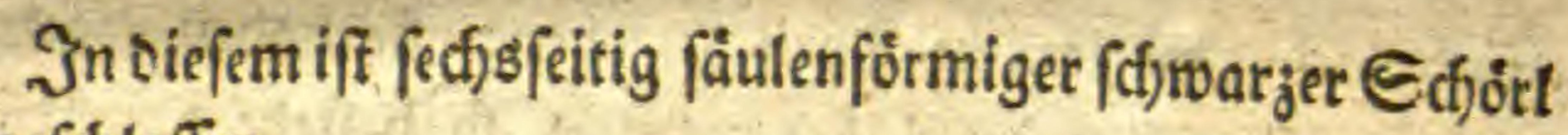
eingefकloffen.

Der Sđjơrl bat, im 2erb̨åltniß̧ ber ůbrigen vier Eei=

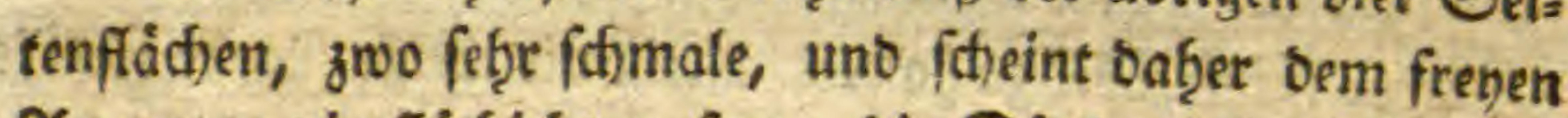
2uge nur vierflädidtt gu fenn; bie Gảulen b̧aben bie Dif.

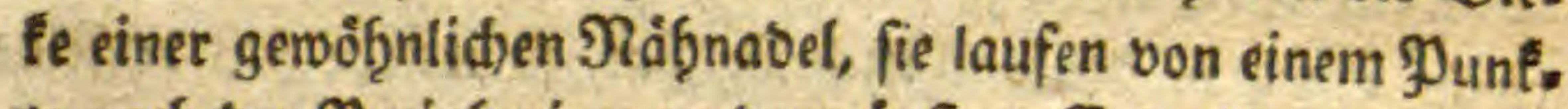
te nact) ber Peripherie; an bem äufiern Enbe ift ber $\mathfrak{B}_{\text {ereis }}$ nigungspunft, uno in ber Subftanj bes Calcebons bie Ber, theilung, ba wo oer Gdoorl liegt, ift felbiger mit einem

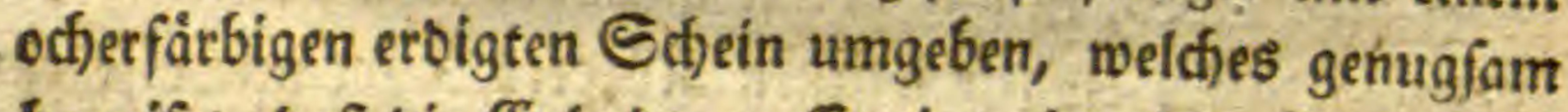
berveifet, baßz bie Calcebonmaffe eine giemlidfe Zeit flüjig

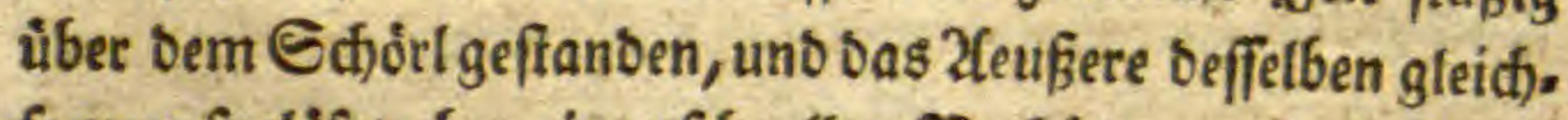
fam aufgelöfet; ben einer fó,nellen ßerb̧årtung, bie fich) aber fobalb niç), benfen låjt, ḩätte fiđh) unmẻgliạ) biefer Echein bitben fơnnen, ba ex bod) gerwís fein Dafeinn dem tḩonigten

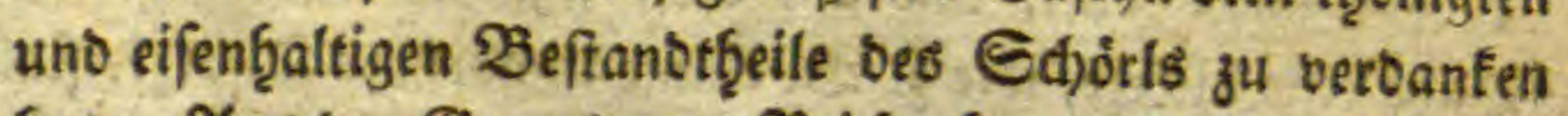

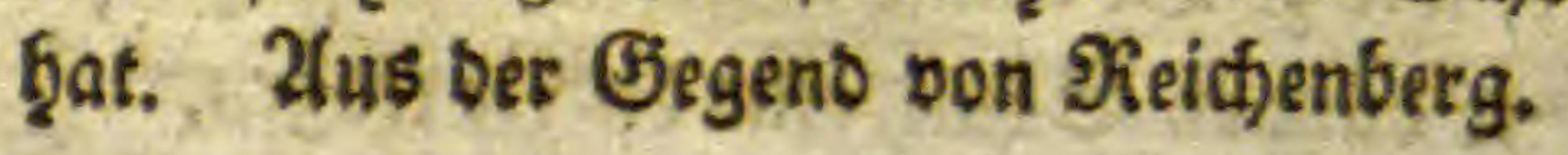


THie biefer Stjorl in ben Calcebon eingeffilofien routo be, ift leicht zu erflåren; vermutblich) ţat er fich zuerft in ei.

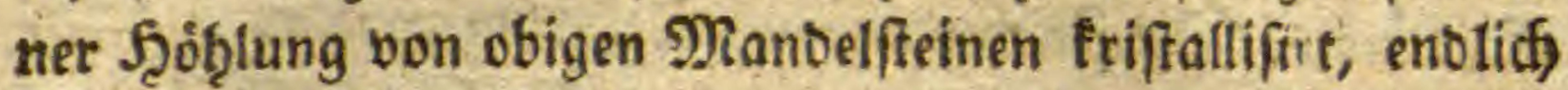
hat fich ùber if̧m eine (alcebonmaffe gefegt, eine Weile bat: ùber geffanden, bis fie Dann erf̧ärtete; Der झRanbelftein wut: be zerftort, no fie ein gleiches Echicfial mit anbern Ealce. bonfugeln b̧atte, auf tas felo gefúf̨rt gu werben.

פ̧erlarauer, halbourdfict)tiger, gleich förmiger Ealcebon; mit eingelnen bुellblauen flecten. In biefem find elingelie

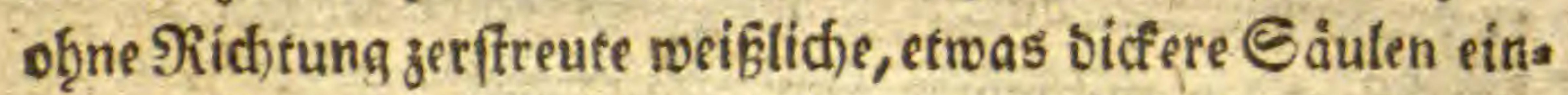
gefchloffen, Die meiftens am Fianbe if̧ren Znfang nef̧metl, uno nach oem innern ₹̧̧eil jugehen; fie ḩaben ein etroas ectigtes 2 nfeḩen, zerfoblägt man fie, to befteḩt oas Innere

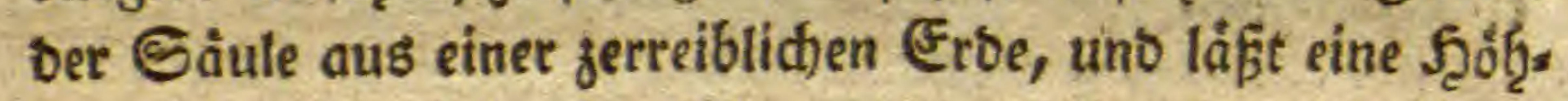

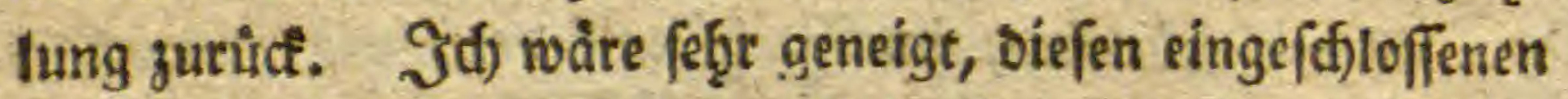

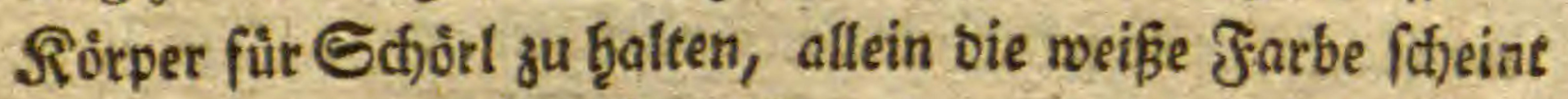
mir bas Begentf̧eil zu beweijen; benn ba jeber Edjoirl et. was Eifen in feiner Nifidung bुat, fo wurtbe fid baffelbe hier ebenfalls ourch sie farbe vertathen ḩaben. Es fit ci=

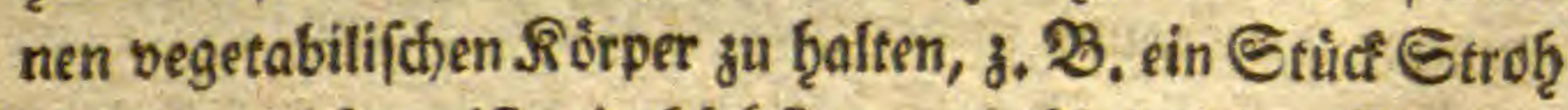
ober bergle:(hen, ift mir ḩöchft unmaf̧rf(h)einlid). Die Er. flärung biefes eingefóloffenen Roirpers bleibt mir alfo ein

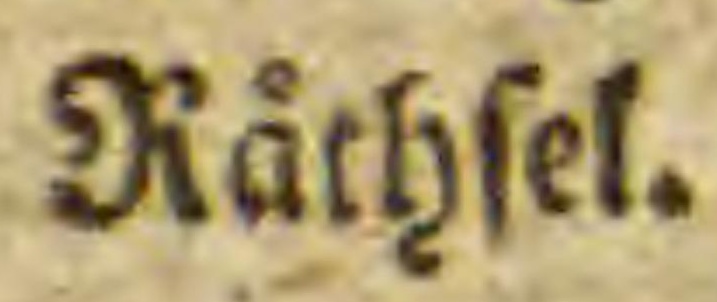

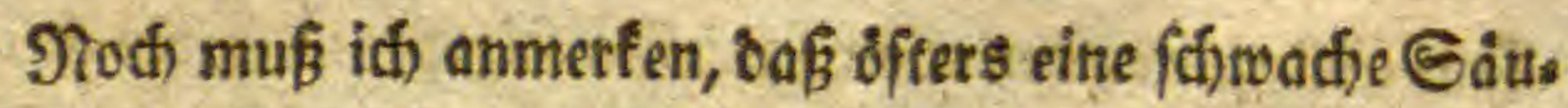

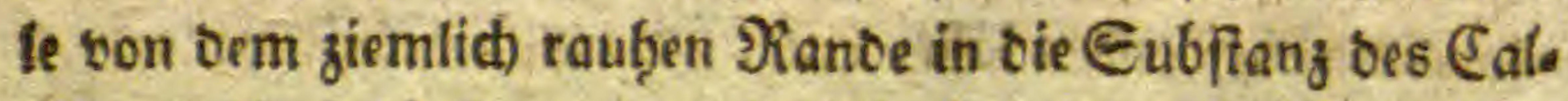
crbons b̧ineinläuft, unb auf biefe fejt fich mit bem cinen Ence eine bicfere, wie z. 25. einige ungarifthe Duarzfriftale

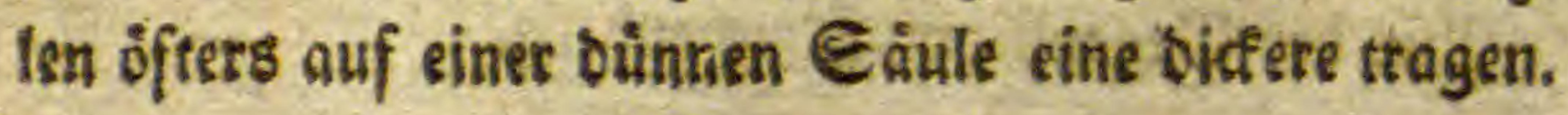




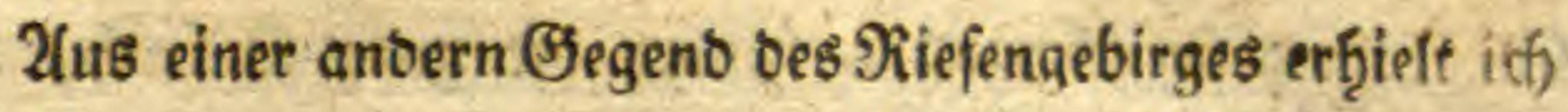
auch Calcebone, worunter zwen angefüb̨rt ju werben verbies nen, als:

Beiplichtgrauer gang gleitfartiger Galbrurctfichtile ger Calcebon, mit eingefd,loffenem wabren Mroofe, uto zmar einer 2(rt feinem $\mathfrak{B}$ affermoofe von einer ptmas lid) in braunen farbe; Daffelbe befteb̨t aus den feinfiten Şaarfalern, bie nur einen einzigen 2 nfang netimen, fich entich in mef)= reve 2lefte theiten, bie etwas ftilangenformig bin uno ber ges bogen, aber boch), menn ich fo fagen barf, parallell neben ein. anber laufen; die Enofpiz̧en fino manchmal mir হnó pfen verfefenen, ober auch nur bicfer. Diefes mabre Mioos ift feineswegs mit bem gewo̊bntict) moosartig ges falteten Braunffein gu verwedffeln, intem fidf bie ffas fern nie fo orbentlich zerebeilen, bann bals oicter balo bunner merben; gleich beym exften Infeb̧en wiro man beyoe wnterficbeiben fönnen.

Das zmente Etùc if gang bem oben befdyriebenen Ealceson mit bem eingefthloffenen פroofe qleich, nur eta

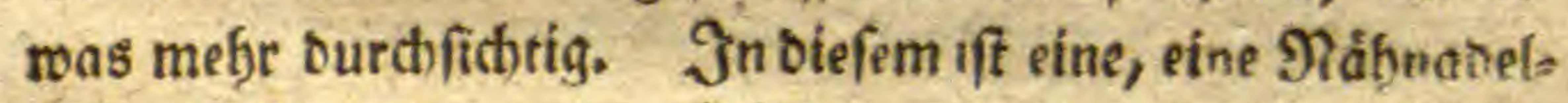
bicfe fieifdrothe runbe Eaule, von ber metrere defte, wenn id) fo fagen barf, unter einem rectiten $2 B$ i fef

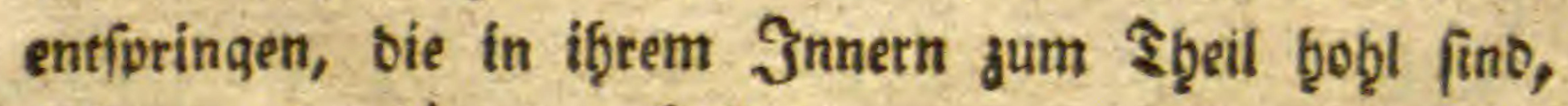
uno etras eroigtes enthalten.

Noc) muß id) zum Efiluffe anmerfen, baf alle unfere Calceoone mefje ober wentger mit einer gruinen

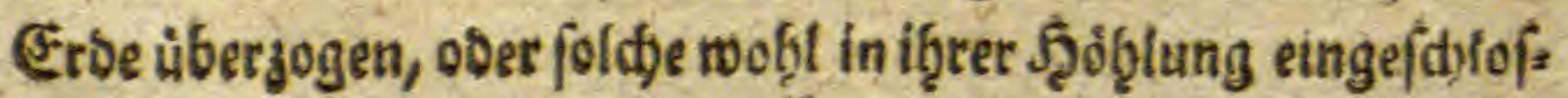
(c) 2 fent 


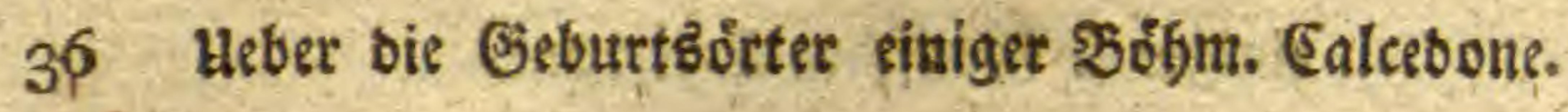

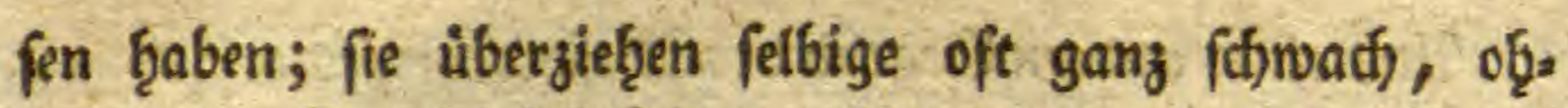
ve beffen Durdffichtigfeit zu binbern, unb f̧aben bann eine vollfommene (Ģryfolitfarbe; id) fạ̧ aud) wurrflid fleinere Stùdfe von biefer, für Ȩ̧ryfolit, in Sammlun: gen liegen; vielen biefer Calcebonfugeln mangelt ber grüne Ueberzug, unb fino, wenn fie burds bas fortrollen nod) nidjt glatt gerieben, mit einem rothen Ddjer übers jegen.

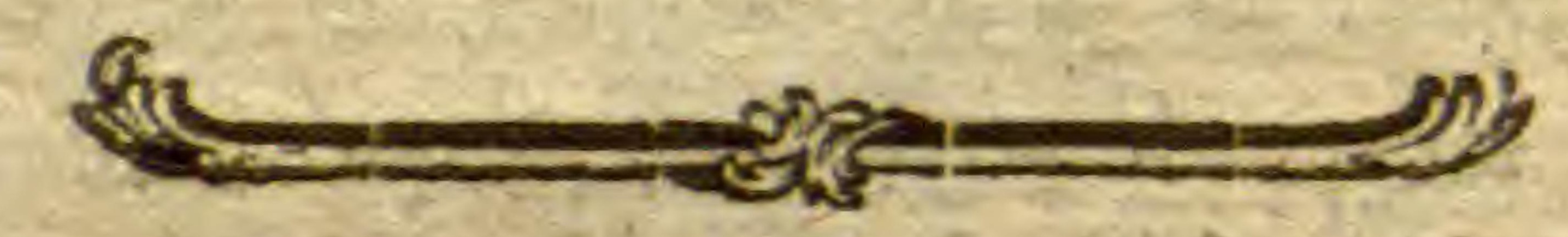


V.

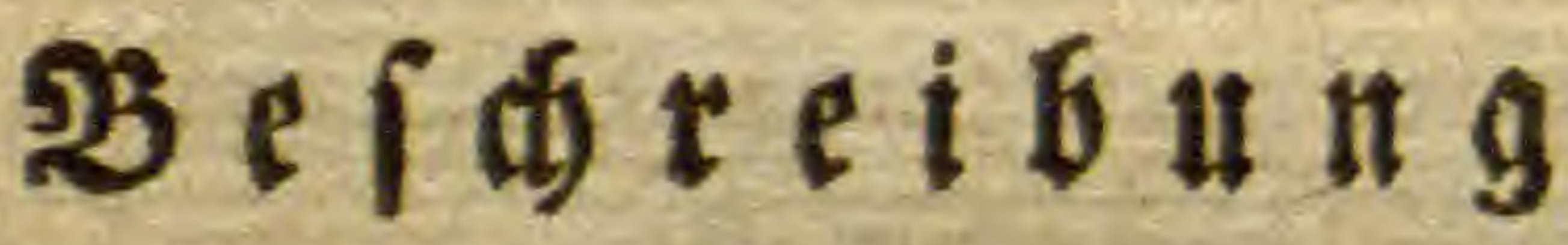

einer

nod) nidht beÉannten

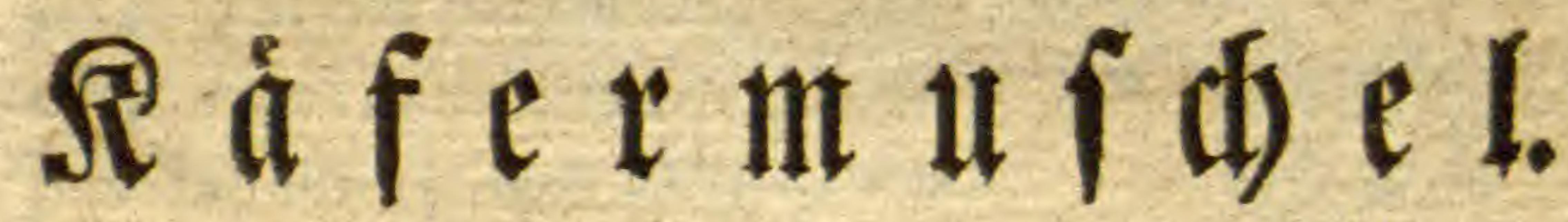
Zon Ebendemferten. 


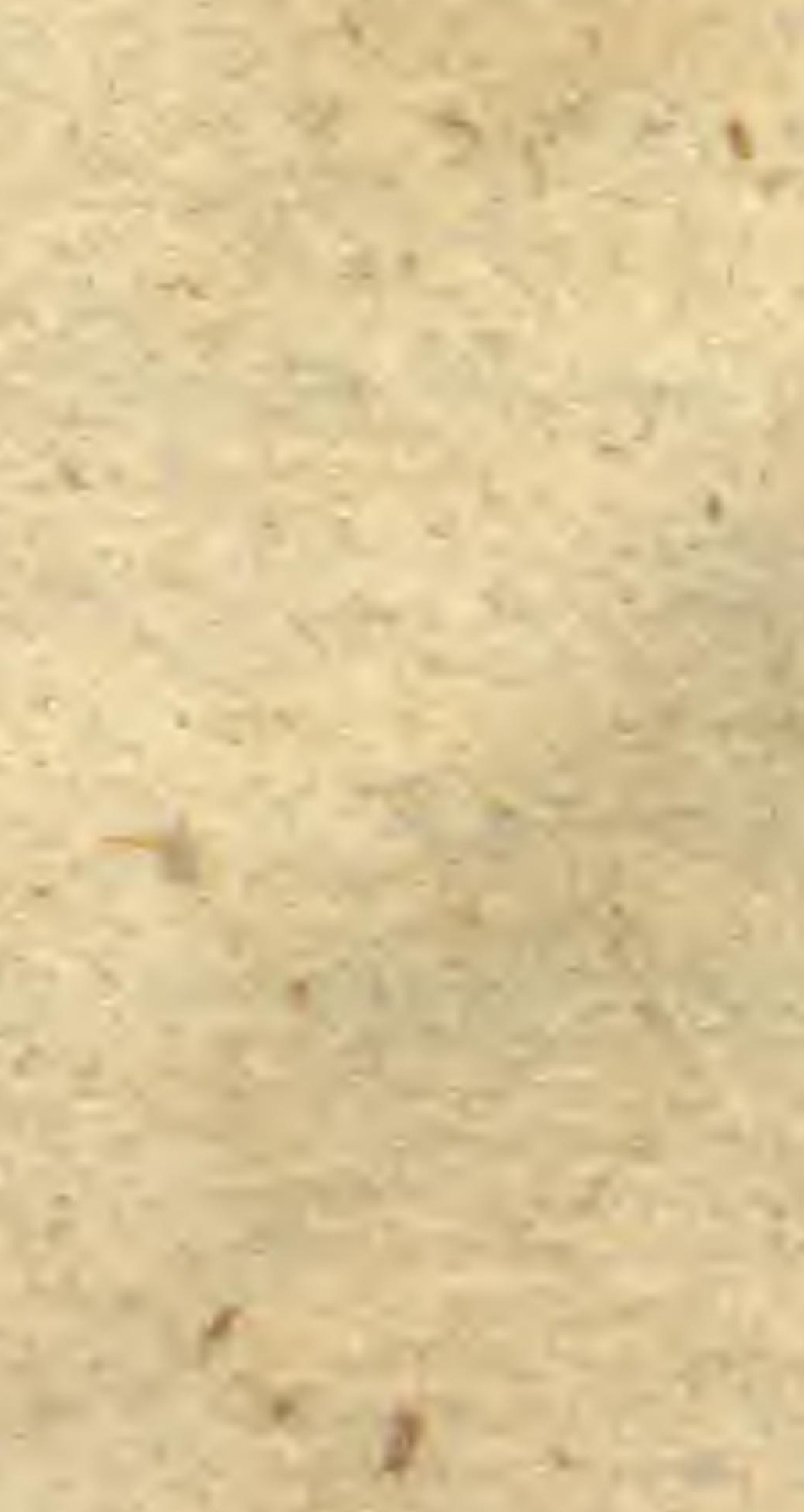

\section{1}

$$
\text { 2. }
$$

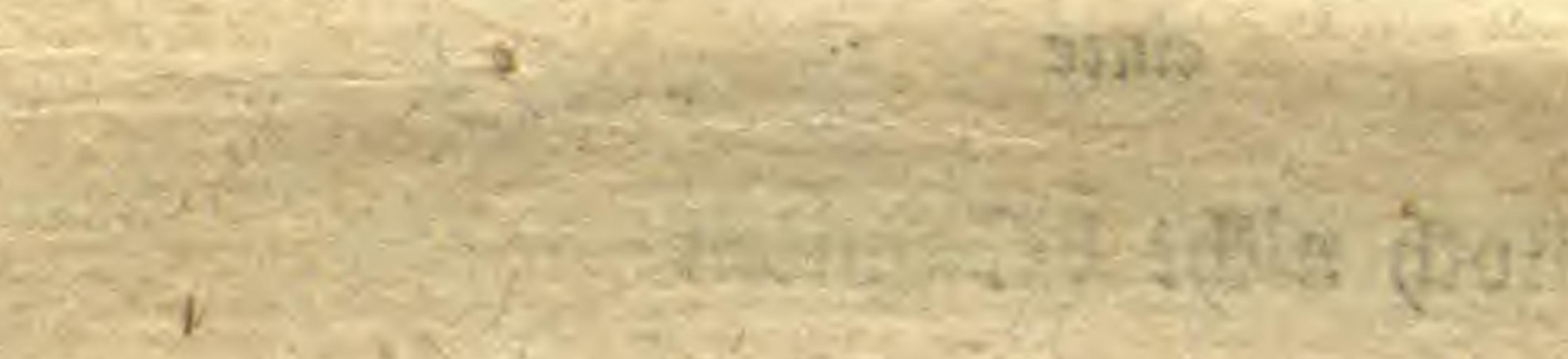

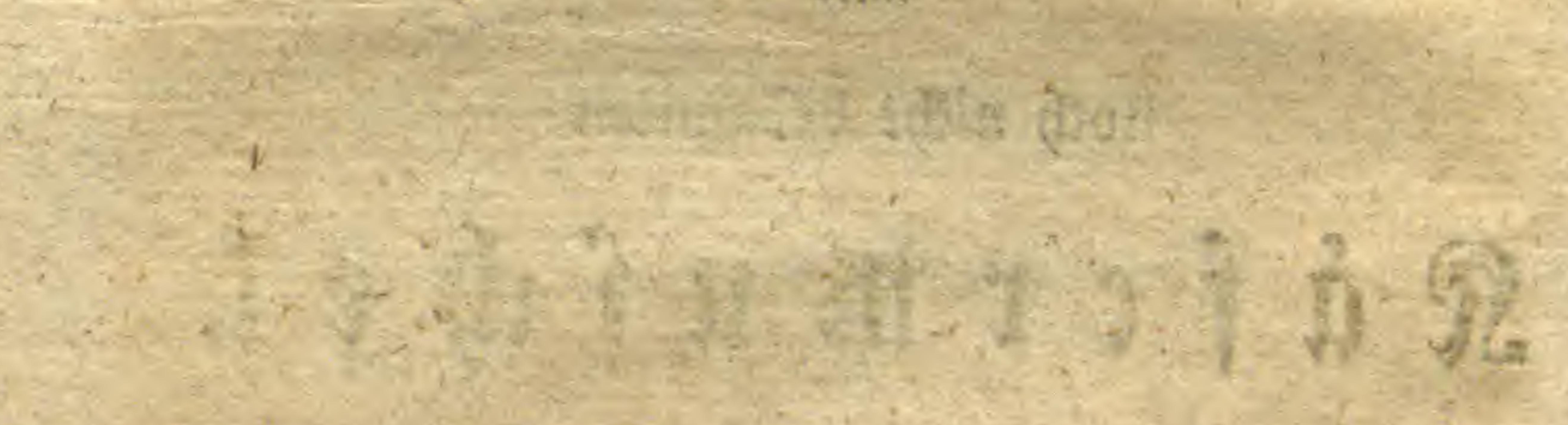

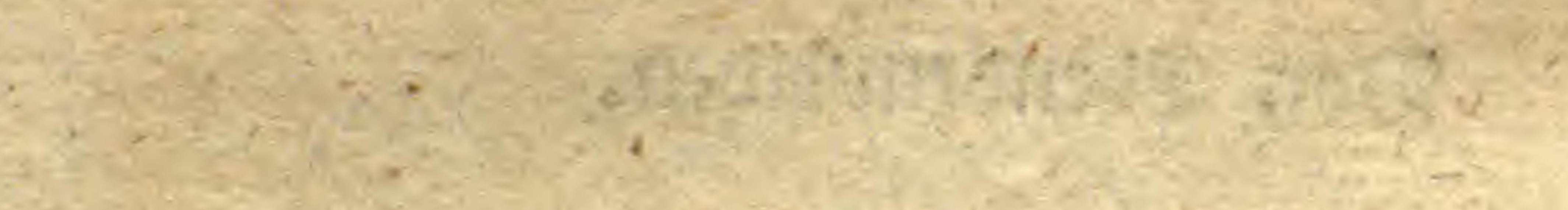

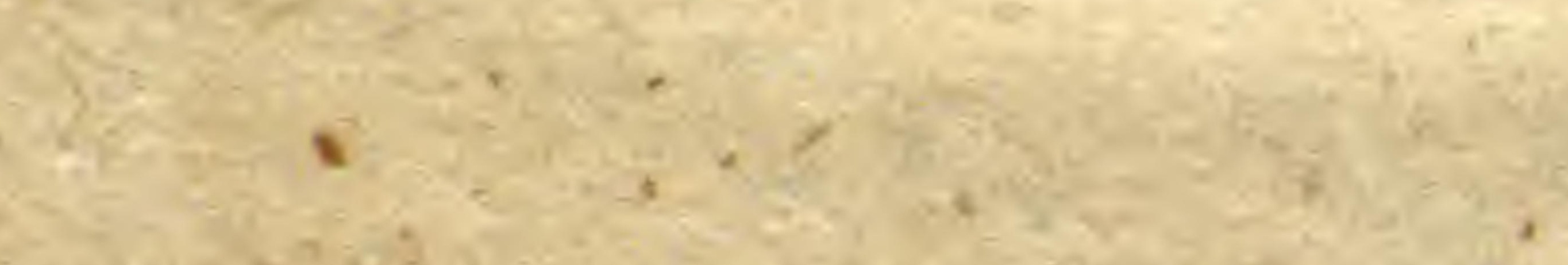

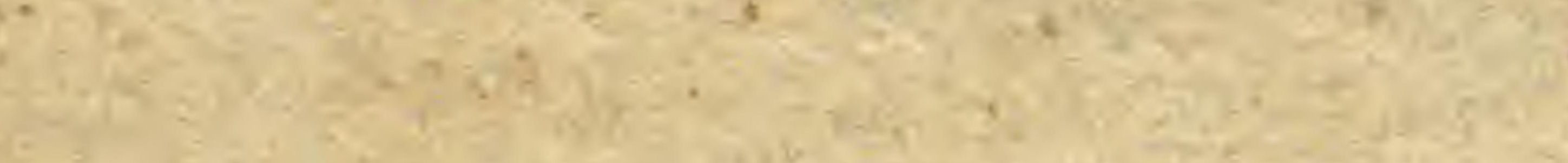
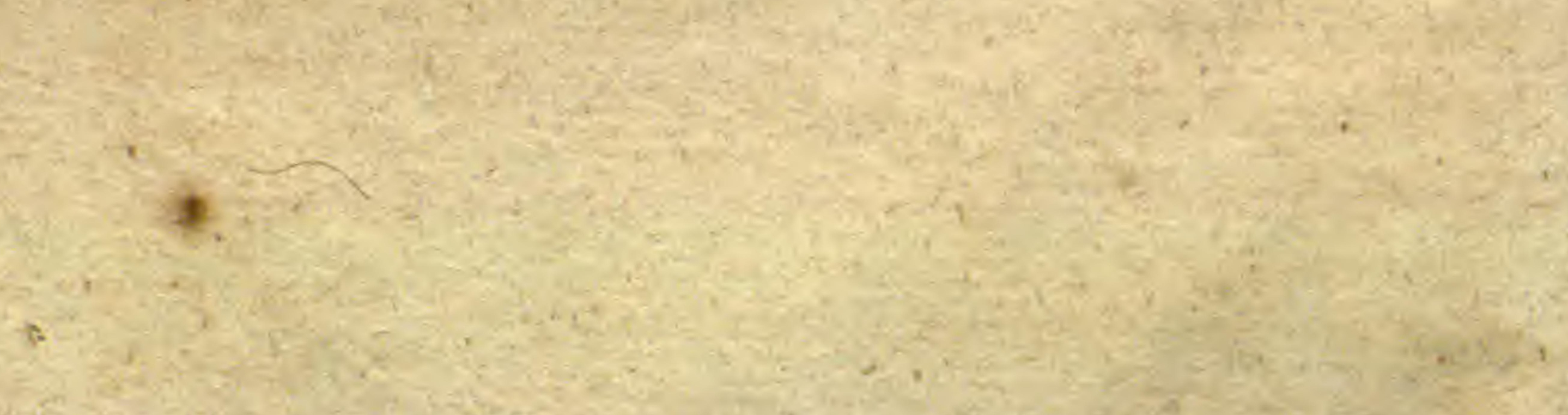


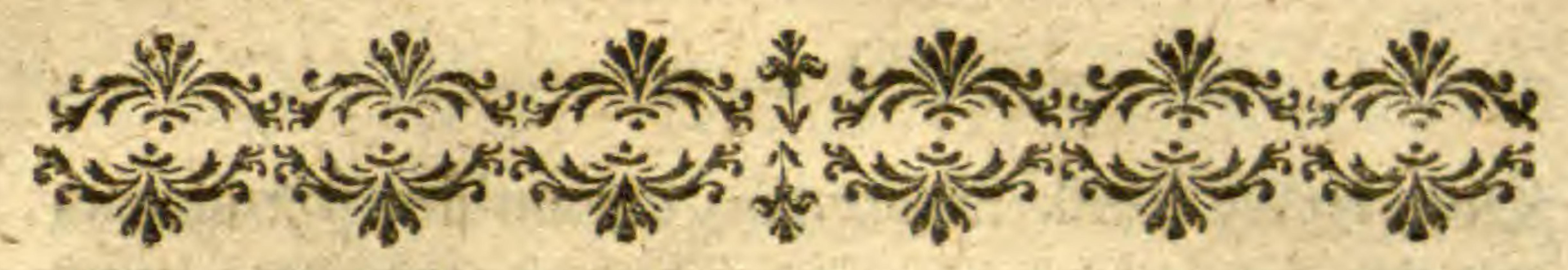

(3)

ie (S)birge um Prag finb meiftens Beburten fpaterer Entfteb̨ung, uno fie fübzren immer bas Bepråge bes naffen IBeges; man erfennet bies theils aus ber fleinern J̧ơf̨e, if̧ren meb̨r gleichartigen einfactjen gemifhten Sieinarten, aber am meiften d)arafteriftiff, fino bie in if̧. nen enthaltenen b̧äufigen Berfteinerungen (Es wed)feln foft immer flóflagen auf einanber $a b$, entweber mit ver= f(t)iebenen Eteinarten, 3. 23. Gruinftein, Ralfffein, Sant: ftein, ober es fino ju unterftheibente sagen won einer uns

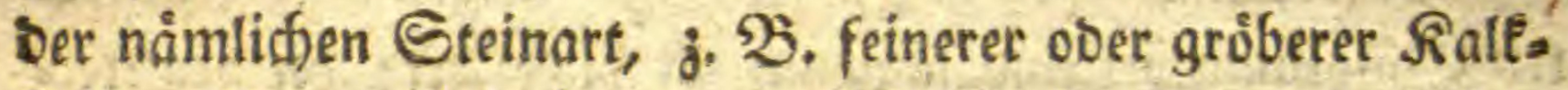
ftein, ober es fino sagen bon Berffeinerungen, entweber etwas fparfam eingemifcht, ober fo angebăuft, bafi fie ganz allein Sagen augzumachen focheinen; bie meiften berfelben

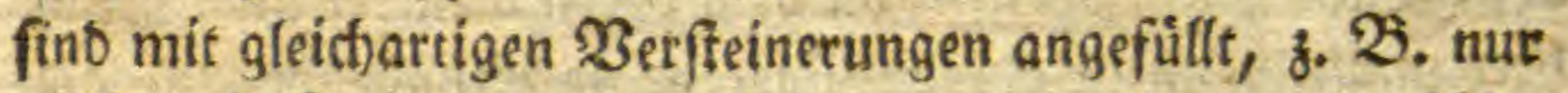
allein mit Drthoceratiten, ober es fino mebe von verfdies

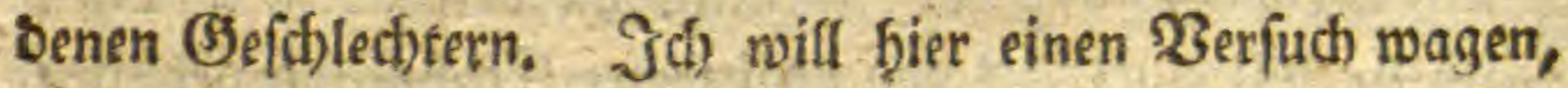
einige ber borzúglidften $z u$ befdreiben; allein id) rerbe mich) bier nur auf jene ßerfteinerungen einfdofränten, bie man im Sandftein findet.

Die im Sanoftein ned) fȩ̣r gut erf̧altenen Råfermute fófln (Entomolithos paradoxus Lin.) verbienen vor allen anbern juerft befdyrieben zu werben; fie liegen immer nur in ben erften uso oberften sagen. Das ganje Thier bqat eine obale (Seftalt, uno beftebt aus einem untern, aus meţ= zern Bliebern zufammen gefezten ₹̧̧eil, uno einem obern einfachern, ber jugleich nur aus einem ₹̧̧eil beftebt, Den - bern wollen wir ben Ropf nennen, ben unteen ben Roirper.

$$
c_{4}
$$

Die. 


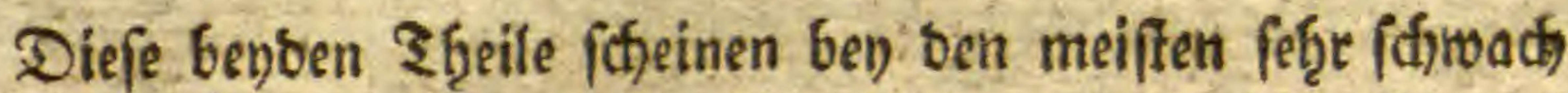
mit einanber verbunben ju fenn, inbem es gar nicfits feltenes ift, fie getrennt ju finoen; faft allegeit getrennet finbet man fie in Ralfiftein, viel fettener in Exfiefer uno Sanofrein. 3u biefer srennung foint mir bie auflófente uno angie.

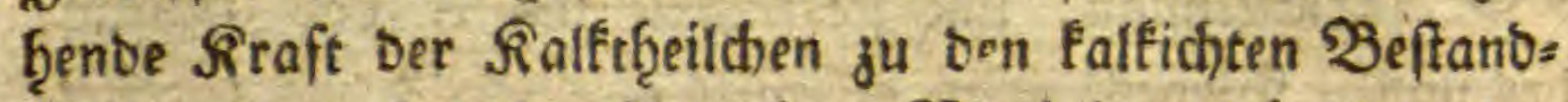
theilen bes of̧neḩin fdtroad)en Bereinigungsbandes bet Ech ale am meiften bengetragen zu bुaben. DaF if̧re Echaale falfigt fer), làßt fich) aus ber Xeb̨nlid)feit if̨ret Ecf)ale mit anbern in ber Matur ficon borf̧andenen Ul. biloern, uno ben 2ufbraufen mit Såuren im teinen Sand. ftein fobliefien.

Da ber eine ₹̧̧eil aus einer neşfỏrmigen ober gegitter. ten (Einfaffung beftehte, fo nenne iff Diefe 2(rt: Die gegitter: te Ráfermufdel.

Das ganze ₹ffier, wie fifjon oben etwåfgnt worben, beftebt aus zwey ₹b̨eilen; an bent obern bemerft man gleid) oren ungleiche mebge ober weniger ovale Erf̧abenţeiten, Die noch) außjerb̨alb, uno wo fie nicht an ben zwonten Theil folließ̧en, mit einer 2ltt von gegitterter fino; bie mittlere Erb̨o̊bung ift am meiften gemơlbt, uno

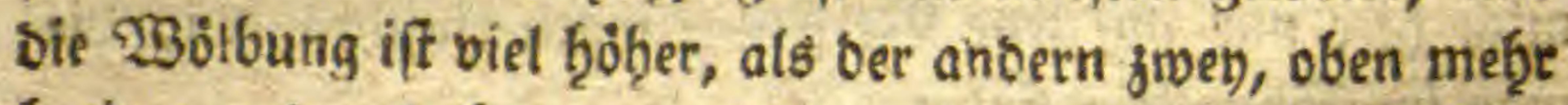
briter und erbabener, zugleich ftumpfer uno gleidffam feilförmig; tie nebenbenliegenten fino viel neniger gewólbt, unb ftellen in iffrem Umfreis einen etwas grojfern ₹heil, als eine b̧albe Rugel, vot. 2(n biefe foliteßet auf ber äuf: fern Eeite eine gitterfö:mige Einfoffung, bie fün neben:

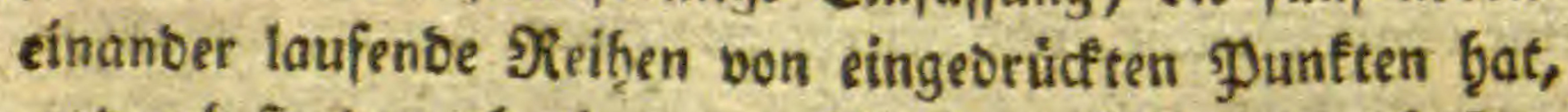
woourd) fie bas obenberiannte 2(njeţen erb̧ailt; ber ăufere ₹heil bes Ranbes if etros einwairts umgebogen. Bon

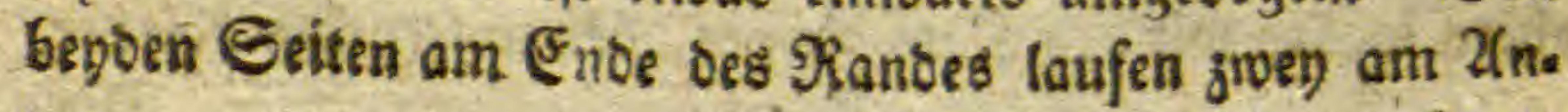


fange ber gitterfơrmigen Einfaffung gleid) breite $\mathfrak{B}$ erlänge: rungen, bie aber immer f(d)màler werben, uno fid) enolic) in eine feine Spisce verlief̨ren; biefe finb meiftens nod) ein.

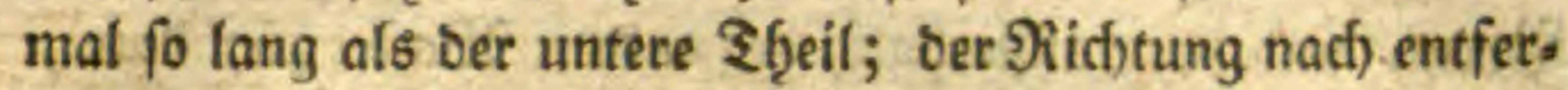
nen fie fid) gleidffam vom Rörper. Eie fofeinen aus einer 2frt von Sliebern ju befteg̨en, uno bann fönnte man fie als

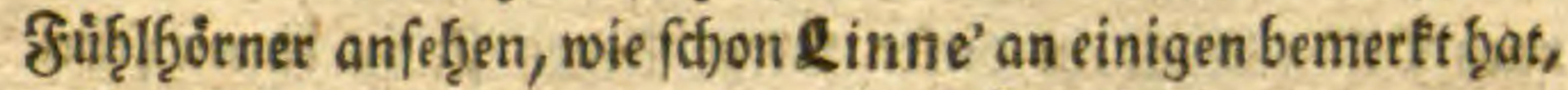
oeffen গiid)tigfeit bon einigen nod) in Zweifel gejogen wirb.

In ben oben befd)riebenen Erbzabenģeiten fidiefit fich ber untere ₹beil an, Der ebenfalls wieber aus oren Erţa. benf̧eiten befreht, wovon oie mittlere ebenfalls oie ḩdd)fte, aber auch zugleid) bie f(f)mälfte ift, fie foblieft fid) an bie mittlere Erb̧abenbeeit bes obern ₹b̨eils, låuft Durch) ben ganzen untern Şgeil f̧erab, uno wiro immer fd)máler, bis fie fich im le jten (S)lieb gleid)fam in eine ftumpfe Epif̧e verliert. Die zmen Nebentbeile fino faum etwas gemólbt, uno faft noc) einmal fo breit als oie mittleren, uno nut an Ranbe etroas einwaitts umgebogen. Der gange untere ₹ ḩeil ift mit 2uerfurchen berfefen, welches bie aneinanber (d)ließsen: Den Slieber finb, woraus ber untere ₹ģeil ganj befteht, bermittelft biefer ift bas ₹Ģier im Etanbe fid) Jufammen zu jief̧en, ober es fann fich ausfrecten; es fins faft immer nur neun foldhe (Slieber, wobon bas unterffe ber lange nad' bas fúrzfte, aber zugleid) am breiteften iff. Man finbet bas ₹f̧ier fowob̨l ausgeftrecter, als auch) zufammen gezor. gen, bod ift bas leztere weit offer zu finben.

Ja) Gุabe biefe $\mathfrak{Z}$ erfteinerung nidjt nur um Prag, fon: bern aud) in einiger Entfernung entoedft. 2lber immer bos Gaupten fie bie erften unb oberften Kagen, wozu i̧̨re binne

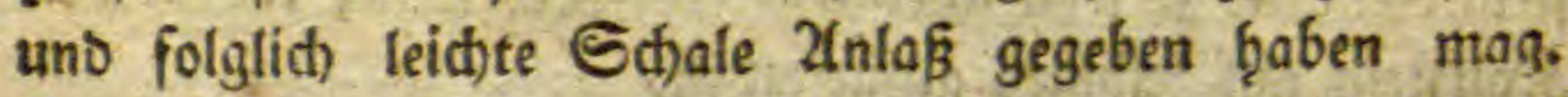
İ) babe fie nur immer im Sanbfein gefunben, und wat 
42 Sुef(h)

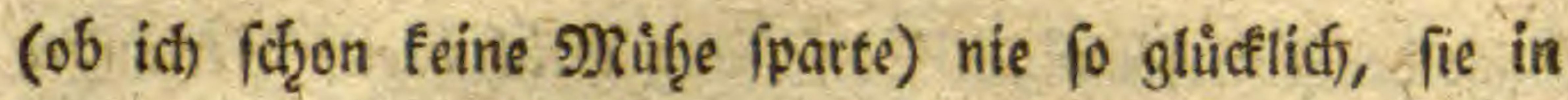
bem boch) naben Salffteine ju entbeffen. $2(\mathrm{~m}$ bàufigften

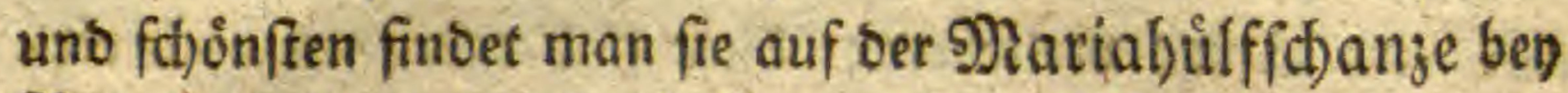
\$rag, uno zroar außerb̨alb, gegen bem $\mathfrak{X}$ affer zu; Dann, eb̨e man in bas Эुrofopilod) formmt, rechter Şant, unb in bem Dorfe 2Braß, welches auf oer Strafe von פrag nack) Pilfen liegt; in biefen Drten liegen fie in einem feit. förnigten, fefre gleichartigen Sanoftein, ber nod) einzelne (Stimmerftåubchen eingeftreut bat, bie farbe bes Ganb. fteins ift von bengemifd)tem (Eifenocher braun, er entḩalt, wiemob̨l felten, ganze Gtüce Ralfffein eingemifht, in ben ủbrigen falfffeinfreven Etellen braufit et nur felten mit Cảuren, aber ba, wo bie Berfteinerungen fino, brauft et immer vollfommen auf; biefer Ganoffein macht einen ei= genen Etrich, von oben benannter Echange nach) ber (B)e. geno vem Profepiled); Der ben bem Dorfe $\mathfrak{B}$ raß̧ muß̧,

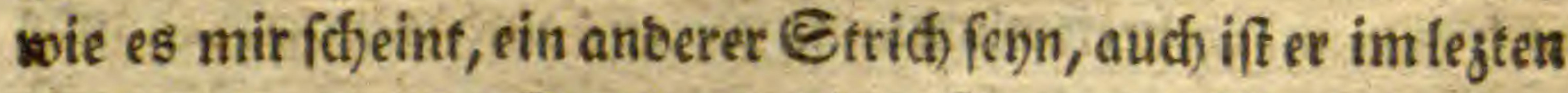
Drte, uno zroar im Dorfe, gleich) zu Tage mit Derfteinerune gen angefüllet, zwar giemlith) b̨åufig, aber bie meiften finb una

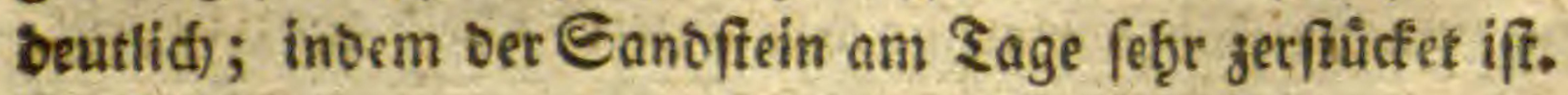

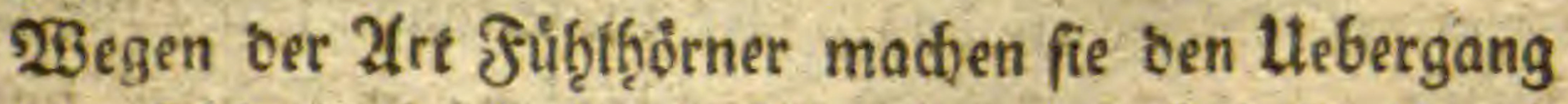
aus ben Ráfermufdieln in bie Nonofulos. Jat) fano nods gno 2frten von Råfermufdefn in fheter (Sefellf(h)aft; bie eis ne werbe id) ben bem Ralffein befohreiben, von ber anoern fant id) ein eingiges Exemplar. Der Sbertheil ift fȩ̣r wenig geroólbt, une bat mur gegen bie jween Eeitenrånber jwo warzenartige Erbabenbetten. Die fig. mirb es am beuta lidffen zeigen. No(h) muß i (d) anmerfen, baßs biefer Sano. ftein bief ctler ju fern fheint als ber Ralfftein; inbem ber Ralfftein auf felbigen aufgefezt ift.

VI. গลatur: 


\section{VI.

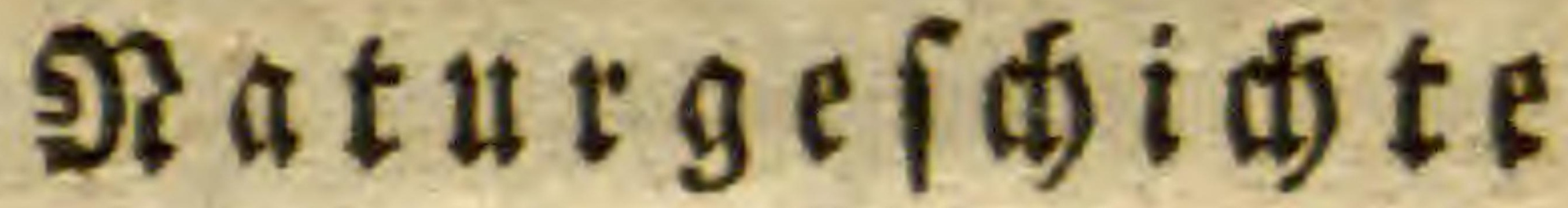 Der}

blaufopfisten Ẽnded) 23on 5.bensem 
bet

$(2)_{1}$

$x \rightarrow \frac{\pi}{20} \sin ^{2}$

if $\left\{\begin{array}{l}2 \\ 7\end{array}\right.$

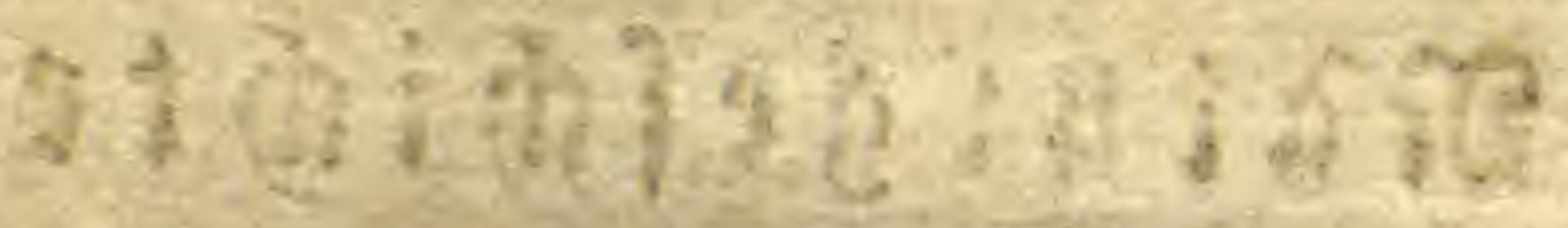

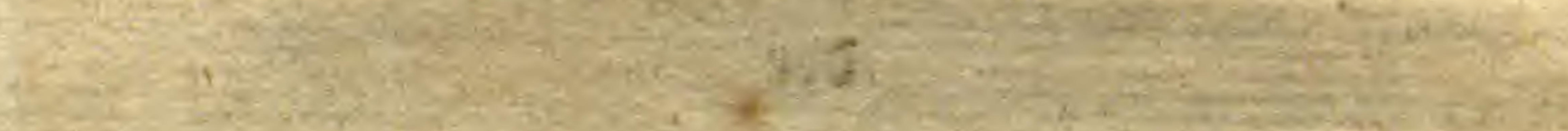

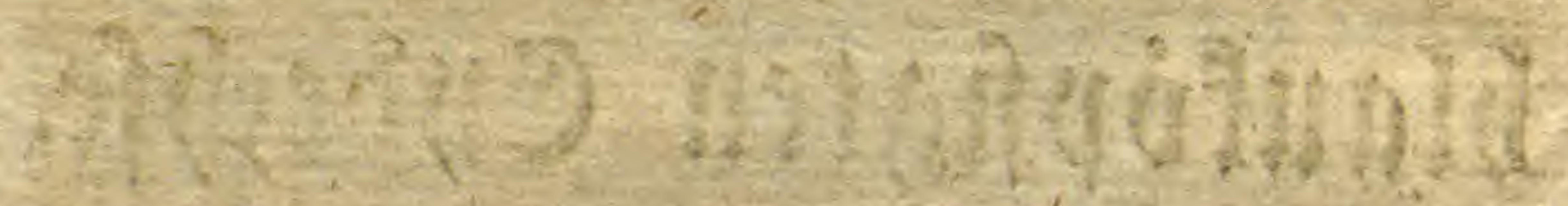

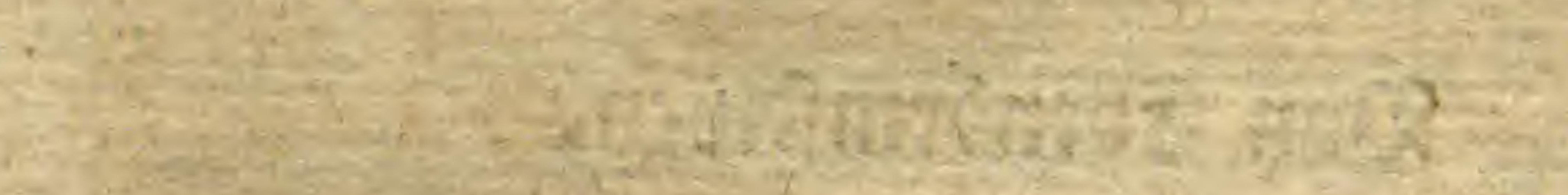

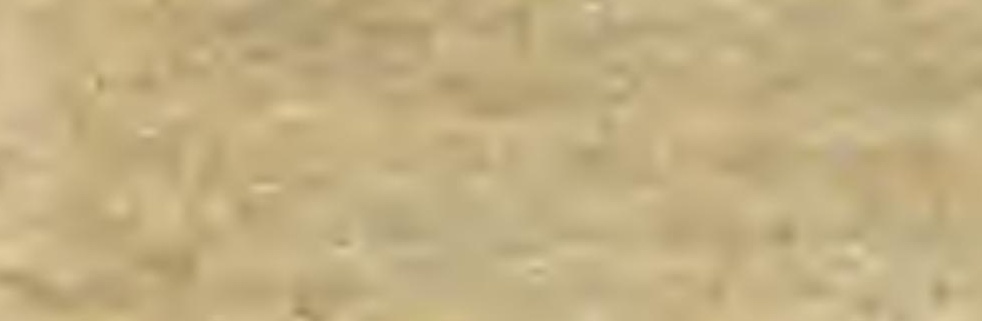

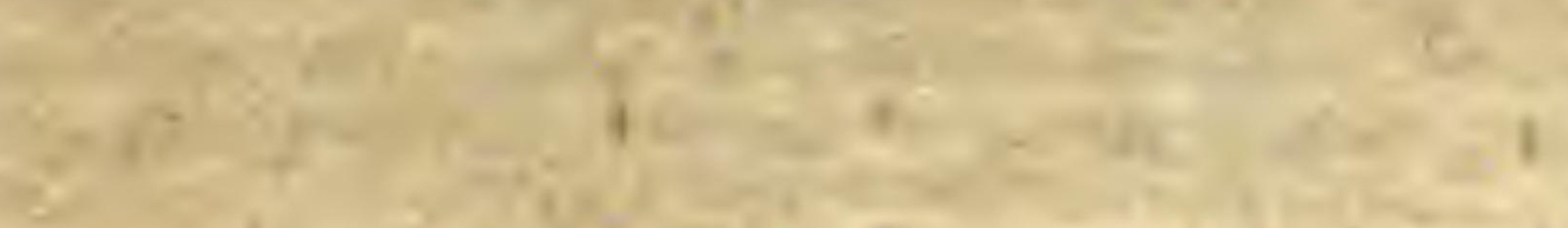

s.

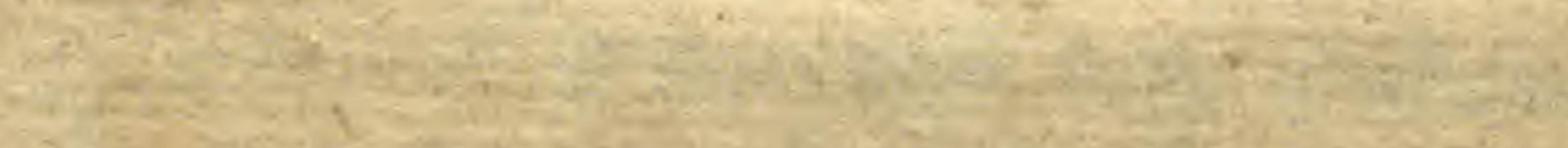

4.

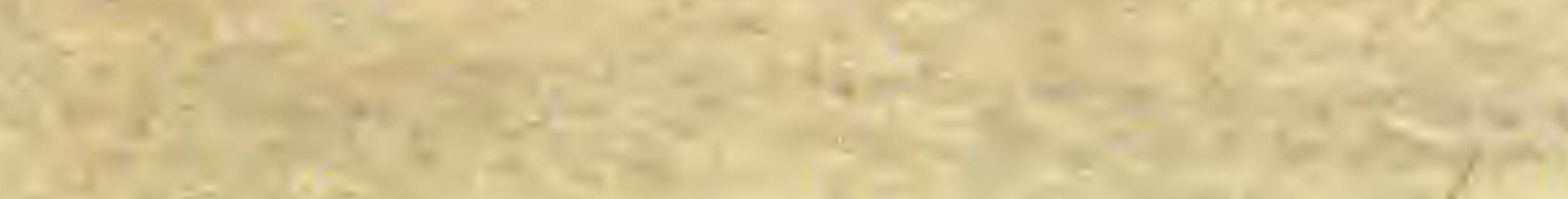

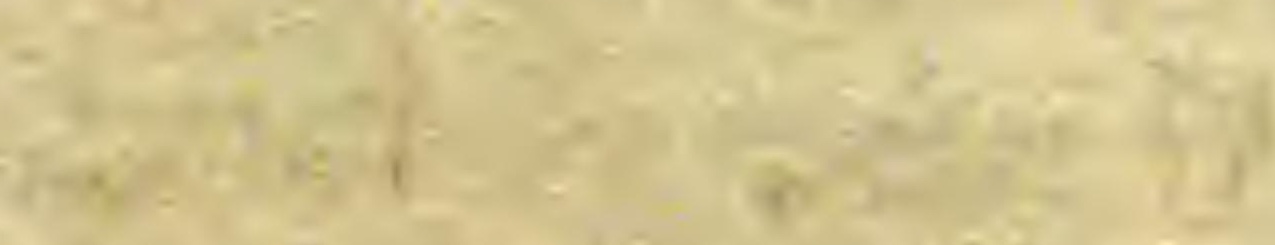




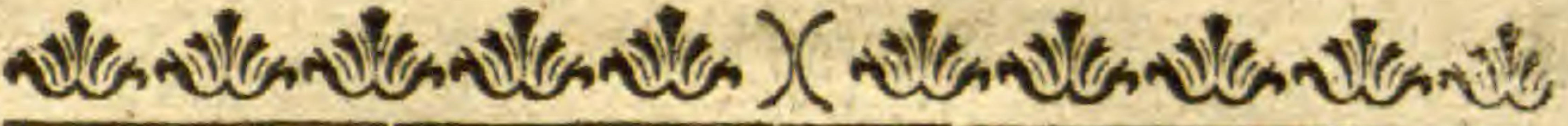

5 ie gange sänge biefer Enveedffe, von ber Epifé ber $\Re_{i}=$

fe, bis an bas auferfte Enoe bes Sdiwanjes, bea trågt bey fleinetn Eremplaten geroóģnlid) $1 \frac{1}{2}$ Epanne; bemogengeadtet finvet man aud) Eremplare bie 2 und 3 Querfinger ůber gwo Epannen meffen.

Um bie Geffalt biefer $\mathcal{E}_{n b e d}$ fe genauer zu beffimmen, werbe id) bier eine Zusmeffung einiger Theile liefern: Der

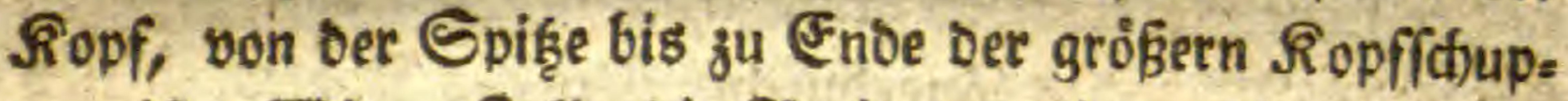
pen, ift 1 Wíener Boll; bie Sreite bon einem 2fuge ju bem anbern nicht gar 5 Sinien; Die $\mathfrak{B}$ reite ber Entfernung ber शiafenlöctier a Sinien; Die Entfernung ber obern Dbren. wintel $\Gamma \frac{\pi}{2}$ Sinie; Die länge bes Rỏrpers, von Dem Enbe ber Ropffthuppen bis an Die Șinterfüffe, 3 Zoll; yon ba bis zu Ende bes Edtranzes ro হoll. Es iff aber hiler ju

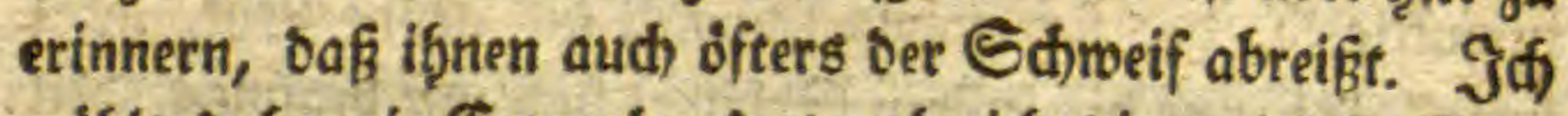
wáblte baḩer ein Exremplar, Das noch nicht oíe geringfte Epue von einem abgeriffenen uno nachgerwadffenen Edfweife jeigte.

Der (Seffalt nach foimmt fie ber gemeinen (Egbechfe fefis nabe, unb wurbe audf von ben meiften bamit verwedffelt; ober man verwect)felt fie mit bem Maannd)en ber gemeinen Enoedffe, bas immer viel fofóner unb grùner gegeidjnet ift.

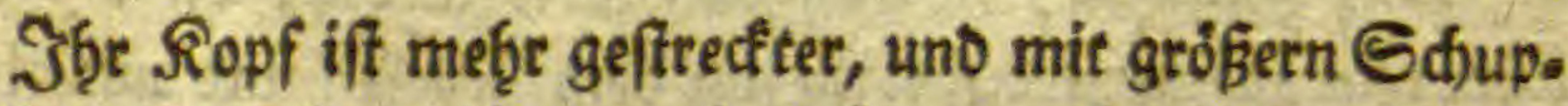
pen bebect? oberţalb von einer braungelben, ber Gonne ausgefejt, etruas in oas goldfärbige fpielenten Gitunofars. be, jebe von ben Edjuppen ift mit lidftgelbgrùnen, meis 
ftens verffhiebenen, boch meb̨r ovalformig geffalteten flels fen verfeben, uno ein jeber von ben flecten ift mit einem Dunfelbraunen Siand eingejafit, aus meldher Urfact)e fie cud) Laurenti in Synopf. rept. pag. 175. 2lugen nennef. Unterbalb ift Der Ropf bimmelblau, uno nur jene Schups pen, bie mebre gegen bie benden Eeitentḩeile bes f̧alfes zufthen, meb̧r meik, uno bin unb roieber mit braunen flef. fen befezt, oie größern Seitenfchuppen an oen untern §inn. laben fohimmern etwas ins fupferrotbe; oer beroglicfe f̧alsfragen beftef̧t aus mebrern grésern an einanber follie. fenben Ed)uppen, bie ebenfalls bimmelblau fino, nur if ber untere frene Rano etwas gelbflecfigt. Die 2lugen befinden ficf in ber Mitte bes \{anaeburdmeffers bes Ropfes, fie find mit berveglidjen 2(ugentiebern verfeb̧en, rovon bas untere gröker ift.

Die 2ugen fint, im $\mathfrak{B}$ erf̧åltnißs der übrigen Sbiere, giemlich groß, fit)marz, uno mit einem etroas fthmalen golofärbigen 2fugenfreiß verfehen. Der Unterleib ift gum. miguttigelb, bas fich efwas f(twath ins gruine jieht, ganz unaeftedt; nur bie ciufern Edjilber fino mit braunen, ben

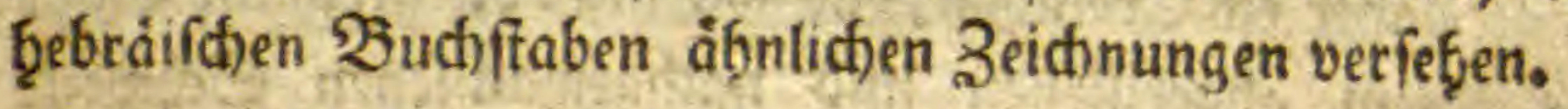

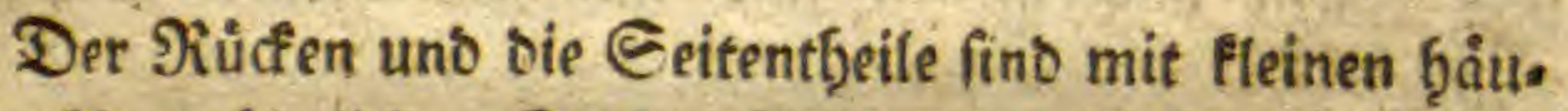
figen förneråbnlichen Echüppchen befejt, oie ziemlich) juge: runbet finb. Der Sdmeif befrebt aus Dachjiegelformigen länglichten Ectuppen, if om Dbetthe!l mit bem Rủcten, uno an oer untern Eeite mit bem Saudfe, uno fwar benm Infange beffelben, volltommen gleichfảrbig; bie Berber: füffe fino oberhalb ebenfalls mit bem ßiucfen unb unterf̧alb mit bem Utnterleib vollfommen gleidffärbig, oer ßeiçnung nad) fino fie oberbalb foff bem গRùcen vollfommen gleich, 
nur finb bie gelbgrinen flecfe exas gro̊ßer, unb bie brau. nen Einfaffungen ftellen manchmal SButbftabenål̨nlidje Seidf)nungen vor; bie f̧interfiffe verḩalten fid), wie bie Borberfuffe, nut ift bie vom after ausgebende zenreihe farafteriftifd, bie bon benben Seiten zufammen aboirt, gewóf̧nlich) vier uno orenfigig ausmach)en, uno aljo fommen fiebjef̧n auf eine Eeite, ba bingegen bie gemeine Enbechfe auf benben Eeiten nur immer fed)s uno zmanjig

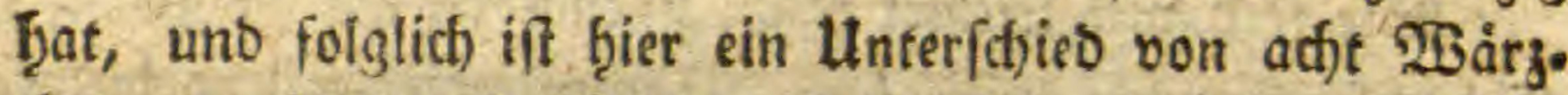
c)en, ber immer beftainoig uno folglich) als (barafteriftif́, angenommen werben mus.

Gie nothnt feltner nuf $2 B$ iefen unb Felbern, am liebfen uno ḩăufigiten aber auf 2(nḩơhenen, bie mit etwas (Gebùfd)e bewact)fen fint, oa hingegen die gemeine (Endechfe meb̨r auf tem ebenen sanbe unb Wiefen moḩnt; fie gräbt fid) ơf = ters Schubtiefe Sager mit ib̨ren গ̧fơtgen, am liebften unter (J)eftraiuchen, ober bejieḩt ein (d)on fertiges झialufeloch;

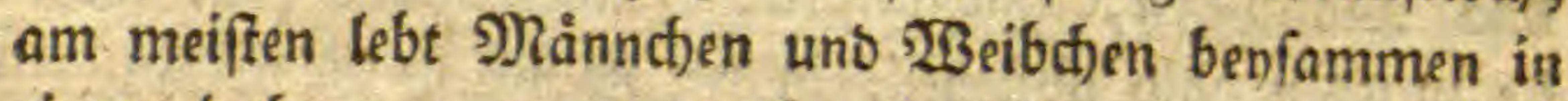
einem (och)e, wo man mandfimal auch etras buirreg Şeu antrifft; vermutblic) b̧aben fie es felbft bab̨in getragen, ent. tweber um fidh ober ib̧ren Evern unb ben erwarteten Jum. gen ein bequemeres Sager zu madjen; fie entfernen fid) nie Pệr weit von ibrer 2 Boḩnung; will man fie fangen, fo flùd)ten fie fich) febze fofnell, uno wenn ibnen ju viel (5) fefaber orobet, verfitiect)en fie fich in ib̧rer Beb̧aufung: uno man

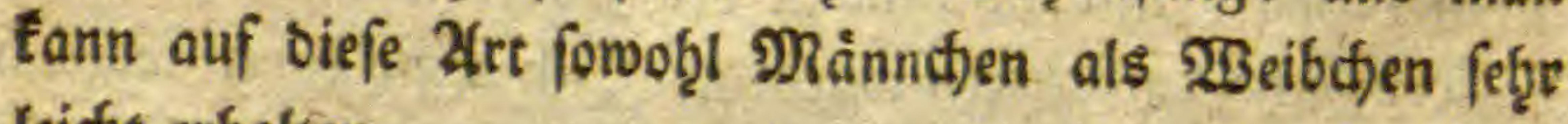
leid)t erb̨alten.

Man barf nue bende in if̧e soch jagen, (roeld)es ge. wo̊thnlid) nic)t weit entfernt iff,) uno bann ausgraben; fie in Saufen zu erḩafd)en, if jiemlid) fünftich, uno man f̧at 


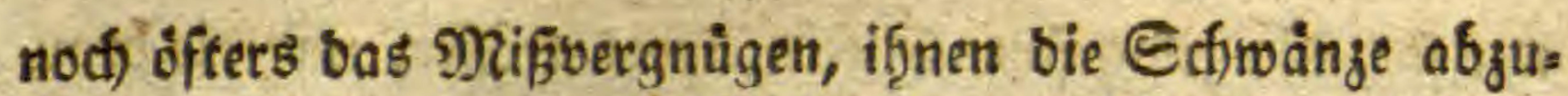
reifen; fänge man fie, fo beiffen fie um fid) beer, allein es iff nid)t im geringften Befab̨r, uno man fann ig̨nen freg. ben finger in ben Ractjen ftecten; fie fneipen ofters jiem. lid) ftare zufammen, aber nod, nie warb mir bie geringfte 2Bunbe gebiffen, obfdjon ich ůber zroen Epannen grope Eremplare fieng.

Eie fino viel leid)ter zaร̨m ju mad)en als bie gemeine (Enbed)fe, Lacerta agilis Lin. bie immer viel roilber bleibt. (ich) b̧atte ib̨nen ein Doppelfenfter zu if̧rem 2lufentb̨alte be ftimmt, legte fie in etwas gruinen $\Re$ iafen, uno gab if̧nen aud) zugleich) Waffer; ich fieng ifnen alletlen Infeften, fie verad)teten feine Battung, aujer bie etwas fteifb̧arigten Raupen; um aber aud) ḩier zu fef̧en, ob fie feibige genie. fen, lief id) fie ad)t ₹age f̧ungern, uno warf iģnen mę̧rere Bärenraupen vor, fie fielen gierig liber fie ḩer, befonbers bas Nånndjen, uno fochuttelten fie b̧in uno ber; aflein fie mufiten balo abfteţen, inbem fie fich) in bie fleif(d)ichten

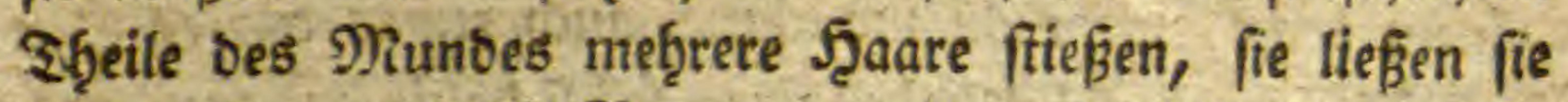
wieber frel, unb bie গiaupen waren nod) nidft im gering. ften toot gebruicft, benn beifen Ėonnen fie nicht, meil fie feine వå̆gne b̧aben; nach roieberb̨otten Zfngriffen auf bie Raupe berlor biefe faft alle J̧aare, unb wäre ficher aufge. zef̧rt morben, wenn id) nid)t geglaubt baătte, bafi bie nod) freifen Şaare in bem Magen ber Enbechfe nidjt bie beffe Wirfung bुerborbringen wutroen. Jach legte if̧nen fogleid) anbere Infeften vor, uno zwar ziemlic) großje. Da id eine grofie शRenge Scarab. Lunar. gefangen hatte, gab ich)

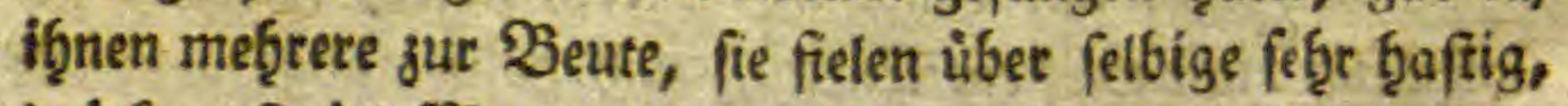

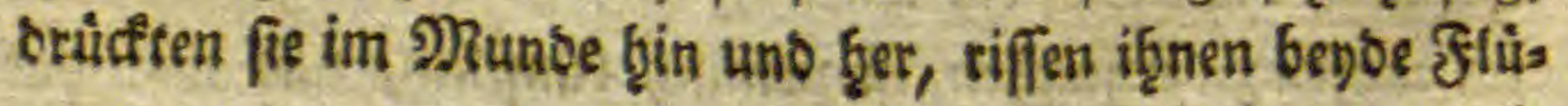


gelbecten $a b$, inbem fie eine in ben शunb nafimen, uns

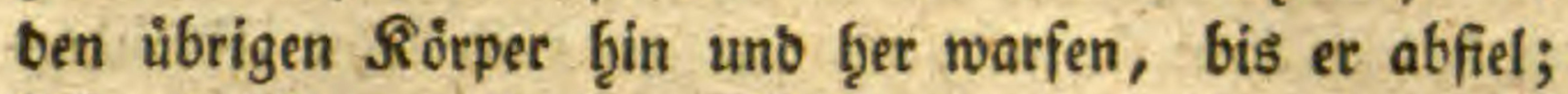

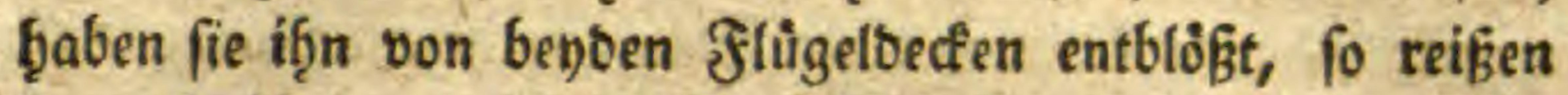
fie aud) efters noch) bas $\mathfrak{B r u f t} f$ tuc $a b$, ober fie jerbrúcfen es nur, uno verfálingen bann ben ganzen Rörper. Edbmet. terlinge lieben fie feḩr, uno mactien ziemlid) gefdominoe Epruinge nach) ib̧nen. 2ud fliegen lieben fie, uno binnen fect)s ober adt) ₹agen fann man es bab̧in bringen, baß fie Fliegen unb anbere Infeften aus Der f̧ano nef̧men, wels d)es mit ber gemeinen faum in fo meniger Deit gefet.

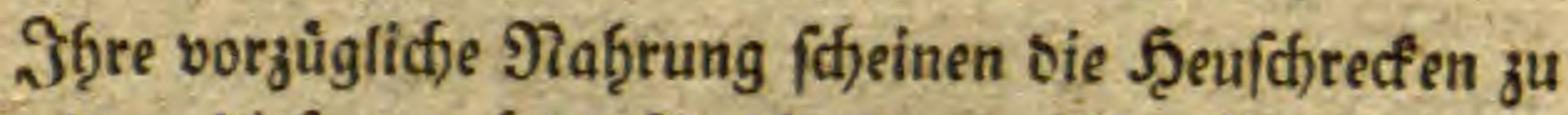
feyn, benn biefe vergeb̧ren fie mit bem größzten 2lppetit, uns ziefien fie faft ben meiften Infeften vor; aus biefem fann man fd)liefen, baf ber Eanomann gar nid)ts von if̧nen zu fürd)ten hat, benn ber $\mathfrak{B}$ iß if faum bie Şaut burchborin= gent, Bjift ḩaben fie feines, uno bie wenigen sodj)er, bie fie madfen, fino gar nid)t ju rectinen: benn unenoficf) ùber: miegend ift ber গluz̧en, ben fie burch) bas 2fufzeg̨ren ber Jjeuffrecten machen. Die Infeftenfoft ift eigentlich) von Natur für fie beftimmt; fie vetachten bem of̧ngead)tet aud

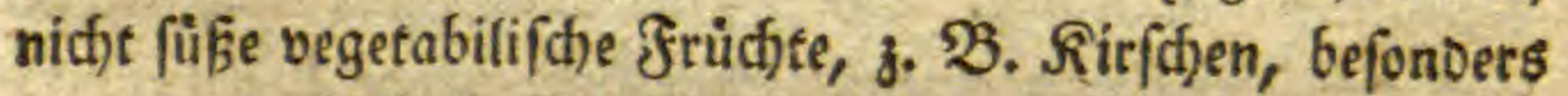
wenn man fie flein fóneiber.

शun hৃătte id) faft bas meifte von if̧rer $\Re$ oft gefagt; fie pfiegen aber auch) febgr oft ju faufen, uno jwar im Jreyen fammeln fie bie nod) eingelnen ₹Ggautropfen ber P/langen;

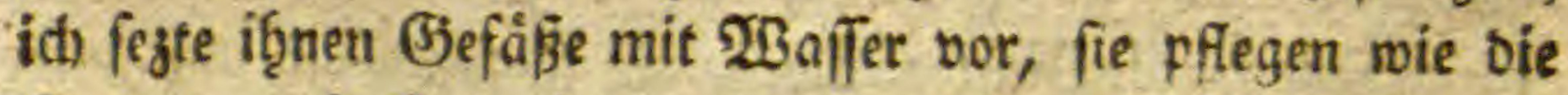
STunbe zu faufen, inbem fie if̧re ftumpfe fiffrargbraune 3unge mechfelsweife in bie Flüßigfeit taud)en, uno wieber

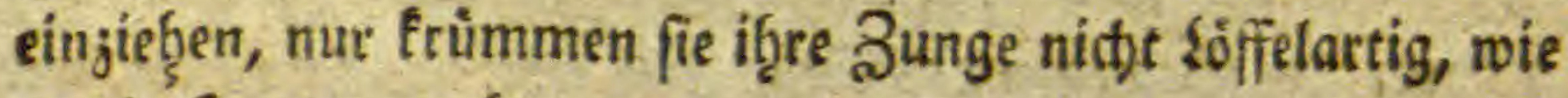
es Die flunde madfen. 


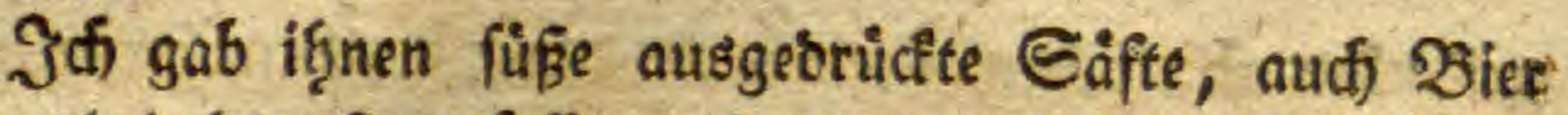
u. b. gl. haben fie gefoffen; fie fins audf feine Beráchter von Mil(d); tunfet man einen finger fo in bie Mil(d), Daß noch ein ₹ropfen f̧ängen bleibt, fo lecfen fie î̧n ab, gerabe wie bie J̨unbe.

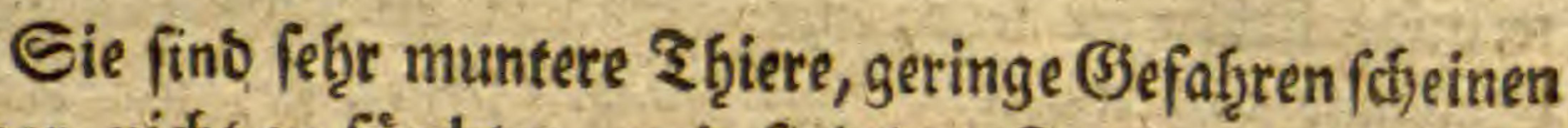
fie gar nicht ju fürdten, uno fino oreufte genug, fich jiemo

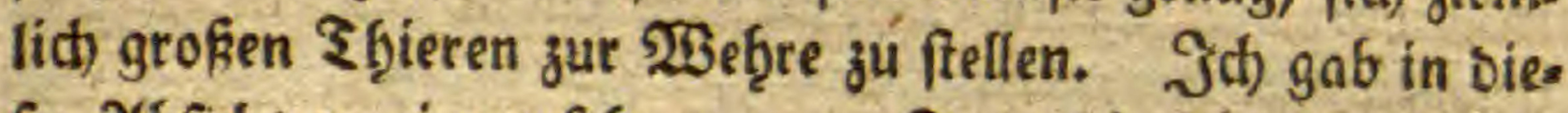
fer 2 bffitht an einem fefgr marmen ₹age bie fogenannte $\mathrm{Co}$ ronella bes J̧errn Laurenti, Synopf. rept. bie fo, wie alle meine 2 mp bibien, biefen ₹ag, wegen einem bevorffeģenten Bemitter, fef̧e mutb̧ig waren, in bas Jenfter zu Den (E)y: bedffen; faum bुatte id fre ḩineingelaffen, als fidh) ib̨r bas Mrånnchen nåberte, bie शatter legte fid fogleid) in einer Ednnecte gum 2fngriffe bereit, bie Enoed)fe naḩete fich) ib̨r mehr uno meb̧r, berwegte den Schiwanz hin und ḩer, und zwar nur ben obern ₹̧̧eil, Denn bie Epigęe bes Ectweifes war jiemlid) rubig babery, fie offinete nach) und nach ben গia d)en, madte einen fleinen Eprung, uno erwifffte die গiato

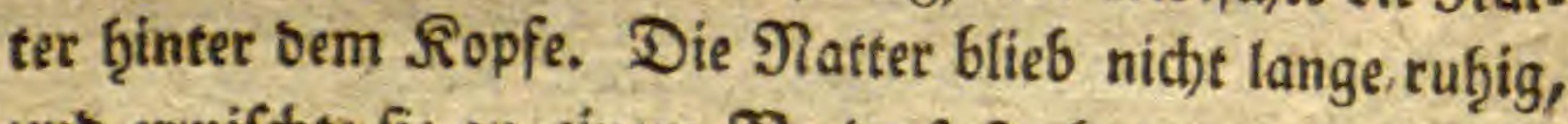
unb erwifdhte fie an einem $\mathfrak{B}$ orberfus, benbe liefen enolid' aub einanter, uno meine (E)bect)fe wollte fffion mieber einen

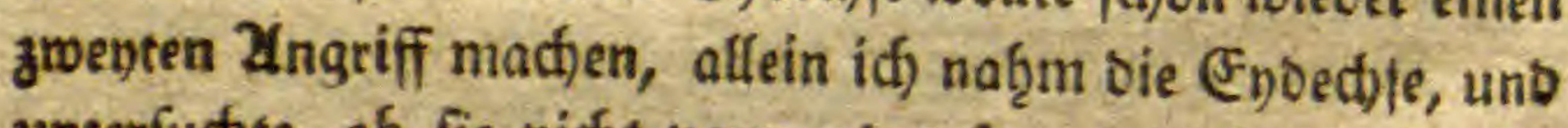
unterfudfte, ob fie nidft verwounbet fep, ba aber nidjt bie getingffe Epur ź feţen war, ließ̧ ich fie mieber fren; abet faum fahe fie bie $\Re$ atter, als fie auf fie losgieng, unb unter ben nàmlícten \$erwegungen ben gwenten 2 (ngriff ragte; fo lanae als ber 2lngriff uno bas Beiffen bauerte, ḩatte bas

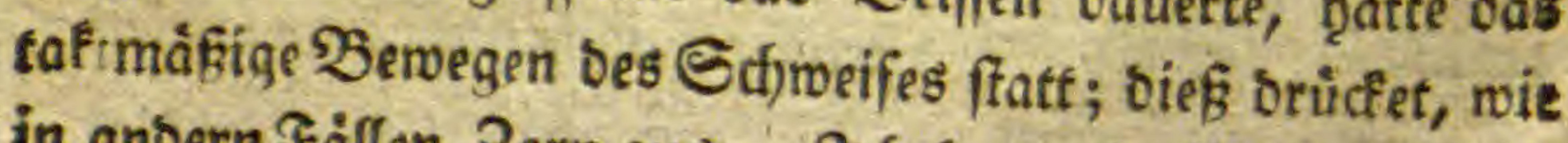
in anbern Jällen, Zorn aus. Ja) batte ein Weib(t)en, bas 


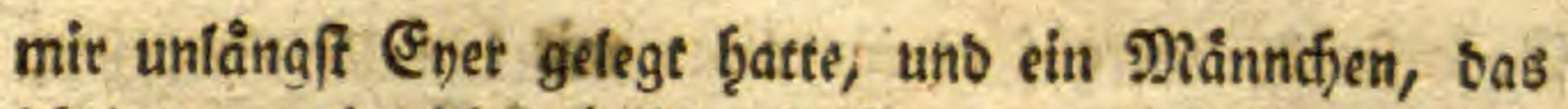
id) in bem námlichentsod)e mit fieng; ba es nod) nicht zu fpait an oet Jab̧rszeit war, fo f̧offte id) eine zroente

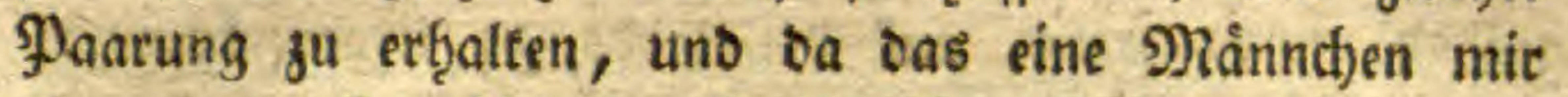
etwas zu tråge fotien, ließ i id) ein zroentes b̨inein, wels ()es mir auch Joffnung mad)te, Die Paarung von bie. fen Şbieren beobadten zu fönnen; ich) bemertfe aber balo, baßß bas áltere Mánnchen gleidffam eiferfüctitg murbe, uno ben netlern Siebhaber, unter alfen Zusbrù= den bes Sorns, aus einer $\mathcal{E} d f^{\prime}$ in bie anbere jagte uns mit jiemlichen Rniffen beläftigte. Da fíf legteres wenig wiberfegte, mußfte id) fogleidf) bas áltere Månn= d)en wegnef̧men uno allein einfperren, um nur bie $\mathfrak{P}_{a a}$. rung beobachten ju fönnen, allein bis jejt blabe ith noc) nichts von berfelben beobachten foonnen; iff) ver.

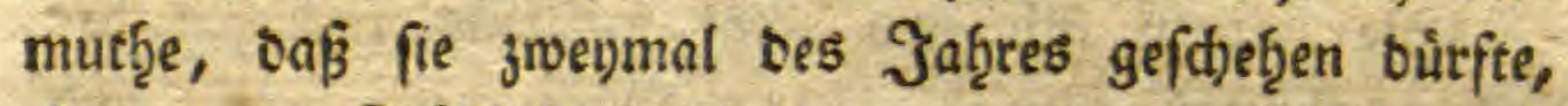
einmal im Srúb̨jab̧r uno bann gegen bie J̧álfte bes Gommers, benn ich befam fhon im 2(nfange bes Mal) ein tragenbes 5 beibd)en, bas mir ju Enoe Junn I4 Ener legte. Die Ener fino oval, an beyben Enoen gleich) ftumpf, mit einer fotmuszig reißjen etwas in bas Belbe fpielenten f̧aut, oie pergamentartig uno mit ei. ner nur etroas ounfler gefärbten flüfigfeit, als bie fark be ber Echaale, angefúllet ift. Diefe Slügigfeit beftef̨t aus zroo Eubftanzen: aus einer etwas buinnern, unb ei= ner anbern etivas bicfern, bie, wenn man fie trocfnet, erbártet, uno viel óligtes f̧at. Das (Bebribien ber Ener geffilef̧s nicht auf einmal, fonbern nathbem ein En geo legt ift, verláuft ungefäb̨r eine Biertelftunde; bie eve ftern Ener folgen in ned) grofgern 3wifhengeiten; bey

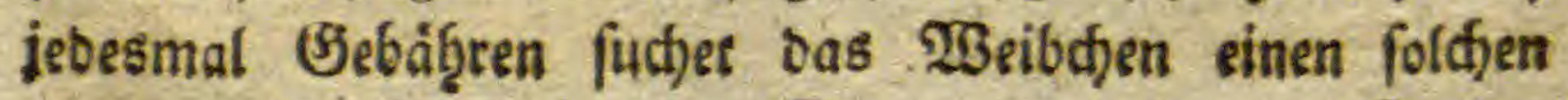


Gegenfiant, morauf es in etwas mif ben Borberfiffen in bie Şöbge friechen fann, bie Şinterfüffe werben meb̨e auswairts uno rùcfwairts gebogen, fo baß bie Becfere gegeno etwas frever auf bie Eroe zu liegen formmt; nun tritt bas Ey in biefelbe ein, uno formmt nach) uns nach oa, wo ber Schweif anfaingt uno fich) ber 2 fiter uno bie Beburtstheile befinben, beraus. Es geb̨t jiem. lich langfam, aud) bann, wenn fiton faft bas ganje

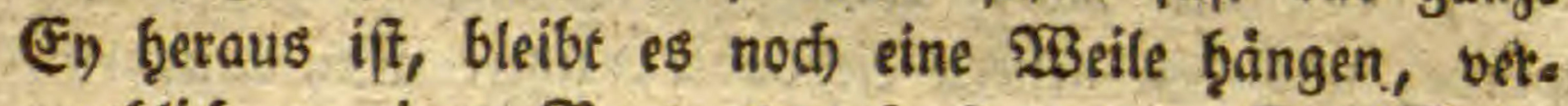
mutblic) an einem Banb ober fonft etwas. Das 2 Beib. d)en ift nach) ber (J)eburt fólåfrig und einige ₹age un. thätig. Da id) ben Fyern feinen gefdicften Drt gee ben fonnte, war ich) audf) nid)t fo glidflid, fie zue voll. fommenen Berwandlung zu bringen.

Sie biăuten ficf) unb zwat meiftens zroenmal bes Jab̨rs, einmal ungefäb̨r in ber Mitte bes Junit, unb Das anberemal gegen ben Şerbft. 


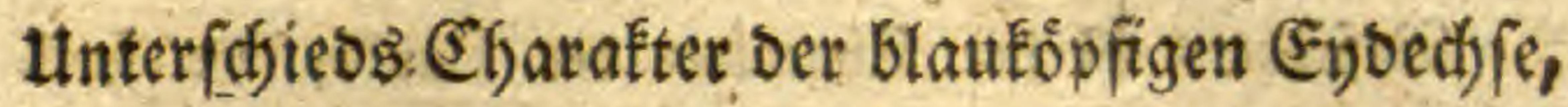
von Der gemeinen, sur fid)ern Beftimumung.

Set \{ange nach) übertrifft sie blautópfige sie gemei= ne Enbedsfe immer um ein Drittheil, ober gar bie Şălfte.

Der Ropf ift viel geftecter als ben ber gemeinen;

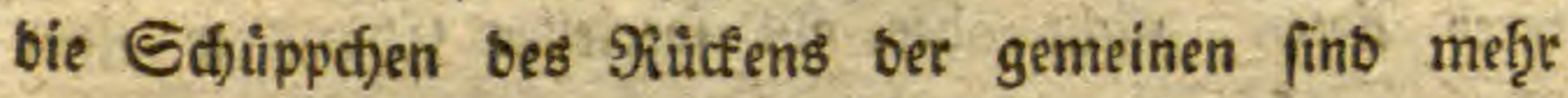
länglidft, wofingegen felbige bey ber blautöpfigen runo fins.

Die 2fngaf̨l ber W̧arzen, bie an ben f̧interfưffen

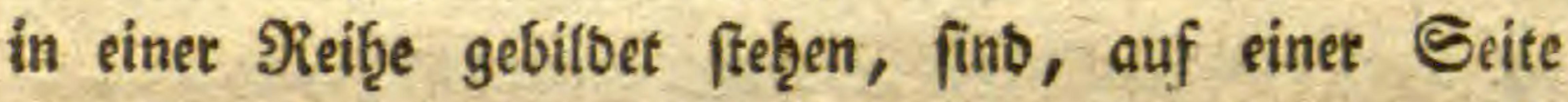
gerechnet, bey ber gemeinen inmer 13 , woţingegen bie blauföpfige immer 17 bुat.

Der farbe nach Ģat bie gemeine einen meb̨e eimfarbigen Ropf.

Der Scalsfragen ift bey ber gemeinen immer mit bem Unterleibe gleidffärbig; bey ber blaufeopfigen aber bes ftänbig mę̧r ooer weniger Ģinmelblau.

Den 2fufentḩaltsort nad liebt bie blautöpfigte meţe bergigte (Jegenben, bie mit (bebuifhen berwadien fino; bie gemeine mef̧r EGGenen uno $23 i e f e n$. Dit finbet man bie gemeine in ganzen Gegenten in unglaublidjer $\mathfrak{M e n}$ ge, two bingegen bie blauföpfige nie anjutreffen ift, unb fo ebenfails im Bregentḩeit. 
Befonbers ift ber Eţarafter ber blaufópfigen fanfo ter unb zaf̧mer, ba bingegen bie gemeine immer wils ber bleibt.

Der beweglitife J̧alstragen, ben Rinne als ein Diefer 2(rt eigenes Rennjeidjen anfüf̧tet, (d)eint bुier nid)t fratt zu finben, unb genauere Utnterfuct)ungen würben jeigen, Daß̧ bies Rennzeidjen als Unterabtheilung meñ. rerer Zlrten, nidjt aber als fpeciefler Ç̧arafter einee Zlrt, angefef̧en werben tank.

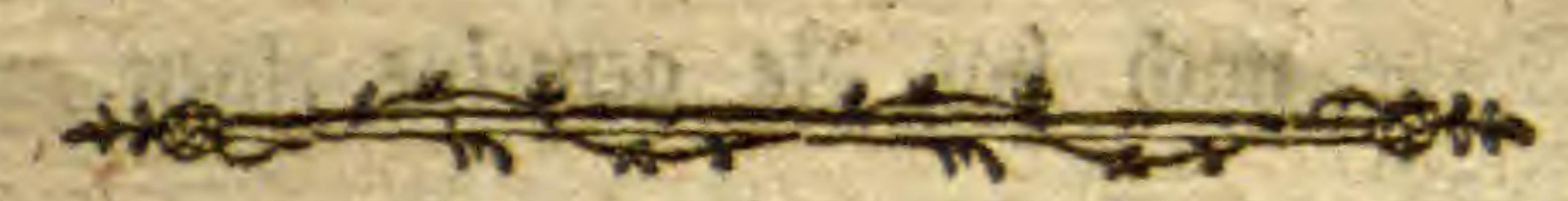




\section{VII.}

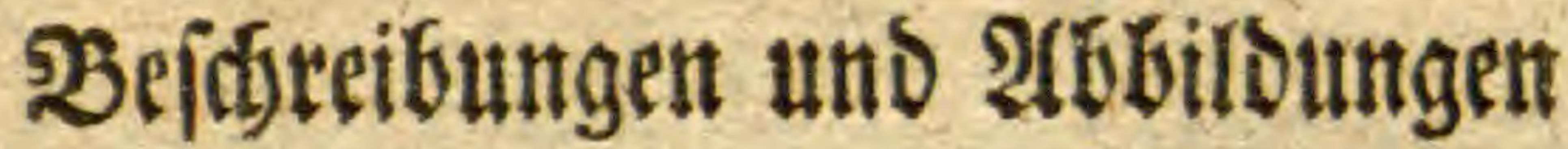

\section{betjenigen \\ Silfefti,}

weldfe in Sammlungen nicht aufsuberwabren fito, Dann aller, Die nod ganz net, uno foldher, von bes nen wir nod) Eeine oder Dod) febr idhledte 2(b: billoung befictert.

Eerfte Sammlung. 2on

Johann Danich Prenblet. 


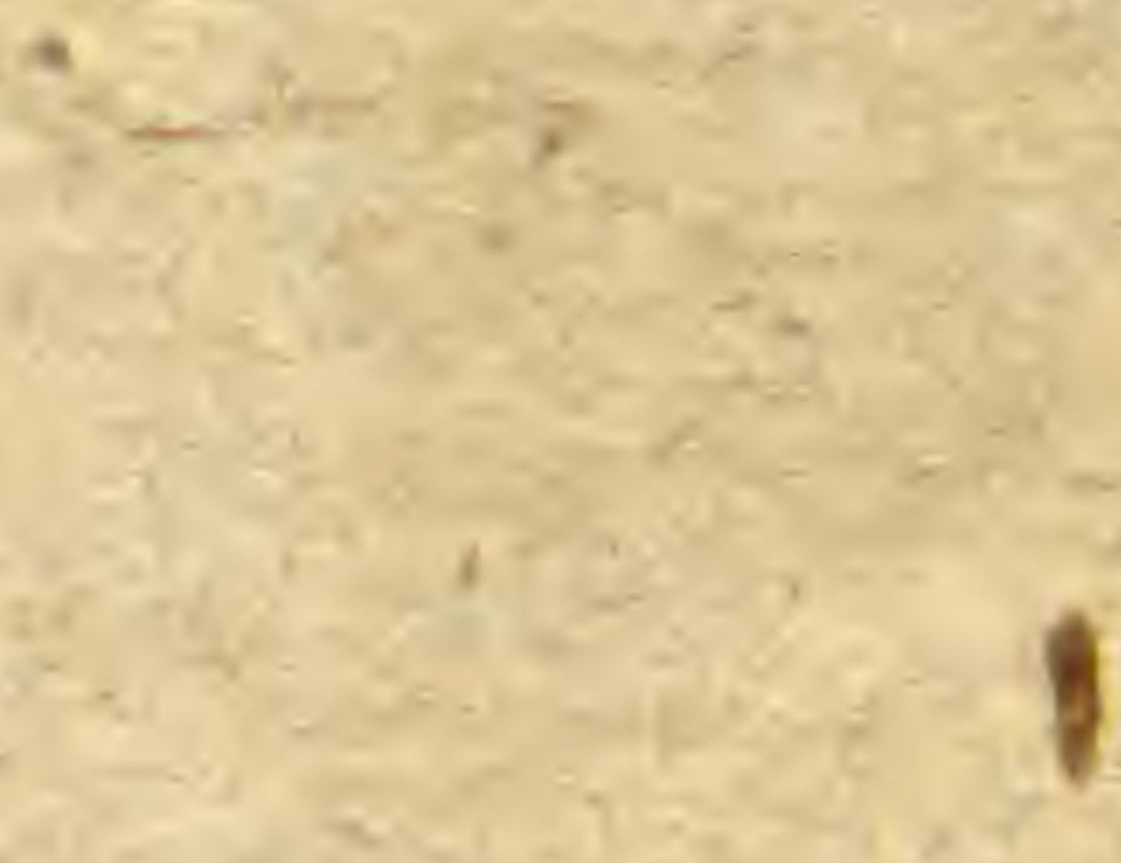

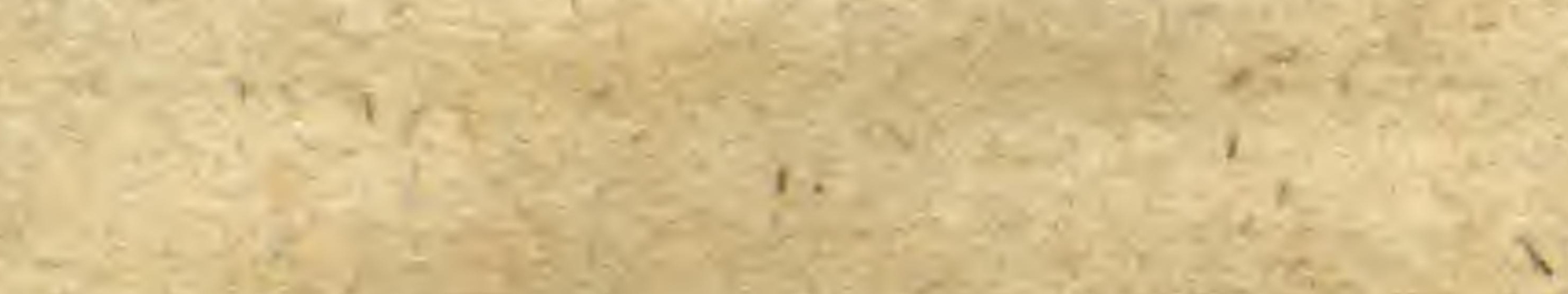

1 .

(2)

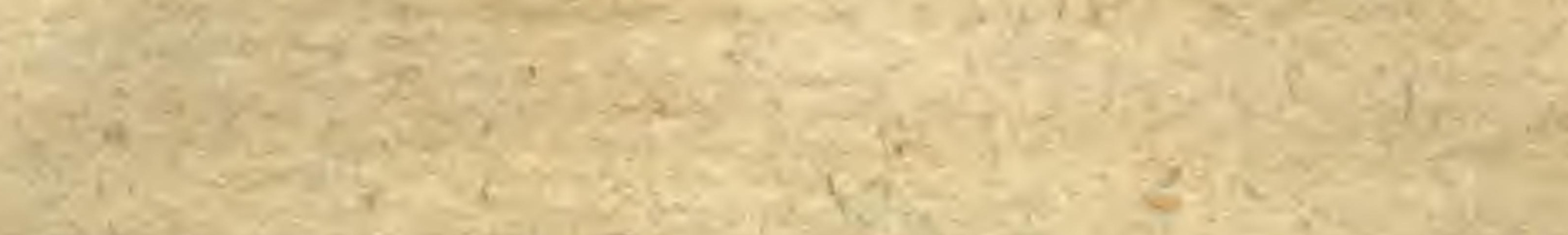

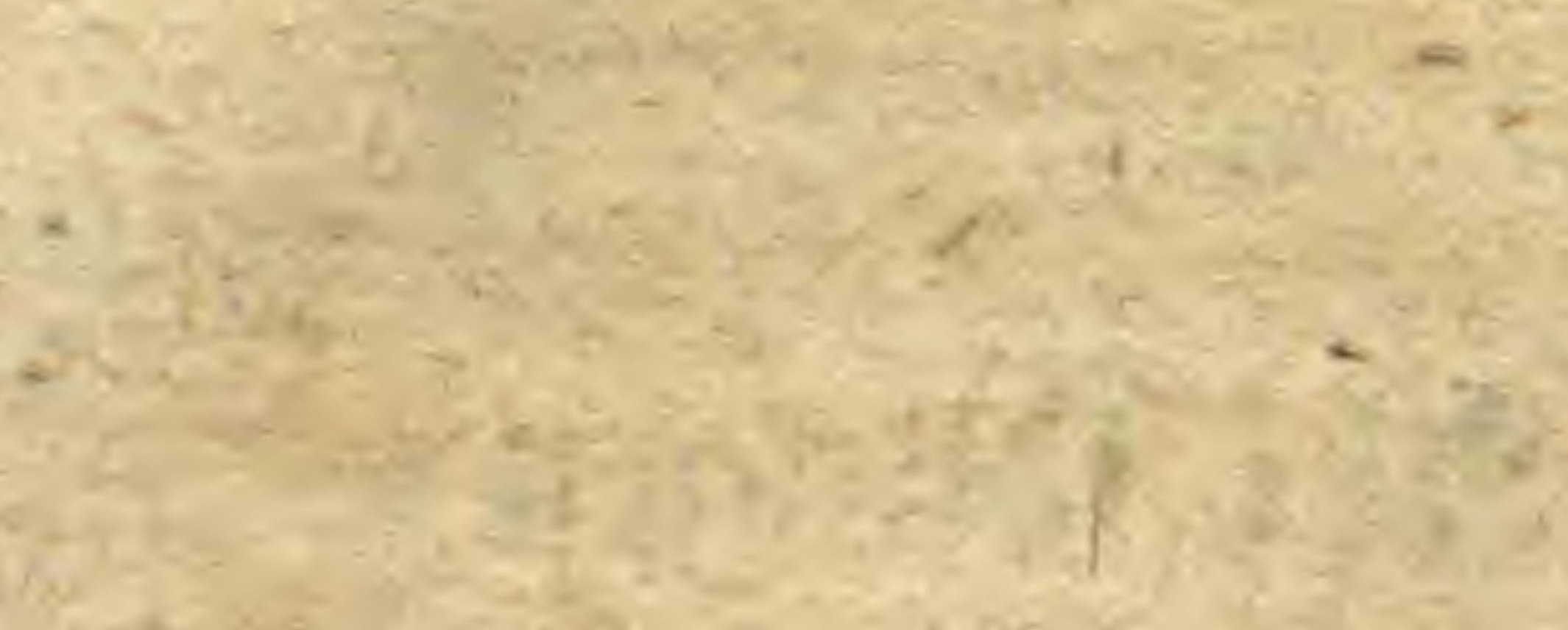

$\frac{2+1}{2+2}=$

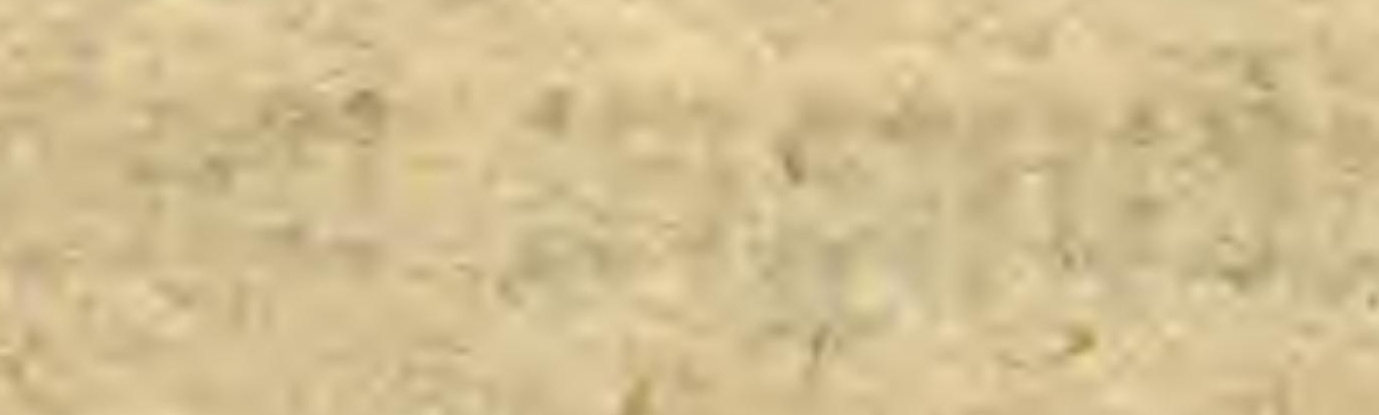

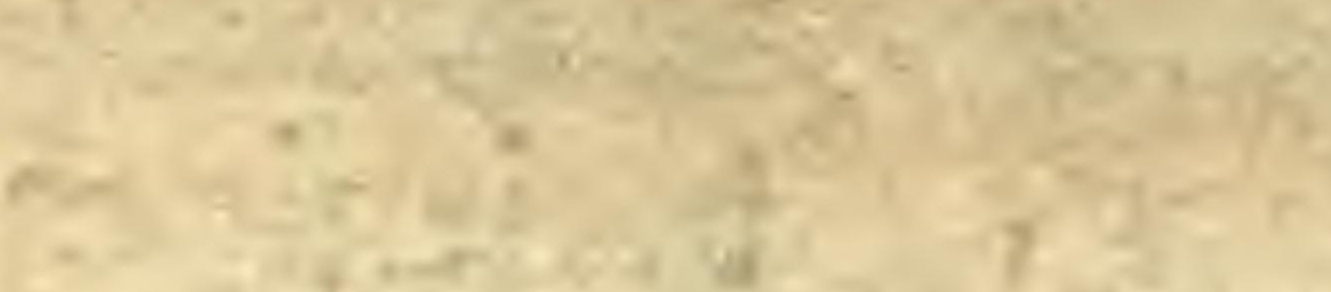

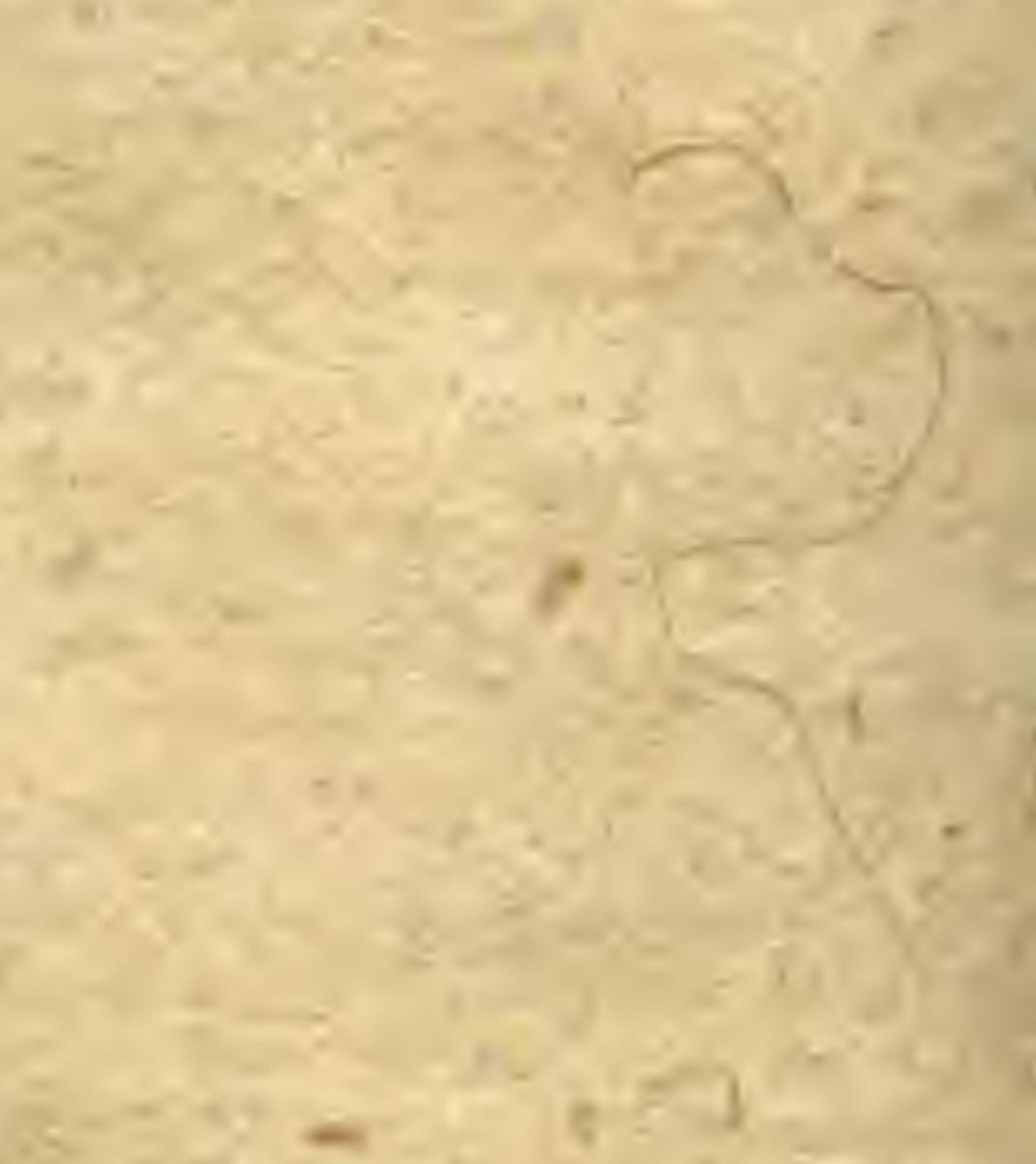

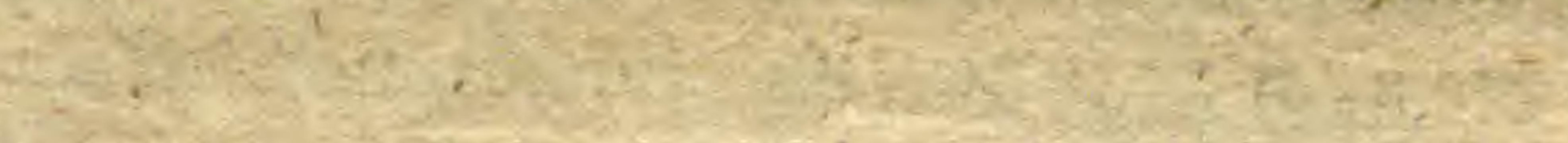

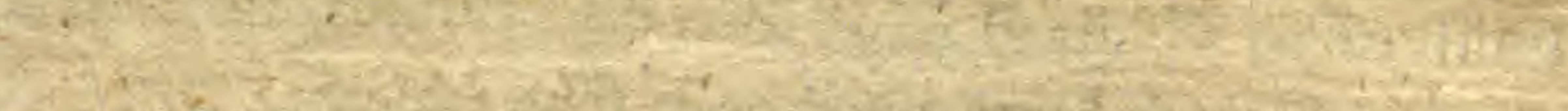

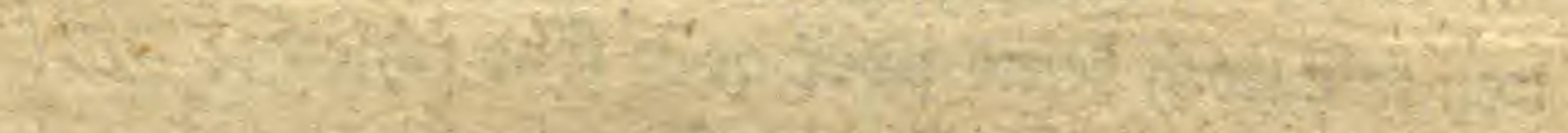

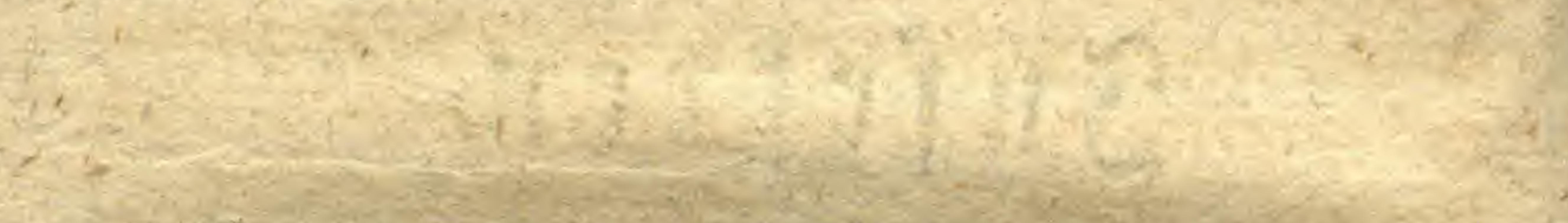
8 $\frac{3}{2}$

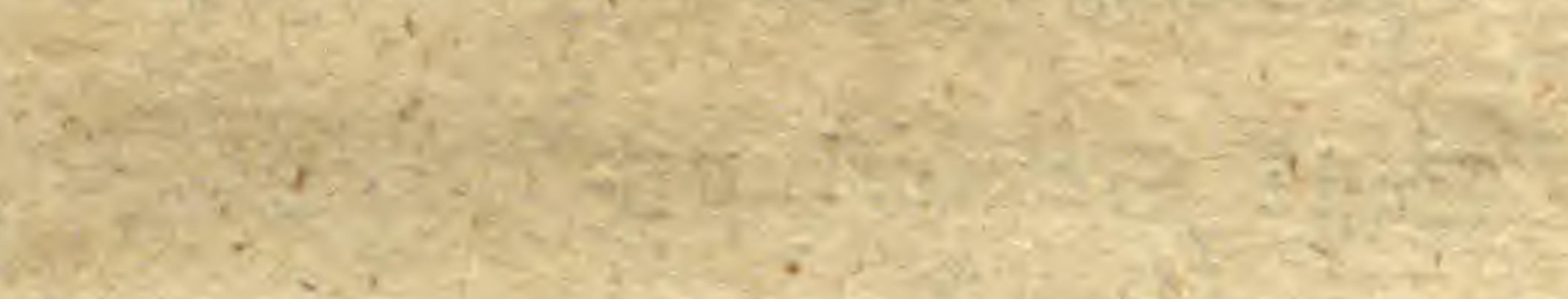

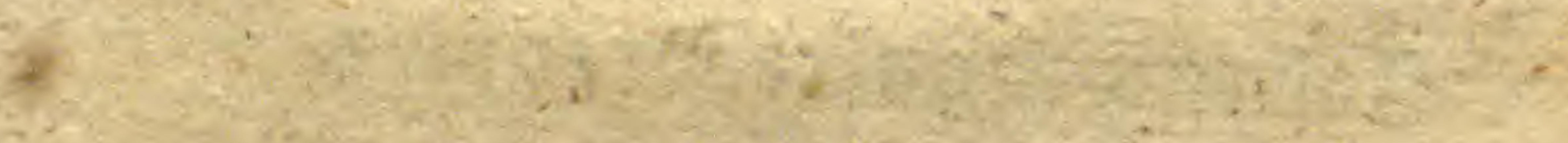

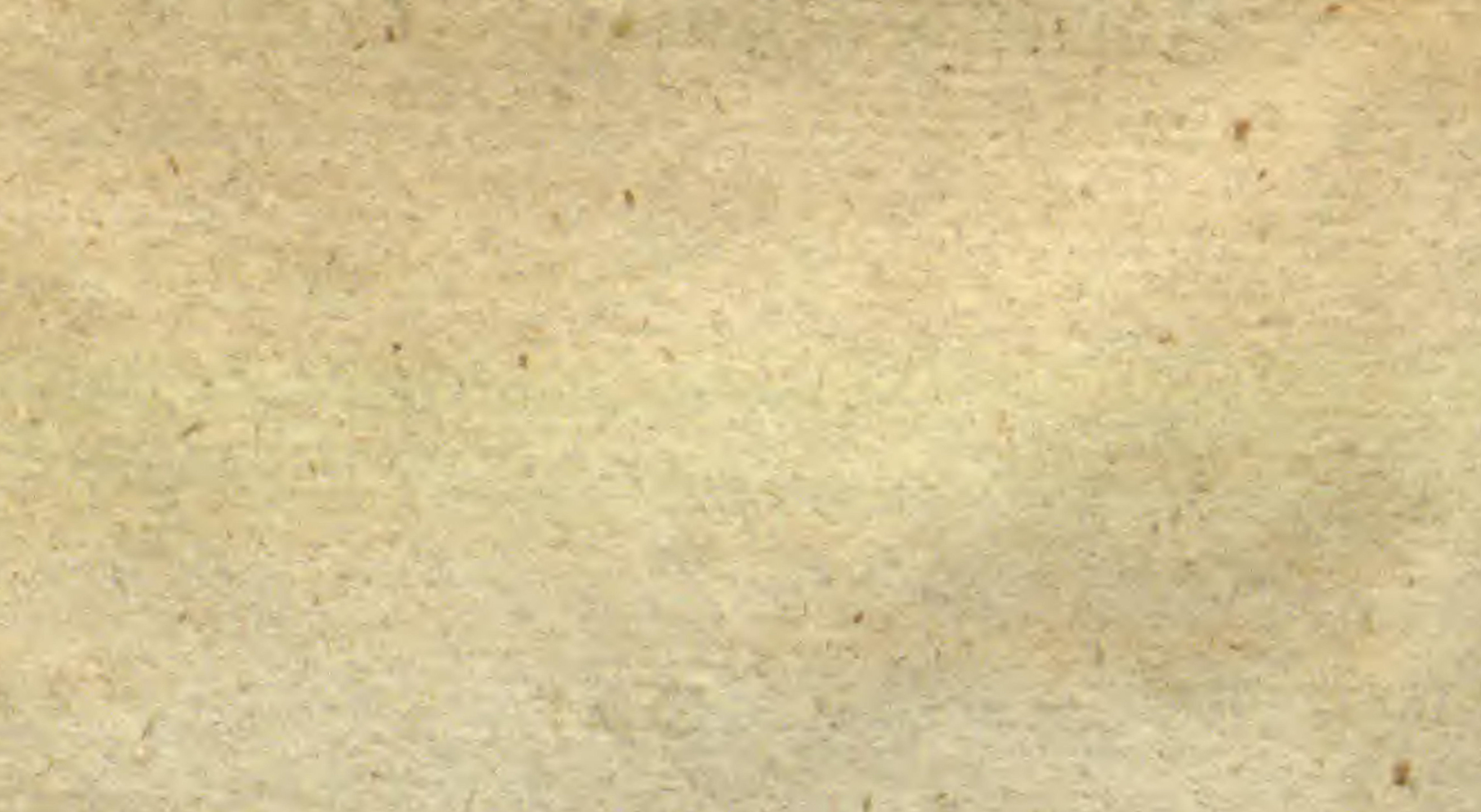




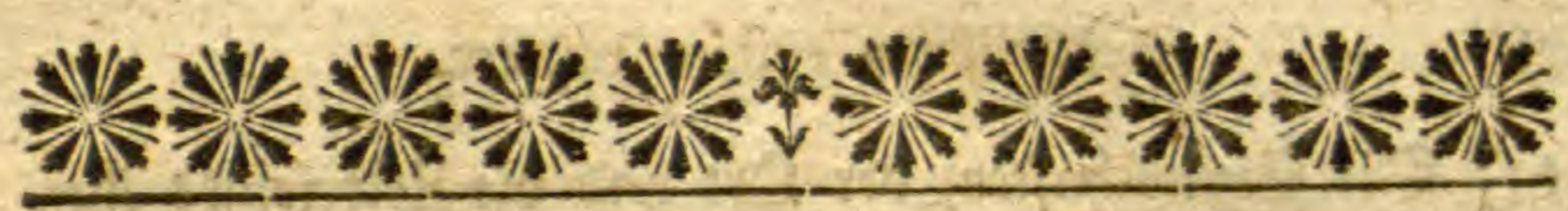

\section{- Sorerinnertung.}

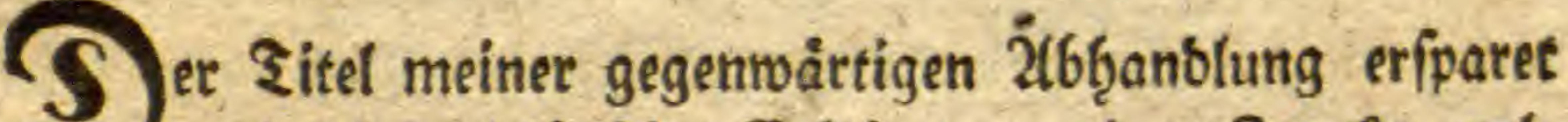
mir bie weitlåuftige Erflärung meines 3 wecfs, welden ich) burth biefelbe ju erreichen bৃoffe. Es ift alfo uiber: flüßig, baß ic) mich in eine ßorrebe einlaffe. Jah ḩabe nur einige wenige $\mathfrak{Z}$ (nmerfungen, in $\mathfrak{B}$ etreff ber $\mathfrak{B e r f a f l u n g}$

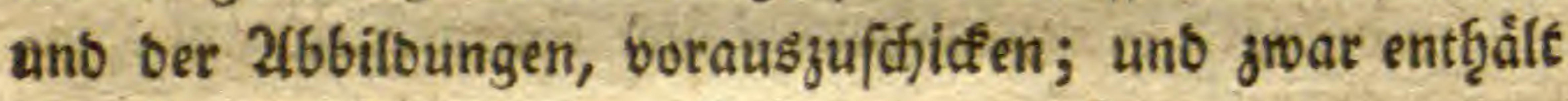
jebe eingelne Infeftenart:

3.) Den lateiniffyen fiftematifd)en Namen, nad Linue, fammt einem beutfden.

2.) bie foftematifhe beutifhe, uno ḩernach bie nämlicje

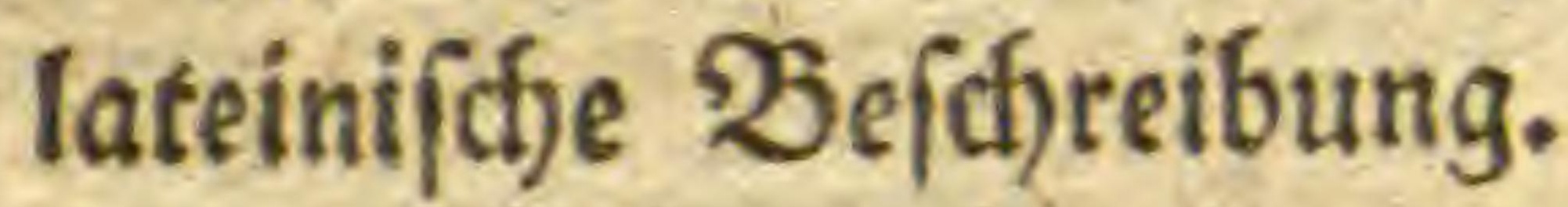

3.) Eitationen ber Sdbriftfteller, wenn einige vorb̨anben finb, bie bas Infeft befdsrieben f̧aben, mit bem bey) gefegten शamen bes Jufefts, wenn berfelbe bon bem eigentlidjen foftematifonen abreid)t.

4) Inweifung, gu welcher (5)attung jebe Infeftenart nach bem Fabricif̧,en Eyfteme zu zåblen iff. Şier ḩa= be id) aber nod) angumerten, baß ûberall, wo bies fe 2nweifung reggelaffen ift, bas Infeft aflegeit uns ter bet nảmlidjen (5attung nach Jabticius su fteben fomme, unter weldhe es nad) bem Sinneifden Sy: freme ftȩ̣et.

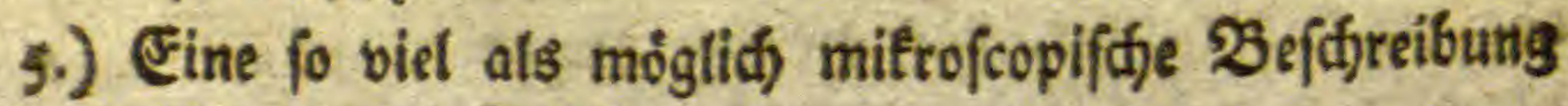
bes ganzen Infetts.
(2) 5
6.) Die 
6.) Die Eigenfdaften, ber Sort und bie aeit feines 2lufs entḩalts.

7.) Die Berifftigungen.

8.) Eine 26bilbung.

(6)

\section{I.}

Cantharis leucogaftra. Det weiß̧6àudige fliegenföfer.

Der braunmetallifotbe Fliegenfäfer, mit roth geranbetem Riüfenffhilbe, an ber Spife rofffarbenen flligefbecten uno gerben Ringeinfd́nitten unb einem flect am .̧̧in: terleibe.

Cantharis fufco anea, thorace rubromarginato, elytris apice ferrugineis, fegmentis maculaque abdominali nigris.

Malachius. Malaçitte̊fer.

(5. gleiđ)et an Beftalt bem gtwenblättrigen Fliegentäfee (Canth, bipuftulata $L i n$.) unterfdoibet fid) aber Docis

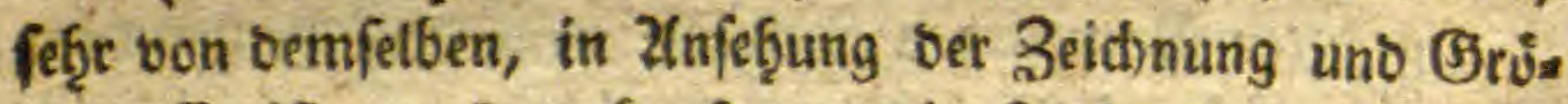
fe. Er ift um $\frac{\mathrm{I}}{3}$ aud oft um bie f̧àlfte fleiner. Dee Ropf ift platt, fotwarz, funfecfig mit abgerunbeten Ecfen,

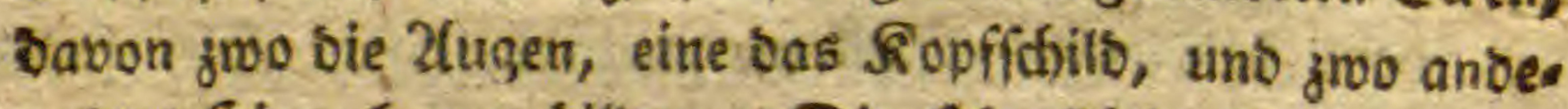

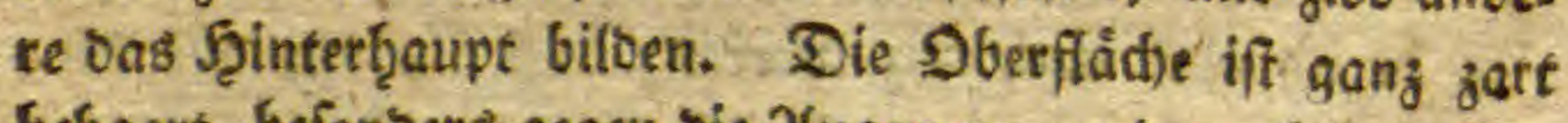
befgaart, befonbers gegen bie 2lugen ju, uno punftitr. Die

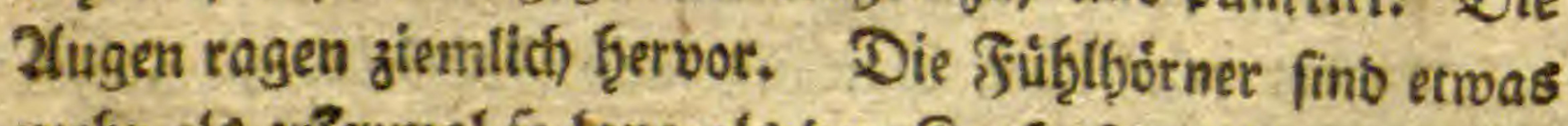
mef̧r als jwermmal fo tang als ber Ropf, fatenformig, eilfs glieorig, bavon bas erfte (Jliebdien bas größte uno biaffe, bas zte bas fleinfte, bas 3te uno 4 te etwas gróper, bas 5te 6. 7. 8. etwas länger unb buinner als bie erffern; bas 
9. ro. unt Ir. mathen bas Enbe bes fühtfiorns aus, uno find am Dùnften, uno werben gegen bie Epifece cins um oas anbere fleiner, fo daßi bas lejte bas fleinfte aus biefen breven ift. Zlle baben eine feilformige (5eftalt, werben aber immer fdowåcher, je nåf̨er fie bem Ence zu fommen, unb alle fino an if̧eem ranbe fein beb̧aart. Sie fino ganj bunfelbraui, nur traben bie erften viere immer etwas, balo mef̨r balo weniger, fdywarges. Die Dbers lippe ift gelb, bey Sem 2 seibahen meb̨r braun, platt, zages runbet, in Jer NRitte in bie Quere getbeilt, uno bebectt Die Epizen ber barunter liegenben Zubenfinntade; an bem Sianbe berfelben befinten fid) einzelne lange Jeärchen. Die Zukentinnlaben fino gebogen, glängent, fd)warzbraun, uno

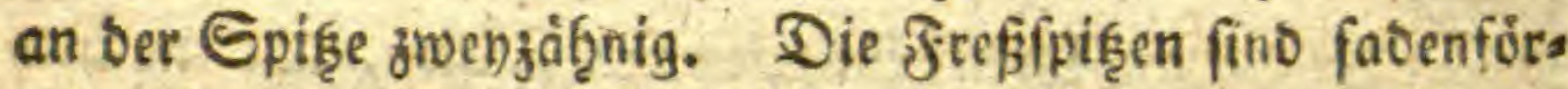
mig, furz, boch aber bie vorberften lainger als bie hinters

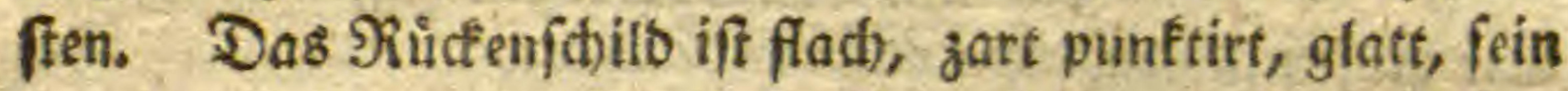
getanber, fómuşig jinnoberrotḩ. Mitten auf Demferben befinbef fich eine vom Ropf bis an bis glügeldecten ḩerabs.

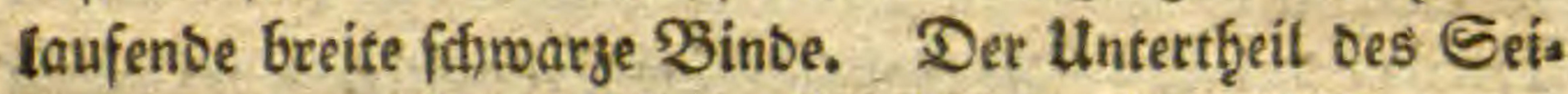

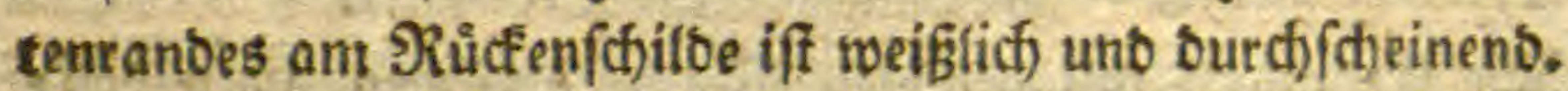
Born gegen bie benoen Ueberecfe bes Ruicenfdiloes befin: ben fich ebenfalls, fo wie aud an ben Seitentfieilen bes Seibes, jene rotben 5 läsđjen, wie an bem zwenblätrigen Jiliegentéfer. (Cantharis bipuftulata Lin.) Das Edfilod)en ift flein, abgerunbet uno fónwarzgruin. Die flügeldecten fint fo lang als ber Sörper, ben bem Weibden ausgenome men, wo fie etwas fưrzer fins, glatt, fótwarzgrùn, fparfant behaart, parallellaufent, an sen Epiçen gelbroth, bas balo sunfler, balo beller erfdjeint. $\mathfrak{B}_{\text {en }}$ bem Männdjen biefer $\mathcal{Z}_{\mathrm{rt}}$ ift nod) bieß bas fonberbarfte an ben Jügelbef.

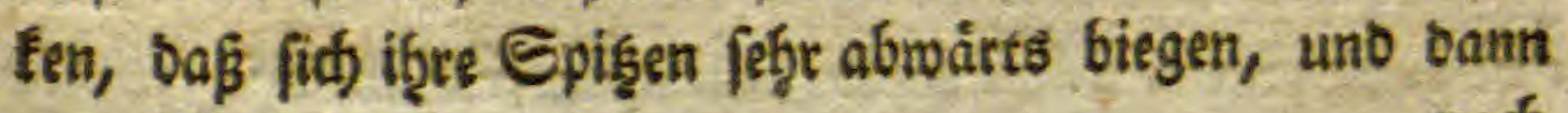




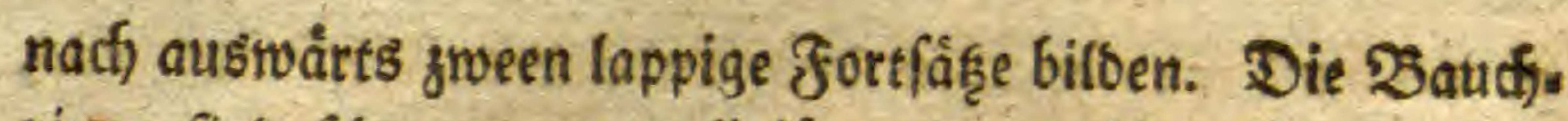

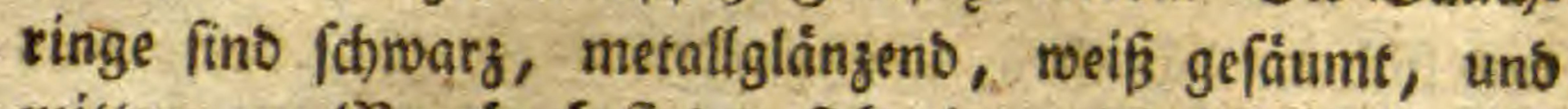
mitten am 'sautije befinbet fich) ein weifer flect. Die

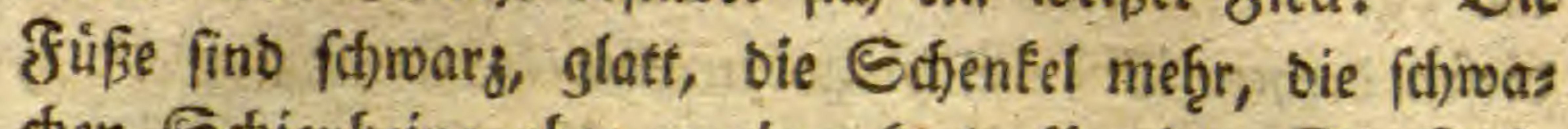
den Edienbeine aber weniger feulenförmig. Die Juse blätter fino braun, gleich)groß̧, uno beftehen aus fleinen feulförmigen (Slieschen. Das ganze Infeft ift nod) eins mal fo flein als ber gwenblätrrige Sllegenfífer. (Cantharis bipuftulata) Diefe ₹̧̧ierchen befinben fid) in ben (sairten

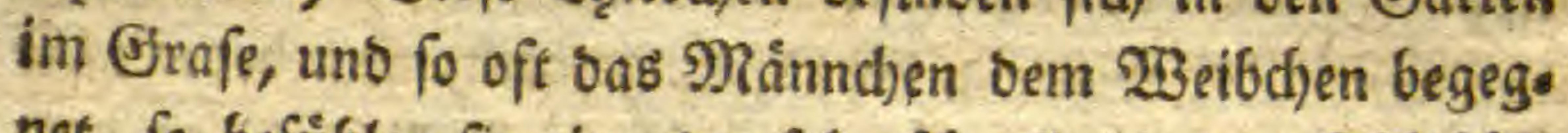

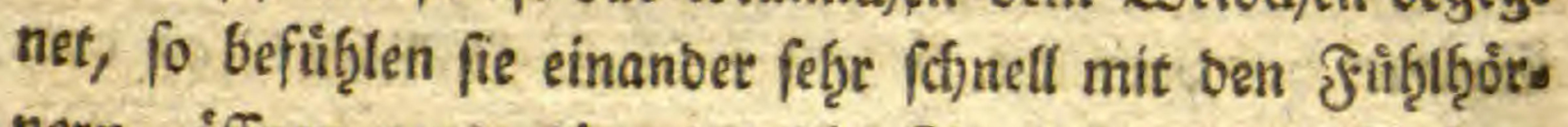
nern, offinen gegen einanber bie Rinnlaben, unb fdeiners fid), fo wie bie \$̇ogel, einanter ju fdnnåbeln. Zudh ftes

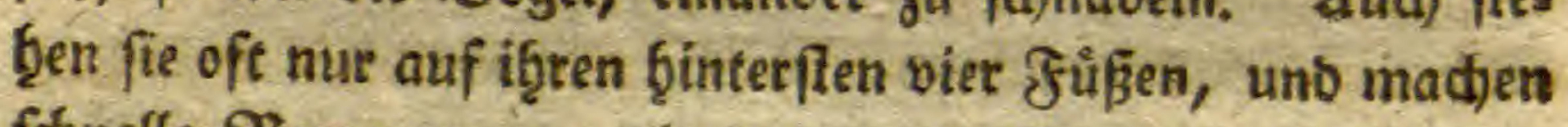
fifnelle Benvegungen mit ben vorberften gegen einanber. Eie laufen fónell.

\section{II.}

Tipula murina. Die mausfärbige Ertomulefe.

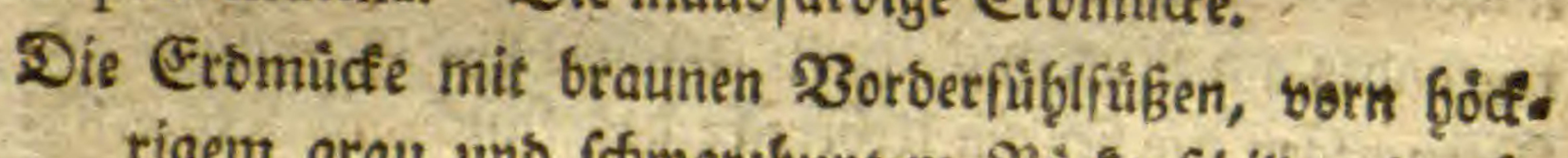
rigent grau unb fdiwargbuntem Riudenfdillo, burds. fidftigen mit vier grauen Jlecten bezeidjneten Jlúgeln, fobwargem Rörper, uno fectsgglieorigen fünffnotigen ङưh̨iţởrnern.

Tipula pedibus anticis motatoriis fufcis, thorace antice gibbofo, cinereo nigroque vario, alis hialinis maculis 4 cinereis, corpore nigro, antennis fexarticulatis pentanodiis.

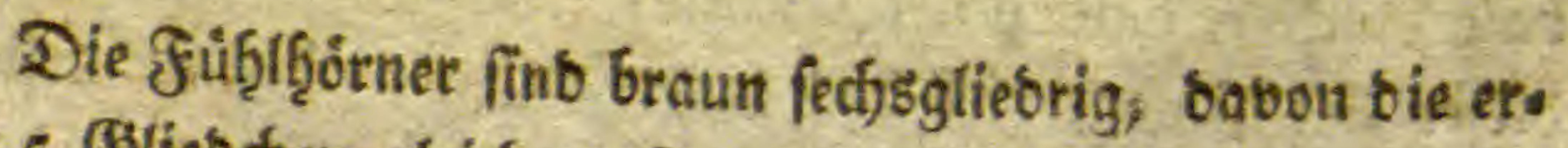
fen 5 Sbliebden gleid) groß, gegen bie Spife aber erwas. 
binner fint, unb jebes an feinem Enbe mit einem Räpf:

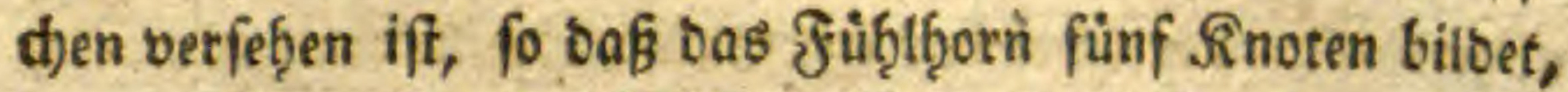
aus weichen allezeit, fowob̨l rect)ts als linfs, oren Bor. frenţaare entfpringen. Das lezte Bltieochen ift lang ges Def̧nt, walzenfơrmig, oủnn uno ebenfalls mit wenigen eins zelnen f̧aarborffen verfę̧en. Die Etime ift ganz grau

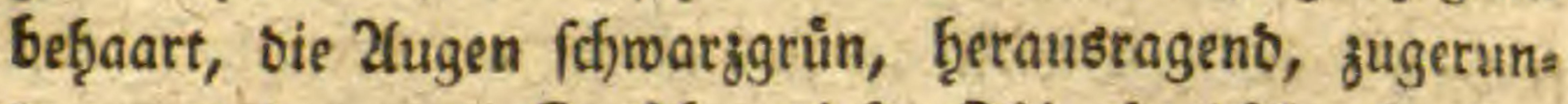

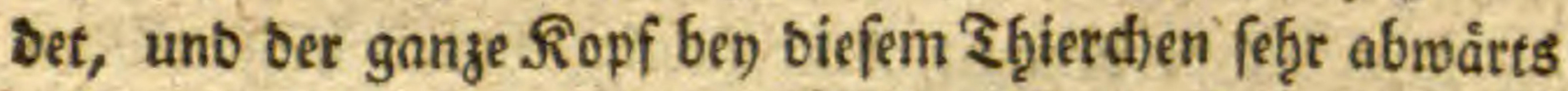

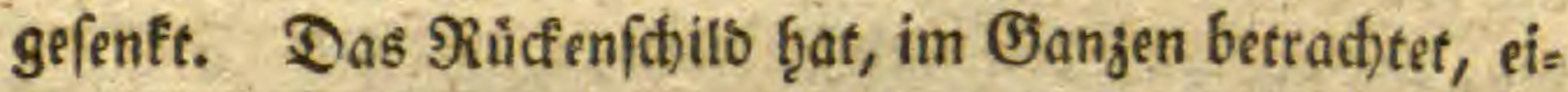

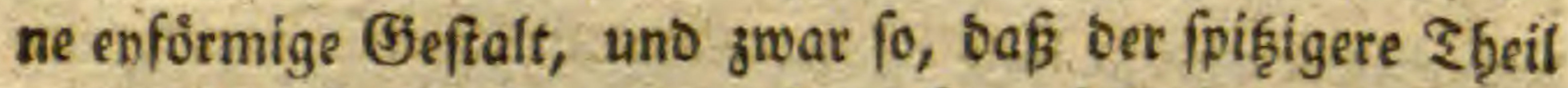
gegen ben $\Re_{0 p f}$, Der ftumpfere aber rưdfroárts ju fteblen fommt. $\mathfrak{B}$ orn bilbet er einen ftumpfen f̧ö́ffer, weldhet

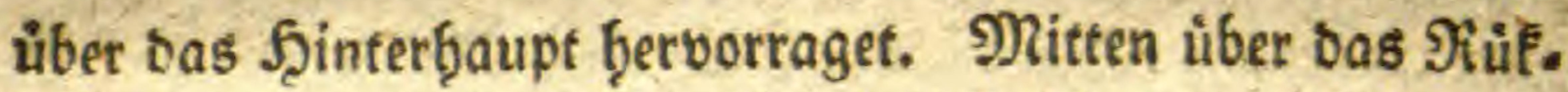

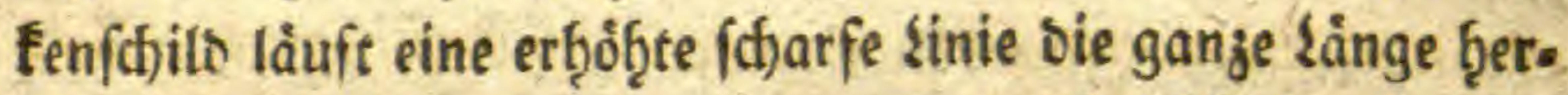
ab. Seine (5runtfarbe ift grau, weldhe fidi) ins braune ziefte, uno bren fdimarze flecte fino befonbers an bemfelben merfmurtoig, nàmlids: in ber Mitte ein langer ourdfous:

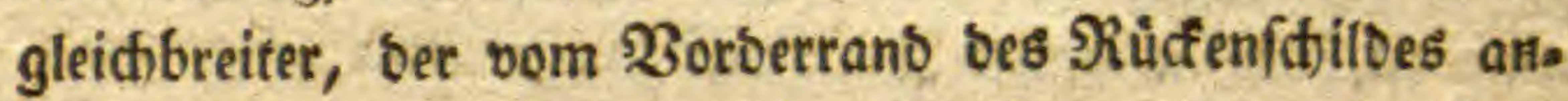
fängt, bis gegen $\frac{2}{3}$ bie sảnge ḩerabläuft, noo er gerabe abge. fónitten ift. Diefen tḩeitt bie erwåh̨nte făfarfe sinie in bie Sànge in zwoen gleiche ₹ b̧eile, an weldher er fich ins graue ver. liert. Sween anbere langrunbe fllecte aber befinten fiid) neben dem jezt ermáb̨nten, auf jeber Geite einer. Sie neţ. men ifren 2fnfana an bem ţintern Rante beiberfeits, ffeie

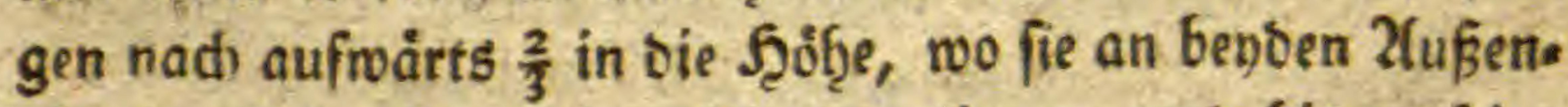
rántern bes erfiggeoachten filect's anliegen, uno bis an feine ba be Sảnge mit ifgm vereinigt ḩinauf fteigen. Das gange

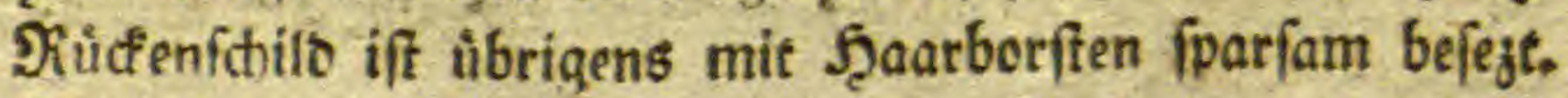
Das Echilbden beffehtt aus zween ₹b̨eilen: aus einem obern, breiten, fdjwarzbraunen, furzen uno gegen ben

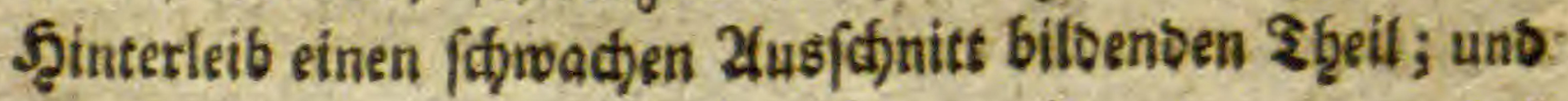


aus cinem fófmålern, etwas lángern, vorn zungenförmig abgerunoeten, weidher bas eigentliche Schilochen ausmacht, bon fow warger (5runbfarbe iff, uno jwo graue in oie sange laufende Macfeln ḩat. Der grau beţaarte Scinterleib ift etwas fånger als bas Bruffftúcf, waljenförmig, ber 2ffter runb zugefpizt, bie গingeinfdonitte grau, utib bie Brunb: farbe fómarz. Die Jlügel fino lánger als ber f̧interleib,

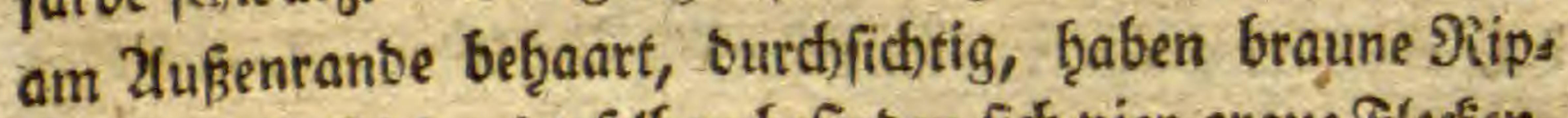
pen, unv auf jeber berfelben befinben fich) vier graue flecten, babon zween großge lainglich)ierecfige am innern Rande, ein fleinerer gegen ben Xuß̧enrans, uno unter biefem, mef̧t einwarts, ein oritter fleiner, balo meb̧r balo weniger bren. ectig erfheint. Die sulnnen Jüze finb braun, mit etwas Dunfletbraunen Edhentels unt Echienbeinfpişen, fie fino

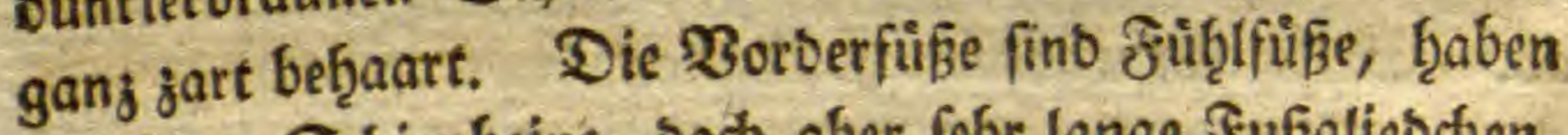
mur furze Gdjienbeine, bod) aber feb̧e lange Jubggliebchen, bavon bas erfife nod) einmal fo lang als das Edjienbein felbft ift. Das gange Jnfeft ift nur I sinie lang, uno fliegt bes 2orgens in ben Bimmern auf ben Jenftern ţerum.

\section{III.}

Tipula virginea. Die jungfråultifje Erromuicfe.

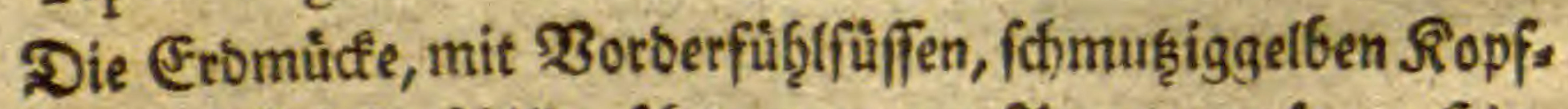

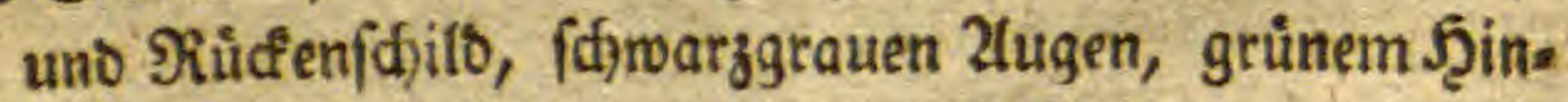
terieib uno ungeflectten beb̧aarten Flitgein.

Tipula, pedibus anticis motatoriis, capite thoraceque luteo, oculis obfcure viridibus; abdomine viridi, alis immaculatis pilofis.

In Der Gieftalt unb (Sro̊ke gleich)et fie vollfommen bet

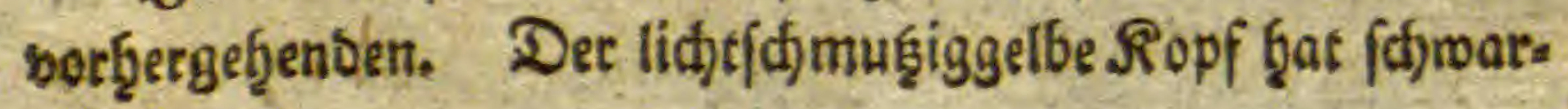




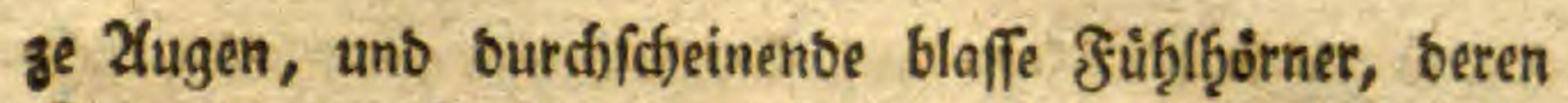

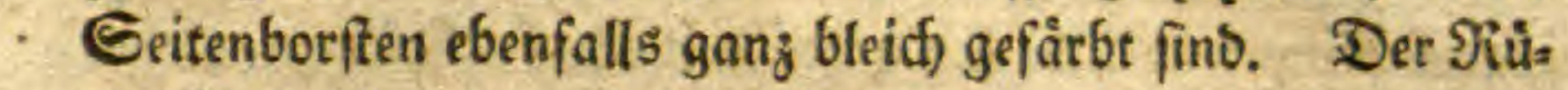
cenfibilo ift etroas fomuşigbleid)geib, uno bat fo wie bie

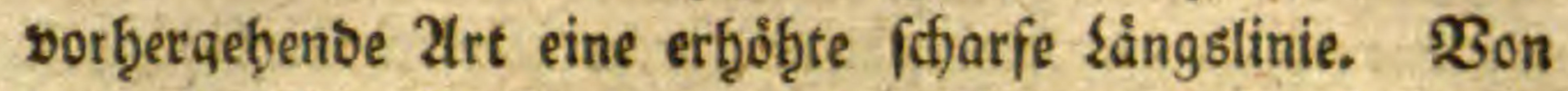
Der námlichen Jarbe fino aud) nod) bas Edbilbchen uno bie Ed)wungfölbchen. Der Şinterfeib ift bleichgrün uns

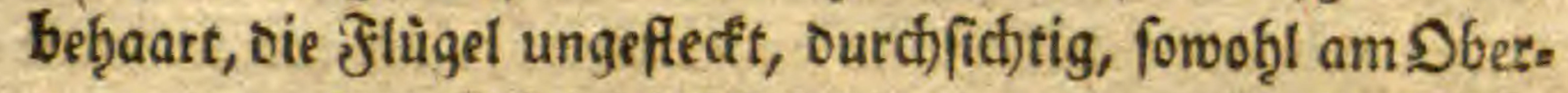
rano als auf Der Fläc)e falbft beb̧aart, uno mit blaß̧gelblic):

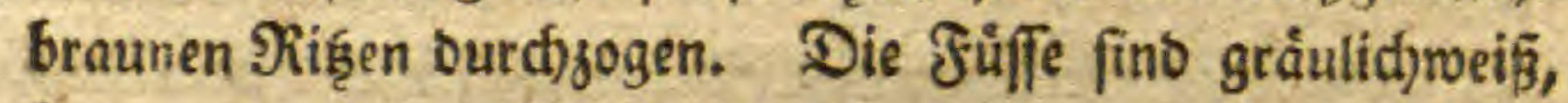
beţaart, uno burch)fheinent.

Diefe Eromuice fliegt im Eommer in ben Mronaten Sunn und July, in ben 3immern, an ben fenftern umber; fie if gemein, und ob fie faton von ber vorbergefgenden in nid)ts an ber (Beffalt unter/chieben iff, fo raire es bod) ḩơchft ungereimt, biefelbe, wegen ber fo fę̣r abmeidjenben Jarbe, nur für eine bloße 刃arietät ă ḩalten.

\section{IV.}

Tabanus cylindricus. Die malfenförmige $\mathfrak{B i e f ̧ b r e m e . ~}$

Die Bieb̨breme mit grůnen, mit orey Purpurbinben veties

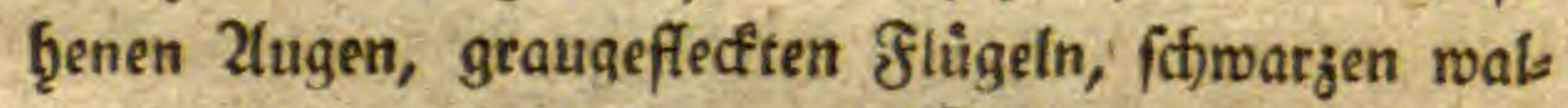
zenförmigen, mit zwen grauen Seitenlinien bezeidfne: ten Şinterleibe, uno fuchstoţ̧en after.

Tabanus oculis viridibus, fafciis tribus purpureis, alis cinereo maculatis, abdomine atro cylindrico, lineis duabus lateralibus cinereis, ano rufo.

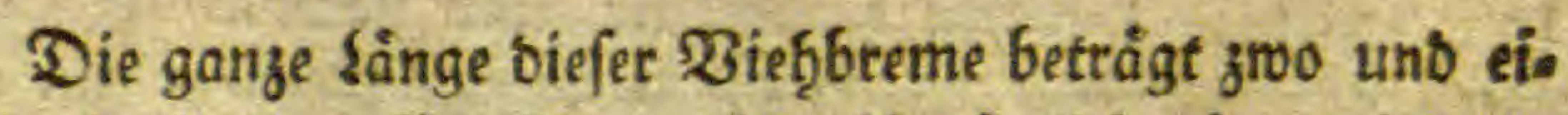

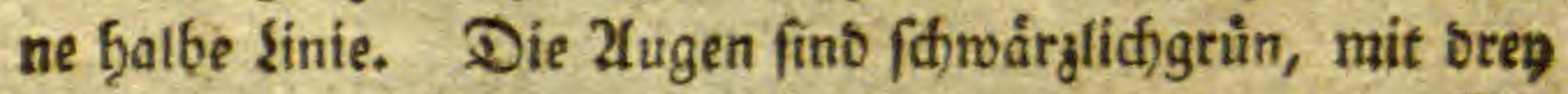

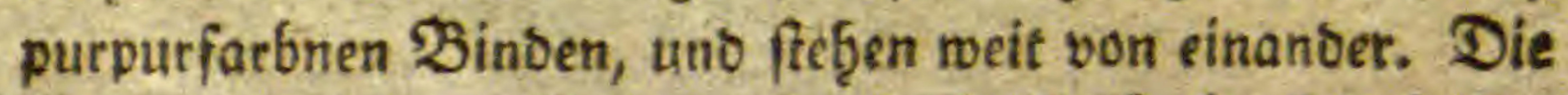

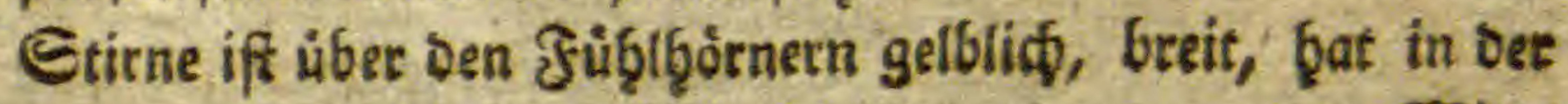
शitte 


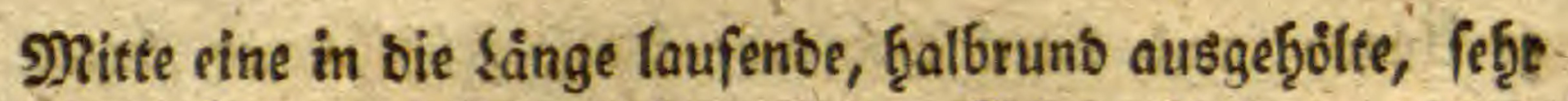

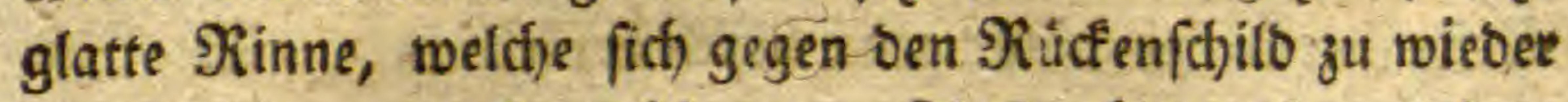
ausgleifhet, uno einen f(j)wargen flecfen biloet, in weichem Die oren braunen Nebenaugen zum Borfdein fommen.

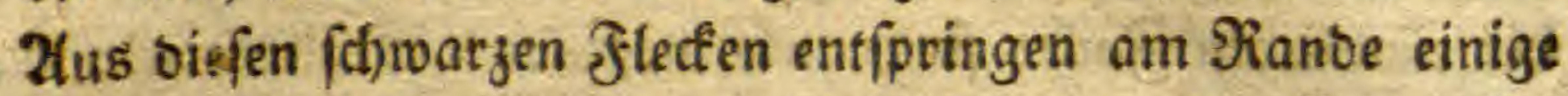
Dorften, uno an ben zwen Seitenraindern ber Etirne bes finben fid) auf jeber Seite zwel) hinter einanter frebente fdfmarge flecfchen, bavon bas vorberfte gròßer, bas hina terffe aber fleiner iff; aus benben aber ein jiemlicher etroas gefrümmter furger Dorn entipringet. Die (5)egeno bes

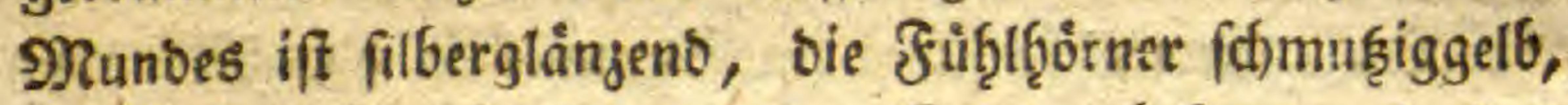
mit fteifen Şaarborften an ben Ranten befegt, uno bas

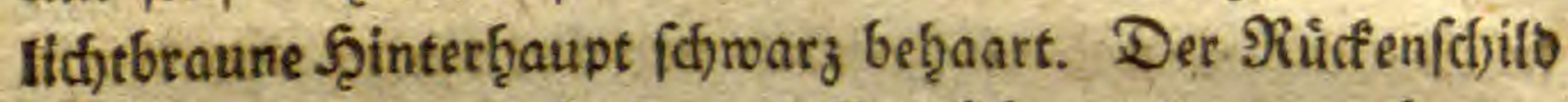
ift etwas länger als beeiter, oeffen Dberrano etwas bogen: förmig, bie Seitentainber oben fanft ausgefdrweift, unten ausgebogen, uno ber Unterran' faft jugerunbet. Seine Srunbfarbe ift grau. Mitten uiber benfelben låuft eine fdjmuşiggelbe Binbe von oben ḩerab, bod) fo, baß fie fich ins (Graue verliert, nod) eḩe fie ben Unterrano erreichet, uns inmer fómåler mirb. 2(n viefe gelbe Sinbe gränzet bey). Derfeits ein fdywarzer, in Der Mitte breiter, uno an benben EnDen zugefpizter flect. Dann folgt ber graue ?̧̧̧eil bes. Siludenfdilbes, auf roeldfem fid) ju beyben Seiten noch ei. ne in bie sange laufenbe, aber braune, fdimale, uno in ser Mitte unterbrochene Binbe befintet. Hebrigens ift oer

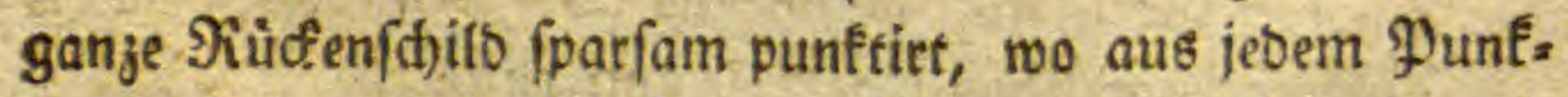
re ein fleines J̧ård)en Ģerbortritt, uno noch ùberoief̧ mit einzelnen, långern, jerftreut ftef̧enben Borften hín uno mieber befezt. Das Schildoden ift groß̧, abgerundet, fá)war z, mit einem braunrotfeen länglidjen Fllect. Der f̧interleib

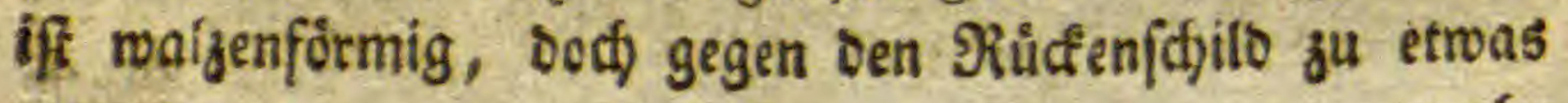
meģe 
mę̧r aufgetrieben, fthwar, bon benben Seiten mit einer grauen, in bie sảnge laufenben Sinbe verfẹten, beţaart,

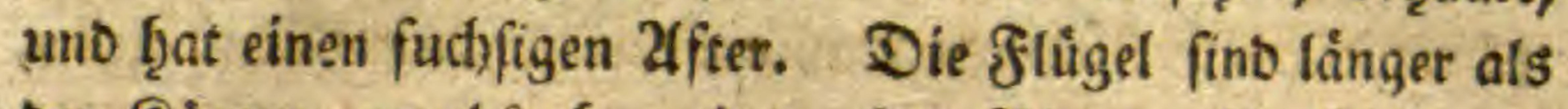

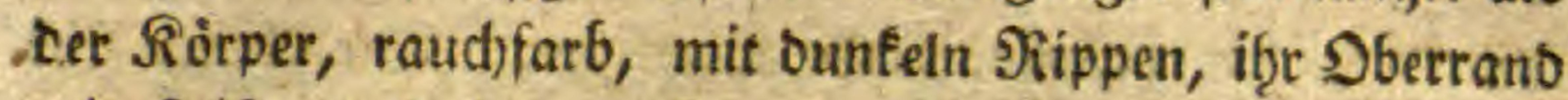
mit fteifen uno furzen f̧aaren gebraimt, uno bie untere

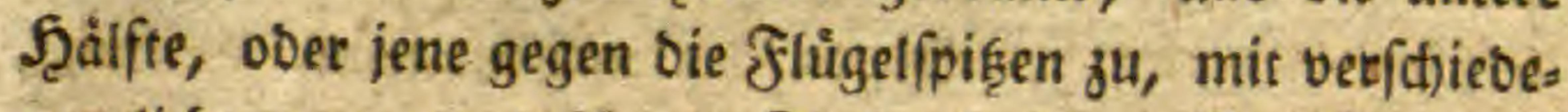
nen lid)tgrauen verlofthenen flecten befejt. Die Jüüe finb bleich f(t)mu(siggelb, oie Juß̧blätter etwas ounfler, Dod)

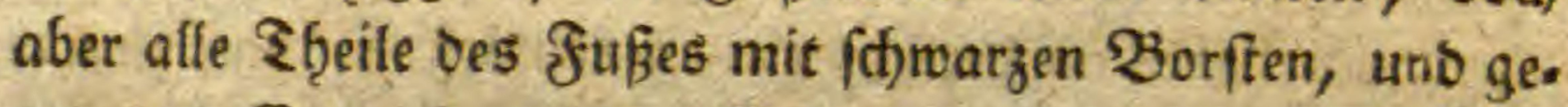
gen bas Ente eines jeoen Gelentes mit einigen Stad)eln bewaffnet.

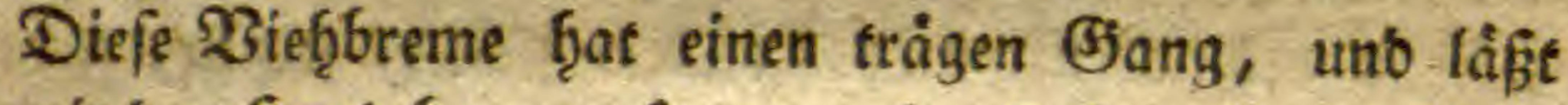
fic) mit ber f̧ano bequem fangen, ofgne baf fie bavon fliegt. J̧̧re flügel trägt fie meiffens úber einanber gefoblagen, unb fiehet Dann einer fliegenden saus ober ber Lausfliege (Hippobofca Lin.) nict)t unåg̨nlid). Sie iff felten.

\section{V.}

Cantharis Cardiacz. Der Şetzgefpannf́äfer.

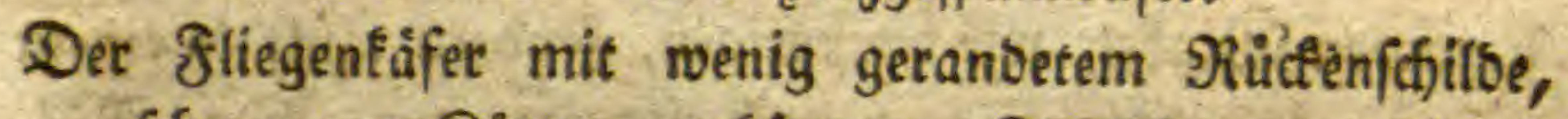

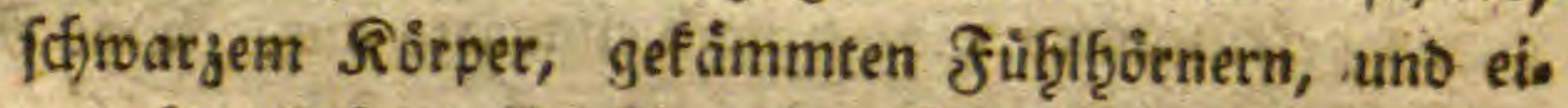
nem blutfarbnen gountt an ber Epiz̧e ber flügelbecfen. Cantharis thorace fubmarginato, corpore atro, antennis - pectinatis, elytris apice puncto ferrugineo.

Lin. Sylt. Nat. T. 1. p. 649. G. 208. Sp. 13.

Id. Syt. Nat. Ed. XIV. T. r. Pars I. p. I893. G. 208. Sp. 13.

Id. Faun. Svec. 720 .

Carl de Villers. Ent. Lin. T. r. p. 295. G. 2 I. Sp. I 2 , Malachits Fabric, 
Ere ift eine uns ein Dritţ̧eil einer sinie lang. Der Ropf ift beyrafge fo breit als bas Rưcfenf(t)ilo, glånzent, f(f)rarz, weld)es fich etwas in ein mietallif(d)es Braun jief̨et, punftirti, uno b̨at eine roth̨e Dberlippe. Die Zugen fino

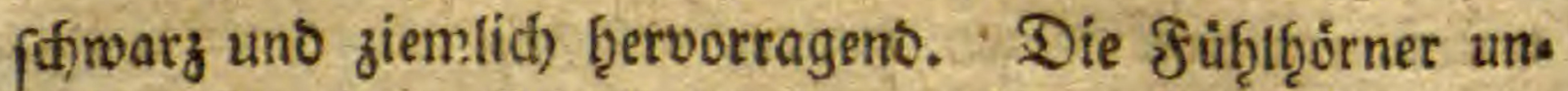
terfheiten biefes Infeft von ben meiften feiner (5)ttung, benn fie fint volffommen, nach ber innern Geite zu ges fámmt, fofrwarg, uno eilfgliebrig, babon bas erfe (Slied. d)en, ober jenes an bet 2fnţeftung feilförmig, bas zweite eben fo gebilbet, boch abet etroas furzer; Das oritte uno vierte fiton meţr an Dem Enoe ber innern Geite fiervor. treteno uno bृafenforrmig ift; bas fünfte, fechffe, fiebente, adfite, neunte unb zef̧nte aber, biltet fojon an feinem En: be, nact) innen zu, einen langen, etwas lappenforrmigen uns ju benben Eeiten mit f̧aaren gefäumten fortfaš, oas von alle von gleicher länge unter einanber fino, uno bem

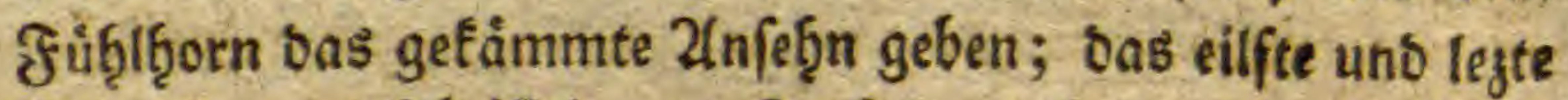
(Sliebchen enblid) ift lang geftrecft, macht an feinem Enbe, mit bem an bemfelben befindidifen fortfaşe, teinen etwas

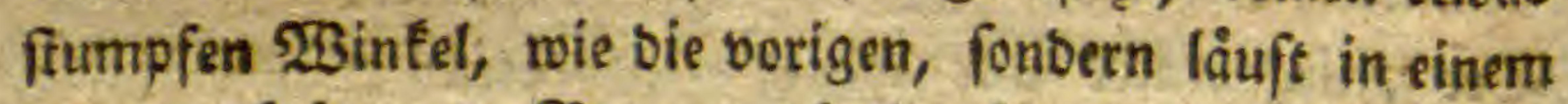
etwas gefruimmten §ogen nach einwairts aus. Das গiuf. fenffhillo ift platt, jugerunbet, etwas getånbert, fef̧r glains genb, mit bem Ropfe gleidfårbig, uno mit feb̨r feinen zets freuten Dunften befejt. Die flügelbecten fins orittb̧alb. mal fo lang als bas Siuffenffitls, faft ourchaus von glei=

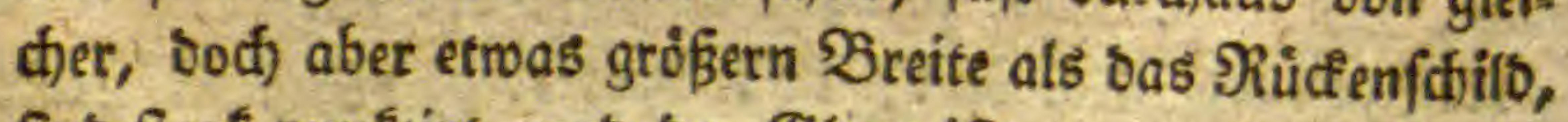
fino farf punf́tirt, uns ber Slang ift, megen ben ziemlich

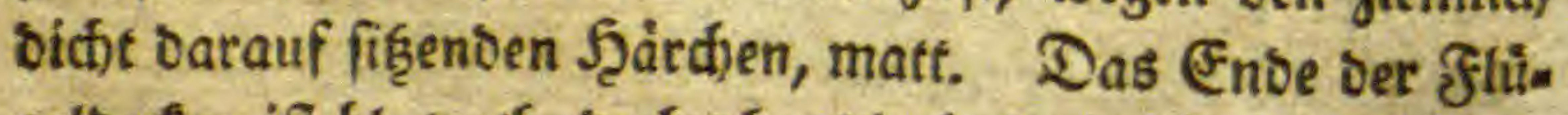

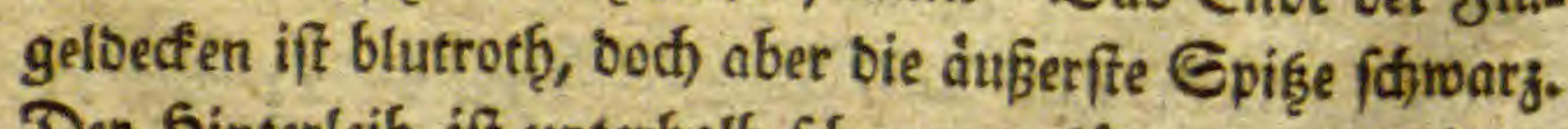
Der Şinterleib if unterḩalb fofwarz, glanjent, unb jeber 


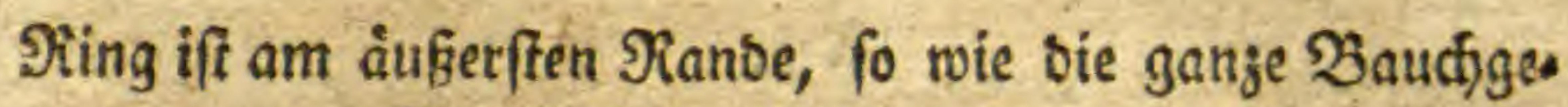

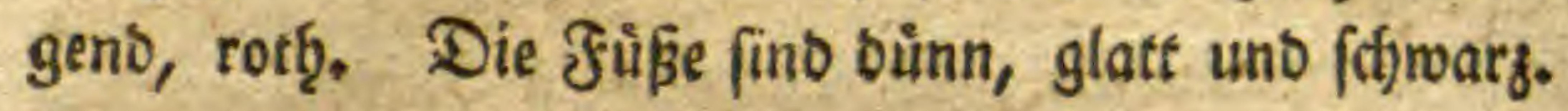

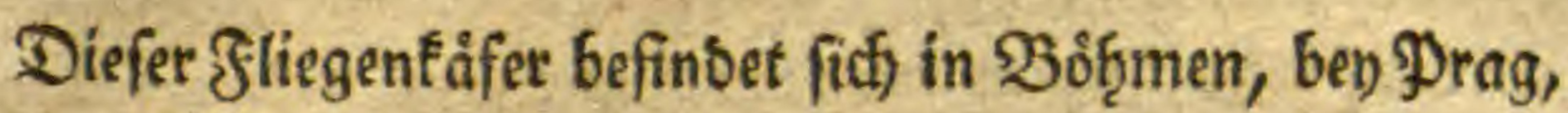
auf bem f̧erzgefpannfraute (Leonurus Cardiaca Lin.) uno ift ziemlich felten. Nur sinne' allein fans iţn in Echowe.

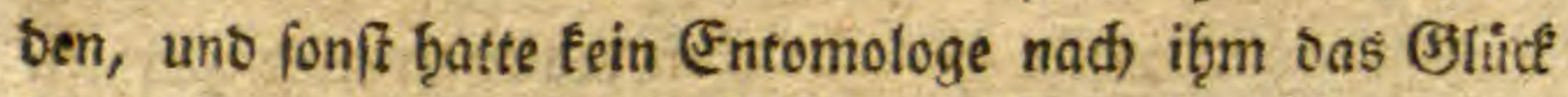
benfelben ju finben. Feerr Fabrizius úbergebet in feinen en= tomologifotien Berfen biefes Sinfeft, weil er nicfte muffte ob es, nad) feinem Enfteme, zu ber (S)attung Cantharis

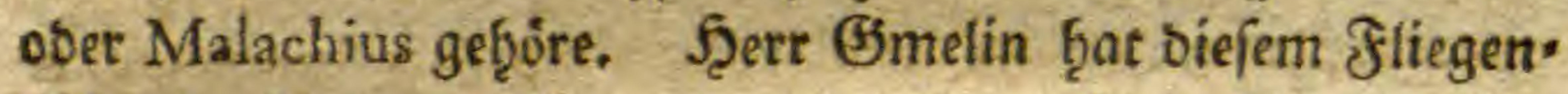
fäfer in feiner neuteften ober vierzeḩnen Zusgabe des sín. neifchen Naturinftems ebenfalls eine unácfte Stefle ange: roiefen. Er ţ̧eilet nåmlid) alle fliegenf́ăfer in zmo unter. abtheillungen, babon bie erfte Ģafenforrmige, bie jwote aber

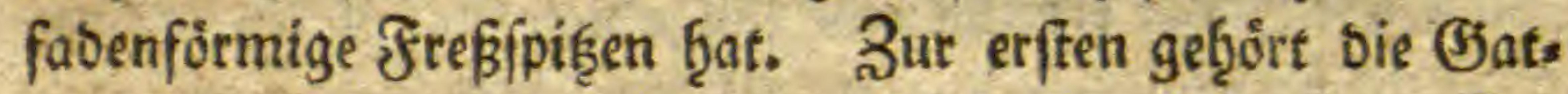
tung Cantharis, unb jur jwoten Malachius bes J̧ertn fas brigius. 23 eil er aber bas gegenwairtige Injeft nicft tanns te, fo fejte et es unter bie erfte Unterabtheilung. Da es aber fabenförmige fref̧pipişen f̧at, uno nact) meiner Unter: fuct)ung ein wab̨rer Nalac)itfăfer (Malachius) bes .̧errn

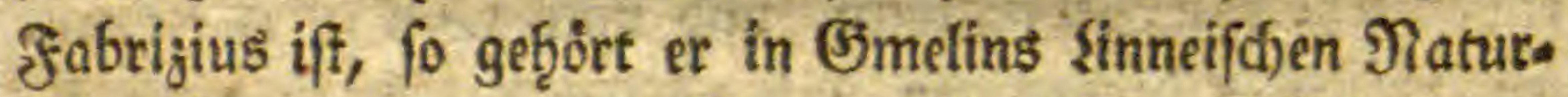
foftene zut zooten unb nicht gur erften Unterabtfgeilung.

Drulct man biefes Infeft etwas, fo treitt es, wie ber metalliftche ffliegenfåfer (Cantharis anea Lin.) Die rotḩen SBläschen fowoh̨t an ben Seitenţ̨eilen Der 2 ruft als bes Şinterleibes heerbor, 


\section{VI.}

Mufca macrophthalma. Die grosångige fliege.

Die Jliege mit graugrunnen, an ber Etirne zufammenges wadffenen, braungeflecten Zfugen, faft finierten, braun.

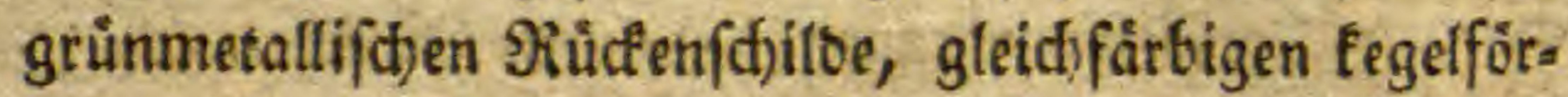

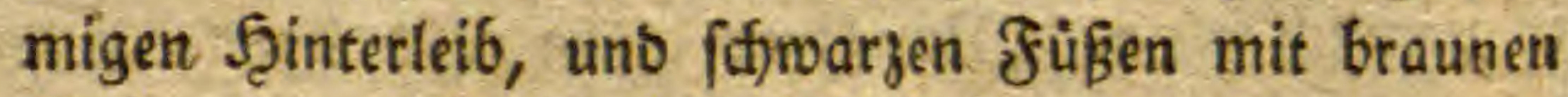

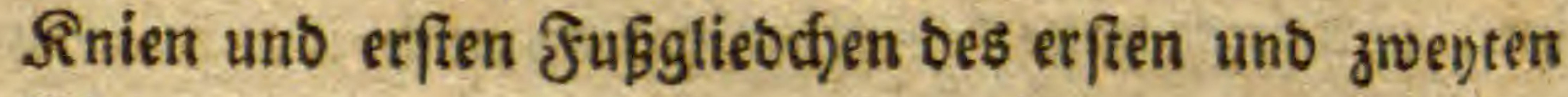
Paars.

Mufca, oculis cinereo viridibus, in fronte connatis, fufco punctatis, thorace fublineato, fufco-viridi-zneo, abdomine concolore conico, pedibus nigris, genubus tarforumque primo articulo, primi fecundique paris, fufcis.

Syrphus. Fabric.

Diefe fliege etreidjt eine länge von fünf sinien. Des Ropf ift ḩalbfugetruno, uno bie 2(ugen mad)en ben gróg. ten ₹̧̧eil beffelben aus, inbem fie if̧n von vorn ganz umges ben, fogar gegen bie Etirn zu fich unter einanber genau vereinigen, uno nur am Ed)eitel einen fleinen (piłzininflich.

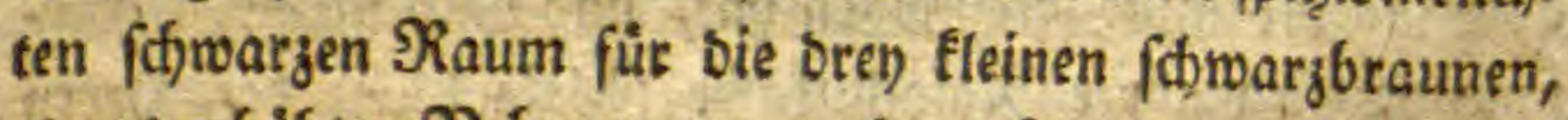
etwas erb̧öbten গebenaugen, uno nach) vorn zu einen gro:

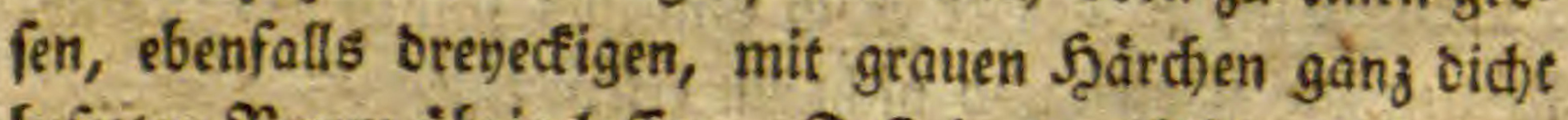

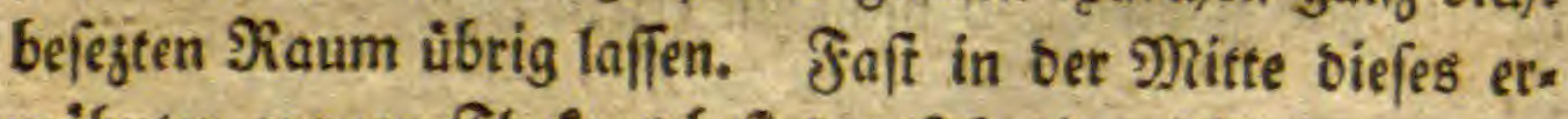
wäḩnten grauen flectens befindet fich) eine fergr glänjenbe, fleine, ffirvarze, länglidfrunbe Erthabenţeit, uno weiter über berfelben, ober fifon naţe ben ber $\mathfrak{B}$ ereinigung ber benten Zuqen fint bie Jüblifórner eingepflangt. Diefe bुa* ben eine lappige Geffalt, finb von Sarbe braun, unb ein jebes befizt faft gegen bie פitte an feinem Obertanbe eine 
einfache fef̧r zugefpizte, unb nach auswairts gerichtete Wior. fte. Die 2lugen felbft fino ganz graugrün, werben abet ben ben tobten uno in Eammlungen aufberwab̨rten Eremt.

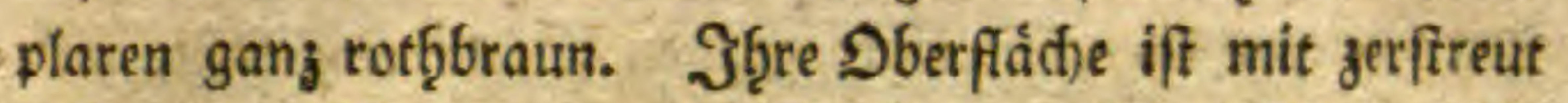
fieb̨enben rotḩbraunen runben flecten ganz bis auf jenen fleis nen ₹ f̧eil, wo fid) bie 2fugen unter einanber verbinben, befezt. Dod) ift aber baben, als ein fef̧e d)arnfteriftifches Renn= zeitien, ben biefer 2 rt anzumerfen, baß biefe Punfte gegen

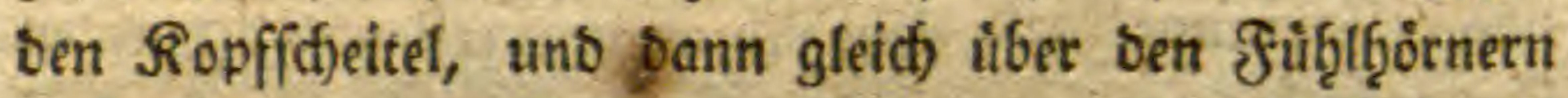
unter cinanber etwas zufammenfliefen, wo fre gleid)fam grós fere braune flecfe bilben. Ulebrigens finb bie gangen 2 (u= gen mit fleinen grauen Eeibenţärd)en befegt. Das গutuden. fofito bat eine freibformige nur wenig gewoilbte Geftalt, ift ctrons fotmåler als ber Ropf, bod) aber etwas lánger, fam: metartig braun beḩaart, ganz braungrún metallglänzent, mit fdroadien Spuren von grauen Sinien, weldhe vom Borberranbe gegen ben f̧interranb ju laufen, ooch) aber benfelben niemals erreicjen, fonbern fhjon gegen ben britten

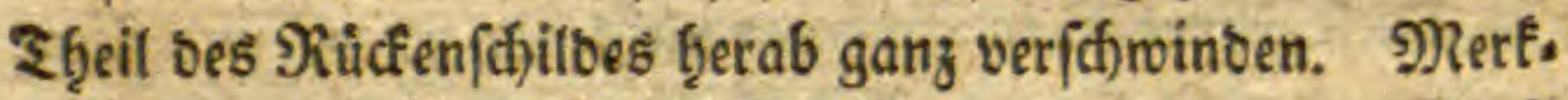
wuiroig fino noch) am Siticfenfditbe grveen fleine graute flect. () en, welche fid, an ben jwen äuzerfien Enoen bes $\mathfrak{B}$ ot. bertanbes beffelben, zu jeber Geite eints, befinben. Das Edjilbden ift Ģintennad) zugerunbet, uno befonbers am Nanbe bef̧aart. Der Şinterleib ift fegelfơrmig, fammets artig braun bef̧aarf, bod) fallen aber biefe f̧ärdien an ben Ringeinfáfniften, ben Geitentb̨eilen bes Leibes uno bem affer, mef̧e ins graue. Seine farbe iff jener, bes গille. fenfchilbes, ganj gleid); nut bemerfet man, baß bet anbere, britte unb vierte Siing fid) gegen feinen untern

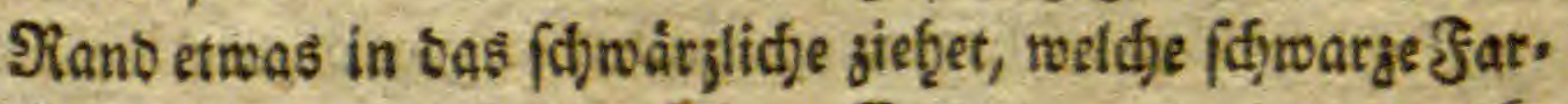


be ben funften ober ben dfterring ganz umgiebt. Det Bauch) ift ebenfalls braungrun metallglängens, bod) aber

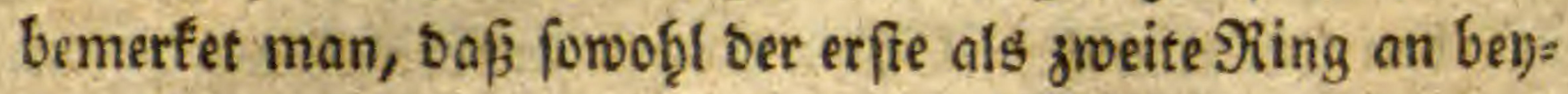
ben Seitentheilen mit einer graten Binbe eingefab̆t, uno Ser vierte blauglangeno ift. Die flugel finb ungefiedt; unb gegen ben bicfern $\Re$ iand etwas ins raudjfarbne fallent, Die frufe fofwarz, boch aber unterf̨alb mef̧r ins grùne fchimmerno. alle Rnie ber sren paar f̧üke fino braun, uno biefe braune farbe ziefgt fid) an bem erften und groenten Jufpaar bis gegen die b̧alben Edjienbeine gerab, fo, Daf siefe balb braun uno halb fd)warz erfdseinen. Die Jußs= blätter fino balo mef̧e bals weniger, wegen ben barauf fif̧enten bunflern f̧aaren, fówarz; bodf fino aber jene, bes lezten f̧ufpaars, immer am ounfelfien von farbe. $\mathfrak{Z}_{n}$ Den Fupblattern bes erften, und befonbers bes zwenten paars, ift nod) ju bemerken, bafs bas erfte (Gliebdjen, obee jenes, reldjes fich an bas Sdjienbein anfidiefit, faft gang von brauner Farbe erficheint.

Diefe Fliege ift in Bóbmen nicht gat feften, uns fliegs bes shonats Jufii uns 2luguft ben bellem Sonnenfdheine auf Dolben tragenben $\$$ flanzen, befonbers bem fenchel unb bem gemeinen 20 gelnefte (Daucus fylveftris Lin.) umb̨er;

\section{VII.}

Mufca punctata. Die punffirte flliege.

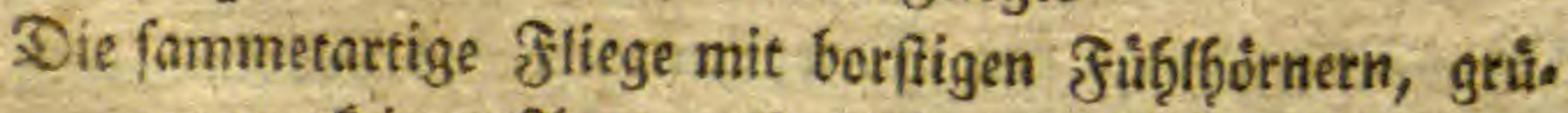
nen punftirten 2lugen, fïnfinirtem Fivicfenfdilbe, uns fiffwarzem abgeftumpften Şinterleib.

Mufca antennis fetariis tomentofa, oculis viridibus, tharace quinque lineato, abdomine nigro obtufo. 
Muill. Faun. Fridr.

Carol. de Villers. Ent, Lin. T. III, p. 465 . G. III. Sp. 143. Syrphus Fabric.

Diefe friege wirb bier sinien lang, boc) giebt es aud) einige bie woh̨l um eine gange sinie fleiner fino. Der Sopf ift beynah̨e halb fugelformig, uno bie 2(ugen mad)en ebenfalls ben gro̊kten ₹̧̧eil beffelben aus, verwachjen aber niemals, fo wie ben ber vorb̨ergeţenben 2 :tt, an ber Etirn zufammen, unb bilben baḩer nicht, fo wie bey jener, zween

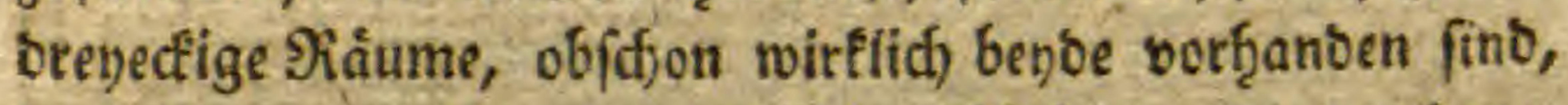
bod) aber unter einanber vereinigt erfajeinen, uno nur bann

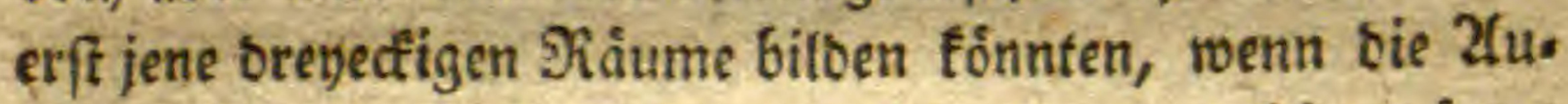
gen vollfommen an ber Etirne jufammen gewach) fen wären. Der Echeitel bes Ropfs, auf weld)em bie bren fleinen (f) wargen গebenaugen ftehen, ift ff)warzgrau; wiro aber gegen bie Stirne, uno befonbers bie э) tunogegent, líthtgrau, mit weiß̧en Şaaren bid)t bejegt. Worn auf bem Ropf, ges rabe niber ber Munboffinung, befinbet fid, fo wie ben oer

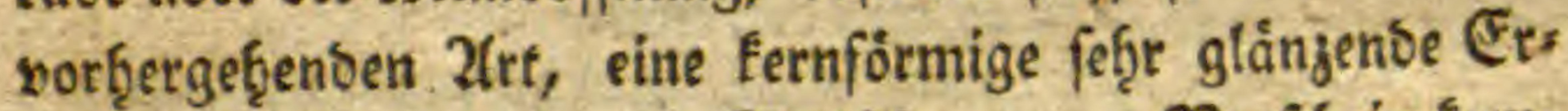

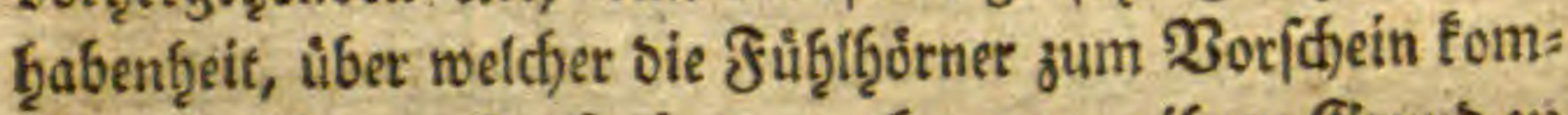
men, welche bon Farbe braun, aber gegen ígren Grunto ju

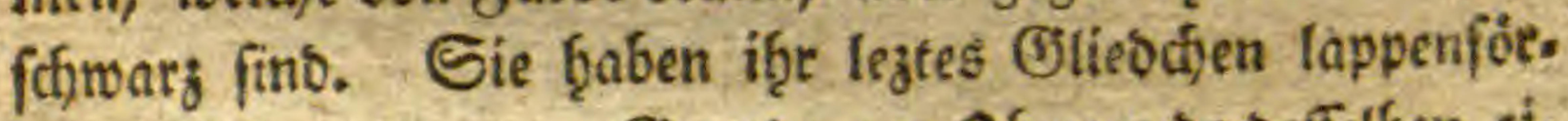
mig gebilbet, wo vom Strunbe am Dberrande beffelben ci. ne braune, feb̨r fpig̨ige, einfact)e, auștoirts gefrůmmte Dorfte if̧ren Sif, Ģat. Die Zlugen fino von Farbe graus gruin, berlieren ober biefelbe im tobten Buftanbe, uno nort= ben bann bunfelrotḩbraun. J̧̨re Đberflád)e ift ganj mit

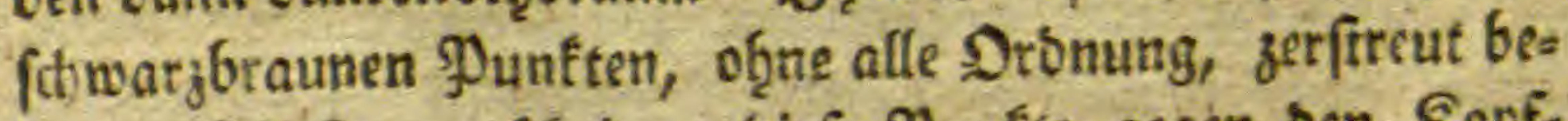

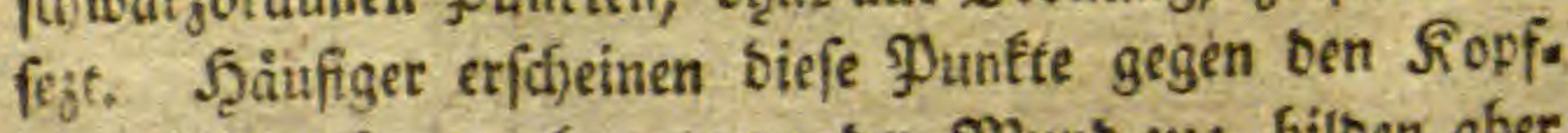
(d)eitel, fparfamer aber gegen ben शiunb ja; bilben aber 
niemals jene flede, wie ben ber vorigen 2(rt. Utebrigens fino die 2(ugen fammetartig mit zarten Şärchen bewachfen. Das Rucfenfthito ift nưr wenig genoolbt, und f̧at eine jus serunbete Geftalt, iff fotmáler, boch aber lainger als oer Sopf, fammetartig braun bef̧aart, ganz fchroarz, nue manch)mal ein wenig ins braune fofinmerno. 2(uf oer. Sberfläthe beffelben faufen vom Dber, bis jum Unterranbe

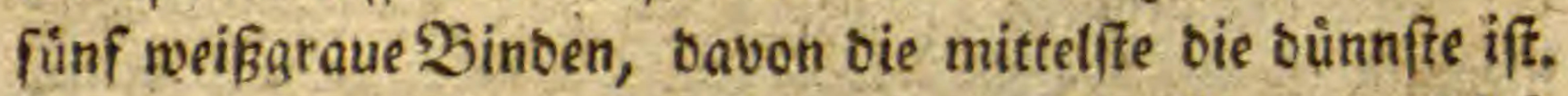
Doch giebt es aber aud) Eremplare biefer 2 (rt, two biefe

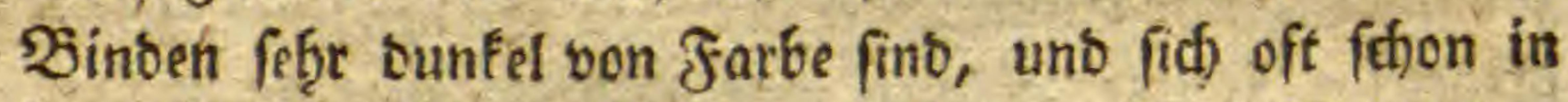
Der f̧ålfte bes Rlucten(d)ilbes vertieren. Das Edjilbdjen

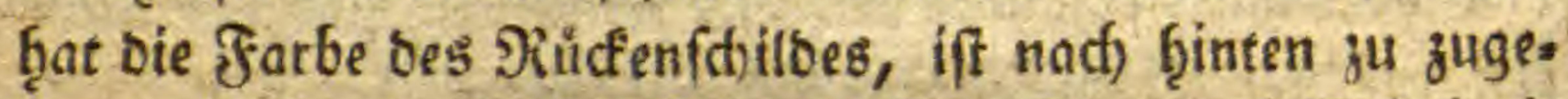
runbef uno mit Şarthen befezt. Der Şinterleib iff fo breit als ber Rilfenfótilb, Fegelformig, glatt, theils grau,

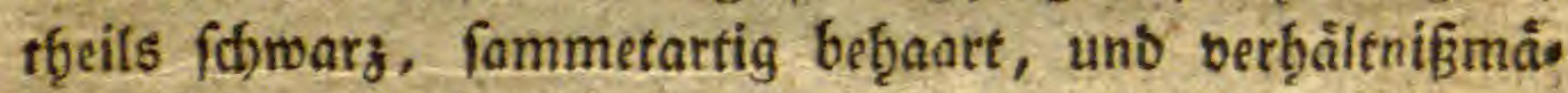
Fia fuirzer als ben ber vorbergehenten 21rt. Die Farbe beffelben ift Braun ntit einem Metallgfanze, uns mitten auf berfelben befinben fich) zwen fdjwarge glanglofe Fledfen, bavon ber eine groffere auf ben jwenten, ber barauf fols

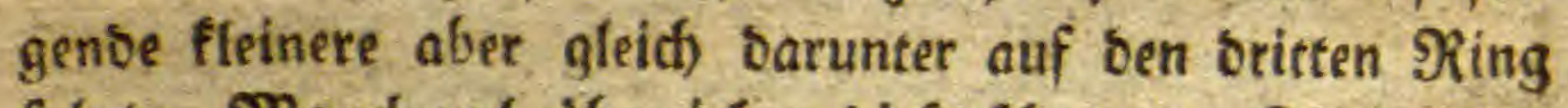
folgt. गRand)mal nibergief̧en biefe fctwarzen Flecten ben ganzen \bertheil bes Şinterleibs, weld)er Dann ein forwar: zes fommetartiges uno alles Stanzes beraubtes 2/nfehcen gewinnet, uno betsoerfeits fohimmert nur noch oie glän. jente (Sruno farbe als ein wellenförmiger Gaum fiervor. Die flügel fino ganj glasartig, of̧ne alle Jlecfen, mit

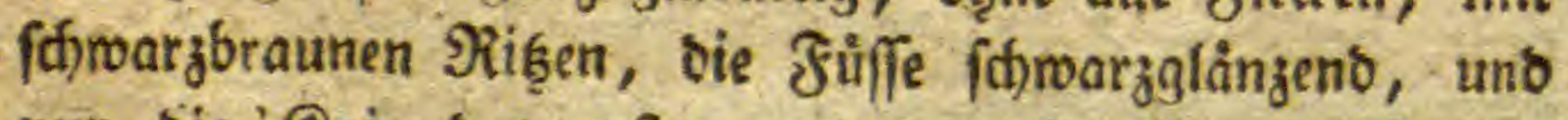
nut bie 'Rnie bes erften uno jwenten Paares braun. Diefe Sliege ift eben auf ben nåmilichen Pflanjen, wie bie

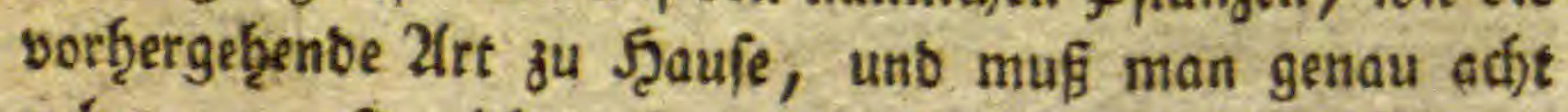
geben, um fie nid)t mit ber vorb̨ergeb̧enben 2(rt ju ver: wechfeln. 
wed)feln. Jith glaube baf jeber Entomologe, bet biefe 2(trt nad) meiner Unterfudfung beobact)ten wirt, bey affer Zleb̨nfidteit fagen wiro, baß bie vorbefthriebene fliege nid)t bloßge Berfchiebenheit oer gegenwàrtigen fenn Eann. Eie ift um Prag nicht gar felten.

\section{VIII.}

Phalæna (Tinea) Echiella. Die Natterfopfsmotte.

Die शrotte mit braunen flugeln, einer gemeinfd)aftlidien

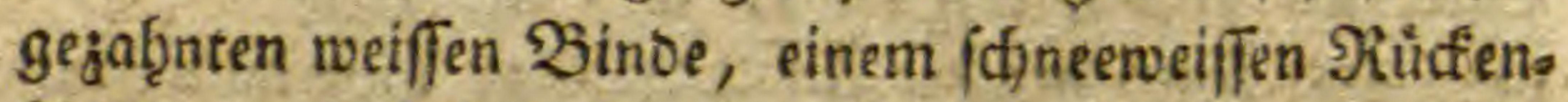
fhiloe, mit fects fofwarjen פunften.

Phalrena alis fufcis: vitta communi dentata alba, thorace niveo, punctis duobus atris.

IBien. $2 \mathrm{er}^{2}$. 140.54.

Encyclop. Method. Hilf. Nat. T. IV. Inf. p. 121. 13. Alucite biponctuelle. Fabr. Mant. Inf. T. II. p. 255. G. 137. Sp. 11. Alucita bipuctunella.

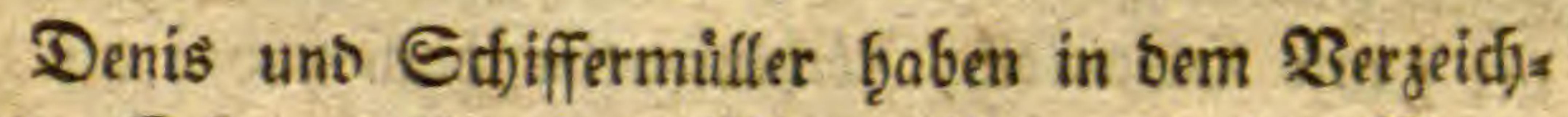

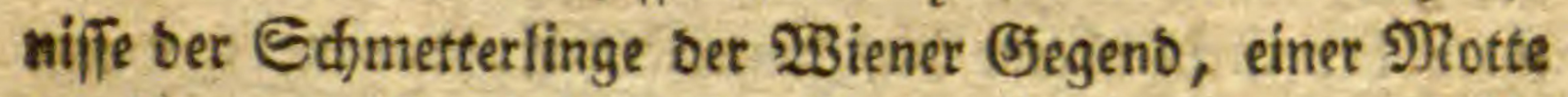

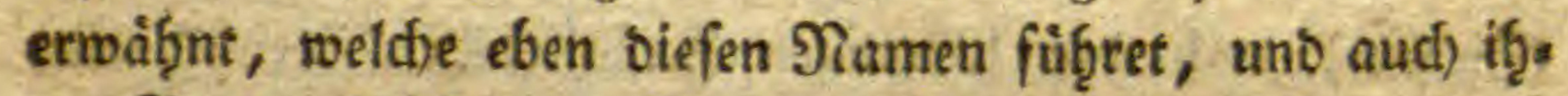
ret Siaupe felbft bas Natterfopffraut angerviejen, boch aber of̧ne alle Befdfreibung, uns id) fann mit (Senib= beit beḩaupten, bẩ biefe গiaupe mit jener, weld)e id) auf eben biefer $\mathfrak{P}$ flanje gefangen, von einer $\mathfrak{2}(\mathrm{rt}$ (en), uno wage es bahere nidje, biefelbe unter einem neuen গtamen

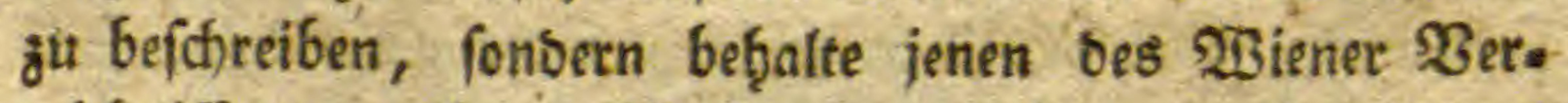
zeid)niffes ganj ber. Noch niemals ift mit eine anbere Raupenart auf biefer $\mathfrak{P}$ fanze, als biefe eíngige, zu Gew

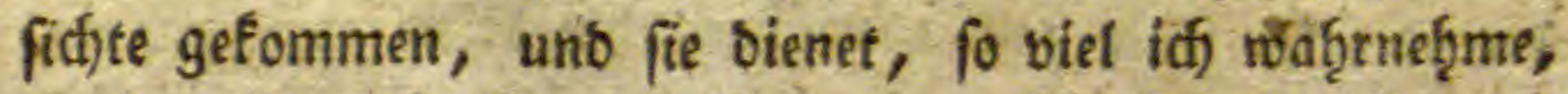
eingig uno aflein if̨r jur গab̨rung. Dod eţe id nod 


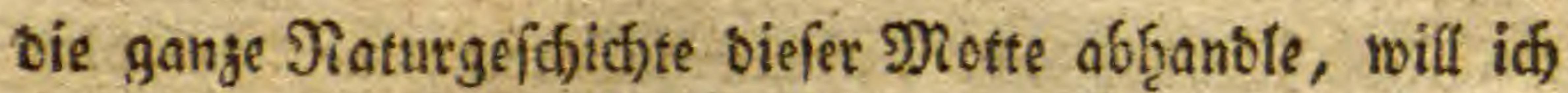
ben 2 Infang mit ber 5 efófreibung berfelben machen, weil biefe, als bas bolffommene Iinfett, inmer bie erfte Etelle verbienet.

Der Rörper ift yom Ropf bis gegen bie Epife Des 2(fters, oten und eine ţalbe linie lang. Der Siopf ift ganj meif, bie 2lugen ffywars, tie frepfipisen uno oie faben=

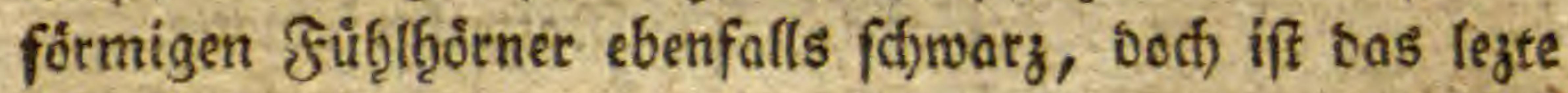

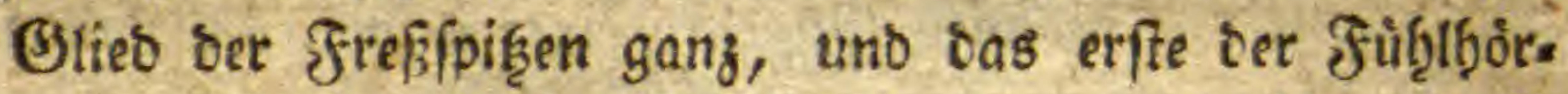
ner, ober jenes ben ter Anglieverung, unterf̧alb von reif,

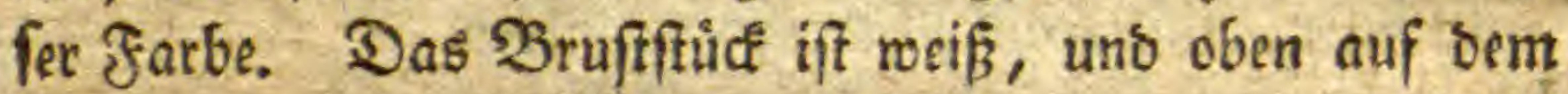

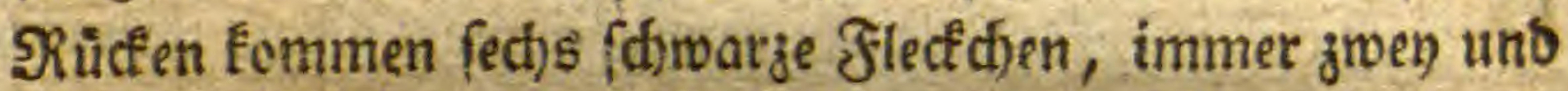

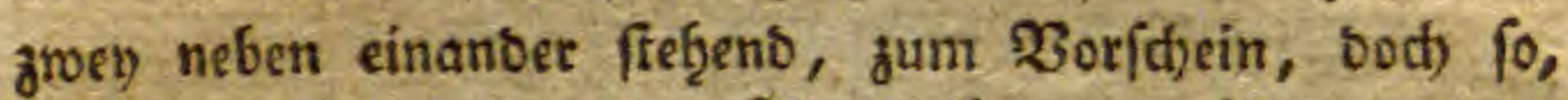
bak biejenigen gegen ben Şinterleib $j u$, náḩer als jene gegen ben Ropf, benfammen ftę̧en. Unterḩalb ift bas gange Sruffftict afdigrau. Wie forberfiten groey Saar J̧üffe fino ganz afd)grau, bie hinterften aber, fo mie aud Der ganje J̧interleib, róth̨licjgelb; bod) b̧aben bie Stas d)eln Der Edienbeine bes Ginterften Jufpaars, fofwarge

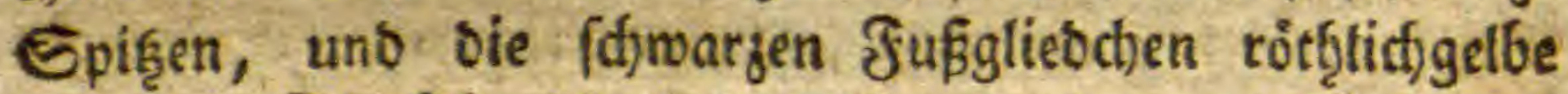
Enben. Die Dberflúgel fino fd)mal, lang geoétint, uns beibe zufammen bon einem Dberect bis zum anbern, in ausgebreiteten Zuftanbe eilf sinien fang. Jeber biefer Dberfluget ift gerabe in ber פritte in die \{ange getbeilf, wo bann bet untere Theil weiß erffeinet. Die ₹Ggeilung gefdief̧t nicht getablinig, fons

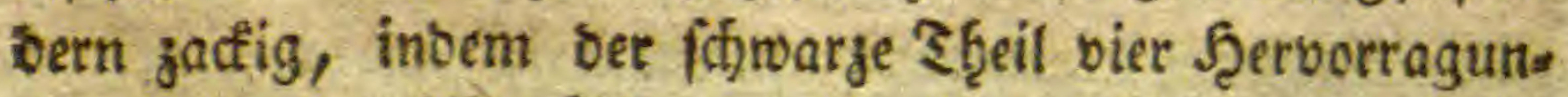
gen in tem reiffen bilbet, bavon vie erfte gegen ben Roirper ju flein, bie jmeite gróß̈er, bie britte nicber flein, unb bie vierte enolich ebenfalls grôper exfdpeinet, Die erfte 
erffe, giwente uno vierte f̧ervotragung, bom ßörpet an geted)net, ift mit ibrem Enbe gegen ben inneren untern פBinfel ber Flügel, bie oritte aber gegen ben 2luffentant jut gefef̧ret. Der 2fuffenrano if beutlich) gefranjt, uno von oben herab, bis faft gegen oie f̧ălfte fó)mairglid)grau. Sangft bem 2luffenranbe ber Dberflugel, befinbet fid) eine Reiţe von fieben fdjwarzen Sunften, uno weiter, fffon gegen ben atnfang bes Linterranbes, bemerft man nod) zmel) fef̧r fleine, faum merffbare Etrid)eldien. Das åuffere

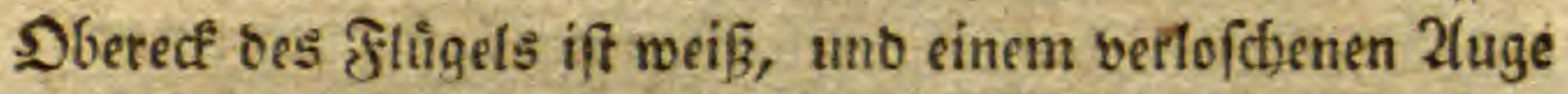
gleid), inbem der erffe \$unft bes 2luffentanbes, gleid)= fam als ein Stern barinnen figet. Die Ltnterfligel fino ziemlich breit, filbergrau, gegen ben Dberranb ins bunf = lere faltenb, fraré gefranjt, uns am innern rianbe, ober jenem, weld)er an ben Jyinterleib anliegt, lid)t fohmujig. gelb beţaart. 2ln ber Unterfeite aller vier flügel if gar nichts ju bemerfen, als baf bie obern (ffwárglid) = bie untern aber lichtgrau ericheinen.

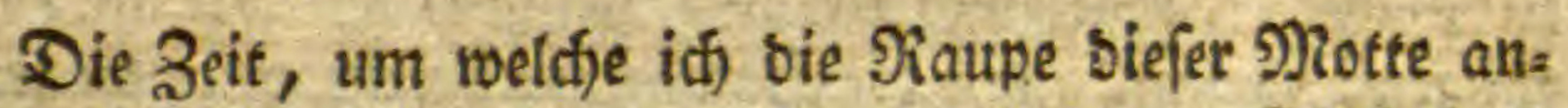
getroffen babe, war ber ḩalbe 2luguftmonat. Sie befant fich) ziemlich) bৃåufig auf bem lufitanifhen, uno bem wege. ridd) Gattrigen Natterfopffraute (Echium lufitanicum unb plantagineum Lin.) im Raif. Rónigl. Prager botanifdsen Garten, uno auf bem gemeinen Natterfopftraute (Echium officinale Lin.) Gen) Melnicf in Sōthmen. Smeimal fogar fanb id) biefelbe auf ber gemeinen Ddfienzunge (Anchufa officinalis Lin.), bod) (d)ien fie nut Bufall auf biefe Pflanje zu bringen, weil id) fie niemals etroas bavon freffen fahe,

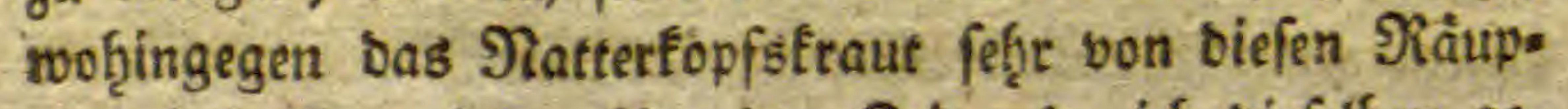
dien befreffen wirt. Um jene Seit, ba ich biefelben ges 


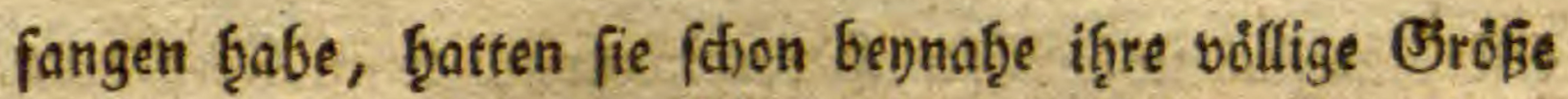
erreid)et, bod) befanben fid) audh nod) einige wenige bar: unter, bie um ein Drittheil fleiner, folglid) aud) jünger waren; biefe (baiteten fich nod) jum legtenmale in meinem Bimmer, of̧ne bie farbe nach ber f̧åutung ju beránbern. Diefe Raupe ift àfferft leb̧aft, bey ber fleinften Se. rúf̧rung fablägt fie beftig unţger, fo, bak fie fich von ifgrer Jufterpflange megfdynellt, uno jur Erobe herabfält, wo fie fef̧r gefdjwino fortläuft. Die järteren Blätter, unb bie Bluten bes Natterfopffrautes, fino ifgre liebfre Nafbrung, uno menn man fie bafelbft bemerfen will, fo múp man nur gleid, unter bie Blátter uno 23lüten ffhen, wo fie geroofhntich in einem unorbentlichen Jabengervebe ganj rubig figen, bod) fo, oaß nur allejeit eine in einem fold)en fleinen (Sewebe iff, und nid)t mef̧rere, fo wie es bey

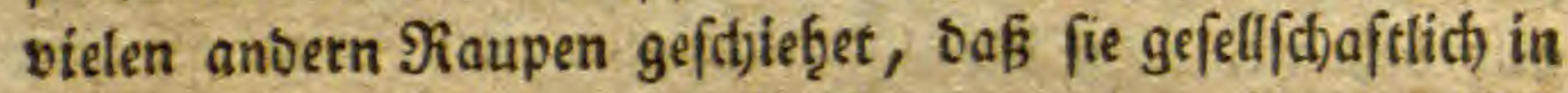
einem groß̧en Seibengewebe beyfammen mob̧nen. Sie

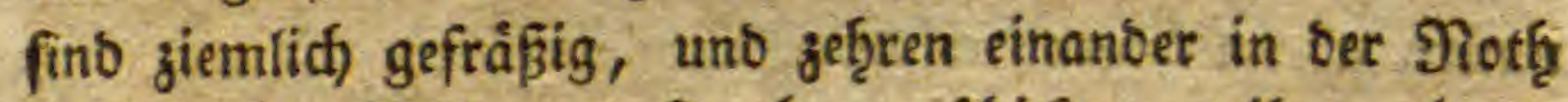
felbft auf. IBill man fie aber gefdidft aus iţrem sager fangen, fo mußs man bie f̧ano gang beḩutfam unter jenen Etraus legen, wotauf fie fich befinben, of̨ne an benfel: ben anjuffoffen, bann beríf̨rt man bie Raupe mit ber anoern f̧anb nue fef̧e wenig, uno fie fällt bann in bie

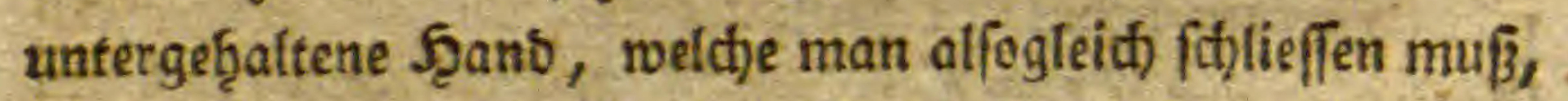
weil fie fid) gern wegidgnellt. Diefe アraupe ţat if̧re eige.

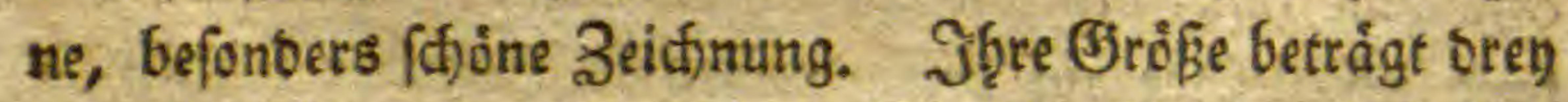
viertel Soll, uno if̧e bicffter Durffmeffer ber mittlern Dinge, in bie Queere, eine uno eine f̧albe sinie. 2lus Diefem angegebenen Iaafe läßt fich) fdlieflen, baß fie eine

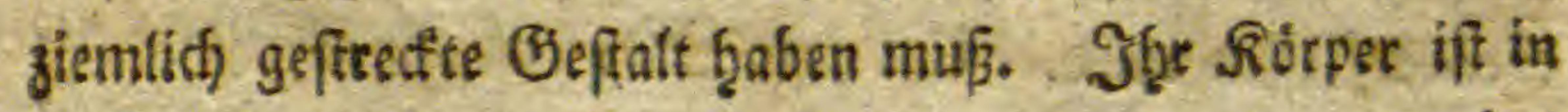


ber Mitfe am bidffen, unb verliert fid) in etwas fonof̧t gegen ben Ropf, als gegen ben 2 fter, ins Dünnere. Er ift ůbrigens ziemlid) waljenfortmig, f̧in uno b̨er mit eini. gen Erb̨abenb̨eiten verfẹten, unb gang, jebod) fef̧r fpar: fam, mit langen lidftbraunen zarten J̧ärd)en befejt, beren

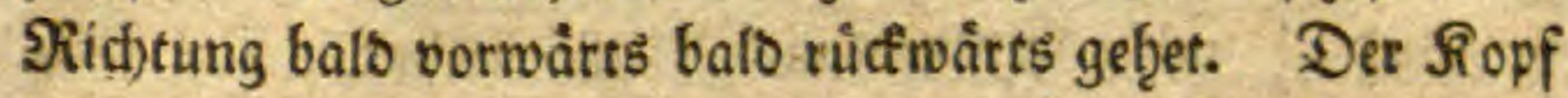

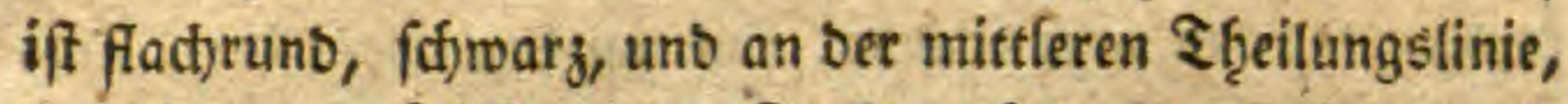
too bie jroey f̧álften bes Siopfs zufammen ftofen, uno nac) abwårts gegen ben श) (uno eine brenecfige Jlåd)e bil. Den, befinbet fich an ber Gtirn ein oreyectiger weiffer flect. Fin anberer von unbeftimmter Beftalt, befinbet fid) fomdhl rechts als linf's an ben Eeiten bes Ropfs, nahe gegen ben erften Ringeinfobnitt zu. Er ift gang fífwargglänzent, uno fparfam mit langen f̧ärdjen befejt, melthe fid) nach allen (Biegenten ridten. Der Siorper ift gang fdyrarz, uno von fef̧r fófroachem (Slanze. Ueber ben ganzen Rủcfen läuft getabe in ber Mitte eine fẹtr fohone refffarbige Sinbe, weld)e iţren 2lnfang naţe am Sopf nimmt, uno fid) bis an bie aufferfte Epiz̧e bes after erftrecfet. 2uf biefer Binbe befinden fíf) länglidforunbe fd)warze Flecten, weldhe einzeln Ginter einanoer ftę̣en, ob̧ne ठaß fich einer in ben anbern verläuft; Dod, ift ber erffe 2Ringeinfdhnitt, vom Siopfe an gerech)net, gảnjlid) biefere flecten beraubt, uno ber zroente uno brifte barauf bias zwar Flecten, bie aber eine unbeftimmte Beffalt b̧aben, weil fie bennahe an jeber Raupe anbers vorfommen. In

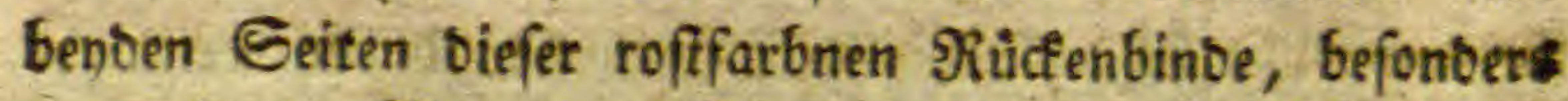

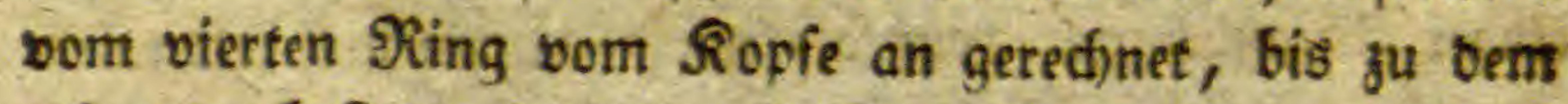
zef̧nten, befinbet fid) jeberjeit in ber פitte ein etwas born formiger meiffer Etrid, meldjer mit feiner Spişe nado 
abwårts fief̧et. Tieben bemfelben, fowohil reçits als lints, befinbet fich) gleichfalls ein ägnnlidher Etrich, bodh ift ex aber viel fitrzer und bunner. 2(n benben Eeiten gegen bie Füfe ju, ift eine breite, aus verfofiebenen roftfarbigen Flecfen jufammengefezte Binbe, weldje um fich b̧erum veriffiebene weiffe Epifen uno flectiden bat. Die rofta farbuen flecte biefer Sinbe; fino on ben erften bren ?ilna gen, vom Ropf an getech)net, von unbeftimmter figur, jene aber, vom vierten an zu rechnen bis zum jeb̧nten, b̧aben gegen ben Ropf, ober naff) vorne zu, einen monb. forrmigen 2fusfchnitt, uno man fönnte jeben biefer Flecte unwegelmáfigig monofơrmig nennen, nur baß̧ bas bintere Enve etwas biaf ift, uno in jmen fpişize Fortfä̧̨e nad, aufroairts fich ridtet. Nebft tenen verfchiebenen weiffen

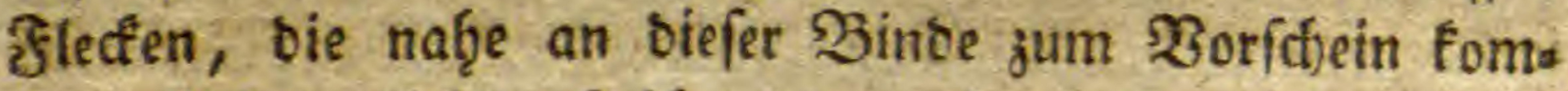
men, befinbet fich noch) uiber jebem fichon angemerften z(use fofnitte biefer rofffarbnen Flecten, eine jarte, weiffe, in Die Sueere liegenbe furze Sinie. Die făffe haben nid)ts

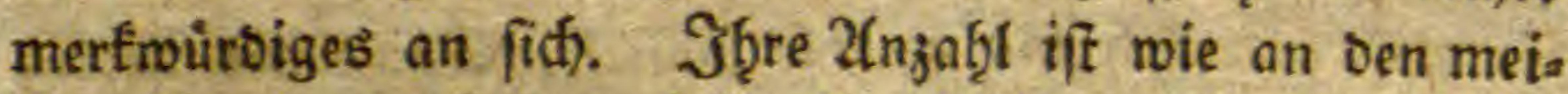

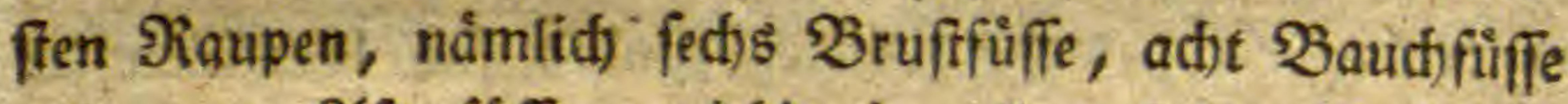
uns zwen afferfüffe, mitḩin in allem fech)sję̧n J̧üffe.

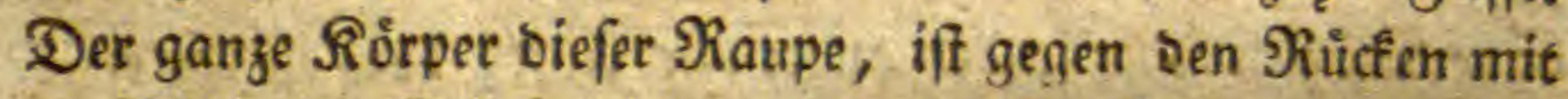
perfdiebenen Erţabenţeiten, gegen bie Jüffe ju aber mit unregeímågigen faiten verfệen.

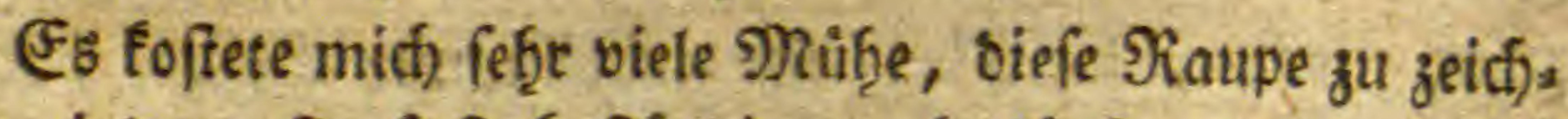
nen, inbem fie faft beftänoig umḩerlåuft, uno wie idf

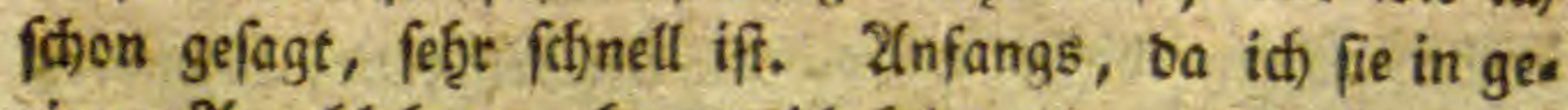

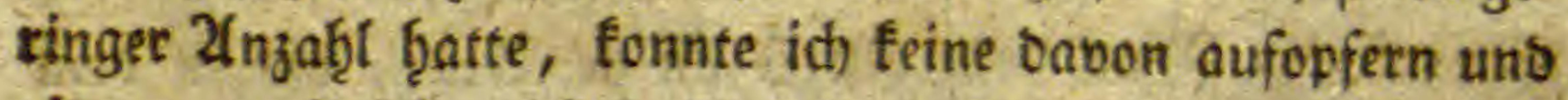
cóbten, weil ich mich) in (Jefabr gefejt b̧aben muitbe, ben Salter ju verlieren, wenn idh nichs sinige Suppen aufber 


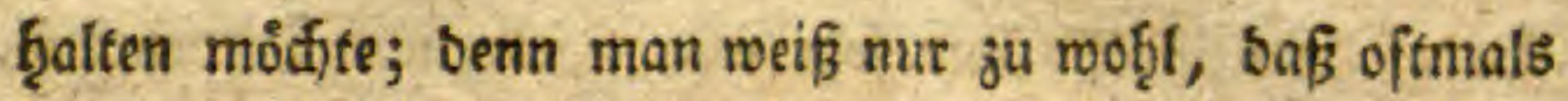

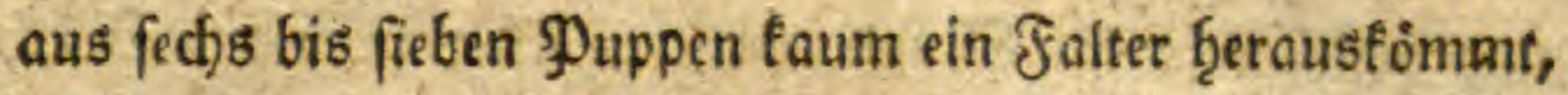
inbem bie ùbrigen abfterben. Dies 3 erlangen, Diefe

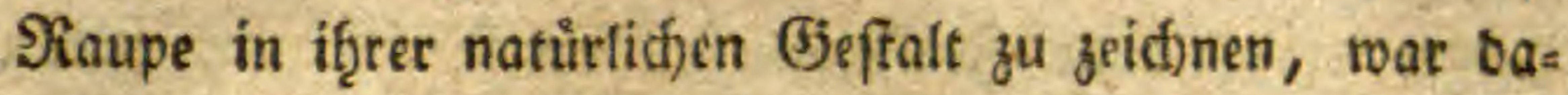
mals mein grópites $B$ eftreben, weil biefelle nod) in feis nem entomologif(t)en 2 serfe abgebilbet ift. Jit) madfe alfo ben Jejten $\mathfrak{B}$ erfud) mit meiner Siaupe, um fie jum Etillfifigen zu bringen. Id) bano námlid) eine gerab geo frümmte Şaarnabel, an if̧ren áufferften Enben, an jwen lange Men(d)enf̧aare, melche ich) enslich) mit if̧ren Enten zufammenfnuipfte, uno fiieng biefefte íber einen bargu

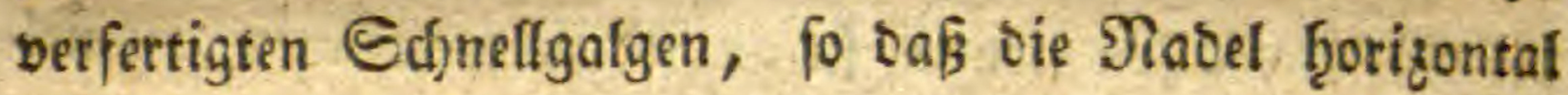
ju liegen fam. গiun fejte id meine গiaupe barauf, Diefe frod) einigemal ḩin unb wisber an ber গlabel, verfuct)te ùber bas f̧aar ju friectien, bod) biefes war feine Mỏga

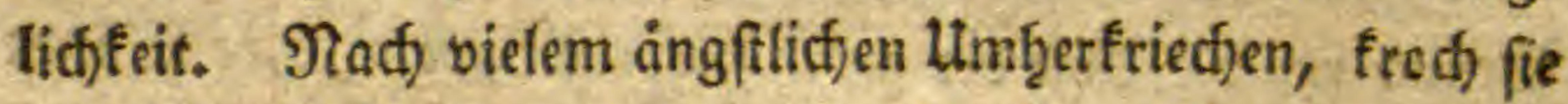
an eines biefer Nabelenten, frrecfte if̧ren Rơrper über bie Nabel weit Ģeraus, taftete nach) allen (Begenben bamit

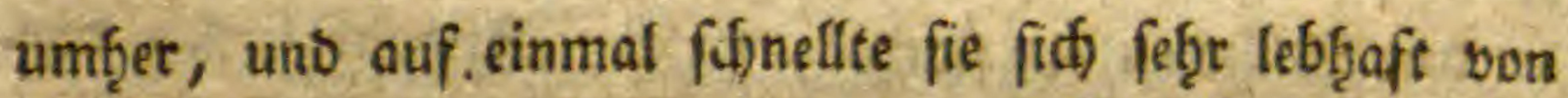
Der Nabel, uno lief eilents bavon. Die Beitfolge trö. ffete mid) aber gang rwieber. İ fano nảmlid) ouf eben Demfelben lufitanifden গtatterfopfsfraute, wo idf oíe erftes ren wenigen Raupen gefunben Ģatte, über jwanjig Ders felben, wo id fie bann nidjt mur in if̧ree natürlidjen Grỏje, fonbern audi) burdh bas berwafnete 2(uge jeidfa

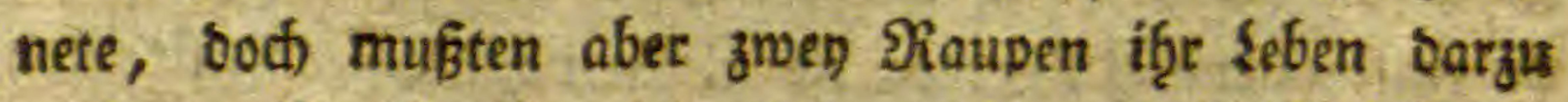
opfern. Itm fie aber fínnell zu tósten, unb if̨rer farbe

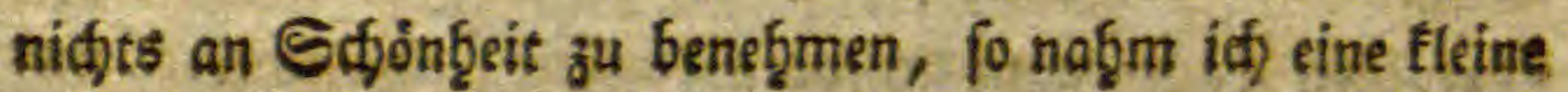


Pabel, taucfite fie nur feb̨r wenig in gutes ₹erpentinòl, uno beftrid) ih̨r ben Muno uno ben 2ffter bamit. Durd Diefes farb fie in Beit von einigen Minuten, befam aber

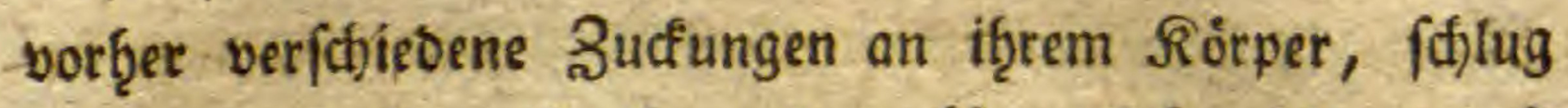

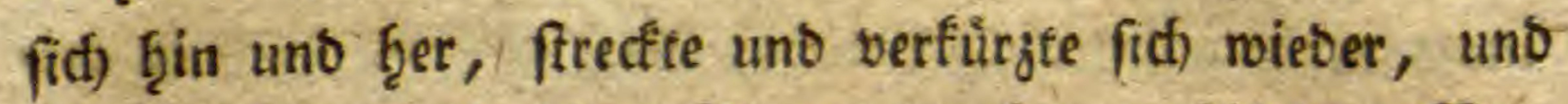

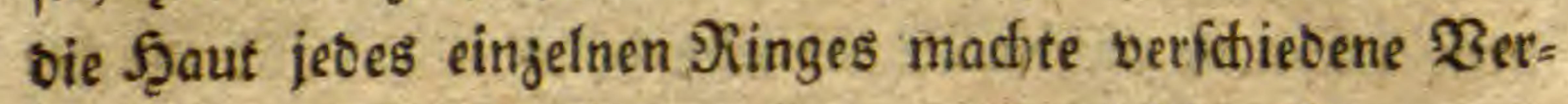
tiefungen, bie fid) balo geigten uno gleidh wieber vers fifrmanben, bis, ber ₹oo ib̨r bie natürlidhe uno rufige Etellung gab, uno auf biefe 2frt war es bann móglid, eine

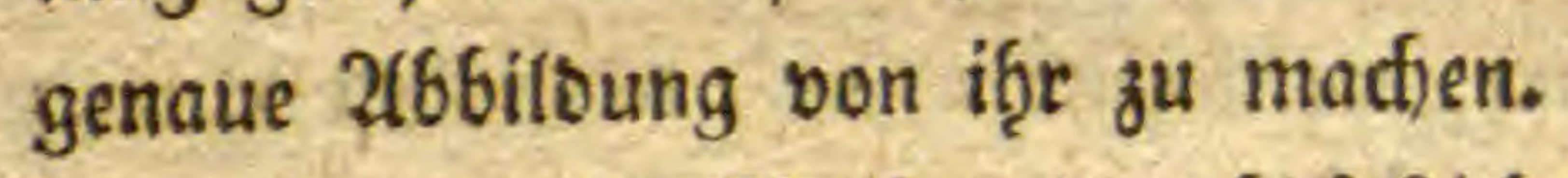

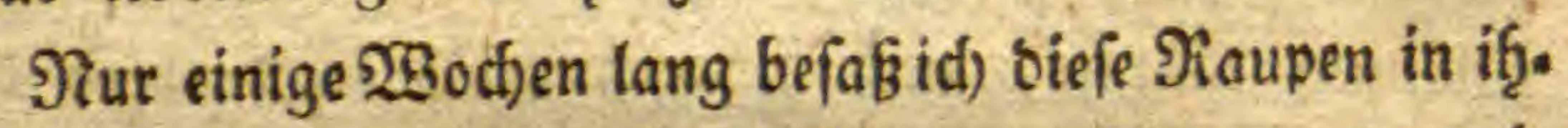
rer Beffalt, Dann fiengen fie an fid) zu verfipinnen, ju wels ther Zeit fie fürzer, bider uno von Farbe nid)e fo lebhaft finb. Sie friect)en bann in bie $23 i n f e l$, bie bie Blatter Threer Sutterpflange bilben, mactjen fich einen etwas weichen Brunt für bie \{age ber zuftunftigen פuppe. Die $2 B$ ainoe

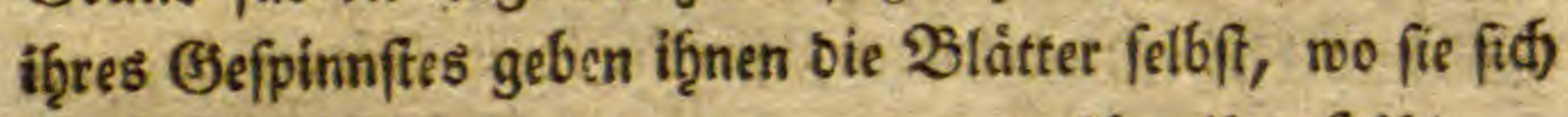
berfpinnen, unઠ fie zię̧en nur von vorn ùber ib̧re Şöb̨lung, an ben Slättern ein flaches, bidites Seibenblättchen bars-

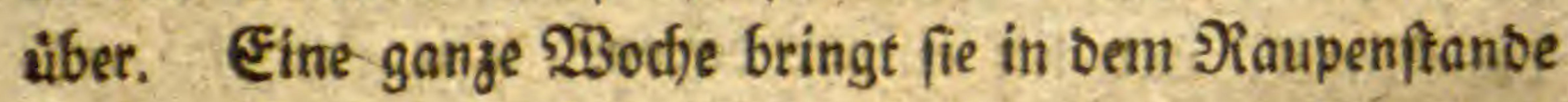

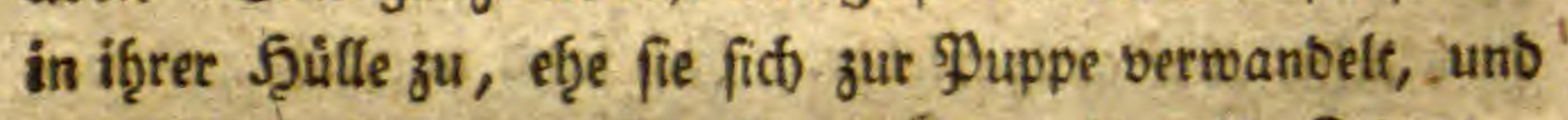

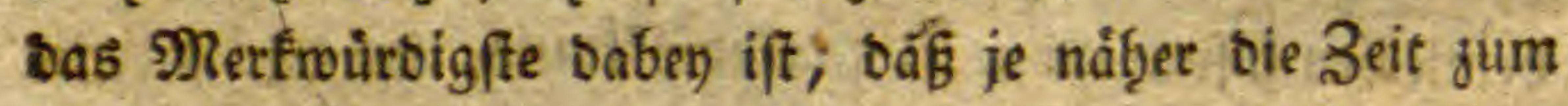

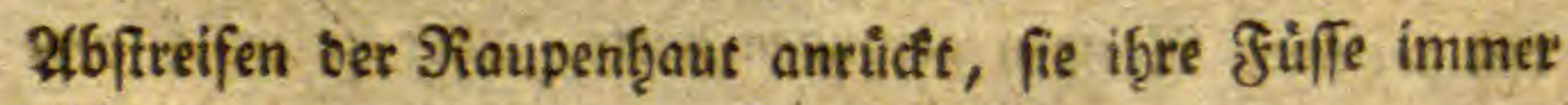
ftärter aus bem seibe Ģervorfitect, fo, baß fie lang unb ganz ffeif vom leibe gerabe abfteţen. Das aus biefer গiaus pe entfianbene Püppdien ift gleid) nach ber abgeftreiften

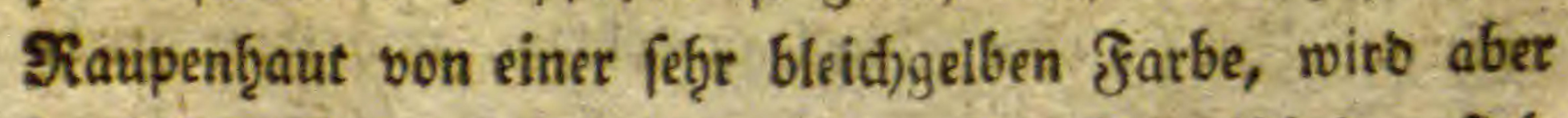
in einigen ₹agen gang lifjtbraun. Die Jlügelf(t)eiben fint 
etwas bunf́ler von Farbe als ber ùbrige Rörper, reichen ůber bie ḩalbe Sånge der Puppe felbft b̨erab, uno bie Jùb̨l:

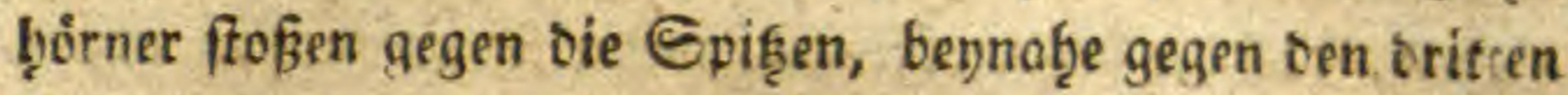
Sheil iffrer sange zufammen, uno laufen mit einanber gleid). fam vereinigt bis gegen bas Ente fort. Das forbetbarfte an biefer Puppe ift bie Ethwanjipiz̨e, welct)e gegen ben Saud) zu nach aufwárts gerichtet iff unb zwen neberinan. Der ffefiende fortfäfe bilbet, welde ben Echmanjfüfien Der Jiaupe febr ábulid) feben. Eie fino gegen bas Enbe zu etwas oiffer, runter, mit ḩáufigen braunen Scădfden nath

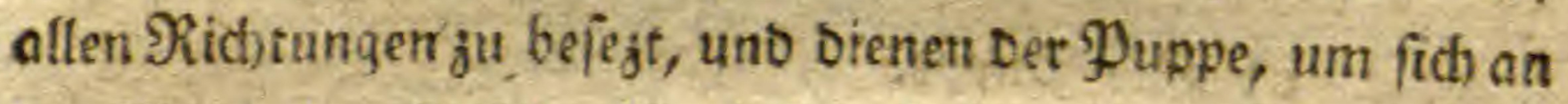
bie $2 B a n$ bes Befpinnftes feft ju Galten, bamic ber Falter, wenn er aus der Puppe friecten will, bas (B) f̧ăufe nicht mit binter fid) fortzieben fann, weldhes feinen flügeln feģr nact)= theilig fenn fornnte. In ber Puppengeftait bleiben fie ben ganzen $\mathfrak{B}$ inter f̧inturd) uno vie Morte fómmt im Monath 2(pril, Nan, Juny uno Juli bas barauf folgente Jab̨e zum $\mathfrak{B}$ orfdein, wo fie fith an bie פaaren zu feg̨en pflegt.

fyerr Fabrizius bat biefe Motte in sem Rabinette bes J̨errn Denis uno Echiefermutter, vermuthlich ourch)

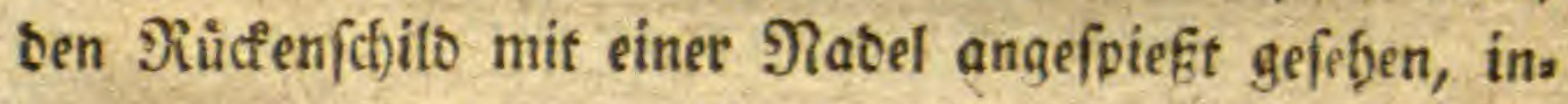
bem er nur jwen fotwarze Punfte an ben flúgeloeden ente becfte, uno bey meinen Eremplaten affzeit fectfe vorb̨an. ben fint. Die Mabel muß̧ alfo oie u̇brigen, wie es feb̧e

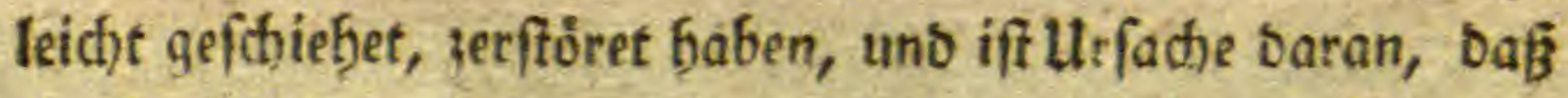
Der Fabrizifthe গamen Alucita bipunctella gar nid)t paf: - feno iff. 
23as Fabrizius burd) feine Beffifreibung, inbem er fagt: vitta communi dentata alba fagen will, ift fo ju vers ftehen, baf bie beysen fluggel, wenn fie zufammen liegen, mit ib̨ren weiffen క̧̨eilen eine gejäh̨nte weiffe gemeinfhaftli. c)e Binde bilben.

\section{Crfflåtung Der Abbifoung.}

Jig. 8. a) Die Raupe in natürlid)er (5ro̊je.

b) Diefelbe vergro̊jert vorgeftellt.

c) Die Suppe.

d) Die Sd)wan\}fpif̧e ber פुuppe fȩ̣r vergro̊fere,

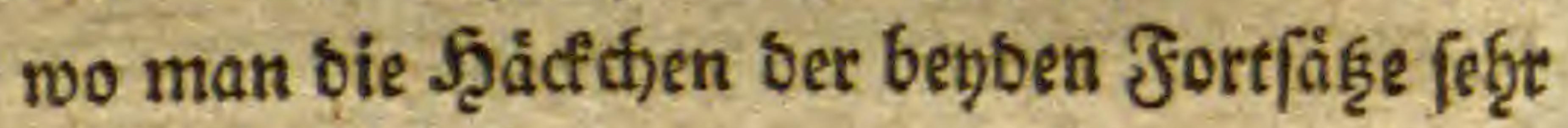
beutlid) fȩ̂en fann.

e) Die গtatterfopfsmotte:

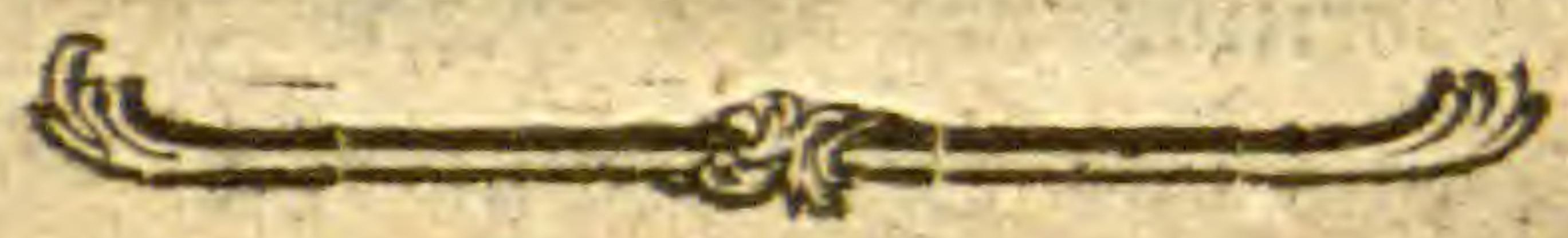




\title{
VIII.
}

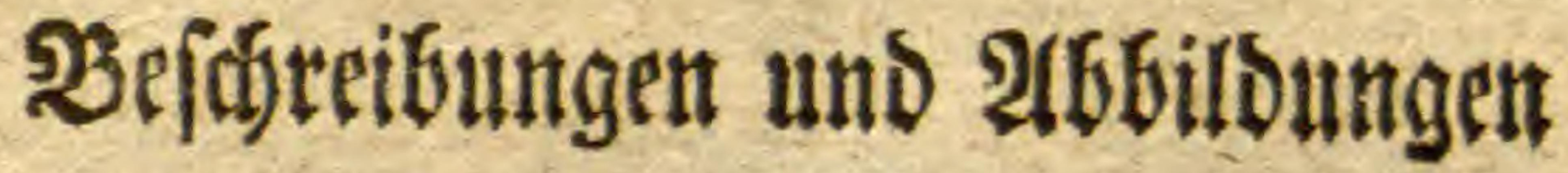

\author{
berjenigen \\ Inleften,
}

welche in Sammlungen nid)t auf Dann aller, Die noch) ganz neu, uno foldher, von bes nen wir nod) fetne ober Dod) febr fabled)te 2(b;

- billoung befikzen.

उweyte Sammlung.

2on

Johann Daniet PrenEter. 


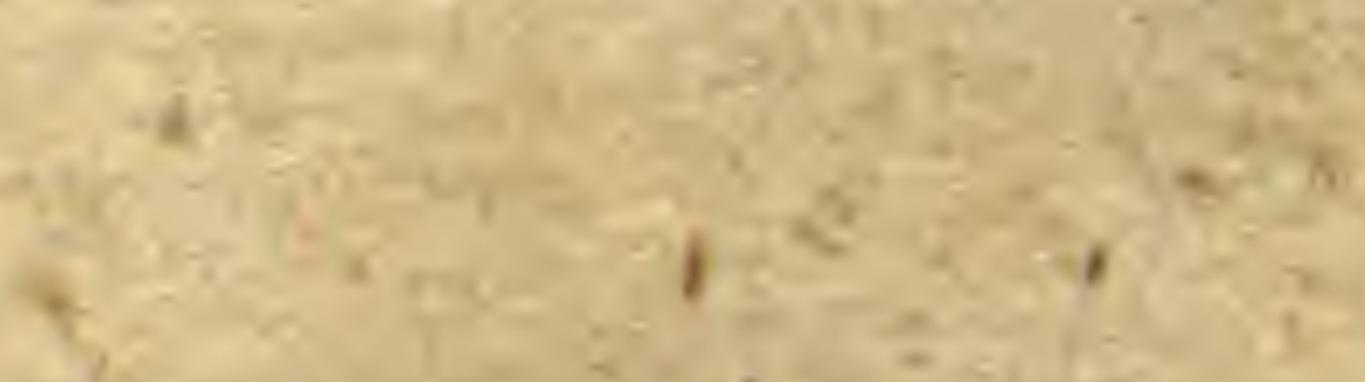

5u

$-20 \frac{2}{4}+2$

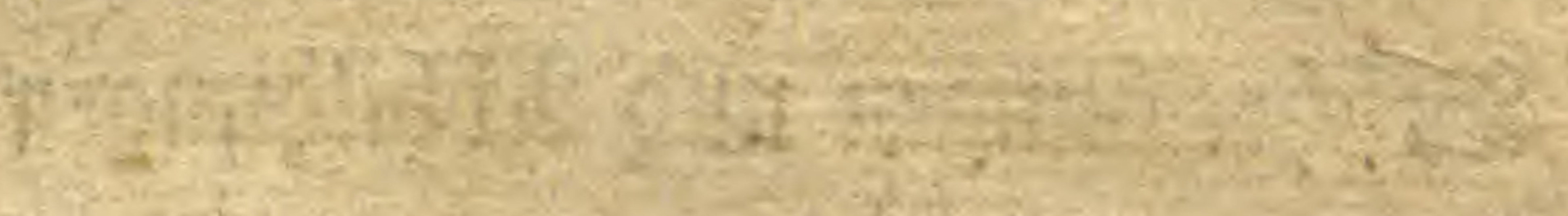

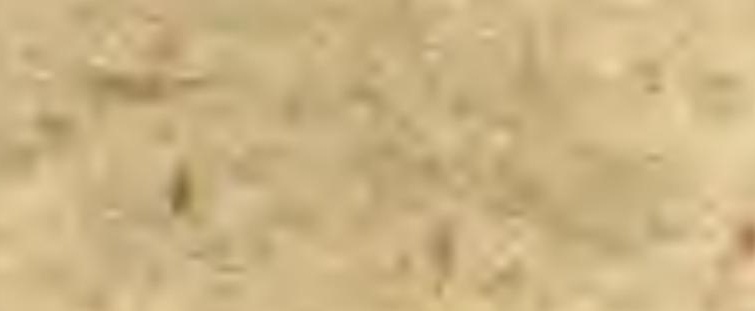
(5) i.

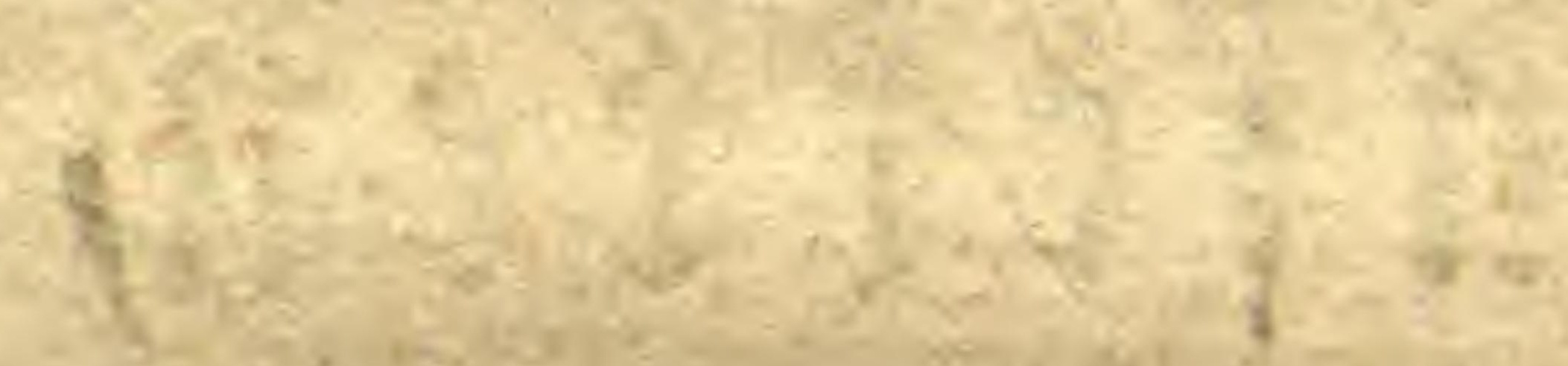

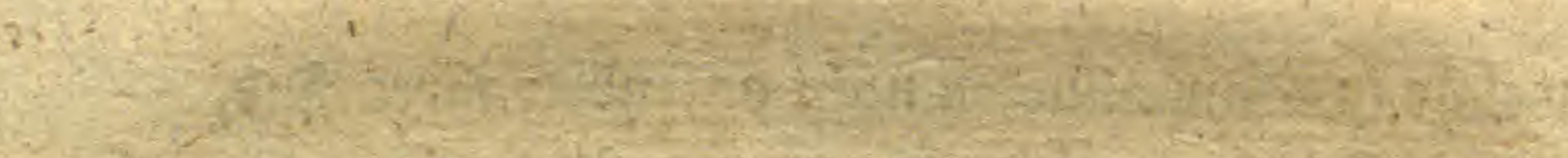

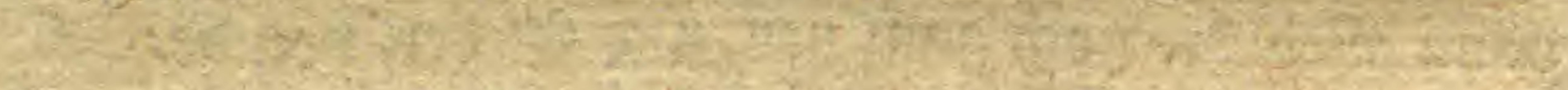

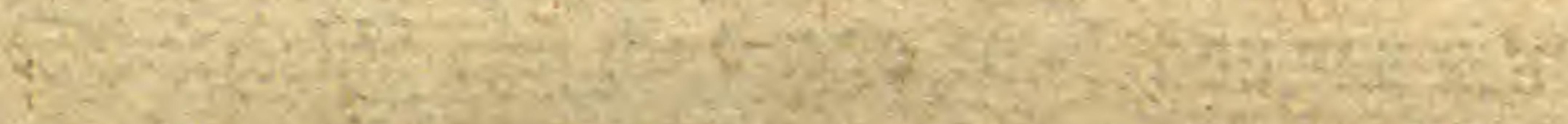

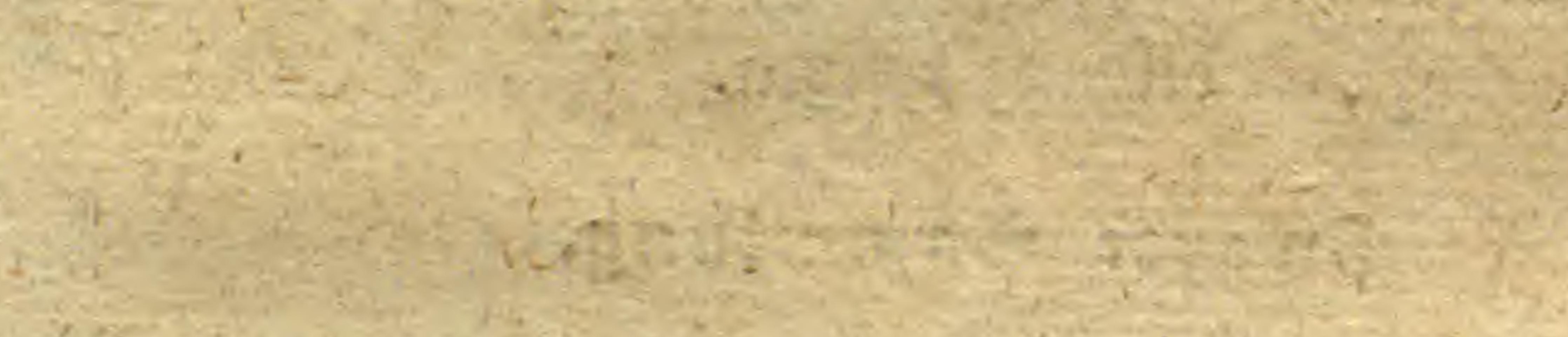

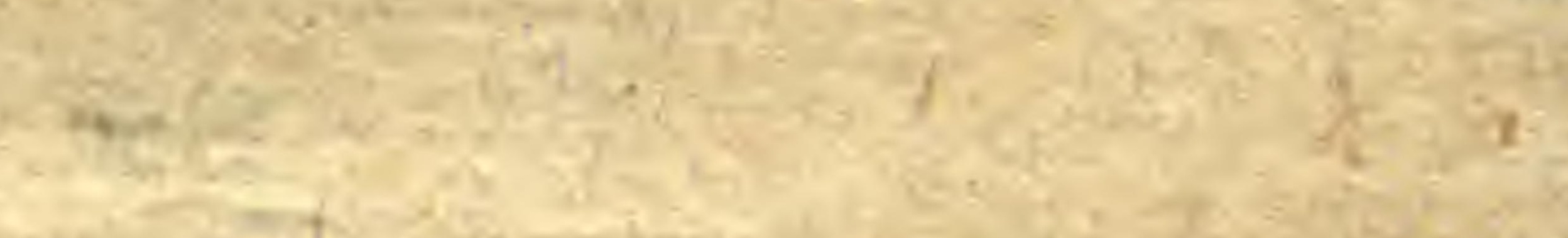

$$
\begin{aligned}
& \text { af }
\end{aligned}
$$

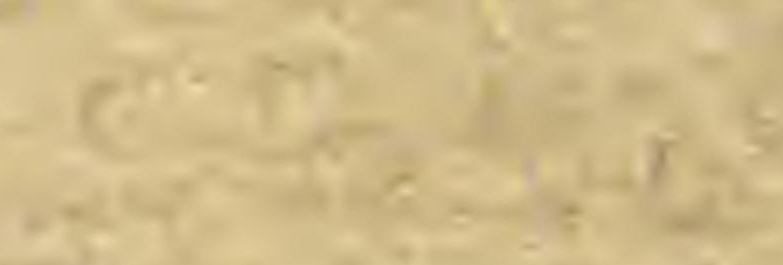

$$
\begin{aligned}
& \text { is }
\end{aligned}
$$

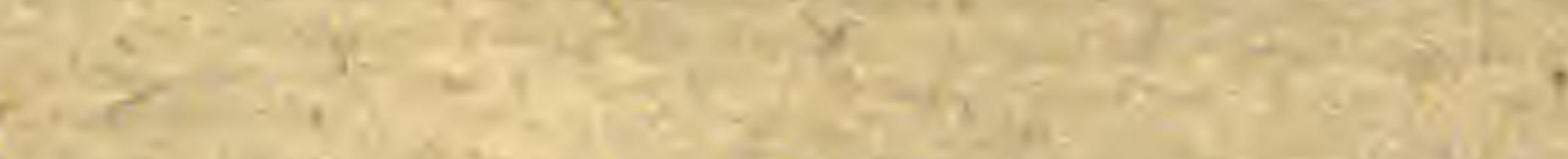

$$
\begin{aligned}
& 2 x^{2}+5=0 \\
& 1: 2= \\
& \text { W }
\end{aligned}
$$

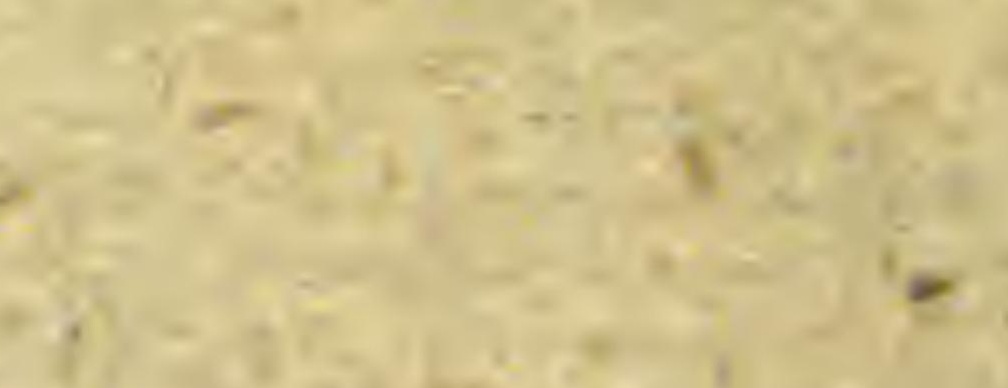

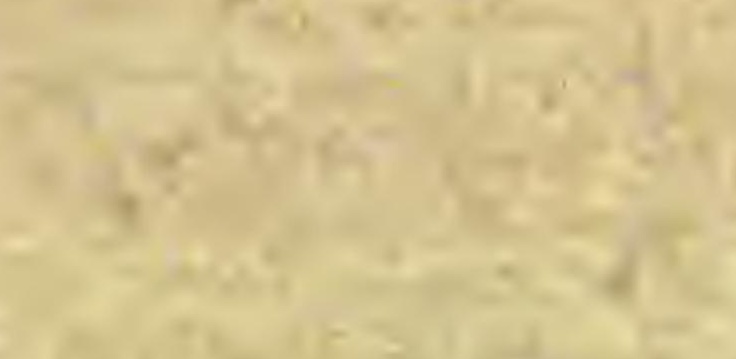
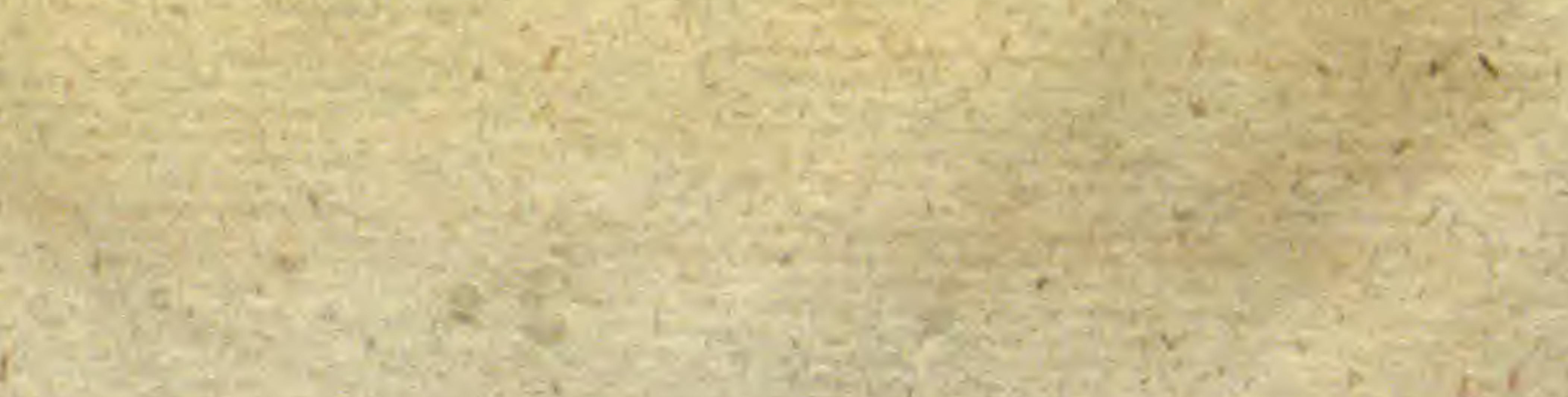


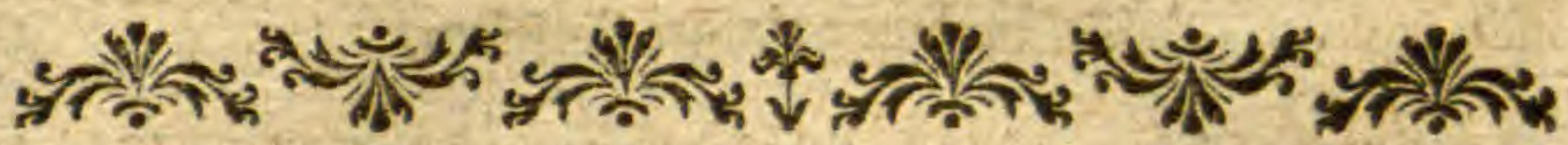

IX.

Mufca rotundata. Die zugerunbefe Slliege.

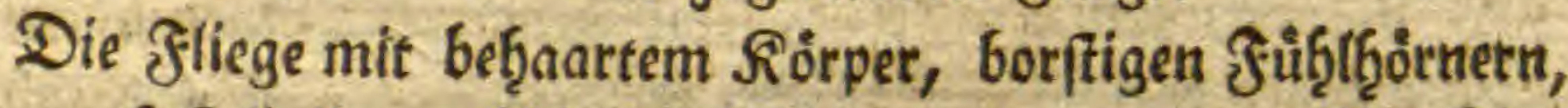

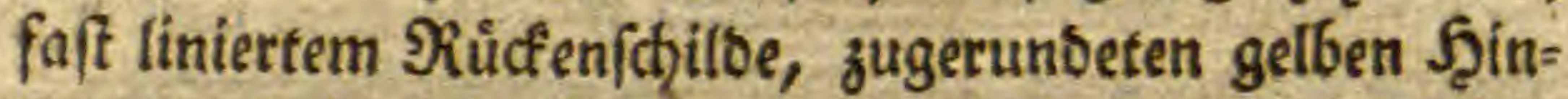
terleib mit lang laufenben braunen flecten angeţăuft.

Mufca antennis fetariis pilofa, thorace fublineato, abdomine fubrotundo flavo, maculis longitudinalibus fus* cis confertis.

Scop. Carn. n. 883.

Fabr. Mant. 33.

DeGeer tom. 6. p. 28. n. 8. Mufca antennis fetariis fubglabra, capite magno albido, thoracce nigro lateribus albido, abdomine fubrotundo rnfo, maculis quatuor nigris.

Mull, Faun. Fridr. n. 735.

Geoffr, inf. parif. T. II. p. 509.n. 32 .

Carl de Villers. Ent, Lin. T. III. p. 486. Ip. 194.

Linn, Syft. Not. Ed. XIII. T. I. p. 991 1. G. 253 3. Ip. 76.

(5) iefe Jfliege erreidjet eine länge von 3 unb einer viertel Sinie. Der Ropf ift etwas breiter als ber গiúcfens (f)itt, unb ḩat eine linfenformige, bod) aber nod) ftärfer gerooflbte Beffalt: befonbers gegen bie Etitn, wo er merf: (id) Getbor tritt. Die Gegenb bes פRunbes, ober jene une

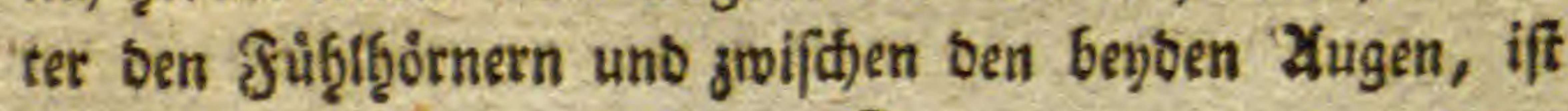


gang wegen benen bid)t barauf fiģentsen J̧ärdien, weiß, mit einem Stlberglanje, uno oie Dberlippe etwas aufgemorfen. Der Şinterfopf, wo bie oren fleinen ftymarzen शebenau. gen fteben, if ganz braun, diefe Jarbe zieb̧et fich bis zut anglieberung ber fühthoirner berab unt mad)t gleithfam einen fanglid) vierectigen fftecf, beffen Dhertheil fict an oie beyoen inmern Eeiten oer 2tugen anfdiliegt, weiter unten aber fid) bon iffnen entfernt, nno benberfeits eínen leeren

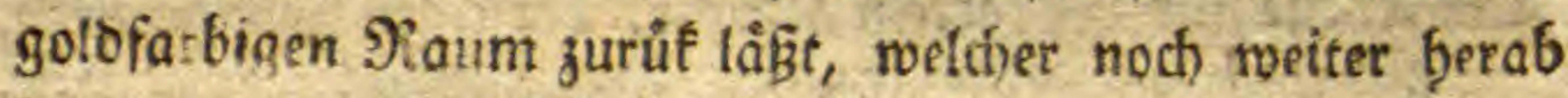
inmer weifer wirt uno fich gainjlich in bie Nunbgegent verlietet. Die 2fngen fino länglid)runb, von einanoer ges trennt uno rotb̨braun. Die J̦übthoirner baben eine braune Sarbe, uno die Etelle wo fie fich angtiebern, ift ein wenig idirarz. Sor erftes (slieochen ift fáulformig, bas jwente långlichruno, meb̧r geopfgnt als ben andern flliegen uns

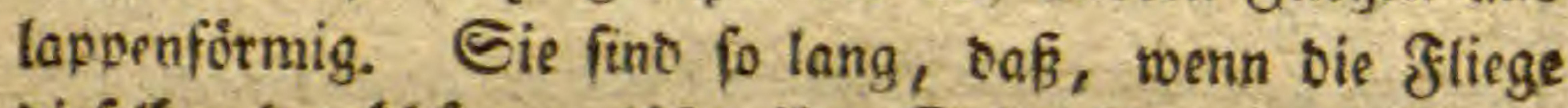

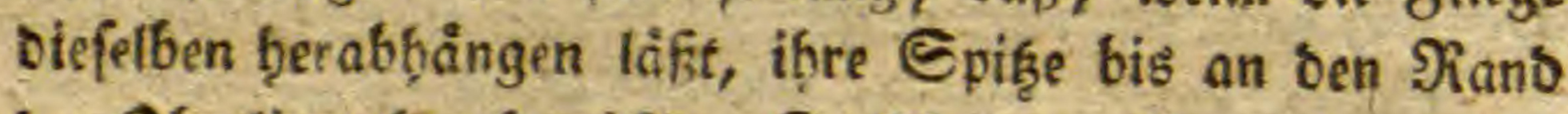
ber Dberlippe ḩerab reichet. Zెrifhen bet $\mathfrak{B}$ ereinigung bes erften mit sem zmenten (Stiesd)en berfelben, befindet fich eine lange, fteife, uno einfache fotwarze Borfte. Uebrie gens fint Diefe Blietdien, fo wie ber Ropf fin und wieber, befonoers aber gegen feinen hintern \$̧̧eil, meģr ober ment. ger mit theils arökern, theile fleinern Sorften befezt. -

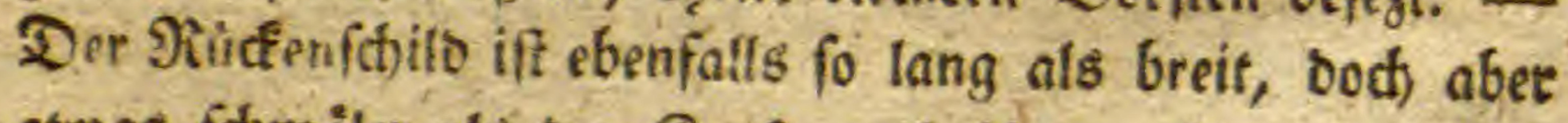
etwas fommalet als ber ßopf, nađ) Ginten abgerunbet, ges gen ben Ropf aber bilbet Derfelbe zwen runbe (F)en. Bee rabe in ber Mlitte wirb er burd) eine vertiefte sueerlinie in greng gleidfe ₹ḩeile abgetbeilt, baton ber vorbere ₹Geil, ober iener gegen ben Ropf ganj gelbbraun, gegen bie beha ben Seiten aber etwas lid)ter ausfállt. Zuf feinet $\supseteq b e t$. 
fiảcje bemerfet man vier ounfelbraune Laingstiniên, babon zwene neben einanber in ber Mitte, uno joen anbere etruas gebogene, neben ben erftern, an jeber Erite eine, zum Bor.

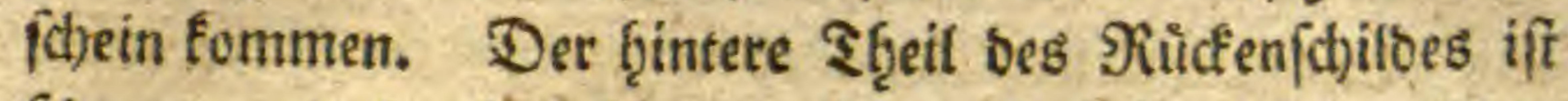
fofwarz, boch aber formmt ein anfefgnlidjer jugerunbeter

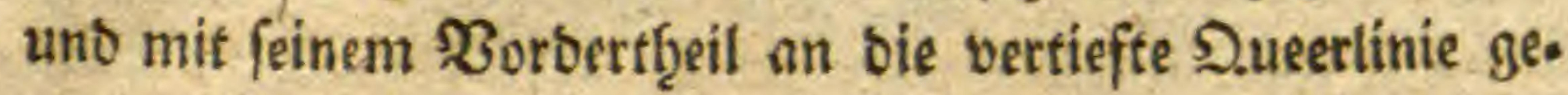

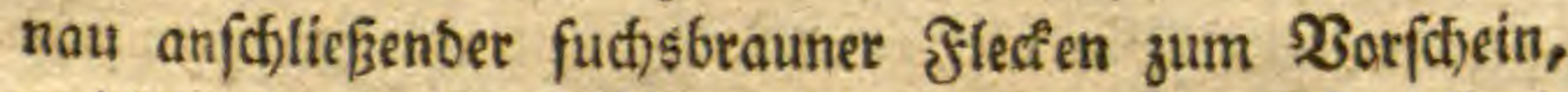
welcher aber in feiner )itte wieber ins sunflere fältt. Das Edjitodjen ift gegen ben Scinterleib jugerunbet, fdrwar;, uno mitfen úber baffelbe lauft eine etwas braune Sinbe in

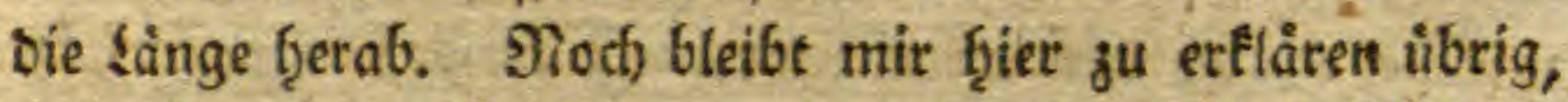

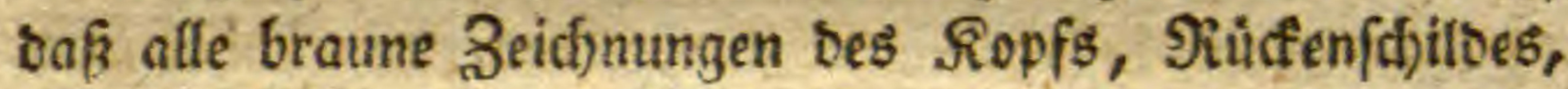

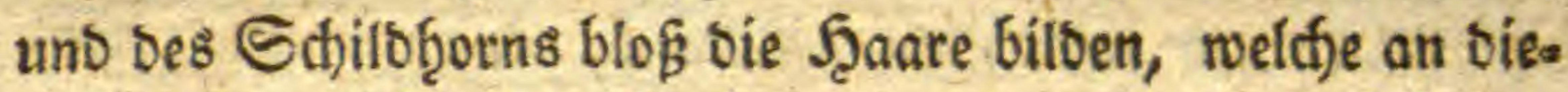
fen şgeilen fef̨r bidit beyfammen ftef̧ent. 2(fud) befinten fich am Ranbe bes Rüctenichiloes, wie auds an ben Gei. tentbeilen an beffen Dberflåd)e, uno ben Sdjilbdjen fiin unb wieber einzelne feine Sorftenf̧árcfjen. - Der J̧inter. leib biefer Flitege ift nod) etwas breiter als ber $\Re o p f$, unb hiat cine runbe, foft ḩalbfugelformige fę̣r gemollbte Beffalt; aus meldfer Utrfache auch Der lateinif(he Sinneifdje Siftenta= tififfe Tame Mufca rotundata entfanben iff. Seine Jarbe if roftig, uno bie Ringeinfchnitte beffelben nut fefre fdyeer baran zu erfennen. Er iff ganz glanjens, punftirt, uno mit fę̧r fteifen uno furzen, barnieber lie*

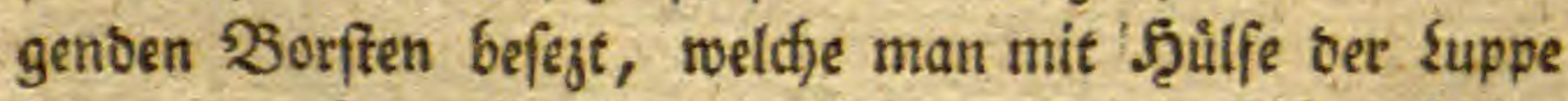
fę̧r genau bemerfen fann. Mitten auf benfelben befin ben fid) viet ffinarge flecten, weld)e in ber Sänge finter: cinanber ffefen, uno bavon ber erfte gleid) beym Edjilo. d)en, bie zmen barauf folgenben runben, an ber mittles

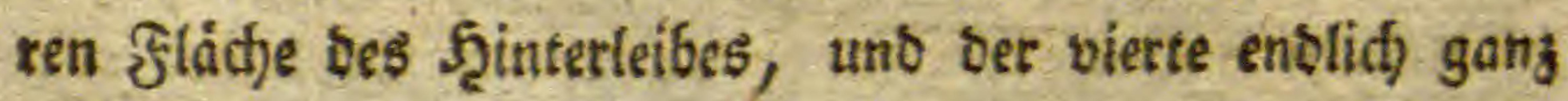

$$
\text { F } 4
$$


om 2ffer fid) befinbet. TRebft oiefem 2fterflecf aber fömmt noch ju jeoer Eeite ein groker, etwas langgebefinter, uno

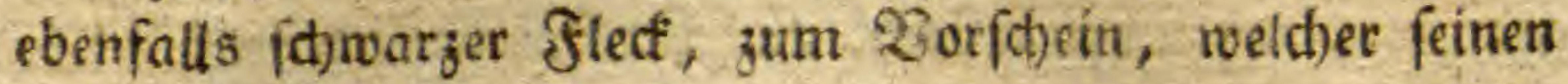

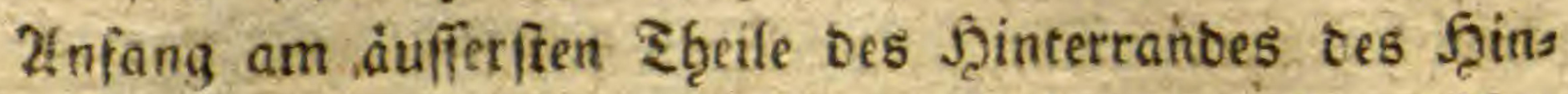
terteibes nimmt, uno mit feinem sinbe gegen ben, über ben alferflect ftehentoen Mafel, geridjtet ift. Die Jüffe finb Durchaus fdwoar, gleichlang, uno mit Sorften be: fegt, bie fllügel blafrauthfarbig, breit, mit rofffarbnet 2Burzel, weldie leztere Farbe anch Die Edwoungfoilbaten

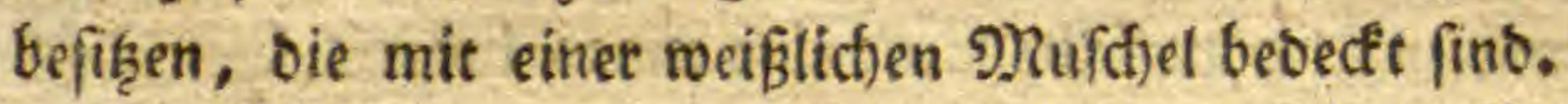

Der ßitter von Linne' fagt, Daßs Diefe. Flliege fünf in bie sànge ftebente fitecten an ifrem Stinterleibe ţaben foll, boch if es mir ned) nicht gelungen, eine mit fünf, fon. bern nur alle mit viet flecten ju finben. Sen bem atk bern (Sefid)techre fino biefe fdwwargen Şinterleibsflecten alle unter einander vereinigt, unv biloen gleichfam eine fnotige Sängsbince. Um ben oiefer Jliege alle if̧re Beidjnungen genau beobaditen zu fòntnen, muj man fie fo vor fid) lie. gen baben, Dafi tas sidjt bom Ropf gegen ben 2 fter hin, barauf fallen fann, gefhieḩet biefes nicht, fo vet, forminoet fébr biel bavon.

Sie iff ben Prag auf bolbentragenten Pfanzen, bes fonters bem gemeinen $\mathfrak{B o g e l n e f t e ~ ( D a u c u s ~ f y l v e f t r i s ~ L i n . ) ~}$ in Sommer gemein.

\section{$\mathbf{X}$.}

Mufca fexmaculata. Die fedisflecfige Slliege.

Die graue baarige fliege, mit gefeberten ffüh̨lf̧örnern,

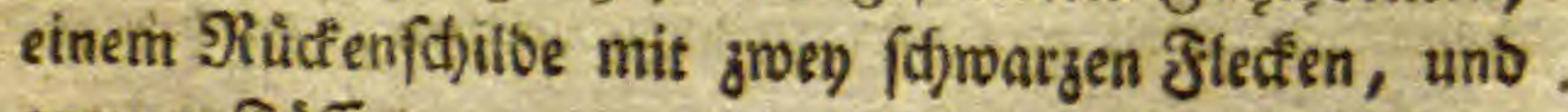
grauen Sulffer. 
Mufca antennis plumatis pilofa cinerea, thorace maculis duabus nigris, abdomine conico acuto maculis fex nigris pedibus cinereis.

Mufca, Jabr.

Diefe flliegr wirb zmei und eine balbe linie lang. Der Ropf ift fo breit als ber अiuctenfthilo, uno bat cine nach) vorn zu faft bqalbfugelförmig gewoilbte Fläche, uno eine hintere platte, bie bem vorbern Theil bes Bruffftudf's

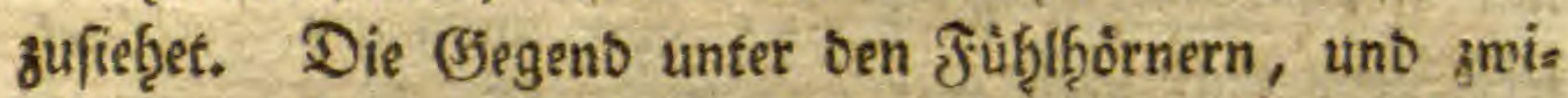
fiten ben 2lugen iff ganz meír, filberglánzeno, uno an Den bensen Seitentheilen bes Nuntes befinben fid) herabs hangende Sorften. Die füb̨ţơrner fino an ber vortern gewoilbten flåche bes Ropfs, gerabe in ber Mitte cinges pflangt. Jorr erftes (Stiebchen ift Eåulformig braun, bas folgende enfurrmig plattgebrüct, folmairzlid, uno fo grof 3 als bas erftere. $2 \mathrm{~m}$ (Stunbe biefes (Stiebchens, an befa fen פberranbe, entfpringet eine nad) auswairts ju gericha. tete Borffe, weldfe nod) um vieles langer iff, als bie

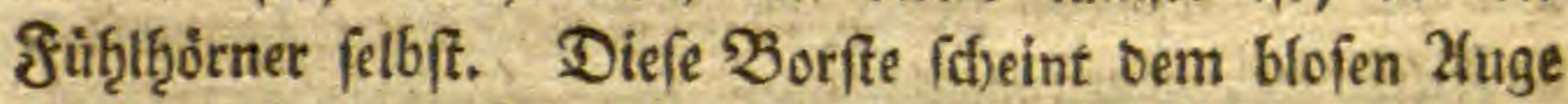
ganz einfach ju feyn, man barf fie aber nur init berwafa heten betraditen, und man wirb finben, bafi fich zroen

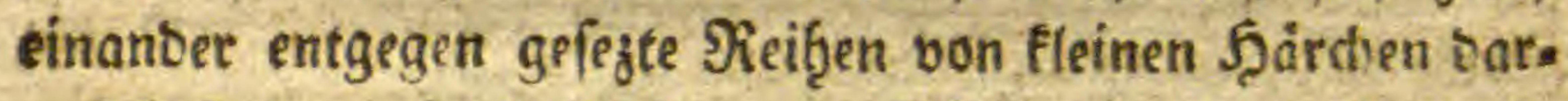
auf befinten, folglich oie ganje Jliege unter bie Interab. theilung bes Ritters von sinne' gef̧ört, meldhe beḩaart, uno mit feberfơrmigen ffüh̨lb̧ornborften (pilofæ plumatæ) berfehen fins. Die 2lugen fino rotbbraun, uno weit von einanber getrennt, fo, ba $\beta$ wenn man ben fiopf bon forn betractitet, ber leere Raum, ober bie Etirn, ein Drite tgeil ber ganjen $\Re$ opfsbreite ausmad)t. Die Stitn fammt bem f̧interghaupte, ift von farbe graubraun, unb nahe 


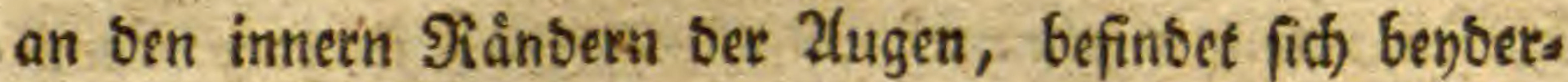

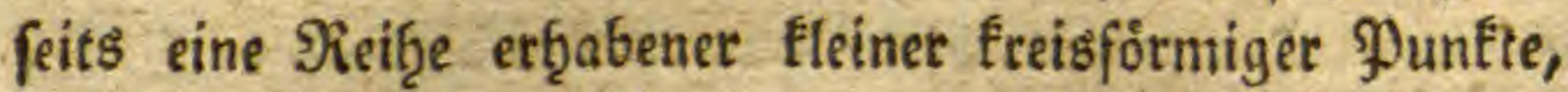
welche altegeit eine fteife uno gegen einanber geftummte Borfte von fidh laffen. Diefe Sorften fino an ber Stim am längften, werben aber gegen bas f̧interḩaupe immer ftufenveife fürger. Z(ud) felbft an bem Seinterranbe ber Zugen, ober jenem gegen ben Şinterfopf zu, befinben fid) ebenfalls folthe Soorften, fie fino aber viel fleiner, unb mit if̧ren Epiz̧en nad) auf= unb auswärts gerid)tet. Uebrigens fino noch vier anfeţnlid)e Borfiten am Ropfe merfmuitoig, nàm(id): jwey aufwair(s gerid)tete, an ten bevien oberh uno innern Effen ber Zugen, ober jenem ₹Ģeile, weldher benen Nebenaugen zu fieb̨et, uno zwels abraartb gebogene, vor ben शebenaugen felbft. - Das

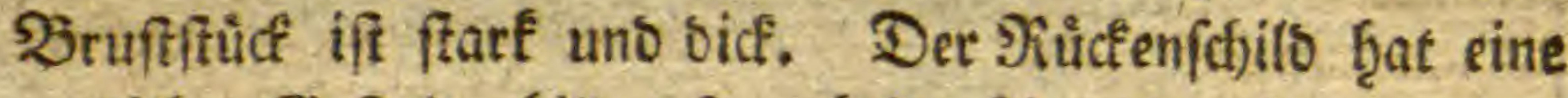
gemólbte Beftalt, bilbet forn beiberfeits ein abgerunbetes (Ect, nac) binten ift er aber faft jugerunbet. Seine Fate be ift ganj graubraun. Etroas tiber ber Mitte an feinet Dberflache, befinben fich jwel) úber einanber ftebende flei.

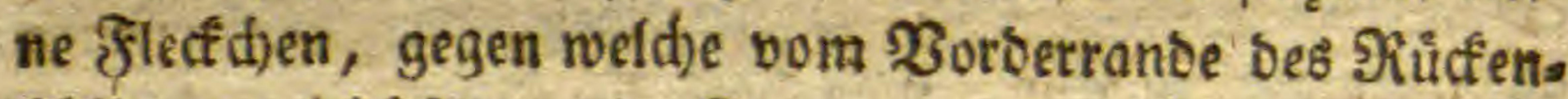
fóilbes, gleidffam zwen Epuren vort verlofdjenen Sinben berablaufen, weldse fict) aber gleids verlieren, uno bie Fleffe nicht erteidjen. Nebft biefen befindet fich am gans

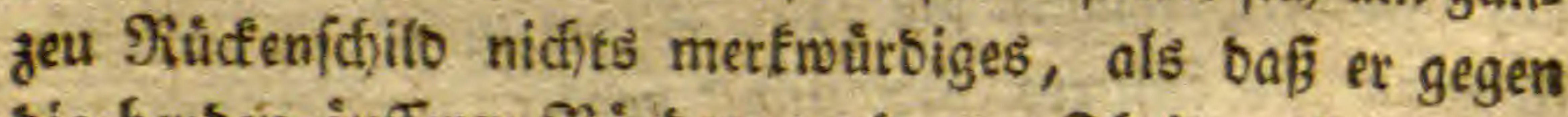
bie benben áufferen Ränber, uno zum ร̧̧eil auch an ben Geitentheilen ber Dberfläcfe, mit meiftens nact) auswärts gerichteten ftarfen Sorften farfam, Dajwiffjen aber gans mit fleinern unb bichter ftehenten, bod) aber ebenfalls borftenformigen Şaaren befejt iff. Das Eschilbchen ift jiemlidf groß, uno gegen feinen fintern ?land jugetunber. 
Es ift gang jart mit fteifen f̧ărdjen bewadffen, graubraun uno mit zwey fdfwarjen fileden verfehen, weldie ifycen Eifs an Den beiben Dberecten iţres Schilbd)ens ḩaben, mo fich) baffelbe mit bem situfenfdilbe verbinbet. Der feinterleib bzat eine fegelförmige, glatte uno feb̨r jugefpizte (Seftalt, ift graubraun, boch) aber etwas meniges megr ins braune fdimmerno, als alle erft befduriebene ?beile, uno fo lang als ber Rùctenf(t)ilo, fammt bem Sdjilochen zufammen. Man fann an bemfelben vier Ringe beutlich mit Dem frenen 2uge unterfideiben. Eeine ganje Dber.

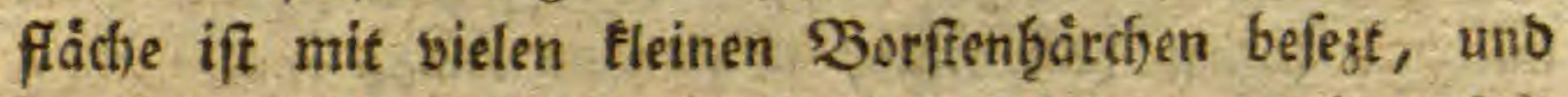
Der Ringeinfásnitt bes zweyten unb oritten, uno jener bes britten uno vierten, wie aud) ber Seitenranb bes Scinter: leibes, ift mit fraten umo langen Borften fparfam befejt.

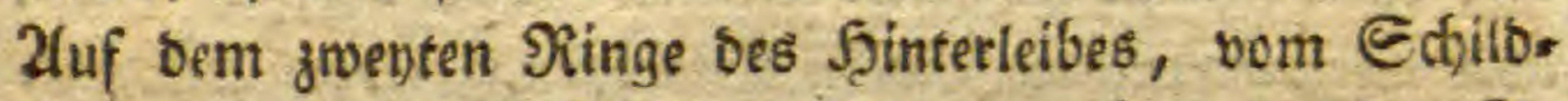
d)en an geted)net, befinben fich brey neben einanber fte: Eqenbe fdfwarzgraue- Flecten bavon ber mittlere etwas bresectig, bie zwein barneben ftehenben aber unvollfoms men nierenformig etfdeinen. Lluf bem barauf folgenben. ober bem britten Ringe, befinben fic) bren anbere Flecten, welche gerabe binter ben bren borbern ju fteb̧en fommen, Savon ber mittlere ebenfalts, aber ein fpif̧winflictes ges fturztes Drenecf bilbet, unb bie zwen Darneben ftehenben audi) eine unvollfommene (jeftalt baben. 2 Beil biefe fechs

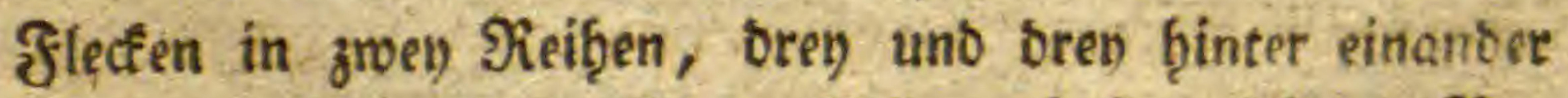
fteḩen, uno bem 2luge feb̧r auffallen, fo finde id) ben Ta: men. Mufca fexmaculata am fofidflidfiten fưt biefe fliege, bon welcher, fo viel mir benuft ift, nod) fein Entomo. log efwas meloet. Der legte, ober ber afferting, tat jwar ebenfalls bren Jlecfen, bavon ber mittelfte ber lángfte 
ift, fie find aber fo matt von farbe, bas fie mit ben bor:

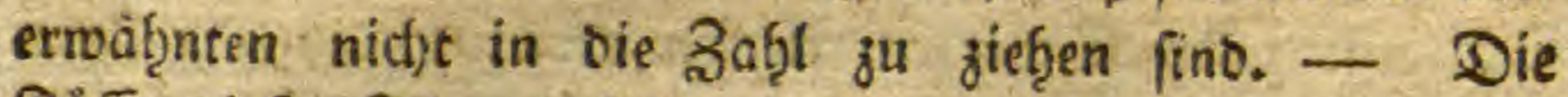
Jüffe viefer fliegen fino ganz bem Rörper gleichfarbig, gitemlid) lang, bie bintern etwas länger als bie vorbern,

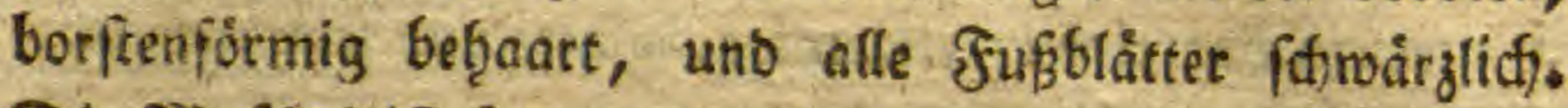
Die Jifufhel ift fammt oen barunter liegenden Ecfroung. fölbchen grat. - Die Flůgel fino grofi, breit, uto ùbertreffen um vieles bie ganje lainge bes f̧interleibes, fie haben einen fef̧r angenef̧men pfauenffiweifigen Blan;,

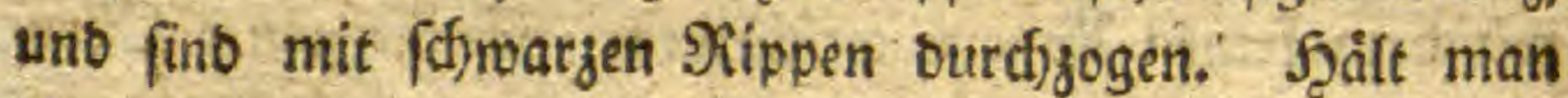
fie aber gegen bas sic)t, fo fino fie etwas rautffarbig. 2(n if̧ret Dberflache, bemerfet man in ber Mitte einen fd) roarggrauen Spunft, uns gleich) batunter, megre einwairts, eine gleidffarbige fafmale Binbe. Beybe Zeidfnungen aber werben nur burd) jwen Berbinbungstippen bet grös feren Jlügefrippen gebilbet, inbem fie beyoerfeits einen fd)warjgrauen Dunft auslaffen.

Diefe Jliege if nid)t gar gemein, unb befinbet fids auf bolbentragenben PFlanjen zur Eommetsjeit. Jab) habe fie im פrager $\Re$. R. botanifdjen (Jarten gefammelt.

\section{XI.}

Mufca cruentata. Die blutteibige Jliege.

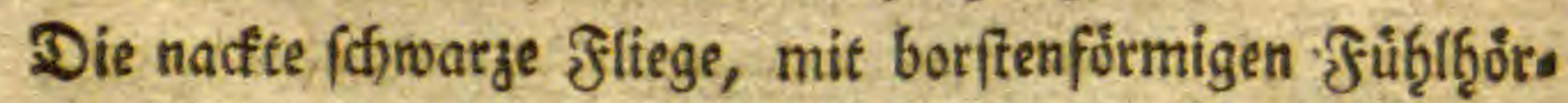
nern, uno einer rothen Querbinbe am Şinterleib.

Mufca antennis fetariis nuda, atra, abdominis fafcia tranfverfa rubra.

Carol. de Villers, Ent. Lin. T. III. p. 462. G. III. fp. 135. 
Diefe Sliege ift flein uno wiro nut gwey sinien lang. Der Ropf ḩat eine fę̣r gewoilbte (B)eftalt, iff o afger einer ḩal= ben Sugel nid)t ungleich un ein weniges breitet als set

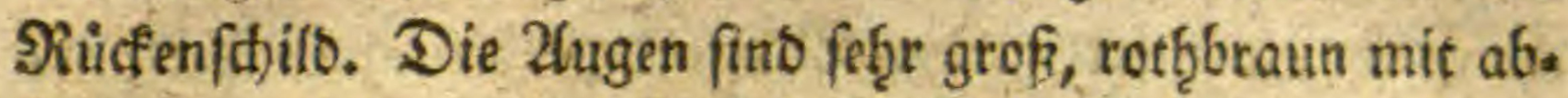
fteḩenden vielen unb fef̧e fleinen Scărchen befezt, neţmen ben grơfiten ₹geil bes Ropfs ein, uno ftofen gleid) ùber ben Juthif̧ornern jufammen. Durch biefes Bufammenfto= fen ber 2lugen werben an bem Siopf zwey teere Siăume ge= biloet, ein anfebntid)er blafigelber zrwifden ben 2fugen uno unter ben füh̨lf̧ơrnern, biejer mad)t bie Gtirne unb bie פunogegend aus, uno ift mit jarten lichten J̧árchen be. wad)fen, uno ein fleiner ein fdjwarzes fpif̨ninflid)es Drens:

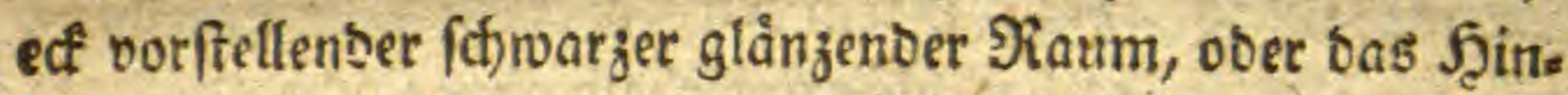

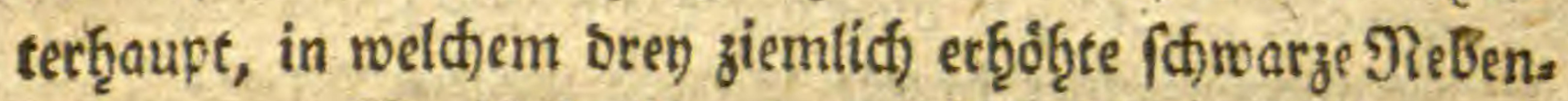
augen jum Borfd)in fommen. Die fdfwarze sinie von weld)er Şerr Billers in feiner $\mathfrak{B}$ efdjreibung Meloung thut, welche über bie Etirn ţerablaufen folf, fę̧lt an mei= nem Exemplare gänzlich); es fcheint alfo biejelbe feb̧r zufäl= lig ju feyn. Die füb̨lf̧oirner fino ganz fffwarz, orenglies. rig, bavon bie exften zwey Eliebd)en ganj flein, bas britte aber langlidbruno nut wenig plattgebruict iff, uno an feis nem Ranbe faff gegen bie Scálfte eine nach) auswairts ge.

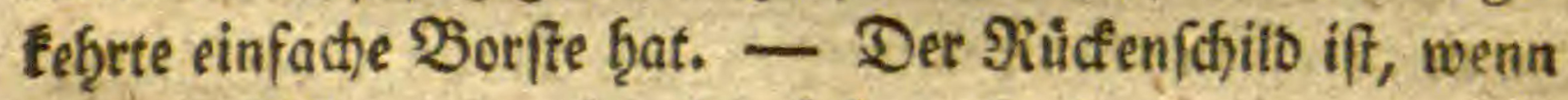
man bie fliege bon oben Gerab betractitet, nur etwas went. ges langer als ber Ropf, vierectig mit jugerunbeten $\mathbb{E}$ ifen, savon bie finterften zren noch) ftumpfer als vie vorbern unb etwas aufgeworfen erfd)einen. Die farbe beffelben ift ganj fhmarz, betrachtet man abet ben Siucenfifjilo genau, fo mirb man zmen áuferft matte SBinben gewab̧r, weldje

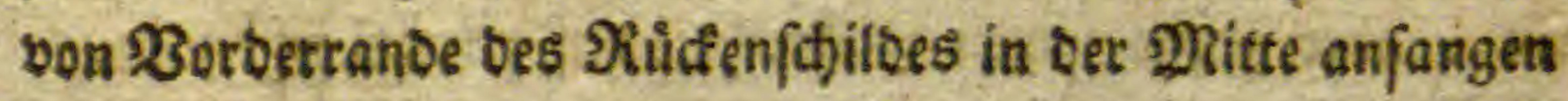


uno faum bie bqalbe Sainge beffelben errsidfen, two fie fid) bann ganj wieber verlieren. Bon ber Mitte bes Seitena

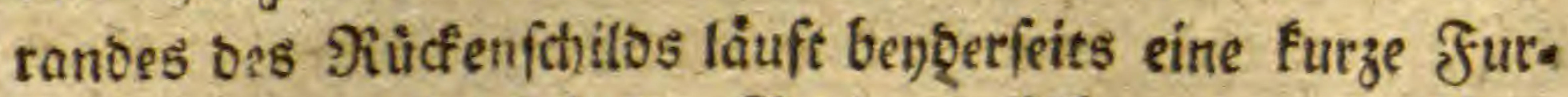
d)e gegen ein viertbeil ber 2 teite beffelben quer bertiber. llebrigens if̂t ber ganze গiùcfenfchilb punftiert, uno Ginten. nach ein weniaes mit braunen Shärd)en jerftreut befejt. Das 6dilt chen ift gegen ben feinterrano volfommen zus gerunbet, am Ranbe befgaart, punftiert, uno ber åuferffe ₹b̨eil beffelben von gelber farbe. - Der f̧interleib bat bie länge Des Ropfs, Rücfenfd)ilos unb bes Ediltbhorns jufammengenommen, if ourcfaus von gleicher Dicfe uns unten ftumpf jugerunbet. Dberf̧alb betract)tet fdeint er waljenfờntig zu fernn, intem feine obere fläche bogenfơr: miz gervoilbt ift, er Ģat aber unferb̧alb eine flache Beffalt, gleid)et alfo nur einer in bie sänge getbeilten $2 B$ alje, uno man fann beutlich) an bemfelben fünf Ringeinfditte, folg: lid) alfo fed)s Finge unterfcheiben. Er ift ganz glänzent, fd, war z, punftiert, uno aus jebem einzelnen Punfte ento fpringt ein fleines graues Şärd)en. Unter Dem erften アRing befinbet fich an bempelben ein anfeb̧nlid)er blutrother in bie

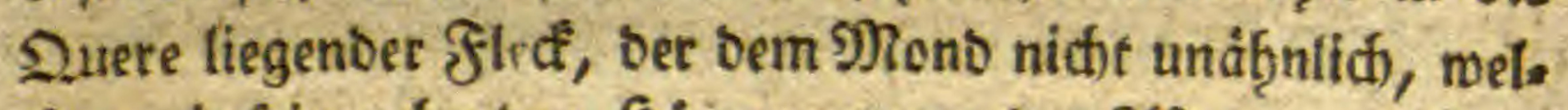
d)er mit feinen benden feoirnern gegen ben affer zu gefeffret if. Diefer Montfiecfen nimmt mit feinem erb̧abenen গiüt.

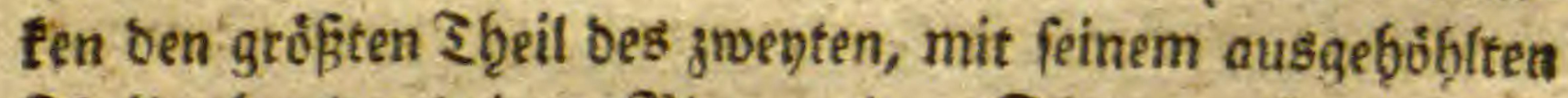

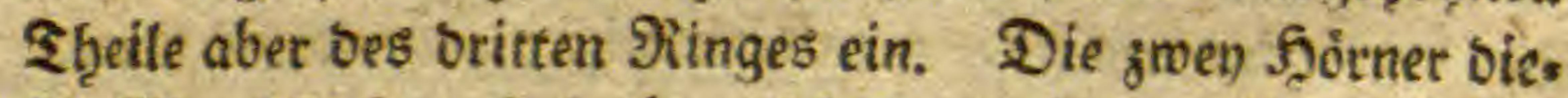
fes Monoflectens fino aber nicht ganz bis zu ifgrer Epiz̧e fichtbar, invem ber Eeitenrans bes oritten গinges eben. falls roth erfheint uno ber gemelbete fflect fid) mit feinen betyoen Epízen batinnen verlieret. Diefen rotben Seiten= rano benterfet man bann noch felbff an bem bierten গing, no er aber gegen feinen Şinterţ̦eil auf einmal fȩ̧r fofmal 
siro unb fich ganz verliert. Diefe blutrotbe Beicfinung brücft Jeerr Billers fẹct unbeftimmt aus, indem er in feinet Defibreibung fagt: tertium fegmentum totum, fecundi magna pars rubra: bas lejtere gilt; boch ift aber bas erffere nicht wab̧r, man barf nur bie Suppe in Die J gano nef̧men uno es genau unterfucten, fo wiro manes, wie id) es izt befdtie. ben ḩabe, finben; obfdion es dem frenen 2fuge gang fo ju fenn

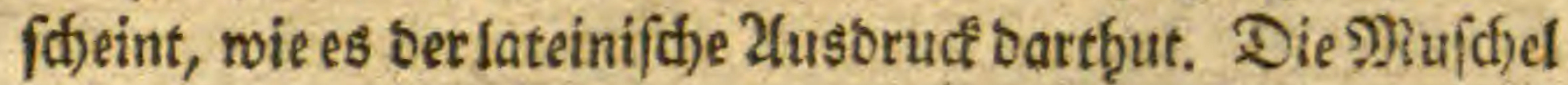
if fammt ben barunter liegenoen Sdjroungfólbd)en meí, bie Flugel etwas länger als ber feinterleib, mit fchrwarzfraut.

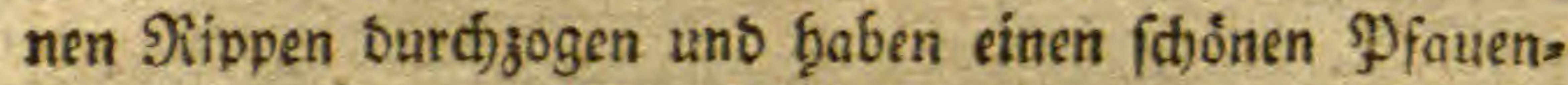

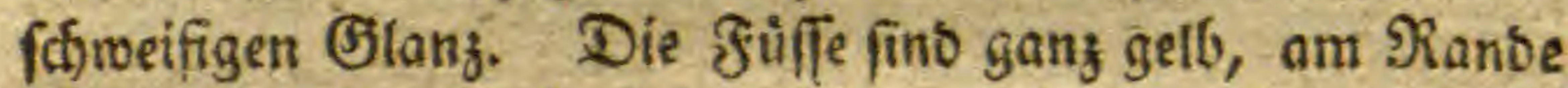
bef̧aart uno bes Echenfels binterer Tgeil, wo er fid) mit sem Sơrper verbintet, fofwary.

Diefe Jliege ift ziemlich felten uns befindet fich im

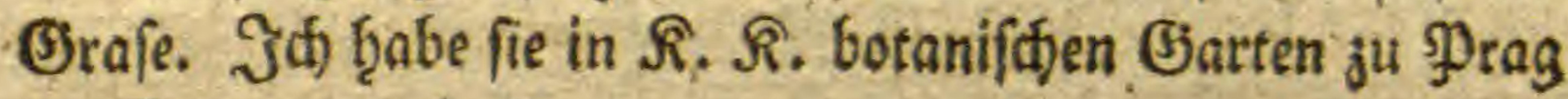
im Sommer gefunden.

\section{- XII.}

Mufca fignata, Die gezeicinete Jliege.

Die graue bef̧aarte mit gefieberten Füb̨lf̧önern berfef̧ene

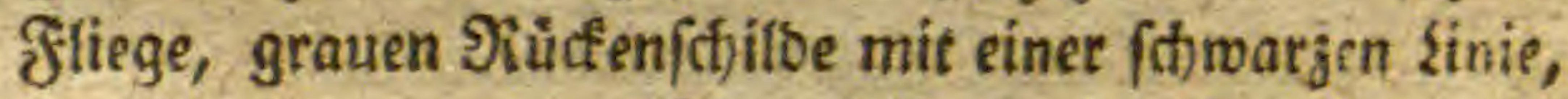
fegelförmigen grauen Scinterleib, mit vier fúwargen Flecten, unb fórwarzen füfffen.

Mufca antennis plumatis, pilofa, cinerea, thorace cine$\mathrm{reo}$, lineis quatuor nigris, abdomine conico grifeo, maculis quatuor nigris, pedibus atris.

Mufca, Sabr.

Diefe fliege erreid)t bie sange bon brittbal6 Sinien, uns b̧at in Setreff Der Seftalt bie meifte Zteḩnlidffeit mit ber 
fect)sflectigen fliege (Mufca fexmaculata N. ro.) Der Ropf ift vorwårts betract)tet faft ḩalbfugelruno gemèlbt, bie bintere fläche aber flach. Die ganje 9 Munogegend bis unter bie Juthtḩórner ift meif, unb befonbers gegen ben

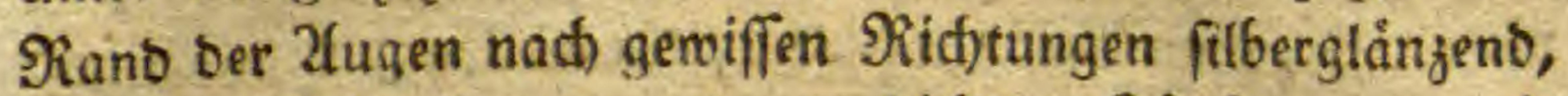
welther Silberglanz von benen bichten f̧ärchen, womit

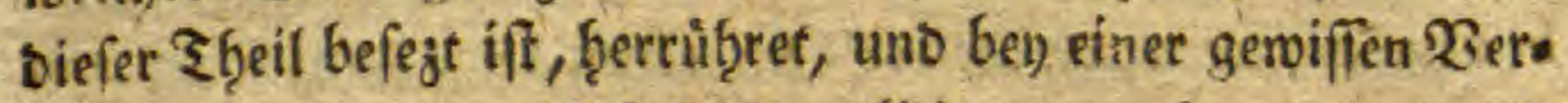
inberung bes barauf falfenben sid)ts mandimal auch bis ins Edjwarze fich verainoert. Der פluno if an feinem Ranbe mit theils långern, theils fưrzern fteifen $\mathfrak{B}$ orften bes fejt. Die Ţübithorner fino fatmarzgrau, furz, uno ib̨r lega tes Gliebd)en enformig, etras weniges platt gebricft. In befien 2 Burzel am Dberranbe befinbet fich) Die gemób̨h liche soorfe, melche ein meniges gefiebert ift. Nan muß genau ben Diefer fliege auf bie Füblthornborffe mit ber sup. pefegen, ebce man gewabyr wirb, ob fie einfach oder gefiedert fer, weil nur bin uno wieber ein feb̨r fleines uno feines

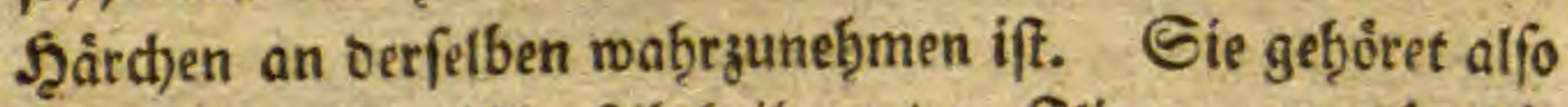
unter jene sinneifche abtbeilung oer Jliegen, weiche oie beḩaarten 21rten mit feberförmigen füḩ̧lb̧ornborften (pilofa plumatæ Lin.) enţ̧ålt. Die 2tugen fino rotbbraun, uno

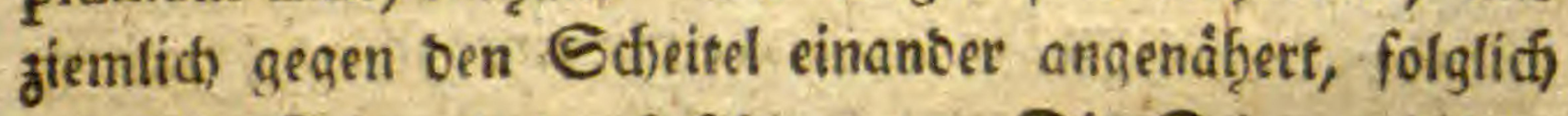
woiro bie Etirne baburch feḩr enge. Die Etirn uno bas f̧interḩaupt fins von farbe farwar, unb bey bem innern Sanbe ber 2lugen formmt, fo wie an ber fechsecfigen fliege

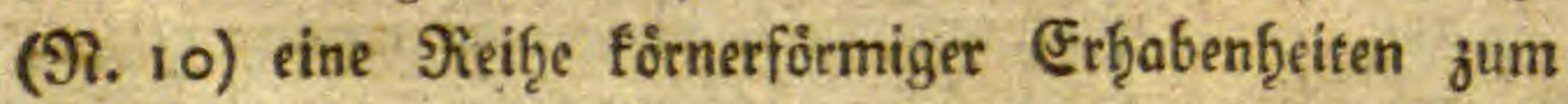
Borffhein, aus roeld)en, gegeneinanber getruimmte fteife Borften entipringen, uno weldte vom Şinterb̧aupte aegen bie Stirn zu, immer an Eånge Stufenweife zunef̧men.

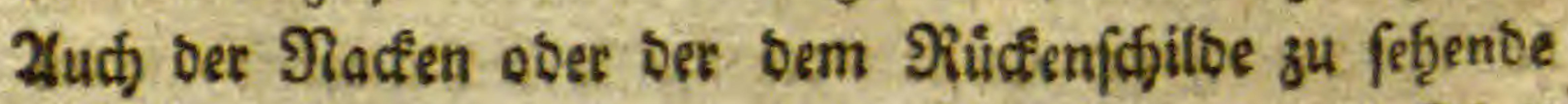


Sheil bes Ropfs ift mit Borften befejt, Dabon eine Reif̧e ganz furger befonbers merfmürbig ift, weldie oen binteren Zugenrano umgiebt. Die Tiebenaugen fint ben biefer fliege von einer alänzenden braunen far'se, uno toenn man itzen eine befondere 2 Benoung benm Zluffallen bes sicteffrals giebt, gleich bem bernftein ourd)fi(d)tig, uno b̧aben einige wenige nad) vorwairts uno abwairts gefrummte Sorften nes

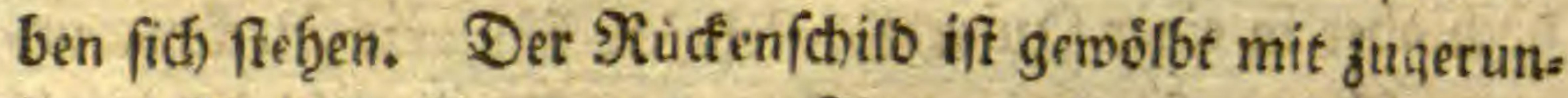
Deten Borberecten, runden Şinterranb unt fo lang als breit, Er bat eine graue Grunofarbe, uno faft mitten u̇ber Derfelben lauft eine etwas fowarze vertiefte Durtinie, bie nur an ber Jliege bann zu bemerfen iff, reenn man bie Sid) tffrofilen vom after gegen ben Ropf ju tarauf fallen 1ift. Man mnß überb̧aupt bey biefer Jlizge diefe Etel. fung annefimen, went man alle Beictinungen an Derfelben beutlid) une vollfommen bemerfen will, - riorigenfalls das

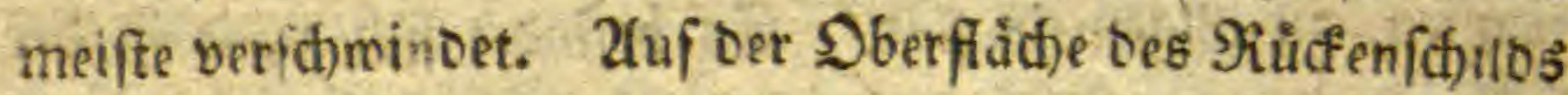
fommen vier fotwarze, gleid, woit voneinander abftefende, und in oie sange laufenbe Binben zum Rorldfein, bavon bie zrwen àuferften in ber Nitfe unterbrochen finb. Diefe

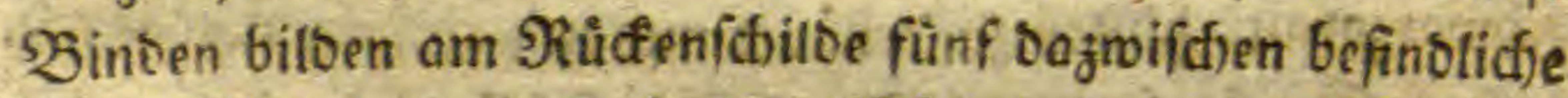
graue Nåume; einen in ber Nitte, uno zu jeber Eeite beffetben zwen andere. Der mittelffe Raum ift mit furzen, freifen, nach) rüctwårts gefef̧rten Sorften befezt, an ben

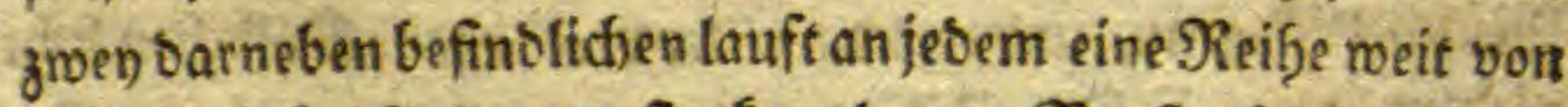
einanber abgefonberrer, ftarfer, langer Borftentgaare berab, uno bie zmen àufferften Säume, fino mit zerftreutfteben. Den ebenfalls ftarfen unb berffieben langen $\mathfrak{B}$ orften befeje. Der f̧interleib bat eine fugelförmige, ftumpf jugefpijte

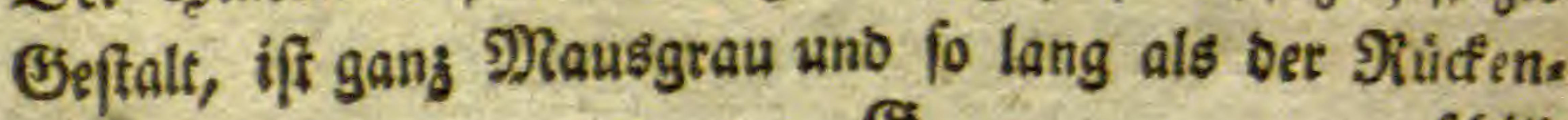


fojito fammt bem Edjilbdjen zufammengenommen. Er f̧at vier beutlich ju unterf(heibenbe গinge, ift ganz mit fleinen Borftenţärcjen befezt, boch) aber fonmen gegen bie bintere F̧älfte beffelben, bis an ben 21 fter, unb an ben Eeitentb̧ei= len viele ftarte uno lange Borften zum Borfdfein. Zuf

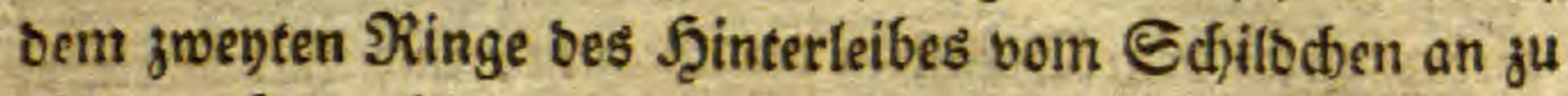
jăb̨len, bemerfet man jwen etwas von einanber entfernte, bo(h) aber in einer Suerreife ftefente fdrwarze flecten, un.

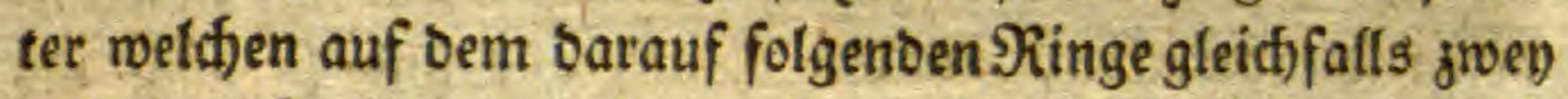
anbere, aber etruas fleiner erid́cinen. $2 B$ bil biefe vier Flef. fen fo farafteriftich) an biefer fliege vorfommen, wollte ich fie anfangs Mufea quadrimaculata ober quadripunctata beifen, ba aber fdjon benbe গlamen anbern fliegen von ben शaturforfhern gegeben finb, fo wat id) gezwungen bie jiemlidf) f(t)wadf)e Benennung Mufea fignata zu wåb̨len, in = bem alle übrigen Ef̧aradter biefer 2(rt, um fie anbers ju be: nennen, zu allgemein finb. Es befinbet fich jwar in ber

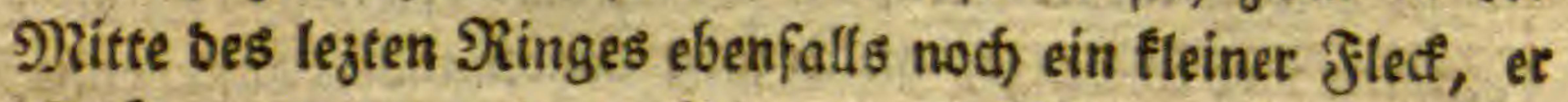
ift aber gu matt unb ju flein, um benfelben mit ju benen

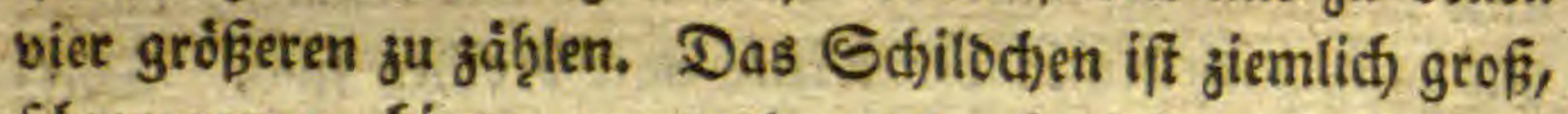
forwarggrau, Ginten zugerumbet uno mit einigen fteifen unb langen Borftenf̧aaren befejt. Die Jitiffe biefer Jlliege fino ganz fówarg, bie bintern etwas länger als bie borbern, uno mif ungleidjlangen Stadjeln uno Borften befezt. Die

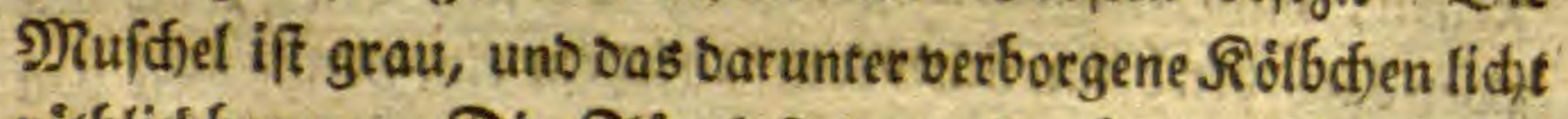
rơtb̨liđbbraun. Die Flůgel fino groß, breit, übertreffer

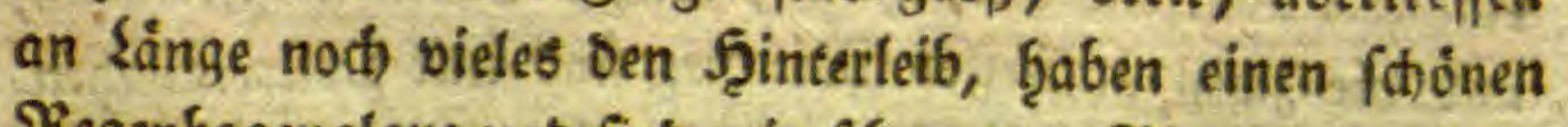
Regenbogenglanz uno fino mit fofwarzen Rippen butd) joe gen. 
*- Diefe fliege wothnt im Sommer auf bolbentragenten Pfanjen unb ift nidt) gar felten. Iक ţabe biefelbe im

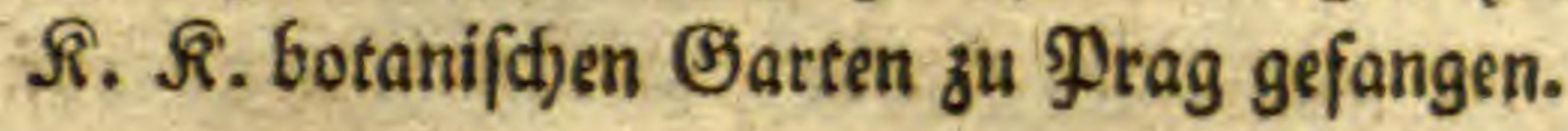

\section{XIII.}

Mufca afiliformis. Die raubfliegenån̨nlidje flliege.

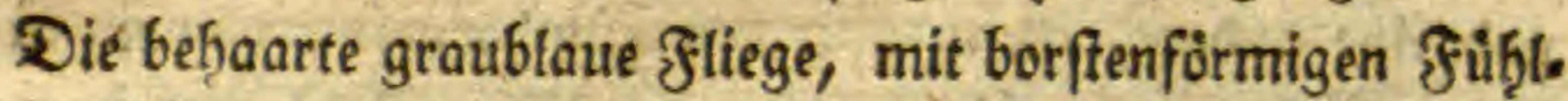
நृơrnern, grünen 2lugen, gelbbraunen füfffen, mit ount.

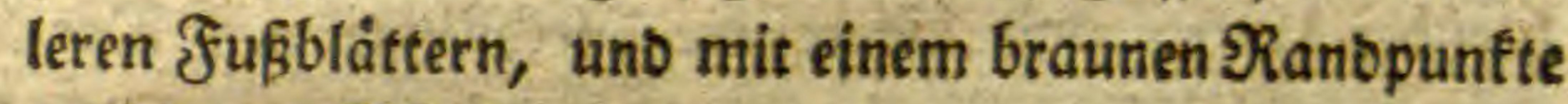
bereferenen ghigeln.

Mufca antennis fetariis pilofa, coeruleo-cinerea, oculis viridibus pedibus flavo fufcis, tarfis obfcurioribus, alis puncto marginali fufco.

Mufca Jabr.

Die natürlid)e Sänge biefer f̧liege, menn man fie von oben betrad)tet, beträgt bon ber Etirn bis jur 2ffterfpise froen uno eine balbe sinie. Der Sopf uno ber Miuden. fhilb fint bennafee von gleichet Breite, uno ber erfere fat eine linfenfortmige, boch aber nach born zu gerwolbte (5ea ftalt, mit einer gegen oie פitte eingefenften Etim. Die Gegeno bes Mundes, ober jene unter ben f̧übitgoirnera uno gmifhen ben Zfugen ift breit, intem fie faft mef̧e gls ein Drittbeil Der ganzen Ropfbreite ausmactit, bon grauer etros weniges ins fomufgiggrùne fotimmernber Jarbe. Bon bem untern গianbe berfelben läuft ju jeber Geite, gegen bie füblbórner zu, eine ounfle, gebogene

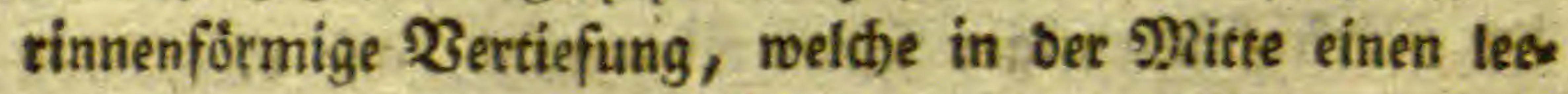

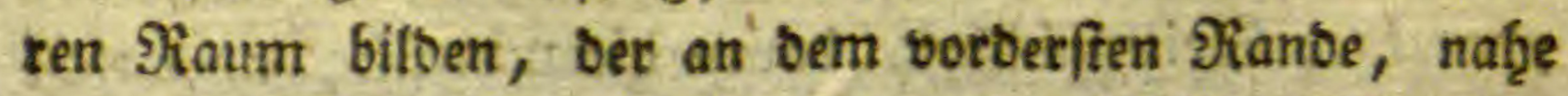

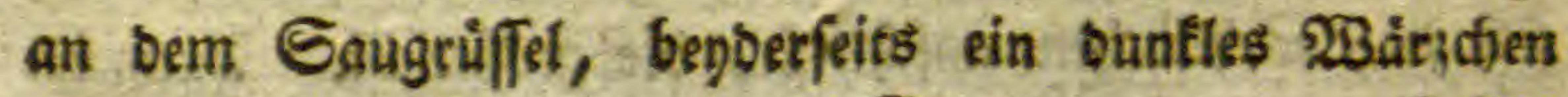


befizt, welches mit ffaarborffen bewadhfen ift, oie conjens trifth Ģerumfif̧en. Die Etim ift fo bucit als sie Muno. gegeno, von bet nåmlidien garbe, unb mán wirt auf ibgrer mittlern fläche eine Epur von einer frcujfortmigen Bertiefung gewab̨r, inoem eine fotwathe furche an oen

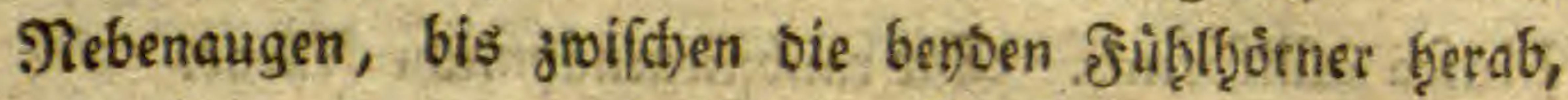

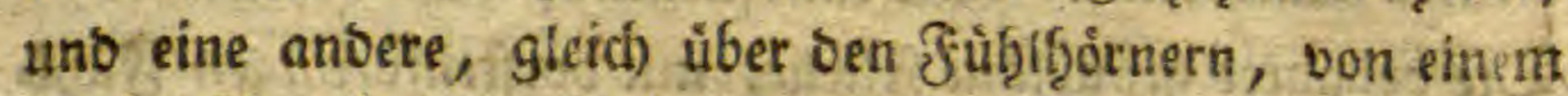
jnnern 2fugenrano, bis ju bem gegenúber fteḩenten queer ḩertiber läuft, uno Die erftere ourchfdchneibet. Der Srt, an bem fich fệr verbreitenten f̧interb̧aupte, wo bie oren शebenaugen zum $\mathfrak{Z}$ orfd)ein fommen, if länglidfruno unb

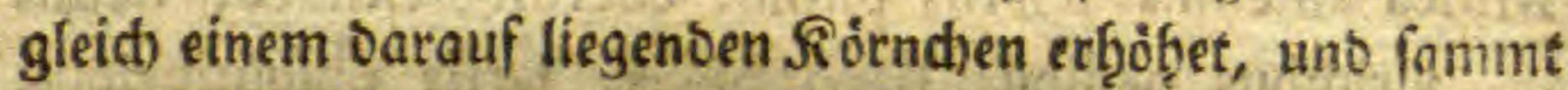
bem Şinterḩaupte ein weniges mit grauen f̧ärden bewack) fen, ùbrigens aber von ber nảmlidjen Farbe, nie bie votbef́friebene Munogegent. Die Zugen fino lánglictrunt,

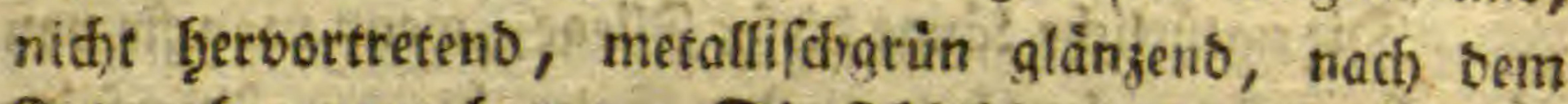

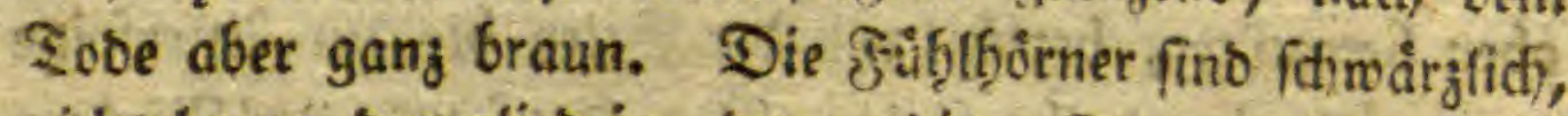
nidjt lang, brengliebrig, bavon bie erffen jwen (siliebctien plattruno, bas lejte aber fugelforrmig erfdeint, uns ficth gegen ben aufferften ₹̧̧eil in eine borfenförmige Epiģe werlaingert, bie gat feine Feter bilbet, Dab̧er alfo diefe

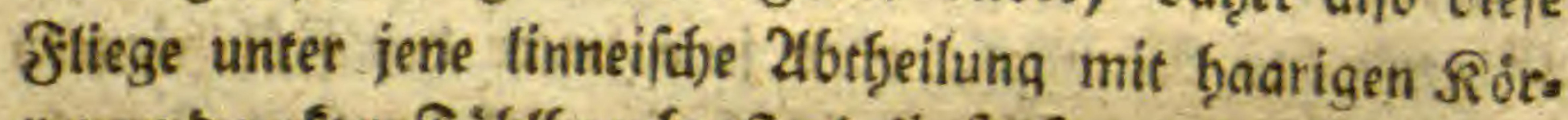
per uno nafter füblfigornborfte (pilofe fetarix) gegóret. -

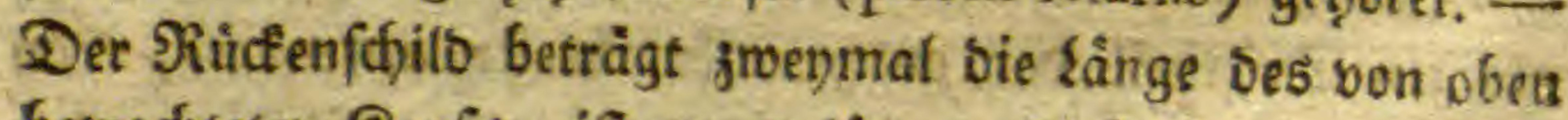
betrachteten $\Re 0 p f 3$, ift efwas länger als breiter, vierectig, Dod) fo, bafs die jwen Dberecfe bes $\Re_{0}$ pps abgerundet, bie jwen hinfern aber gerabe abgefdinitten eridheinen, und

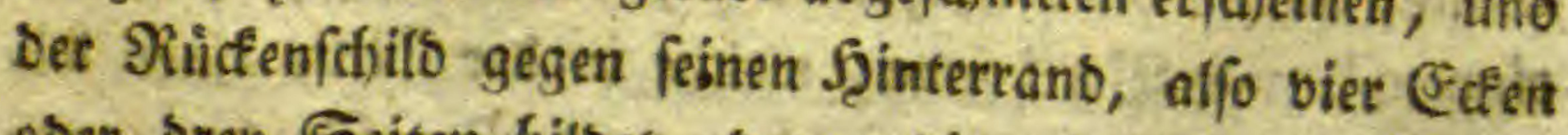
ober bren Seiten bilbet, bavon bie mittelffe, an weldise

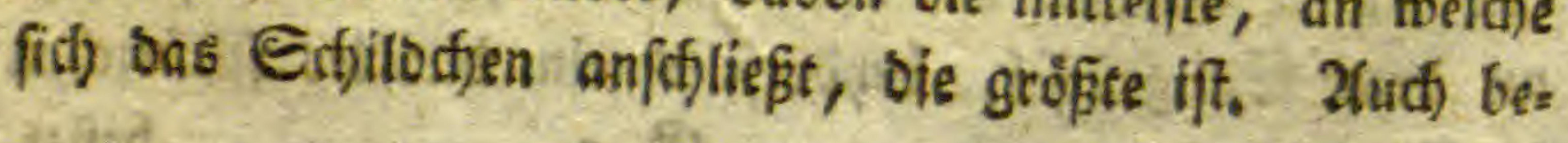


merfet man noch, in গiucfficht ber (Seftalt beffelben, jeber. feits eine Erf̧abenţeit an Deffen Dberfichibe, nabee bent Geitentanbe in ber Mitte. Er ift gand von afdograuer Farbe, nur Ģin unb wieber mit einigen braunen Şärchen fpariam befezt, uno mit matten fofwärjlid)en flecten bes zeidfnet, bavon einer eine breite, in ber शitte beffelben in bie sange laufente Sinbe bilbet, weld)e vom Borber rano anfängt, etroas über bie bqalbe sänge bes Siùcfen= fdilbes bुerabläuft, unb bann gerabe abgefdynitten ift; bie übrigen fins runb, uno ftefen benterfeits barneben, fo,

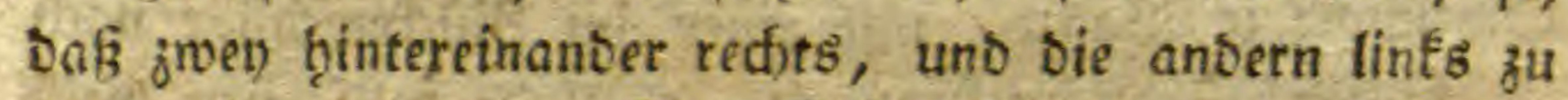
ftepen fommen. - Das Echiloctien ift fo lang als ocr Ropf von oben betractitet, grau, uns nacb finten vollfom= men zugerunbet. Der Sainterleib if zivenmal fo lang, als

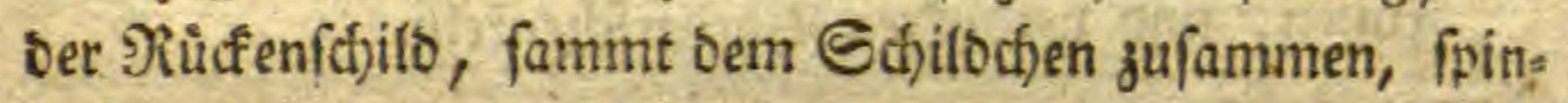
Delformig, lang, uno ganj von grauter etwas ins licict= blaue ffimmernoer farbe, uno mit braunen f̧ärchen fparfam befejt. Man Fann Deutlid) an bemfelben vier Finge beobat). ten, baven jeber an feinem 2 nfange etwas bunfler iff. Şife

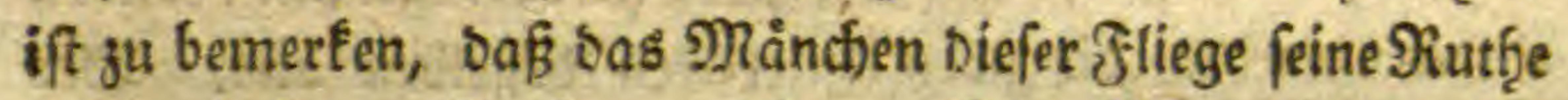
feher weit ţerausftrecfet, weld)e aus fech) S Fingen, oren gro:fern uno orey fleinern beftef̧et. Diefe gef̧ören nid)t mef̧r mit in bie నab̧l ber feinterleibsringe, uno finb aud) leidt)t zu unterf(d)eiben, inbem bie erften breye eine lidytere farbe, uno einen aufgemorfenen breiten গiano ḩaben. Die Filffe

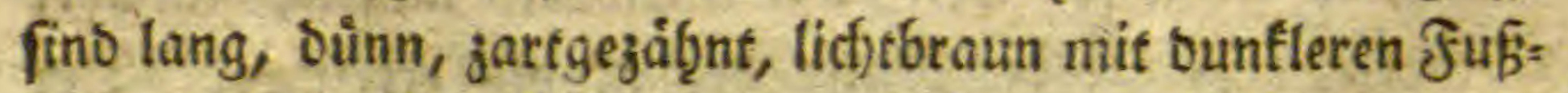
blättern, bie Jlügel glasartig, mit braunen アiippen burch). zogen, uno mit einem ounfelbraunen Ranoflecten verfẹten-

Diefe fliege trabe id im Eommer, in bem $\Re$. $\Omega$. Saumgarten ben Srag, auf einem J̧afelnuffftrauche ges 
fangen. Eie ift nicht gar gemein, unb bुat bas vollfom mene $\mathfrak{Z}_{n}$ feḩen einer $\Re$ Rubfliege. (Afilus Linn.)

\section{XIV.}

Cimex Bardanæ. Die Rlettenwanze.

Cimex niger, thorace poftice fafcia fufcogrifea, elytris ferrugineis, albo nigroque variis, Elytrorum appendicibus nigris', macula alba, pedibus ferrugineis, femoribus anticis incraffatis.

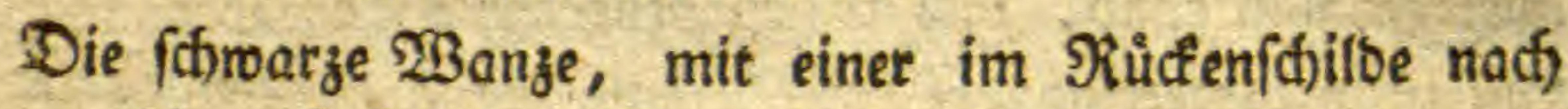
binten befindlid)en braungrauen $B_{\text {inde, }}$ rofffarben, weís

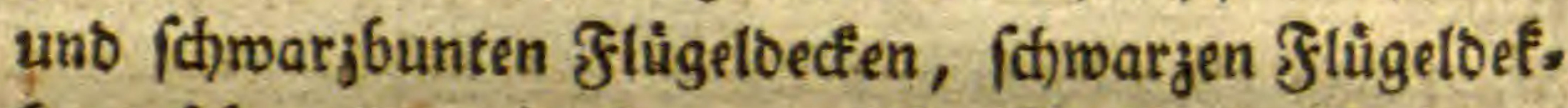
fenanb̧ången, mit einem weiffen Jllect, rofffarbenent Süffen, uno verbidten Borberfidenfelti. Cimex Babr.

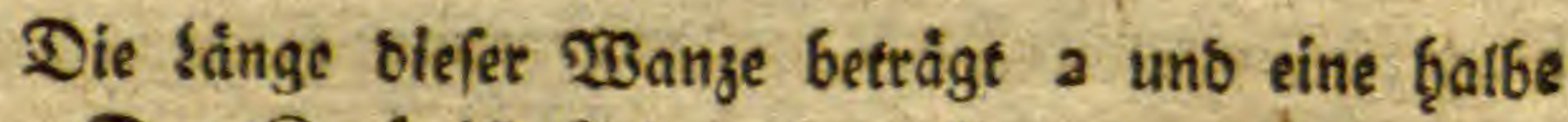
Sinie. Der Ropf iff flein, brenectig, ber Şinterrano etwas nusgebogen, unb bie zwen hervortagenben braunent 2lugen mactsen bie jwes Utnterecfen befferben aus. Der Eeitenranb Des $\Re$ opfs bilbet gleid) über ben Zfugen ein formaches Ede, uno tritt bann, inbem benbe Geitenrain= oer gegen ben Muns jufammen foBken, in eine frumpfe Epiģe, oie etroas mit Saaaten befejt ift, aus, von weld)er jwen) Fleine Jurchen nach) rúctivairts laufen, fich) aber verlieren, efge fre Die Mitte bes Ropfs etreidfen. Der ganze Ropf ift fdwar fid) binter jeoem 2luge, etwas nach einmairts ju, eine fleis

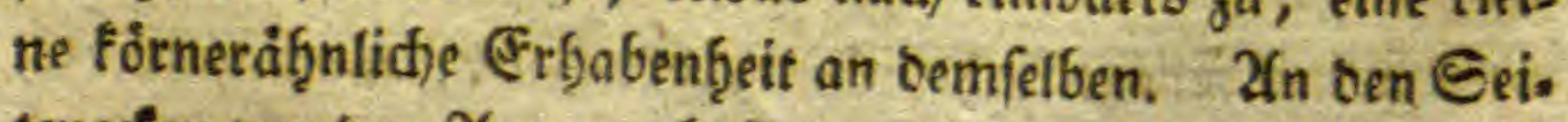
tenecfen vor ben 2(ugen, befinten fich) bie füb̨l(ţörner, mele 
che viergliebrig, fabenförmig, fein beb̧aart, uno fo lang als oie Fluigeloefen finb. Das erfte (Stiedd)en berfelben ift bas bicfite, fürzefte, walzenfơrmig, vom Grumbe an ůber bie Şâlfte fobwarz, bann aber braun. Das jwente unb britte nod) einmal fo lang als bas erfte, bunner, un= ter einanber faft von gleitiser sange, fd)wad) feulfórmig uno erfteres ganj braun, mit fówwarzer Epiz̧e, lezteres aber ganz fotwars. Das viette Gliebchen, ober bie Siol. be ift etwas weniges langer als bas oritte, mit bemfelben von gleidfer Didfe, walzenförmig, gegen benbe Enbe zu= gefpizt uno fdwwarz. - Die sänge bes vierectigen গiúE. fenfidjilbes bettigt etwas meţe als feine $\mathfrak{B r e i t e , ~ u ̈ b r i g e t i s ~}$ if es glängenofd)warz, punftirt, uno an ben Eeiten auf= geworfen ober geranbet. Der $\mathfrak{B o r b e r r a n o}$ ift ber fleinfte, fanft eingebogen, bie zwen Eeitenräner mit einjetnen Dorften fefer fparfam befezt, etras ausgebogen. Der Seintertanb ift giemlid) bogenförmig ausgefdnitten, fo, baß sie jwen Şintereffe runo, ftark b̨erbortteten. 2(m fintern Ranbe beffelben befinbet fid) eine fómuşig getbbraune, mit jerftreuten bunfleren Punften befegte 2ueerbinbe, wels c) aber an ihren beyben åufferften Enben in einen mat. ten weiffen flecf úbergeţet. Der obere Rano berfelben ift bogenförmig ausgefd)nitten, uno nimmt feinen 2 nfang in ber f̧älfte bes Geitenranbes bes Ruicfenfdjilbes. Der untere låuft aber mit bem f̧interranbe bes গiůcfenfffilbes genau vereinigt fort; verlåßt aber benfelben ben ben f̧in:

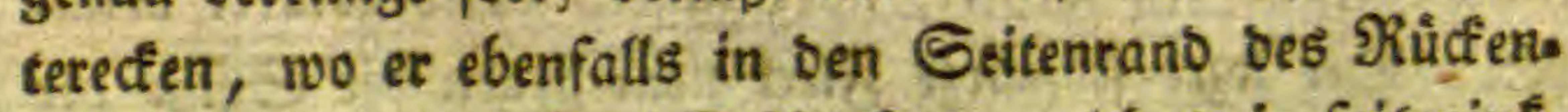
fóilbes tritt. - Das Sffilbchen, weldjes ein fpięrwint. liges Drenecf vorfteffet, ùbertrift bie sange bes Ropfs nod) um bie Scálfte, ift fópualler als ber f̧intertano bes 
104 . Wefjecibung siniger Inffeten.

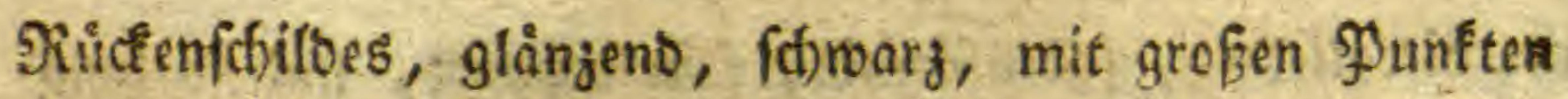
jerftreut befeat, uno nut bas áufferfte Epiz̧chen rofffarb. Die Flugeloecten fino, wenn fie on einanber lirgen, in Der Witte etwas breiter als ber Siủcfenfchilo, nef̧men ig̨ren Znfang ben ien sufferften Sinterceten beffelben, find rofts farb, mit weif uno f(t)warzen Zeichnungen. (bleich von

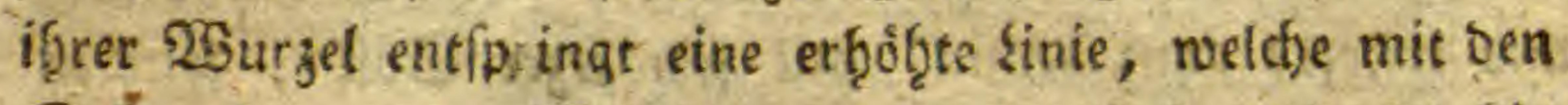
Eeitenràndern bes Éfillod)ens parallel láuft, uno fidh bis an bie Spig̨e erffrecft, weldhe bie łlugelbectenanbiange bil. Den. Neben Derfelben befinbet fid benderfeits eine গieif̧e Bunfte, in einem etwas braunen (5runde. Swifchen bies fer sinie uno bem Eeitenrande des Shilochens, uno bann auf ber ganjen Dberflàche ber flígelbecfen, laufen bers

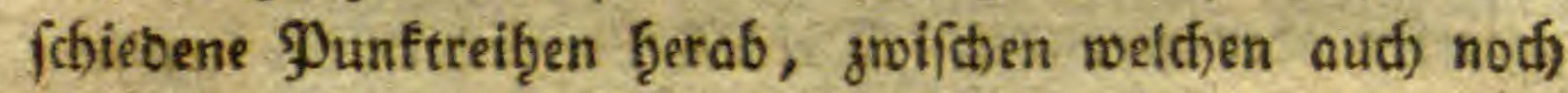
viele einzeln unb zerftreut vorfonmen. Su ben fofrorjen Seidinungen ber fflugelbecfen, geb̧ert ein lffwarger flect, weldfer an benfelthen ba entfpringet, wo fid) oie fdwwargen J̧intercfe bes Edjilddens befinben, nad) Deffen zweij Sei. tentänbern zulảuft, uns fict) gegen if̧re ljalbe sănge vet. liert. Unter bieferm fömmt gleid) ein fét)maler, langet weiffer Fled zum $\mathfrak{B}$ orfhein, weldjer an ber befagten erfૃo. bzeten sinie fdief b̧erabläuft. (Fin anderet lintenförmiget (d)warger flecf, befinbet fich gleid) unter bet oben bef(f́riee benen erfoffren linie, vom Zuffenranbe fojief gegen oen innern Эiano ju, berliert fict) auf feinem balben 23 ege, wo fich ebenfalls ein reeifler, aber jugerunbeter Mafer befin. bet. Der lejte fotwarze flect liegt gegen die Spif̨e ber Jlügelbecte am 2fuffentanbe. (Er ift ber grofigte, unb hat ebenfalls einen gröien reiffen flect unter fich, ber bie flu. geloectenfpişe ausmadit. Der Xuffenrand ber flitgeldef. 
Fen ift blaß̧ gefárbt. Die Flügelbectenanţånge fino f(f)warz, und baben an if̧rem åufferften Enbe einen rü. ben weiffen flecf. Der ganze Ropf ift fchwarz, glanzent, nur bemerfet man bren meiffe sinien, benberfeits an ber Sruft, reldf) von ben Seitentheilen berfelben, gegen jebes eingelne fuppatat zulaufen, unb bavon bie mittelfte bie Dimnfte iff. - Die Jutfe fino rofffarb, bie binterften am längften, bie' Schentel bes erften Jufipaars verbictt, uno am untern Sianbe, faft in ber Şálfte, mit einem farfen Zaf̨n bewafnet, uno fo wie jene bes binterften Jufpaars an ber Epişe, mie aud) bie Edjienbeine bas.

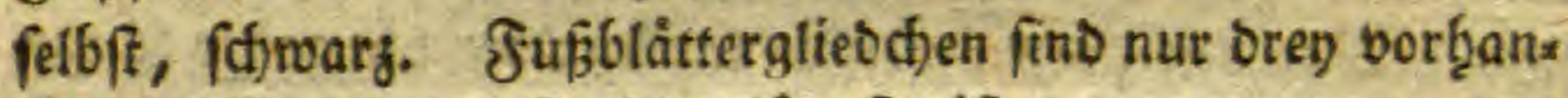
ben, bavon bas erfte das längfte ift.

Diefe $23 a n z e$ ift bey uns ḩáufig auf ber gemeinen Rlette (Aretium Lappa Lin.) zur Eommerzeit. Eielåuft feb̨r fánell, uno fáltt bẹ ber geringiften Berůtgeung alo

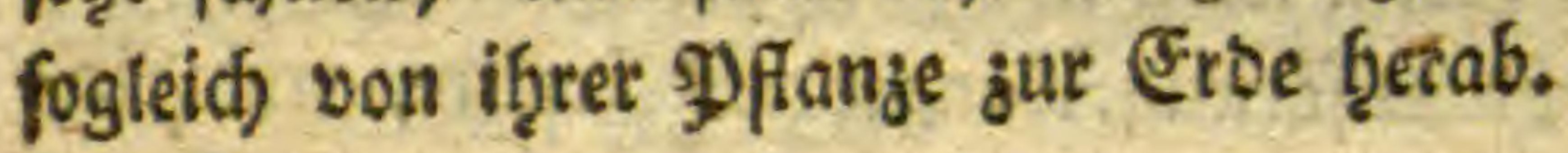

\section{XV.}

Aranea cretata. Die Rreibenfpinne.

Die roige Epinne, mit zugerunbetem Sinterlëb, mit oren an ber $\mathfrak{Z}_{3}$ utzel in ein Dreyecf georbneten eingebrùdten Dunften uno vorn groen orangenrotben Flecten an Den= felben, uno vier feb̨r furzen J̧interfüffen.

Aranea alba, abdomine rotundato, punctis tribus ad bafin in triangulum dispofitis, maculisque duabus antice aurantiis, pedibus quatuor pofticis breviflimis.

Aranea, Fabr.

Die Sange ber gangen Spinne betraigr vier linien, uns

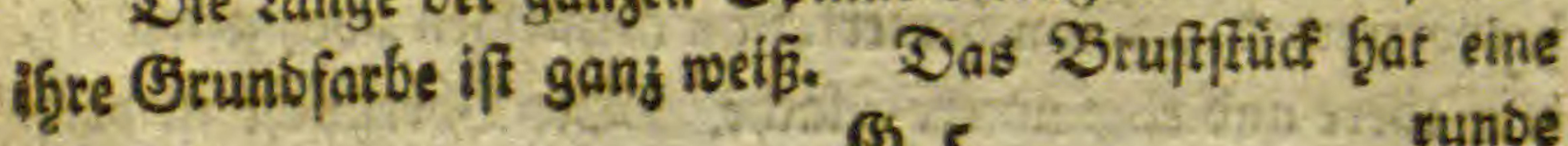


runbe, gegen oie 2tugen ein wenig hetbortrêtenbe, obera byalb genoélbte, unten aber flad)e Beftalt. Es ift ganz nildfweiß. Born fommen an bemfelben bie ad) 2lugen zum $\mathfrak{B}$ orfhein, welche in brey Nieifien fteben; zwey sanz: fleine meben einanber; zwen großje ebenfalls neben einars: Der, bod) weitet voneinanber, f̧intet ben erfteren, uno mef̧e austwäts; bann biete in einer querteihe, bavon bie mits telften zrove fo flein, als jene in ber vorberfter ßieifie finb, uno gerabe b̧inter if̧nen in eben ber Entfernung ftȩ̧en, ne. ben welchen zu jeber Seite noch bie tibrigen zu ftę̂en foms men, uno von mittleter Giróbe untet ben úbrigen 2lugen fino. Won ben zwen áujerften laufen ùber bie ganze sánge

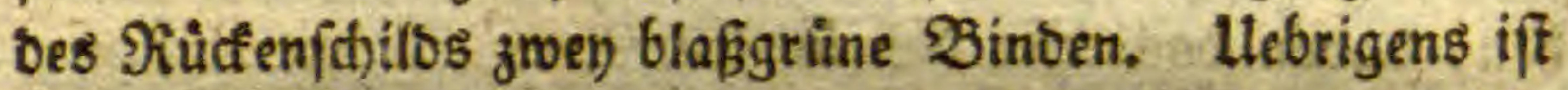

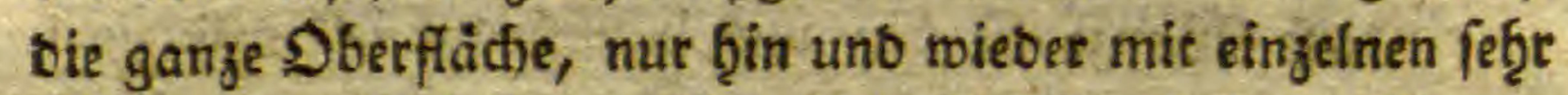
fleinen faum fidt)tbaten fofwargen Borften befejt. Unter. balb ober an ber $\mathfrak{B}$ ruft felbff ift nichts merfwúrbiges. Die Sinnlaben fino blafenfortmig, langer afs breiter, mit ein.

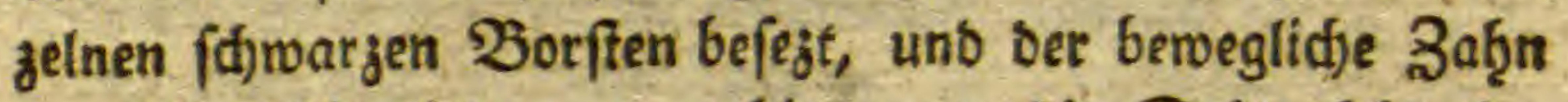
von feiner 2Anglieberung an bis gegen Die Epiz̧e fef̧r ein:

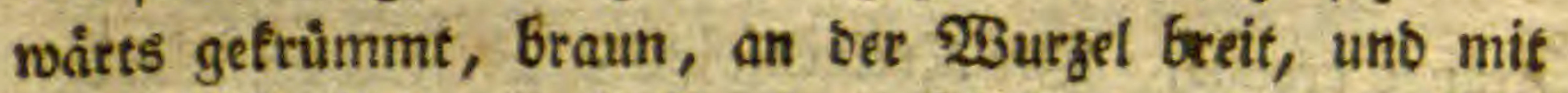
einigen fę̧r fleinen zaf̧nfơtrmigen Jjöcferchen be fejt. Die Jrefffpişen fino mildf)reif, ourd,ffheinenb, furz, oiff, gegen Die Spif̧e etwas ouinnet, als an ber $\mathbb{B}$ Burjel, mit einjelnen

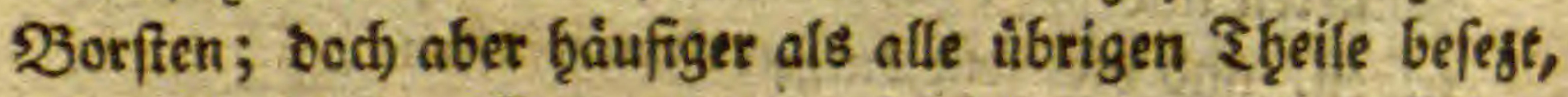
uno viergliebrig. Davon bas erfte, oritte uno vierte (j)lieb. dhen Das Gròfte, uno faft naljenförmig, bas jwente aber aus allen bas Sileinfte if unb bie Geffalt eines furzen, bod aber immer geftugten Regels b̧at. Der f̧interleib b̧at eine fugelfortmige (S)eftalt, ift aber bod) vorn etwas weniges meţe berbortretenb. Nan bemerfet an bemifelben jwen getwólbte, eine obere unb aine untere Jlähe. Die Sbetfläje if votn 


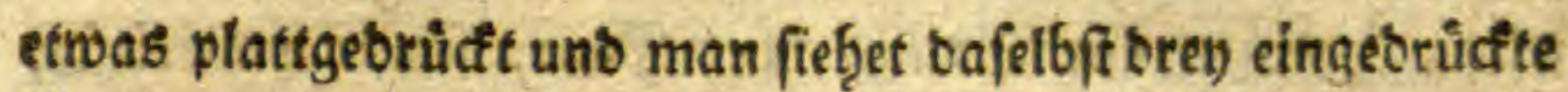
Dunfte, weldfe in ein Drenecf georbnet fint, intem ein einziger ganz vorn, unb groene neteneinanber finter beme felben erfdheinen. $\mathfrak{B}$ en genauer $\mathfrak{B e t r a d}$ )tung bemerfet man auch noch zwey fefgr fleine in bie Duere neben einanber ftes Genbe punfeforrmige Jlecfd)en, in ber פRitte Der Dberflàche Des Sinterleibes, fie finb aber feineswegs vertieft, uno folglid) fönnen fie nid)t zu ben exften bren puncften gerect)a net merben. Dberb̨alb vorn am Şinterleibe befinbet fids zu jeber Seite ein rofffarbiger länglid)runber Flect; wo einer von bem anbern fo weit entfernt ift, als bie Breite

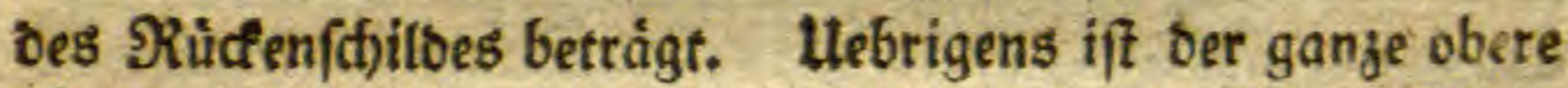

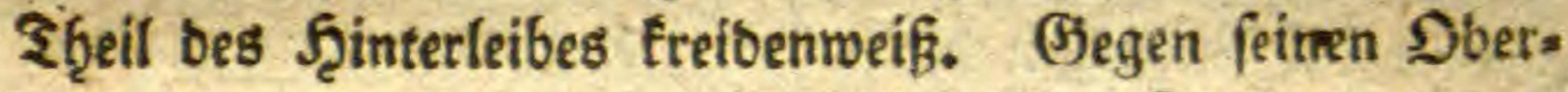
rano foimmt eine gegitterte gleid)färbige Seichnung zum Borfhein, weld)e fef̧r viele 2(ę̧nlid)feit mit bem gegitter: ten (Servebe bes in bie Quere Durdifthnittenen EIfenbeins bat, uno viele fef̧r jarte, sunflere in 3weige vertbeilte Stridje fommen an beyben Seiten berjelben vor. Die untere Fläd)e, ober ber Baud) ift ebenfalls meif, bod) aber ift bie Beichnung benberfeits fef̧e flectia, ober gerons

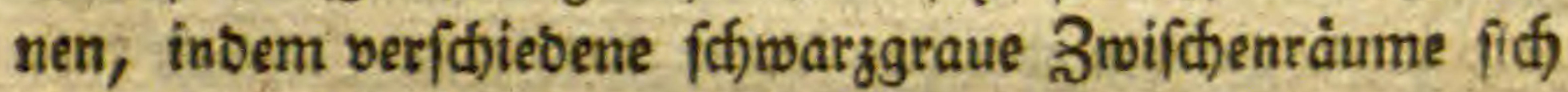
in biefer weifen farbe verffjieben ourd)freuzen, unt etwas u̇ber ten 2 fter benberjeits einen unregelmäpig geftalteten fifwarzgrauen Jlecten bilben. Der 2ffter befinbet fid)

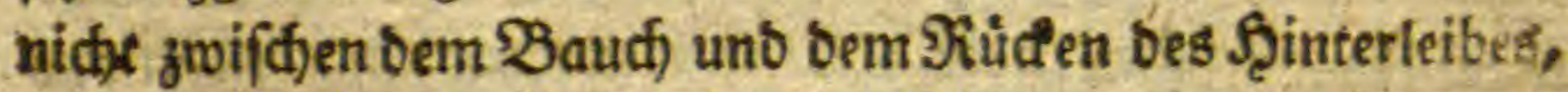
fonbern faft an ber f̧älfte bes 2 auches, ift jiemlia aro uno bie fünf ounfleten $23 a$ äzditen beffelben nicht berausta: gent. Zwif́d)en bem Bauche unb ber Dberflactie bes fhima terleibs rùcfwårts befinben fich, zreey Gintereinanber ftebene be, in bie \&uere laufenbe matte roffarbene furze Duerlis

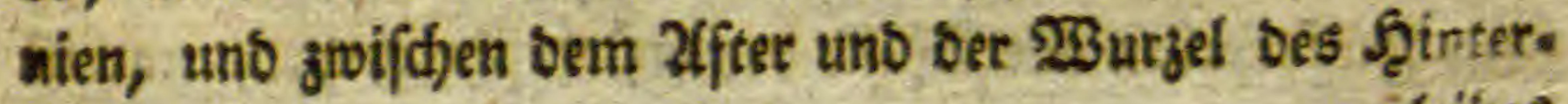
leibes 
leibes fommen am OBaudje brey Paar, (d)wads bertiefte,

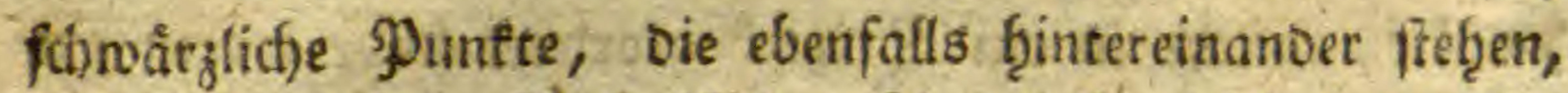
zum $\mathfrak{B}$ oridjein. 2(ud) ift ber Feinterleib gleid) unter ber Bruft am Baudje etwas bunfler, uno gleichfam von einer wátarigen farbe, in melcfer benberfeits ein etwas gelblid)er zugerundeter flect ericheinet. Die friffe' fino von mildik ger farbe, fparfam mit fleinen, anllegenben, fdrwargen Sorften befejt. Die vorberften zween פaare fino noch eins mal fo lans afs oie b̧interften, uno fect)gglieorig; baven Dos erfte (Slieodien flein, furz, waljenförmig, uno unmit: tribar an bem 2 rufffticfe anfozt, auf weldjes bann erft ber Sd)entel, als ber zwente ₹heil des fuffes folgt. Er ift aus allen Sḩeiten am bicfften, rums, uno fo lang als ber Shüfenffhilo. Dann folgt bas oritte Blieschen, Diefes ift rieber fo, wie bas erfe ganj furz, malzenformig, uns verbinbet ben Echenfel mit oem erften Edyienbein, mele d)es ben vierten Sheil bes Juffes biltoet, rollgenformig iff, uno fammt bemt etften (Sfietchen, bie \{ange bes gaingen Edjenfels bat. 2(ud) fommen an bemfelben am inneren

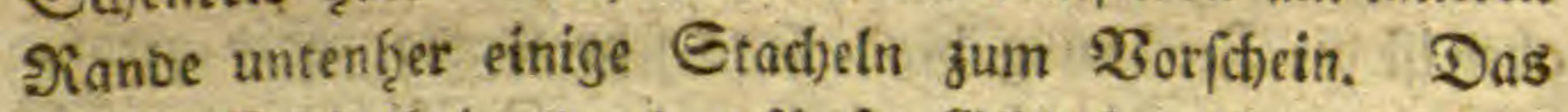
jwente Echienbein ober bas funfte (Jliebchen ift ctrons fuit: zer als bas erfte, bủnner und am innern $\Re a n b e$ mit grvels Sieif̧en brauner anfeg̨nlicher Etad)eln befezt, weicfe mit ibgren Epił̧en gegen das Enbe des Jutres zu fef̧n. Das lejte Jufiglieschen oder oas fufblatt enolich), if etwas ge(blid) von farbe, fdjwad) feulenformig, uno ḩat am Enbe zwey fobarze gefrummte fleine fubflauen, unter weldien nod) ein fleiner, gegen felbige nad) aufwairts gebogener Fort: fạ jum Borfdhein fơmmt, uno bazu beftimmt ift, um ben Raub defto fefter Galten zu foinneh. Die binterften greey paar Jüffe Ģaben alle ₹g̨eile Des erft befdriebenen, uno ift 


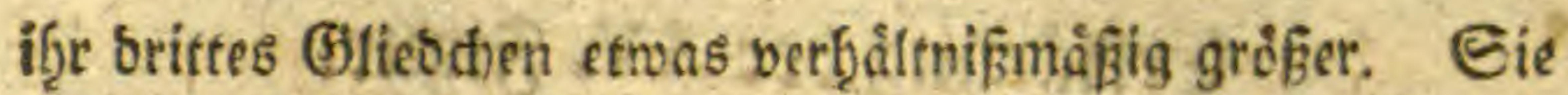
fino um bie Scálfte türze:, uns sie Gtad)eln feb̨len fowob̨l am erften als zroenten Edienbeine gånglid), bis anif jwo

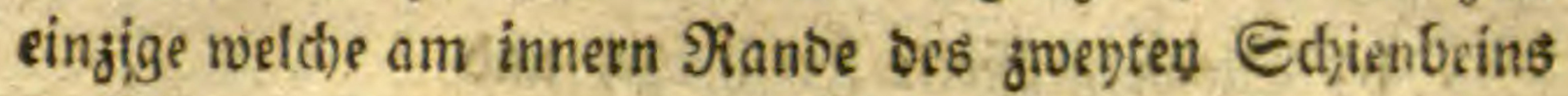
zu Enbe anfigan.

Diefe Spinne iff felten, uno wiro im Nonofge Nai, auf veridbiebenen PJ fanien, theils in, theils unter ben Blu. menfronen in einem unorbentlichen (Jemebe gefunben. Eie ift fefr bojz uno beifet in alles, was man ibr nur immer

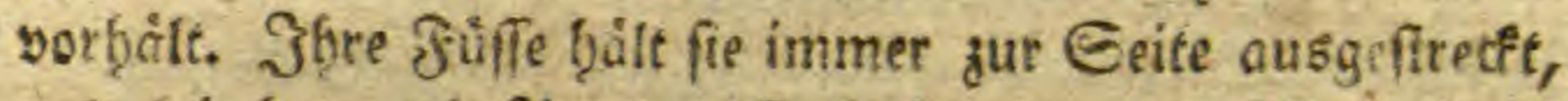
uno fricthet noci 2(rt bet Rrebsfpinnen bes Ritter sinne' (Phalangium Liii.) balo vor, balo rúdfwárts. Edfnell Iauft fie niemals anthalteno fort, ood) mad)t fie, wenn man biefeibe ftơret, balo f̧in, balo ber einige feģrfthnefle Ed)ritte, bleibe aber bann alfogleid) wicber ftehen. Gie fann feḩe lange f̧ungern, reil ich siefelbe of̣ne alle शlaḩrung ùber ein viertel Jab̨e in einer Jlafdhe eingefdloffen bุatte, swi= fthen weldher Beit fie sod) nod) faum merflid) einfiel,

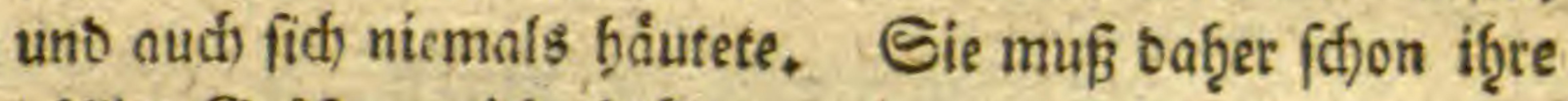
bo̊llige (5ro̊fe erreid)t baben.

Id) ruirbe biefe Epinne für bie Reldfipinne bes פits ters Sinne' (Aranea Calycina Lin.) Ģalten, wenn efwas gelb. lich wåre, unb ib̨r bie jnen roftfarbne flecten born am Scinterleibe fêţlen moichten. 2(uch) felbft bie Aranea Osbekii bes fererrn Ecopoli fann fie nicht fenn, weil fie feine fo grofie 2fnzabfl von Punften befizt, uno es fheinet ùber Ģaupt, baß bie Beffimmung tes Sitters von Sinne, im

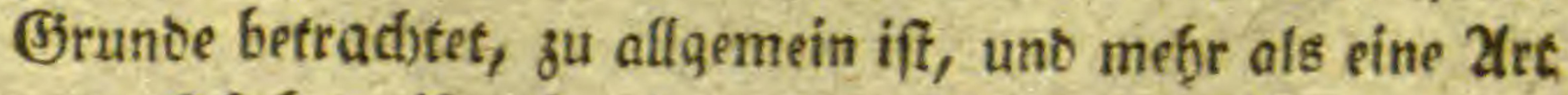
unter fich begreifet, fo mie es bey vislen anbern bunflen Dr. ten bon if̧m zु gefdhetgen pflegte. 


\section{Erfflirung Der XV. Figur.}

a) Ein bergro̊ß̧etter $\mathfrak{Z}$ orberfuß.

b) Dievorgro̊ßerte F̧reffipiz̨e, unb

c) Die vergro̊gerte Rinnlabe an weldjer man uniten

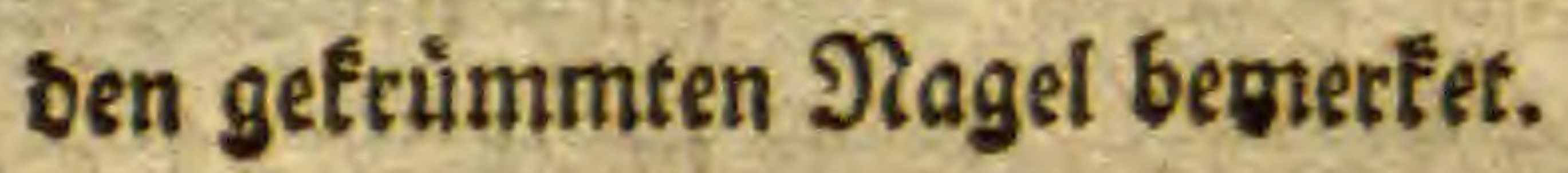

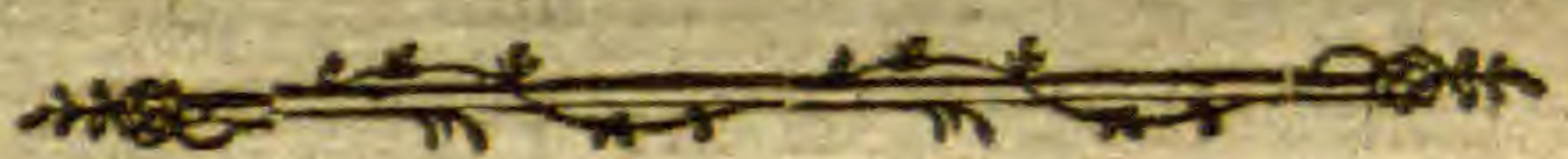




\title{
IX.
}

\section{Be(f)teifutugen und 2(66ilbungen}

\author{
Derjenigen \\ Iniffen,
}

weld)e in Sammlungen nicht aufáubervabren finb, Dann aller, Die nod) ganz neu, uno fold)er, won De: nen wir nod) Eeine ober Dod) febr (d)ledtete 2 (b; bildung Eefikgen.

Dritte Sammlung.

アon

Johann Daniel \$renEler. 


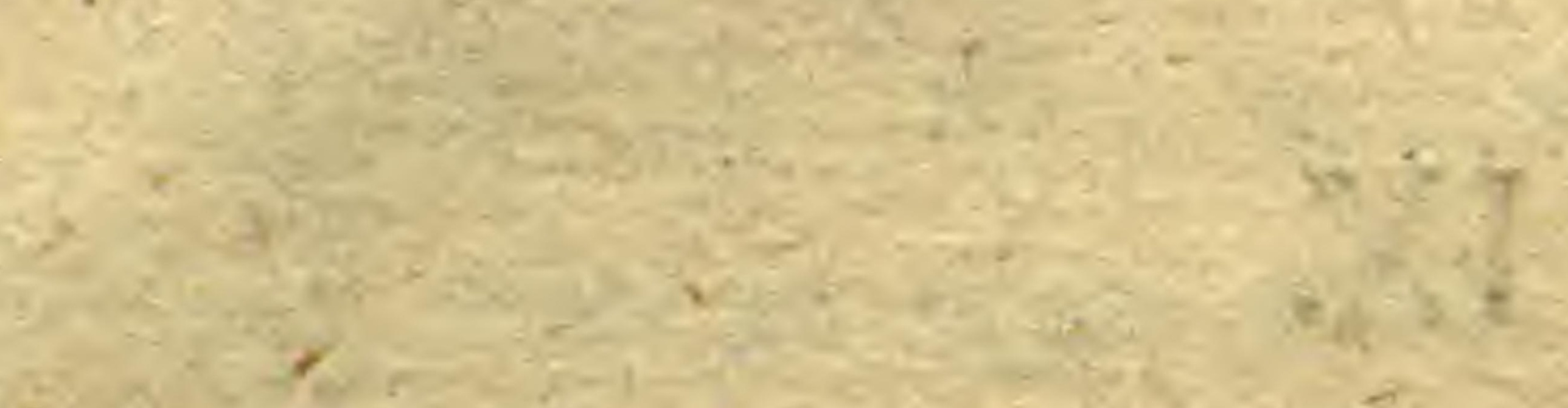

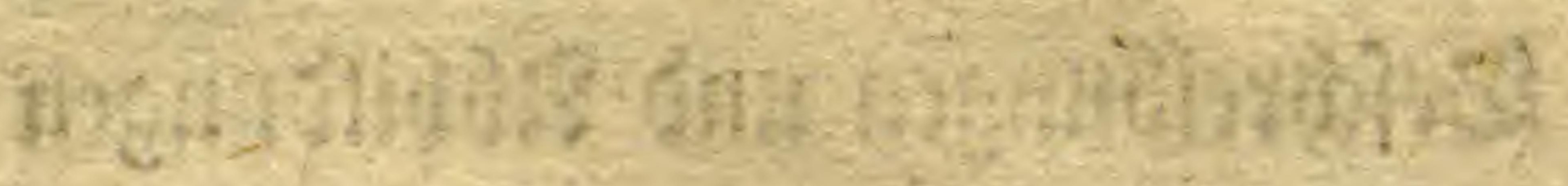

$$
\begin{aligned}
& \text { jughatis }
\end{aligned}
$$

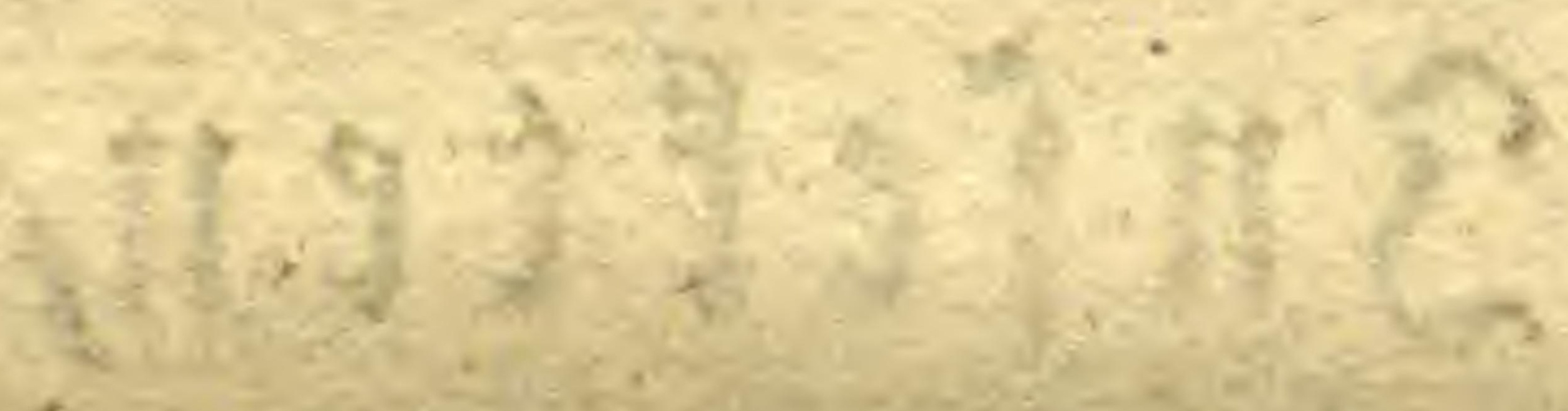

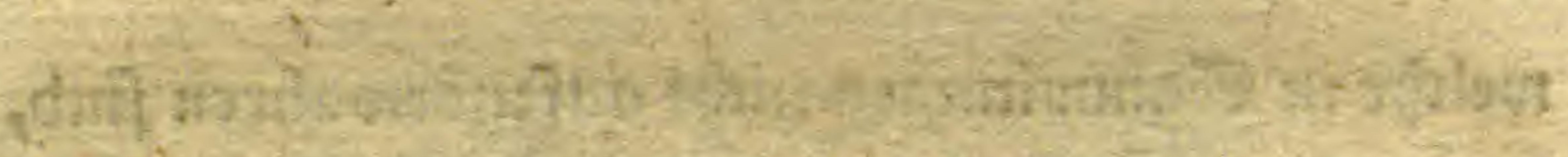

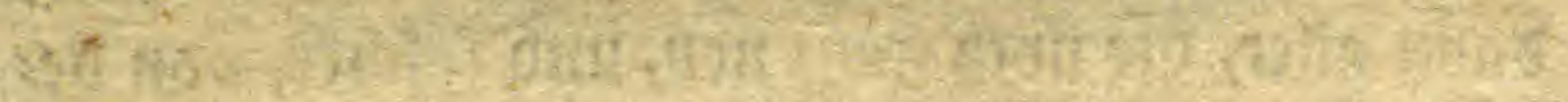
a. Qhe

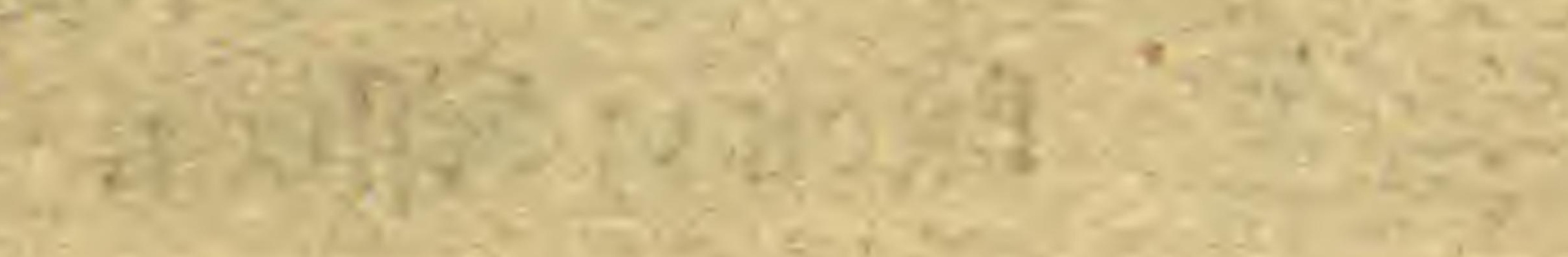

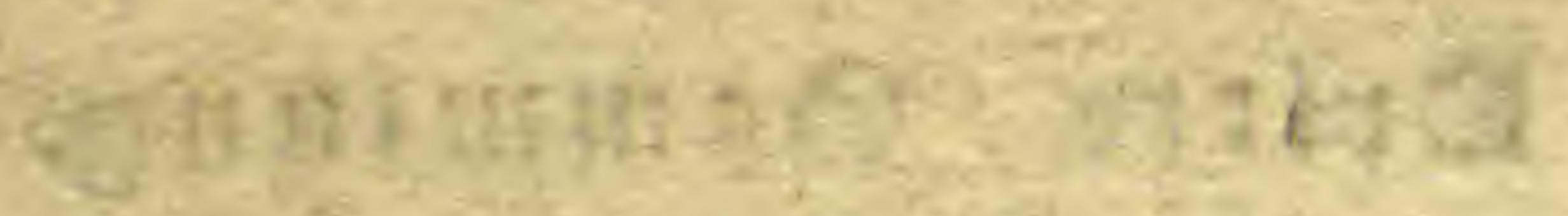

$$
11:-25
$$

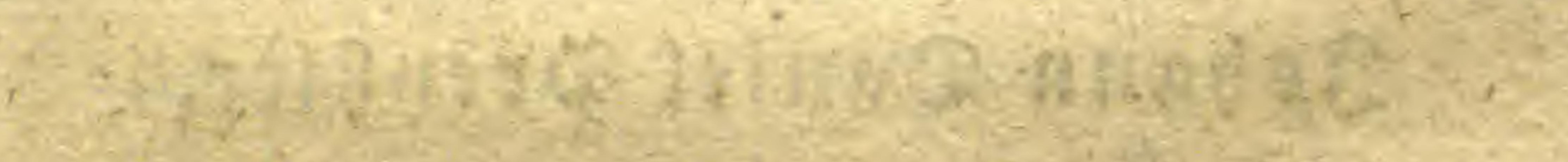




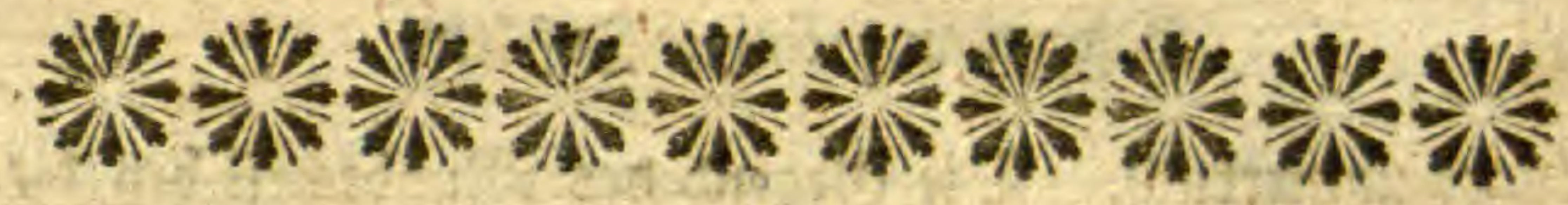

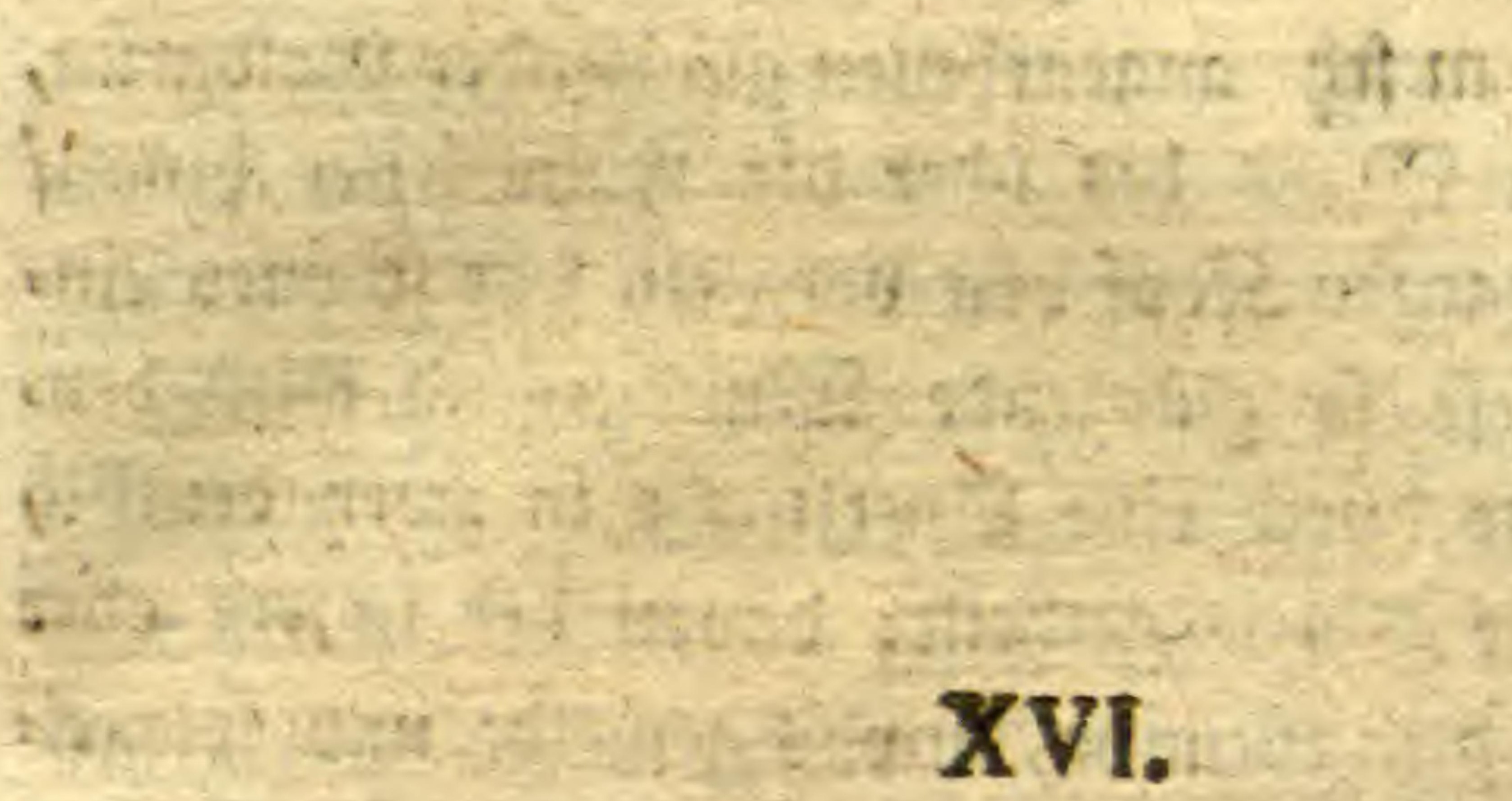

Mufca rofrata. Die Ectnabelfiege.

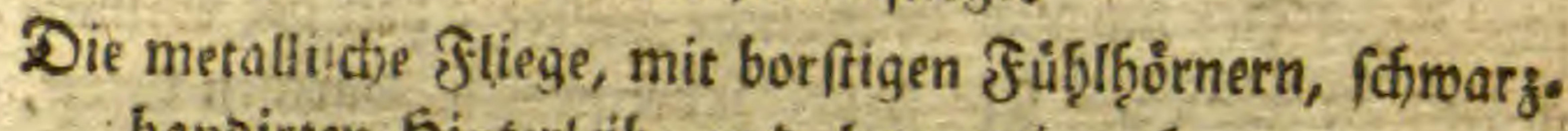
bantirten f̧i interleib, uno ḩornartigen ḩerausragenden f(t) ar zen Nunt.

Mufea antennis fetariis ænea, abdomine nigro fafciato.

S ie Singe ser ganzen flliege betrågt etwas ùber żwe" Sinien. Der Sopp hat, menn man benfelben ven yorn betract)tet, wegen bem ein werig eingefenften f̧intere haupte und bem Gerbortretenten Miuno, eine Gerjforrmige (Sea

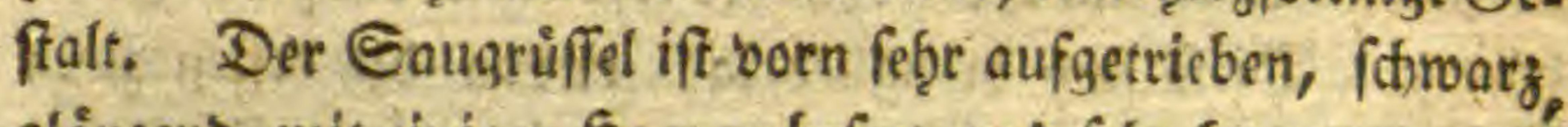
glånzent, mit einigen f̧aaren befegt, uno fegre berausragende. Berm erften 2 (nblicf follte man faft glauben, Diefe Sfliege balte ein fchwarges Siornchem ober fonft einen fleinen glän: zenten runben Siorper am Munbe, fo unfortmlic) grof ift

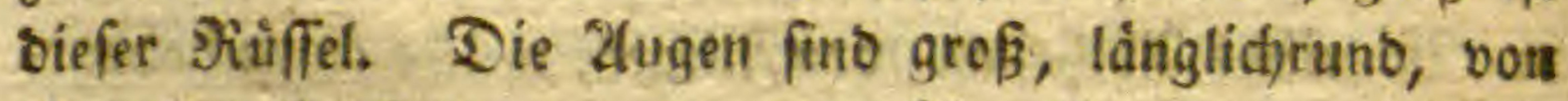
einanter abgrfontert, gegen bem Şinterhaupte etwas ùber baffelbe herbortretent, und pon einer metallifthen Jarbe; fo gmar, baf ber untere. Sheil, ober jener weldher bemt Nunb jufief̧et, grùn, Der obere aber ins braunrotbe fáltt; benoe frarben aber werben burd) feine Brainglinie von ein. anber getrennet, fondern fie verfliefen gegen ber MRitte des 
Zuges unmerflicf. Die (segent bes Miunbes ift been bies fer Flliege von einem feb̨r angeneţmen glängenten Jjologruin, welches fich vom Muno bis ùber Die frùblį̧orner b̧inauf

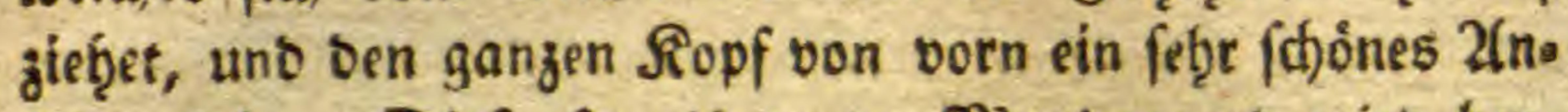
fȩ́n giebt. Diefe fo glänzenoe Minnogegend wirto bey.

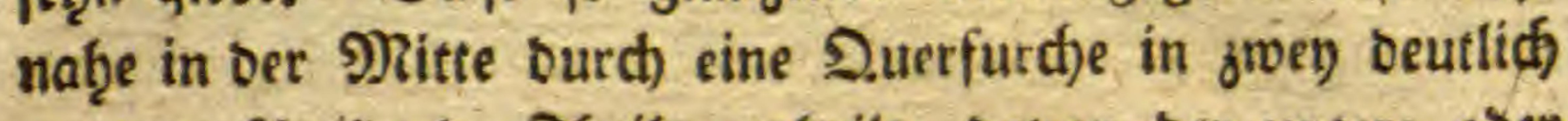
zu unterf(d)eibende ₹b̨eile getb̧eilt; Davon ber untere obee jener gleích ủber bem Nunbe, etwas gerooilbt uno fpiegeb glänzent, ob̧ne allen Bebaarung, und ofgne Punfte ets fdeinet. Der Daruber befinoliche anbere ?heil ver Miuno.

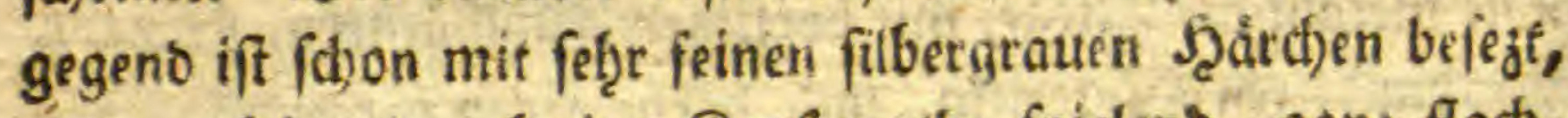
zart punftiert, meb̨r ins אupfertotbe fpielenb, ganj flach, uno ift gegen ben erften ₹ heil zu fogar efwas engeotuldt.

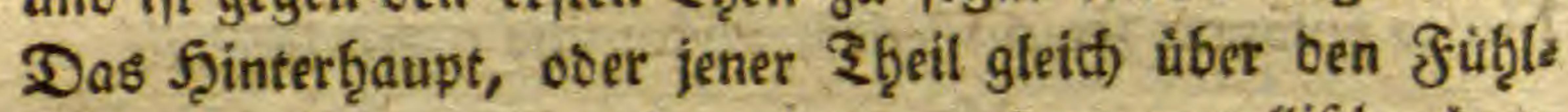
f̧örnern, biat zwar nod) etwas von bem metaflif(t)grùnen Btange ber Muntogegent, es iff aber viel matter, meţe ins graue falleno uno feb̧r b̧ăufig mit zarten grauen J̨ărd)en befegt, welde meiffens turfache fino, warum fidf ber (Blang

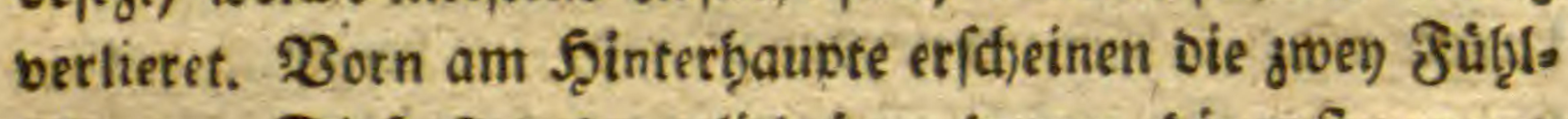
Gootner. Diefe fino brenglietrig, bavon bie erften jweis (Glietchen fệr furz, biff, oas britte aber långlid)runo ers foheinet, une an feiner Epize eine lange einfache borfte

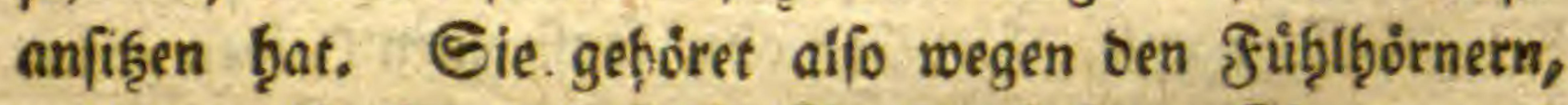
unb bem mit einzelnen fteifen Borften befegten אörper unter je eie linneifthe 2 bbtḩeilung von flliegen, weldte einen beţaat: ten Rörper uno eine einfache friblthornborffe (pilofx feta-

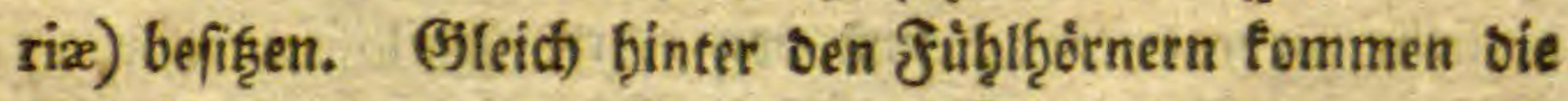
bren Nebenaugen jum $\mathfrak{B}$ orfhein. Eie finb eitres vom atth beren jiemlid entfernt, unb habeen jwifhen fid) grwey nads auswärts gefrummte ftarfe Borften fig̨en, gegen weldfe fid groen antere, jeberfeits am innern 2tugenranbe eine, 
gleid) neben ben গtebenaugen ftrimmen. Der शacten ift

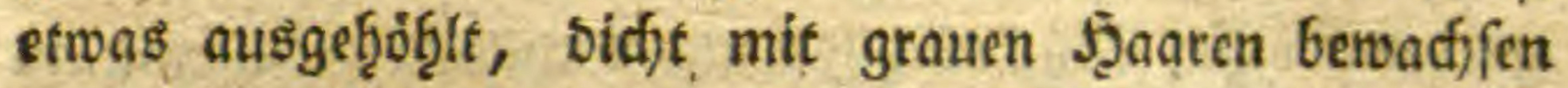

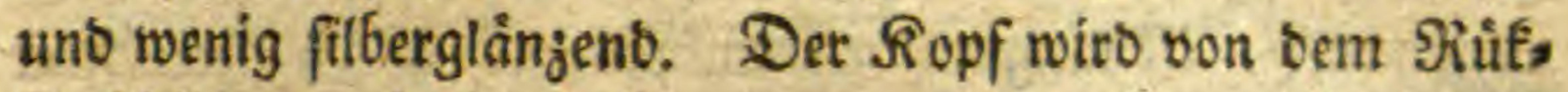
fenf(h)iloe burcf) einen bünnen uno runoen furzen f̧als ge:

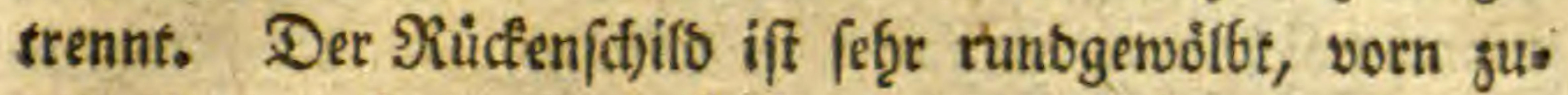
geruntet, mef̧e lang als breit, uno ber f̧interrano bilbet vier Ecfen, inbem bie Jwey Şinterecfe bes hiintern গians bes gerabe abgeffonitten erfd)einen, mithin fino bren fleis

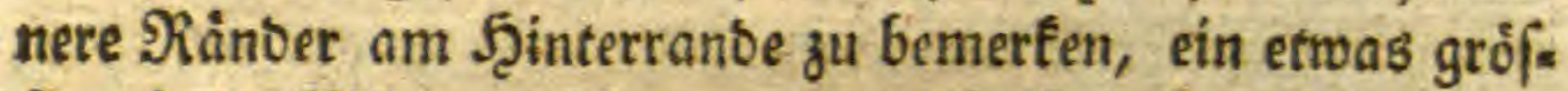
ferer in ber Mitte, welcher gerabe nad) rúdfwárts fieb̨et, uno zu jeber Seite Deffelben noch) einer, ber ebenfalls nach ruicf: wairts, aber audf jugleí() feitroairts gerich)tet ift. Die ganje

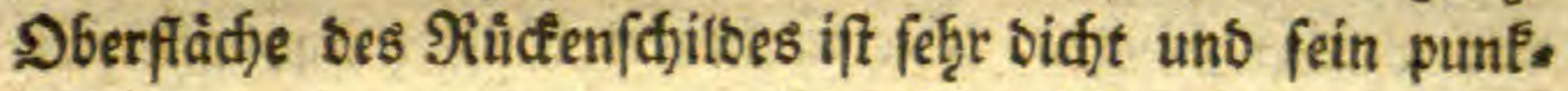
tirt, von einem matten graublaulid)en Metallglanze, mit einzelnen furgen grauen, unb ḩin uno ḩer mit farten efroas

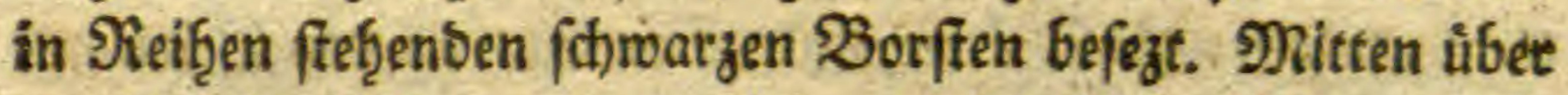

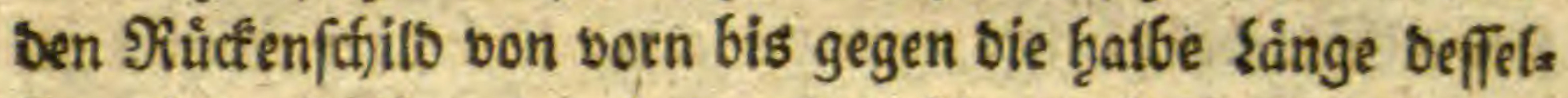
ben lauft ein braunes ins golbfarbige glånzenbes $\mathfrak{B}$ anb,

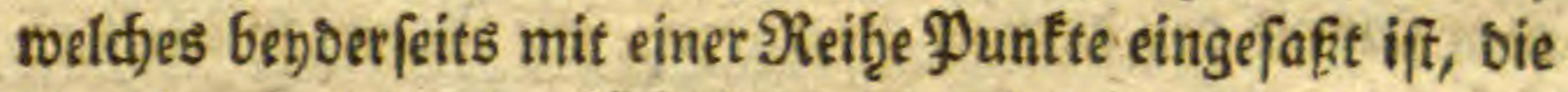
mand)mal ein graues f̧ärdjen bon fich) taffen. Mitten in biefem 2 anbe befinbet fich eine vertiefte sangsitinie, weiche

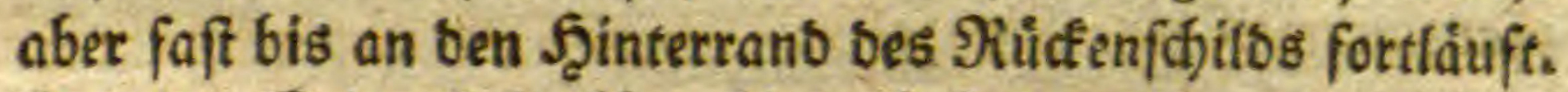
ล" jeber Eeite biefer \{aingsbinbe befinbet fid) nod) eine an. bere gleidffårbige; biefe ift aber um vieles länger, unb gee gen ben Dberranb bes Siucfenffiltoes viel beteiter, uno bie S) Rittelbinbe fofeint fid) an if̧ren Enben in grvely 2(rme zut theilen, wo fie fidf mit ben zroen Eeitenbinten vereinigt. Das Scfilbd)en ift um vieles breiter als länger, gegen Den f̧interrand zu gerunbet, filbergrau, glängens, fo breif

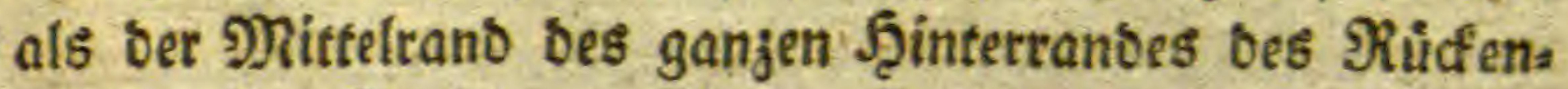

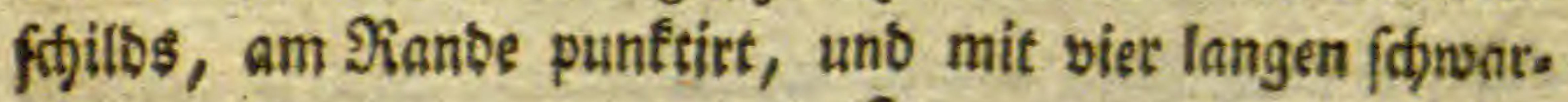


zen fteifen Borften befezt. - Der J Sinterleib ḩat sie län=

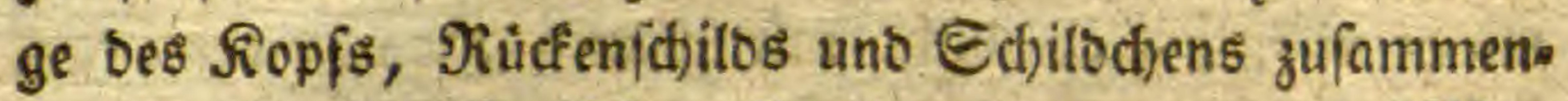
genommen, ift lainglidh enformig, uno gegen ben Iffter ziemlid) zugefpizt. Seine farbe if ganz filtergrau, mand)mal mit einem fudffigen Gilanze, uno bie গRingein

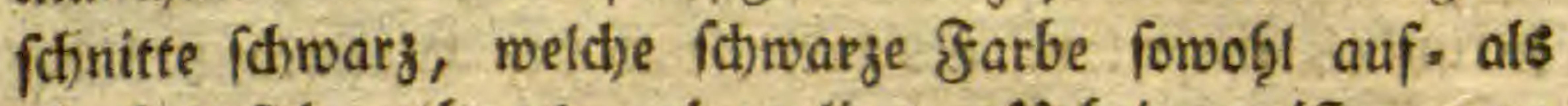
abroàrts fich nach) uno nach) verliert. Uebrigens ift ex gang

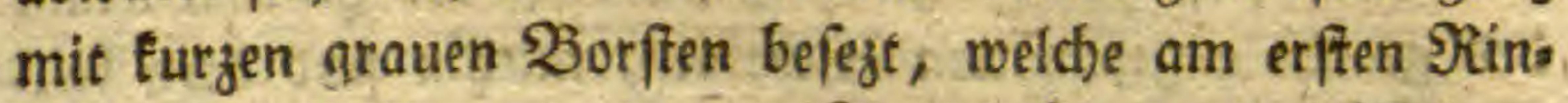
$g e$ in vier Neihen, uno vom Scinterteibe gerabe abftetgen; auf bem folgenten aber von benben Seitentbeilen bis STine terleibes, meiffens gegen einanter gericfitet finb. - Die Saiffe fino lang, bưnn, braun, unb faft unter einanbet von gleicher sainge. Die Edjenfel fảulformig, mit feth fen furjen Şärdien berwachfen, gegen bas Enbe braun, übrigens aber gang fofwarz. Die Edfienbeine und bie langgebef̧nten füblatter fino vierecfis, an ben Ecten mit feinen Stacheln befejt, gang braun; bod, aber ùberall ges

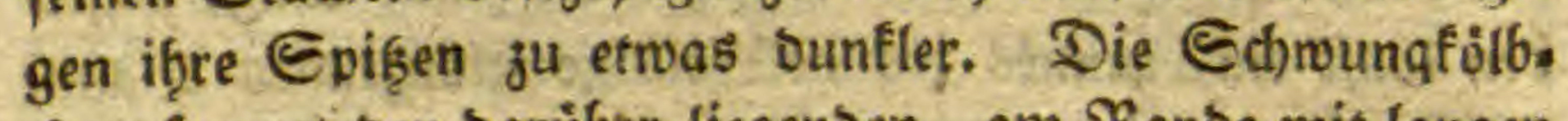
den fammt ben baruber liegenten, am Ranbe mit langen Şärchen gefäumten Nufdeln, fino weiß, bie flügel um vieles länger als ber f̧interleib, breit, mit einem fhoinen pfauenfdb)eifigen (Jlanze.

Eie ift im Nonate July uno Zuguft gemein. Id)

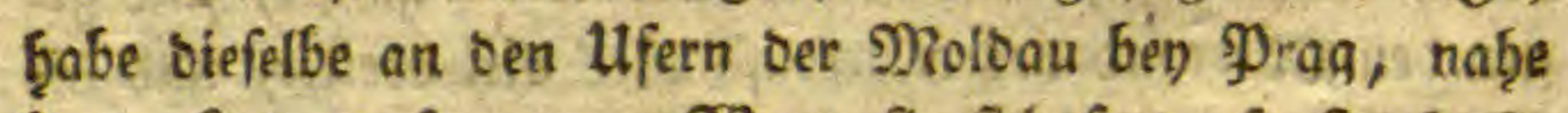
beym Syolze gefangen. $23 e n n$ fie fith fejt, fo frectt fie Die frúffe fehre weit vor fich bin, unt freget gleidifam auf Etelgen, und bie Slůgel liegen Dann etwas Dadfförmig. 


\section{XVII.}

Silpha denticulata. Der gezáf̨nelte Brabfáfer.

Der braune Grabfäfer, mit einem an ben Eeitentänberk

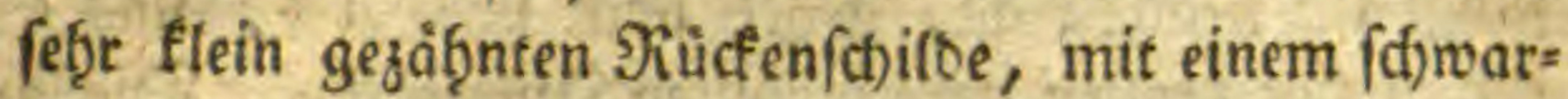
jen Jlect, fotroargen glänzenten flügelbecten, mit

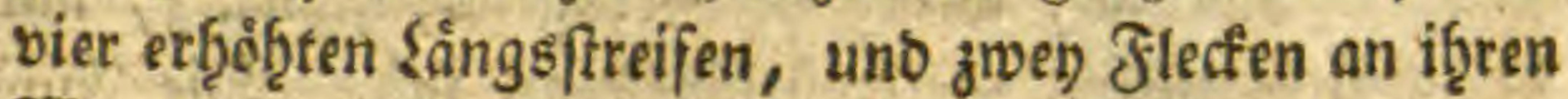
2Burzeln.

Silpha fufca, thorace, margine laterali minutiffime dentato, macula nigra, Elytris nitidis, ftriis quatuor Jongitudinalibus elevatis, maculis duabus ad bafin ferrugineis.

Ips. Sabr.

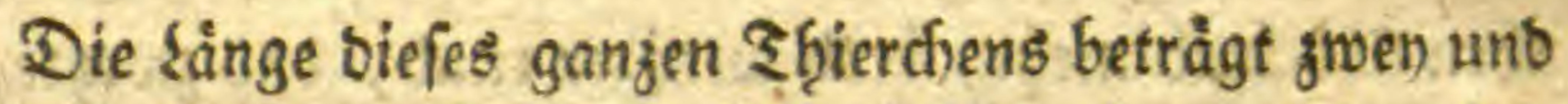
eine Galbe Sinie. Geine Beteftalt ift fȩ́r platt, uno weber ber untere, nod) obere ₹̧̨eil ftartfer gewèlbt. Der Ropf bat, bon oben betraditet, eine orenectige platte (b)eftatt, ift rotḩbraun, glänjend, in ber Mitte etwas bunfler, ges ranbet, uno ganz beutlid) mit פunften befezt. Die zwer Eeitemanoer bilben gleidf) úber ben 2lugen einen runben Zfusbug, uno bie Sóerlippe if gleidfalls zugerunbet. Mithin fino bren neben einanter ftehente 2lusbuge am Sopf bemerfbar. Einer in Der Mtitte vorn, Der bie Dbers lippe madfit, uno greng nidf)t viel fleinere gleid) tarneben, über jebem 2luge; man fann alfo ben gangen votbern uno obern ? Geil oes Sopfs, (d)wadi) brenlappig nennen. Uebri. gens fino nodh brel Jurdien, an ber obern ganjen Ropibs fládhe ju bemerfen: eine fleine montoformige, meldie fíd) an ber Dberlippe ober bem vorberen 2lusbuge befinbet,

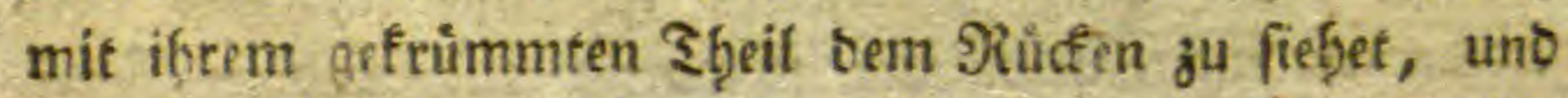

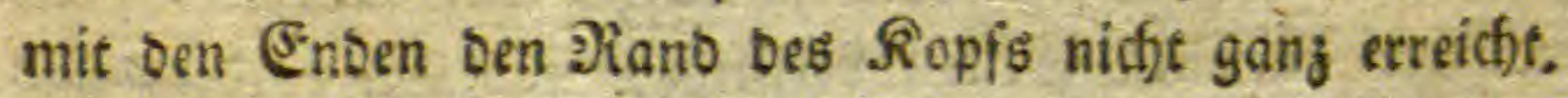


Eine anbere låuft vom åufierfiten Sianbe bes einen Eeitens ausbugs, bis zu bem anbetn quer hertiber, unb eine britte enblicf) låuft in ber Mitte bes Ropfs in bie sånge. Sie fängt im Nacten an, geţet nach vortwairts, uno enbige fich in ber großjen vorerwåh̨nten Duerfurdje. Die 2fugen fino långlidjruns, wenig ḩerborragent, fofwarz, uno ḩas

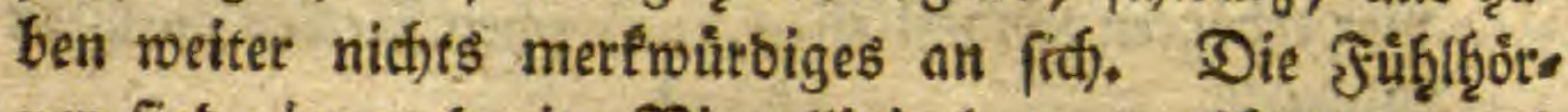
ner finb eine unb eine Biettellinie lang, rotb̨braun, perff(d)nurfơrmig, puntétirt, uno mit feinen gelblid)rotben

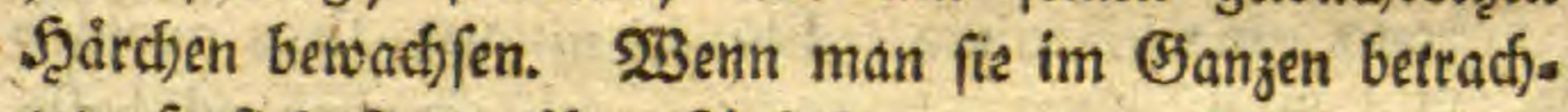
tet, to fino fie an if̧rer 2lntefeftung uno gegen bem Enbe zu am bicffen; weil bas erffe uno bie vier lezten Stlieb. d)en berfelben, bie grofften unb bicfften finb. 2ulfe (J)lieb: den finb balb meโ̧r, balb wentger runs, bas grwente, von

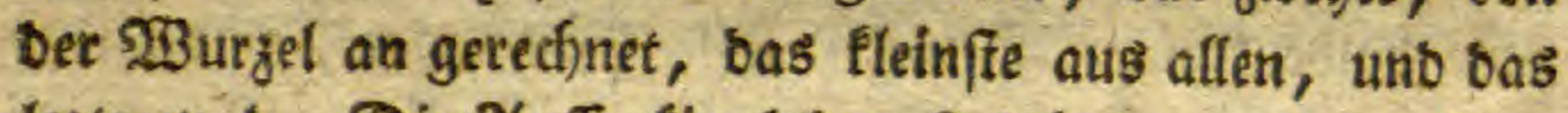
Iezre obal. Die 2tuffenfinntaben fino ḩerbortageno, furs,

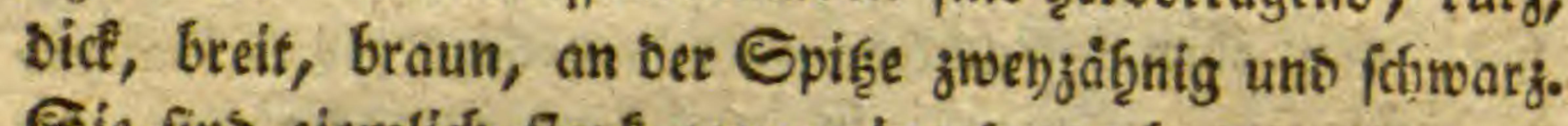
Eie fino giemlidi) ftart' gegen einanber gebogen, uno mit zarten, faum fithtbaren Jgätchen benachfen. - Det פiucfenffbito ift von bem Scinterleibe burd) einen fȩ̣r fur. zen Scals getrennt, Er Ȩat eine vieredfige Geftalt, ift breiter als langer, getanbet, binten etwas ffjwácjer als. born; aber alle vier Rånber fanft ausgebogen. Die zwen Seitentánber ḩaben biefes bejonbere an fid̄), baß̧ fie fünf fef̧r fleine Båt̨ne bilben, aus weldfer Utrfacte ich) biefem

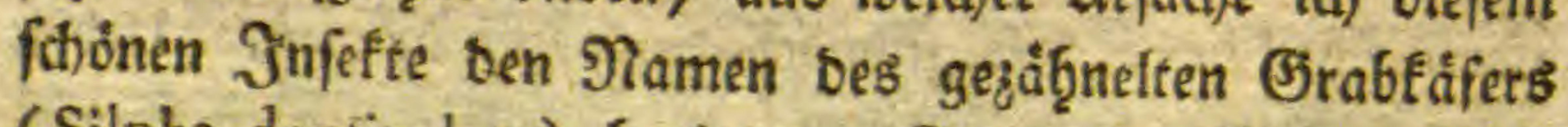
(Silpha denticulata) benlegte. (S)egen ben beyben Eei. bentånbern bes Siúcfenffdilbes, befinbet fich ein breiter 23 ulf. Die ganze Dberflåd)e ift punftirt, uno vorn

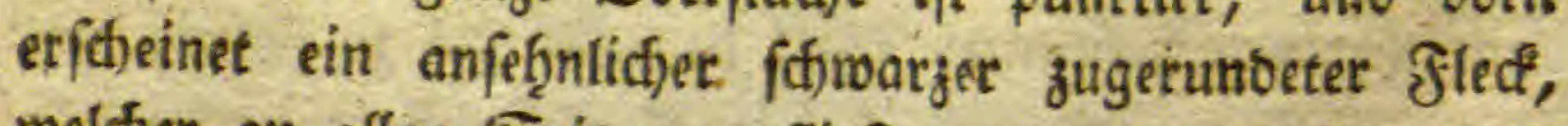
meider an allen Seiten verfließ̧t, und ben vorbern uno 


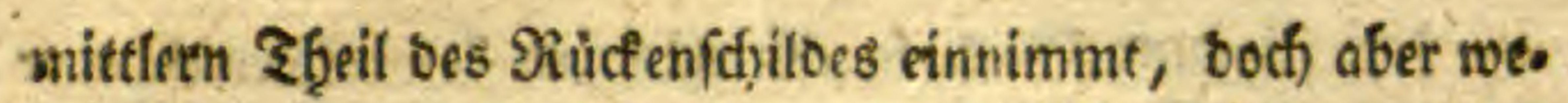
Der vorn gang in Den $\mathfrak{B}$ orderranb, nod) beyberfeits an ben mulftigen ₹beil anfto̊ft. - Das Edjilod)en ift rofffar. big, ftumpf zugefpizt uno giemlid) beutlid) zu unter(d)eia. ben. - Die Flůgelbecten finb platt, bebecfen ben gans gen Şinterleib, frarf zugerunbet, etwas meḩe benn zmer)s

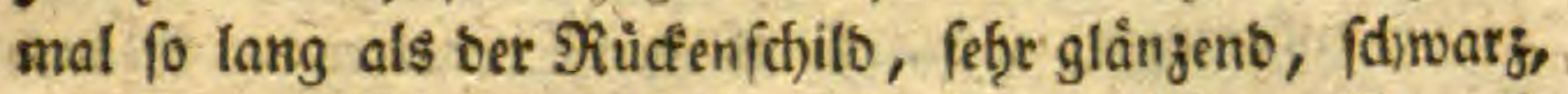
mit viet erb̧öbten in bie länge laufenben sinien, bin unb wieber jart punftirt, uno mit jwen anfeģntidjen, grofien, langlid)bierectigen, jugerunbeten bunfelroff farbigen Tflecten nab̧e an if̧ren \$urzeln gezieret. Nan muß bie flúgels becfen felge genau betrad)ten, wenn man bemerfen wifl, baß fie erb̧ơht geftreift fino, weil fie ben einer gerwiffen Berånberung ber barauf faillenben Sidftftralen, fo fef̧r tåu. faien, Daßz man fictier qlauben follte, fie wáren fẹtr tief gefurdft: - Die Jüffe fino braun, furg, bon gleider sánge, etwas platt. Die Echentel bič, feulenförmig, mit feinen f̧ård)en befejt, gegen bạs Enbe zu mit einem fleinen Etachel verfeben, uns von fdwwader feilförmiger Beftalt. Die Jugblätter fino fệt zart, uno beftef̧en aus vier (Sliebdien, bavon bie etften orene furz, fegelformig, gegen Das Enoe bes Juffes immer fufenweife an Bro̊ge abnebzmeno, bas lejte aber feb̧r gebebnt, unb ebenfalls feilformig erfheint. Die Rlauen fino flein. Die Flüget.

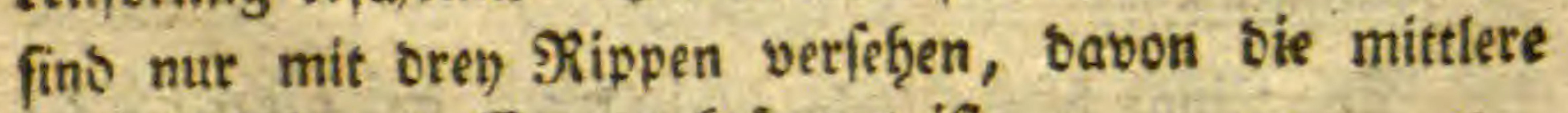
bqafenformig am Enoe gefrummt ift.

Der 2fufentb̧alt biefes Infefts if mir unbefannt, ins bem id) es nur jufällig auf meiner Erube, im פlonate 2luguft gefangen babe. Den linne'ifdjen Renngeidien nach), geboirt es ju ber Battung ber Brabfäfer (Silpha Lin.). Nach bem Enfteme bes Jeern Fabrigius, glaube 


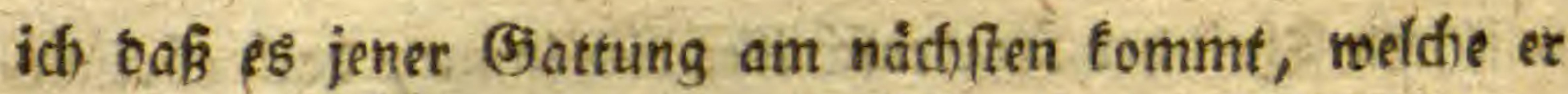
Ips nennt. Frewlid) b̧at es perlichnurförmige fJübltbơrner, (antenne moniliformes) uno eg follee surd)blátterte (perfoliatze) Gaben. 2(ber wer weis nicht, wie trüglich die früblo Georner jur genouten Beftimmuna der Battungen fino, ba

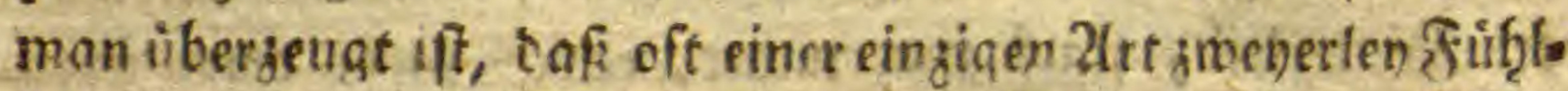

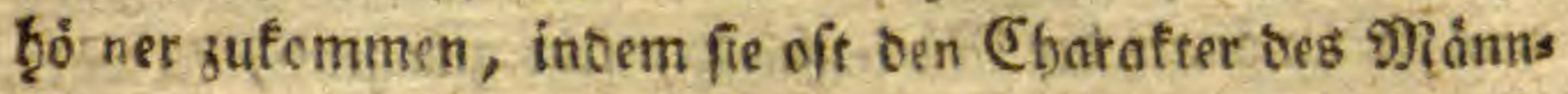
d)ens vom 2 Beibchen ausmachen. Doch wage id) es nicht

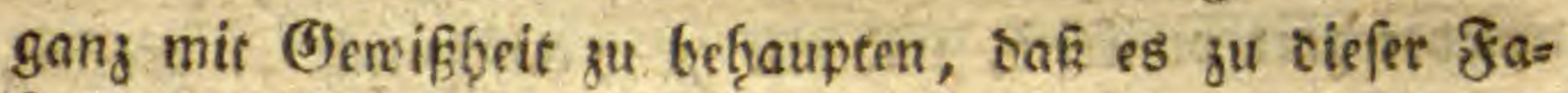
brigiffyen (Gattung gefeore, meil bas Infeft zu jelten uno zu llein if, um es einer genauen Ltrterfuchung gu unters jiegen, inbem man die frefinetfjeuge vom Ropf trennen mijpte.

\section{XVIII.}

Pbalæna (Tinea) compofitella. Die jufammengefejte Mrotte.

Die Nact)tfaltermette mit braunen Flingeln, uns einem aug vier sinien zufonmengefejten firbernen গiúcfenflef. Phalren (Tinea) alis fufcis, macula dorfali argentea e frigis quatuor compofita.

Fabr.Syft. Ent.p. 663.G. 147.Sp 46. Tinea compofitella. Car. de Villers Ent. Linn. T. H. p. 501 . Sp. 964 . La compufée.

Die länge viefes fleinen nietlidfen Machtfalters bee erảgt zwen, uno die Sreite von einer flügetípige bis jur andern, im ausgebreiteten Suftante, vier Sinien. Der אopf if flein, jiemlich, vom Brufftucf gu unterid)eiden, runo,

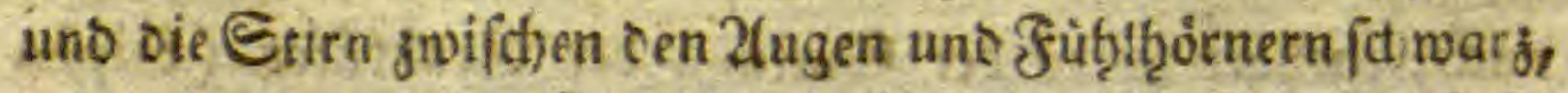
mit vielen soiffen Jecoerd)en oft fo Dif befezt, Daß fie 
ganz meiß ausfief̧et. Die Ifuzen fins fchmargbraun, zut

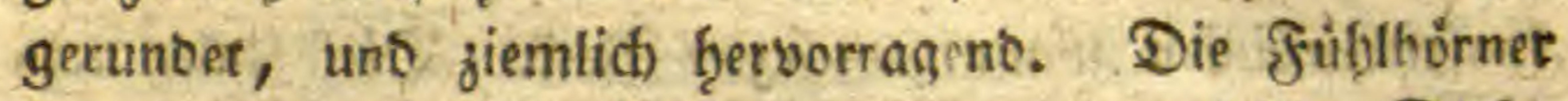
fino farf, boxftenformig, faft surchaus von gleicher Diafe, fotwarggrau, uno jectes eingelne (Stlieod)en fdient in -ois Sànge ueftreift zu fenn. Gie fraben bie sange bes fiòmers. Die frefipizen fino aufwátrs uno etmas rúcfwárts gea frumme, gegen bas Enve zunefpijt unt brengliebrig. Das erfte (Glisodjen, obet jenes an Der 3 burzel, ift bas fleinfte, bas gwente nod) einmal fo lang, bente weif, uno tas lejte, befonbers gegen oas Enve uno oen Rorberranb zu, mit băufigen weiffen Jeoerfotupphen befegt. Das lejte Blieoden iff runb, etwas fürjer als tas jwente, unb jus gefpigt, an ber ciuffern Eetite faht uno fobmairglid, an

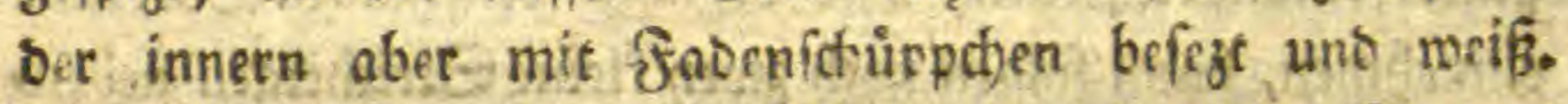
Das jwente Paar, von fref́pifsen, weldhes ben Miotten. gattungen, afs ein Sauptennzeichen bon fyerrn f̧abrizius beyalegt wiro, fonnte id nidit finoen, uno es ift aud faft Ulnmogglidhfeit, megen ber Rleinkeit bes Ropfs, Dafe felbe-ju fuchen. - Das 2 uffticf iff runs, graubraun, metallglänjeno, une bat nichts merfwuirciges an fids. Der fointerleib etfoldeint fpinoelformia, jiemlid) juacipizt,

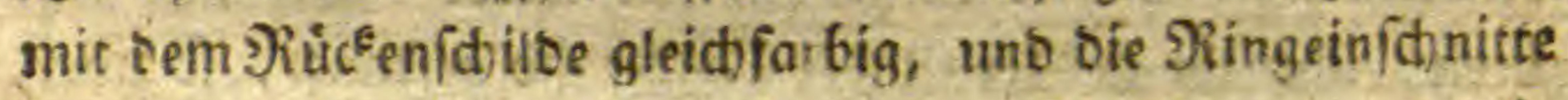
fino faum fict)bar. Die Sberfliget fint fo lang als die Mette felbft, von gewoobntidfer Breite, ber Dberrano faft gerablinigt, ber 2luffenrano etwas jugerunbet, uno bet Unterrant anfangs fefoe fifwach ein, bann aber mebge ges gen ben Sórper ju wieter ausqebogen. Die Brunbfarbe

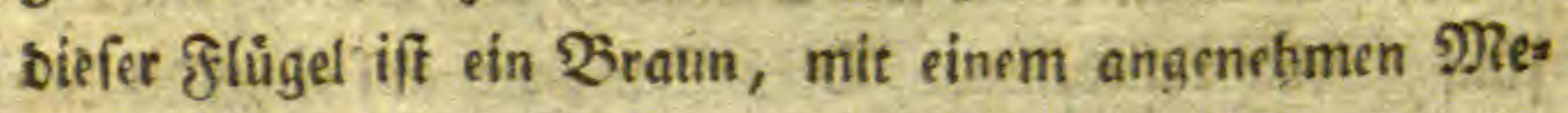
tallglanje. Bom Unt rranbe eines jeten Sberfigigels, etwas ůber feiner halben länge, gegen ben 2(uffentano 
su, befinbet fich ein vierectiger, weiffer, aus biet parellelo faufenten Sini n julammengefegter Flect. Diefe Sinien neţa men afle binter einanber ibren Urfprung am Unteranbe ber Sberfligel, unb laufen (d)ief nad) auf unb auswairts,

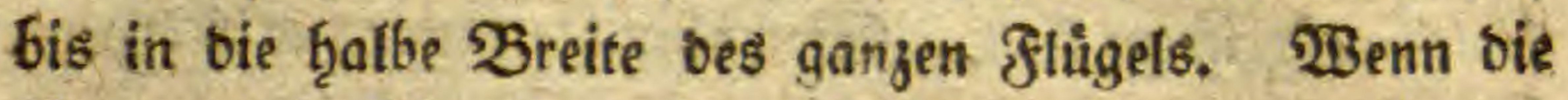
Niotte Diefe Dberflugel beym Sif̧en zufammengeffilagen Ģält, fo madien bicfe zwen Flecten einen gemeinfdhaftl. c)en länglict)vierectigen Flecf zufammen aus, uno weil Diefer fflecf aus Sinien zufammengefegt iff, gab J̧err ffar brizius ifge ben शamen Tinea compofitella. $21 \mathrm{~m}$ Dber: ranbe ber Dberfligel befinden fich ebenfalls febre furge meiffe Striche, bavon fechs von sem Dberecfe anfangen uns Ginter einanber fteģen, uno bennab̧e ben b̧alben Dberranb einneb̨men, Dann folgen nod) zwen fleine Strid)eigen neben. einanber, weldhe aber etwas von Den ůbrigen entfernt ffea ḩen. Utebrigens ift ber Zuffentanb ber Dberfligel gan fdfroargarau gefranzt. Die thterfutiget reichen mit ibrem Unterranbe nich) ủber ben Şinterleib bुeraus, finb gang braun, wie bie obern, unb gegen bie - Mitte verliert fich biefe farbe ins graue, bas gegen ben Dberrano uno bie:

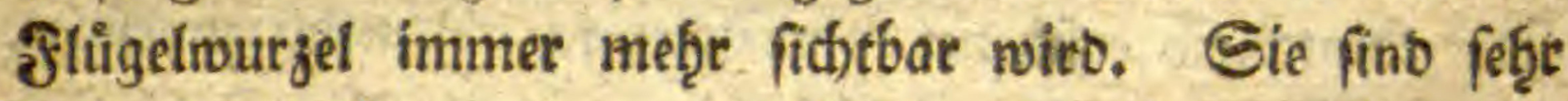
breit, uno ib̨e grofier runber Unterrano gefranzt, fo zwoar, baß bie freanzen gegen bas áfferfte Enbe des Ranbes, vorn ganj fdwwarzbraun, nach uno nad) grau, uns gegen ben feinterleib gu enolid) gar mild)weiß werben. Das vorberfte paar Juiffe if aus aflen ưbrigen bas fürzefte, grau, b̨at einen boppeiten Stbentel, ein Edhienbein unb

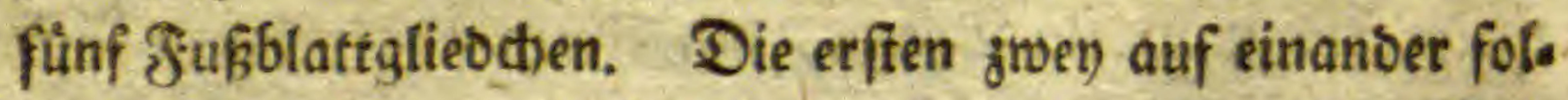
genben Sdientel fino f'åulenformig, bid, obgne alle Stae theln, uno unter einanber von gleidjer sänge. Das 
Erfienbein ift ebenfalls bicf, nod) einmal fo futg als ter Sdjenfel, an weld)en es angegliebert ift, ebenfalls feuls förmig; es madjt aber nach auswairts, gegen bas Enve zu, einen fidjtbaren weíggrauen Etacjel, neben weldfen noch anbere, aber viel fleinere, an bem Edjienbeinente anfif̧en. Jener গianb bes Sdjienbeines, weldjer, wenn Daffelbe an ben Sdjenfel angejogen wiro, Denfelben berîtho ret, ift gleidffam gegen bie Epiģe etras von bemfelben abgetópt, als ob ex angefpalten waire, vereinigt ficf abct balb wieber genau, uns man bemerft am Ģintern Piante Des Edfienbeins, nur eine fofrache in bie länge laufente Surche. Das Jußsblatt ḩat eine fabenformige, bas ift burchaus gleichbicfe Geffalt, ift aus allen befagten Sube theildgen bas bünnfte, uno beftehet aus fünf GSfiesd)en,

- Davon bas erfé bas gröste ift, von ba aber bie uibrigen, bis zum fünften ftufentweife an sảnge abnef̧men. Diefes fünfte Gliebchen if wieber etwas långer, feine Filauen fef̧r flein, uno ganz, fo wie auch) bie ùbrigen, f(d)wárglid) grau uno mit ftarfen Stachelf̧ärchen be feje. Das mittlere

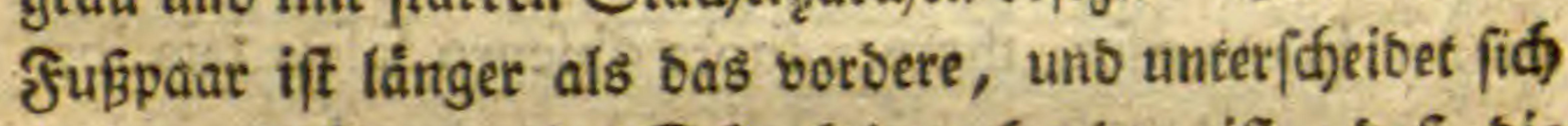
bavon, baß nur ein Eđientel vorţanben iff, baß bie Edjienbeine balb bie sånge bes Edjenfels faaben, uno an if̧ren Enben mit zwen langen Stactjeln befejt finto, oavon aber immer einer fúrzer als ber anbere iff. Die Fưfbläto

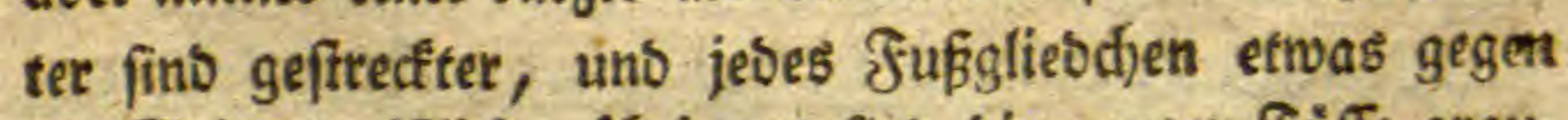
bie Epiłe weißllif), úbrigens fino bie ganjen fǘffe grau. Das legte Jukppaar ift enolíd, bas längfte aus allen. Syier übettrift bie sainge bes Edienbeines, jehe bes Edienfels um vieles, uno fowobgl an Der Spişe, als am innetn

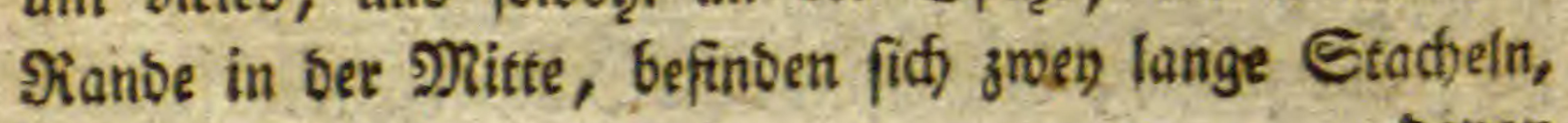


bavon einer länger als ber anbere iff, und alle mit if̧ren

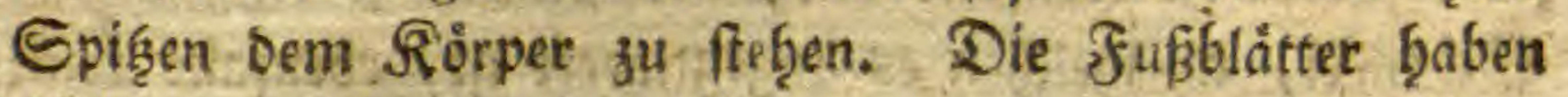
uibrigens nidfts merfwuiroiges bor jenen Des gmenten \$aas

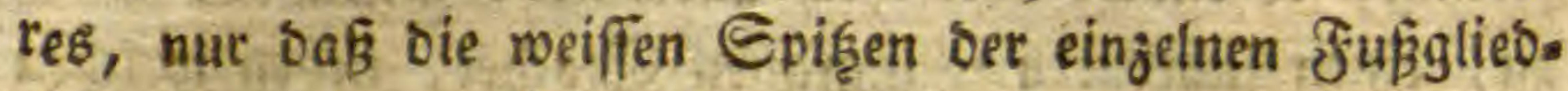
cjen beutlicjer zu bemerten fino.

Diefes ₹f̧ierchen if bey uns in sen Monaten Jult uno 2fuguft, auf bem gemeinen 20 gelnefte (Daucus fylveftris Lin.) nicht felten. Şerr Fabrizius fagt, Daß biefe Motte filberslängente Streife beabe, ín fann es nicht las. gen, weil fie an meinen Eremplaren immer ganz heís voro

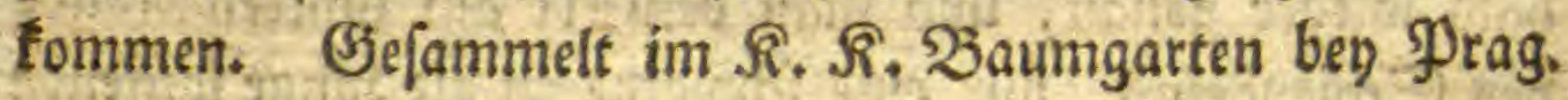

\section{XIX.}

Aranea folium. Die Slattfpinne.

Die braungraue Epinne, mit oberḩalb ounfeln, mit eis net breitern fotmufiggelbgrinen sangsbinbe berfefee nen Rưffenfduilbe, enförmigen oberb̨alb sunfeln, mit einem blattformigen flecten begeidineten Sointerleib, unb vier furjeren Sinterfüfen.

Aranea fufeogrifea, thorace fupra obfcuro fafcia lata longitudinali luteo-viridi, abdomiue ovato, fupra obfcuro, macula foliacea fignato; pedibus quatuor polterioribus brevioribus.

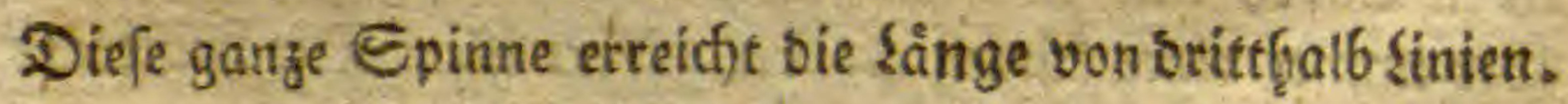

Det $\Re$ utenfchito ift fo breit als ber feinterleib, un= ten platt, oberbalb aber gerwolbt, uno weun man feine (Ges ftalt von oben betraditet, birnfórnig, fo, baß ber breitere

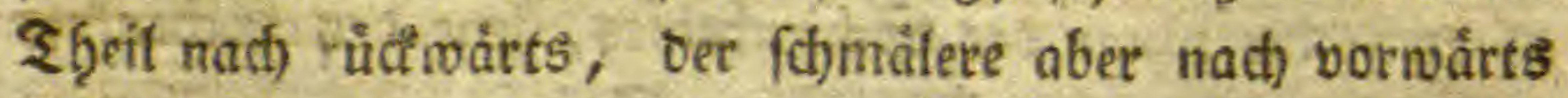
geri(f)et ift, uno ben Siopf ausmatht. Die fdiwarje etras ins graue follende Brundfarbe bes Ricfenfdiltbes fdeinet Dem 
Dem fremem 2uge gleichfam aus lauter fónargarauen, bicht aneinanber fteb̧enben Punften zu beftef̧en; nimmt man aber bas Bergrókerungsglas, fo wiro man gemaḩr, baf biefe 3eict)nung aus unoroentlicfen den arabifchen (Ęaral: tern niçt unáb̨ntichen flecten zufammen gefejt iff, unb oas von jene eingelnen fllectchen befonders mertwurtig fint, welche gleich) an ben zroen Eeitenrånoern bes Riùcenfchil. bes vorfommen. Eine fdfmuşiggelbgrùne bey mand)en Eremplaren aud) faft gang grùngraue breite Binbe fömmt

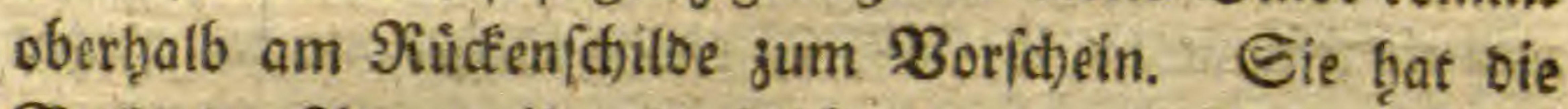

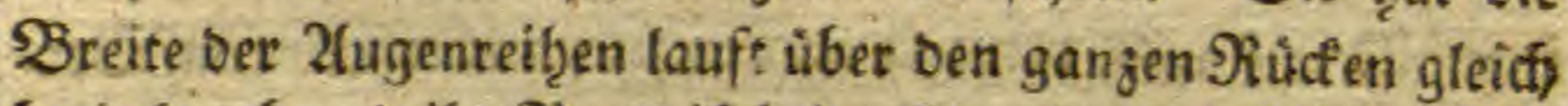
breit berab uns ib̨r Siano if beiberfeits unorbentlich gezåb̨nt. 2In biefer breiten Sinde fino noch) bren matte furge linien gu bemerfen, Dabon bie mittlere bie sangfte ift, welthe vom.

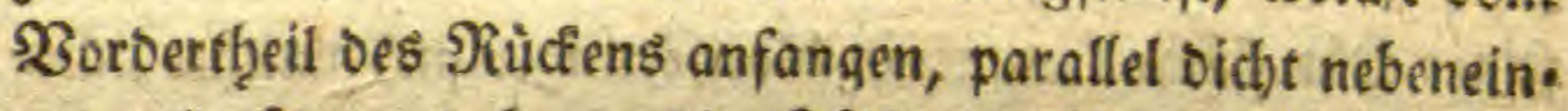
anber faufen, uno faum bie f̧ålite ber länge bes গRicfen. fhilbes erreichen. Das fonberbarfe von biefen bren $\mathfrak{B}$ in. Den iff, Daß̧ fie augenblicelicf) verffhrinten, wenn man bie Epinne gegen Das einfallenbe sicht, fo baß ber Edfatten

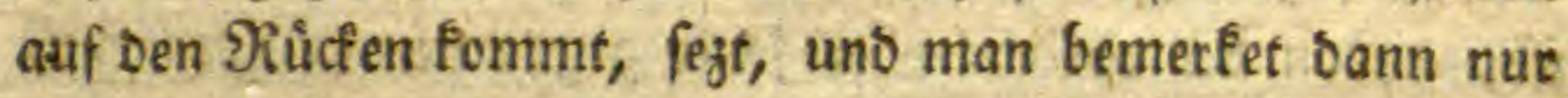
einen ffilif̧förmigen fómalen flect, weld)er von ber mitte leren oiefer bren) Sinien gebilbet wirb. $4 \mathrm{~m}$ alfo biefe bren Sinien genau zu beobachten; müs man bie fichtfiralen gerabe barauf falten laffen. Bu benben Seiten ber fobon ermeg̨ne ten breiten binbe befinben fict) noc) zwen anbere aber nur ganj fámole ebenfalls in bie sảnge laufenbe gleichfärbige Sänber, jeberfeits eine, unb werben von ben fohmargen:

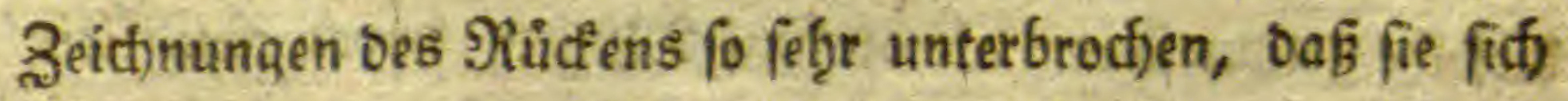
befonders geaen ben 2 orbertfeil beffelben gang berlieren. Hebrigens ift ber Siùdenfthilb oberḩalb mit zerftreut ftef̧en 
ben Stachelborften befezt, Davon jene Die längften uno bicf: ften fino, weld)e gegen bie 2lugen zu fiehen. Unterḩalb ift bie ganze Bruft fd)muşig gelbgrún. Die acbt 2lugen

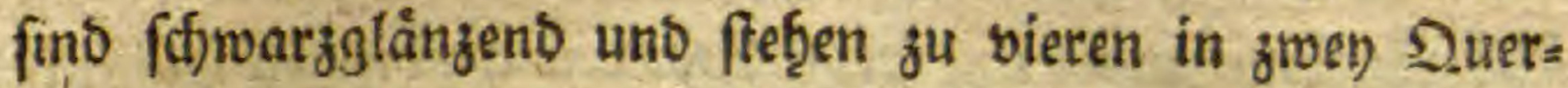

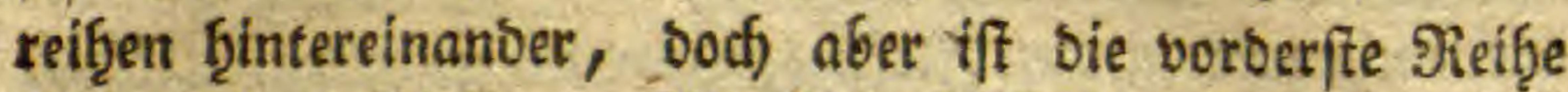

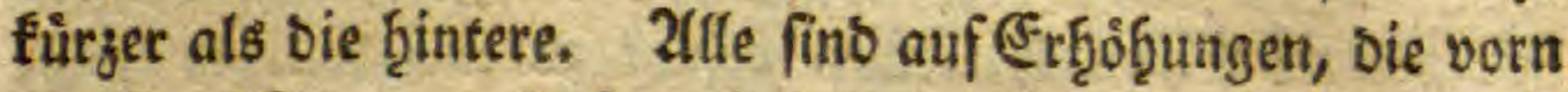
Der Ropf bilbet, aufgefejt; befonbers aber bie vier åuferften,

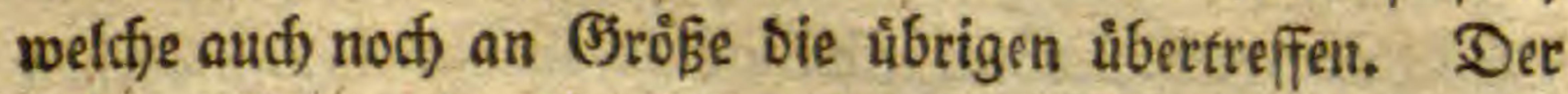

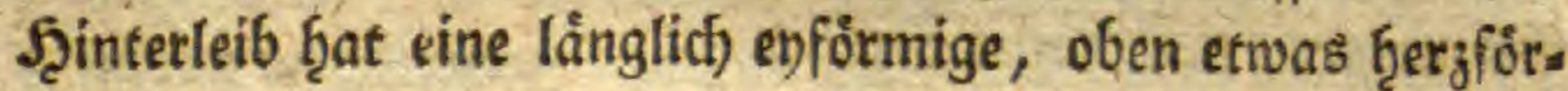

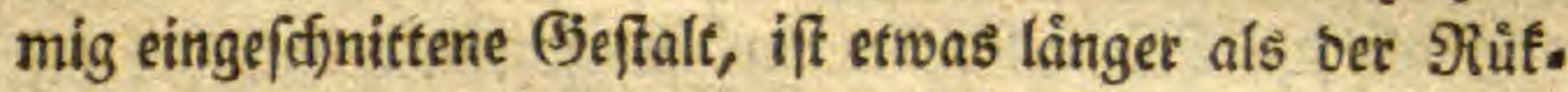
fenfthilb uno man bemerft an bemfelben obethalb fünf $B e t:$ tiefungen, bavon eine ganj botn, jwene in ber f̧âlfte bes Scinterleibes, jeberfeits cine ant Seitenranbe, jroen andere gleid) binter biefen jum 3 orf(d)ein formen. Mitten auf

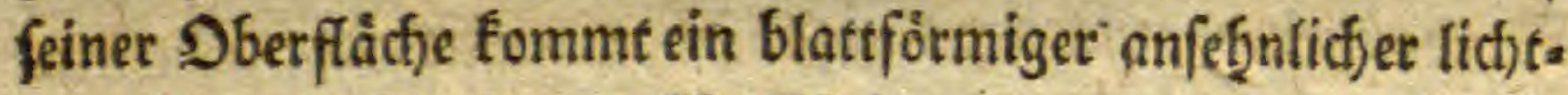
graubrauner Flecf jum $\mathfrak{B}$ orfffjein, ber an feinem Ranbe etruas gejåţnt iff. Setrad)tet man siefen flect aber unter Det Suppe, fo toiro man gerwab̨r, baß betfetbe, gleidffam aus fünf Gintereinanter ftef̧enten fJlecfen jufammengefezt

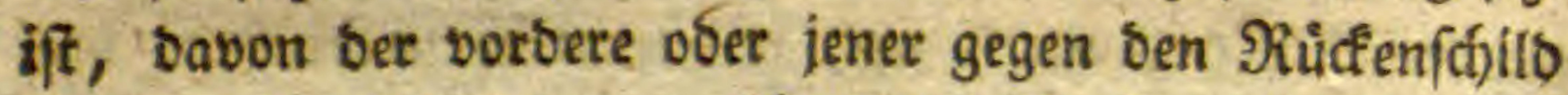

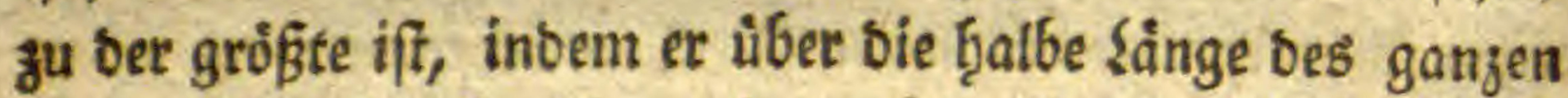

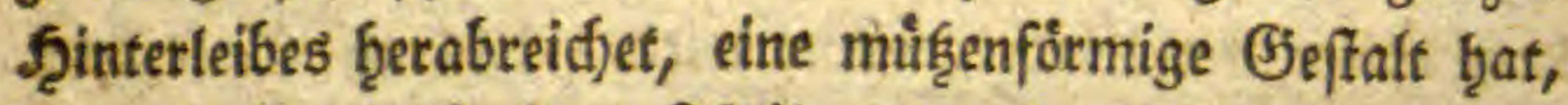
uno mit feinem breitern ₹̧̧eile gegen ben 2 fter ju ftę̧et. Die übrigen bier flecfen fommen bann f̧intereinanser zum ßorfdocin, unb werben nur burcf) Queerlinien boneinanber getrennet. Ilm aber von ber gänzen blattfortmigen Beichs nung ben beutlidften Begrif burd) Worte ju geben; lfo fief̨t

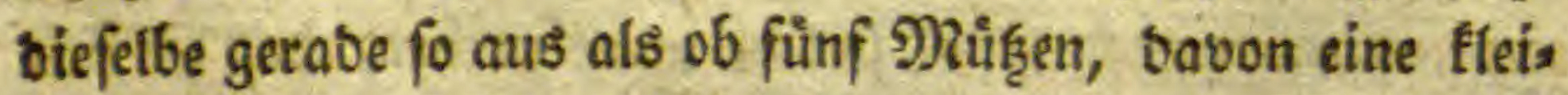
ner als bie anbere ift, in einanber fteften, fo jwar, oa $\beta$ man bie erfe gan?, bie übrigen aber nur van iğrem untern ?̧̧eil 
zu feben befömmt. Diefer ganje Fled ift i̊brigens mit' bunfeln wolfenforrmigen Beichnungen befejt, uno ouf feiner Ditte fommt eine befllere Sångsbinde zum Borid)ein, wel= d) if̨ren 2Infang von ber vorberften Bertiefung Des J̧in= terleibs nimmt, bis in feine bৃalbe sánge ḩerablèuft, uno ounfel gefäumt ift. Da biefe blattförmige Scinterleibsgeid). nung ben vorgugglidfften Unterfd)eibungsct)arafter bey bic= fer Epinne liefert, fo f̧abe id) ih̨r ben Namen, Die Slatt. fpinne, Aranea folium bengelegt. Id) ḩàtte fie zmar lieber foliata nennen fo̊nnen, ba aber fafjon in ber parifer Entomo: logie eine Aranea foliata vorfömmt, fo ḩabe idi biefe Benen. nung wegen Der Daraus entffę̧enben Jrrung bermiesen. Diefer blattförmige J̧interteibsflef roito von jeter Eeite mit einer braumen ins fdyorale fallenben breiten Binbe be. gränzet, meldhe neben benfelben ùber bie ganje länge her. ablaufen, fidó gegen bie Epiz̨e bes 2afters einanber náhern, boch abet fich niemals vereinigen. Die Eeitentheile bes

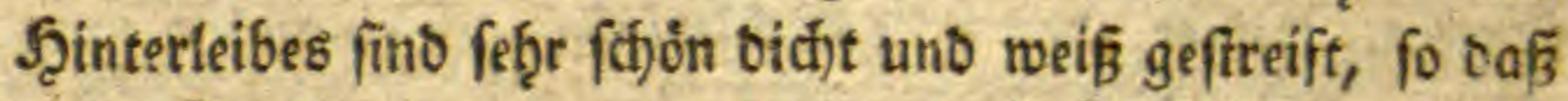
Diefe Streifen nur gang enge linienformige fufwarggraue Zniffienräume grwifthen fich laffen. Zllle biefe Grreifen laufen fhief bom sBaud nad) abwairts unb aufwairts gegen

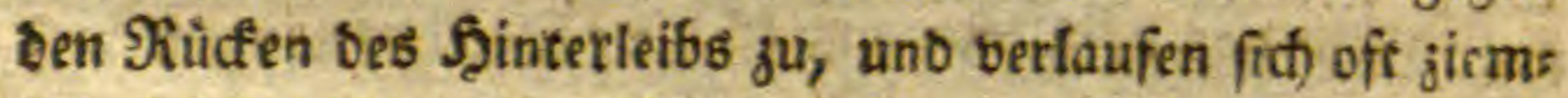
lid) tief in bie ben blattforrmigen Flect umgrånzenbe fdfivarz. braune Binbe. Uebrigens if ber gange Jeinferleib mic

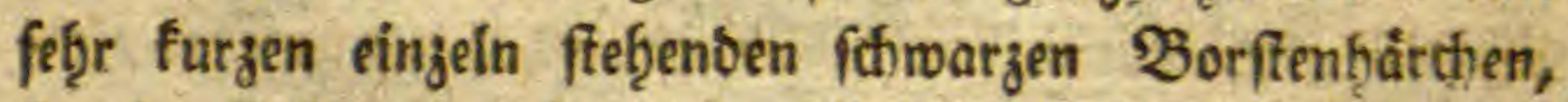
fparfam befegt, weldhe an ben Geirenftreifen bes seibes in Reiţen georonet vorfommen. Die Futfle fint gelbbraun, mit bunfelbraunen Punften zerffreut befegt, aus weld)en allemal ein gegen bas Enbe bes ₹uffes mit feiner Epige gu

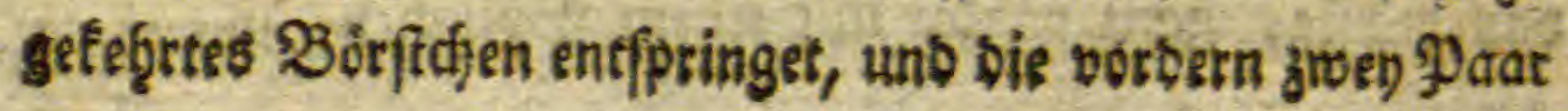


um vieles länger uno ftäffer als bie hinterften. Thbft bie. fen Borfftien fommen aber aud nod) antere feife frachele formige fdomarge f̧aare an ben Jîffen jum Bordhein, welo c) aber mur bin uno wieder, Dech aber niemals b̧äufig vors fommen. Noch fino an jebem Suffe, am Echenfel, berm Darauffolgenden Rniegetente, uno oem Echienbeine an bet obern Seite gren in die sange laufende jarte Sinien von brauner Farbe ju bemerfen, bavon iene, welche fid am

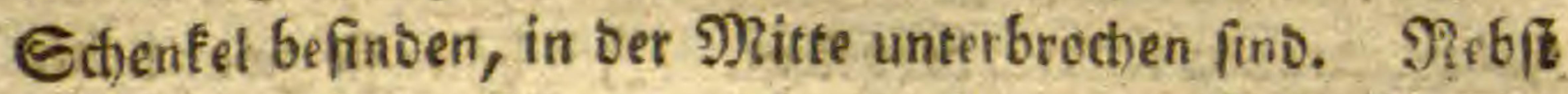
biefen zroen tinien formmt noch) eine furje am Echenfel, an feiner bem after ju fehenben fläche jum 23orfd)ein. Zfuch) fino bie Sdienbeine uno bas frusblatt all jeit mit längern faaren als bie úbrigen Juftheile befegt. Die fchmargen Jufflauen firo an ber inneren Seite gezåbnt. 23as oas

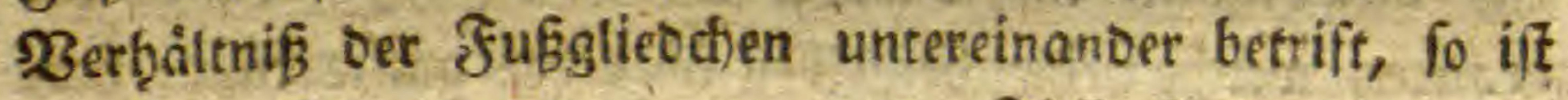
Der Edjenfel ber vorbern fwey paar fliffe fo lang als tee Riucfenidillb, bas barauffolaenbe Rniegelenfe um zneh brittheile fleiner, bas erfte Echienbein not) einmal fo lang als bas Rniegelente, bas jwente eben fo lang als bas erfe, uno cas Jubblatt nod) einmal fo furz als ein Edienbein.

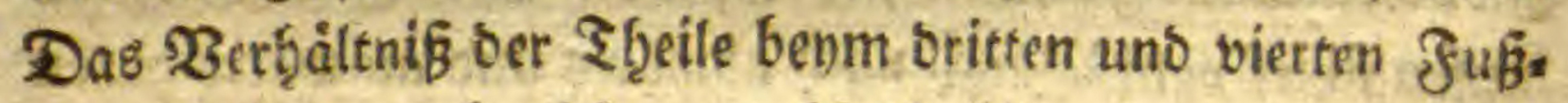

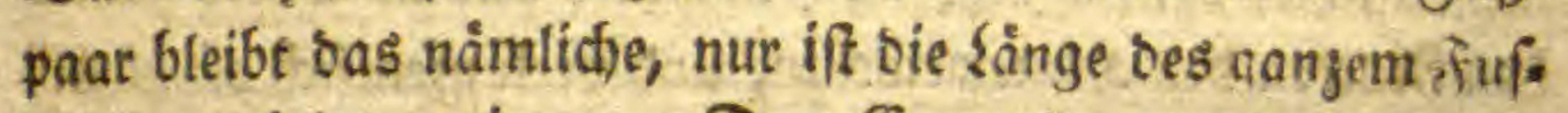
fes um vieles geringer. Das Excmplar roldhes ich vor mir f̧atte war ein Männdfen uno batte feulförmiae, viere gliebrige Jrefipifzen mit Etadfulborften befegt. Das erfte Oliebchen Davon ift walgenformig und bas längfte, tas grente runo, bas oritte etwas trichterformig, fo furg als Das zmente uno bilbet nach auswarts einen leb̨r fleinen hqaadenförmigen idbroargen fortfas, bas vierte enolid) iff Das bicfite, ganz tuno, mit einem Epifigjen, unterhalb 
(lach) unb man bemerfet an bemfelben eine etrwas ffinecfene

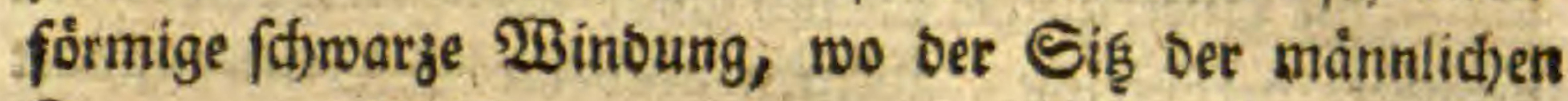
Seugungstheile iff.

Diefe Epinne formmt bey Prag auf ber gemeinen Rlette (Arctium Lappa Lin.) im Monaţ̧e Juln und 2u. guft vor.

\section{$\mathbf{X X}$.}

Mufca Alcere. Die Papperfiliege.

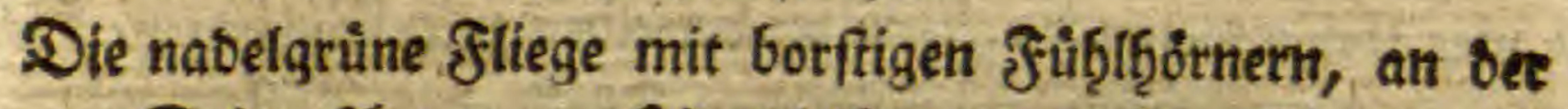

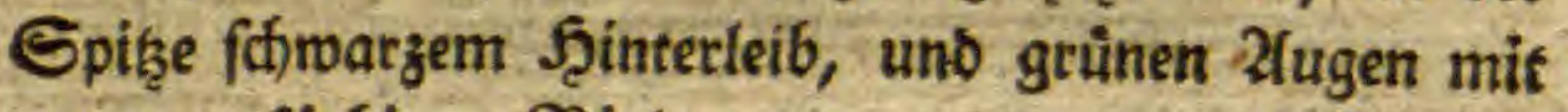
5 purpurfärbigen Binben.

Mufca antennis fetariis, viridiznea, abdominis apice nigro, oculis viridibus, fasciis quinque purpureis. Mufca. Jabr.

Diefe fliege erteidft von ber Stim bis zur Epif̨e bes. 2(fters gered)net eine sainge von oren uno einer bुalben Sinie.

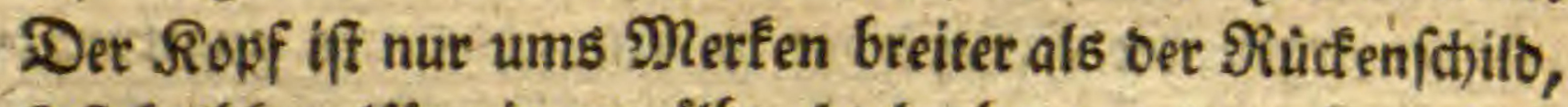
faft Ģalbetugelfơrmig genoolbt, boch aber von vorn betrad)tet bon feinem volffommen runben Utmriffe, weil er gegen Den Scheitel breit, uno gegen ben शuno ju fith verengert; bod) aber immer bafeefbeft lange noch in feine Epige aus. låuft. Die Strim if lánglidyvierectig, gleich) ùber ben Eüb̨lbòrmern burd) eine Querfurche bon ber Manogegeno getheilt uno von fdoỏner rothbrauner, bey vielen Eremplas ren oft ins fudistotģe fallenter farbe. Nitten úter oie gange länge ber felben låuft eine ffirache linienfórmige $\mathfrak{B}$ ets. tiefung, welds)e ib̨ren $\mathcal{Z}_{n}$ fang von ben oren am Edteitel

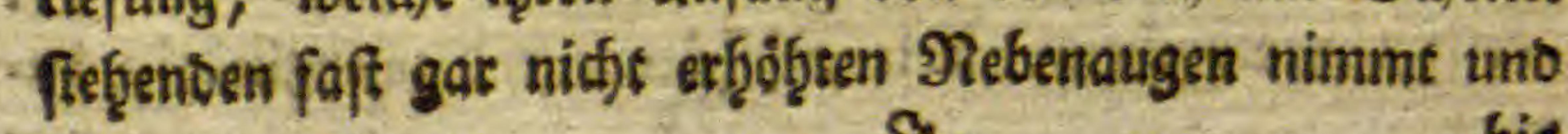


bis an bie Dueerfutche, bie ficf) g(eld) über ben Jüb̧lföthern befindet, herabreidit. Mitten aber an ber Stim befinbet fich eine $\mathfrak{B}$ ertiefung, welche bie befagte saingsfurche burchfreuget. Dann fommen zulezt noch zwen rinnenformige Bertiefungen zum $\mathfrak{B}$ orfhein, babon eine jebe einzelne if̧ren Znfang am Ropffcheitel gerabe zwifchen sen Tiebenaugen uno ben eigentlithen 2lugen nimmt, bie balbe sänge ber Etirn Ģerab gegen ben $\$$ Rittelpunft julauft, unb fich in ber mittleren Qucerbertiefung enbigt. 2(ud) fommen nod) vier fleine weiße fleced)en an berfelben jum Borfd)ein, DQ $=$ von jwel) grófere am mittleren Theile bes 2(uffenrantes, jeberfeits eines, uno zwen fleinere an ben unteren Ecfen

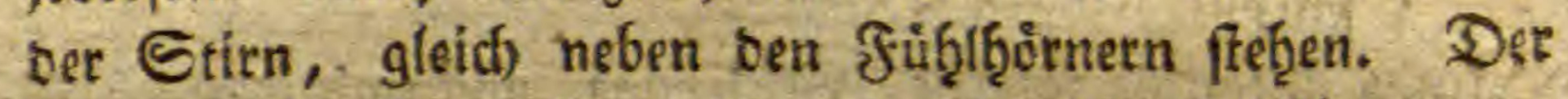
Ed)eitel Des Ropfs ift glețí) neben bem innern 2(ugenrans De berberfeits mit einem grünen metallifich) glänzenben flecf gejiert, uno ber Nacfen bunfetrotb̧braun. Die 2tugen, Davon jebes einjelne ben britten Thęil ber ganjen Ropf\&a breite ausmacht, fino metallgruln, rüb, uno if̧e SRans

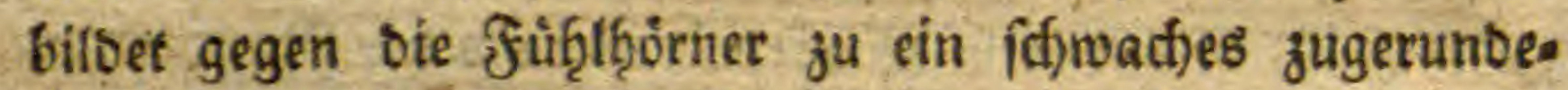

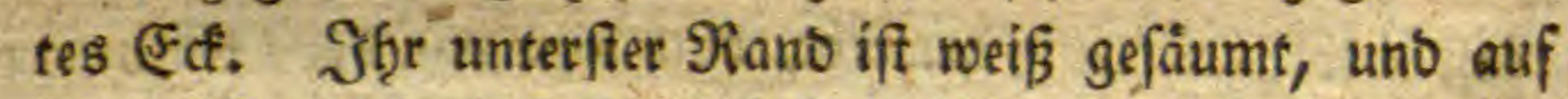
if̧rer Dberfläc)e befinoen fich fünf feḩr angeneţme purpurs rothe Sinben, bavon bie oberfte, welche bem Ropfficheitel fu fiebet, aus allen bie fleinfte uns ounnfte ift. Die Muns= gegenb ift ebenfalls rothbraun, gegen if̧r Enbe feb̨r aufge. worfen, unb iḩr unterfter, ins fó)warggrüne glängender Rano febe farf ausgeffinitten, zwifdien melchem Yusa fidnitte man bie fleine foffrarze am 2fufferranbeganje Dber. lippe beutlich) unter ber suppe bemerfen fann. Der fí)marge glänjenbe behaarte Gaugruffel ragt etrvas berbor uns bqa

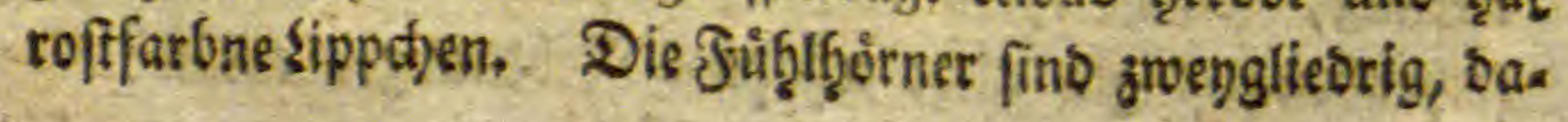


Ion bas erfte Blisod)en fef̧r flein, bas folgente aber unt vieles grofier unb enformig jugerunbet erfdieint. Sie fins ùbrigens ganj rothbraun, bas legte (Stiebden geaen bas

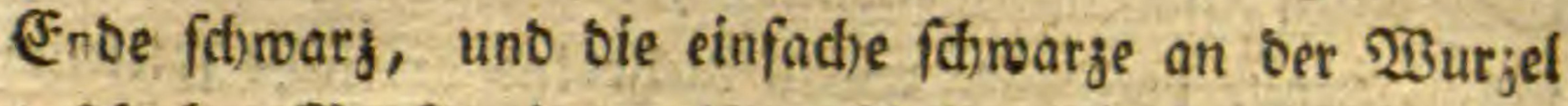
rofffarbne Borfte nimmt if̧ren ánfanq gleid) úber ber $\mathfrak{X}_{\mathrm{n}}$. glieberung beffelben am oberen Fbeile. Zuch bas erfe

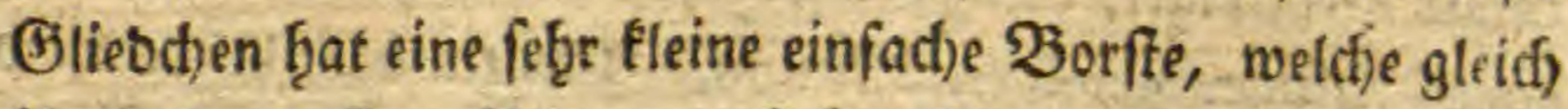
binter teer erfterwähnten ju ffebzen fömmt. Uebrigens iff ber ganze Ropf unbeb̧aart, bis auf einige Sorften, welche ben áuffern Seitenrano ber Lugen umgeben, zwene, wel. d) gleich neben ben 2(ugen am Ed)eitel, uns zroen andere zroifchen ben Nebenaugen ju fteben fommen. Der Siopf if von bem Brufftucte surd einen furgen Şals gee trennet. Der oben qanz metallgringlänzende glatte Rü.. fenfffilto bat von oben betrachset eine vierectige Geftalt. Die zwen Dberecte exffelben fino aufgeroorfen, uno fómarz. Die beiben Geitentånber neigen fiá) gegen beit Ginteren Rand jufammen, mit welchem fie fich fo fanft vet.

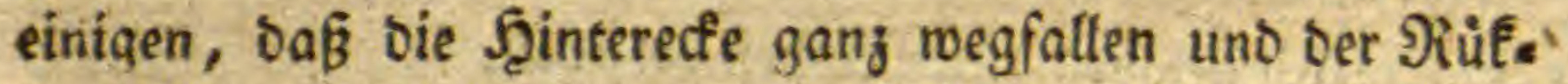
fenfdhito nad) Giinten ju gerunbet erf(h)eint. Benberfeits am

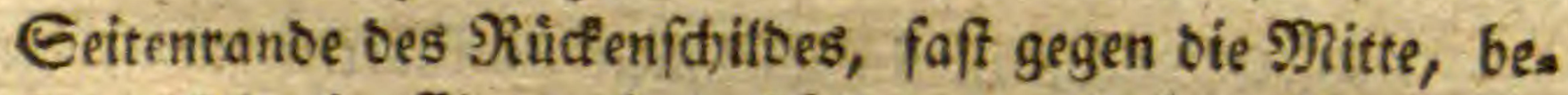
findet fich ein (Einbruct, weldjer nur ganz furg ift, in bie Dueere uno nach vormárts láuft. 2luf ber Dberflache bes

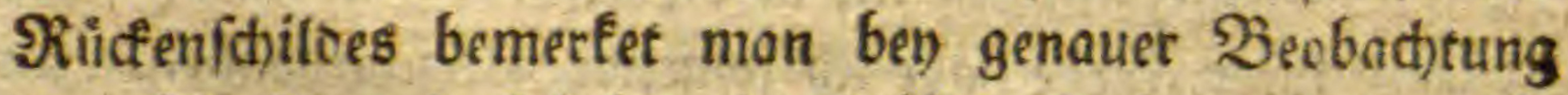

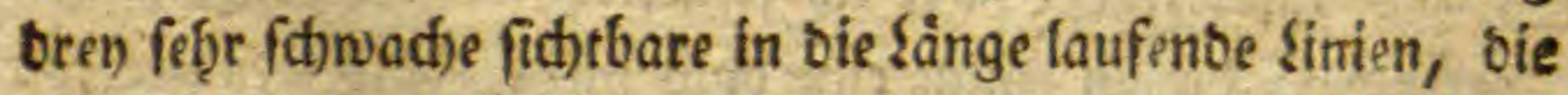
aus febr fleinen Punften zufammengefejt fins, uno tavon bie mittlere befonters matt in bie 2(ugen fällt. 2(uth) foms men an ben berben Eeitenränoern einige Stadjelboriten jum $\mathfrak{B}$ orfdhein. Die Eeitentģeile bes ganzen $\mathfrak{B}$ ruftifüd's fino fammt ber $\mathfrak{B}$ ruft mę̧r Siupfer als grủnglånjeno. Det

$$
\text { I } 2
$$

Şin 
Scinterleib if platt, faft brenecfig, glatt, nut am 2 fter ein meritg bef̧aart, fo lang als ber Rilifenfchillo fammt bem Edjilbchen zufammen genonmen, gleitffalls grünlich me* tallglämeno, boch) aber etwas meb̨e ins gelblidje fpielenb. 2(n bem erften f̧̧interleibsringe erfheint ein Sthilbchenfös miger breyectiger, von zwei fJurd)en uno bem Dbertano bes erften Ringes gebilbeter Raum. Segen bas Enbe mirb ber ganje J̨inter(eib nach) unb nach) fdwwarz, weld)e Farbe befonders an feinem Untertḩeile zu feţen iff. Das Schillo. c)en if zugerunbet, fupferglangent, uno glatt. Die Futfe fino untereinanber von gleiffjer sainge, fófroarz, etroas ins blaue fpieleno, furz mit Borftchen befezt. Die Beftalt ber Styenfel unb Sdjienbeine ḩat nid)ts befonberes an fidf, unb Die Gliebdjèn ber frufblätter, weldje bleidjbraun, ausgenommen am erften fußppar, wo fie alle bis auf bas erfte, (c)warg erfacheinen, neţmen gegen bas Enbe bes f̧uffes im. mer an länge ftufenmeife $a b$. Die flùgel finb etwas meif.

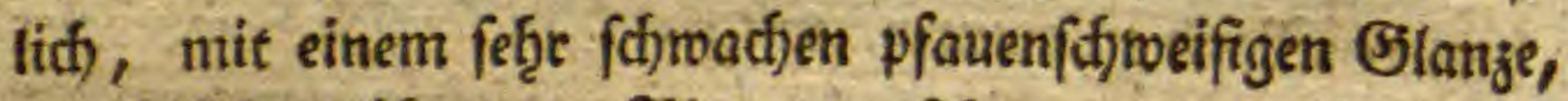

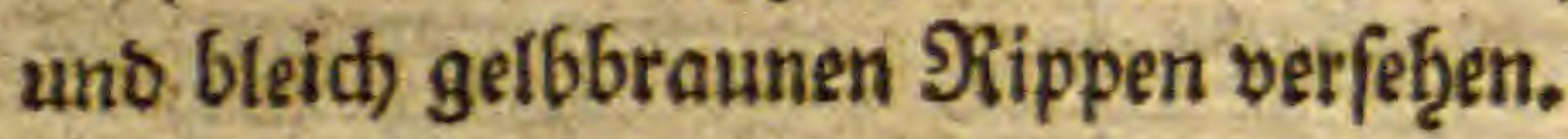

Diefe Fliege ift in SBof̨̨men in Bảrten zut fpatten

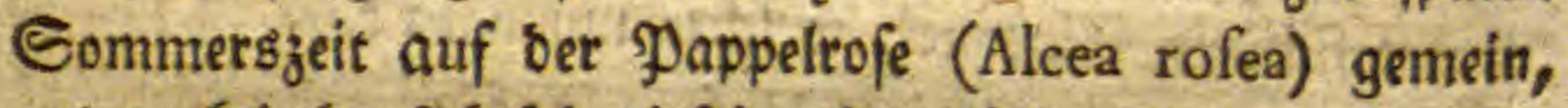
uno verfriect)et fich fef̧r tief in bie gefüflten Bhumen, Im Setref if̧rer Jatbe babe id) folgenbe Berfofiebenţeiten an. getroffen; bavon einige eine balb mefgr, balb weniger roft. farbne Stirn f̧atten; eine ober, weld)e bie merf trùroigfte iff,

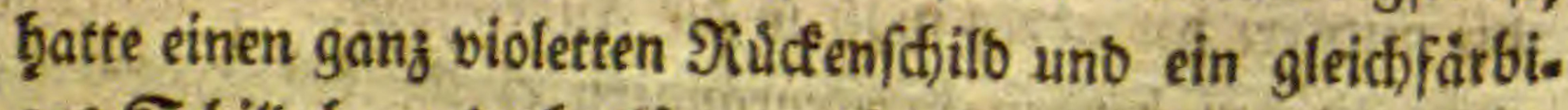
ges Sdjilbchen, bod glänaten aber beybe ₹g̨eile metallifक. 


\section{XXI.}

Conops bimaculata. Die jweyfectige Stedffliege.

Die fobrarze Stedjfliege, mit zroenmal in bie sainge grau

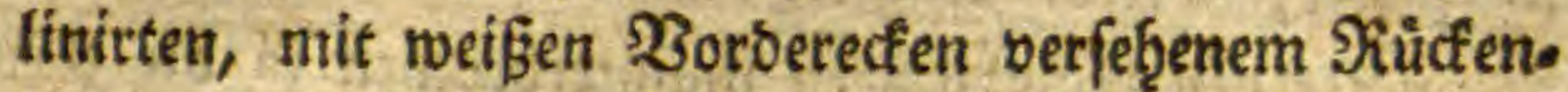
fobilbe, uno braunen Fluggeln mit braungelber 23 urzel. Conops atra, thorace cinereo-longitudinaliter bilineato, angulis anterioribus albis, alisque fuscis, bafi teftacea. Myopa. కabr.

Das gange Thiercjen etreidjet von ber Stim bis jur

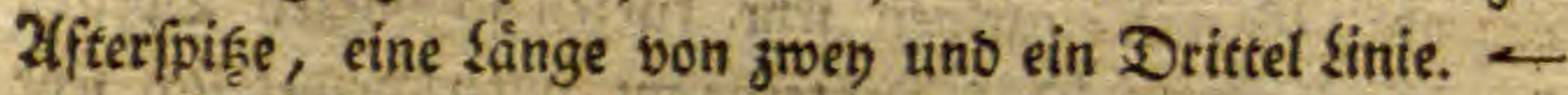
Der Ropf b̧at, im Banzen betradffet, eine runbe, bod) aber gegen bie Ettirn, uno ben if̧r entgegengefejten Nafo fen, eine etwas platte Bseftalt. Er ifit ein weniges brei.

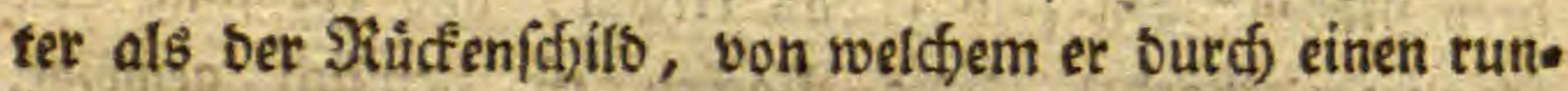
Den, gegen ben Ropf zu aber etwas buinner werbenden 5̧als, beutlid) gettennet wito. Die 2lugen fino rotḩbraun, Jänglidfruno, unb jebes einzelne nimmt ein Drittheil bet ganjen Ropfbreite ein. Die Şüblģoirner fint braun, brey.

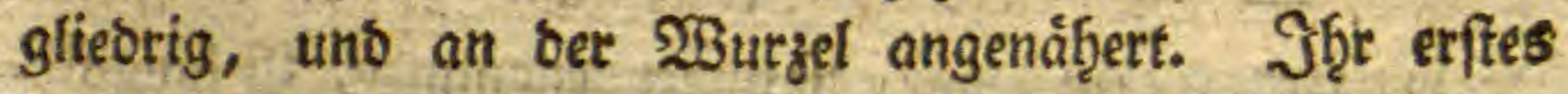
(J)tiebchen, ober jenes gleid) an ber Stitn, ift aus allen bas fleinfte unb eifórmig, bas zwonte faft orenmal länget als bas erffe, fåulfơtmig, bas britte etrvas fúrzer afs bas zwente, Fegelfơrmig, bod) aber etroas baudúig aufgetrie. ben, von lidferer Farbe, uno mit bem frumpfen F̧̧eil an

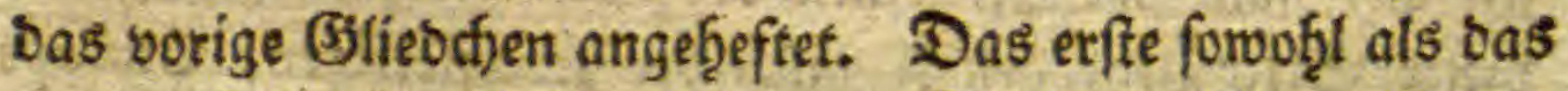
zmente (S) lievdien haben fofwarge Etadjelborften zerfitreuet um fid) Gerumfteţen, bas lejte aber ift nur fệr fein, feiDenartig bef̧aart, unb bुat mitten auf feinem obern ₹̧̧eil,

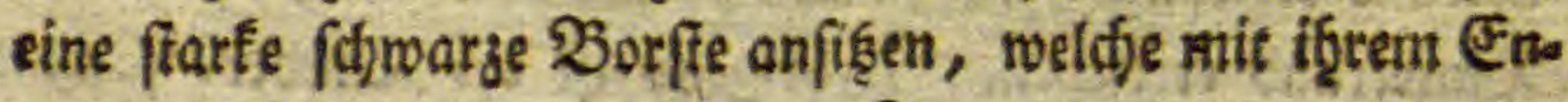

$$
3_{3}
$$

be 
be nach vor: uno nuswarts gerichtet iff. Die Etirn ift fd)muşiggelb, uno wenn man beu Sopf von oben genaut betract)tet, ưber bie 2tugen berausragent. Eie berlingert

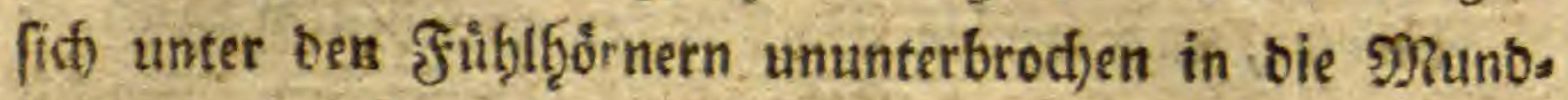
gegent, reldhe fribergrauglainjent, uno gleich zroen gro. fen zugerunteten Sappen, neben bem Runbe unter tent Unterrante ber Zfugen ţerabtängt, groifdeen weldien bie etwas fanft ausqefdnittene Dberlippe, bon gleidher Farbe zum $\mathfrak{B}_{0}$ f fhein formmt. Die Etirn fowobl, als bie शruno. gegeno, ift mit einzelnen febr furzen fowwarzen Boorften fparfam befezt. Das Jeinterb̧aupt unterfheibet fich fef̧e beutlicf) von ter Etirn, insem es ganj fdhwarz erfcheinet, uno nact) finten mit einigen langen borften be $e_{j} t$ iff. Die bren) Nebenaugen fino etwas erḩdb̧t, unb ebenfalfs wor fonvarger Farbe. Der Nacfen ift giemlid, gewoilbt, fthratz, in ber 5 ?itte von ofen efwas eingefenft, uns mit Sorffen beiegt. Der Siuffel iff fdwarg, uno ragt im nas

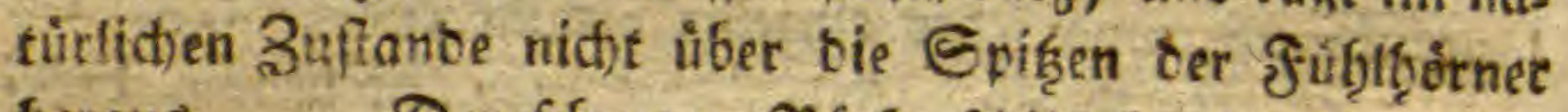

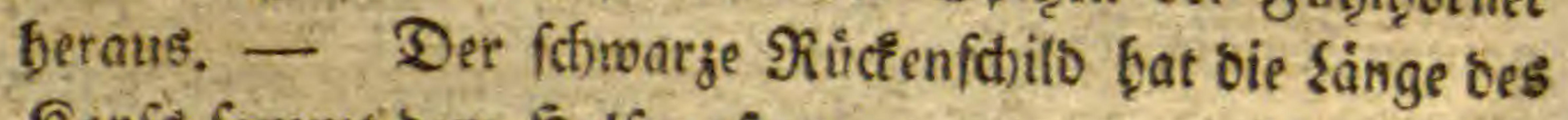
Sopfs fommi bem Jalfe zufammencenommen, if länglich)= vierecfia, febr genodibt, mit abgefdinittenen feintereden, inger ber Şinterrano vier Ecten für fich bilbet. Die $\mathfrak{B}$ or:

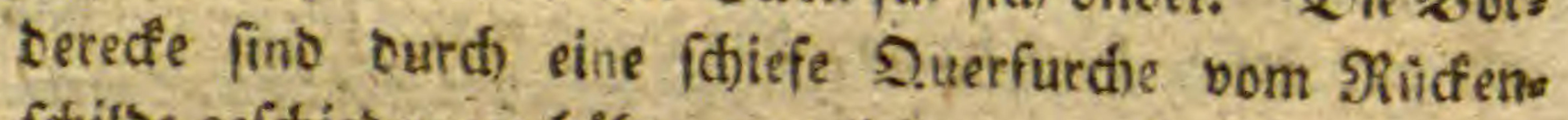

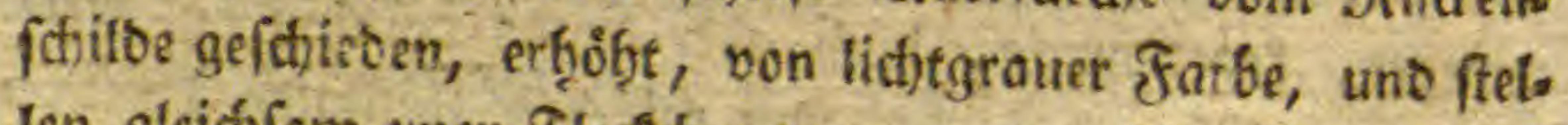
Ien gleiç)(ant zroen Jledfchen vor, aus weldier Urfadje id,

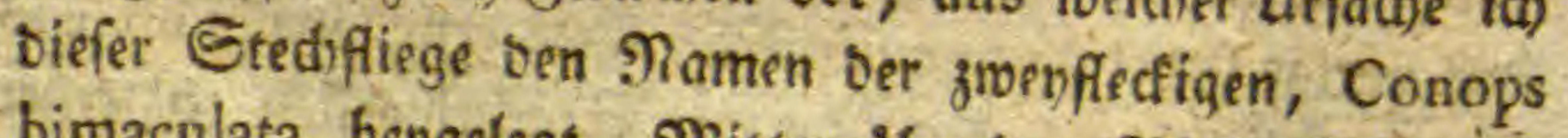

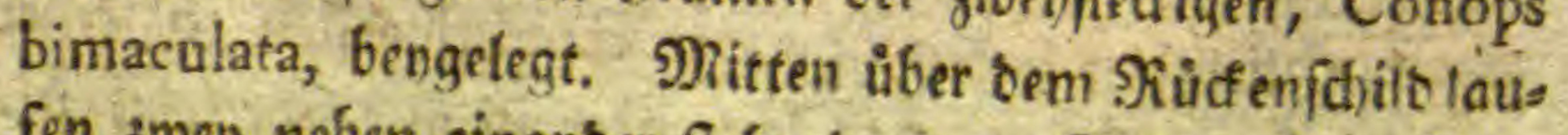

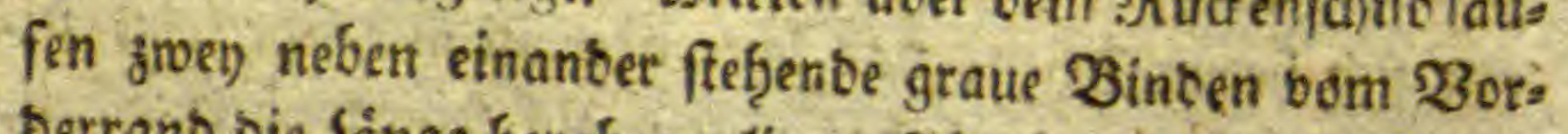
berrano bie lánge berab, verlieren fich aber nod, ebge fie ben Jgintertand erreid)en. Uebrigens ift bet Worber. fammt 
Sen Eeitenrainbern ganz grau, und bie ganje Sberflácje Des 2ilidenfchilbes mit fofwarzen SBorftentärofen befezt. 52Benn man alle graue Beichnungen ben biefer Etechfliege genau bemerten will, mufs man fie fo balten, bafi bas barauf fallenbe sicft vom Ropf gegen ben 2 ffter fin foheint, wibrigenfalls bie meiffe graue Beidfnung berfdrwindef. Das $€ d j i f(d) e n$ if unten zugerunbet, breiter als länger, fdiwarz, unb mit einzelnen langen Borften befezt. - Dek

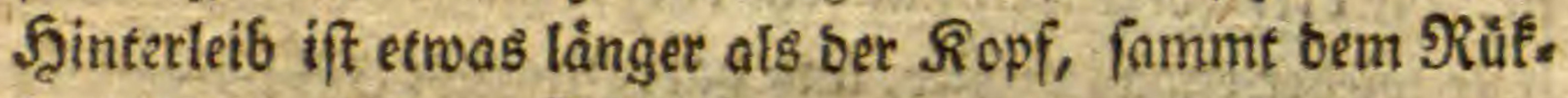
Fenfftiltse uno bem Sdfilbdien jufammen genonmen, bon fáuformiger ermas berabgebogener Geftait, fo zroar, bak

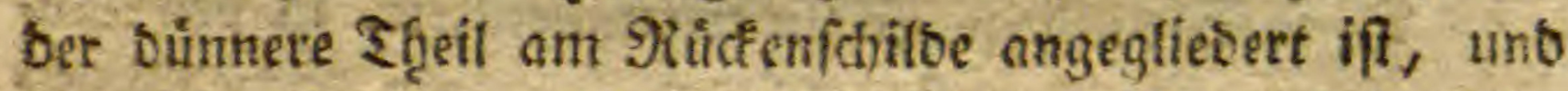
Sor sidere ben affer biloet. Er ift ganz fdfroarz, in fedys Finge getheilt, bavon ber jwente, britte uno vierte bie grògten fino, uno mit fofwacken, langen, überaft nact)

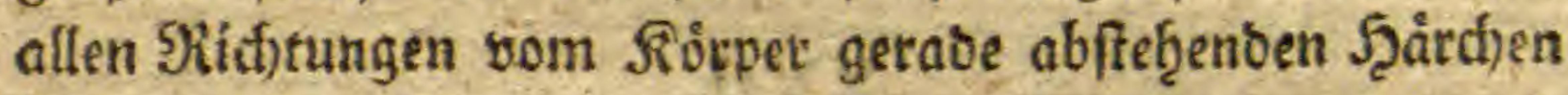
befegt. Die Eeitentheile oes Sinterteits fino grau, wei. d)e Sarbe man auch) befortibers an bem gwenten, britten uno vierten Pinge, two fie fegre breit ausfälit, bemerfet, fo, baß swenn man bas ganje Ş̧ier(f)en mit unbetwafnetem Zluge betrad)tet, man bafelbft ziemlid) beutlid)e graue Fledfe waf̧rnimmt. Die Sdjwungfơlbdien finto reißs, runo, mit cinem bunfeln Etielcten, uno bृaben feine Fiufdhel gu if̧, rer Bebectung. Die Jlugel trägt biefe Stedffliege int Siuţeftanbe über einanter liegens. Eie finb ein weniges raudjfarb, mit einem ongenefinten pflauenfóneifigen

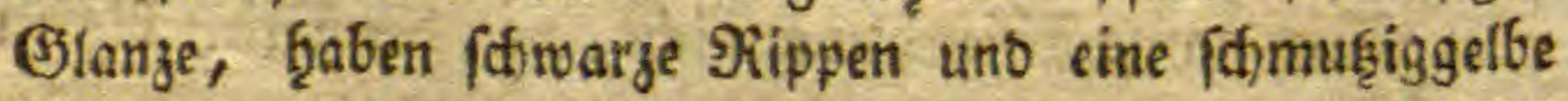

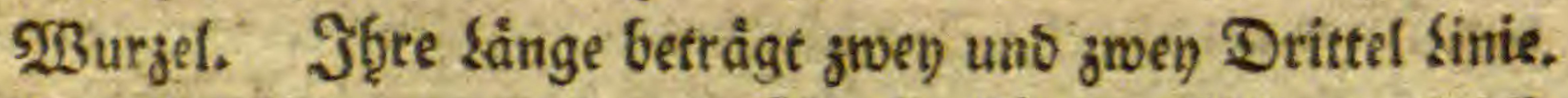
Die fdjwarzen, mit furzen Borftenஞ̧ărden befegten Füfe fino von gewơb̨nlid)er sånge, bie biintern nur ein weniges

$$
\text { I } 4 \text { lànget }
$$


lảnger als óie borberften, uno nur ums gierfen färfet. Der Edenfel ift aus allen కbeilen bes fuffes ber längfe, an ber 3 urzel bleichgelb, bas barauf folgente Sthienbein etwas fürzer, ebenfalls an ber WGurzel von bleid)er Farbe, uno ganj bưnn. Dann folgen bie fünf fofublattgliebdien, welche alfe zufammen faum bie sainge bes Echienbeines ausmad)en. Itneer if̧nen ift bas erfte (Stiebd)en bas lång. fte, bie brey folgenben nur feb̧r turz, herzfötmig, uno bas

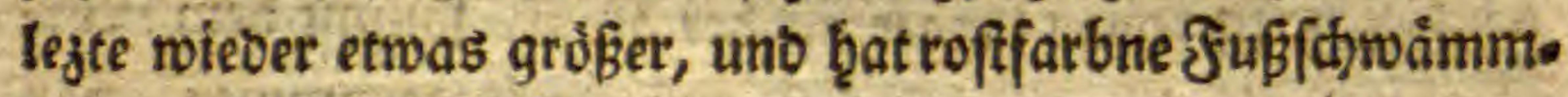
djen uns fofwarge Rlauen.

Diefe Etechfliege ift zur Sommerszeit, in ben \$ro. naten July uns 2luguft, auf bet gemeinen Ed)aafgarbe (Achillea Millefolium Lin.) um gुvag, in grafigen $\mathrm{Gb}^{\mathrm{k}}$ genven nidit gar zu felten.

\section{XXII.}

Chryfis candens. Die glũţenbe Botoweipe.

Die Soloroefpe, mit purpurfarbglänzenbein Ropf, Rhit. fenfibiloe uno f̧interleib, grünen Edjilbdjen uno Gitun, Glauen fruffen uno gangen 2 ffter.

Chry fis capite, thorace, abdomineque purpureo-nitente, fcutello fronteque viridi, pedibus caruleis, ano in. tegro.

Chryfis. Jabe.

Das ganze ₹̧̧ierdien erteidt, von ber Etirn bis an

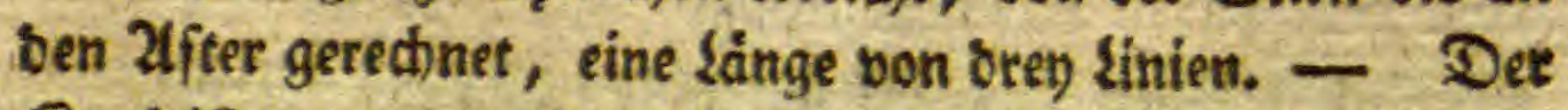

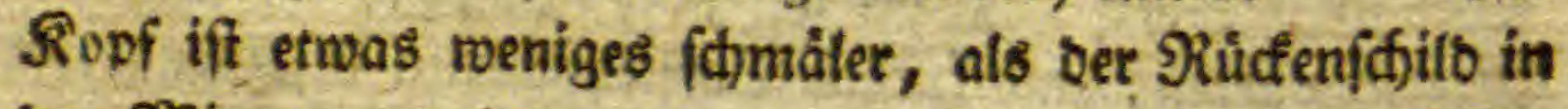
ber Mitte, uno bुat, wenn man į̂n von oben ḩerab bes trad)tet, eine glattgebruicite, bon vorn aber eine brenef. 
fige Beftalt, mit zugerunbeten Ecfen unb einem etwas

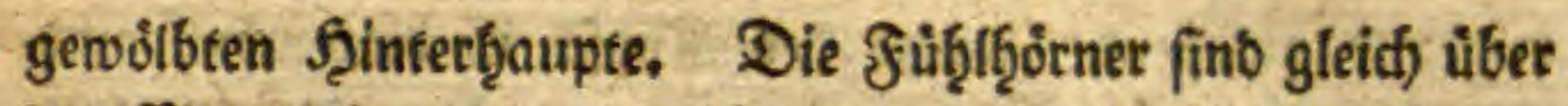

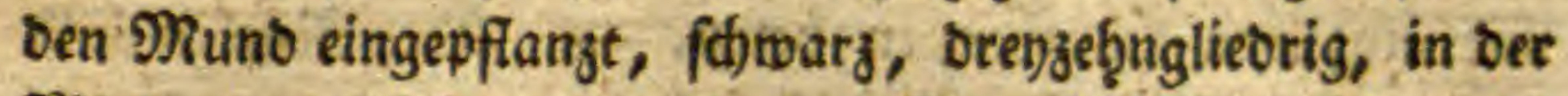
Mitte etwas biffer als an beyben Enben, äufferft fein grau

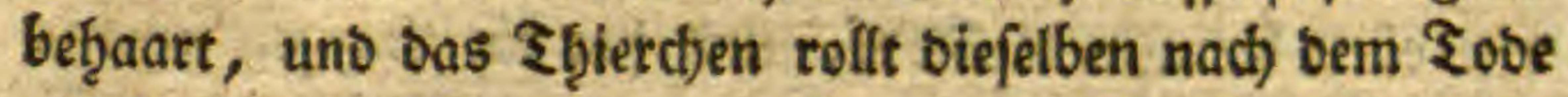

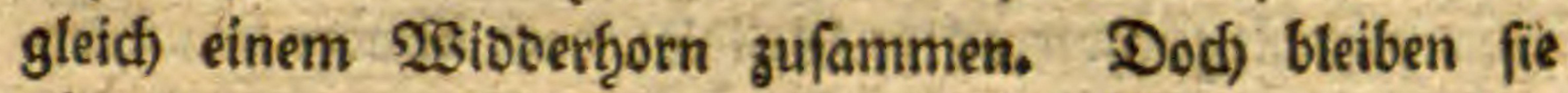
aber immer, nach bem erften anfetenliciffen, etwas ins graue fohimmernben, uno alle uิbrigen an Sånge ùbertref. fenben, fäulförmigen (Sliebdjen, nach) auswairts gebrod)en. Zlusgeftrectt ḩaben fie bie långe bes Rủctenfabiloes.

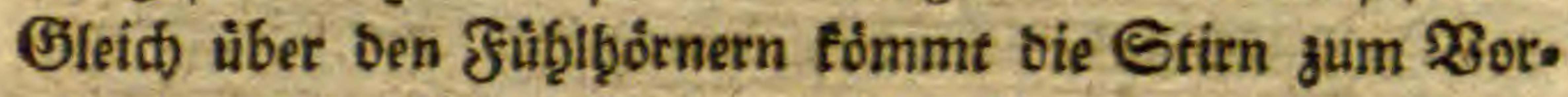
f(t)ein. Sie ift vertieft, uno biefe Bertiefung oienet bie.

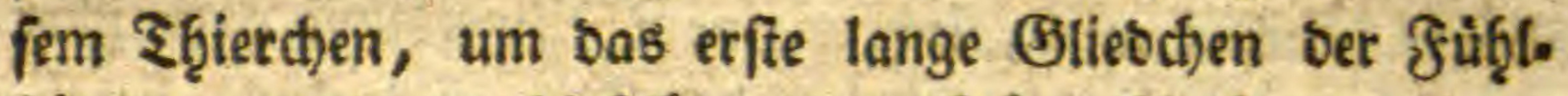
ḩơrner, wenn es biefelben emporb̨ebt, Giinein zu legen. Ulebrigens glängt von berfelben bas angene⿻̧mfte Gologrủn,

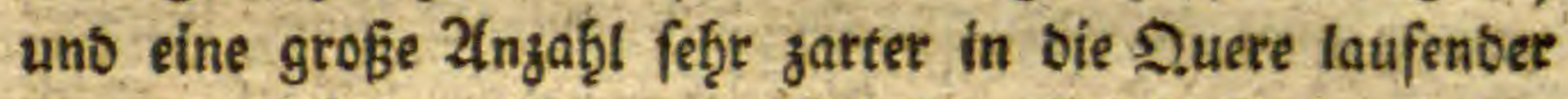
falten, befleitoet iţre ganze fläd)e. Diefe Jalten f̧ơren aber nodh vor ben benben innern 2lugenränbern, uno mit

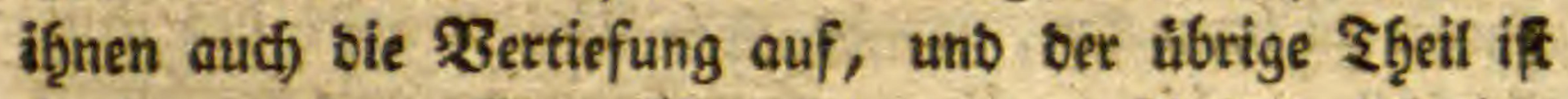

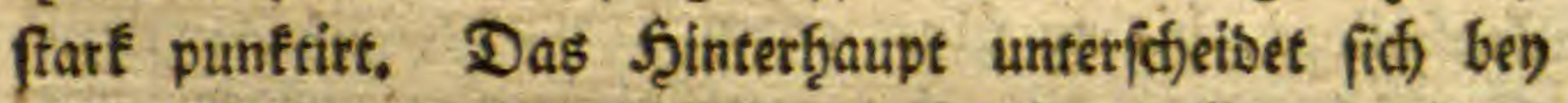

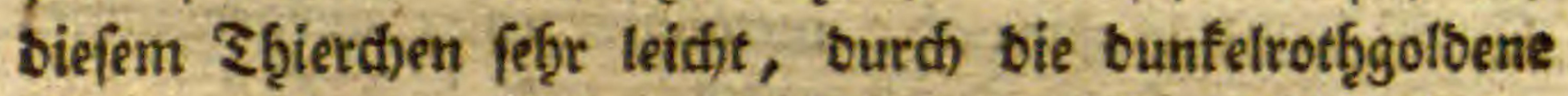
Farbe, bon ben übrigen Ropfţeilen. Es ift fę̧t breit, fo jwar: bak, bie 2(ugen von oten betract)tet, jebes nur ein Biertel ber ganzen Ropfbreite, bas Şinterţaupt aber allein

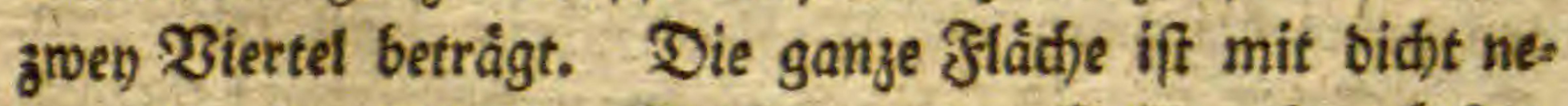
ben einanber ftebenten (Bruibchen ober Şob̨lpunften befezt, Davon jebes pingelne rod) einen fleinen \$ुunft in ber शitte b̧at, aus weldiem ein furges Şärch)en ent(pringet. Uno

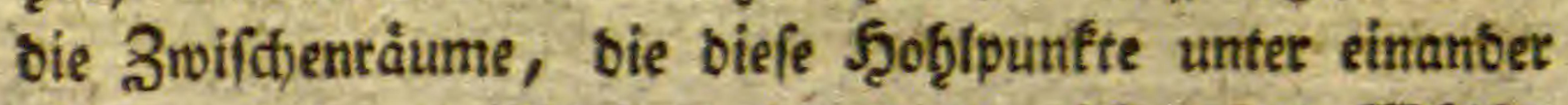
bilben, madjen verfकhisbene einanber burdftreujenbe $\mathfrak{B}_{\text {ŭlfte. }}$ 


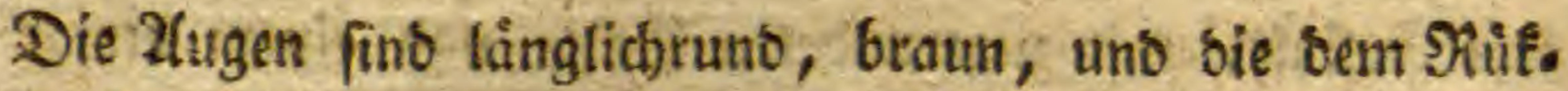
fenftillo zufebente Jläd)e bes Ropfs ift blangruin, unb mit einzeltuen Saarborften befezt. - Der Ricten(thilo bet eine gewólbte (Geftalt, ift faft oreymal länger als oet won oben betradifete Riopf, uno hat im SSanzen genome. men cine långlidjvierectige (Beftalt; bod) ift aber fein $\mathfrak{B o r}$ : Derrans faft zugerumbet. Unter ben 20 orberranbe beffel: ben, låuft benberfeits von einem Seitenranbe bis ju bem Scals, ein fotwarzer, herborragenter Rragen, wo or fich

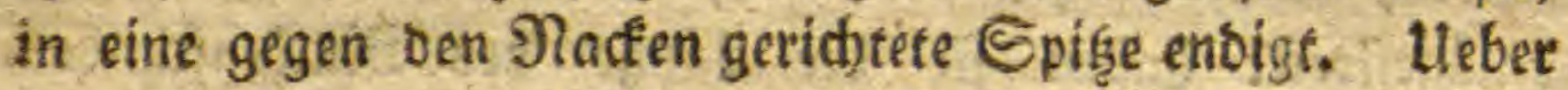

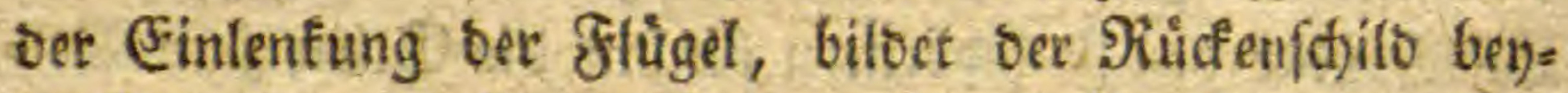
berfeits ein nat) Ginterwairts geridhtetes (ápp(h)en, weld)es bahet gebifbet wirb, inbem eine ₹beilungstinie quer uiber Denfelfen láuft, bie fid bev ber frhigeleinlenfung berab. fenfet, unb ein foldies runbes Sáppchen biloet. Eine

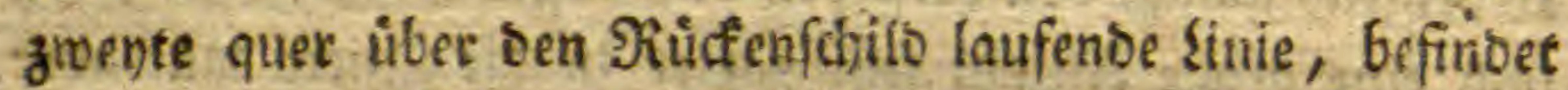
fid) gerabe zwifden ber 2tnglieberung ber Jlügel, gleich)

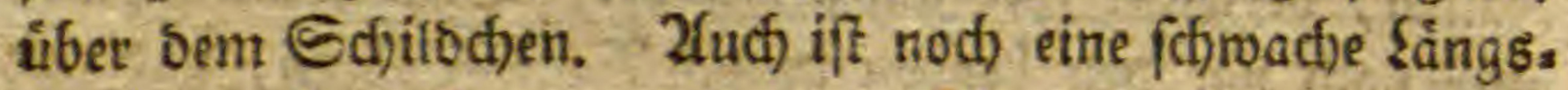

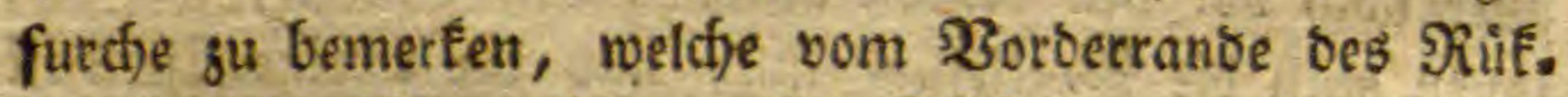

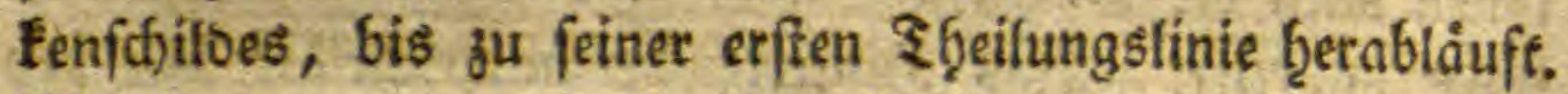
Er ift ganz purpurroth, metaliglänjent, ausgenommen grwifden ber lezten Fbeilungslinie uno bem Edjilodjen, wo et naimliaf in ber Nitte einen, einem von finiten juo

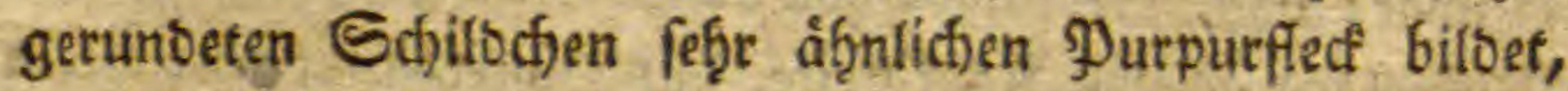
wo bann bie zrey auffern Eeitentheile blau erfocinen. Das Edjiloden ift ganj von angenefymer bunfelblauer, metallglainjenber farbe, breiter als lainger, unten zugee runbet, unb beyberfeits befindet fid) an bemfelben eir nad) auswairts gerichteter, zugefpizter, gleich farbiger fortfaßs. Die oreyedtigen Eeitentgeile des ganjen $\mathfrak{B}$ ruffftud? fino 


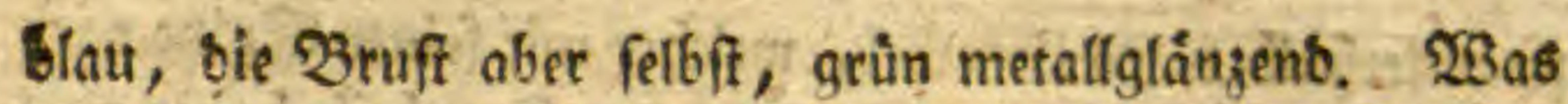
ben Ueberjug des Siücfenfchilbes uno bas Edjilodien be. trift, fo ift er jenem bes Ropfs ganj gleich); er beftę̧et naim. Jid) ebenfafts aus lauter Sobhlpunften u. f. w. - Der Shinterteib hat oie sainge bes Brufffticfs, fammt bent Edjilodien, ift oberţalb fefer ftart getwolbt, unten fę̧r platt, an ben Seiten zugerunbet, ganz, uno bennab̧e b̧albfugelformig. Er ift in brey Ringe eingetheilt, bavon Der mittlere ber grojiste, uno ber etfte ber fleinfte ift. 23 as nod) in 3 etref Des Baues von temfelben ju bemet. fen vorfomme, ift: baf ber erfte গRing gegen feinen obern Dano, ober beffer zu fagen, ber ßorbetranb tes f̧interIeibs einen Einorud b̧at, uno oer 2ffter eine feinem Unter. ranbe paraffellaufente forractie furdise befizt, weldhe ben felben etwas am Ranbe wúlftig macht. Der ganje Jfitta terleib ift zart punftirt, uno mit fobr furzen fuchfigen J̧ärd)en befegt, aus aflen librigen Ţ̧eilen am meiften glän. geno; unt von rother metallifh glänzeneer farbe, weldfe fid) gegen bie Mitte bes f̧interleibs, in einen fệr anges neţmen blauen fledf nach) unb nad) verliert. Interb̨alb ift oer ganze f̧interleib fdwarz, unbehaart, unb fpiegele. glatt. Die fligel fint raudffarb, ins Gelbe fallent, wie an ben ubrigen Goltweipen geffaltet, uno ḩaben theils Dunfelbraune bice, theils lidjtere uno bunnere flügelrib. ben. Unter ben brey Paar friffen iff bas mittlere uns Ginterfte von gleicher länge, bas vorberffe aber etwas füre zer. Die Echenfel affer sren פaare fino bicf, furg uno fáulfơrmig, Die Edhienbeine viel suinner, ebenfalls von făulformiger, boch nid)t fo platter (jeftalt, uno mit erfiea ten bon gleidjer Sånge. 24n ib̧rem braunen Enbe b̧aben 
fie unterţalf einen Stachel, nelther mit feiner Spiz̧e naơ) vorwarts getidftet ift. Diefe benden \$ußstheile ḩaben eine fdoone blaue, oft ins Biolette (dfimmernbe farbe. Die fünf fuksblattgliebchen zufammen, b̧aben bie sainge bes

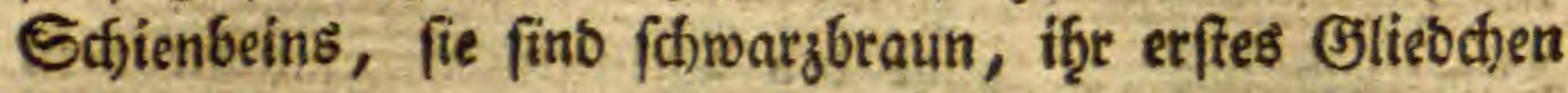
ift bas lángfte, walzenförmig, bie folgenoen fệr furz, fåulförmig, uno bas lezte, an welchem bie geftrummte

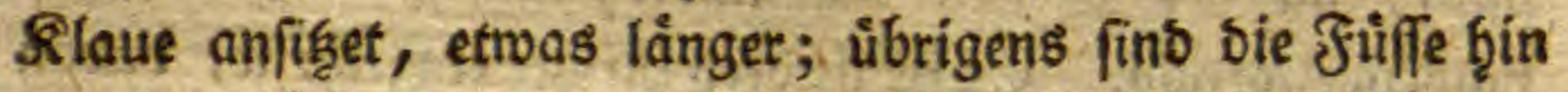
unb ḩer, befonbers bie Sdjienbeine, mit eingelnen fómars. zen Borftenţaaren befegt.

Diefe Bolbwefpe fommt im Monate 2(uguft auf bet Solute ber Edjaafgarbe (Achillea millefolium Lin.) vor. Sie ift nifft gar gemein, unb id ha habe biefelbe im Sdjang. graben bes Sanotḩors ben Prag sefangen.

\section{XXIII.}

\section{Mufca Menthaftri. Die Maingfliege.}

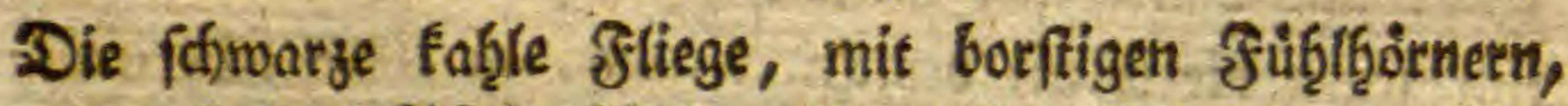

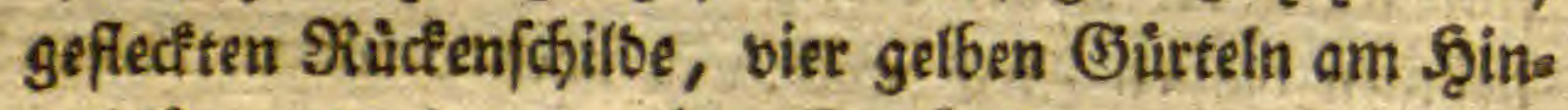
terteib, uno einem gelben Sdjilbonen.

Mufca antennis fetariis nigra nuda, thorace maculato, abdomine cingulis quatuor feutelloque flavis.

Lin. Syft, Nat. Ed. XII. T. I. p. 987. G. 233. Sp. 53.

Id. Faun. Svec. 1819.

Geofr. Paris. 2. p. 5r4. In. 4 r.

Faun. Fridr, n. 722 .

Schrank Enum. Inf. Auftr. n, $9 \circ 9$.

Degeer inf, I. 6. p. rng. n. 10. 
Villers Ent, Lin. T. III. p. 448. G. HI. Sp. 102. M. de la menthe.

Fabr. Syft, Ent, p. 771. G. I 72. Sp. 43. Syrphus Menthaftri,

Die ganze Stiege, erteicft voñ ber Stitn bis an bie X(ferfpişe, eine sånge von bren uno ein viertel Sinie. Det Ropf ift in Betract)t bes ganzen Infeftes großß, faft balbfugelrunb, bod) aber bey bem Mtunb etros nad) vor. märts ḩerbortreteno. Die 2fugen, nef̧men feitrwäts bie ganze sänge bes Ropfs ein, machen beffen grópten Sḩeil aus, fino fệr fdjơn rotţbraun, nietenfỏrmig; inbem fie

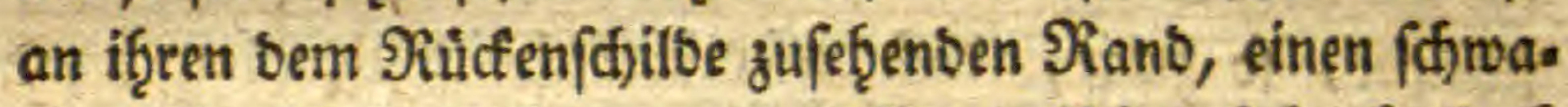
djen 2tusfdinitt bqaben, unb laffen zwifdjen fid) oberḩalb

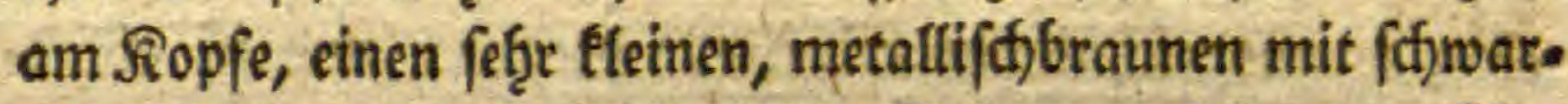

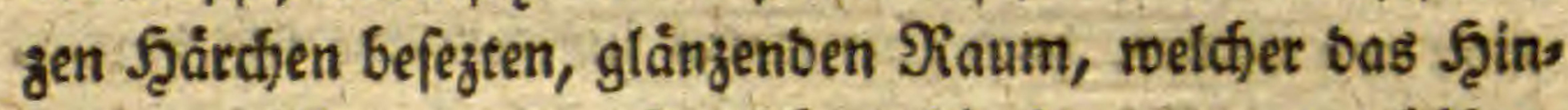
terḩaupt bitbet, unb auf melajem bie bren etrvas erḩǫh̨ten গebenaugen zum Borfdfein fommen, weld)e fofwarz, unt in einem recfjtrointlicten Drenecfe eines nad born uno zroen

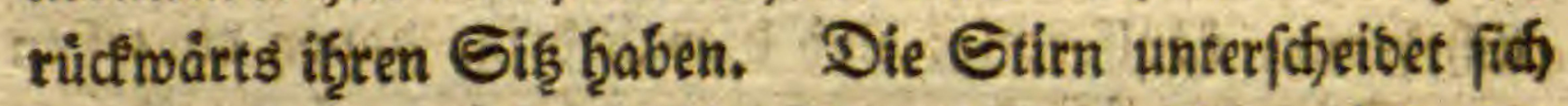

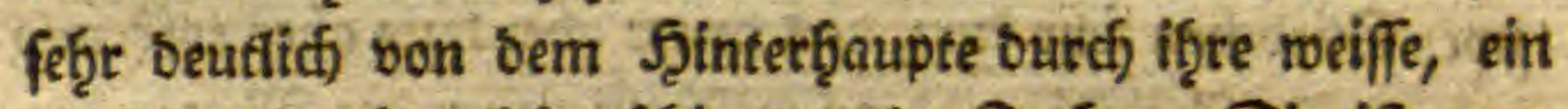
meniges ins blaulithe fojimmernbe farbe. Sie ift ganz glatt, uno von fotmelzartigen 2Infę̧n. Won oben fauft eine metallbraune, gleidjbreite $\mathfrak{B i n b e , ~ b i s ~ f a f t ~ z u ~ b e n ~ S t u ̈ b ̨ t - ~}$ bृơrnern, weldje in ber Mitte ber Stirn, fiemlid, ange= náh̨ert nebeneinanber anfî̧en, Ģerab; ober beffer zu fagen: verlängert fich oas braune finterb̨aupc, born über vie

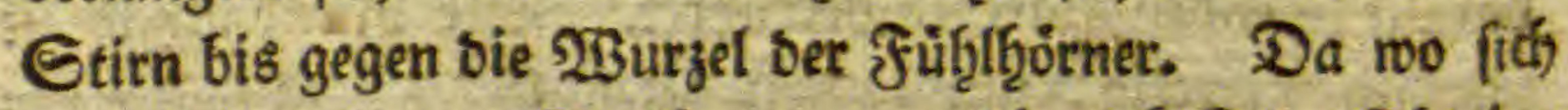
biefe fómarzbraume Berlängerung enoiget, befinbet fid) eine

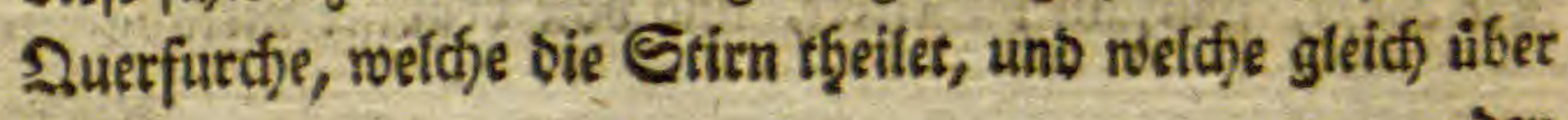


bet fübifgơnern einen mit feinem ausgebogenen ₹ beile sem Sopfichetel jufebenden runben 30 qen bitbet, welcher fich benberfeits gerablinigt, f(hief nad) ouf unb auswairts bis an ben innern Zfugenrans erftrecfet. Unter bem von tiefer D.ueerfurthe gebilbeten Bogen, befinter fich eine bunfle (Fr. habengeit. Unter ben Jiblbornern, ober gegen ben Muno

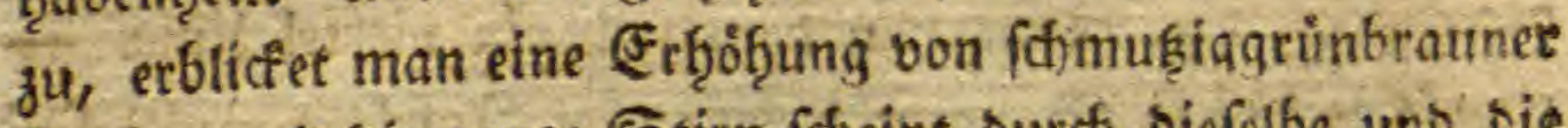
Sarbe, uny bie gange Stirn foleint Durd biefelbe uno tie vorbefdriebene Şinterfgauptebinte in ter Mitte in die Län ge getheilt zu fenn. Die Etirn berlängert fich gegen ih̨r Enbe zu unmerf fich in bie gleidffarbige Nuntogegent, melo

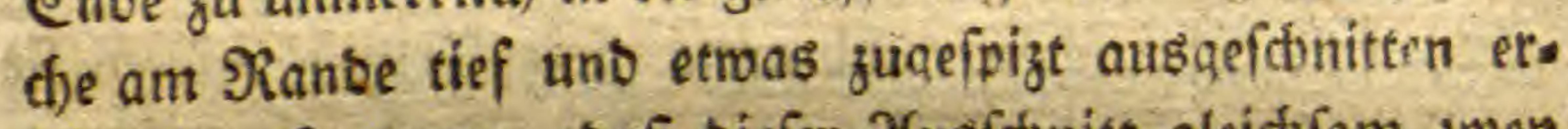

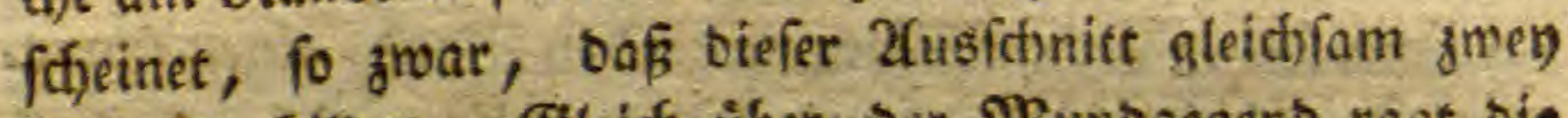

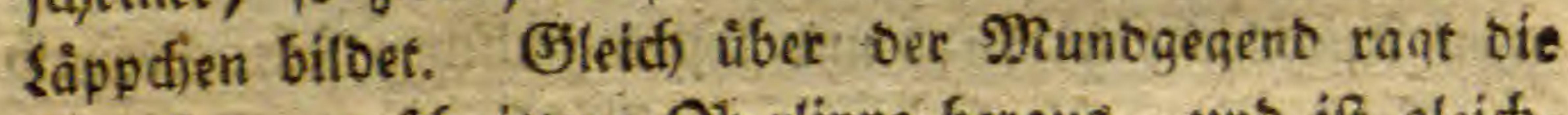
eben fo ausgefdgnittene Sb rlippe beraus, unb iff gleid)s falls von weifer, bod) aber etwas ins gelbliche fdimmern. ber Jarbe. Die ganje Nuntófnung bildet ein fpiģwinf. liches orensecfiges sod), in weldem oer braune Eaugruif. fet gans verborgen liegt. Die futhlfhorner fino glate, liffțbraun, fáulfợmig, uno brengliebrig, bavon bie erfen

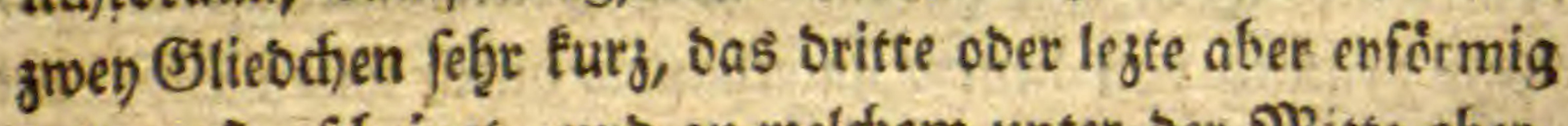
unb grof erfffeinet, unb an weld)em unter ber शhitte obere halb eine gang einfact)e Burfte entfpringet, weldhe balb liber

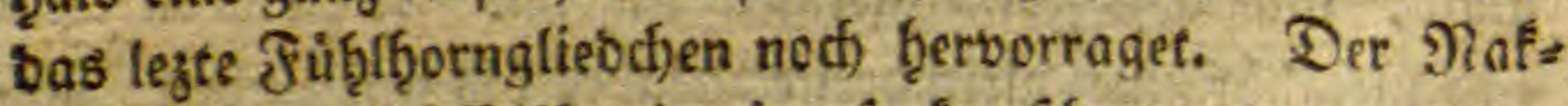
fen ift feid)t fourffelformig eingefenft, fdywarggrau uno bet

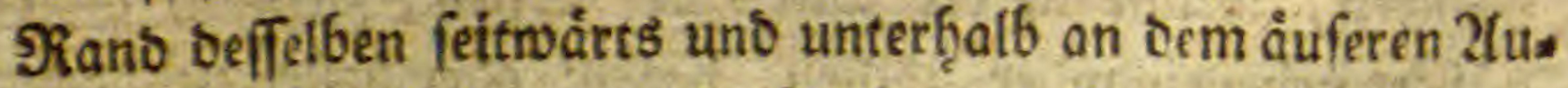
gentante filbergrau, welche Jarbe von oenen feinen biche

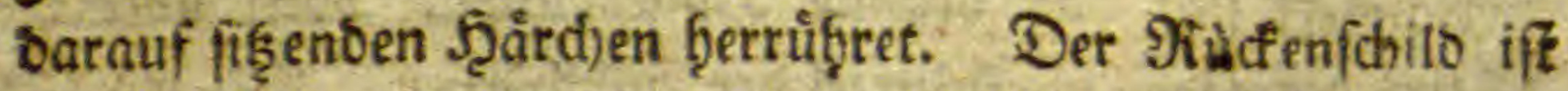
långlid) bierectig, mir jugerumbeten (Ecten, fhmäler als ber $\Re o p f$, fparfam punftist, uno von brauner metallglän. 
zenber farbe. Eein Geitentans ift vom oberen Seltenedt bis zur flúgeleintenfung benderfeits gelb. Unter ber Flit. geleinlenfung if tas Bruffituice ebenfalls gelb, unb groen gelbe glectchen fommen an jeter Seite beffelben zum 2Borfidein; bavon eines gleidf) neben ber (Einlenfung bes erften, bas anbere aber bey) ber (Finlenfung bes zwenten I uppaates feinen $\mathcal{E}_{i}$ bु bat, unb von bem grofen gelben Jfted unter ber Flügeleinlenfung nur burd) eine D.ueerfurdie getrennt wirb, Ulebrigens ift Das ganje Sruffftúcf mit getabe abfftef̧enben feţr feinen J̧árchen bewachfer. Das Etfiltotjen ift gang won gelber farbe unb einer b̨alben Birfelf(d)eibe gleidf), bes ten gerablinigte Seite an bem গRücfenfffitto genau anliegt.

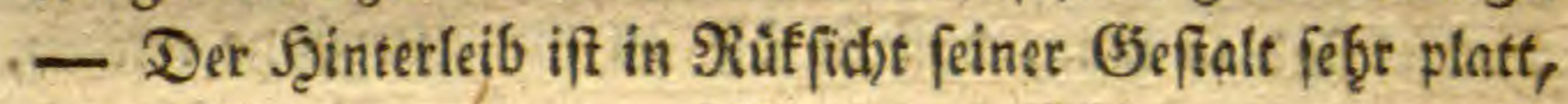
lang, fotmal, gegen ben zffter etwas breiter, unb enthále

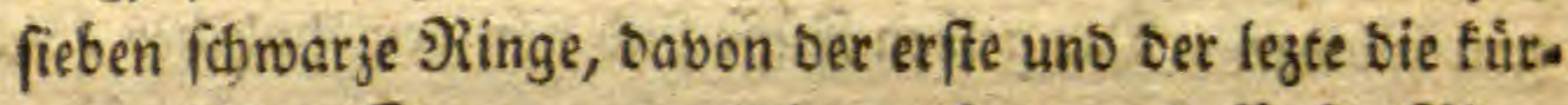
zeften fint. Der zwente, oritte, vierte uno fünfte $\Re i$ ing, bat eine breite in ber Mitfe unterbrodjene 3 inbe, bavon

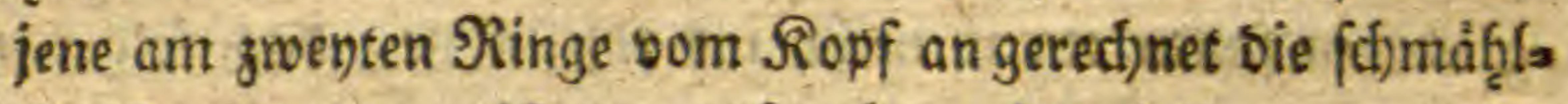
fte ift, unb am meiften unterbrod)en wirb, jene am jwenten if etwas breiter, aus allen am wenigften unterbrodfen, bie am vierten nod) breiter unb etwas meg̨t als bie vorize un's terbroctien. Die am fünften Sing ift entlid) fo breit als jene am vierten, both) aber nimmt fie faft bie ganje fläde

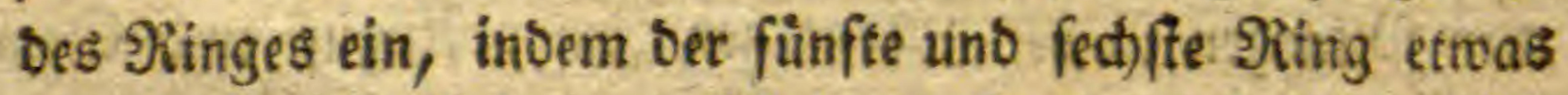
fleiner als bie úbrigen, nebft ber erften und fieberben iff. Sie ift in ber Mitte ebenfalls unterbrod)en. Man mu[ wirtlich bie Einbiloungsftraft etroas ju Şưlfe nef̧men, um

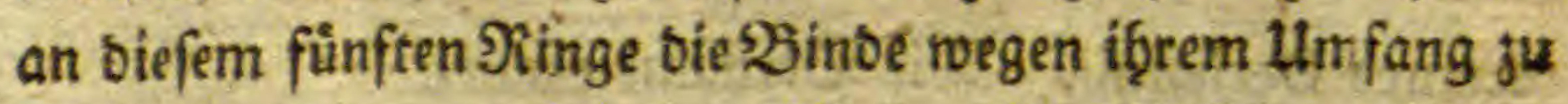

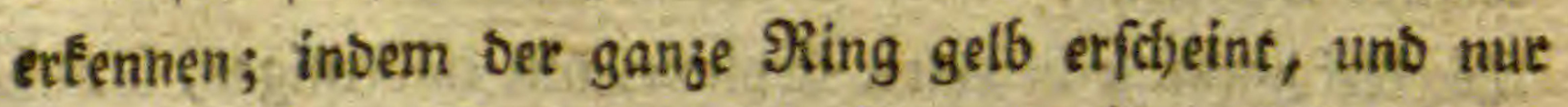
gnee) fobrarge Dbereffe, eine fofwarze sangstinie in ber 
Mitte, uns neben siefer am Unterrande benberfeits einen gleidffårbigen brenecfigen Jlecf bzaf. Diefe auf folgenoe Zurt georoneten fofwarzen Seid)nungen f̧interlaffen ben bin.

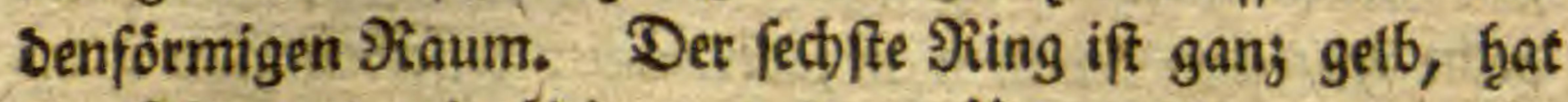
am Dbertande ein fleines, unb am Unterranbe zwey, mito

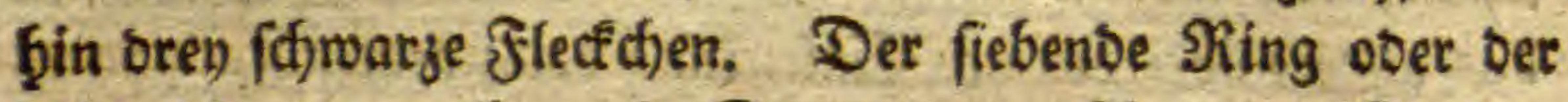
after ift gang gelb, mit Sputen von ffinarzen Fledfen. uebrigens ift ber ganze fointerleib grau beḩart, tho oie Saárden an ier \berfläc)e liegen am Rơrper, jene aber am Seitenranbe fteģen gerabe weg. Unterb̧alb ift ber ganje Şinterleib gelb, von welcher farbe aud) Die Ectjwungtólb. d)en fammt ib̧rer barüber liegenben शrufthel fino. - Die Slügel fins fo lang, baf fie bis an bie 2(fterfpişe reicf)en, fómal, burchffid)tig, unb von angeneb̨men pfauen/chroeifis

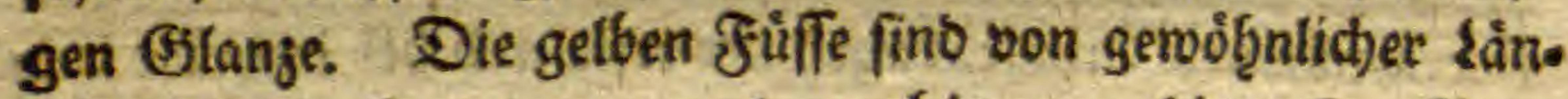
ge, bủnn, nef̧men vom vorberen bis zum bínterften פaar

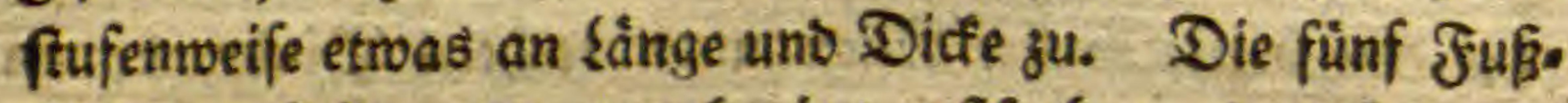
gliebchen fallen etwas meḩr ins roftfarbne, oas folgende gro̊ker ats bie brey von gleidjer Bróß̨e Darauffolgenben, uno bas lezte aus aflen bas Rleinfte, uub gat rofffarbne Slauen. Zflle biefe fupglieod)en fino mit fef̧ct furgen Sgarborften befezt.

Diefe Sliege ift in Bǫ̛̣men ḩäufig auf bolbentragen ben Pflanjen in Den MRonathen July, 2(uguft unb Eep: sember.

\section{XXIV.}

Aranea Derhamï. Die Derḩamsfpinne.

Die bleidbraune bef̧aarte Spinne, mit enfötrmigen, braun: gefteften Şinterleib uno feilförmigen J̈reffpif̧en. 
Aranea pallide fufca, hirfuta, abdomine ovato fusco maculato, palpis clavatis.

Scop. Ent. Carn. p. 400. fp. I I 04.

Scheff, icon. inf. Rat. T. CLVIII, f. 6. T. CVI, f. 4.

\&ifters Rat, Der Epinnen. 2lnf̧ang p. 201. Sf. 228. p.

293. Sp. 282.

Jrifd) Ini. Deutich. Die Rolbenfpinne.

Diefe Epinne erreict)t, von ber Epifee bes 24pters bis an ben vorberften Sheil ber Grirn, eine sănge von fieben sinien. Das Brufffud ift in Betract)t bes ganjen Infefts, feger fraré uno groß, hat von oben eine enfors: mige Jiqur, fo jwar, Daßs Der fpişigere ₹̧̧eil gegen oie Zugen, Der ftumpfere aber gegen ben J̦interleib zufteget. Es ift nach) born ju an beiben Eeiten etroas eingeoruidt, unb von farbe grau, mit einem marten Slanje. Diefe graue farbe am Doertheile bes Sruftftüs, beftę̧et aus einem fd,muşigen Uleberguge, weld)en man von bemfelben febr leid)t mit einem feinen Inftrumente abjieben fann, wo alsbann ber ganze গiùcfenfd)ilto barunter fdion braun, glatt uno glaingenb erfit)eint. Nitten auf bemfelben be. finbet fidh eine ßeibe langer, fparfam ftebenber, aufgee ridfteter Borffen, meldhe in bie länge lauft, uno bor ben Zugen fommen ebenfalls, bod) Gåufigere Borftenḩaare zumt 2orfhein. Die acht 2ugen fteben vorn in zmen Reifjen, fo jrat, oaß ganz vorn vier gleicharofe in einer Duerlinie ftebgen, jwen etroas fleinere befinten fid hinter ben

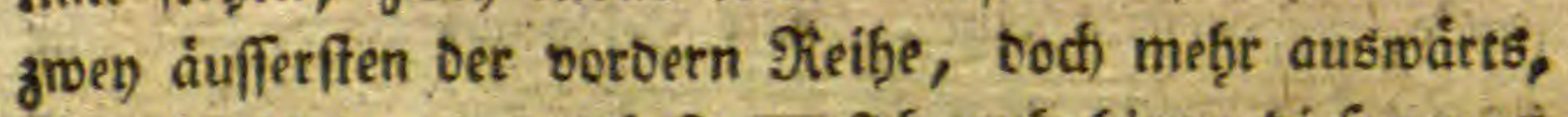
uno bie übrigen zwen befinben fid) noch) finter biefen groes legteren, uno fommen gerabe binter ben groen mittlern bee borberften Risib̨e, both etwas bavon entfernt ju fteben. 
Sie fino übrigens ganz burdfififtig, uno von einem ßetna

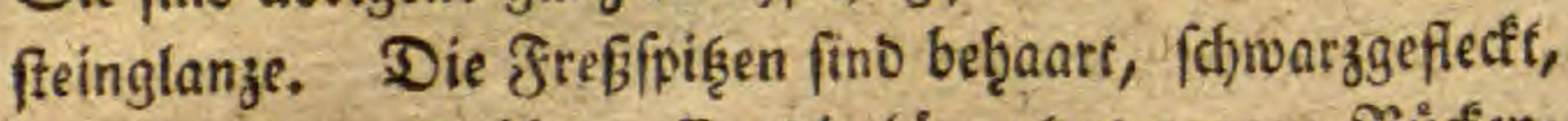

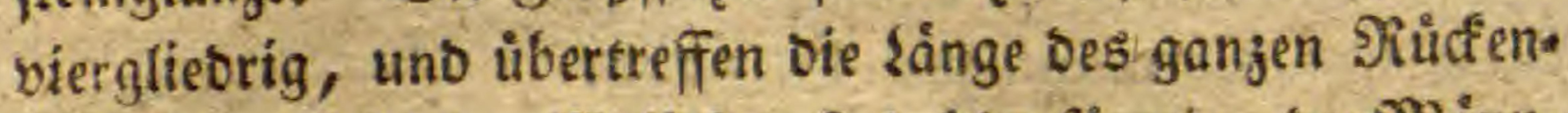
fajilbes. Jene ber 23 eibchen fino feber formig, ber Mlän= den if̧re aber gleid)en jwen ftarfen Edjläglin, inbem fie

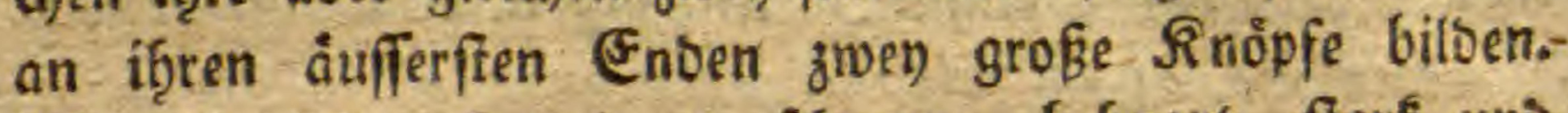
Die Rinnlaben fino lang, fotwar $z_{z}$, befgart, fratf uno glánjento. - Der Şinterleib ift etwas lánger als ber

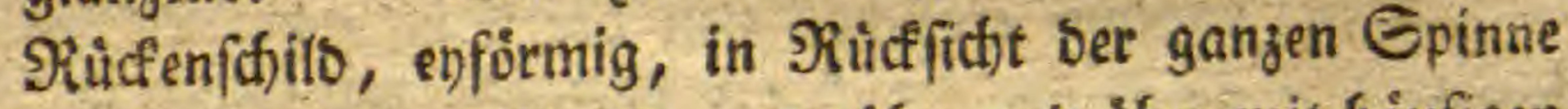
nur von mittlerer (5)ớge, uno ùber uno ủber mit ḩăufigen fotwarzbraunen f̧aarborffen befegt. Die Brunofarbe bef* felben ift ein lid)tes, fotmuşiges 2 raungelb, weldhes abcr, wegen ben ḩåufigen fodwargen Jlecthen, balo buntler, balo lid)tet etfaheinet. Diefe ijt erwábznten fleinen flects dhen bilben bie ganze Seicfjnung bes Scinterleibes, Durdf iḩr Bufammenfieffen an verfotievenen Etellen. Befono bers aber an ber Dberflache bes Scinterleibes, wo fie, in. bem fie zufammentreten, zwen fdwarze, benderfeits vers lofifhene Längsbinben bilben, welche parallel neben einane Der berablaufen, unb bavon jebe fectis licftgelbbraune Flecten entbălt, Dabon bie zween vorberften bie anfergnflid): ften fint, uno oie übrigen frufenweife an Brớbe abneţe men. Unterthalb am Şinterleibe, ober am Sauche, befina bet fid in ber झRitte ein anfebrnlidier, efwas länglid) vier: ecfiger fifwarjer fflef, unb zroen grofe braune fferjen naz

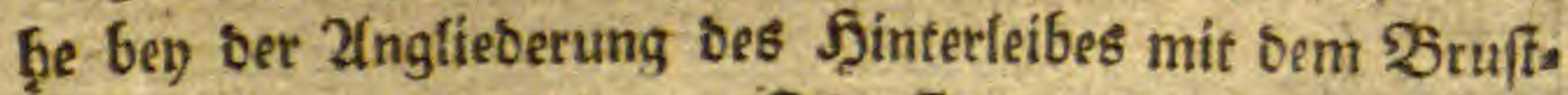
ftücfe, benberfeits einer. Die Epinnwaàrzhtien fino nur ein weniges ḩervorragent. - Die futffe fino surdfaus lang, unter einanber bon ungleicher lánge, bick uno von

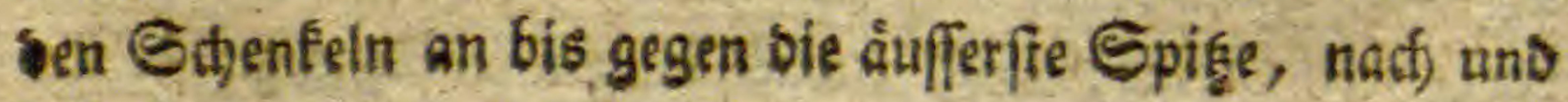


nach in bas Dủne auslaufeno. Das längfe ĐुJaar ous allen ift bas vierte, barauf folget bas erfe, Dann bas zwente, unb entlich bas britte $\mathfrak{P}_{a a r}$. Eie finb afle turd). aus mit fatwarzen und langen Sorftenţaaren befegt, von. Jarbe lichtbraun, Durchficheinent, uno mit fdwarjen, in Der Mitte aber fid) immer in bas Braune verlierenten Sinben berfę̧en. Die Jup̧tlauen fino fȩ̣r flein uns fकnaty.

Simne' glaubre, onf feine f̧aukfipinne (Aranea do. meftica) und bie Derbamsfpinne des Ecopoli cinerlas 2frt wairen, wo et aber fegr ittt, weil oie erftere fotwarge Flecte auf einem graubraunen (5icunte, Diefe aber lid)t: braune auf einem braunen Grunte fgat. Die Epinnen. art, fo siffer in feiner Naturgefofidte, unter bem Niamen Aranea domeftica befdreibt, fheint ebenfalls nur gegen. wårtige 2lrt ju fenn, weil er fagt, baß fie eine fo anjef̧n. lid)e (Gro̊ge erreich)e, flat aber wieber im Gegentbeeil, wemt man feine Sefdreibung lieft, bie wab̧re J̧ausfpinne bes Sinne' mit eingemengt; folglich bende Epinnarten mit eins ander verwedffit, fo wie es bie meiften Entomologen ges than Gaben. Echaffer b̧at Die Derbamsfpinne zreymat,

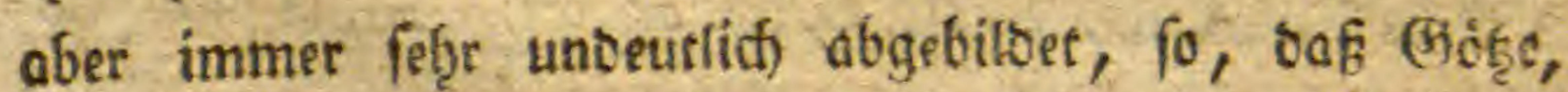
weld)er ben 2lnbang zu sifters Ueberfę̧ung ber Naturge. fdid)te ber Epinnen gejdrieben, Diefe bense albbiloungen, jebe für fid), als eine netre 2(rt anfüb̧ret, uno jwar jene auf Der 158.9 latte fig. 6 . Aranea novem maculata, tho Die auf ber 106. §.6. Aranea flava nigro maculata nenne. 
Diefe Spinne befinbet fich b̧áufig in Bebåuben ben ganjen Sommer burd), iff fef̧e wilb und von einem furdt). Garen, für viele Mienffien (Efel erregenben Ilnfeḩen. WBenn man fie in Seţăltniffe fpert, wo fie if̧re Befangenfthaft merfet, bauert fie nidit lange unb fittet balb. Jht (J)= webe fpinnt fie feb̨r oict), floräb̨nlict uno groß, in ben

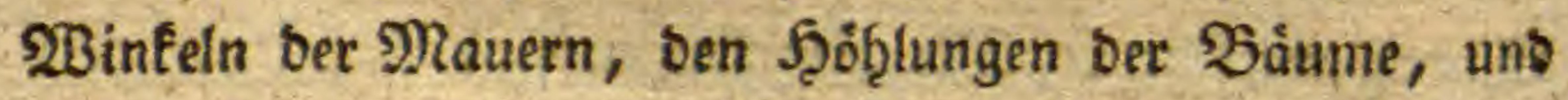
anbern finftern Dertern. Echon in ibrer erften Jugent fann man biefelbe von allen übrigen 2frten leidt) unter. Theiben. Die Werfhiebenģeiten berfelben betreffen nur blos sie bals lidftere, balo buntlere Sarbe und వeidnung.

\section{XXV.}

Mufca noctiluca. Die nahtleuctstenbe fliege.

Die wenig fammtţaarige, fffwarze, mit borftigen Süḩ6

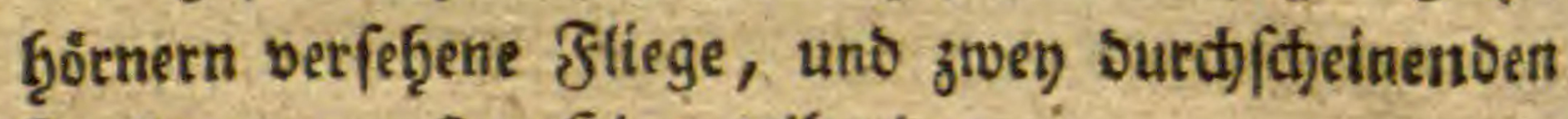
Jlecten am erften f̧interleibstinge.

Mufca antennis fetariis fubtomentofa atra, abdominis primo fegmento maculis duabus pellucidis.

Linn. Syft. Nat. T. I. G. 283 . Sp. 48.

Villers Ent. Linn. T. III. G. III. Sp.97. M. Ia phosphorique.

Faun. Fridr. n. 713 .

Fabr. Syft. Ent. Sp. 54. Syrphus noctilucus:

Die Sainge Der gangen fliege beträgt, vom Ropf bis zum 2ffer, 5 sinien. Der Ropp ift fo breit als bec शiủcéen 


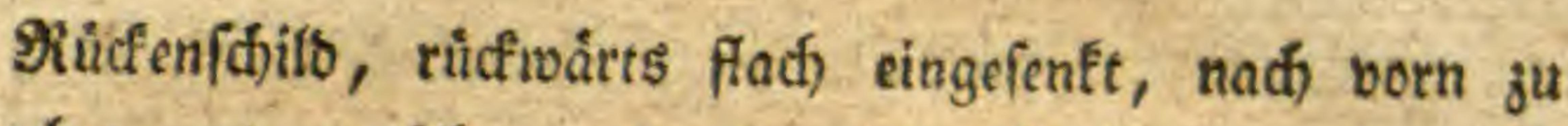
aber runo gewoolbt, uno menn man if̨n bon born berrad, tet, fo iff fein ttmriß länglichruno. Die 2lugen fino rotfos braun, unb ftoken an bem J̧interf̧aupte nid)t zufammen,

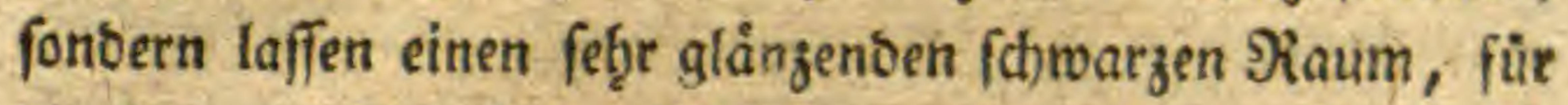
bie bren -gleichfarbigen Niebenaugen jurüd, weld)er ficf benberfeits nod ůber ben Dberrano ber 2(ugen f̧ingief̧et, gegen if̧ren 2luffenrano grau wiro, uno an Unterranbe berfelben wieber glängent fotwarz erfheinet. Die Etirn

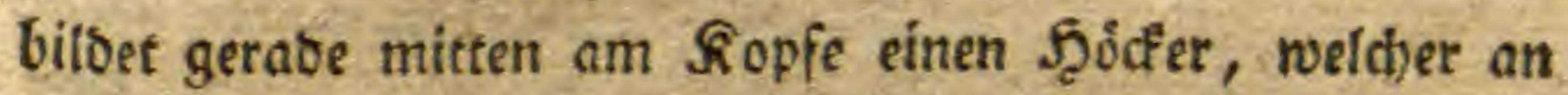

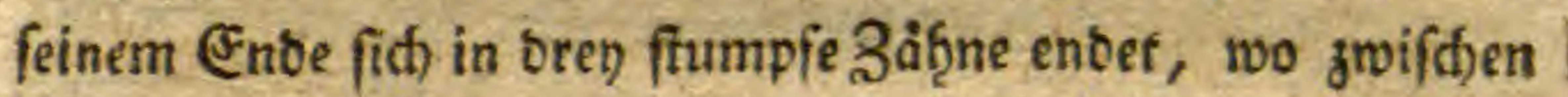
Den zwen Cinfdinitten, weldo fie unter einander bilben,

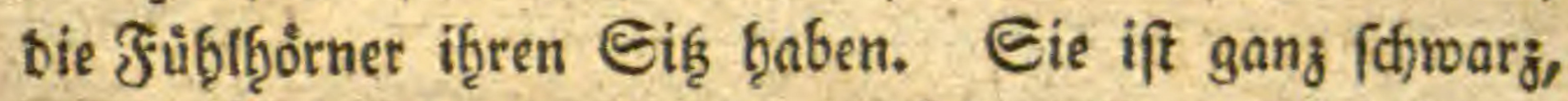
glänjeno, punftirt, graubraun bef̧aarf, uno ḩat jebers feits gegen ben innern 2ugenranb zu, einen fdumusigs: reeiffen flect. 2(n Dem Stimb̨ơcter befinben fich fafmarze,

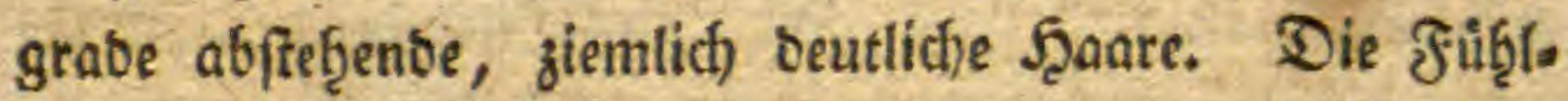
Gornet fins orengliebrig uno fofmarg, bas erfte (Jliebcjen if fegelforrmig, bas zmente plattgebruicft, benbe etwas mit Borften befejt, oas oritte aber ift oas grỏßte, ofgne Bot: ften, uno gleidhet einem breiten furzen säppcten, uno b̨af am obern Flanbe eine, von feíner $\mathfrak{B}$ Burjel auslaufente ftarfe, uno über bas lejte (Gliebd)en fid) berausffrectende

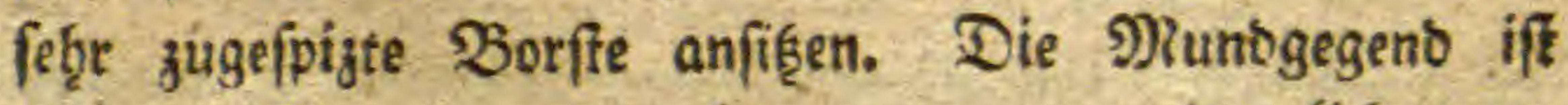
glainjens ficwarz, wito aber, wenn man bas sidht vont Saupte barauf fallen lákt, ganj graubraun, wegen ben

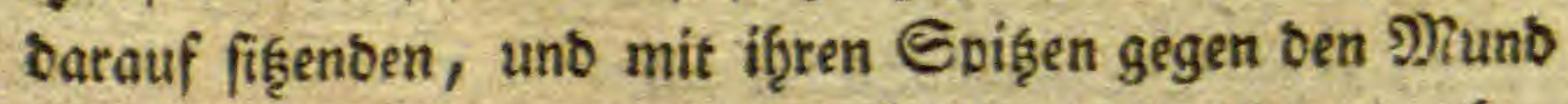

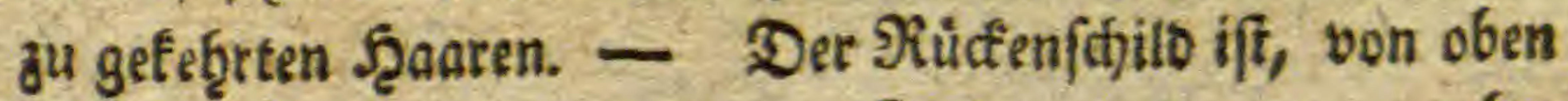
$\Omega_{3}$ 
betradbef, faft fo breit als lang, fdmadt gewoilbe, ganz forvarj, punftirt uno fein beglaart. Das Ediloctsen gleidffarbig, zugerunoet, furz, breit, uno ebenfalls, bodg ster mit längeren f̧aaran von graugelber farbe befezt. -

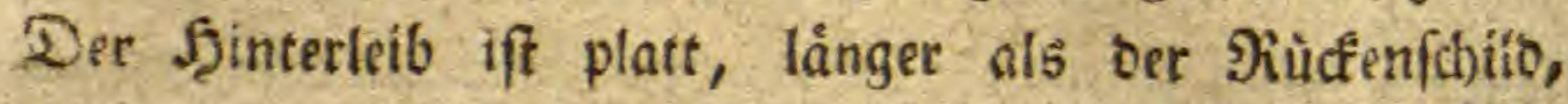
formmt bem Sopf und Edjitodien, fpişig auslaufent, formarz, brenringidt, punftirt, unb am ganjen Sianbe mit graugelben Şanten bidt) befezt. Der erffe Şintets feibsring ben biefer fliege if ganz, bis auf einen fleinen ₹(jeil, námlich) ben unter= Dber= uno Geitenrand, weißs. gerblich und gang surchfffeinens. Dft bildot otefe meiffe, turdifdeinenbe Farbe nur zween grofe flecfe, inbem eine Lángstinie tiefelbe in ber Mitte theilet. - Die Jlügel fino blaß tautbfarb, und b̧aben am Sberrante einen Funfefraudfarbnen grefen, gegen bas Enbe berfelben

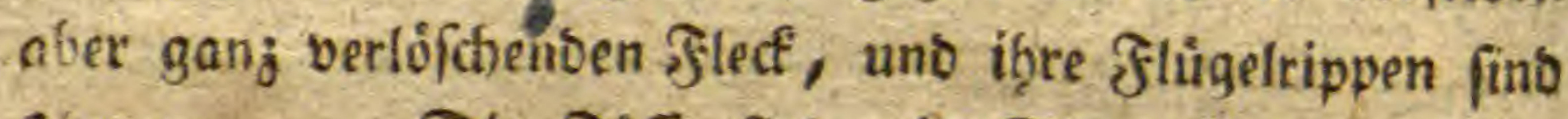
f warg. - Die friffe fint, in Eetradjt ber ganjen Stinge, von mittelmáfiger, unter einanber aber von uno gícider länge; inbem fie von bem vorbern bis zu bem

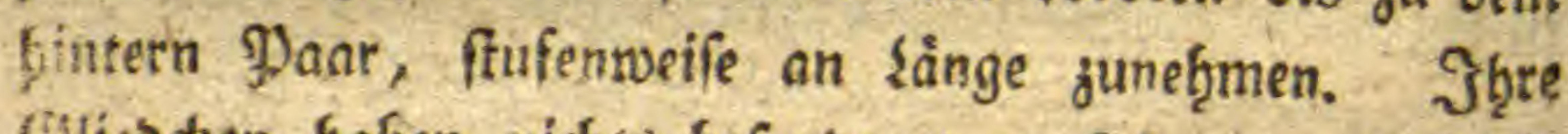
OStisodien baben nichts befonteres an fid, nur baj bie Edhenfel bes Ginterfen surbaars um vieles oicfer, als jene ors erfen uno zmenten fint. Mebrigens fino afle Echenfel Pfiwarj, uns cas àufferffe Enbe berfelben, an

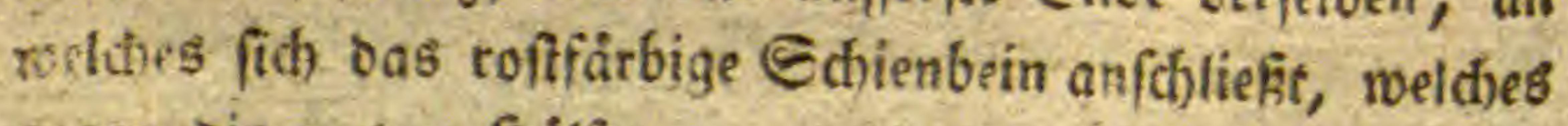

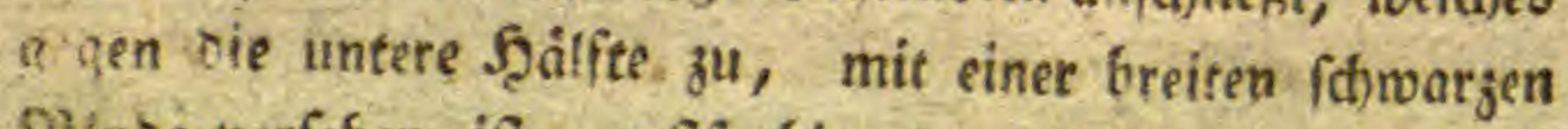
23inbe perfegen ift, reffarbig, meldje Sarbe bie Jufs Elórter alfer Şüffe ebenfalls befigen. 


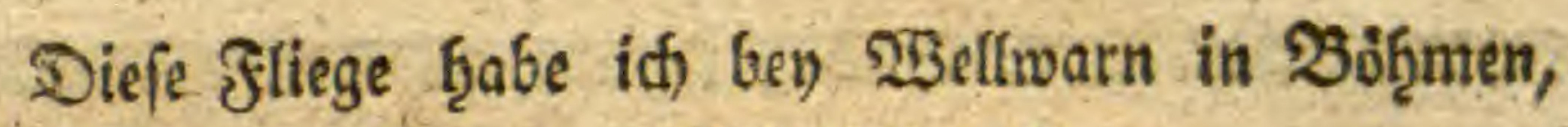
in bem Monate July, auf $\mathfrak{B}$ iefen gefangen.

Billers fagt: Daß̧ feine Eremplare einen Stadfit an ben Sdjenfeln bqaben, weldben id aber nicht finben fann. Bielleid)t macht biefer Stad)el oen (Befolectits. unterfofieb ben Diefer 2frt aus?

Die fortfeghung folgt funftig.

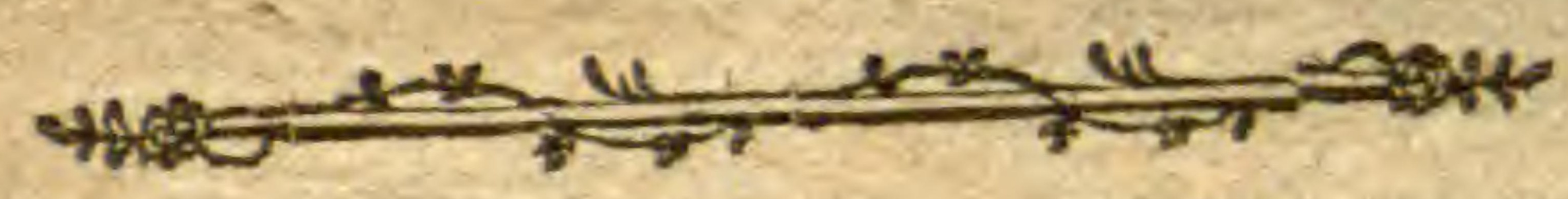




\section{In $n$ balt.}

I. Cantharis leucogaffra, Nova Species.

I1. Tipula murina N. Sp.

III. Tipula virginea . N. Sp.

IV. Tabanus cylindricus. N, Sp.

Pag. 58
60

v. Cahtharis Cardiaca. Linn.

VI. Mufca macrophthalma, N. Sp.

VII. Mufca punêtata Müll.

VIII. Phalæna Echiella, Schiefferm.

IX. Mufea rotundata. Fabr,

X. Mufca fexmaculata. N. Sp.

XI. Mufca cruentata, Villers.

XII. Mufca fignata. N, Sp.

-

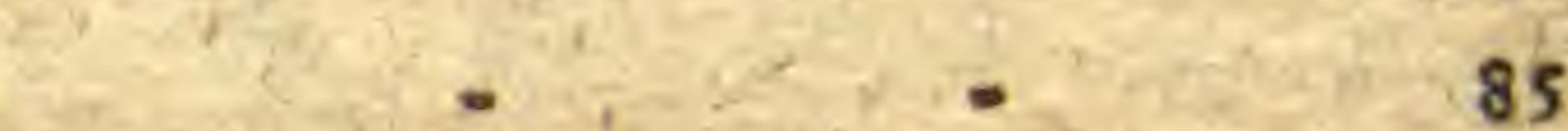

XIIL. Mufca afiliformis. N. Sp.

XIV. Cimex Bardanx, N. Sp.

XV. Aranea cretata. N. Sp.

XVI. Mufca roftrats. Fabricii,

XVII. Silpha denticulata. N. Sp.

XVIII. Phalena compofitellis. Fabricit.

XIX. Acanea folium. N. Sp.

XX. Mufca Alcez. N. Sp.

XXI. Conops bimaculata. N. Sp.

XXII. Chrilis candens, N. Sp.

XXIII. Mufea Menthaftri,

XXIV. Mufca Derhamii,

XXV. Mufca noetilpea.

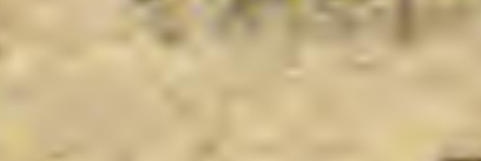

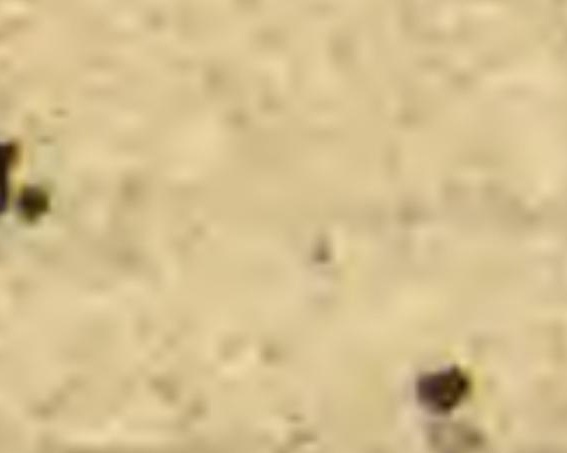


X.

\section{פefdreffung}

bes

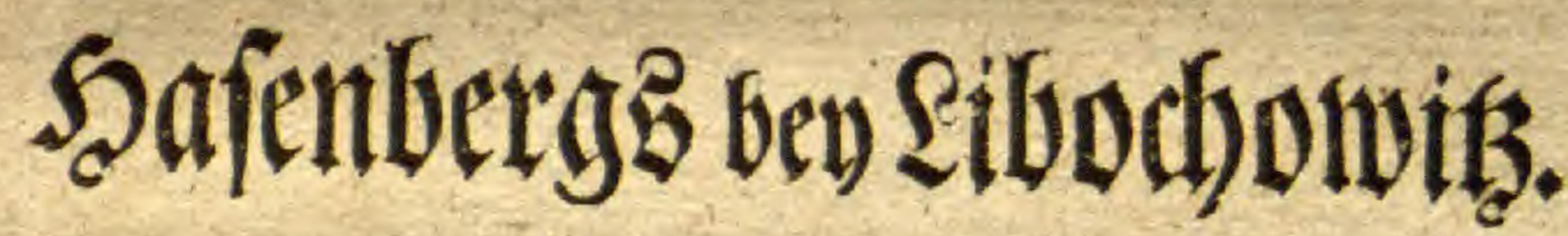

Bon

ADalbert von Sd)mirfizfy,

fanomeffer.

(E. bis Sitel=2Bignette.)

\& 5 


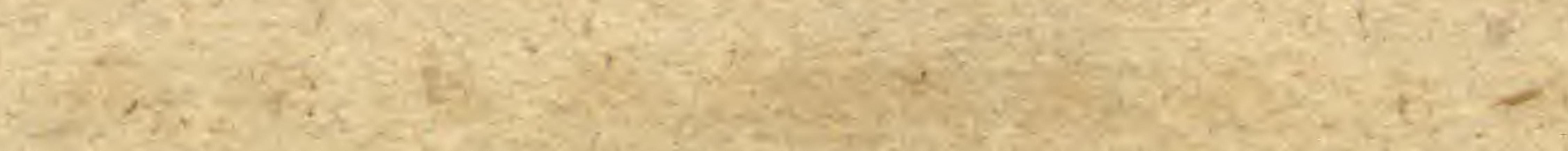

$\left(-\frac{1}{2}\right.$

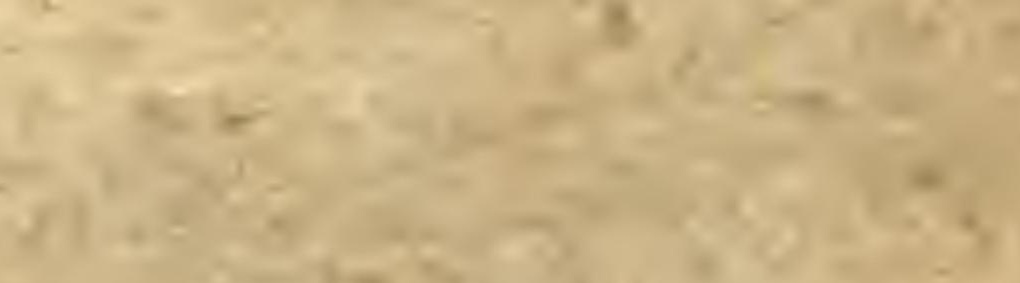

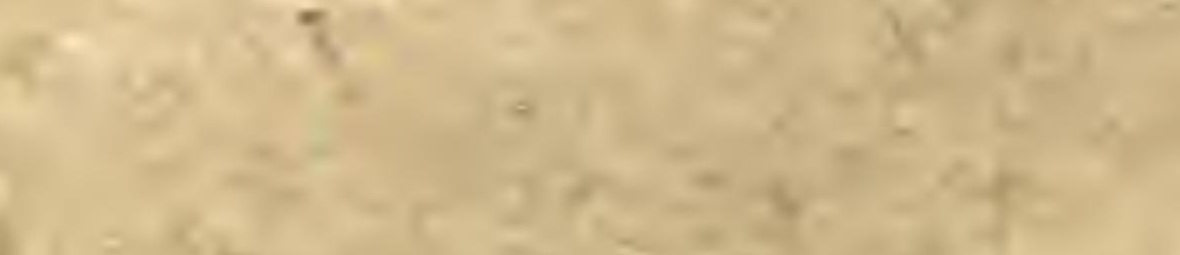

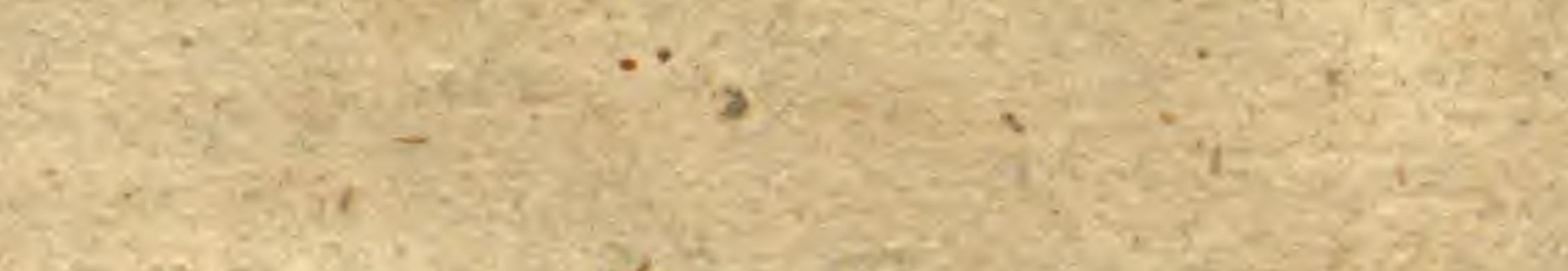

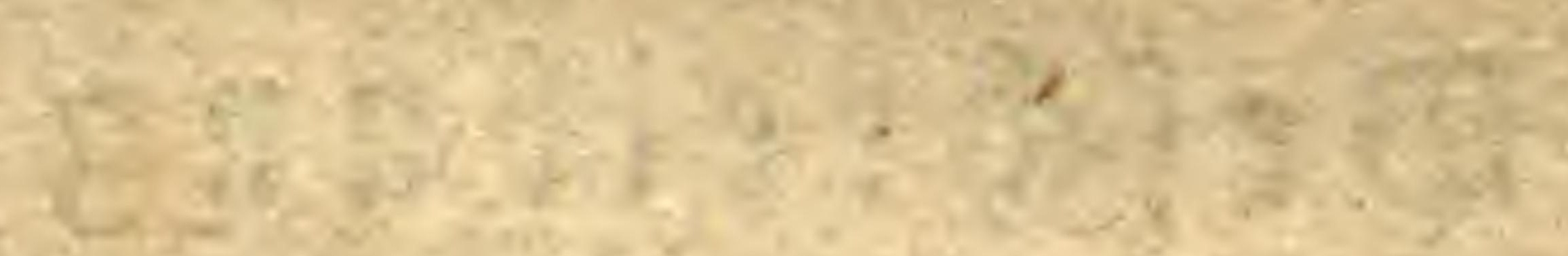

$x^{2}$

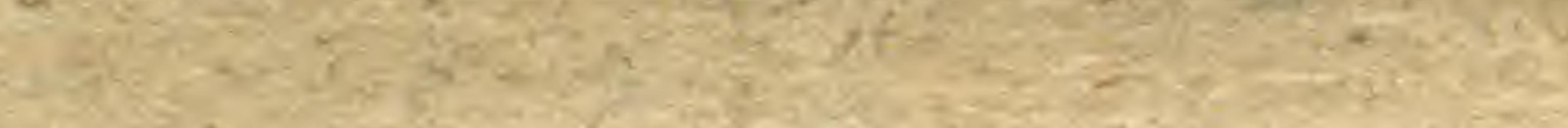

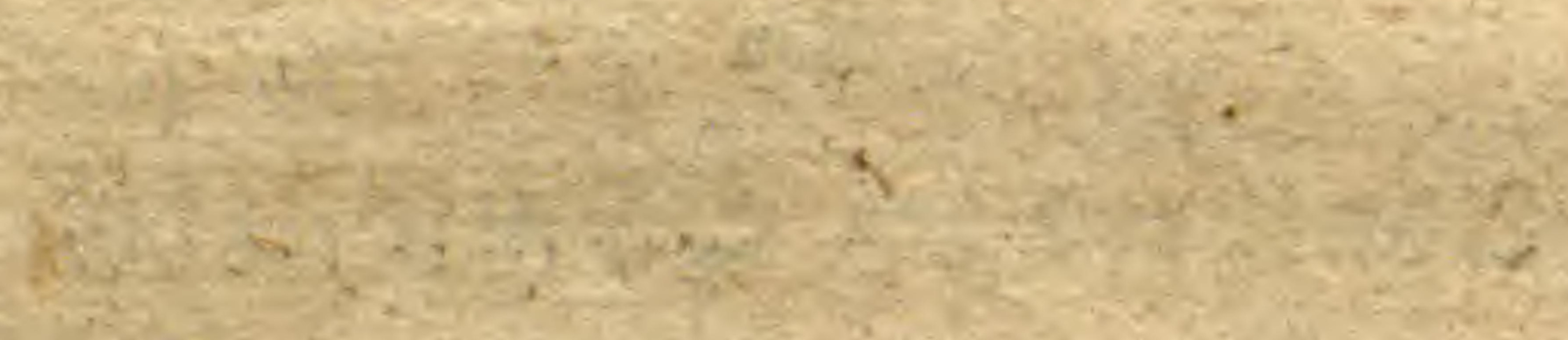

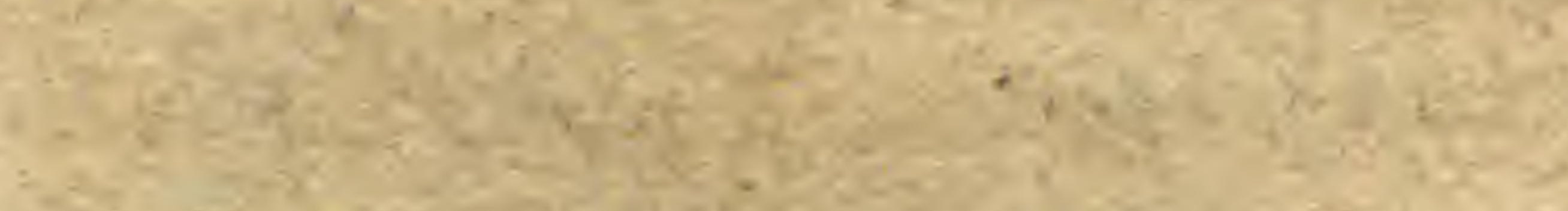

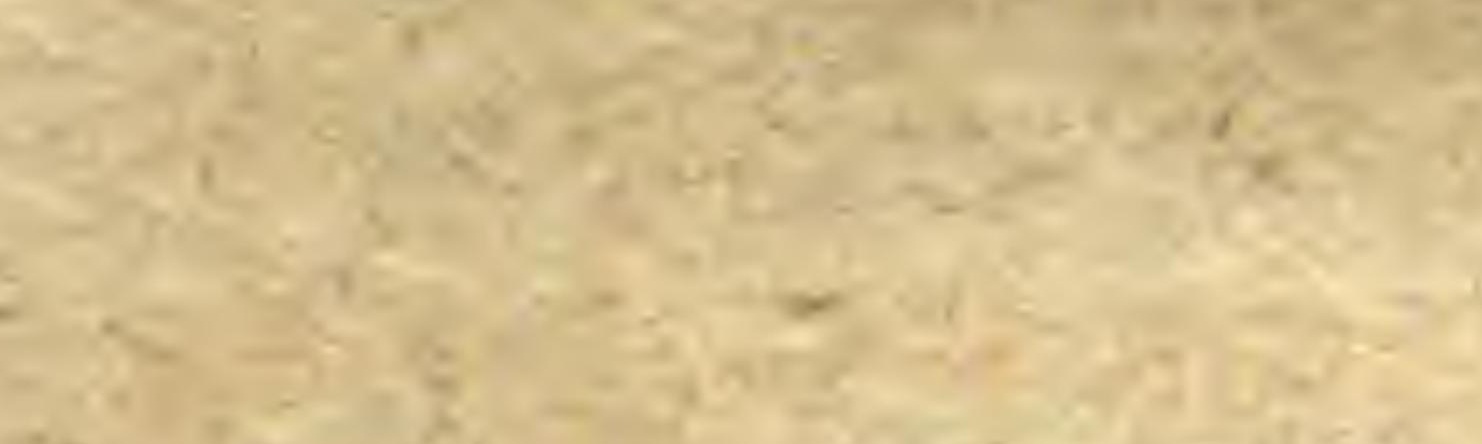

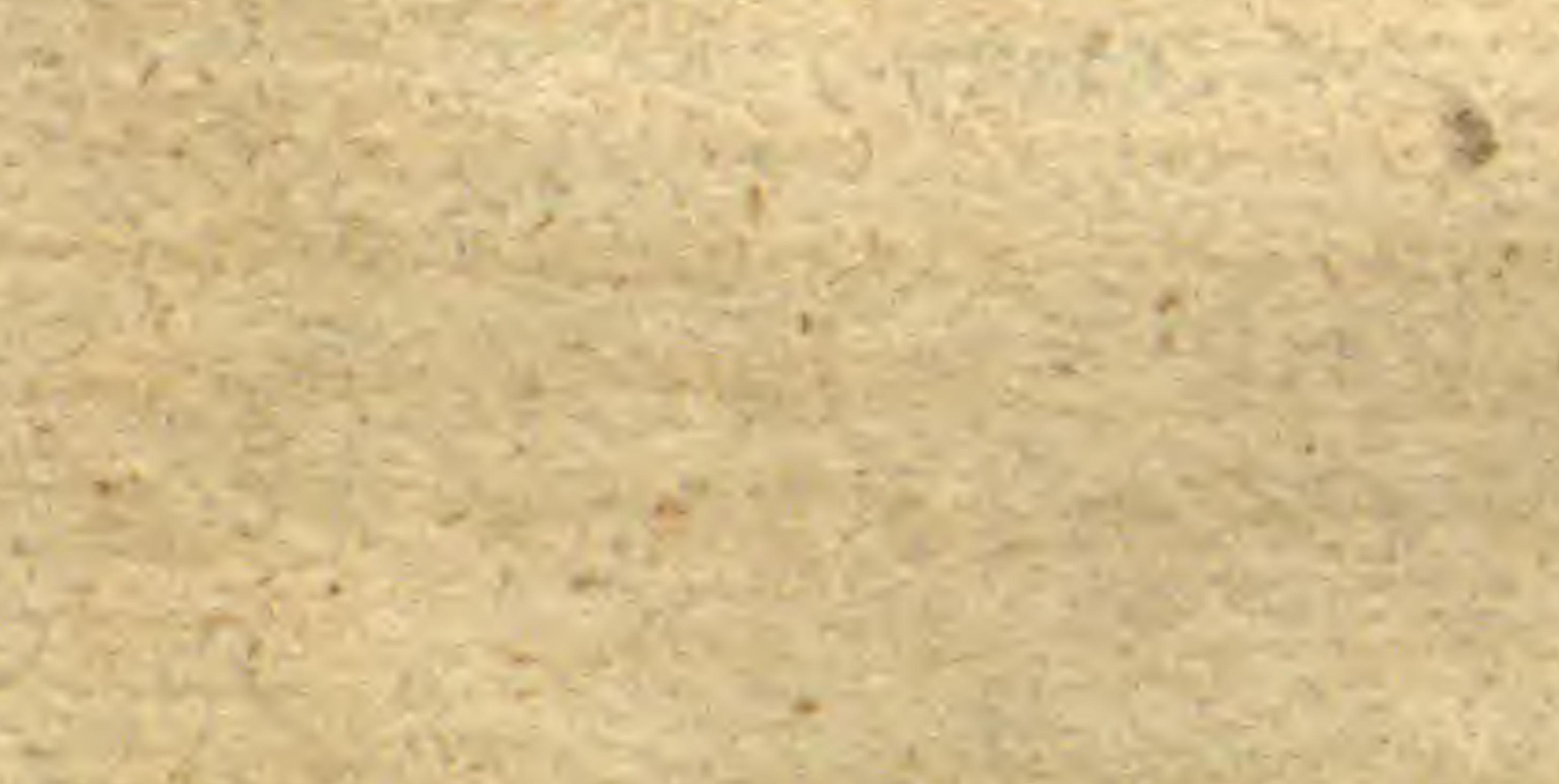
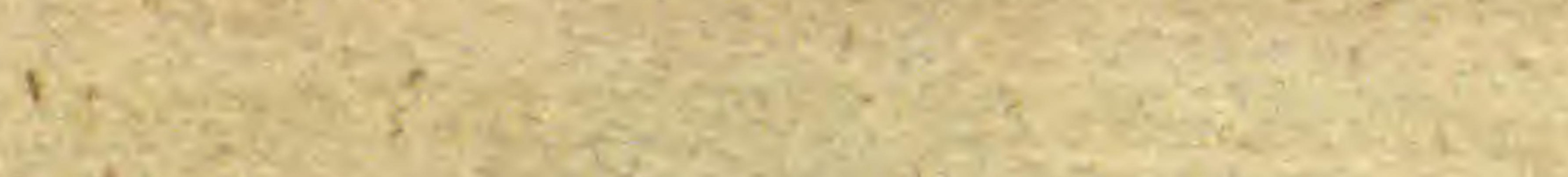

Fit:

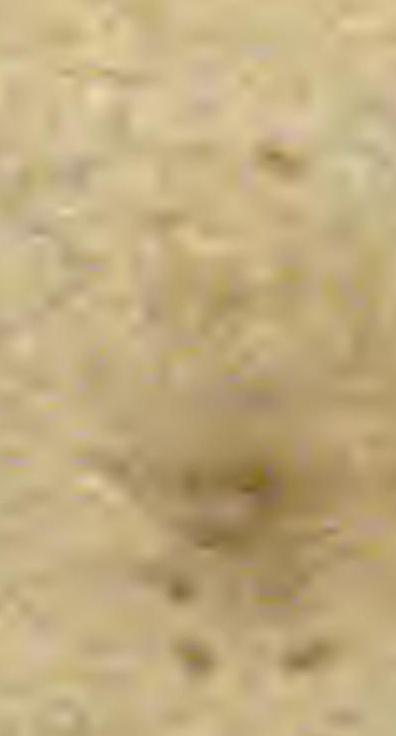

i. $1=$

$$
x=
$$




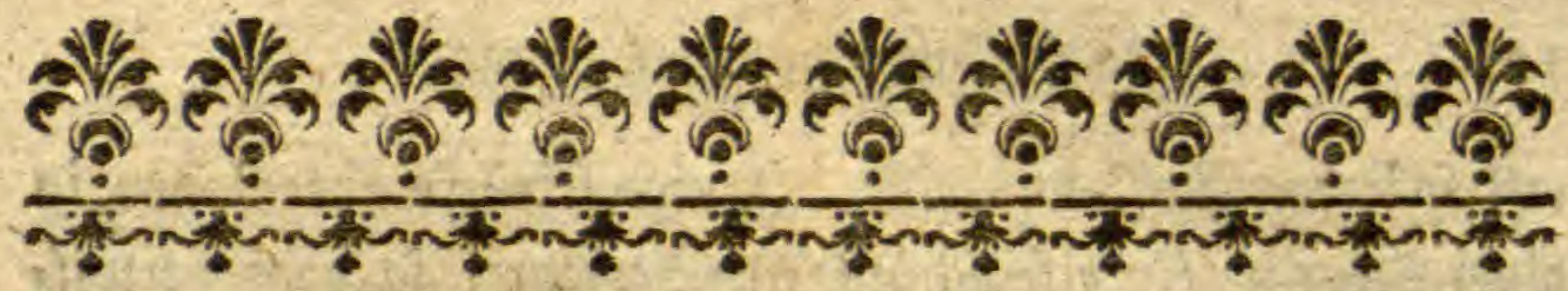

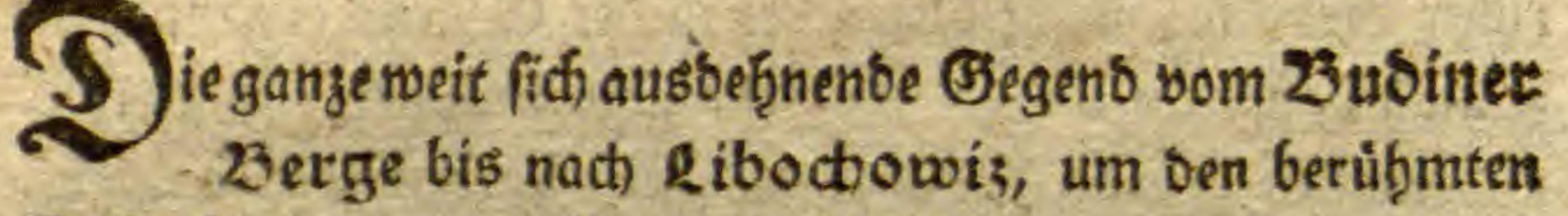

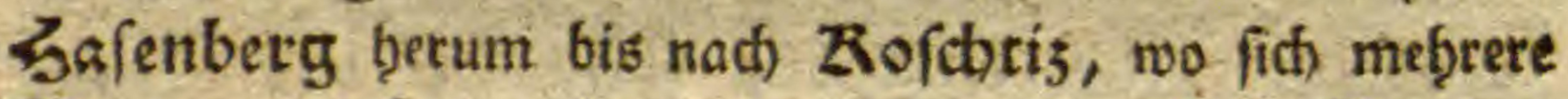
Berge zu erbeben anfangen uns bas eigentliche Mittelge.

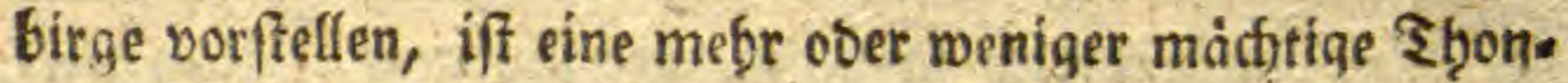

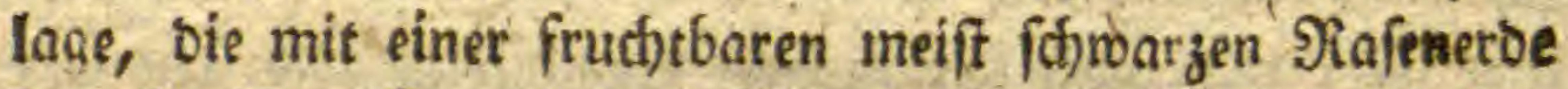
bebecft' iff. In biefer måchtigen ₹bonlage finb bảufige DBånf̧e von einem feģr guten Mergel zu finten, ber meg̨e ober meniger etḩártet, mef̧e ober weniger falfigt iff. Tabe an ber Etaot Ribocbowiz wirb waf̨re teilie ftaus biate Ralferbe gefunten, bie im Jeuer ibre Jarbe nidte vera antert. ' Feier aber wirb biefelbe in verbårteten Maffen ge* funten uno als Rireibe gebraucti, wie fie benn audh hianfig

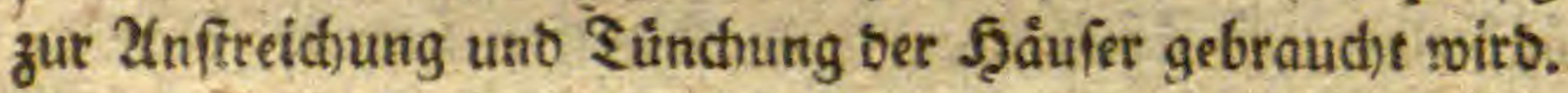
In ber Dammerbe finden fidf) adthte Branaten von verfdies Dener (B)ro̊fe, bie, weil fie etmas fparfamer um ben Şa fenberg verfommen, erft eigentlich ben Kioftbtiz uno an bem Grůnberge orbentlich gefammlet merben. Da fie meift lofe in unbeträchtlicher ₹iefe gleich an ber Dberfläche,

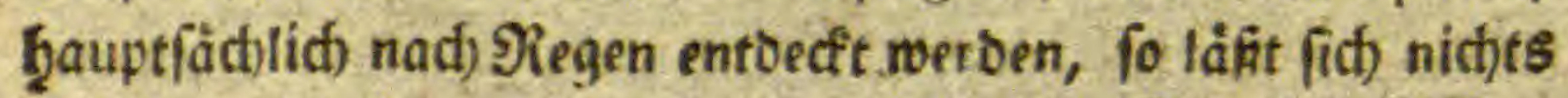
auf ihren Gieburtsort fdlieffen. Einige Etrice berfelben

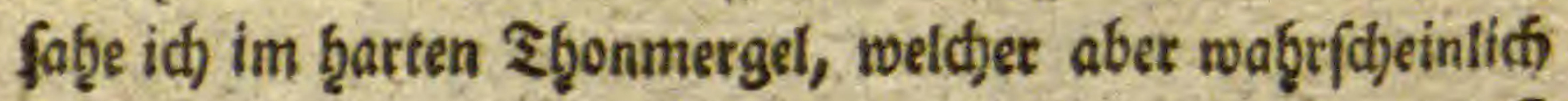


erft fpàterer Entftę̣ung ift. Einige Stưcfe aber lagen in einer verwitterten eifenf(h) terten (5tunftein gleid), uno viefleid)t gu ben Gerpentinar. ten geboiren ourfte. Diefe aber fino blos (5ejhiebe. Die Geftalt ber (B) ctwas unbeutlich) uno von ungleict)er flacche. (Jroß̧e finoet man niemals. 2(uffer biefen (stranaten fommen noch) als (Befchiebe vor, einige feornfteine, ऽuarzfiefeln, uno glimme. ridfte Branite; nebft biefen ber in ber (Biegeno einbeimifate Safalt, fobenn einige Sthorin von brauner, fhrwarzer, uno enolid) griner farbe, die ber కafenberg hergiebt. Su Seolez bricht fofidftweis Steinmarf uno failedfte פoarcellainerbe. (B)gen Die Etrafe nad) Drag auf Juoin ot, wiro bas (Erbreid) fanbiger, ber ffhrarge Soben ver. liert fidh, uno audi) verfabiebene Sanofteine unb ₹f̧onar. ten fommen hervor. 2tud) jeigen fich verfólebene $\Omega_{\text {alf. }}$ und f̧arte Mergelarten, fo $\mathfrak{B e r f f e i n e r u n g e n ~ e n t f ̧ a l t e n , ~ w i e ~}$ 3. B. auf bem berge Salominta, mo Z1mimoniten oft bon ungebeuter (5rófe gefrniben werben, weldje jebod) an ber Dberfảdje gànglid, verwittert fint.

Der Ђafenberg felbit if ein fojomer Bafaltberg, dufferlid) jum ?heil mit biefen (Frolagen bebect, aber ba wo er entblo̊ßct, nichts als regelnáßig gebilbeter $\mathfrak{B}$ afalt. $\mathcal{E}_{r}$ hat bie gemointidhe fegelformige (Boftalt, ift mahrfd)einli. d)etpeife mit sem Raußnizer St. Georgenberg (ben

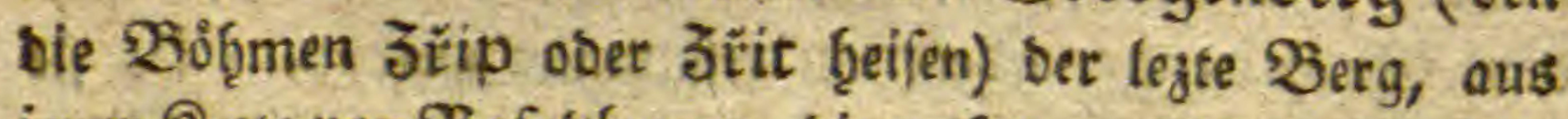
jener Rette von Bafaltbergen, oie unfere wefflicfe uno nórb. liche Srånge umgeben. Er fteţet ganz frey uno altein in

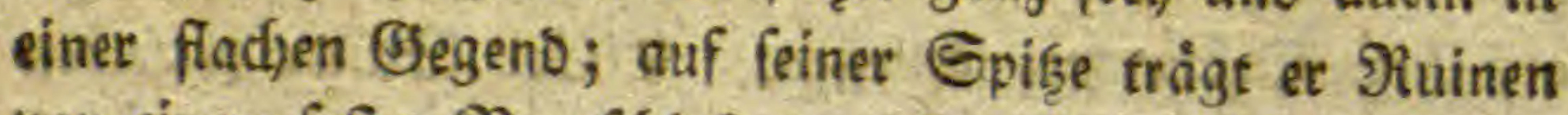

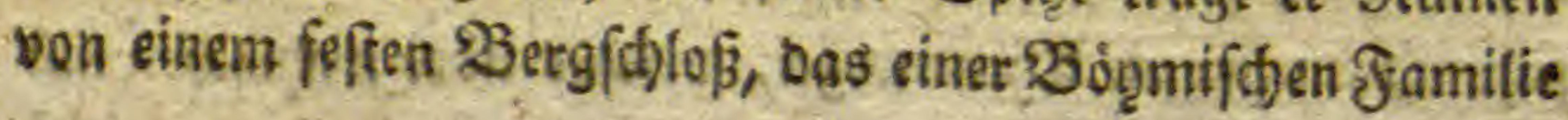


Den গRamen gab. Der Bafalt gleid)t gänglid) bem Stolps ner in Ead)fen; beftef̧et aus feb̧r grofien langen zufamment= biångenten Såtuen, von fofwarzer farbe, oidt, uno mit báufigen gelbgruinen, fie uno ba aud) fd́marzen uno braus nen Edtoorln gemenge.

- 2fn verfffiesenen Drten fat man sie Eảulen gebro= d)en, wie in einem Steinbruch), wo man fef̧r beutlid) fíf) aud) von ber innern Etellung ber Säulen Begriffe madben tann. Sie liegen nid)t immer in einerley Steflung, fons bern meiftens b̨alb aufrecht, etwas fich neigens. Eetjr grofie oft oren bis vier Sdyuh im Durdhmeffer betragenbe Sáulen, merben auf $3=4 \mathrm{flcine}$ of blos einen Sdut im Durdfmef = fer ḩabente, aufgêfeat, uno gleidffam wie Gielente jufams. gefügt.

Die Billoung ober Rryffallifirung beffelben ift mata ftens fectsfertig, gewơţnlid) unregelmåfig. Fleinere Ciu. Ien von fünffeitiger (Geffalt finbet man jerftreut um bas Dorf Zilapey, im Dorfe Seolız u. f. m. Sar nidt fels ten finbet man Jeoliungen in ben lofen berumliegenden SBafaltfåulen, bie theils mit geftreiften ffralichten Sialfo fpatḩ ober aud) ganj mit Eteinmart angefüllt finb. Ben Seolez bricft ber $\mathfrak{B} a$ falt ganj unregelmáßig auf einer tlci. nen f̨ervorragentoen నuppe, bie bem bafenberg unterge= orbnet zu fegn fम́,eint. *)

Dex

2) F⿻err D. Keuf bat eben ijt ju gleidier zeit eine furge abex pefr bủnoige Szefchreibung Diefes Berges gelicfert, Die Derglidhen ju merden veroienet; $f$. Deffen Orographie

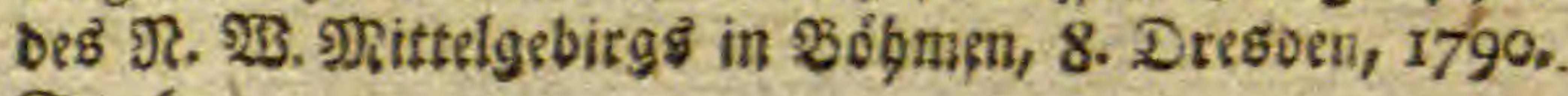
- ङ. 163 .

Stnm. 0.52. 
Der $\mathfrak{B}$ afalt ift in oer (Jegend nicf)t oḅne গuţen. Df̧ngeaç)tet feiner groß̧en Edjuere braudtit man ib̨n bod) jum Sauien. Uno wegen des feften unzertrennlictien (bes fteins, Dienter ju Braing= unb Ecffeinen, ju Felomarfungeu

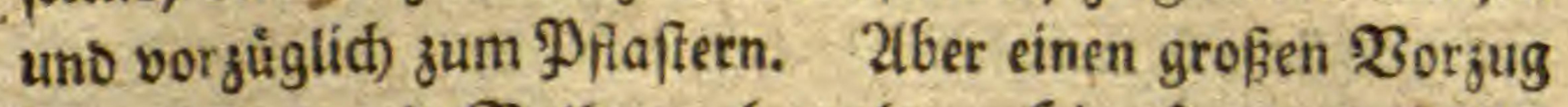
beb̧auptet er als Balfen gebrauchte. Şier findet mañ if̧n foroble als \$Pfeiler, als aud) jur Belegung als 'Batten bey einigen Sruucten ber (Jegeno, no er roegen feiner Jeftigfeit, ,uno Unjerftórbarkét, vortreflíche Dienfte leiftet. Diefer lejtere (Sebraud) verbient vor allen anbern 2 fufmerffamteit

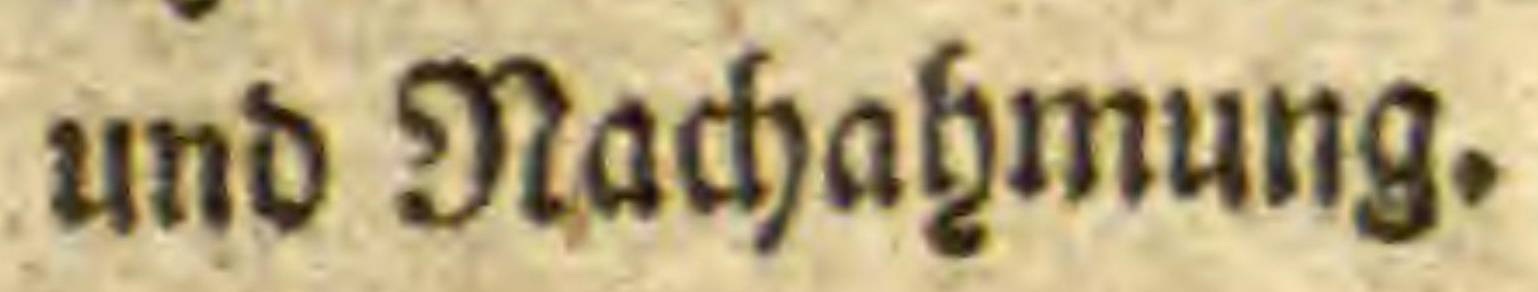

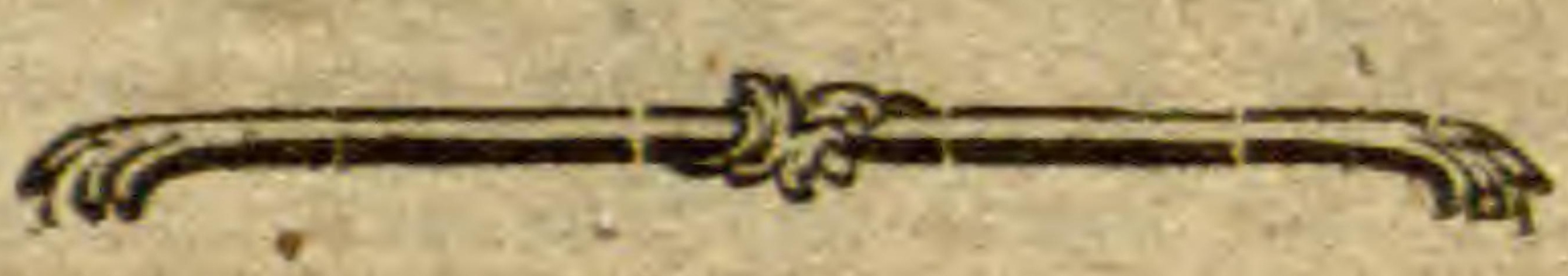




\section{XI.}

\section{2)}

úber bie verffjtebenen

(J)ade Der 23 arme IIIt

i b

2) \erfuchen uno Beobadtungen von Sุeren

$$
\text { Anton }
$$

א. Aftronom. 


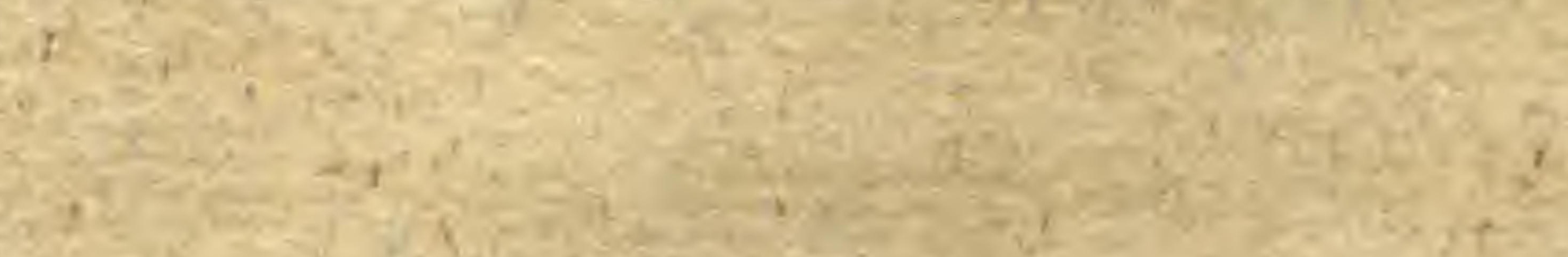

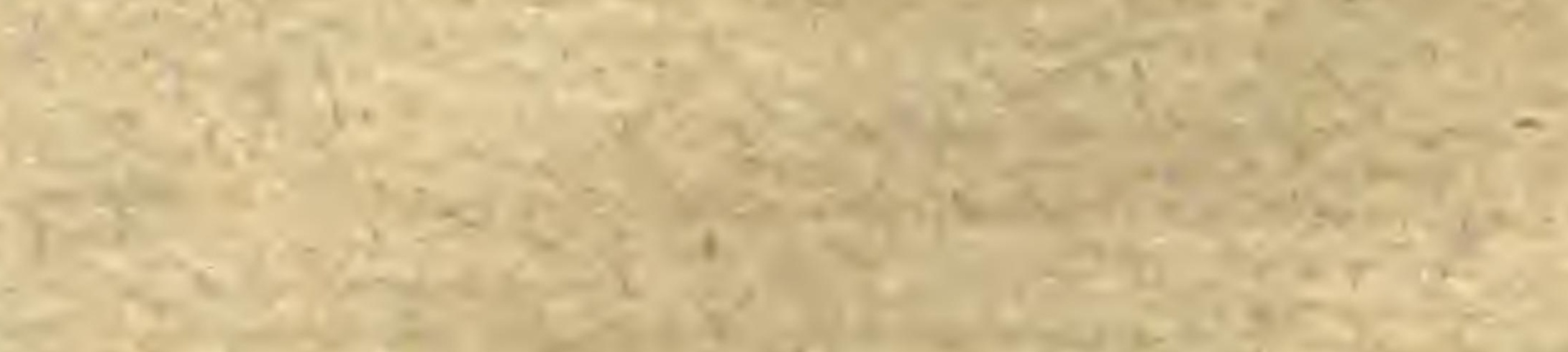

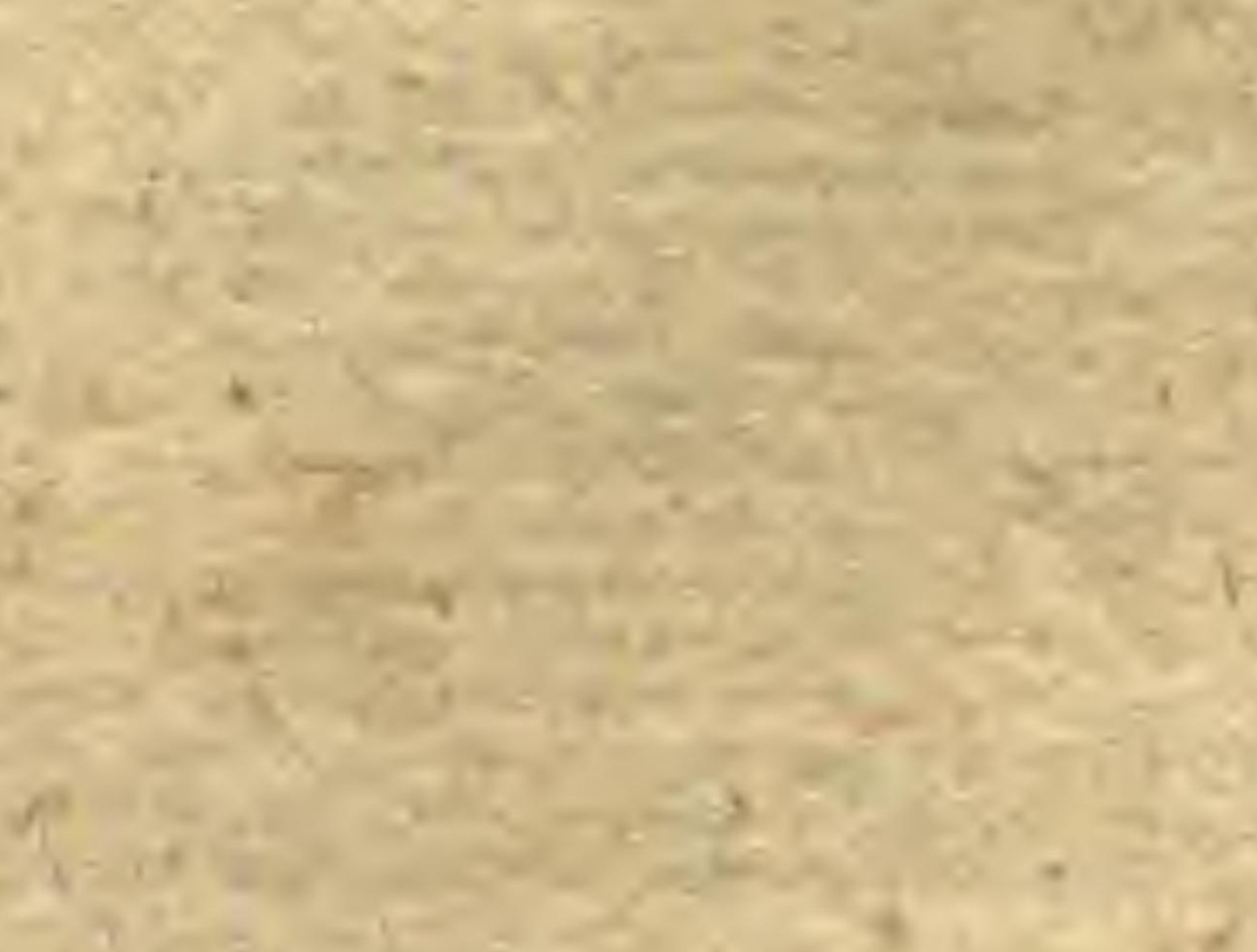

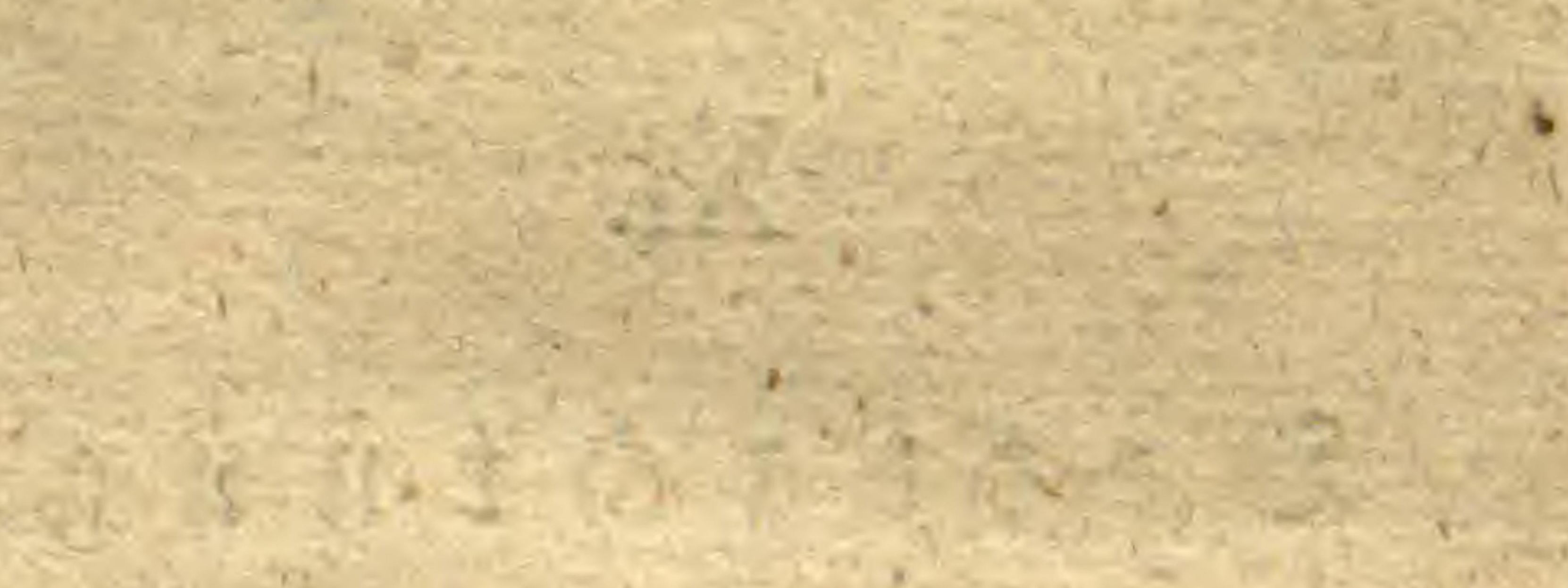

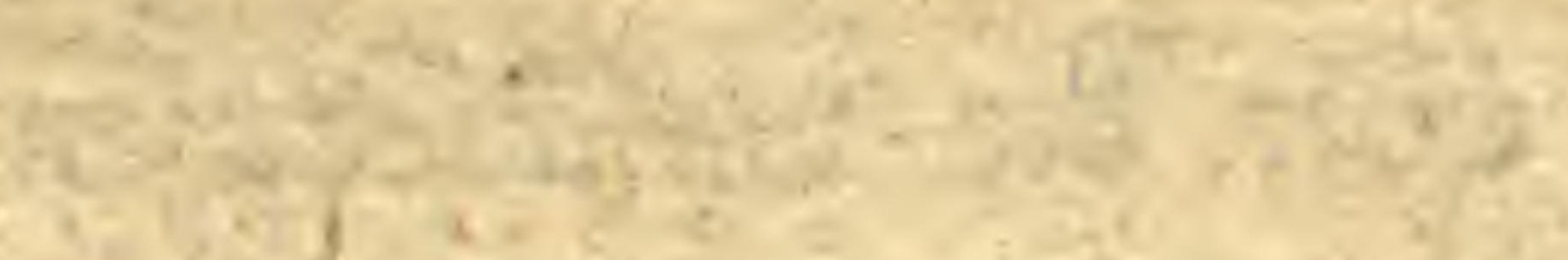

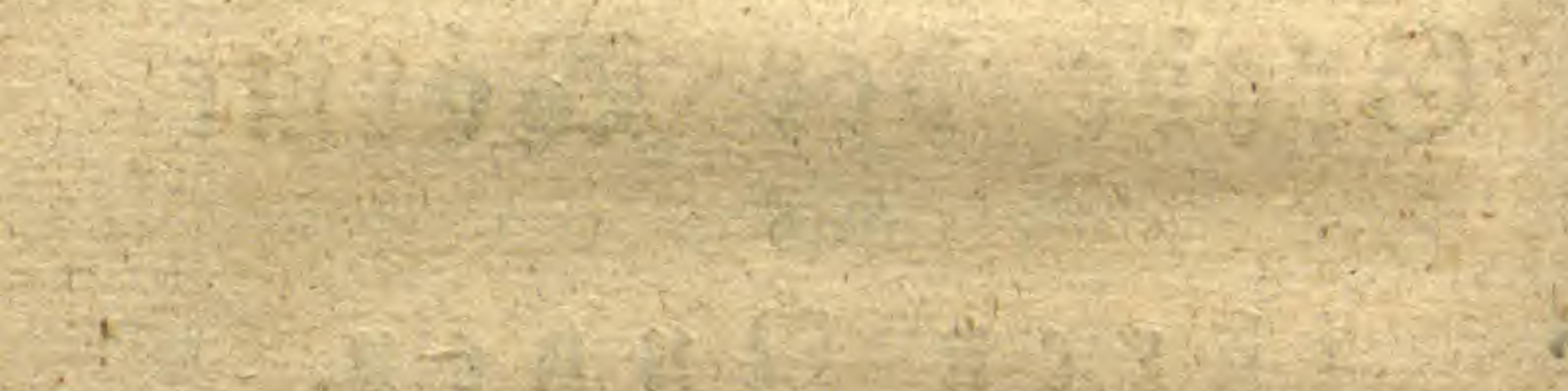

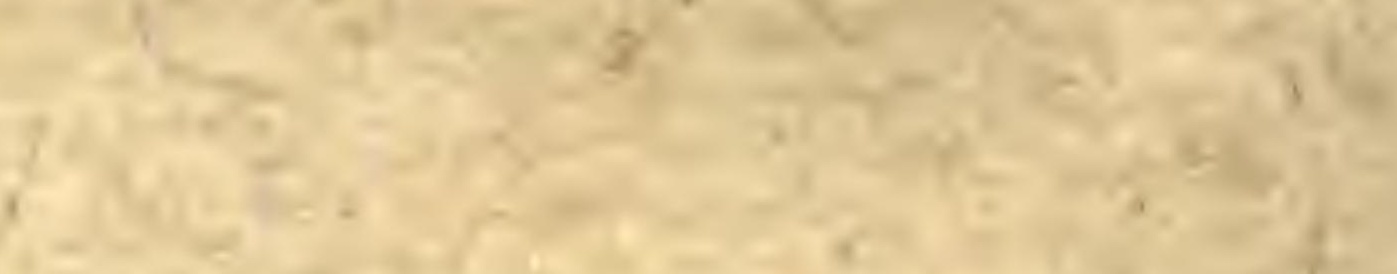

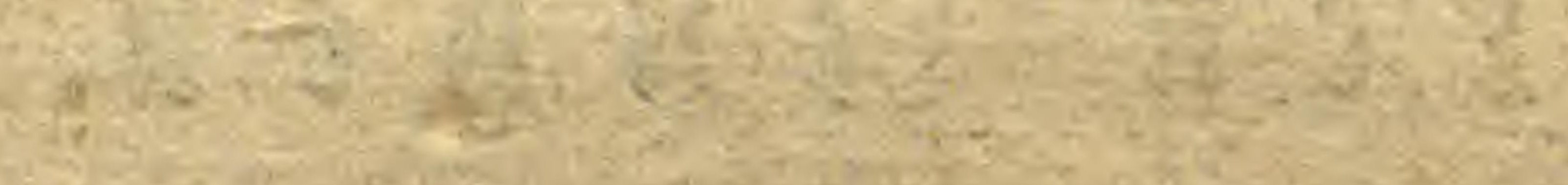

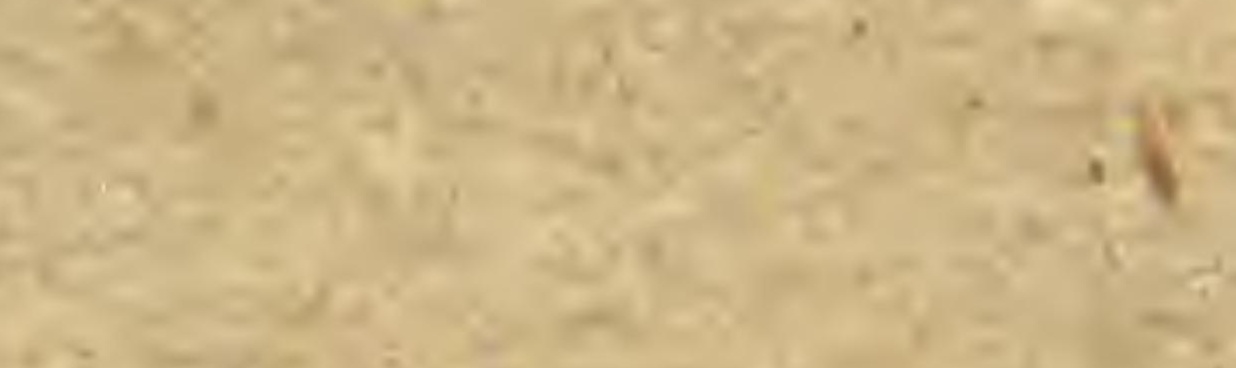

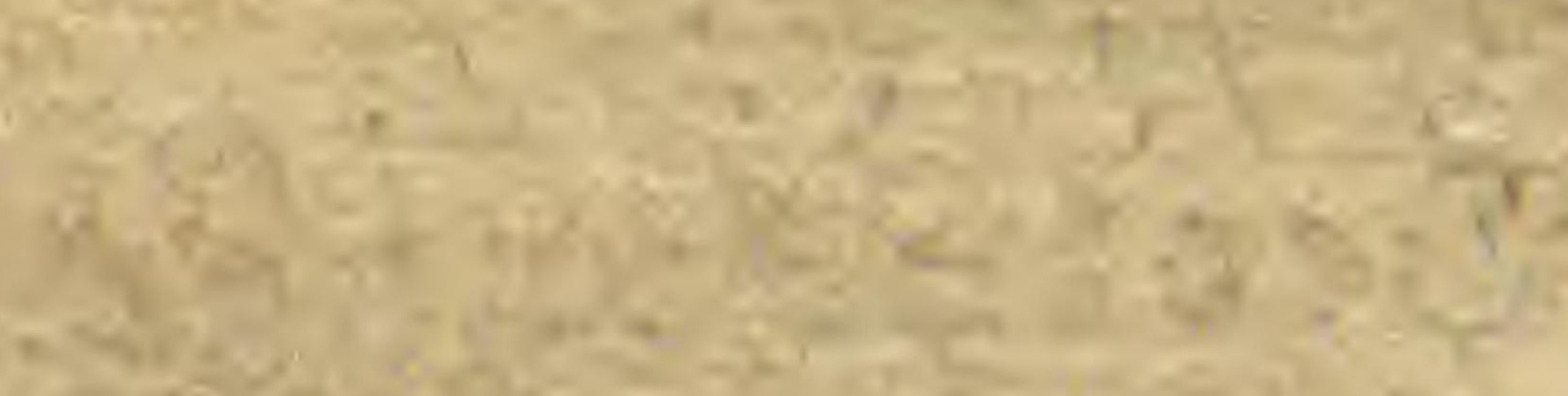

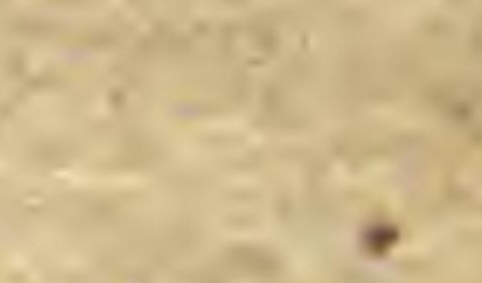

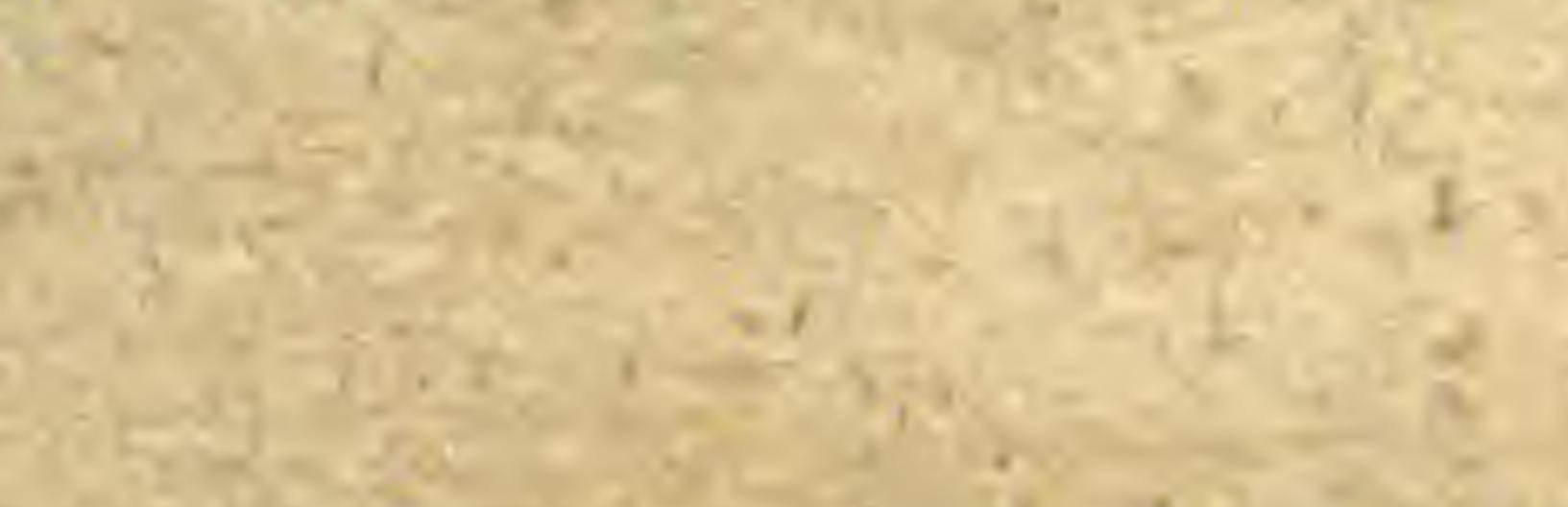

$\lim _{i 2}$

mexty

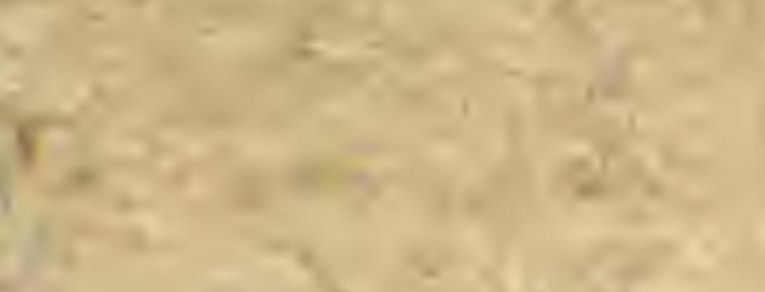

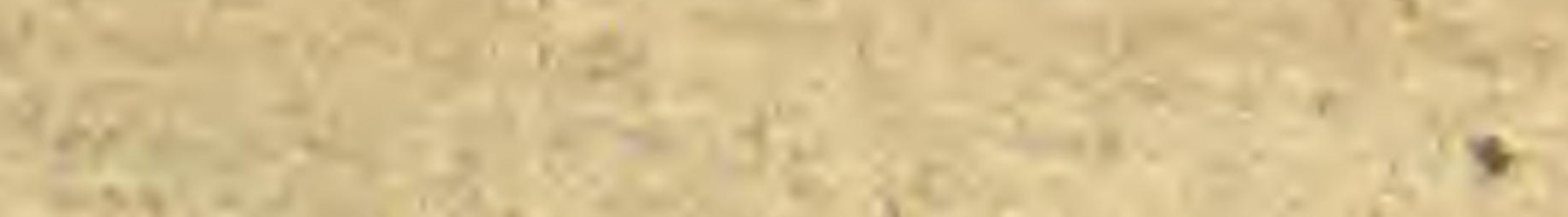

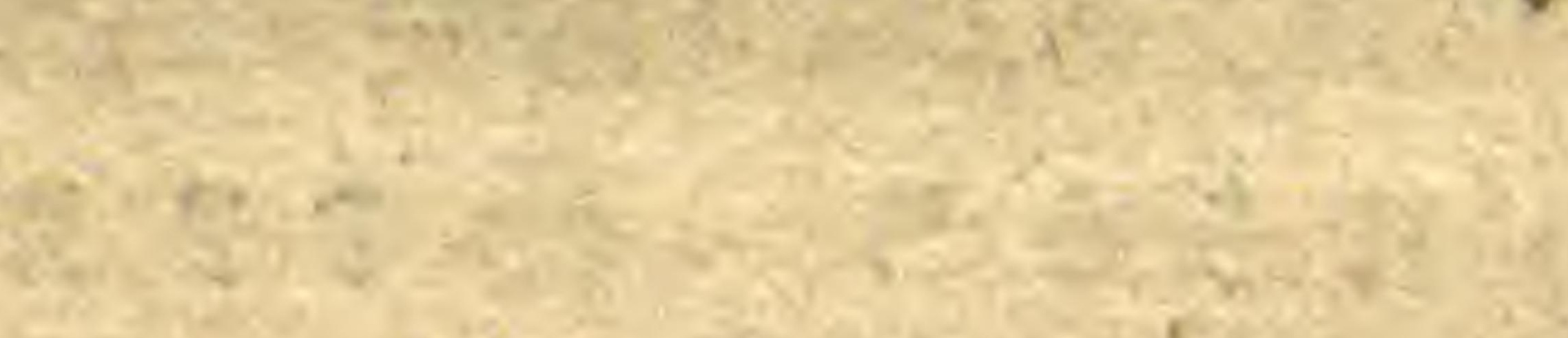

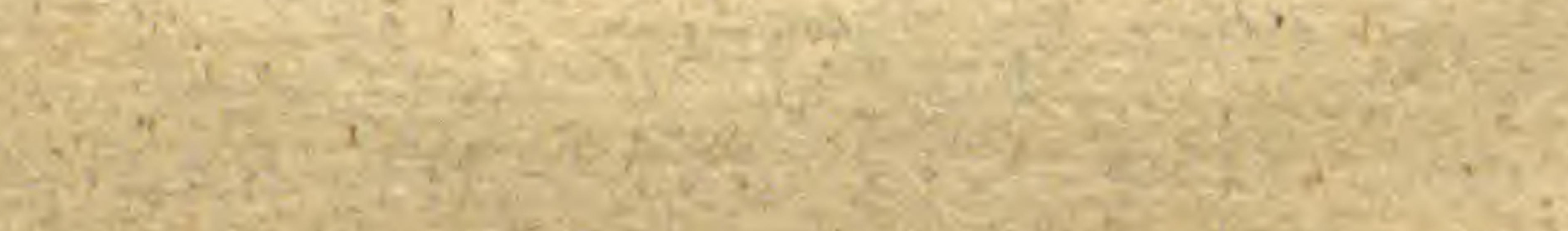

(2)

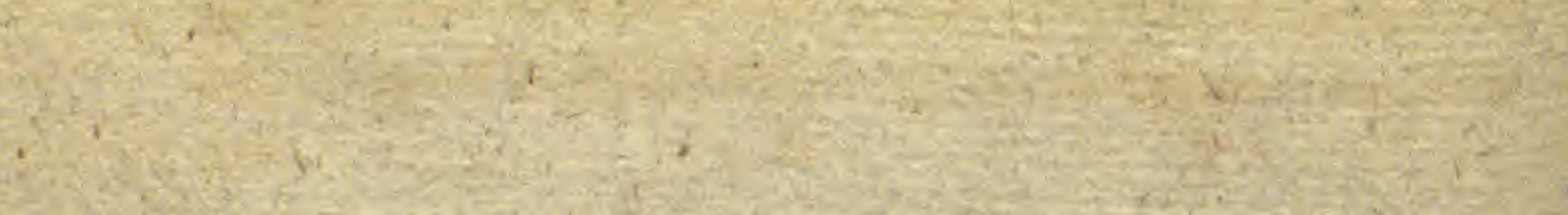




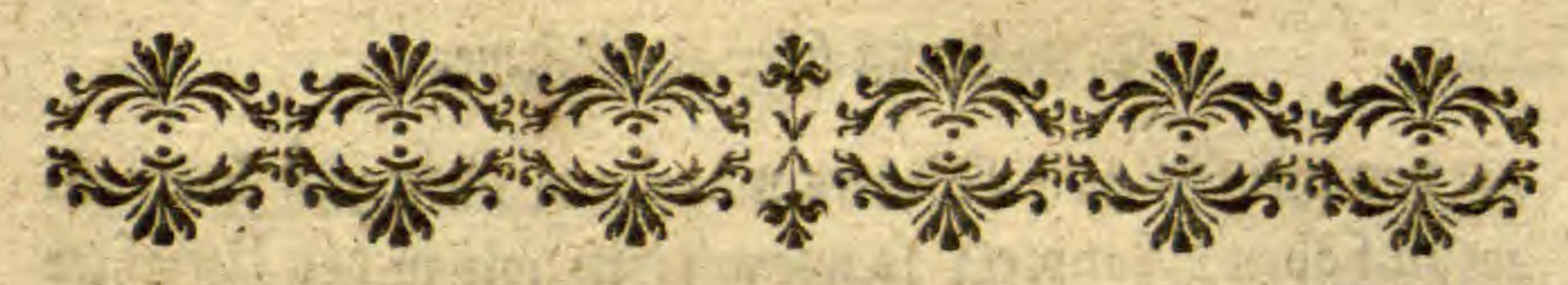

Wु

abe uns nusqemactit if es: bafs bie suft, ober bie

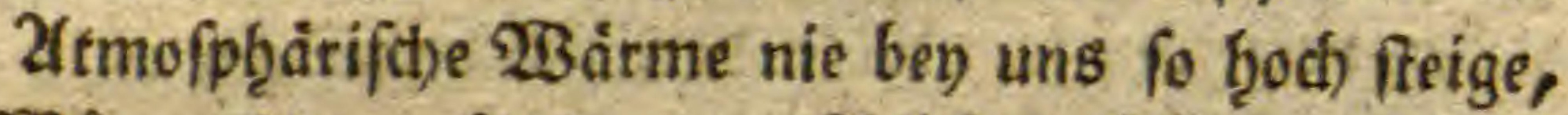
als oie $\mathfrak{3 a r m e}$ bes gefunben menfdflicten Rórpers insge. mein ift; unb, wie biefer (Strab gemeiniglich) an bem ₹̧̧et. mometer angejeiget riro, in bem hiơdfften Sommer et $\mathrm{C}_{2}$ nicula etiam apud nos fervente, ift ber gemeine $23 a$ arme. grao, eines im Edjatten ausgefejten ₹ ḩermometers, mei. ftens geringer als Derienige Grat ift, oen es anjeiget, wenn es in ber Şano geţaften wiro; uno wir wiffen feit sojäb̨ri. ger Beobad)tung oa $\mathrm{B}$ er $=25^{\circ}(\mathrm{el})$. Rieaumut bewies es in feinen jwectmåß̧ig vorgenommenen গiei jen, fo mie ungåţli. che anbere es nactipruiften. Die Erfaf̧rung leģrt uns ferner: Daß ber menffjliche entieelte Sörper eben ben (Brao ber ISarme annimt, ben bie umgebente Suft anzeigt, fo wie ein befeelter im (J)egentb̧eil biejenige Rraft befizt, einen grôfo. fern $\mathfrak{B}$ armegrab zu erweden, uno in ber క̧̧at von auffen zu duffern. Diefe 2Bärme, weldfe burdi bie innerfider) Ren: fhenfraft in ber Sunge erzeuge wirb, geigt meiftens bey uns,

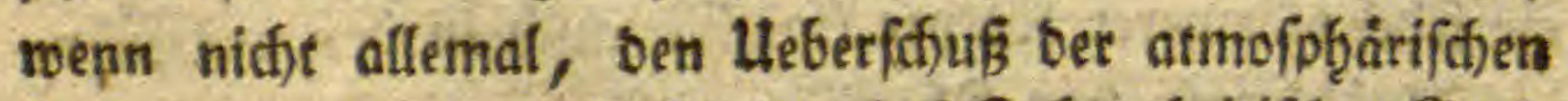
शुärme; man pflegte saher ben $64^{\circ}$ Jab̧renf̧eitifid)en (Srab als febr roarm anzuzeigen. Doerbave mennte, baf ber 80, bơdiftens $90^{\circ}$ Deffelben. F. Thermometers ben ₹fieren

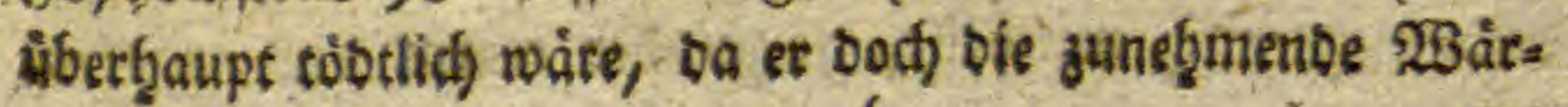


me bes menffhlidjen Rơrpers mandf)mal ůber $94^{\circ}$ beobadj. tet gu ḩaben bef̧auptet; fo mie mit if̧m, wie in ben Lttrechter Ephemeriben ju feģen iff, ein Pitcatn, Zmonton unb mirbenbroet eben baffelbe beţaupteten; Der $12^{\circ}$ Des शeutonianifd)en ₹̧̧ermometers, weld)en Zleuton ber áuf:

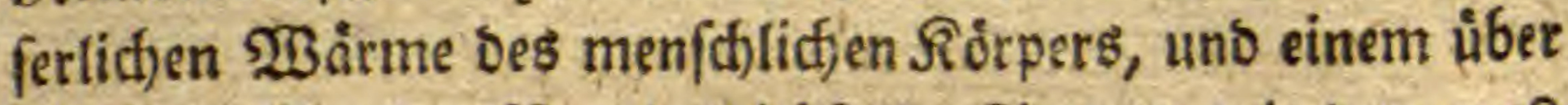
Die Ener fichenten $\mathfrak{B}$ ogel gleich)egte, ftimmet mit bem $95^{\circ}$

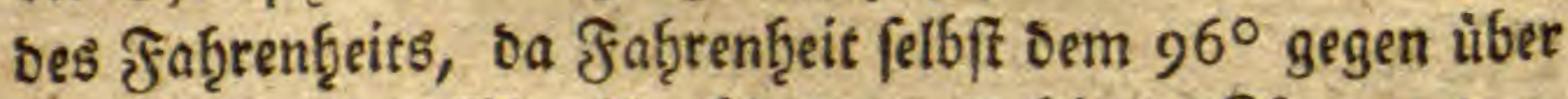
sie $\mathfrak{2}$ Barme ses Rentchenbluts, uno feines Rorpers bar. neben vergeict)nete. Man barf fich) baher gar nicht varwun= Dern, baß̧ bie ₹̧̨ermofopi(d)e Flüpigfeit, bes im Sd)atten ausgefejten Werf́feuges, (WBărmemeffers) feb̧r felten bem Ėrabe ber $\mathfrak{3 a r m e ~ D e r ~ e i n j i g e n ~ \Re e n f d ) e n t ̧ a n o ~ g l e i d f ) ~}$ fomme, ba im Segentheil defefes fefgr auffallend ift, meni folche aus ber Suft in bie Şano übergetragen fålt, uno zroat

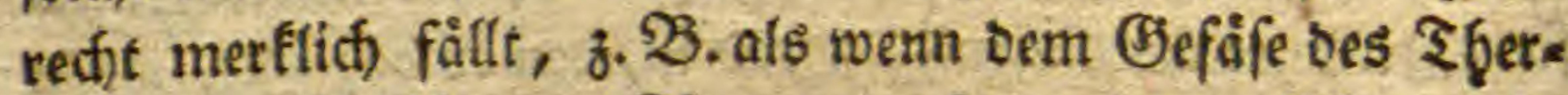
mometers ein fálteret Rórper jugefejt wirb. Man weißs

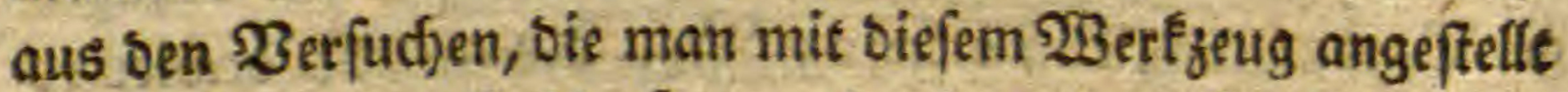

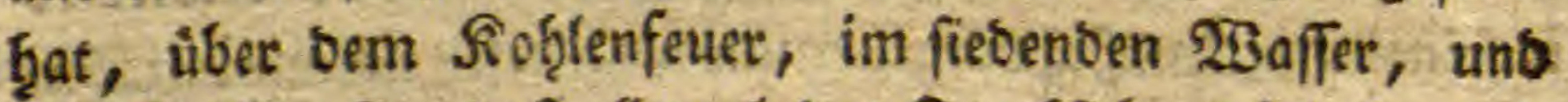
WBafferbåmpfen, baß̧ allemal bas 2uecffilber biel ef̧er uns

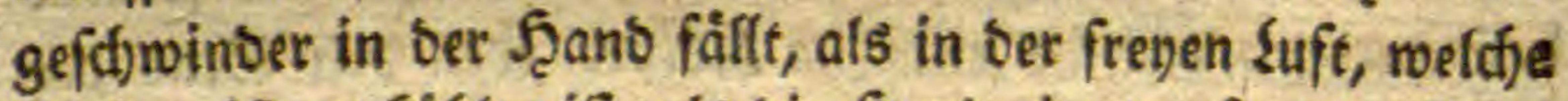

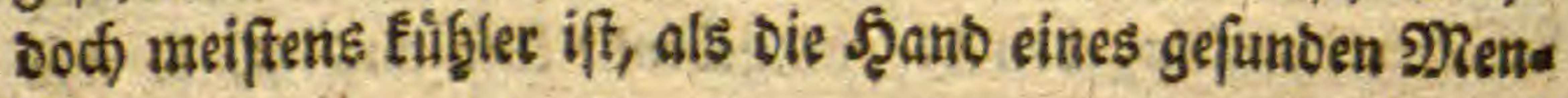
fóen.

Diefe Sirfung, bie man in fold̄en fătlen waḩtnimmt;

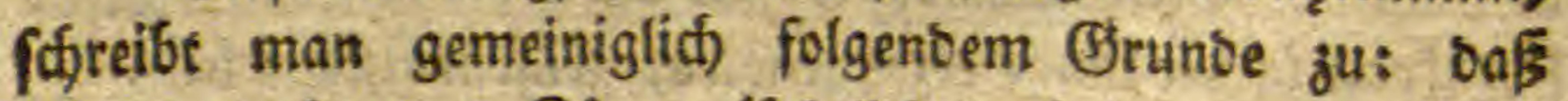
ein jeber waitmerer Rórper (folglich) auc) in ben angefüb̨rten Ulmftanben bas ₹̧̧ermometer) anbern minber war-

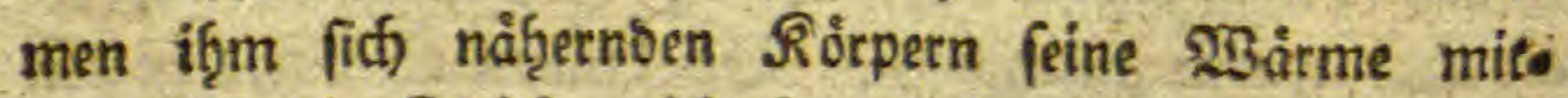
theile, bis bas (Sleiff)gewidjt ḩergeftellt wirb, uno zrwentens befto mef̧r gudf mittbeile, je minber warm ber angraina 
genbe ober nabe liegente Sörper ift, je bidter berfelbe ift, unb je mefor berfelbe nad) feiner Sberfläise ober

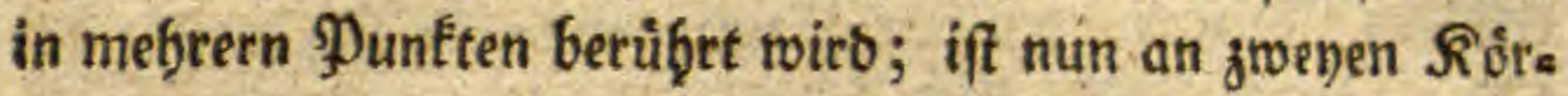
pern, weld)e man nach) unb nach) an bas $₹$ (zermometer bringt,

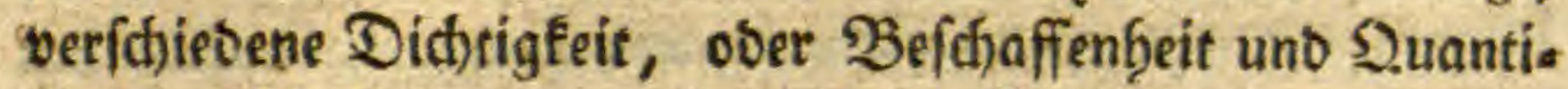
tåt ber Naffe, als auch in mebreern Punften bes Rörpers

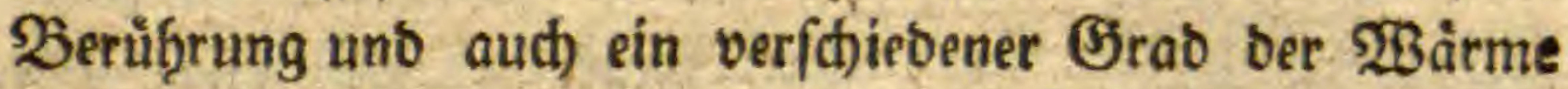
vorbanoen; if ferner in bem bititern Rörper bie $23 a$ arme um fo biel geringer, je gròßer bie Naffe unb Berủbrungs. Quantitàt ift, bann in bem bủnneren mieberum befto grò Bere

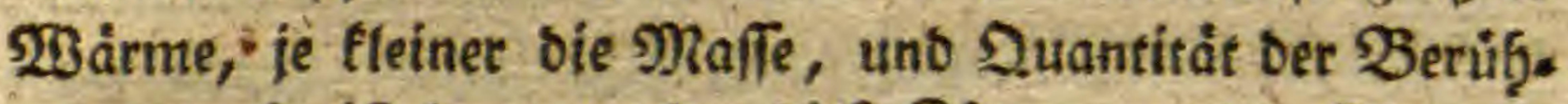
rungspunfte ift, bann werten biefe R ortper aus bem ₹ḩermo.

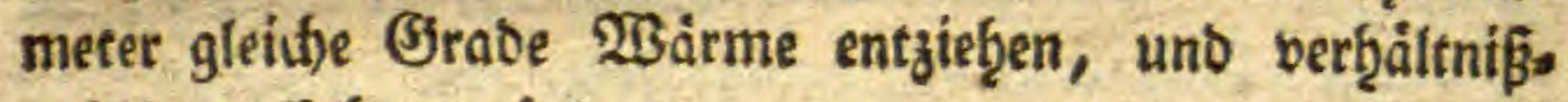
mäjig baffelbe veränbern.

Wenn aber bes bicftetn uno wårmern Rơrpets feine Maffe, als auch bie §uantität ber Serúţrungspunfte, in Bergleidjung bes anbern Roirpers, viel gróker ift, als

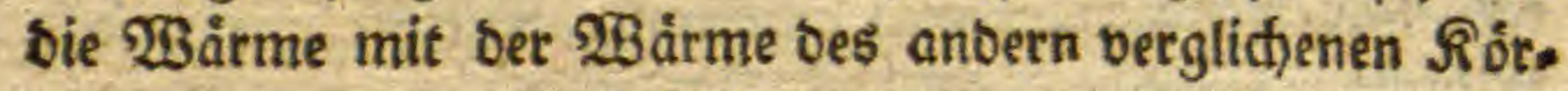
pers, bann wirb ber bidtete Rörper eine grökere uno ge.

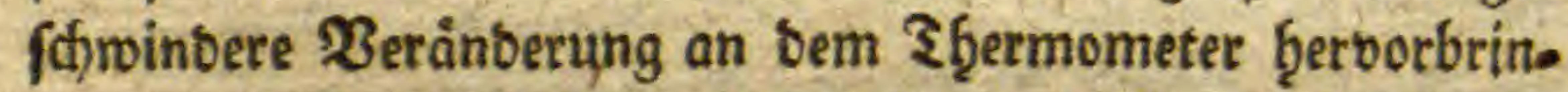
gen, uno bie flükigfeit wiro falten mùffen; biefes ift ber nàmliche Jall an bem ₹̧̧ermometer, wenn foldhes von bèm

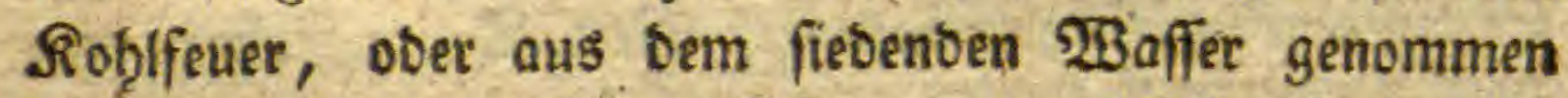
wiro, es ift námlich bas ₹̧̨ermometer viel twärmer als bie Suft, ober bie f̧ant, in welkhe es übertragen witb, baher muf es beyben Rörpern, weld)e minber warm fint, bon feiner $\mathfrak{B}^{3}$ arme mittbeilen, wie man fdbon oben ermáf̧nt

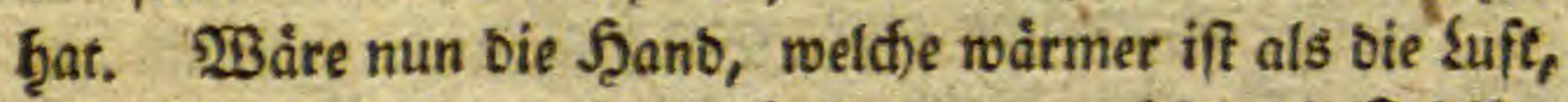
eben nur fo bidt, wie bie Suft, bann múste bie Flüfigs feit bes Thermometers fangfamer fallen, fils wenn bie suft 
allein bas ₹̧̧ermometer umgiebt; ba aber bie relative

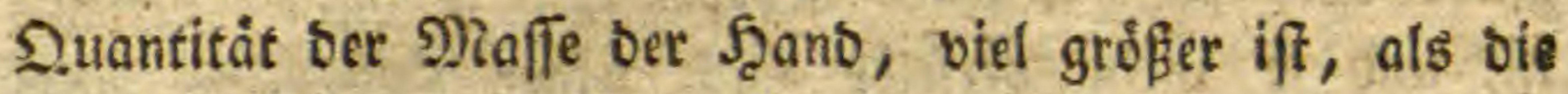

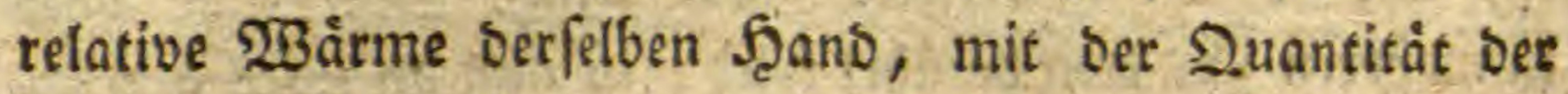
Suft verglid)en, fo muß auch bas S(germometer vial geo (4) winber fallen, ourch bie roarmere Scant, als Joenn if̧m

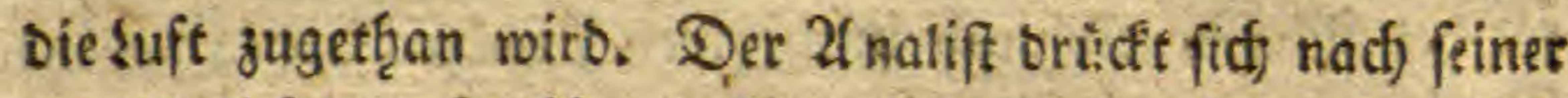
gewöh̨nlic)en, abgetůrzten 2(rt, folgenbermaß̧en aus: Die

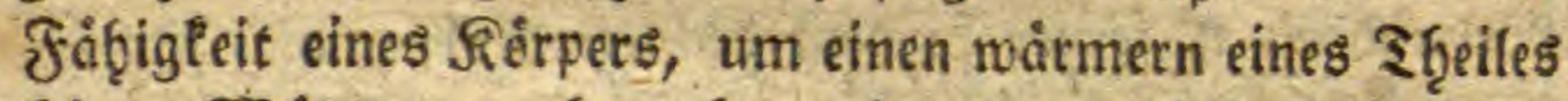
feiner \$̇arme zu berauben, in bem zufammengefezten Berf̧åltniffe, ift ber Dicftigfeit gleich), uno umgetefort mie bie $\mathfrak{B a}$ arme, ober wie bie Didftigfeit (= D); bie 233 arme $(=C)$ angewande (appliciret), o. i. (F:f =

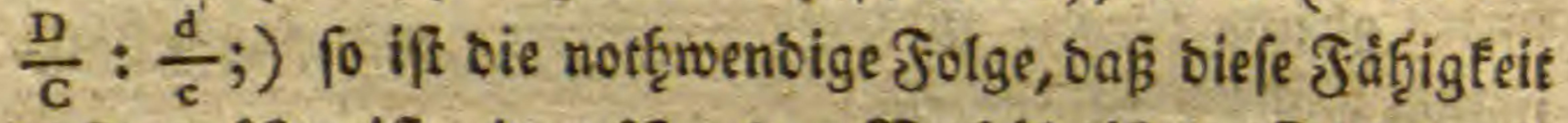

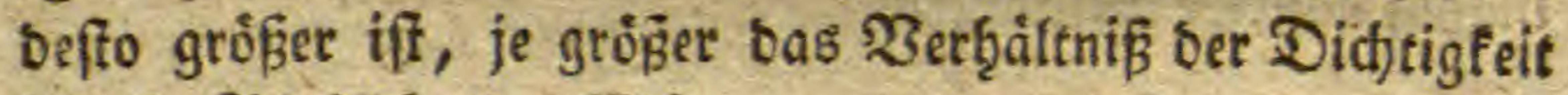

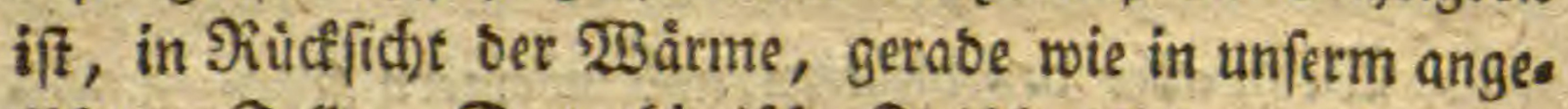

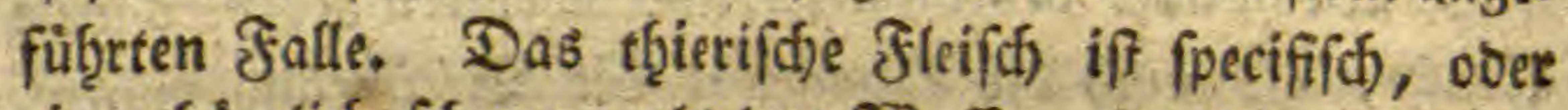

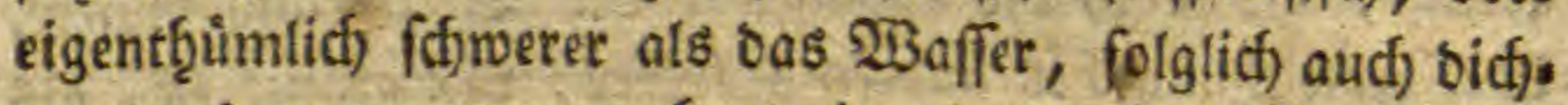
ter, uno wenn man aud) annimmt: Dẩ biefes nur eben fo bicht waire wie bas $\mathfrak{W}$ affer iff, fo b̧ätte man bas $\mathfrak{B}$ ers

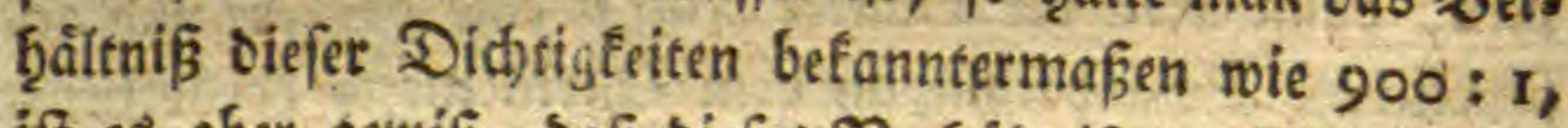

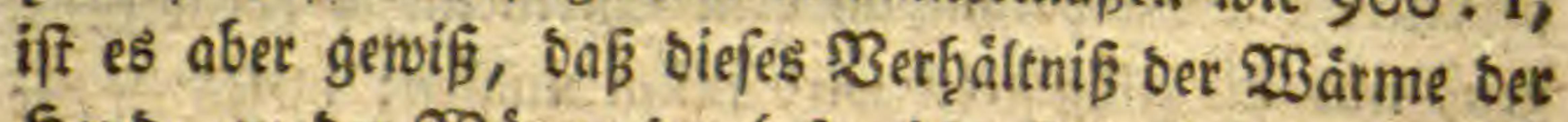
Şanb, zu ber 28 ärme ber Suft nicjt ftatt finbe, wiemob̨t Die suftwairme feght gering wäre, wie 3. 2 . im Jab̧re 1738 zu Rirenga in Sibirien, ba ber Shermometer $275^{\circ}$ De

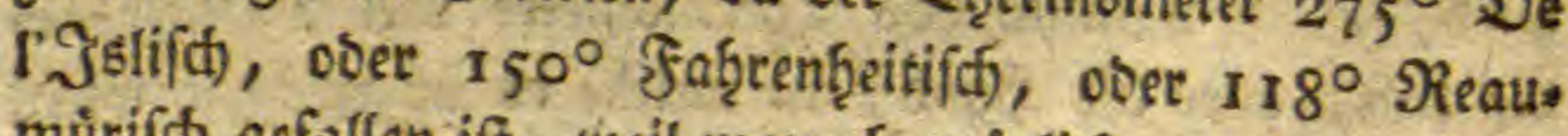
mutrif(h) gefallen ift, weil man of̧nmo̊glid) annef̧men fann,

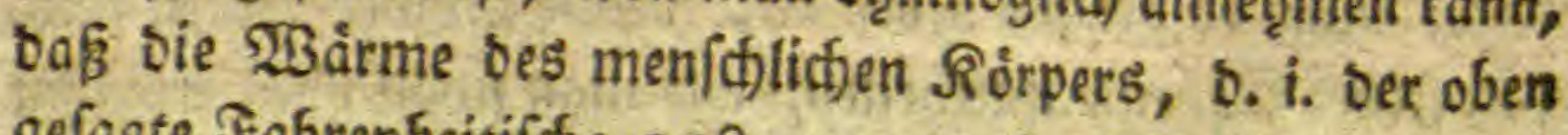
gefagte faţrenḩeitifife $94^{\circ}, 900$ mal grơ jenige Brab, ben sajumal ju Sirenga ber \$ Ģermonteter anzeigte. Wit wollen fold)en fidf alftảglich ergeugenten 
Euftheinungen, nosh antere âţnlidje benfeģen. Die uns

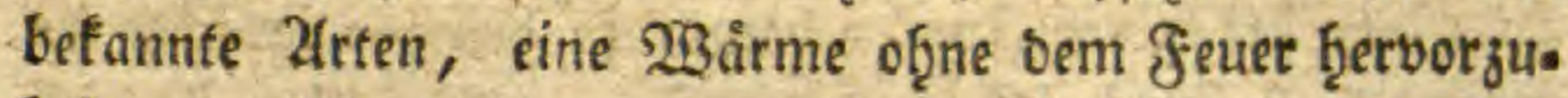
bringen, fino nur zween, uno man nennt biefe, um fol. (f) gut unterfheiben zu fönnen, bie mecfjaniffe uno bie

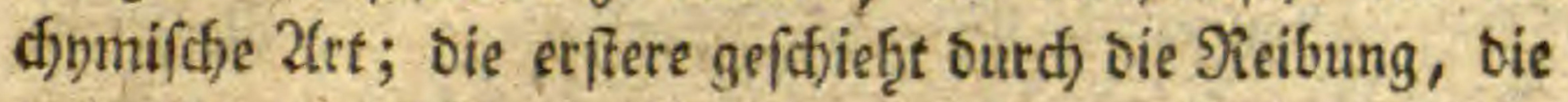

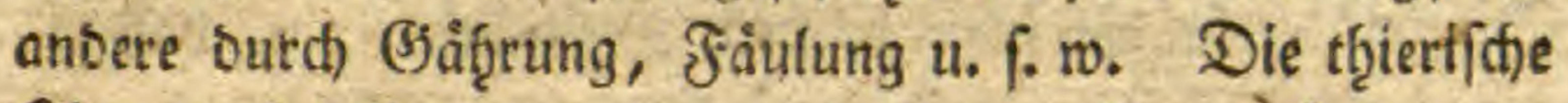
Şi̧̧e mus bab̨er entwober nad) einer, ober nad) ber an=

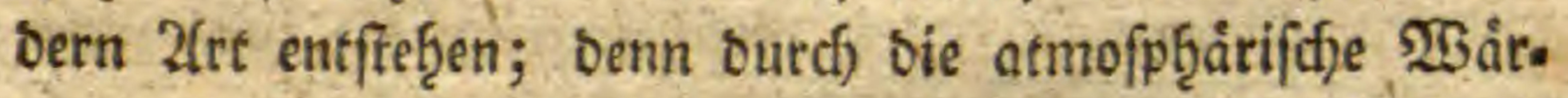
me, wiro in oem thierifchen Siorper nut biejenige $\mathfrak{B a i r m e}$ Gerborgebractit, bie ba allen benen, in bem atmofpḩari. fóen Raume nicf)t fef̧r weit entlegenen Rörpern gentein

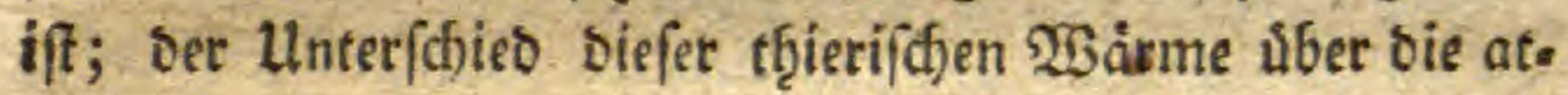

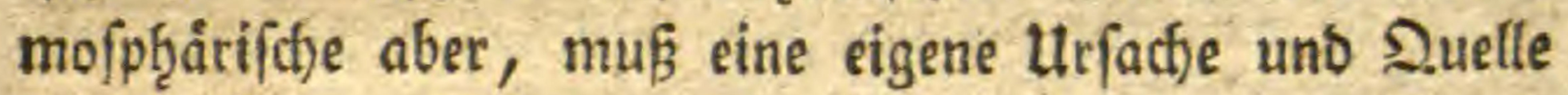
in oem Rơrper felbft ḩaben, uno man fann fagen, baß biefe entweber bie शieibung fer, ober eine bon ben dymmi.

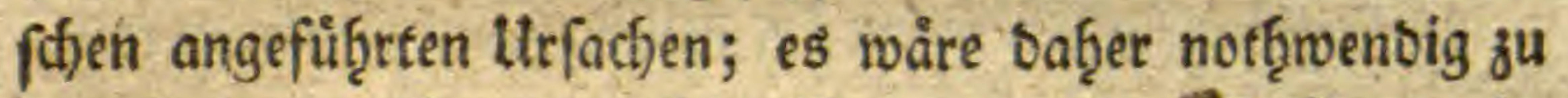
unterfuctien: $o b$ uno welche (5attungen ber sieibung, in einem tḩierifhen Rörper Gtott finben? Dies ift gewißß, baßz forwohl fefte an feften, liquibe an feften, ober bie liquiben an liquiben אörpern gerieben werben fönnen; reis bet man einen feften fiorper an einem anbern feften ge. fdiminbe, alsbenn ift allemal bie Folge biefer Reibung, baßß nid)t nur eine feişe, fondern aud) bas gebunbene Feure aus bem reibenben uno geriebenen Rörper fith) ent. roidtle; Diefes gefdieh̨t fowoḩt an ben feilen ber Riunftler, an ben Scammern, uno an benen um bie 2(re fich be:

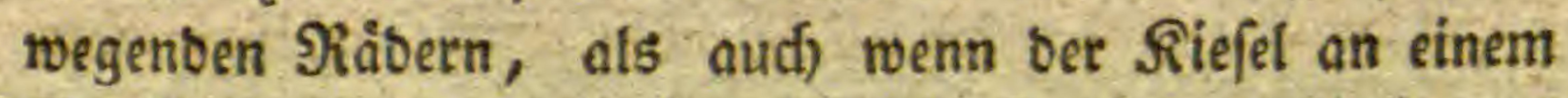
Staf̧le geffilagen wiro; felbft bie Inbianer lef̧rten uns

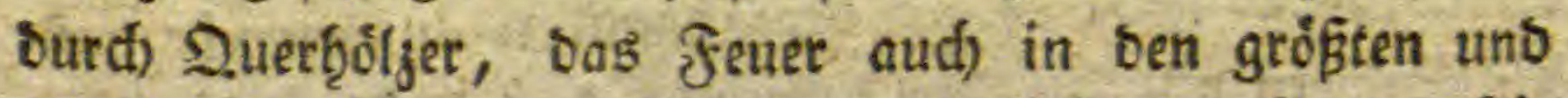
b̧ödfften (jebirgen ju madjen, wenn fold)e ourd) gegenfei. 
tige Bewegung getieben merben, wo man fonften nach

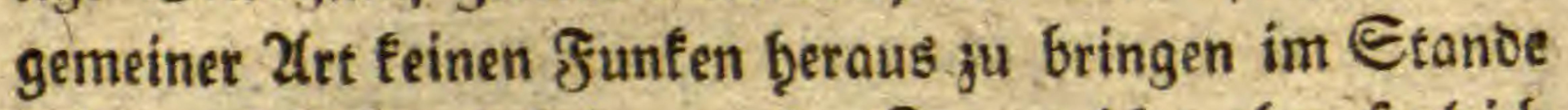
waire; biefe ferborbringung bes fouers hoört aber fogleich auf, mie berougt if, fobalo man mit Dele bie freilen, mit

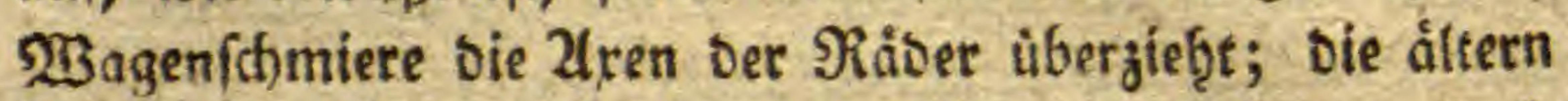

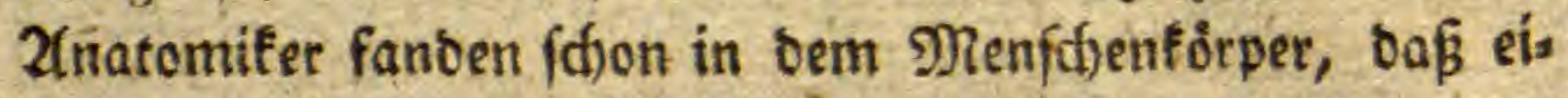
nige innerfiche fefte ?̧̧eile ůber anbere fefte fid) reiben, uno mit einer ólid)ten flù

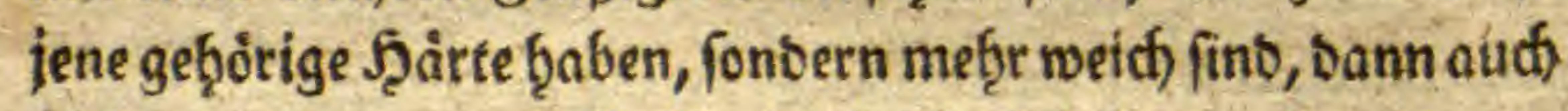
nid)t mit berjenigen (Gefdfmindigfeit fidf bewegen, als man fonften zur J̧if̧e uno Feuer. Erzeugung erforbert; baf aber

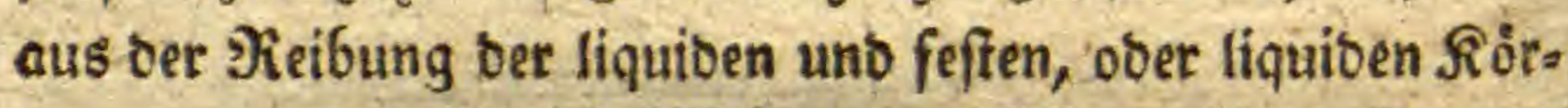
per unter einanber bie $\mathfrak{3}$ årme entffę̧e, nirb niemans

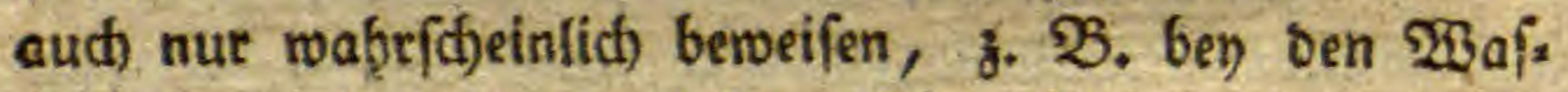

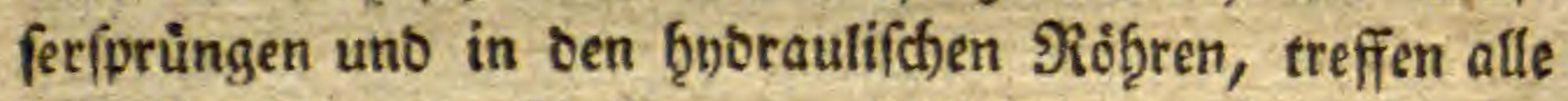
biefe Umftånbe ber Nieibung ber flübigen mit feften ůberein, uno bennoch if feine Spur einer $23 a$ arme vorbanoen: wiro man alfo fagen uno fó)(üffen fönnen, baß entweber burch)

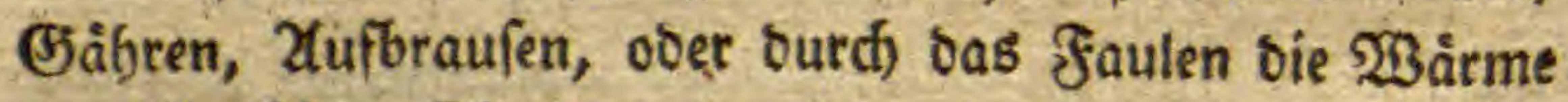
im thiterifthen $\Re$ örper ergeuget werben mulffe; es ift aber - ausgemadit, Daß bie Bjäbrung nut in Dem vegetabillifichen Reidie Plaş babe; es bleibt baf̧er bie Efferbefcenz ober bie Jaulung übrig.

In einem gefunten Rörper jugleids bas fraulen juzu. faffen, wáre to viel als wiberforecheno, folglich wåre bie Urfache ber tf̧ierifden $\mathfrak{B}$ ärme bas 2(ufbraufen allein.

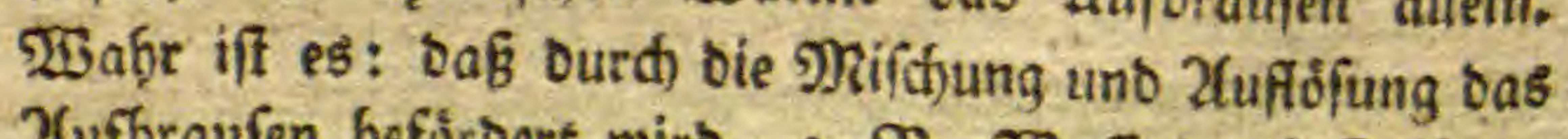
Zufbraufen befortoert wirb, 8. B. Waffer auf Rale ges f(d)ưttet; bas iff überķaupt ben Chnmifern ausgemadt, baf bie Sảuren mit ahtalien vermifdst, bas 2ufbraufen ber: vorbringen. 
Die 2luftojung einiger Metalle in bem Edjeibenaffer bringt eine fratfe f̧if̨e, ja mand)mal bie Jlamme felbft bervor, fo wie bie aromatifdsen Dele, wenn fie mit bem Seifre mineralif(her Eauten vermif(f)t wetben. In einem thieriff)en Rörper gef(f)ief̧t fowot̨t bie Mifffung, ats bie 2lufiofung; benn bie Epeifen in bem Munbe werben mit bem Epeichel, in bent Nagen mit bem gaftrifhen siquor vermifhet, ju weld)em fich bann ber \$anfreatif(h) Siquer, bie (J)alle, bie Symphe gefellt, uno in ber ḩoḩlen 210er wirb mit

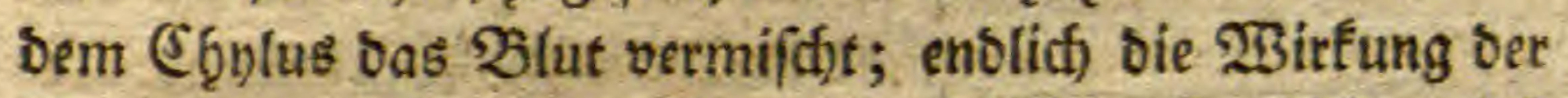
eingeatḩmeten suft in ber sunge barf nicht aufer 2(d)t gelaf. fen werben. Die 2luflofiung in bem ţ̧ieriftjen Rơrper nnch) einet genoffenen Naḩrung ober Speife ift immerwåt?= rent, bis folche in ein volffommenes $\mathfrak{B l u t}$ verwanbelt wirb. Seit Ђales Beiten fdon fennen wir bie Entwickelung uno Jeerborbringung einiger elaftifchen suftarten, eben burd) bie

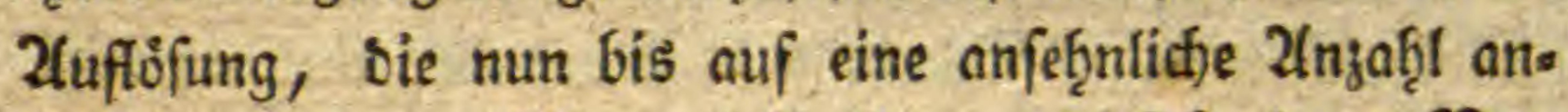
wächft, unb beren Berwanb/haften unter fid), beren $\mathfrak{B e t}$. miffoung uno ůbrige (Ȩaraftere fo genau angegeben wet=

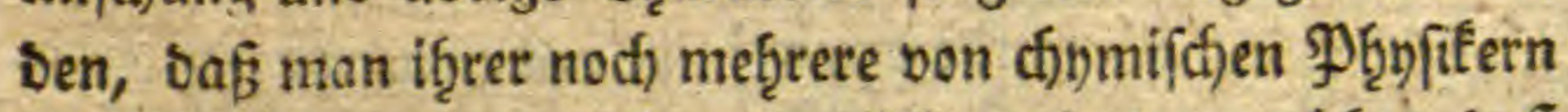
mit (Grunbe erwarten fann: wiffen wit benn nid)t, baf siefe ober jene Suftart mit bem $\mathfrak{P}$ g̨logifto uno thiterifhen Schrefel aufbraubt? wenigftens längft focion byat man es ats befannt angenommen, baß̧ Der গ̧̧ৃospḩor, welther aus

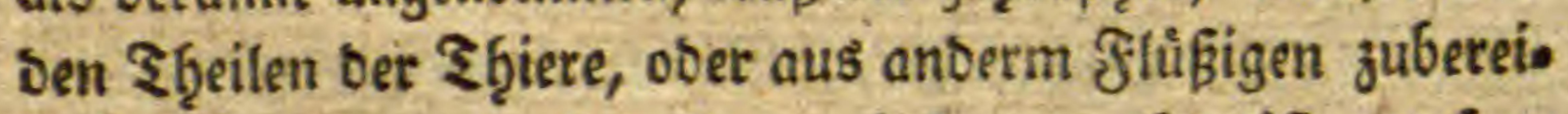
tet wirb, wenn er ber frenen suft ausgefezt ift, aufzu.

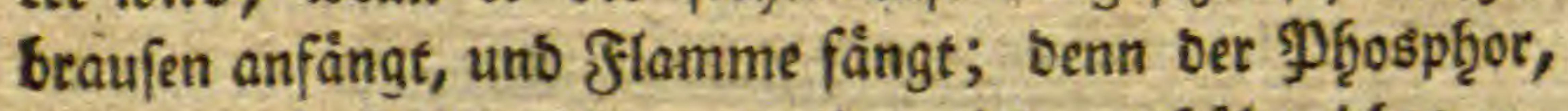

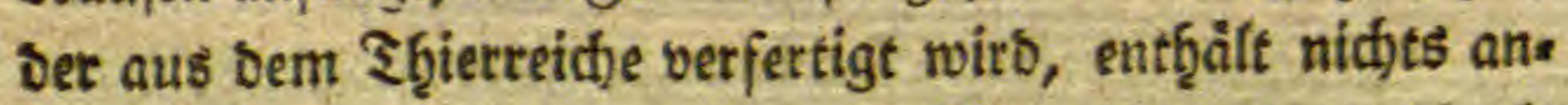
bets als bas tḩierifoffe concentritte Stennbare, bas von al. len $\mathfrak{\$}$ affertheil(d)en abgefonbert ift, wie es Mortimet,

$$
\{4 \text { ber }
$$




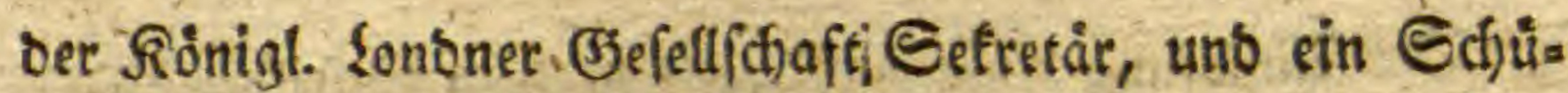
ter Doerf̨avens, fdoon erflarte.

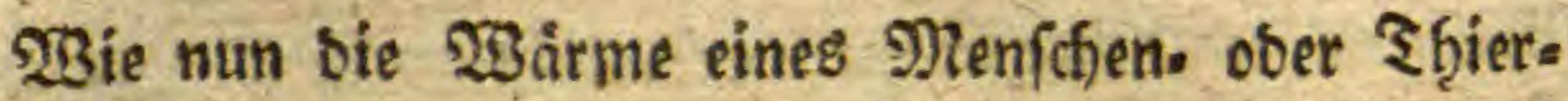
fơrpers, befonoers Der vierfüfigen ₹̧̨iere, gemeiniglich) grơf: fer ift befunben morben, als Die Attmofphairifde, fo fonnte man ebenfalls ben 23 ármegrab anberer $₹$ f̧iere, uno be. fonbers erftens ber fifithe unterfuchen, of uno wie groß Diefer Grao ifrees Rürpers, uno of er gróber als bie bie fifche umgebende flügigfeit fen)? biefen WBarmegrab ber Sifche a priori ju beffimmen, ift lefgr fdymer, weil bie Ut.

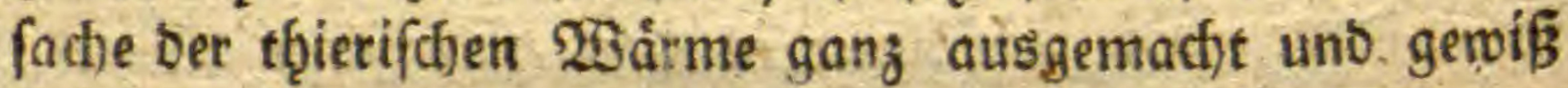
berwiefen feyn mulfte; aber auch) oie matfematifdye (Erfenntnißz oiefer Uriache wảre nicht binlanglich), weil bie Quantis

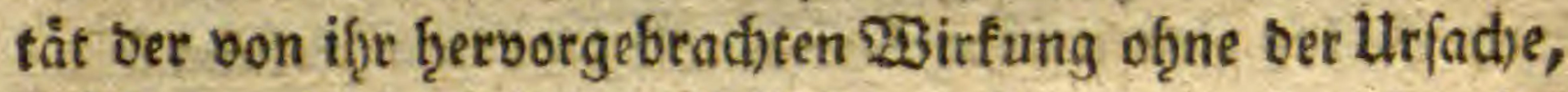
felbft bie 2uantitat Der Urfache ju fennen, nie fider bes fimmet werben fonnte; man musiste baber einen anbern

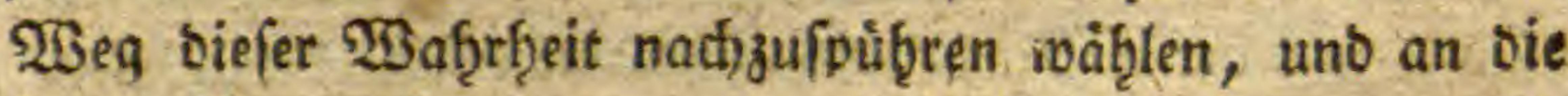
in ber Naturlef̧re fo treu uno eng verbuntene $\mathfrak{B}$ erfuche oie Şand anlegen; idf) werbe beren einige bon anbern unternom: mene dnfüf̧ren: bes J̨rn. Martin, Der Rönigl. Sononer uno (Foimburger (Sefellfhaft ber $23 i$ iffenjhaften Nitglie* bes, gemact)te Berfuct)e mit Condjylien unb 2(uftern bes weifen, baf man in Diefen faum eine Spur ber thieria

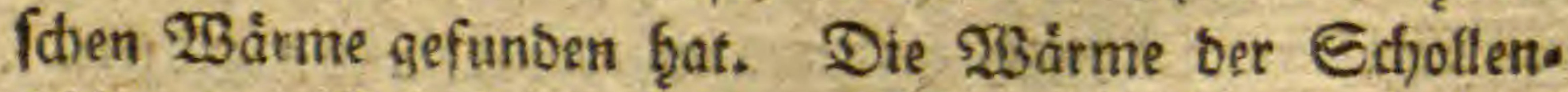
fiiche, bes Sdiell: uns Stodfifiches liberfiteg faum einen (5rab bes Meerwaffers, wo fie fid auffielten. Scr. Mnattín

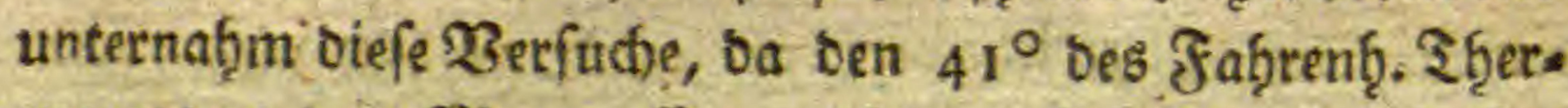
memeters tas Neerwaffer anjeigte. Die Jorellen auffer= ten ben $62^{\circ}$, ba bas Sedfroffer ben $61^{\circ}$ zeigte; Der Rar= 
Pfen unb 2tale SBärme war eben oie nåmliche, weldje

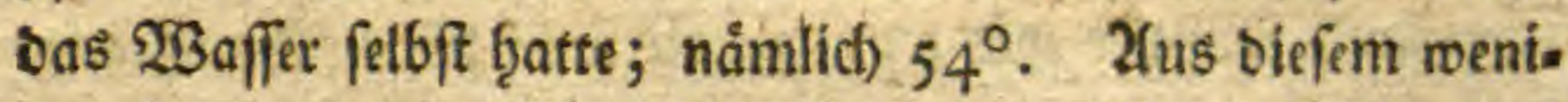
gen fann man wof̧l auf bie frage verfallen: $B$ ie groß

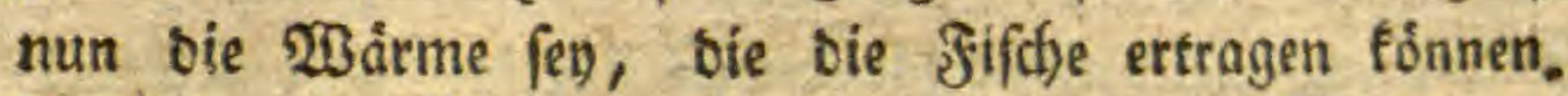
mufbenbroet bebauptet in ben Jlorentinifd). Berfuchen:

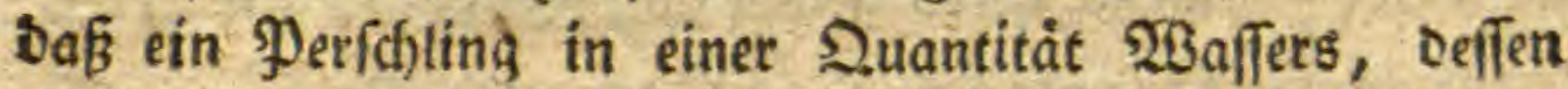
IBarme $72^{\circ}$ Faf̨renfi. Gatte, eine Stunbe lang fich er. bृalten biaitte, fo balb aber biefe $2 B a$ arme bis auf ben $96^{\circ}$ geftiegen, waire ber \$erfobling in 3 פ) gen. Fetnere $\mathfrak{B}$ erfude, weld)e in biefem Fache murben: broek obet anbere gentad)t ḩatten, finb nicfte fo leidt) augs finsig zu madjen, uno oaf̧er muf man fich begnúgen, ano

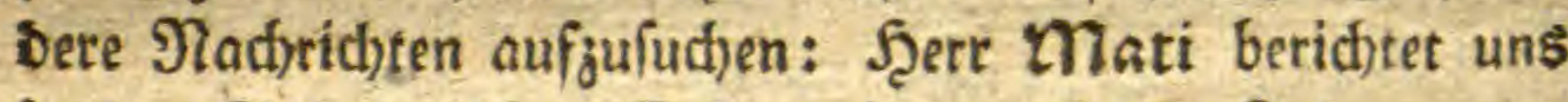
in ben 3ritannifthen Eppemeriben auf bas Jabr 1750. Daß im 2luguftmonate burch) eine aufferorbentlid)e suft: fibe eine grofie Menge von Jifhen barauf gieng; bas

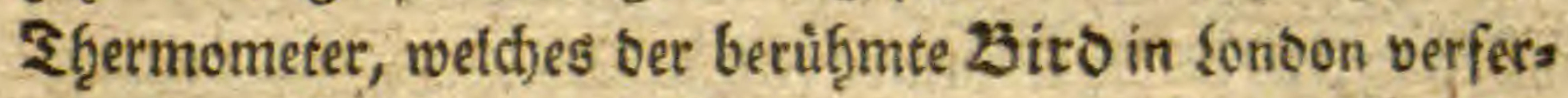
tiget b̧at, hatte am 15 . Şeumonats um 3 Uḩr nach) Mits tage 90\%, (obnfebibar nad) Jaḩrenţeits Etufenleiter, Die in Englano in (Ssebrautje iff) gezeiget. $\$ 6$ zwar nact bem vorf̧ergeţenben Werfuch Des Mufbenbroet ber Perfoling ben bem $95^{\circ}$, in siner Seit von 3 श2tinuten batauf gieng, fo fheint nidtsts befto weniger biefer (Brab nicht notb̨wentig zu fenn, fonbern es fann auch ein geringerer z. 5 . wie tes von $90^{\circ}$ uno barunter feyn, ber wenigftene einigen ffifthen fdifon tobtlich ift, befonders wenn biefe Şiţe ourd mehrere

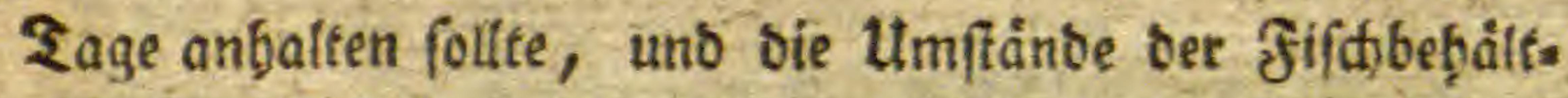
niffe fid) eben barmach ridfeten; idf finbe biefen in Enge lano beobadteten (5rab mit oem unferigen hitefigen Drts eben in Diefem Jaf̧re verglidenen: Daß jener ben \$rager 


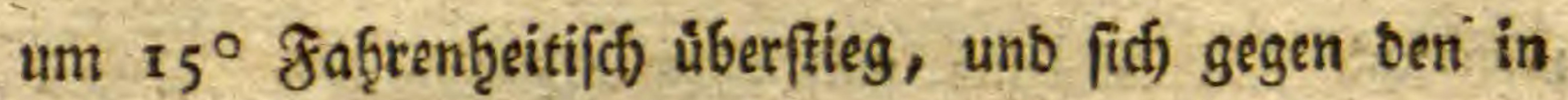
Engellanb verḩatte wie $18: 13$, of man zroar ficher fagen

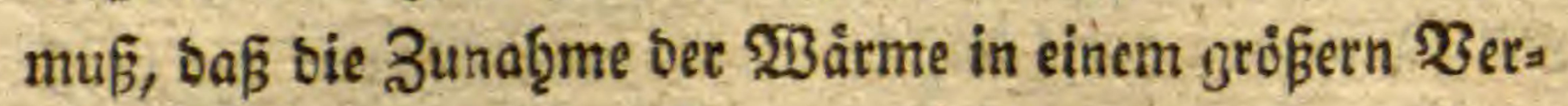
Ģältniffe mact)fe, als bas (Srabemeife Eteigen an bem ₹get. mometer; úbrigens iff es genug auffallent, warum Mus Thenbroet eine gange Stunbe in bem $72^{\circ}$. Stras warmen

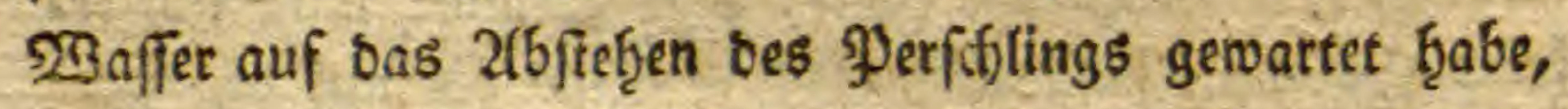
meti es auffer alfen Sweifel gefejt zu fern fdjeint: baß int boben Sommer bie Fiffhe, uno befonders jene $\mathfrak{W}$ afferbe.

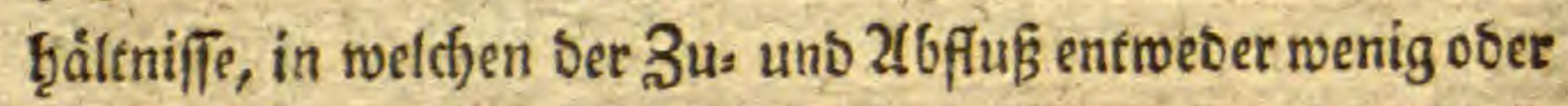
gar nidje marflich iff, eben fo ftarf erf̧iģet merben müffen, unb biejenigen am meiften erf̧işt roerben, weld)e weniger tief fint, faft wie sie suft.

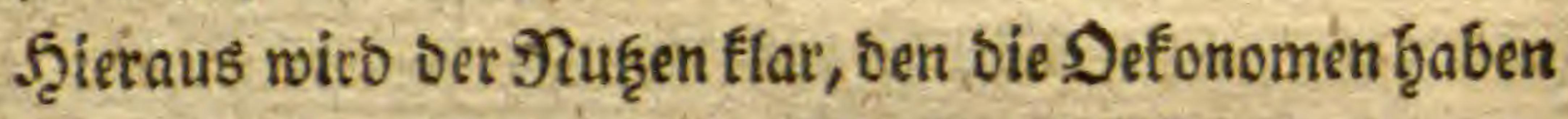

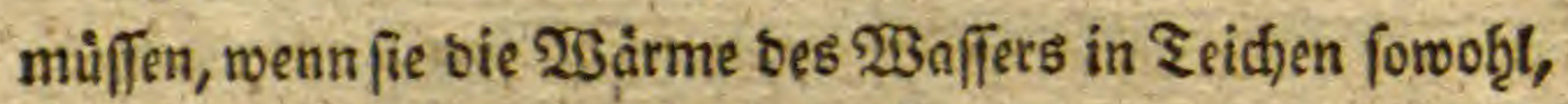
als ben flut|Ten, auf äf̨nliche

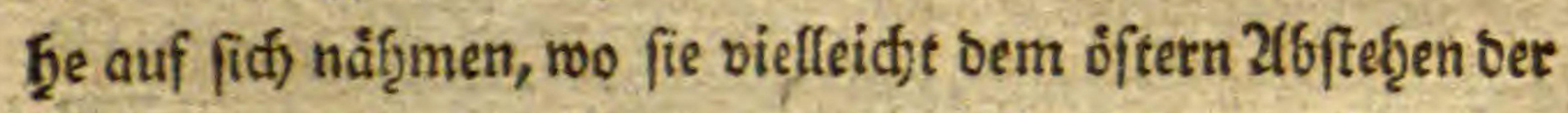
Jifche mandjutal auf ber Stelle abbelffich fenn fönnten; nebft biefem wurbe ber Befliffene ber Naturwiffenfd) aft noch

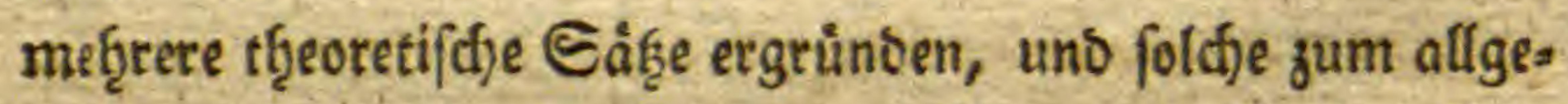
meinen (Sebrauch) zu erweitern, im Etanbe feinn; id habe zwar bas $\mathfrak{B}$ elfpiel meines $\mathfrak{B}$ orfafgrers, Şertn Step. Iings, *) vor einigen Jabzren nadjgeafcmet, uno fo wie er, bie $\mathfrak{B a r m e ~ u n f e r s ~ \Re o t b a u f f u f f e s ~ t a ̊ g l i d ) ~ z u ~ u n t e r f u c h e n ~}$

ver.

*) Vide Mifcellanea Steqling. Pragx, 1759. imprefla in 8. p. $18 .-22$. 


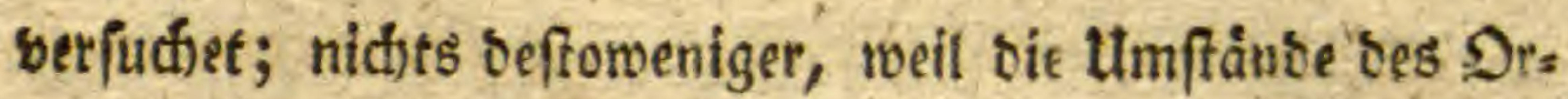
tes, wo id) Diefe Berfuche nachmadite, burch bie Llebers fab̧rt viel gef̧inbert, uno auch umgeandert roorden fins, bृas be id foldhe fabren laffen, aber bennod) mit ber Leberjel.

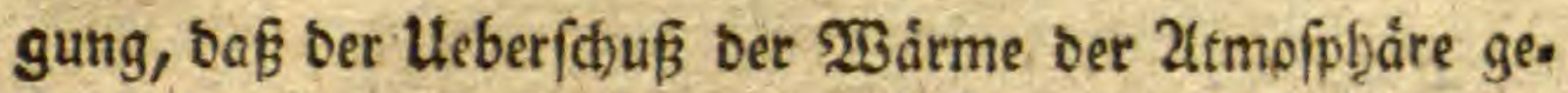
gen bie rom $\mathfrak{B}$ affer nid)t allzugroß fen, wie es fdon mit Stepling anbere befunden b̧aben. WBenn man nun die

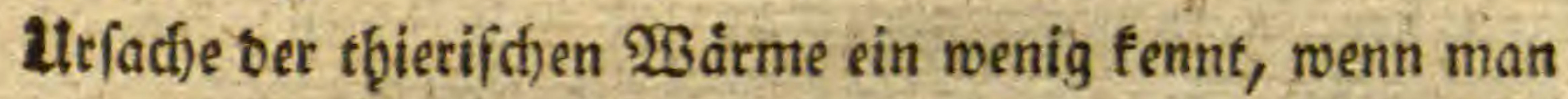
aud) bie $\mathfrak{B}$ årme ber $\mathfrak{B}$ afferbewob̨ner, bie fie ausłubalten im Stanbe finb, unterfuchet, fo bleibt bem elfingeaditet nodf) eine frage uibrig, ob sie tḩterifd)e 23 ärme fo b̨od) anmad).

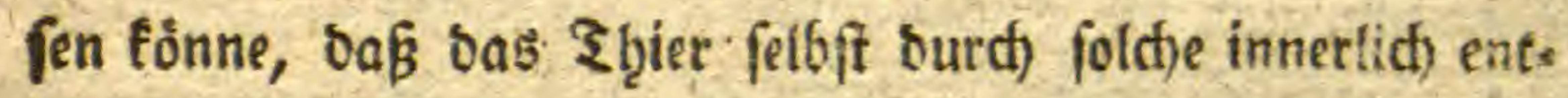

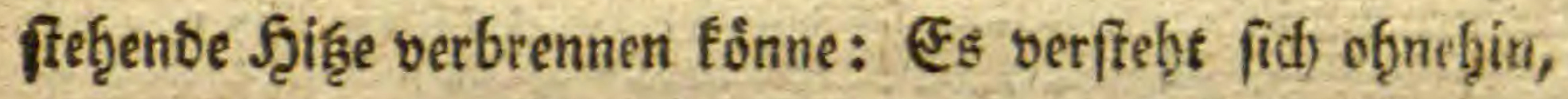
baß́ man f̧ier nicht einen gefunben Thierforper annimmt,

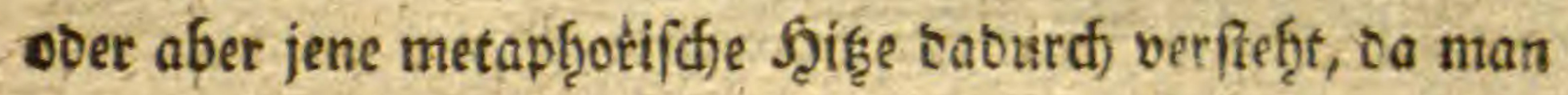

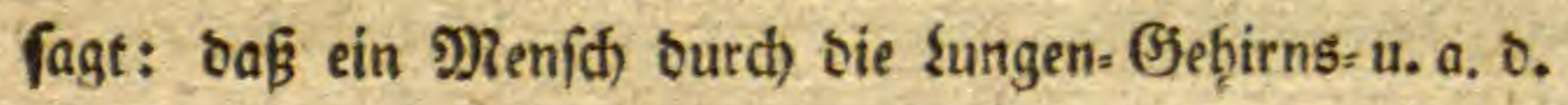
Entzünoungen barauf gienge, fonbern es fragt fid hier, ob,

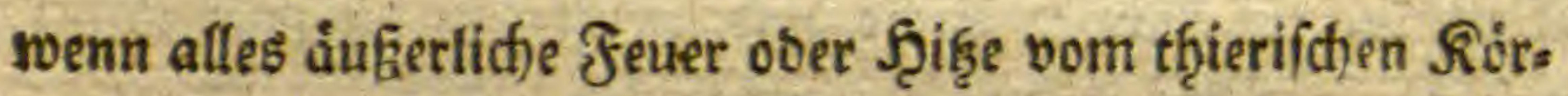

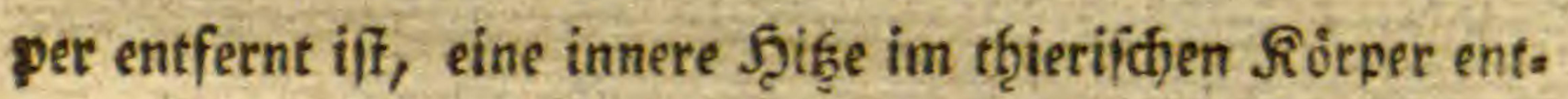
fteb̨en fönne, weld)e wirflid) flamme ober eine ford)e $2 B$ ir: fung berborbráchte, bie einer flamme nåh̨er, obst bie Bets brennung eigentlid) wáre.

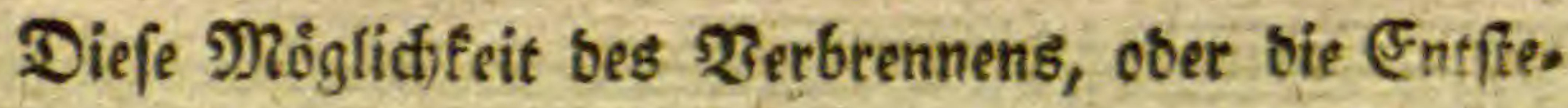

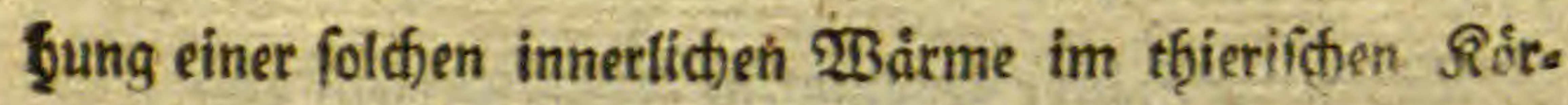
per, befonbers in bem menfidichen, fann man aus ein 
paar நeenfpielen, bie Ģier folgen, abneţmen. Şert Jos

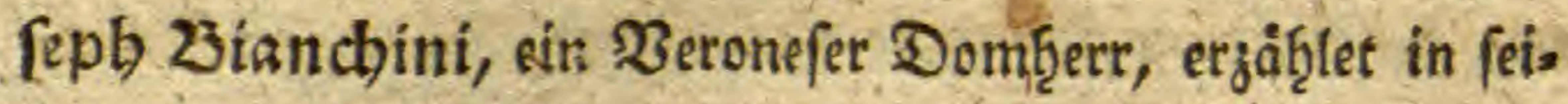

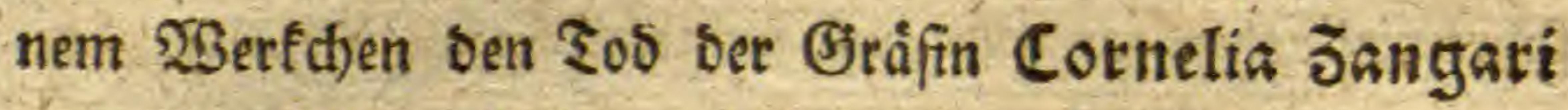
uno Zandi von Cepena mil folgenben $230 r t e n:$

Die Gráfin Cornetia 23anbi, 62 Jaf̧e alt, als fie eines

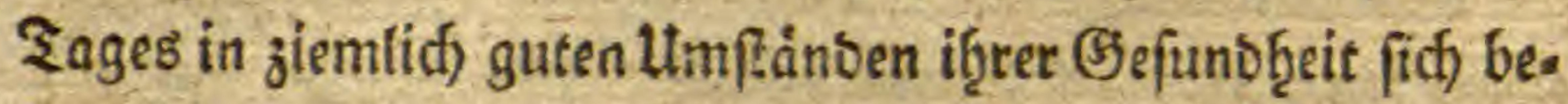
fanb, fieng 2fbenos auf einmal an fid su beflagen: baf fie eine Bef(d)werlichfeit empfinde; fie begab fid) baher ju

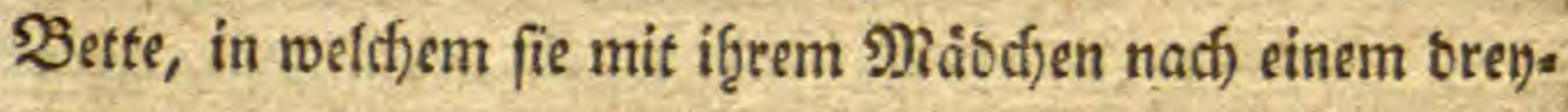
frünoigem (Sebete cinfdylief, morauf bas Stubenmaibchen weggieng, unb bie ₹ģuire zuff)loß; Da Jrüf̨morgens, um Die gemóthnlidhe Etunbe, bie (Ståfin nidf) rufte, gieng bas Mà่bd)en in bas Echlafzimmer, bie Gråin aufzuweden: auf feine erfolgenbe 2(ntwort mach)te fie bie Fenfterlaben auf, uno fanb, wiber $\mathfrak{B e r m u t h e n , ~ g a n g ~ e r f d y r o c f e n , ~ f o l g e n . ~}$ be Utmftånbe: in einer Entfernung von 4 Sd)uḩen vom

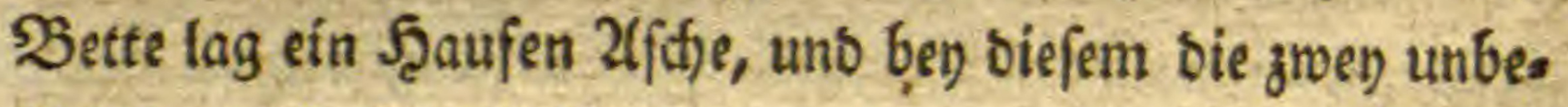

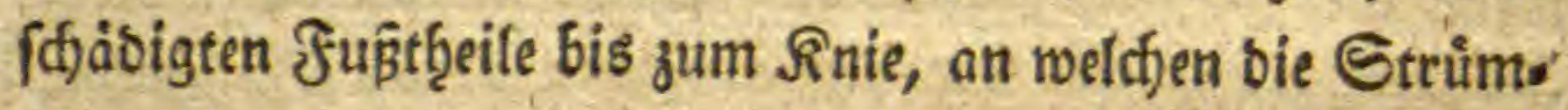
pfe nod) unverlegt waren, zwiffjen siefen lag ber Ropf;

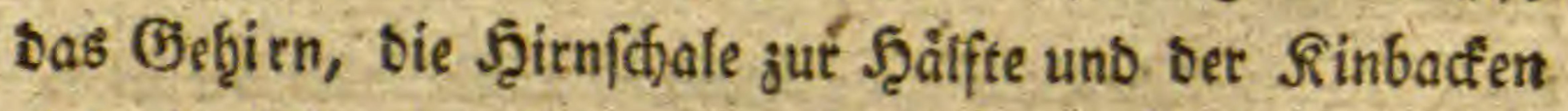

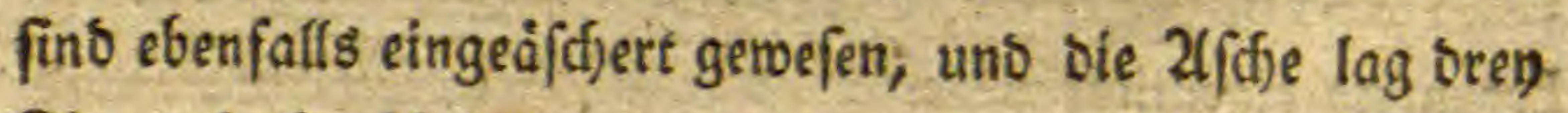
Finger f̧och, übrigens war fein anberes Heberbleibjel von ber Gråfin mef̧r zu finben.

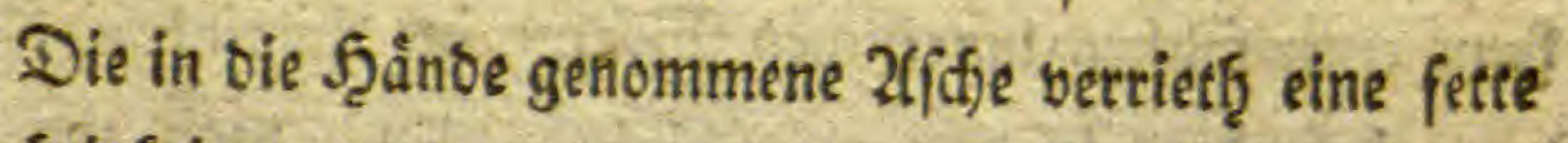
F̧eudjtigfeit, umb einen unangenę̧men (ङerud). 
Det grwente fall aus einer Engliffen Tacfjeidft ift fol. genber: (Fin Rofgletturenner bitchel, ber burdf) féne ₹ages.

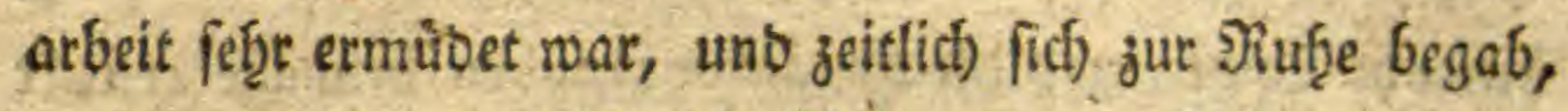

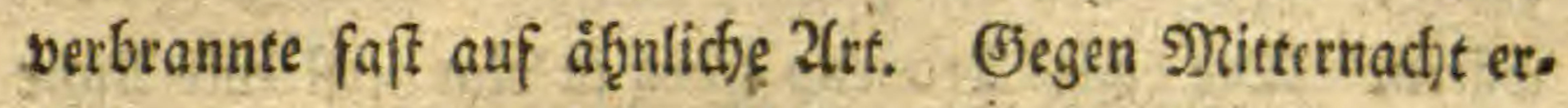
fotien ein plóf̨liches sidft, über weldfes bie Edjwiegermut. ter (2lgnes Siuffel) erroadte, bie ₹ochter rufte und um Şülfe bat; ba feine Z(ntwoort erfolgte, follid) bie allte aus

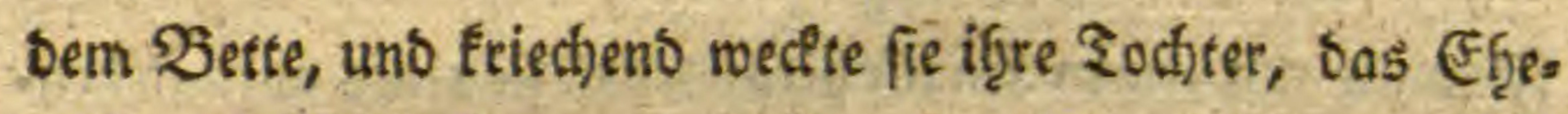

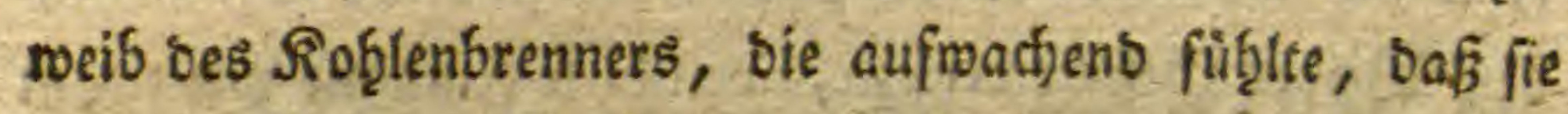

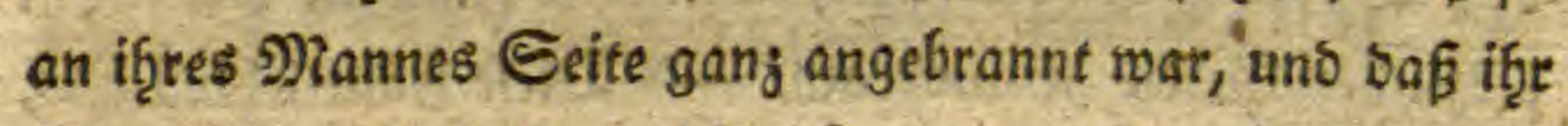

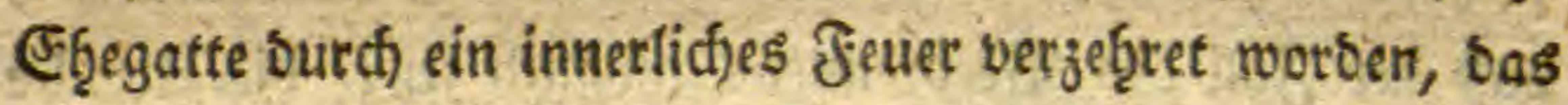

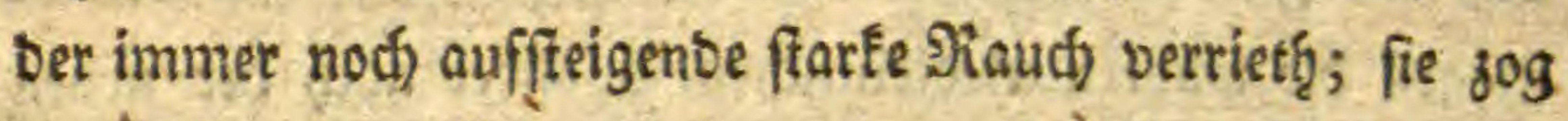

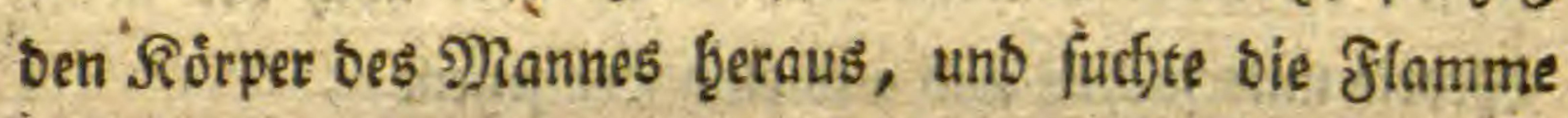
zu erfticfen, nidfts beftoweniger Ģielt biefe, ob

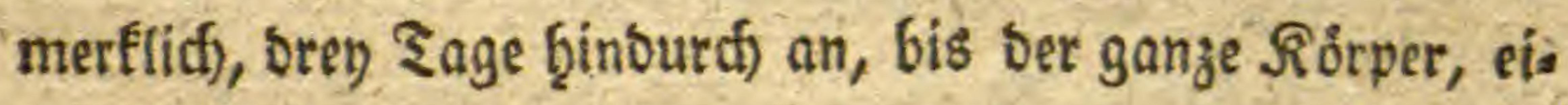
nige Bebeine ausgenommen, verjefgret wurbe. In ben Englifhen Transactionen auf bas Jaḩr I744. wirb ebene falls folgenber $\mathfrak{3}$ orfall beridfet: Eines Jifders 23 eib, (Gratia शुetti) bie 60 Jab̧r alt war, unb bie faft alltäglich, von

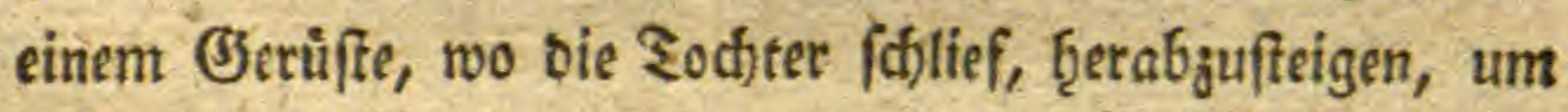
₹abaf ju f(t)mauchen, bie (jewwoţnţeit ţatte, ftieg aud) am

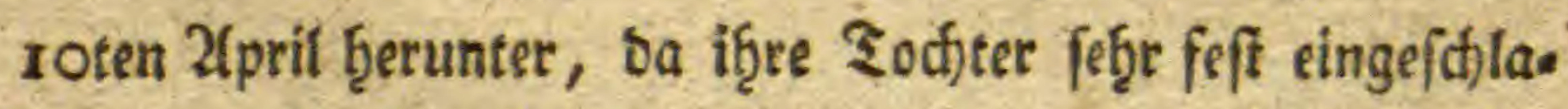

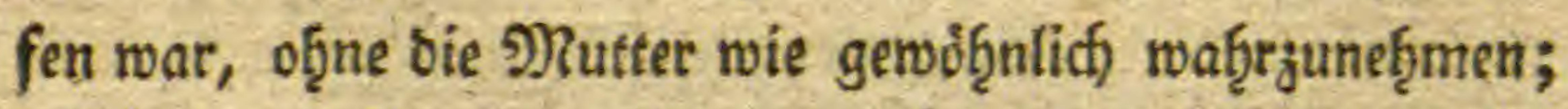

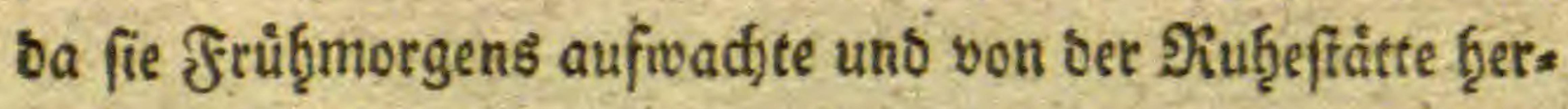
abftieg, fanb fie ben Siórper ber Mutter zroar rauffjent, aber oģne flamme; fobalo man bas Seuer mit úbergegofe 


\section{4}

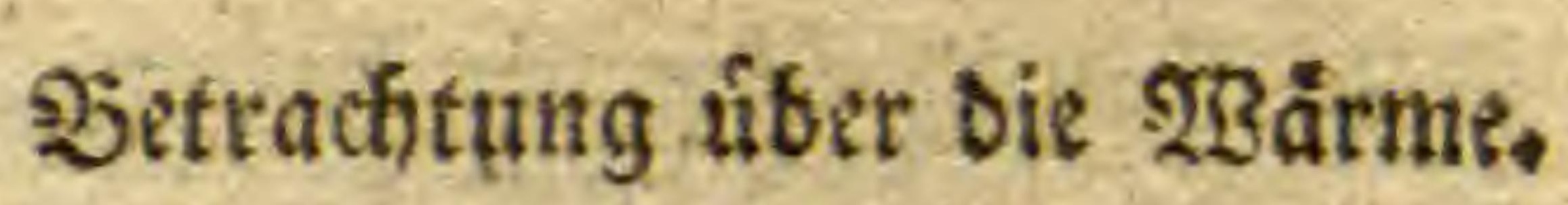

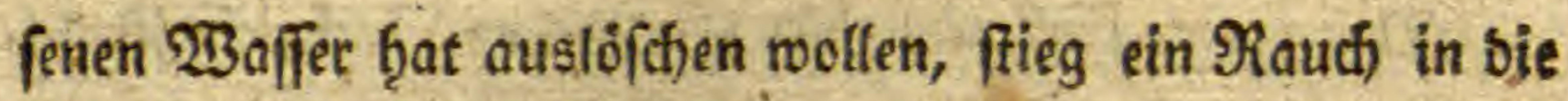

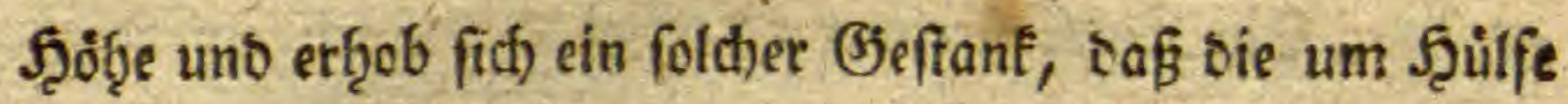
bittenbe Zuchter uno bie Sceranfommenben bennabe erfficft wairen. Der ganze Truncus gieng in eine jerftreute 2(fd)e ưber. Fin ăb̨nliches $\mathfrak{B}$ eyfpiel if von eines Raufmanns Rörper in Paris auf bas Jahtr 1681, vergeidfnet, benn ba beffen Baud) aufgefdnitten murbe, fub̧r eine fo lebhafte Jlamme mit einem Rnalle b̧eraus, Daß fie sines naţe ftę̧en: ben $\mathfrak{B}$ eibes (Gefid)t berlezte, weil biefe flamme mit einem

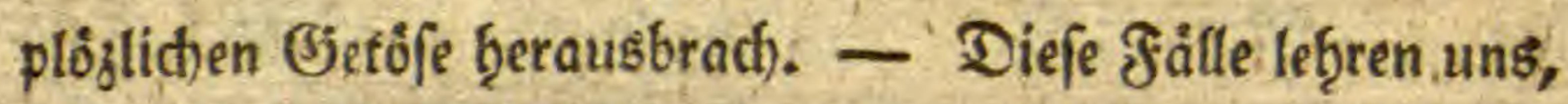
Daß ser Falf des Berbennens moglidf fen; bie Urfadje

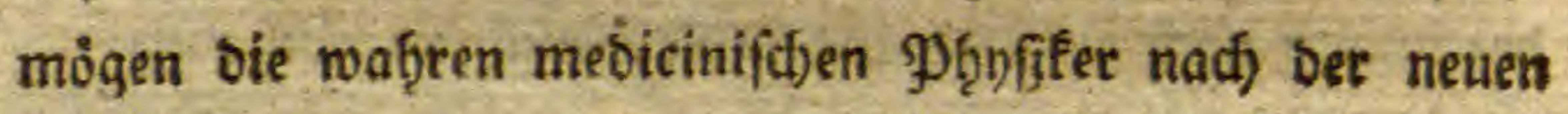
Tgeorie unterfucf)en unb aus einanber feร̧en.

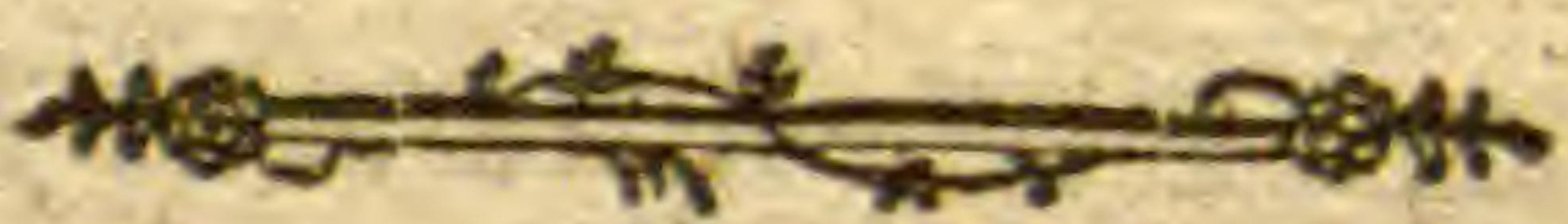




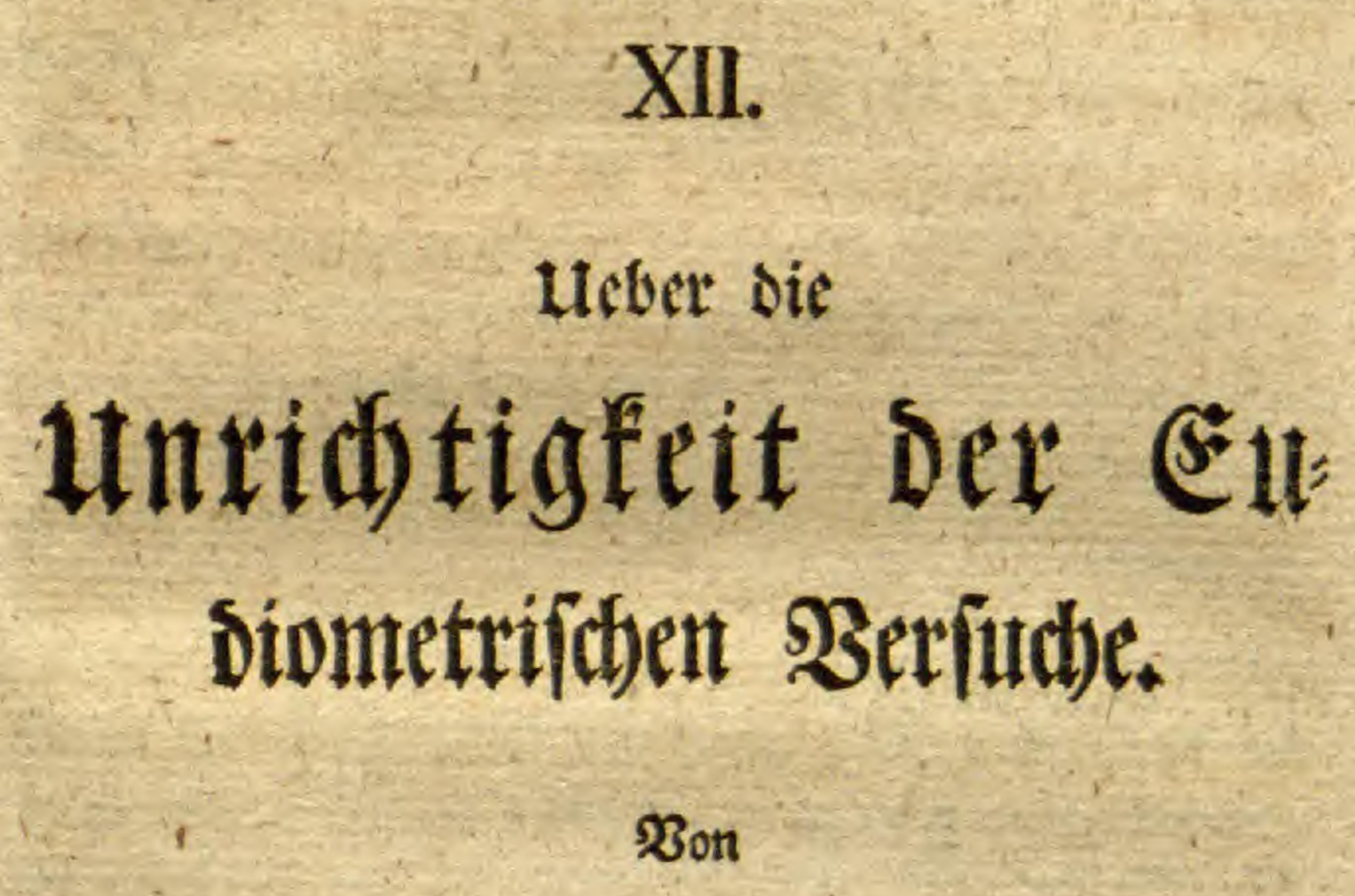

\author{
Bon
}

Joadjin Grafen bon Sternberg. 


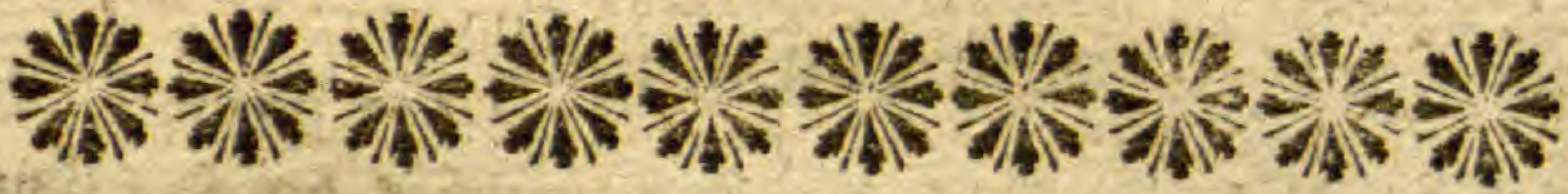

5 ie berffieberien Erffheinungen, bie ben ben suftar: ten burch fo biefe $\mathfrak{B}$ erfuctie bemerft wurben, verleis teten mich ebenfalls, eintge Prüfungen úber bie Eubiomes trifthen $\mathfrak{B}$ erfuche anzuftellen, um deren ridtige $\mathfrak{Z}$ (ngabe in Betract)t oes reinen suftţ̧eils zu erfaḩren. Zu biefem En. De naţm ich eine Portion atmofpha arifther suft, theilte fols che in 4 gleidhe Ftgeile, uno fejte bie, bis auf Den beffinm=

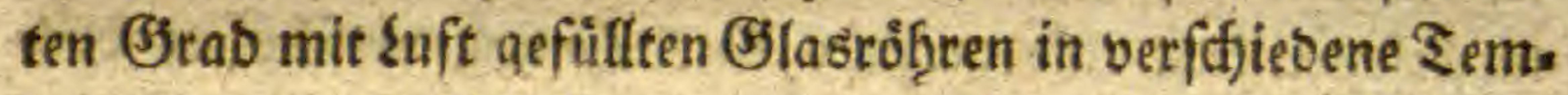
peraturen; gleichfalls wurbe mit bem baju befitimmten Miaaß̧ von Ealpeterluft verfaf̧ren. Der erfte Grad ber

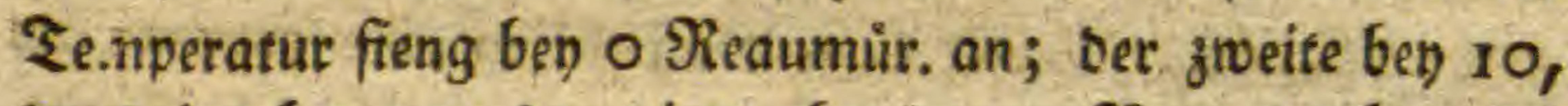
Der b:itte bey 15 , Der vierte bey 20 . Nun ergaben fí,

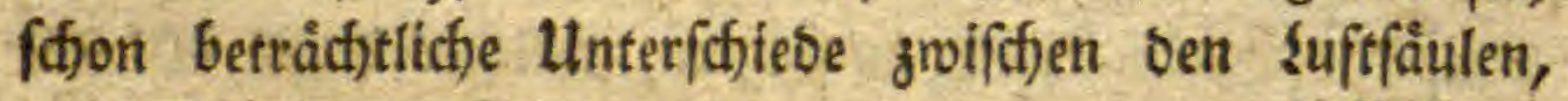

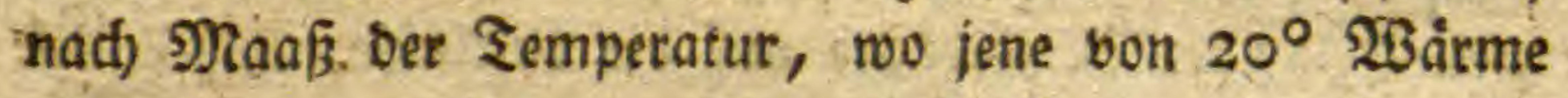
gegen jene bon $5^{\circ}$ umt 0,0670 mȩ̂r Raum einnah̨m; je. ne ber Salpeterluft aber verḩielt fich nid)t gleid) mit ber

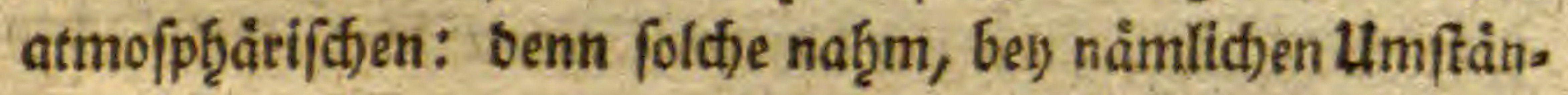
ben, einen গiaum von 0,0985 ein; biefes geigte, baß̂ bie

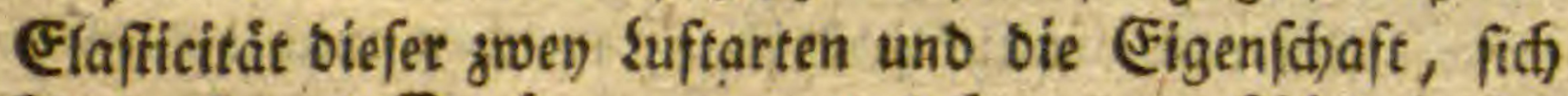

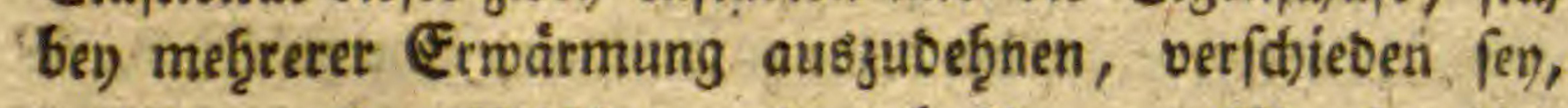

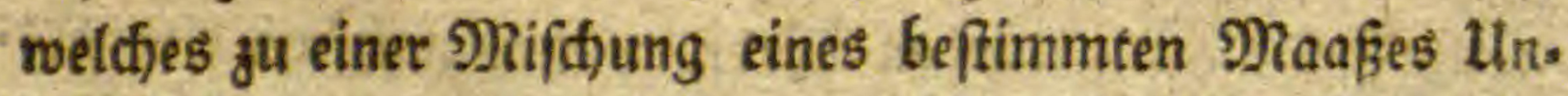
riffitigfeiten veranlaf̧t, menn nidf)t vorf̧er if̧e (5rab ber 2Bärme, nebft iḩrer Zfusbef̧nungsfäbigfeit gepriłft wor: Den. Die vielfärtigen $\mathfrak{B}$ erfuche Ģaben gejeigt, daß̧ wenn bas Berţăitnís ber Ealpeterluft nidjt gef̧ơrig angewante 


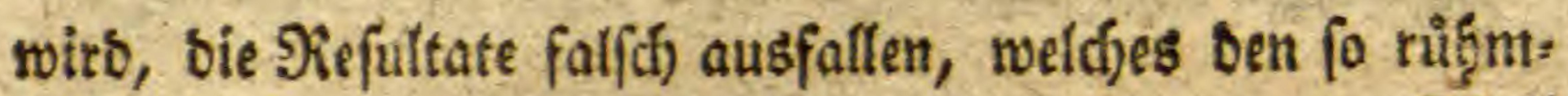
licbft befannten Ingenbousz verleitate, ben innetn S ḩeil bes bie Ealpeterluft entf̧altenoen (S)efábes mit einem mea

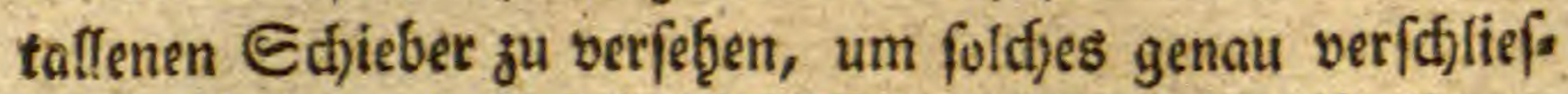
fen zu fönnen; bod) ḩebt biefe Gorgfalt nicfjt ben thmftant,

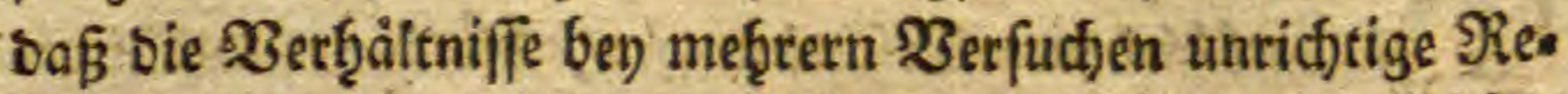
fultate liefern werben, weil fie von ber Temperatur abḩän= gen, wozu nod) folgenbe Befdywerlichfeiten eintreten: (Ex: ftens, bilbet bie Ealpeterluft, mit ber im $2 B$ affer entḩaltenen reinen Suft, Salpeterfáure; jwentens, wirb bey ber Mifádung ber zwey Suftarten 23 àrme entwicfelt, weld)e fidj mit bem

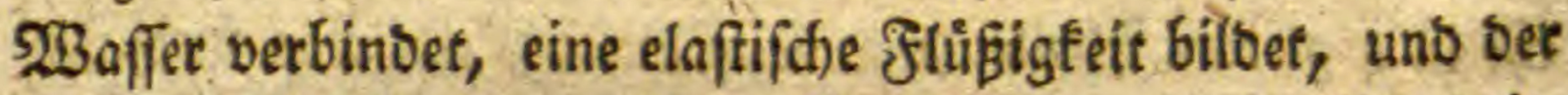
unzerfezten Suft eine gróßere 2lusbef̧nung ver\{chafft; orit=

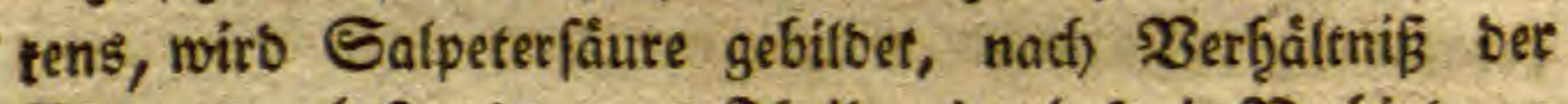
Menge ber suft; benn 28 ₹̧̧eile reine Suft, in 2 erbinsung mit 66 Tḩeilen nittrọer Suff, conftituiren eine concentrirte

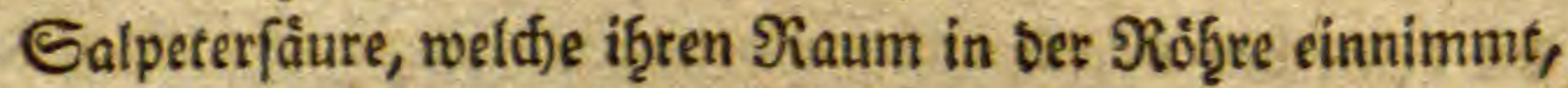

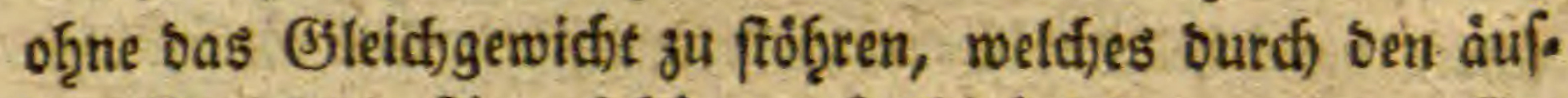

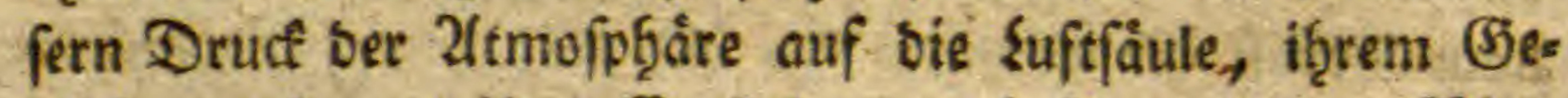
roif)te nad), vor ị̧rer Entftę̧ung geảufert wurbe. Bier= tens bemerfie icf) bey meinen Berfudjen, fo id ůber bie

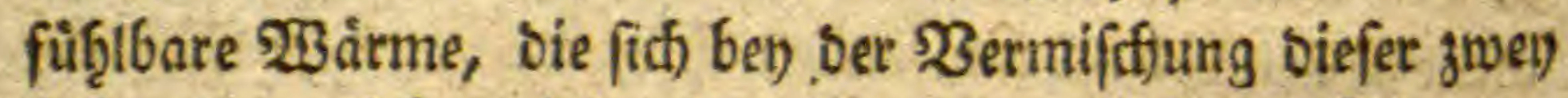
Suftarten ergiebt, vielmals wieberh̨olte, baf bas ₹̧̧ermometer von $10^{\circ}$ bis auf $40^{\circ}$ ftieg, weldfes midh berleifete,

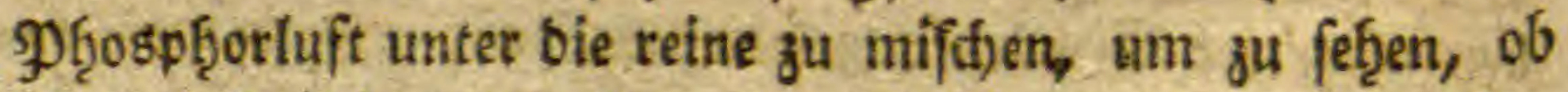

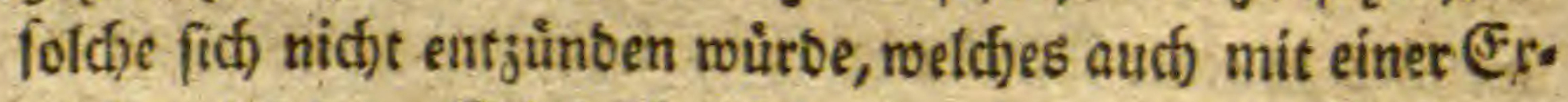
plofion erfolgte. Diefes beftátiget, baß̧ eine maḩre Berbren nung biefer jroen fuftarten bey if̧rer ßufanimenmifdjung bỏrgeţe. Wean nun nad) de la Metherie (Journal de Phyfique, Jauvier, 1782, \& I 784.) Die Ealpeterluft aus brentw 
barer Suft, burd) einen Stoff mobificirt, beftefget, to mirb biefe art Safpeterfäure erzeugt, wie foldoes in ben Berfus d)en von Prieftley uno Cavenoifh, ourd) Berbrennung ber entzünbbaren und bepf̧logiftifirten \{uft im pneomatifhen 2lpparet gefchieg̨t, nur baß ģier bie Entżunoung von felbft, Durd) Die Benmifónung Diefer zwen Suftarten, nåmlid) ber reinen uno ber Galpeterluft, vor fid geţet. Diefe వeries

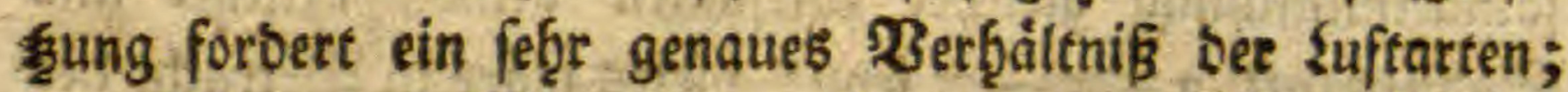
fonft bleibt ein ₹̧̧eil als ungerlegt úbrig, uno macht ben

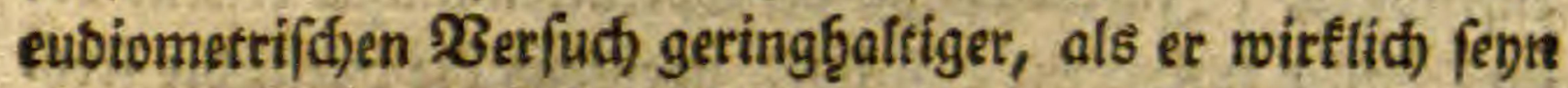
follte; gegenţ̨eils wiro fold)er gróker ausfallen, weil bie überfübige Ealpeterluft von ber erzeugten Ealpeterfäure abforbiret miro. WBenn nun so Rubitzoll reine Suft 4,450 Gran wiegen, fo geţơren 11,790 Gran Galpeterluft bazu, um bamit Salpeterfäure b̧erborjubringen, welches 16,240 Gran Gaure betragen wirb, welche, pen bote ber angefüb̨rten Ltrfactien nach, bem Bolumen eine falfidje

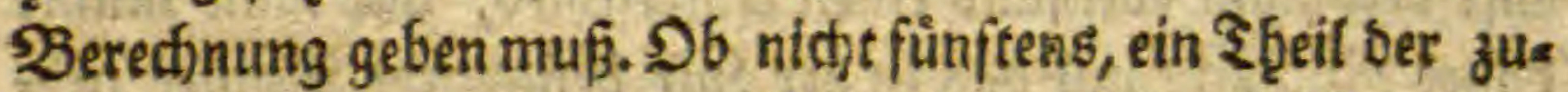
fammengemifd,ten suft in eine anbere suftart übergeb̧et, lágt fid) aus benen nut fo oft roieberf̧olten $\mathfrak{Z B}_{\text {affererzeue }}$ gungs = Experimenten mutf̧maßen, wo von ber brennbaren unb reinen immer ein tleberreft von phlogiftifoter jurüd

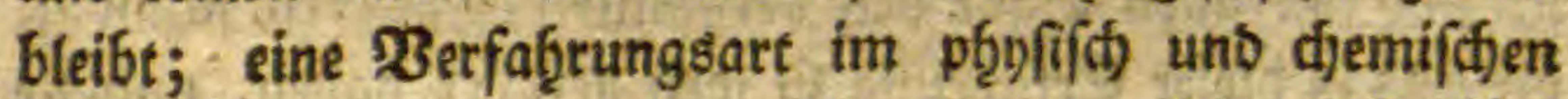
Fache follte, meines renigen Eradjtens, nicht oiefen Un. ridjtigfeiten unterworfen (enn, wenn man ficfere Edflupe folgen baraus fđjöpien will. Die Fẹgler, bie bey bet elle Diometrifd)en Speration borgę̧n, ließ̧en fich allenfalls fol= genbergeffalt berectinen, naimlia) bie suftfåule ber atmofpḩą: rifhen suft ben o Reoum. $=a$, die ben $20^{\circ}=a+b$. Die Salpeterluft ben $a=c$ ben $20 c+d_{4} d$ ift abec M 2 gro̊ger, 
180 Uleber bie thitid tijfeit ber eubiometr. Werfudfe,

größer, bem $\mathfrak{Z}$ of men nad), als $b$, wenn fie bel $20^{\circ}$ fich) befunben, of̧neradseet bie Maffe $a=c$ bleibet; oa aber bie Bermilffung bem Bolumen nad) gefdhieb̨t, fo folget, Dab twenn gleiche Volumina angervanot werben, bie Malfei unter fid berffifeben fino, weil $b=0,0670$ unt $d=$ 0,0985 ; nennen wir bie Differenz $x$, fo wiro in bet 3 ut

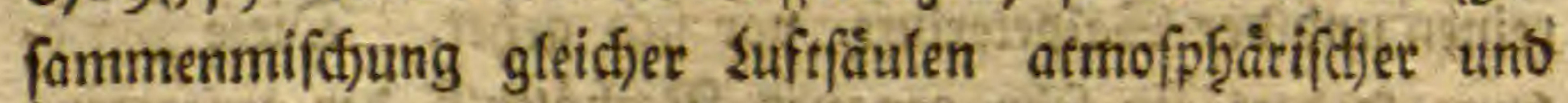
Ealpeterluft, $\mathrm{a}=\mathrm{c}-\mathrm{x}$ fenn; biefes wáre in $\mathfrak{B}_{\text {etradbe }}$ e s Iuftifoffes. In 2fnfef̧ung oer Speration múste erftens bet

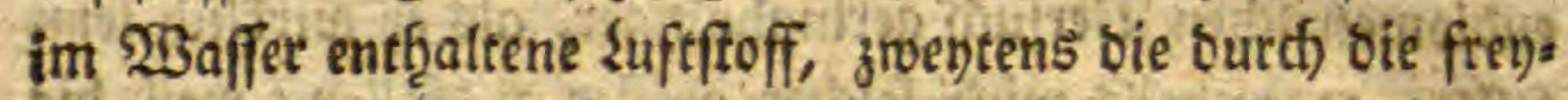

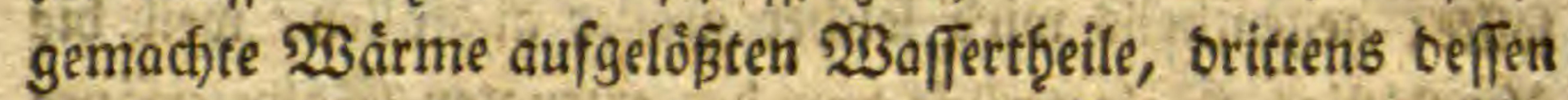

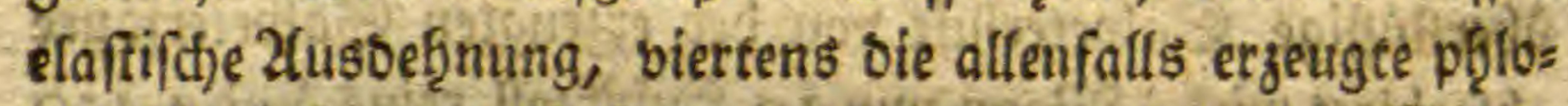
giffiche suft, uno fünftens enditid tie entfanberte Salpes

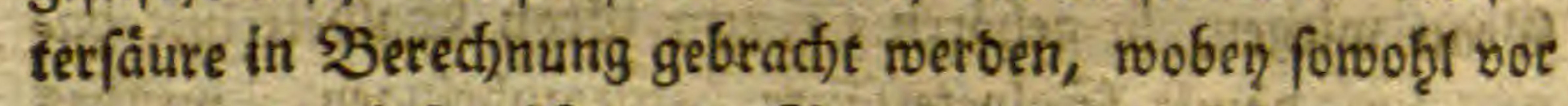

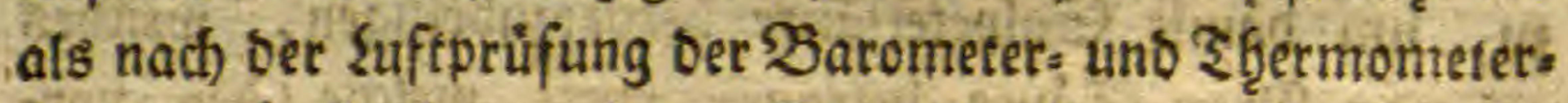
ftanb ju beobadjern wäre. Die meb̧r ober weniger feudfte Suft beranlafit ebenfalls einen Unter foliet, ino mah müste

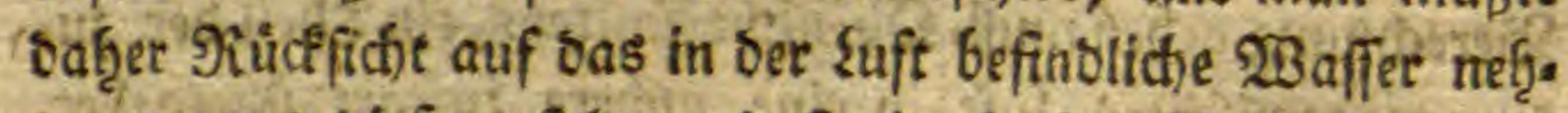
men; aus biefern forget, bás ein folcher Berfud) vielen EchroferigPeiten untertworfen iff, unb man biefervegen wes hig Zutrauen auf beffen Fidjtigfeit haben fann; unterbef

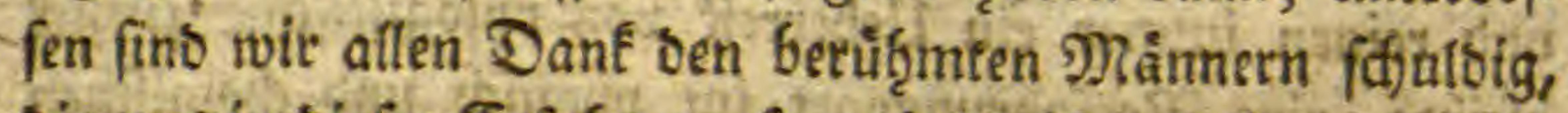
bie uns in biefer Erfaģzung fo weit gefübzrt haberr, und fie werben fets mit altem Redte fagen fónmen: Inventis fà cile eft addere.

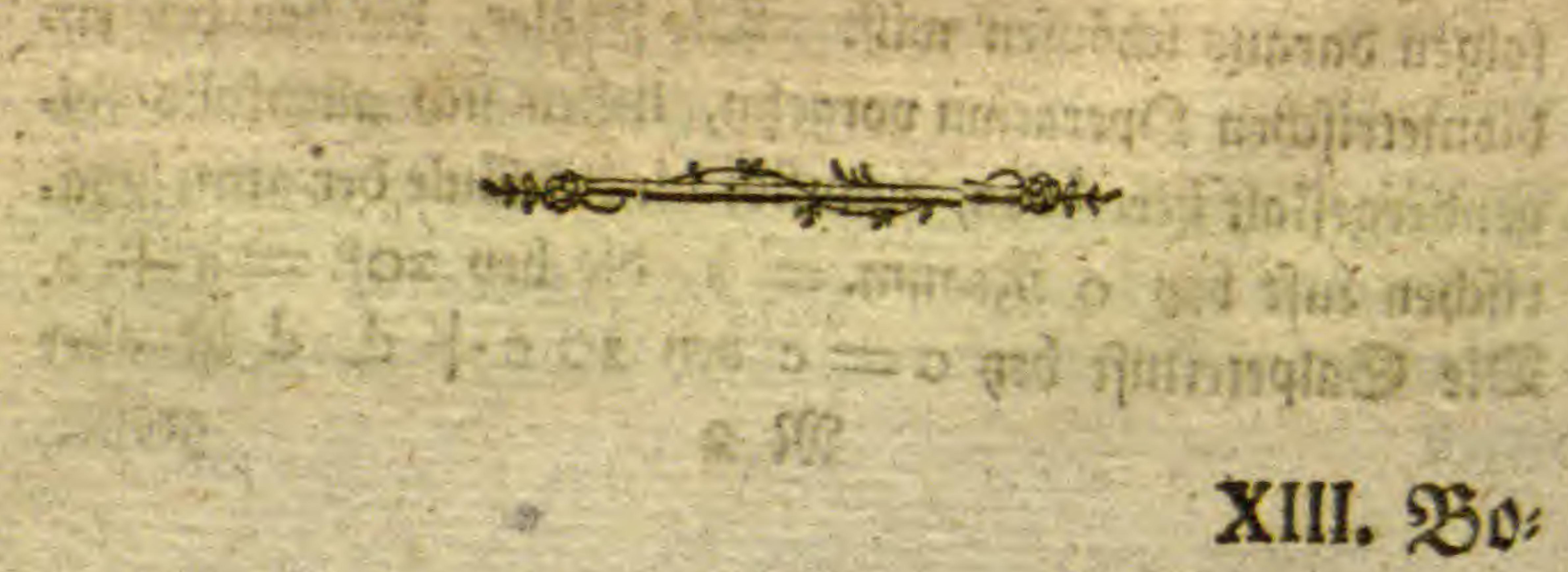




\section{XIII.}

Sotanifobe

כ่eobad tungen, volt

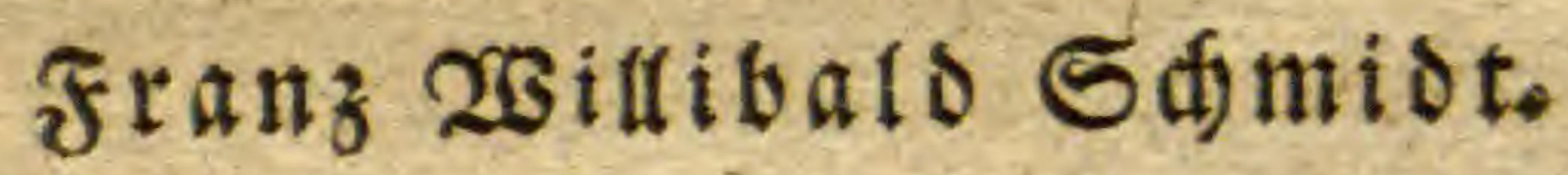

2 3 
b.

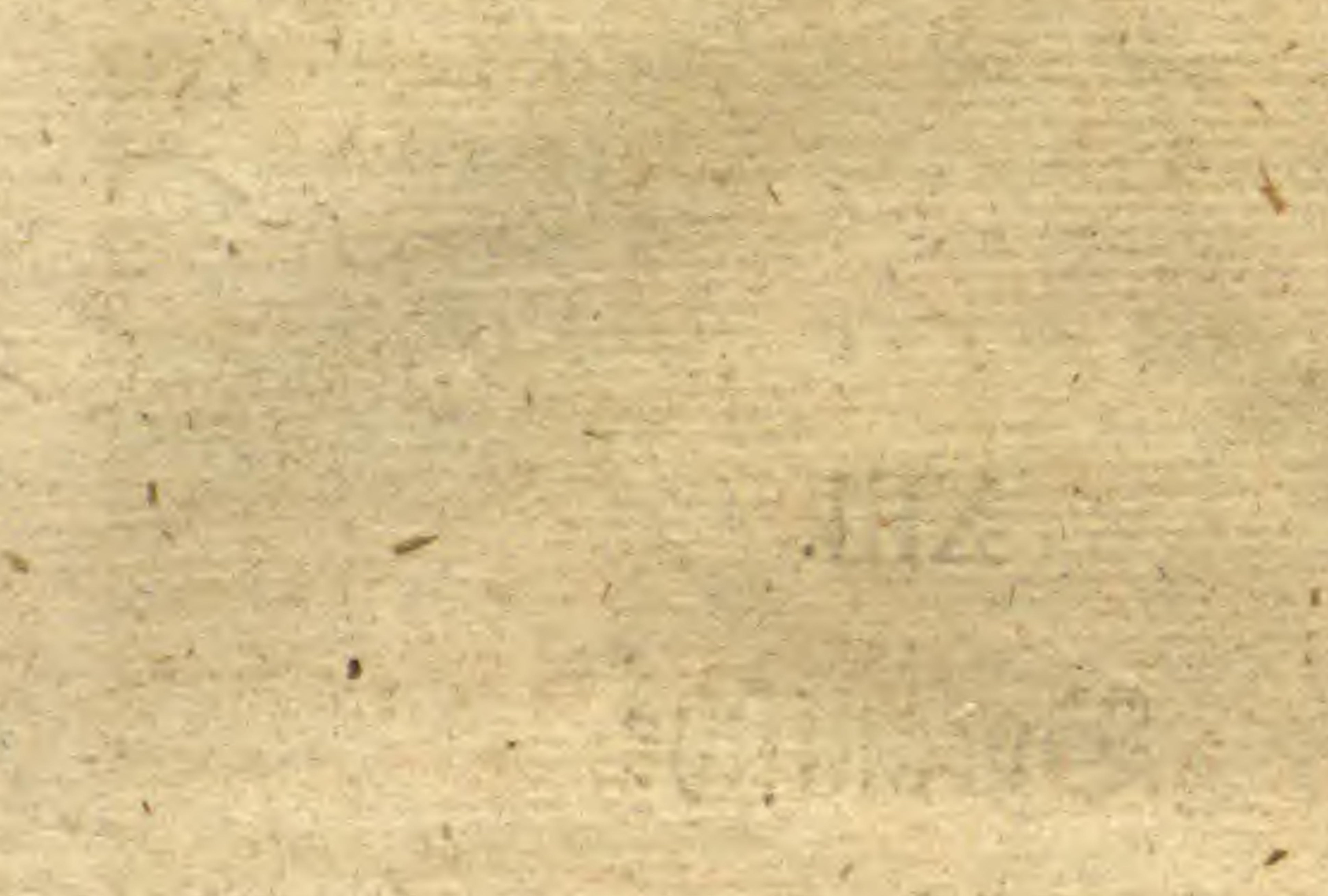

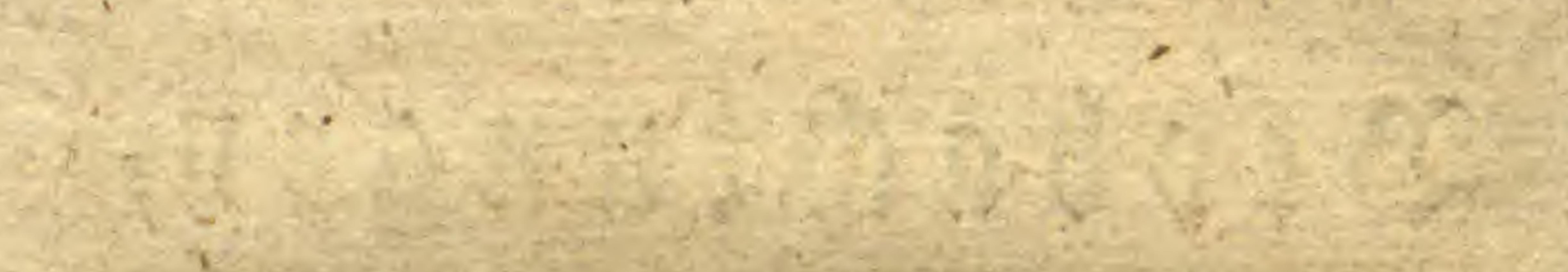

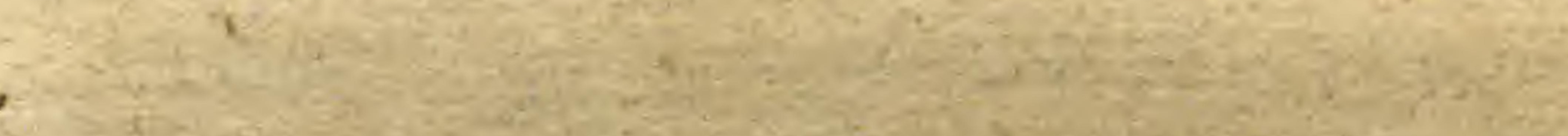

34 की

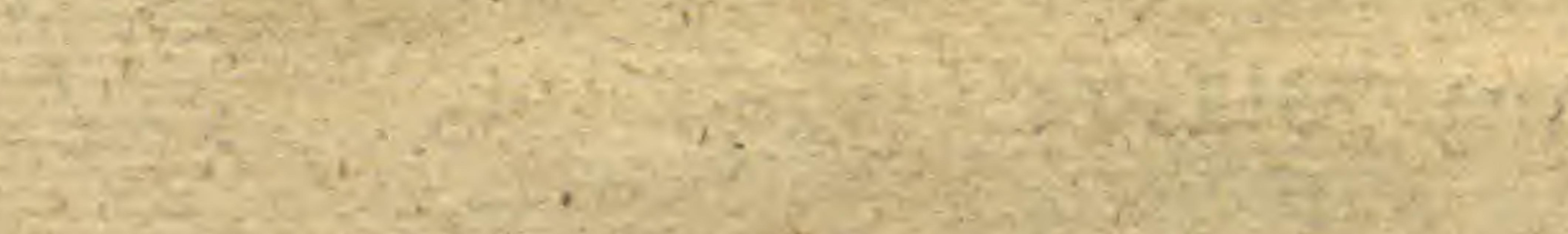

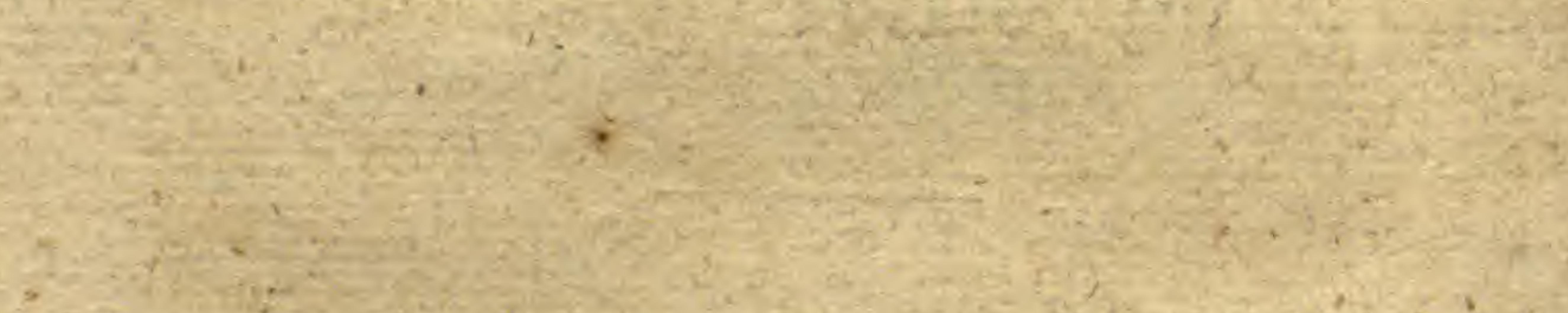

(15:
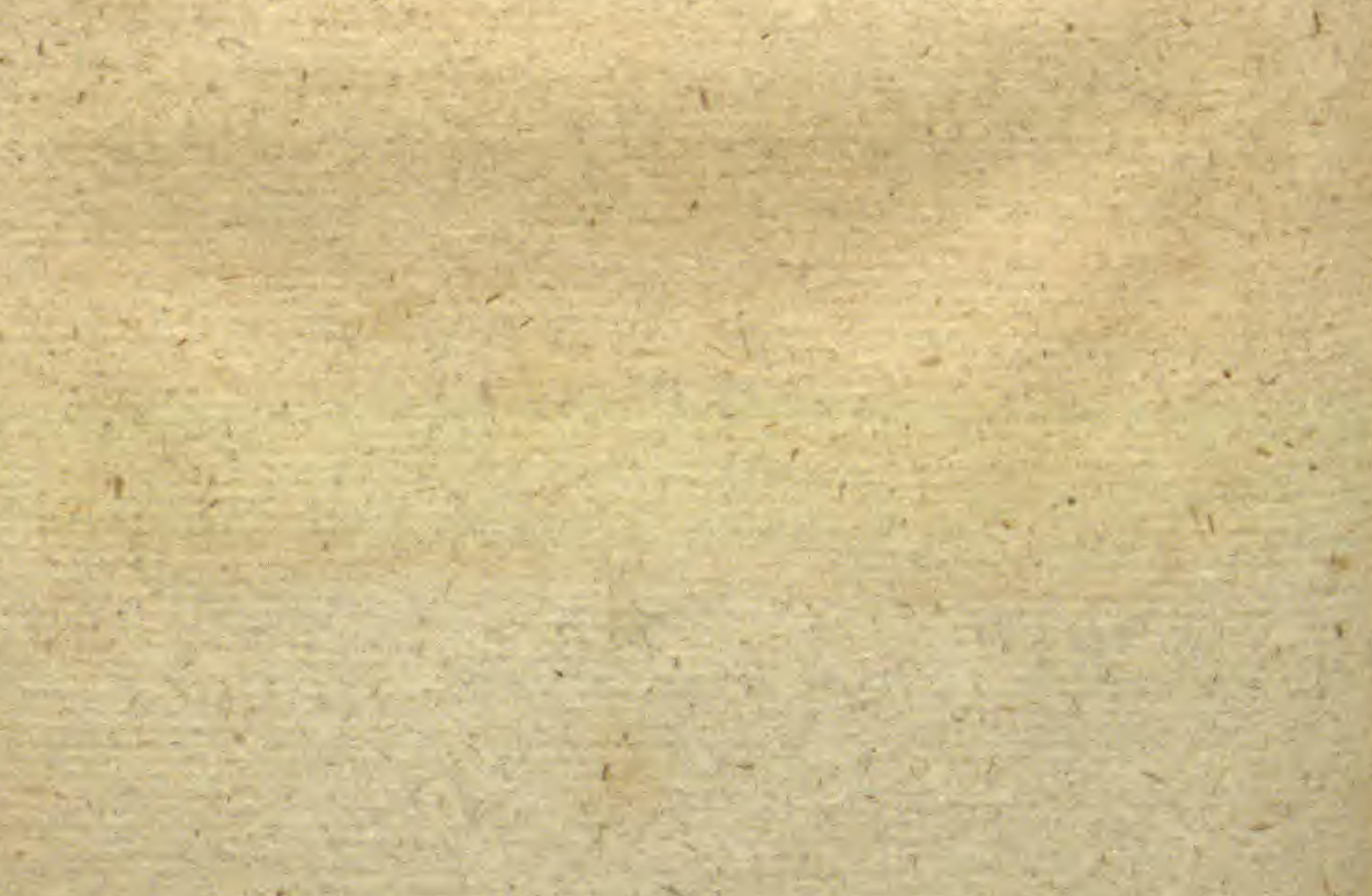


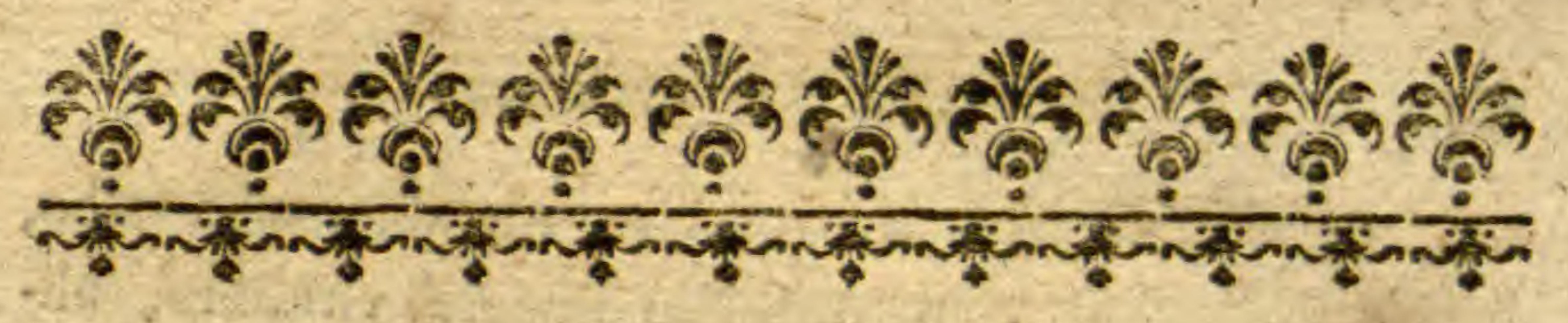

\section{Rivina Humilis. Lin.}

\section{Divina racemis fumplicibus, floribus tetrandrüs, fo-} LC lis pubefcentibus. Linn, fyft. veget. p. 165. Solanum barbadenfe, racemofum minus tinctorium. Pluck. alm. 353. tab, ita. f. 2.

Amaranthus baccifer, eirczefoliis. Commel. hort. I. p. I27. tab. 66.

Radix perennis craffa, lignofa, ramofiffima, flava. Caulis perennans, lignofus, erectus, dichotomus; a folio ad folinm angulatus, angulis cartilagineis, pubefcens, glaucus,

Folia alterna, petiolata, ovata, acuta, plana, integra, villofa, mollia; antiqua fuperiori pagina tomentofa, glauca, inferiori folum pubefcentia, nervis craffis percurfa; margine modicum revoluta.

Petiolus, femiteres fubtomentofus, fupra canaliculo exaratus, qui etiam per nervum folii continuatur.

Flores e dichotomia fimpliciter racemofi. Racemi florigeri erecti; fructiferi nutantes.

Pedunculus communis teres, gerit flores plures pedicellatos \& inordinate alternantes.

Caly $x$ nullus, nifi corollam velis, Corolla calycina, tetrapetala.

Petala oblonga, obtufa, infra convexa, fupra concava, $\mathfrak{X}_{4}$. ex 
ex albo virefcentia, margine membranaceo albo, perfiftentia; polt Anthefin majora viridiora, aliquando colorata.

\section{Stamina quatuor.}

Filamenta plana, linearia, alba.

Anthere rotundx, planx, fimplices; polline albo tecta. Germen glabrum rotundatum, vtraque parte argute compreffum.

Stylus brevis, incurvus, perfiftens.

Stigma fimplex, planum, glandulis obfitum.

Bacca rubra, nitida, monof perma, fucco croceo plena, corolla reflexæ infidens, acumine incurvo.

Semen lentiforme, fubrotundum, compreffiusculum, fcabrum, nigricans, futura fcabra cinctum.

Obferv. Non femper flores monogynos obfervavi. Sxpiffime racemos inveni, ubi quilibet flosculus duo germina geffit, duosque fylos elevavit; nunquam tamen duas baccas fecit; cum ftylo alteri ftigma defuerat.

Colitur in horto Illuftriflimi Comitis de Canal; floret toto anno, continuo arbufcula racemis florentibus \& fructificantibus onufta. Viget in Tepidario per totum annum optime; rgrotat tum cogitur reftate fub diu vegetare.

\section{Rivina lævis. Lin.}

Rivina racemis fimplicibus, floribus tetrandriis, foliis $\mathrm{gla}$. bris, Linn. fyft. veget. p. 165. Kniph. cent. 2, n. 74 . Solanoides americana, circæexfoliis glabris. Tournef. act. parif. 1706.

Caulis lignofus, ftrictus, ex rufo viridis, friatus, laviffume pube- 
pubefcens; primo intuitu anguilis confluentibus, cartilagineis, albicantibus angulatum diceres; tum autem tentamini fubjicias, in fricto fenfu lavem invenies. Sic/etiam rami,

Folía ovato-lanceolata, acuminata, alterna, patentiflima, imo nutantia, integerrima, plana, aliquando etiam margine undulata, atro-viridia, margine rubicundo picta, glabra, nitida, fubtus ad coftas villo veftita, petiolo re. clinato, fuperne canaliculato, nec non hirfuto infiden. tia.

Racemi e dichotomia caulis longi, digitales \& vltra, patentes, fubhorizontales.

Pedunculus hirtus; pedicelli filiformes, breves, brattea lineari-lanceolata inftructi.

Petala quatuor patentia, linearia, parva, viridia, extus rubore colorata, perfiftentia.

Stamina quatuor patentia.

Filamenta longitudine petalorum, perfiftentia; una cum petalis in fructu reclinata.

Antherce finplices, flaver.

Stylus recurvus, unicus, brevis, perfiftens.

Bacca unilocularis, carmefianæ coloris, nitida.

Reliqua vt in Rivina humili.

Floret \& maturos tructus dat una cum antecedente in horto Illuftr. Comitis de Canal. Toto anno in tepidario hof pitatur.

\section{Rivina viridis. Mihi.}

Rivina racemis fimplicibus erectis, foliis ovato-oblongis glabris, canle, pedunculisque angulatis. 
Nata hac elegantifima Rivince Species e feminibus fub titulo Rivina lavis ex Italia translatis.

Eft arbuscula quadripedalis, \& vitra.

Caulis lignofus, fragilis, erectus, glaber, angulatus; angulis eminentibus, cartilagineis rubicundis, pellucidis, ad folia \& ramos confluentibus, \& finubus inter angulos profundis viridibus.

Rami dichotomi, eadem forma vt caulis, gaudent.

Folia alternantia, glabra, læte viridia, ovato-oblonga, acuminata, per anaftomofin coftarum \& nervorum hinc inde rugofa, margine integerrima, aliquando undulatoreflexa, plerumque autem acumine reflexa, \& revoluta. Petiolus longus femiteres, fupra planus, angulis quatuor cartilagineis inftructus, \& tribus canaliculis fulcatus, ad exortam \& bafin folii fupra hirtellus. Nervus medius folii fubtus craffus \& eminens, vtraque parte pubefcit. Racemi e dichotomia erecti.

Pedunculus communis late bafi originem debet, continuoque attenuatur; eft angulatus \& fulcatus vti caulis. $P_{e}$ dicelli plerumque tetragoni, bractea fetacea, marcefcente \& caduca fulcrati.

Calyx nullus.

Corolla. Petala quatuor ovata, obtufa, concava, erecta, interdum conniventia \& ad germen quafi adglutinata, glabra, viridia, perfiftentia; poft deflorefcentiam majora excrefcunt \& reclinantur.

Stamina quatuor; flamentg linearia perfiftentia. . Stylus unicus.

Cetera fe more congenerum habent, fed omnia majora. Vegetat in Tepidario horti Illuft. Comitis de Canat. 
- Obferv. Differt a Rivina humili foliis glabris, nec villofis; a Rivina lavi foliis ovato-oblongis; nec ovato-lanceolatis; pedunculis angulatis, nec teretibus; caule angulato, nec lævi; foliis unicoloribus nec margine coloratis; petalis ovatis, viridibus, corniventibus, conc2vis, nec linearibus, extus coloratis, patentibus planis? ceterum etiam latioribus, majoribusque.

Conftantiores differentiales harum fpecierum Characteres obfervatione continua detectas, fubjicere lubet.

\section{Rivina humilis.}

Rivina racemis floriferis erectis, fructiferis nutantibus; foliis ovatis, villofis.

\section{Rivina lævis.}

Rivina racemis patentibus coloratis, foliis ovato-lanceo? latis glabris, caule tereti lavi.

\section{Rivina viridis.}

Rivina racemis erectis, foliis ovato-oblongis glabris; caus le angulato.

\section{Veronica Buxbaumi.}

Veronica floribus folitariis, foliis ovato-oblongis incifis? villofis, pedunculo longioribus.

Veronica Chia cymbalarixfolio, verna, flore albo, umbilico virefcente. Buxbaum. cent. I. p. 25, tab.39.f. I. Non infrequens in locis ruderatis cultisque; florens primo vere, non procul Praga verfus Podbaba, Radix debilis, fibrofa, annua.

Caulis teres, fubrepens, ramofiflimus, pubefcens. 
Folia alternantia, ovato-oblonga, ferrato-dentata, aut incifa, fere feptemlobata, pedunculo longiora, fuperiori pagina villofa, viridia, inferiori glabra pallide virefcentia.

Flores folitarii, ex alis foliorum oriuntur.

Peduniculi pro magnitudine flosculi fat longi, tamen minores foliis.

Caly $x$ quadripartitus: Segmentis omnibus requalibus, m2gnis, lanceolatis, retroflexis, fubeymbiformibes, viridibus,

Corolla calyce minor rotata, mox decidua, alba, aut carnea, aut inconftans cærulea, venis dilutioribus picta, an nulo aut umbilico virefcente; laciniz tres condata acuminatæ majores, una ovata minor.

Filamenta duo incurvata.

Anthere exigux, albx, fiffx.

Germen fubcordatum, medio fulcatum.

Stylus brevis, clavatus, albus, ftigmate obtufo, graffo, virefcente.

Capfula bilocularis, fubcordata, obtufa, polyfperma.

\section{Poa prolifera.}

Poe panicula fubfecunda coarctata, fpiculis fubtrifloris longius mucronatis, fubariftatis.

Gramen paniculatum fparteum alpinum, panicula angufa, fpadiceo-viridi, proliferum. Scheuchz. agteft. p. 213. Radice nititur perenni, ex ea

Culmus unicus aut duo palmares, folidi, teretes, geniculati, ad bafin bulbofi; geniculis duobus, interdum etiam unico nigro notatus. 
Folia caulina linearia, uncialia; radicalia in cxpitem congefta biunicialia.

$P$ anicula coarctata, anguftata.

Spicule ovato-acuminatz, viridi-purpurafcentes, ,

Glume calycine inxquales, lanceolate, viridess zir sige Valyule corollacex ovato-lanceolatex; purpureex, in pres: longuin mucronem indeterminate; mucrones valvularum floseuli ultimi \& fupremi, longiflimi, incurvati, viridis, vt primo afpectu ariftatas ificulas diceres.

Obferv. Poa bullofa admodum affinis; differt tamen fpiculis conftanter bi-aut trifloris \& flosculis longis mucronatis, quod jam per quatuor annos in uno \& eodem loco obfervavi:

Crefcit in pascuis montanis apricis, ericetis afperis, Circa Pragam in rupibus ad Kuchelbaad \& Podbabá. Floret Majo, Junio.

\section{Vl. Bromus Bohemicus Mihi.}

Bromus culmo indivifo erecto, ficulis alternis fubfeffilibus diftichis, ariftl's longiffinis, folitis capillatis.

Radix tenuis, debilis, fibrofa, annua.

Culmi ex eadent radice tres, quatuor, quinque; interdum folum unicus erectus, tenuis, glaber, duobus genicalis, nitidis, fusco-nigricantibus notatus, frape in primo genu infractus, altitudinem femipedalem (fpica non exclufa) non excedens.

Folia radicalia capillata, etiam linearia, emarcida unam \& dimidiam unciam longa, glabra; folia caulina paulo longiora, latioraque, plana, rigidiufcula, fenfim in mu. cronem attenuata, ftricta, duabus unciis longa, dimidiam lineam \& paulo amplius lata. 
Tagina longx, ancipites, ftriatx, fubventricof $x$; fupremą folio longior usque ad fpicam culmum tegit; omnes ad folii bafin membranula brevifima, albicante, emare cida, aut denticulo vix obfervabile inftructz.

Spica vix abfolute e vagina folii exit; eft difticha.

Spicula bi-aut triflore cum rudímento flosculi quarti;

alternantes, diftich $x$, glabre, breviflime petiolatx, arifta fubtiliflima \& pro magnitudine flosculi longiffima inftructæ; ad interiorem bafin glumarifin pubefcunt; no fpicula inferiores fepius binæ longius pedunculatæ, \& fubpaniculata.

$\mathrm{Ab}$ allis fui generis fatis jam his notis diftinguifur.

Elegans hoc gramen invenitur in locis moritanis arenofis, apricis; \& iisdem arvis. In diffrictu Peraunenfi in monte ad Lodernitz vbi via ducit Peraunium. Floret Junio \& Julio.

\section{Myolotis aryenfis.}

Myofotis feminibus lavibus, foliis hirfutiflimis, corollarum fauce nuda.

Myofotis foliis hirfutis. Linn, hort. cliff, 46 .

Scorpiurus annuus, radice exigua. Hall. hift. helv.n. 590. Myofotis annua. Schrank. Fl. Bavar. n. 325.

Myofotis calycibus ovalibus, acuminatis, hirfutiffumis; tubo corollæ longioribus, foliis ovato-lanceolatis. Roth. Fl. germ. I. pag. 87. 2. p. 222. Botaniffe 216̧̧anot. p. 20.

Myofotis annua caule ramolo, folits ovato-lanceolatis. Moench. Fl. Haff. a. I53. 
Myofotis arven 2 ss feminibus lavibus, caule sumofo, foliis ovato-lanceolatis hirtis. Wildenow. prodr. Fl. Berol. n. 240.

Myofotis fcorpixrus annua, radice exigua. Reichard. Flon Moeno-Francof. n. I I I,

Heliotropium foliis hirfutis. Boehm. Fl. Lipf. n. 32 , Auricula muris cærulea. Tabernem. p. 5 ri.

Echium fcorpioides arvenfe. Bauh. pin. 254:

Vulgaris planta in locis cultis, arvis aridis, collibus faxofis apricis. Floret primo vere per totam zflatem.

Obferv. A Myofoli fcorpioide paluftri pracipuis nee cultura mutabilibus attributis difcrepat. Nltitudo totius plantulæ digitalis \& vitra, etiam minor; radix annua; caulis, \& folia ovato-lanceolata hirfutie obducta. In Myofoti fcorpioide paluftri radix perennis; caulis pedalis \& vitra; folia lanceolata glabra, interdum pro vario folo natali villo pubefcentia aut minutim fcabra.

Plurimas corollulas fauce nuda repéri.

Nunquam Myofocim paluftrem, in arvenfem, nec hanc in illam mutari animadverti, etfi vtrasque culturæ tradiderim. Ludit floribus cxruleis, carneis, albis \& flavis,

\section{Gentiana Vaillantii.}

Gentiane corollis quinquefidis infundibuliformibus; limbo claufo; caule trichotomo.

Centaureum paluftre minimum, flore inaperto, Vaillant. Bot. parif, p. 32, tab. 6. f, 2. Leyf. Fl, Hal. n, 240. var. $\gamma$. Willdenow. prod. Flor, Berol, n. 294. var. $\gamma$.

Radix debilis, fibrofa, flavefcens, annuh. 
Caulis filiformis duabus unciis altus, per trichotomiam ramofus, angulolus, fubtetragonus, glaber, ex flavo viridis; rami fimplices triflori.

Folia radicalia pauca ovalia; caulina oppofita, anguftiora, obtufa, connato-feffilia, integerrima, glabra.

Calyx pentagonus usque ad bafin in quinque fegmenta æqualia obtufa partitus.

Corolla infundibuliformis; limbus in quinque ovales lacinias divifus, contractus et claufus, atropurpurens; tubus albps calycis longitudinem vix adæquat.

Capfula ovalis, bivalvis apice dehifcenns. Semina innumera minima, ovata, fufca.

Habitat in pratis montanis Sylvaticis. Im Böţmertwalb gegen bas fügnifche Bebirge zu; auf bem 2001 fsberge

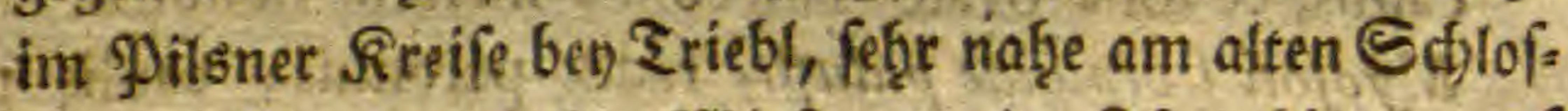

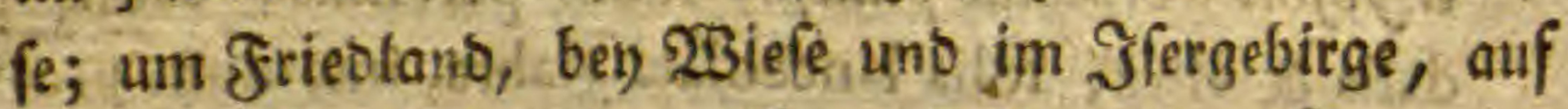
bem welidien Ramme. Floret Julio; Augufto.

IX. Gentiana Gerardi.

Gentiana corollis quinquefidis infundibuliformibus, caule proftrato ramofo, corymbofo.

Gentiana corollis quinquefidis infundibuliformibus, cau. le brevifimo ramofifimo; Gerard. Flor. Gallopro. P. 3 II.

Gentiana caule ramofo: foliis acutis enerviis lævibus. Villars Plant. de Dauph. 2. p. 530.

Centaurium minus paluftre ramofiffimum, flore purpureo. Vaillant. Bot. parif. p. 32, tab. 6. f. 1 .

Centaurium purpureum pufillum five minimum. Ber-

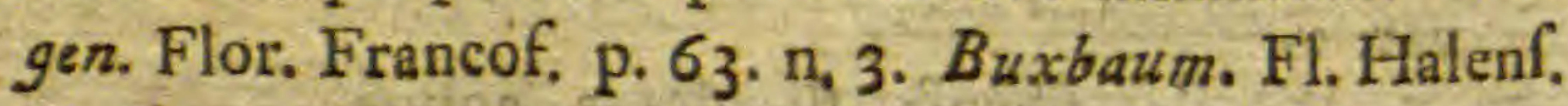
p. 60 .

Cen- 
Centaurium minus Valerianæe facie. Rupp. Flor. Jen, p. 22.'

Radix annua, exigua, albida, innumeras fibras emittens. Caulis vix palmaris etiam minor, a bafi ramofiffimus, corymbofus, obtusangulus, fubquadrangularis.

Folia radicalia conferta, in rofulam congefta, abverfe ovata, integerrima, obtufa; caulina ovaro-lanceolata, tamen obtufa, conjugata, feffilia, femiamplexicaulia, læte viridia.

Stipula nullæ.

Rami difparfi, hinc inde dichotomi et ex dichotomia florem breviter pedunculatum emittentes.

Calyx pentagonus, fubprismaticus, glaber, profunde quinquedentatus, rqualis.

Corolla purpurea, limbo quinquepartito patente, fauce flavefcente nudo, tubo ealyce longiore albicante.

Capfula oblongo-ovata, comprefta, bivalvis.

Semina plurima rufa.

Habitat in pratis depreffis vliginofis; hine inde ad Salinas. Bet) Den (\$efunobgeitsquellen Des bittermaffers ju Eeiojithuses. Floret Julio, Augufto.

\section{Gentiana campeftris. Lin.}

Gentiana corollis quadrifidis fauce barbatis. Lin. fyft, veget, p. 269 . Sp. pl. p. 334. Weber. Spic. Fl, Gett. p. 9. Ley Jf. Fl. Hal. n. 242, Scop. Fl. carn, ed, 2. n. 289. Weigel. Fl, Pomer. n. 178. Plan. Fl. Erford, p. 93 .

Gentiana corollis fubquinquefidis, fauce barbatis, calycis laciniis duabus majoribus. Rosk. Flor, germ. 1 . p. I13. 
Gentiana faucibus barbatis, calycis foliis quaternis, alterne majoribus, Hall. hift, helv, n. 650 .

Gentianella alpina verna minor. Baze. pin, 188.

Crefcit in pratis pascuisque montanis. Ad Hohenelbe, Gottesgab, Joachimsthal etc. Floret æftate.

Obferv. Difficilis omnino fecervenda planta a Gentiana amarella. Modo calyx in quatuor fegmenta fubrqualia divifus; modo profunde fere in quatuor foliola feetus; modo duo Segmenta majora latioraque; modo quinque fegmenta adfunt. Planta lecta ad Hohen5. elbe calycem habet ventricofum, inflatum, tetragonum, in quatuor Segmenta profunde usque ad bafin fere divifum; duo Segmenta ovata, acuta, plana, latiffima, duo alia anguftiffima linearia. Vix pro Gentiana campeftri agnofceres, quam magnopere difcrepar; et ego fcrupulo non adhuc exemptus fum, numne hæc fit Gentiana campeftris, an prorfus alia ab ifta diftincta Species? - An non Gentiana auriculata, (Pallas Flor, roffic. Tom. I. part. II. tab. 92. f. J.) hue revòcari poffit?

\section{Gentiana tetragona. Roth.}

Gentiana corollis quadrifidis, imberbibus, pedunculis tetragonis. Roth. Flor. germ. I. p. 1 1 3. 2, p. 290. Roth. Sentr. jur Botanif, I ร.ุ. p. I 6 .

Gentiana corollis quadrifidis imberbibus, pedunculis tetragonis longis terminalibus in caule dichotomo, fubramofo, foliis ovatis. Oedert. Fl. dan. t, 318 .

Crefcit copiofe in pratis fubalpinis; vulgaris ad Gottes. gab, Joachimsthal; in diftrictu Perawnenfi ad Tettin 
rara; ad Zbirow in montibus Oftrowitzenfibus cópiofior. Floret Augufto, Septembri.

Obferv. Pedunculi tetragoni; flores conftanter imberbes; fed quadri et quinquefidos in una et eadem planta vidi. Magnitudo varia; digitalis, fequidigitalis communiter; pedalem er fesquipedalem plantain quoque obfervavi ad Elbogen urbem in fylva communiter Kaiferwald dieta.

\section{Gentiana Jirafekii, Mihi.}

Gentiana acaulis, corolla hexafida infundibuliformi, calyce ventricofo tridentato.

Nullam apud rei herbarix Scriptores mentionem de hac Gentiana reperio.

Incolit montes Salisburgenfes. Floret in Septembri. Radix perennis, teres, cicarricibus nodofa, fufca, fubrepens; plura in fuo decurfu emittit folia in orben digefta.

Caulis nullus.

Folia omnia radicalia aggregata, in fafciculum congefta vel orbem denfum expanfa, terre incursbentia; individua oblonga vel ovata. feffilia, acutiuscula, integerrima, enervia, firma, fubrigida, glabra, nitida, utraque parte læte viridia. Ex horum centro prodit

Flos acaulis, feffilis, pro ratione plautulæ fat niagnus. Caly $x$ monophyllus, tubulofus, ventricofus, angelatus, ftriatus, tridentatus dentibus fubineurvis, uno minore, ex flavo viridis, glaber, tubo corolla triplo minor; in medio foliorum rofulæ ftricte feffilis, ut ne vix quidem breviffimus pedunculus deregi poffit. 
Corolla magna monopetala infundibullformis. Limbus. hexafidus; fegmentis oblongis acutiusculis fublanceolatis, integerrimis, longis, glabris, dilute cæruleis, patentibus aut plerumeque erectis; curn auriculisinterge: ftis alternantur; hæ funt fubcordat $x$, roundatæ, obtufæ, bifidæ, læte cærulefcentes, in medio ad fiffuram us. que linea alba notate.

Faux corollæ pervia, glabra, imberbis.

Tubus ex bafi anguftiore fenfim dilatatur, usque in lim. bum panditur, ut formam infundibuli angulato plicati adquirat; eft ceterum longus, fexplicatts, feu angulatus, aquofe crerulefcens, in plicis ab auriculis albus; quare variegatus afpicitur.

Stamina fex tubo breviora.

Filamenta fubulata bafi dilatata, medio tubi interna pa. rieti innata.

Antherce breves, fubconniventes, oblongæ, flaventes.

Cetera ut in reliquis Gentiance fpeciebus.

$\mathrm{Ab}$ omnibus reliquis huc usque notis ita differt, ut ne quid fupra fit.

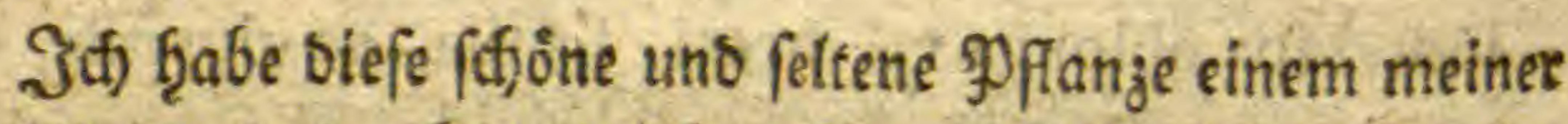
Jreunbe gu betbanfen, bet bey feinen bৃăufigen (5)efdjäftent soch noch immer einer oer fleifigften uno unberdroffenften 9ुFanjenfammler bleibt; mit einem.5Beobad)tungsgeift be. gabt, bleibt von them auf feinen f̧äufigen Jieifen aud) nid)t Die fleinfte uno unanfef̧nlid)fte PPlanje unbemerft. Er tbeeilt

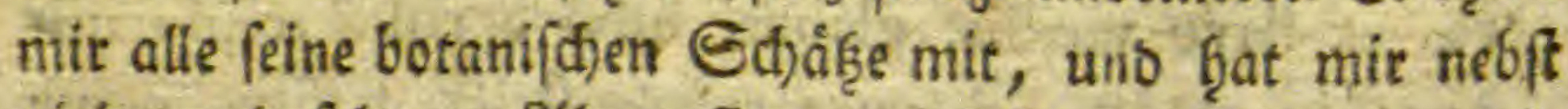
vielen uno feítenen 2flpempflanjen, Diefe Gentiana uno bie folgente Potentilla von feiner Reife in Das Salgburger 
Cicbirge mitgetf̧eilt; baf̧er id biefer Gentiana ben Tri. vialnamen bon ifrem erften Entoed er bengelegt babe. Es if ter J̧err Jobam wenzel Jitajê, Jૈürft. Salzbur.

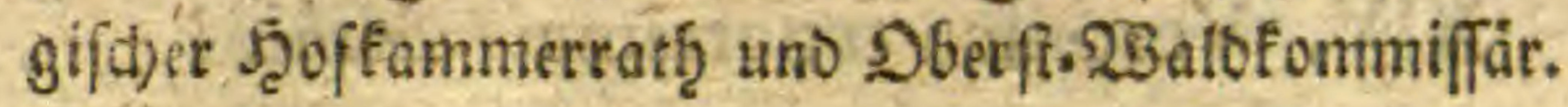

\section{Potentilla feffilis. Mihi.}

Potentilla acaulis; foliis ternatis, quinatisve, cuneiformibus, fubtus pubefcentibus; petalis fubemarginatis.

Plantam quoque amico meo Jirafekio debeo.

Crefcit in montibus Salisburgenfibus. Florefcit Autumno.

Radice nititur perenni, lignofa, crafla, ramofa, fubrepente, fufca, parum fibrofa; hinc inde gemmas gerit, e quibus fólia plura in cefpitem congefta prodeunt.

Folia folum radicalia plura ex una \& eadem gemma in fafciculum aggregata; funt petiolata, digitata, quinata aut ternata, craffufcula, nitida, lete viridia, fubtus fericeo incana, pubefcentia; ipfa foliola cuneiformia, obtufa vel apice truncata, \& obtu. fe ferrato-dentata, feffilia in ipfo petiolo communis Gemmarum fquame imbricate, ovato-acuminata, concavæ, margine minutiffime ciliate, fubcoriacex, marcefcentes, fufcr.

Caulis nullus.

Flos magnus aurei flavedine, brevifime pedunculatus, ex iisdem fquamis, e quibus falciculus foliorum oriuntur, nafcitur.

Calyx, petala, famina, germina reliquis Potentilla fpeश) 3 ciebus 
ciebus communia; præfertim quoad magnitudinem Potentilice aurece conveniunt.

\section{Veronica tenerrima. Mihi.}

Veronica racemis terminalibus binis, paucifloris; foliis ovato-oblongis integris.

Radix annua, tenerrima, fibrofa, fufca.

Caulis erectus, aliquando genu verfus radicem infractus; imo etiam frictus, tener, teres, fimplex, glaber, coloratus.

Folia oppofita pauca plerumque duo paria; ovatooblonga, acuminata, integra, feffilia, enervia, nitida, fubfucculenta, glabra, viridia fubtus rubore fuffufa.

Caulis in racemos binos terminatur, quorum unus brevior plerumque aphyllus \& ex axilla foliorum derivatux, alter autem quafi continuatus caulis elongatur \& duo aut quatuor foliola oppofita ovatoacuminata gerit.

Racemi fimplices, rari, pauciflori.

Pedunculus erectus, teres, tenerrimus, filiformis, glaber, viridis.

Fiores cxrulei pedicellis bractea feriformi triplo longioribus in pedunculo communi alternant.

Calyx quadripartitus, perfiftens, minutus; lacinix æquales, lineares, acutæ.

Corolla rotata, plana, decidua, quadripartita, lacinia infima anguftiore, lineari, reliquis ovatis acutis; onmbus lucide caruleis venis dilutioribus friatis; tubus brevifimus albidus aut aquofe cærulefcens. 
Stamina duo.

Filamenta patentia, incurvata, tubo corolle innata, albida.

Anthere fimplices, rotundata, carnex.

Germen compreffum obcordatum viride.

Stylus filiformis, perfiftens, incurvus, albidus.

Stigma capitatum fimplex.

Capfula obcordata, compreffa, apice dehifcens, bilocularis.

Semina plura, minuta, fufca.

Inveni menfe Julio locis uliginofis, in pratis penes

Moldavæ fluvium ad Pragam non procul a Caftello Wifcherad.

\section{Plantago uliginofa. Miki.}

Plantago foliis ovatis glabris finuatis, trinerviis, fpica ovali.

Radix annua, conftat ex fafciculo fibrarum.

Folia radicalia, ovata, margine raro dentato-finuata, glaberrima, in rofulam congefta, fed erecta, nervis tribus longitudinalibus percurfa, unum $\&$ dimidium pollicem longa, unum lata, læte viridia, glabra, petiolis longis, bafi dilatatis \& coioratis, fuperne canaliculatis, ftriatis inftricta.

Scapi nudi teretes, teneri, erecti, aut procumbentes, glaberrimi, albicantes, bafi colorati, plerumque duo aut tres.

Spica unica, terminalis, ovalis, denfa, pauciflora, nuda. Flores feffiles imbricati minuti, ex virido bruniufculi, glabri. 
Cetera fe more congenerum habent.

Habitat in uliginofis undis \& pratis Moldava fuvii inter Pragam \& Kcenigfaal; aliquando etiam fub aqua demerfam animadverti. Floret Julio \& Augufto.

Objerv. Differt a Plantagine majore tota figura minore, tum etiam foliis conftanter glaberrimis, trinerviis \&. finuatis, nec non fica femper ovali. 


\section{XIV.}

צe bon Ģunbert feltenen

( II

wildwad) fenden \$flanzen. Zon हैbendemferben. 


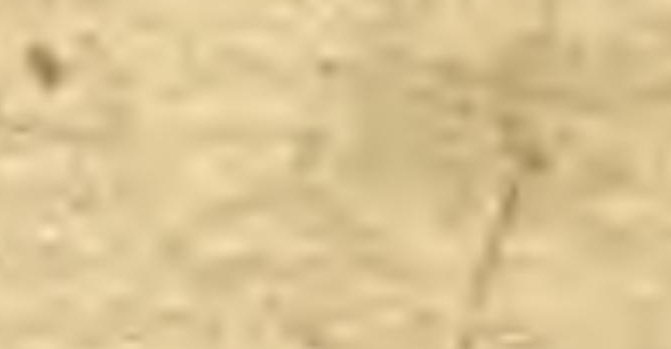

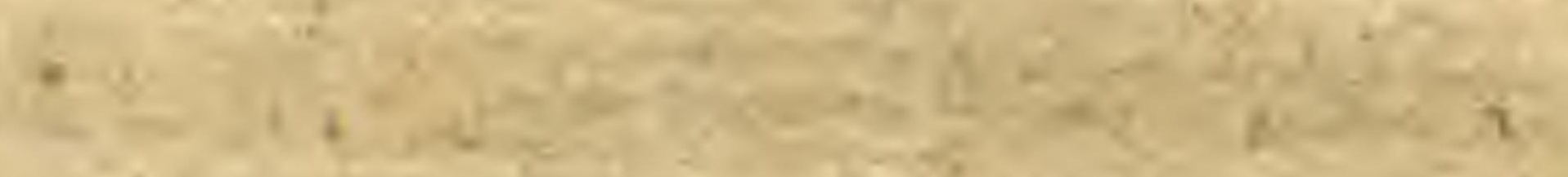

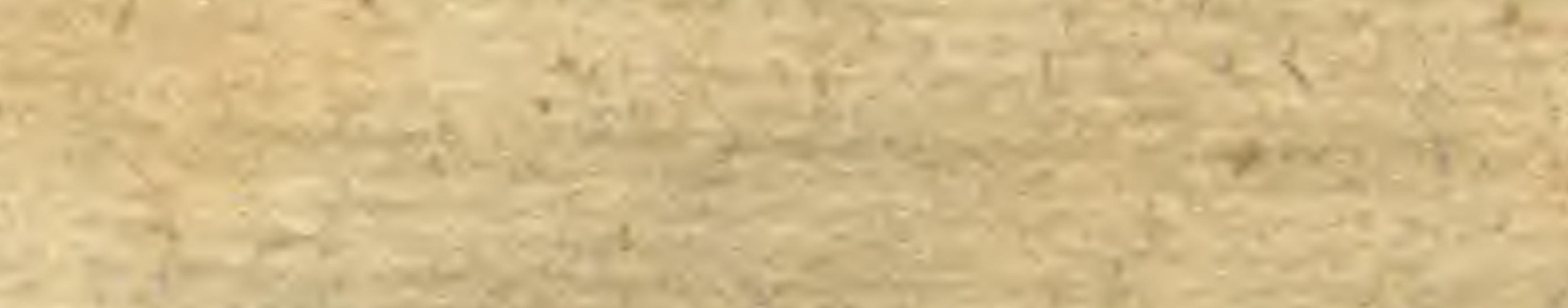

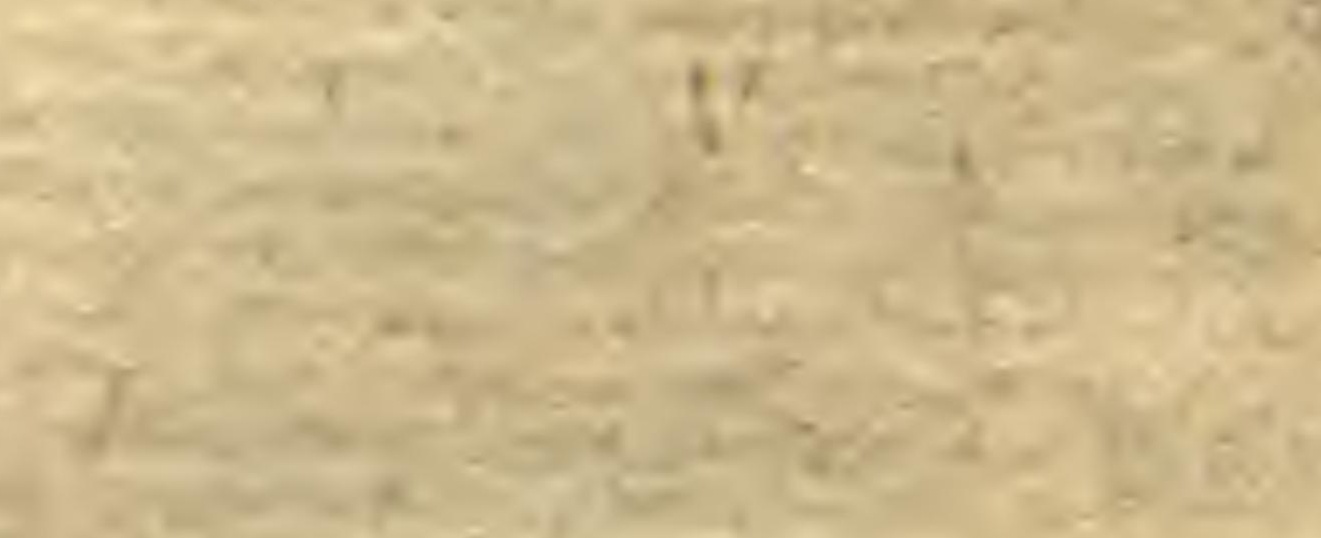

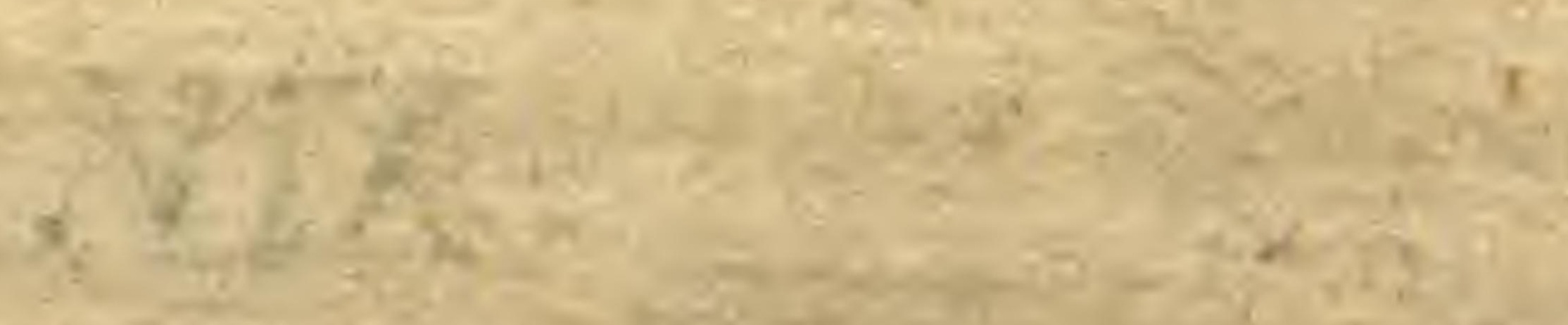

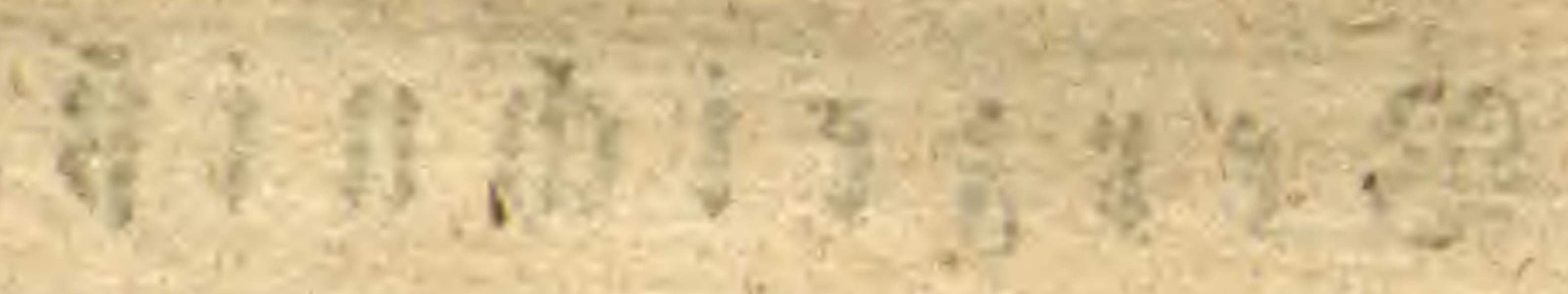

et

a

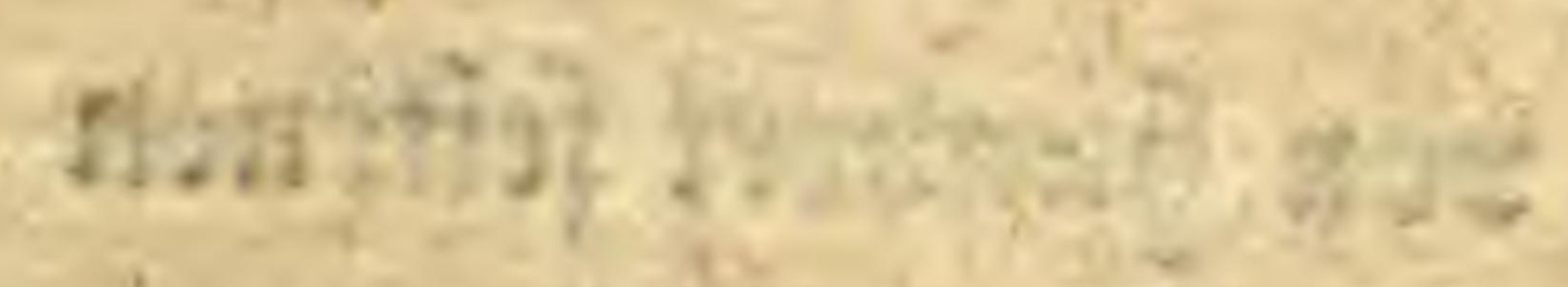

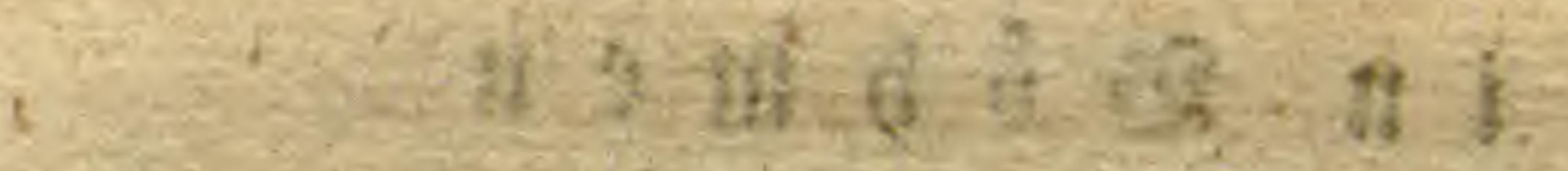

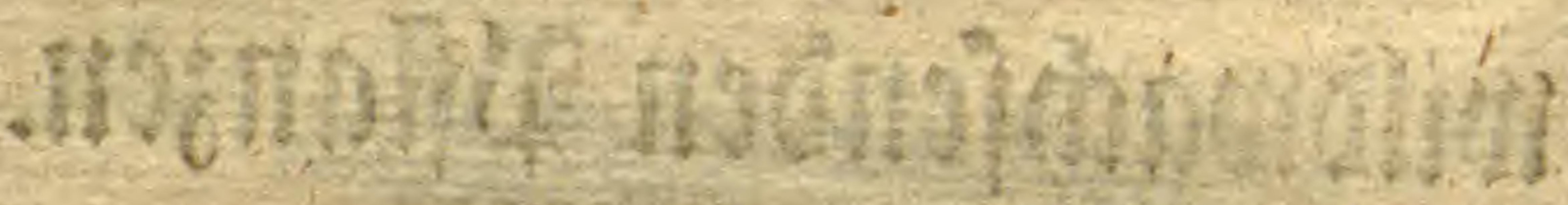

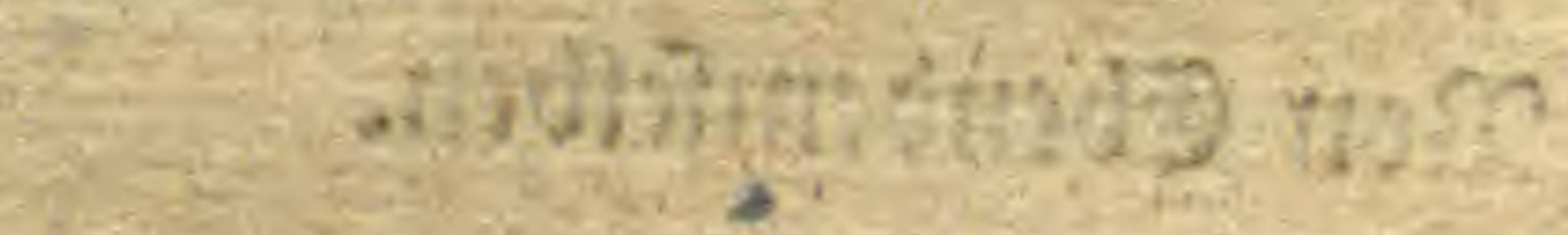

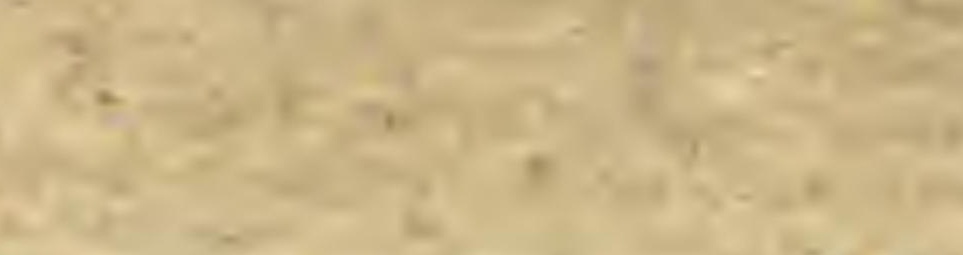
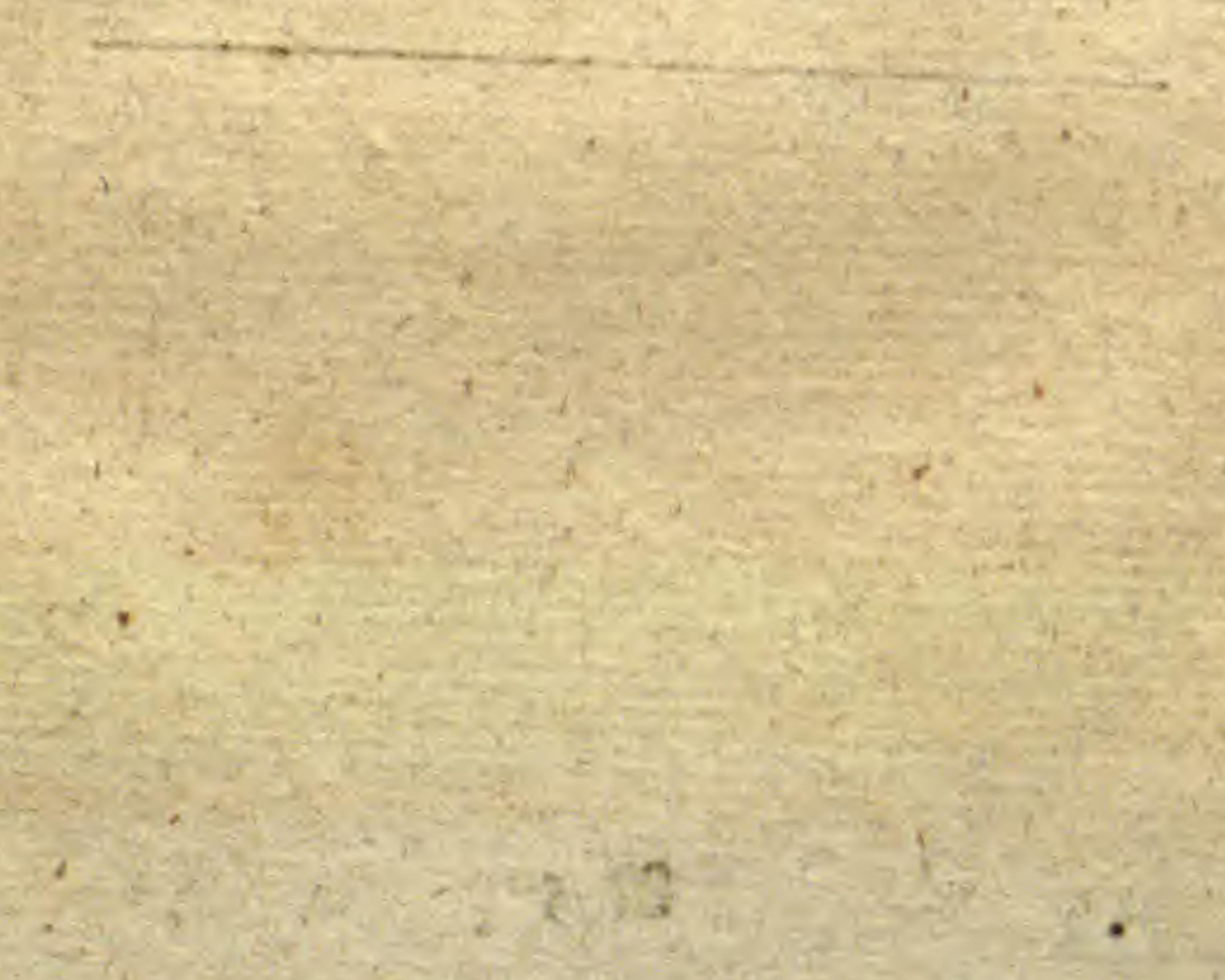

$x^{2} x=252$ 


\section{I.}

Satyrium repens. LiN. Crefcit in montofis fylvis ad Thermes Carolinas.

2. Hieracium pumilum. JACQ. In montibus Iferæ ma- joris fluvii; Zluf Dem Jeobenfall bey f̧ainoori.

3. Hieracium alpinum. LiN. In montibus lfere. 2luf Dem weilfóen Ramm.

4. Hieracium alpeftre. LiN. In montibus Ifera.

5. Hieracium aurantiacum LIN. In montibus Iferæ. Zuf ber $\mathfrak{B i e f e}$ unter bem Bucbibrg.

6. Hieracium montanum. JACQ. In montanis faxofis ad Thermes Carolinas.

7. Hieracium chondrilloides. LiN. In fubalpinis non procul Reichenberg.

8. Hieracium humile. LiN. In fudetis.

9. Hieracium pyrenaicum. LiN. In fudetis.

10. Hieracium florentinum. ALLIONI. In faxofis undis Moldava fluvii, \& Safava.

11. Hieracium Halleri. Villa Rs Flor. delph. In montibus Tferæ. 2luf oem welf

12. Hieracium valde pilofum. VILL. Fl. delph. In montibus circa St. Benignam.

13. Hieracium Spicatum. Allion. In monte Wolfs. berg, Fraunberg. Circuli Pilfnenfis.

14. Hieraciym Liotzardi. Vill. Fl. delph. In montibus fubalpinis non procul Friedland.

15. Hieracium lanceolatum. VILL. Fl. delph. In mont tanis fylvaticis inter Reichenberg \& Friedland. 
16. Hieracium danubiale. POLLiCH. Ad Friedland.

17. Thalictrum aquilegifolium. LiN. Non procul Plana in fylva Bohem. vulgo dicta Etabt obar feodimalb.

18. Chry fofplenium oppofitifolium. LiNN. Ad Friedland locis yliginofis.

19. Calla paluftris. LINN. Ad Reichenberg copiofe.

20. Lilium bulbiferum. LiNN. Ad Reichenberg in du-

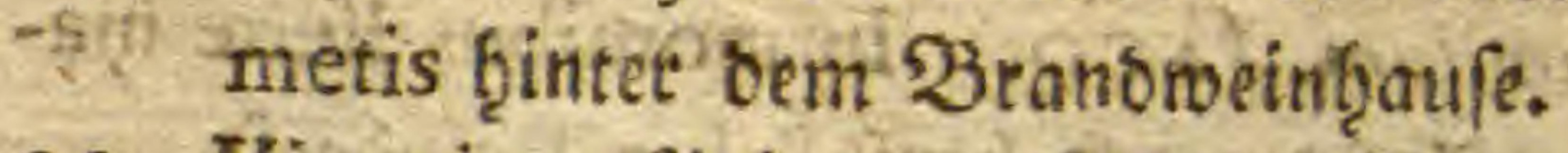

21. Hieracium Ripitatum. LiNN. Non procul Reichen-

7 berg ad Neundorf an tem शisisfufle.

22. Carduus heterophyltus. LiNN. Non procul Reichenberg in pratis ad Reinowitz.

23. Carduus rivularis. LiNN. In pratis fupra montem Jafchken ad pagum Hannchen.

24. Dentaria pentaphylla. LiNN. In monte Jafchken; rariffima planta.

25. Leucoium ceftivum. LiNN. In monte Jafchken; non vulgaris.

26. Plantago maxima. In monte Jafchken.

27. Sonchus alpinus. LiNN. In fubalpinis circa Reichenberg copiofe.

28, a) Uvularia amplexifolia. LINN. In monte Jafchken \& fubalpinis circa Reichenberg \&z Friedland vulgaris.

28. b) Poa alpina. LinN. In montibus Iferæ fluvij.

29. Poa fudetica. HeNKE. In fubalpinis circa Reichenberg \& Friedland vulgaris.

30. Poalaxa. H不NKE, Ad Heindorf; auf Dembुoben Fall.

31. Tufulago aipina. LiNN: In fubalpinis circa Reichenberg \& Friedland copiofe. 
32. Tufulago fylvatica. LiNN. Non procul Reichen. berg ber ber Scotzflópe; rara planta.

33. Tuffilago hybrida. LinN. Ad rudera arcis Hammerftein non procul Reichenberg.

34. Cineraria integrifolia alpina. In monte Jafchken.

35. Cineraria longifolia. JACQ. In monte Jafchken.

36. Orchis pellens. Linn. Ad Reichenberg ben ser fgold. flóke.

37. Juncus bulbofus. LiNN. Circa Reichenberg in pratis fubalpinis copiofe.

38. Juncus vliginofus. RotH. FI, germ. Ad Reichenberg.

39. Ranunculus aconitifolius. LiNN. In fubalpinis ad Reichenberg; ad Gottesgaab.

40. Acreftichum maranthe. LiNN. In montibus lfere. 41. Fefuca heterophylla. JACQ. coll. 2. Ad Reichenberg in monte Hammerftein.

42. Fefuca varia. JACQ. coll. 2. In monte Hammerftein.

43. Galium Bocconi. JA CQ. coll. 2. In montibus Iferr, ouf oem Etrittffucf.

44. Polypodium monianum, JACQ. coll. 2. In montio bus Iferæ.

45. Juncus triglumis. LiNN. In montibus lferæ. 2fuf ser Jferwiefe.

46. Juncus trifidus. LIN. In montibus Iferæ. 2fuf Der Bu(f)bergwiefe.

47. Senecio doria. LiNN. Non procul Reichenberg ad Friedrichswalde, rarius.

48. Salix arbufcula. LiNN. Ad Friedrichswalde, beym Şolafloß, fetgr felten. 
49. Drofera langifolia. Linn. Circa Friedland in fyle vaticis vliginofis non vulgaris.

50. Osmunda lunaria. LiNN. In fylvis circa Reichenberg, prafertim im Eaugarten.

51. Afplenium Adianthum nigrum. LiNN. In montibus Iferx, in fifuris rupium; benm ₹abad'sfifein.

52. Lycopodium inundatum. LiNN. In montibus Iferæ.

53. Lycopodium denticulatum. LinN. In montib. fierre.

54. Afer Tradéfanti. Linn. Prope Monafterium Teplenfe.

55. Milium confertum. Ad montem \& arcem Hammerftein prope Reichenberg, rarius.

56. Hypericum barbatum. LiN N. Ad arcem Hammerftein non procul Machendorf.

57. Aräium perfonata. Linn. Ad arcem, Hammerftein. 58. Carpefum cernuum. LiNN: Ad arcem Hammerftein verfus montem Jafchken.

59. Epilobium alpinum. Ad arcem Hammerftein, verfus montem Jafchken.

- 60. Fragaria ferilis. LiNN. AdFriedland trans fluvium Wittich in faxis.

61. Rhamnus pumilio. JACQ. coll. 2. In fummo jugo montis Jafchken; non vulgaris.

62. Viola biflara. Linn. Prope Heindorf in fiffuris rupium benm boben fall.

63. Aconitum camarum. LiNN. Prope Heindorf beym boţen fall, rarius.

64. Aconium Napellus. LiNN, In montibus Ifere, ouf Der buthberywiale, copiofe.

65. Tulfilago difcolor. LinN. Prope Heindorf beym ḩoģen foll; rariffima planta. 
66. Soldanella alpina.|LINN. In montibus Iferæe \& beum ḩofien ffall, non vulgaris.

67. Lunaria rediviva. LINN. Prope Heindorf, benm Gof̧en foll, vulgaris.

68. Roja alpina. LiNN. Prope Heindorf, benm ḩoţen Fall.

69. Aira alpina. LiNN, In montibus Iferæ.

70. Agrofis alpina. HeNKE. Prope Heindorf, beym b̧oţen Jalk.

71. Scandix odorata. LiNN. In territorio Friedlandenfi verfus Saxoniam \& Silefiam vulgaris.

72. Stheuchzeria paluftris. LiNN. In montibus Ifera.

73. Andromeda polifolia. LiNN. In montibus Iferæ copiofe, cum Empetro nigro, Vaccinio vंliginofo E oxicocce, \& Erica carnea.

74. Pinus pumilio. H 75. Gentiana afclepiadea. LinN. In montibus Iferr. 2uf ber 2 butbergwiefe.

76. Eriophorum alpinum. LiNN. In montibus Iferæ,

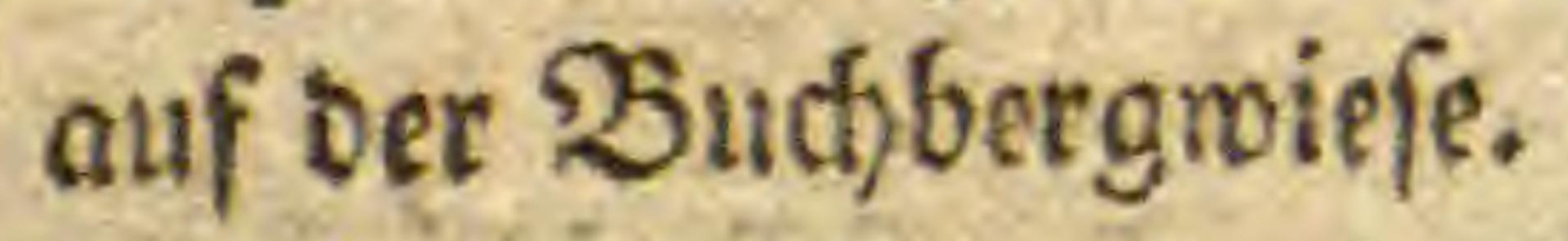

77. Solidago alpina. In montib. Iferæ, ouf oer Iferviéée. 78. Veratrum album. LiNN. In fubalpinis prope Reichenberg, ben ber Seljflöp; auf ber Jerniefe uns \$uth)bergiviefe.

79. Orchis fimia. Villans Fl. delph. In fubalpinis, auf ber 2 budibergriefs.

80. Erica cinerea. LinN. In montibus Iferæ, fub Pino pumilo; etiam in montibus ad St. Benignam; non vulgaris.

81. Swertia perennis. LiNN. In montibus Iferx, auf bet 2uhblergrwiefe, \& in montibus ad Gottesgab. 
82. Veronica auftriaca. LiNN. Ad arcem Carlftein in alto monte Wiffokahora.

83. Iris pumila. LunN. Prope arcem Carlftein in monte Wiffoka hora, rariffime.

84. Avena Scheuchzeri. In rupibus arcis Carlftein.

85. Phyteuma Halleri. Allion. In montanis fylvaticis undis Moldavæ fluvii ad Slapp.

86. Thefum alpinum. LiNN. In fiffuris rupium ad St. Ivanum.

87. Saxifraga grcenlendica. LINN. In fiffuris rupium excelforum ad St. Ivanum.

88. Pimpinella orientalis. JACQ. Ad Liebwerda non procul Friedland in dumetis.

89. Anthericum offifragum. LiNN. In rupibus excelfis ad St. Ivanum; raro.

90. Cucubalus italicus. LINN. In fummis jugis faxorum ad St, Ivanum.

91. Prunus pumilus. Pallas. Ad arcem Carlftein, in dumetis.

92. Gypfophylla repens. LinN. In fiffuris rupium ad St. Ivanum.

93. Rofa fuavifolia. OEdER. Fl. dan. Prope arcem Carlftein in monte Wiffoka hora.

94. Dracocephalum aufriacum. LiNN. In rupibus ad St. Ivanum; nec non in monte Wiffokahora prope arcem Carlftein.

95. Vicia tenuifolia. Roth. Fl. germ. In agris inter fegetes prope Carlftein.

96. Trifolium ochroleucum. LiNs. In montibus inter Carliftein \& Peraun. 97. Thlajpi 
97. Thlafpi montanum. LiNN. Ad St. Ivanum \& arcem Carlftein.

98. Turritis alpina. LiNN. Ad àrcem Carlftein.

99. Orchis incarnata. LiNN. In montibus circa arcem Carlftein.

100. Artemifia Mutellina, Villars Flor. delph. In monte Wolfsberg Circuli Pilfnenfis.

Nuper Dianthum illum pufillum in novis aetis Bohemicis pro anno 1790. a me defcriptum etiam dominus Lindacker copiofe invenit prope Kommotau, in arvis montanis aridis, afperisque.

-

Chloris Motavica, Circuli Znaimenfis. 23on ebendermfelben.

$\gamma$

I. $\ell$ hippuris vulgaris.

2. Callitriche verna.

3. — autumnalis.
Monandria.

4. Callitriche dubia. Leers.

5. Blitum capitatum.
6. Liguftrum vulgare,

7. Veronica fpicata.

8. - - hybrida.

9. - - officinalis.

10. - - ferpillifolia.

II. - Beccabunga.

12. - - Anagallis.

Diandria.

13. Veronica Chamzedris. I4. - - agreftis. 15. - - arvenfis. I6. - - hederæfolia. 17. - - triphyllos. I8. Salvia pratenfís. 19. Anthoxanthumodoratum,

\section{Triandria,}

20. Polycnemum arvenfe. 2r. Iris Sibirica.
22. Iris pleudacorus.

23. Schoenus albus:

24. Schoe- 
24. Schoenus compreffus. 25. Cyperus flavefcens. 26. - - - fufcus. 27. Scirpus paluftris. 28. - - cefpitofus. 29. - acioularis. 30. - lacuftris. 3I. — fetaceus. 32. - - maritimus, 33. - - fylvaticus.

34. Phalaris arundinacea. 35. — oryzoides. 36. Panicum verticillatum. 37. - glaucum. 38. - germanícam. Roth.

39. Phleum pratenfe. 40. - nodofum. 4I. - - arenarium. 42. Alopecurus pratenfis. 43. - - geniculatus. 44. Agroftis fpiea venti. 45. - canina. 46. - Atolonifera. 47. - capillaris.

48. - alba. 49. - - minima. 50. Aira aquatica. 51. - cefpitofa. 52. - caryophillæa,
53. Aira pracóx:

54. Melica uniflora. Jacq. coll. 2.

55. Melica nutans. 56. Poa aquatica, 57. - fylvatica, Pollich. 58. - trivialis.

59. - anguftifolia.

60. - pratenfis.

6r. - annua.

62. - comprefla.

63. - nemoralis.

64. - montana. Allion.

65. Briza media.

66. Dactylis glomerata.

67. Cynofurus durus.

68. Feftuca ovina.

69. - - elatior.

70. —u fluitans.

71. Bromus fecalinus:

72. - inermis。

73. - - fterilis.

74. Avena elatior.

75. - fatua.

76. Arundo Calamagroftis.

77. Lolium perenne,

78. Triticum repens.

79. Montia fontana.

80. Holofteum umbellatum.

\section{Tetrandria.}

81. Globularia vulgaris.

82. Dipfacus fullonum.

83. - - laciniatus.

84. Scabiofa fuccifa.

85. - - arvenfis,

86. - - fylvatica.

87. — columbaria.

88. - ochroleuca.

89. Afperula lrevigata.
90. Galium rubioides.

91. - paluftre.

92. - - purium.

93. — faxatile.

94. —— pafillum.

95. - verum.

96. - montanum.

97. Plantago major.

98. - - media. 
99. Plantago altilfima. IOO, - lanceolata. Ior. Centunculas minimus. I02. Sanguiforba officinalis. 103. Cornus mafeula. 104. - fanguinea. 105. Alchemilla sugaris. 106. Cafeuta epithymum.
107. Potamogeton natans.

Ios. - - lucens.

109. - - crifpum.

110. - - ferratum.

III. - - gramineum.

I12. Sagina procumbens.

113. - erecta.

Ir4. Elæagnus anguttifolia.

\section{Pentandria.}

I15. Heliatropium europæ-

I16. Myolotis paluftris.

$$
\begin{aligned}
& \text { um. } \\
& \text { arvenfis. }
\end{aligned}
$$

II8. - - fruticofa.

I19. Cynogloffum fcorgeides. Jacq.

I20, - officinale.

121. Pulmonaria officinalis.

I22. Symphyrum officinale.

123. Echium vilgare.

I24. - violaceum.

325. - rubrum.

126. Primula veris.

I27. Cyclamen europæum.

128. Lyfimackia vulgaris.

129. Convoivulus arvenfis.

I30. - - fepium.

131. Campanula rotundifolia.

132. - - pufilla. Jacq.

133. - linifolia.Scopol.

134. - uniflora.

135. - rapunculus.

136. -

137. - Trachelium.

138. - glomerata.

I39. - cervicaria.

I40. - - fpeculum

I41. Lonicera caprifolium.

I42. - xylofteum.

143. - nigra.
144. Lonicera cærnlea.

145. Verbafcum Thapfoides;

146. - - lychnitis.

147. - nigrum.

148. - phoeniceum.

I49. Evonymus europæus,

150. - latifolius.

151. - verrucofus.

152. Rhamnus cacharcticus.

153. - frangula.

I54. - faxatilis.

I55. - purnilus.

I56. Ribes alpinum.

157. $\rightarrow$ groffularia.

I58. Hedera helix.

159. Datura framonium.

I60. Hyofciamus niger.

16r. Solanum dolcamara.

I62. - nigrum.

I63. Thefium linophyllum.

164. - alpinum.

165. Vinca minor.

166. Afclepias nigra.

167. - vincetoxicum.

168. Ulmus campeftris.

169. Gentiana pneumonan. the.

170. - verna.

I71. - centauriam.

I72. - - amarella.

I73. - terragona.Roth.

$$
\text { D2 174. Gen. }
$$


174. Gentiana ciliata.

175. - cruciata.

176. Eryngium campeftre.

177. Sanicula europæea.

I78. Bupleurum falcatum.

179. Daucus carota.

180. Conium maculatum.

181. Athamanta cretenfis.

182. Laferpitium latifolium.

183. Heracleum fphondilium.

184. - auftriacum.

185. - longifolium.

I86. Angelica fylveftris.

187. Sium angultifolium.

188. - nodiflorum.

189. - falcaria.

190. Aethufa cynapium.

19I. Scandix anthrifcus.

192. Chærophyllum bulbo-

$$
\text { fum. }
$$

193. - temulentum.

194. - - fylveftre.

195. - aromaticum.

196. Sefeli montanum.
I97. Sefeli glaucum.

198. - annuum.

399. - hippomarathrum.

200. Paftinaca fativa,

20r. Carum carvi.

202. Pimpinella magna.

203. - faxifraga.

204. - nigra. Roth.

205. - - dioica.

206. Aegopodium podagraria.

207. Viburnum lantana.

208. - opulus.

209. Sambucus nigra.

210. - racemofa.

2II. - ebulus.

212 Alfine media.

2I3. Parnafía palaftris.

214. Linum tenuifolium.

215. - auftriacum.

216. - catharticum.

217. Statice armeria.

218. Drofera rotundifolia.

219. Myofurus minimus.

\section{Hexandria.}

220. Leucojum vernum.

221. Allium arenarium.

222. - carinatum.

223. - vineale.

224. - flavum.

225. - angulofum.

226. - oleraceum.

227. fchoenoprafum.

228. Lilium martagon.

229. Ornithogalum luteum.

230. - umbellatum.

231. Anthericum ramofum. 232. - oflifragum. 233. - calyculatum, 234. Convallaria majalis. 235. —— verticillata.
236.

237.

238.

239. Acoras calamus.

240 . Juncus conglomeratus.

24r. Juncus effufus.

242. - articulatus.

243. - bufnnius.

244. - ericetorum. Pollich.

245. - nemorofus. Pol-, lich.

246. Loranthus europreus,

247. Peplis portula.

248. Rumex crifpus.

249. - - maritimus. 250, Rumex 
250. Rumex obtufifolius,

25I. - aquaticus.

252. - acetofa.

253. —- acetofella.

254. Triglochin maritimum.
255. Colchicum autumnale. 256. Alifma plantago.

257. - natans.

258. - ranunculoides.

\section{Ottandria:}

259. Oenothera biennis. 260. Epilobium anguftifoli-

$$
\text { um. }
$$

26r. - latifolium.

262. - hirfutum.

263. — montanum.

264 . - paluftre.

265. - tetragonum.

266. Vaccinium myrtillus.

267. _- vitis idæa.

268. Erica vulgaris.
269. - herbacea.

270. Daphne mezereum.

271. - cneorum.

272. Polygonum amphibium.

273. _- hydropiper.

274. — perficaria.

275. —— aviculare.

276 . _- convolvulus.

277. — dumetorum.

278. Paris quadrifolia.

279. Elatine hydropiper.

\section{Enneandria.}

280. Butomus umbellatus.

\section{Decandria.}

$28 \mathrm{r}$. Tribulus terreftris. 282. Monotropa Hypopithys. 283.

284. Pyrola rotundifolia.

285. - minor.

286. - fecunda.

287. - umbellata.

288. Chryfofplenium alternifolium.

289. Saxifraga rotundifolia.

290. - - granulata.

201. Scleranthus perennis.

292. Saponaria officinalis.

293. Gypfophylla muralis.

294. Dianthus carthufiano.

$$
\text { ruin. }
$$

295. — prolifer.
296. Dianthus diminutus.

297. — deltoides.

298. - - fuperbus.

299. Cucubalus behen.

300. —- bacciferus.

30r. otites.

302. Silene nutans.

303. - noctiflora.

304. - conica.

305. Stellaria dichotoma.

306. - nemorum.

307. - holoftea.

308. - graminea.

309. — fontana. Jacq.

310 . Arenaria trinervia.

3Ir. - rubra.

312. - laricifolia.

$\mathrm{D}_{3} \quad$ 3I3. Sedum 
3I3. Sedum Telephium. 3I4. - reflexum.

- 315. - rufeitre.

316., - album.

317. - acre.

318. Oxalis acetofella.

3x9. Agroftema Githago. 320. Lychnis flos cuculi. 321. - vifcaria. 322. - dioica.
323. Ceraftium vulgatum. 324. — vifcofum. 325. — femidecan. drum.

326. - - arvenfe. 327 - - dichotomum: 328. —- ftrietum. 329. - - aquaticum. 330. Spergula arvenfis. 331. - nodola.

(Die Fortfesung wirb folgen.)

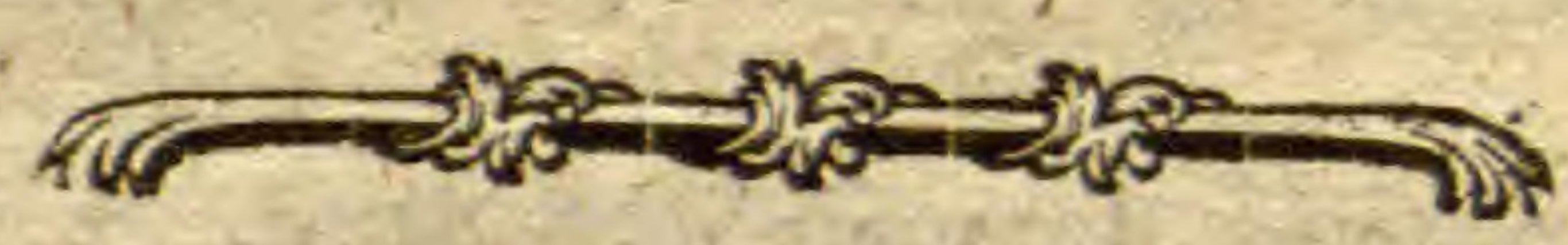




\section{XV. \\ Die \\ i \\ wilbwad)fenden 9flanzen aus Dem (Jefdled)t Der Orchis.}

$$
20 \text { it }
$$

Franz 2 sitibals Sdmit.

(2)it 2166 ilb.) 


$$
\text { A }
$$

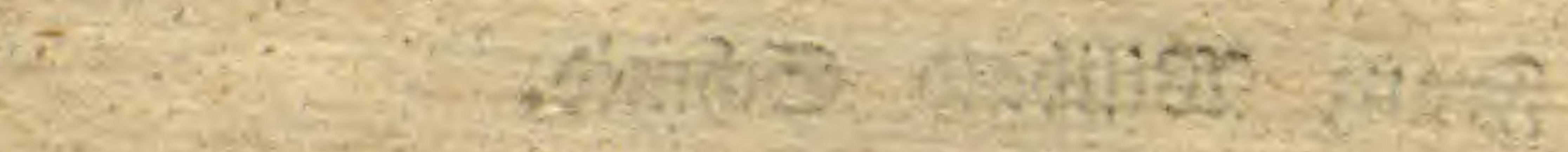

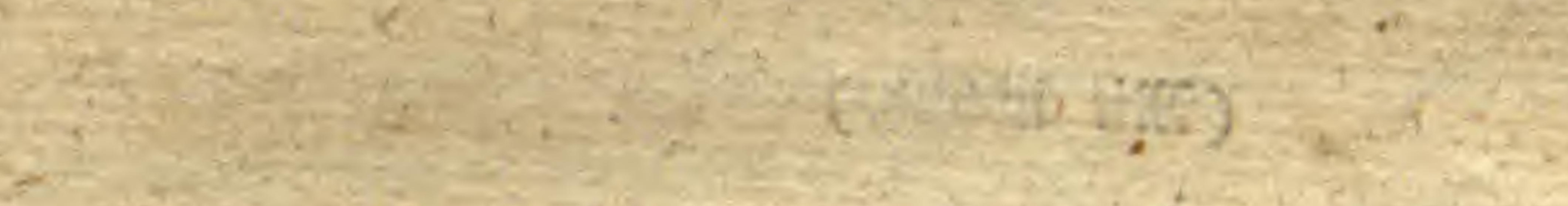

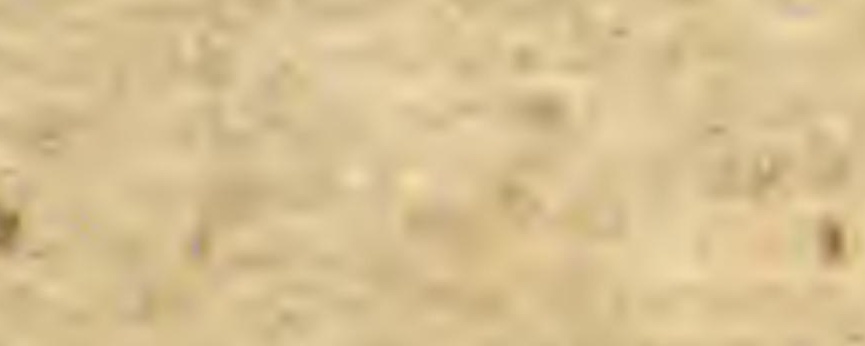$$
\text { 1. }
$$

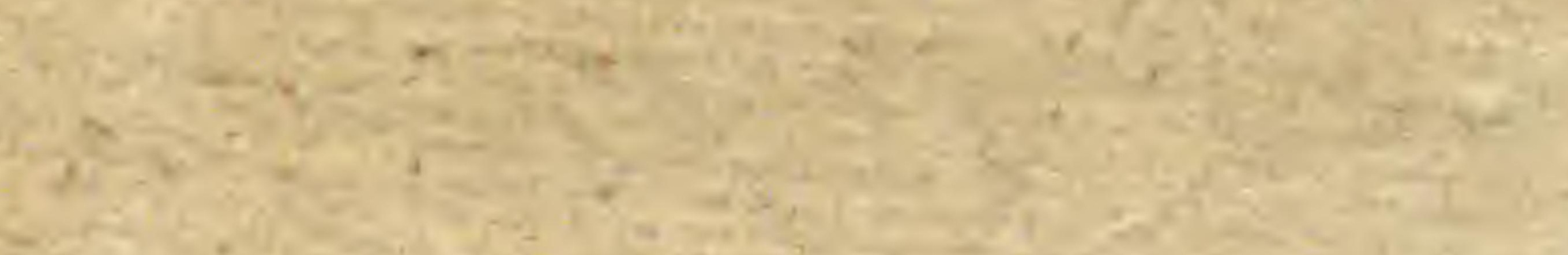




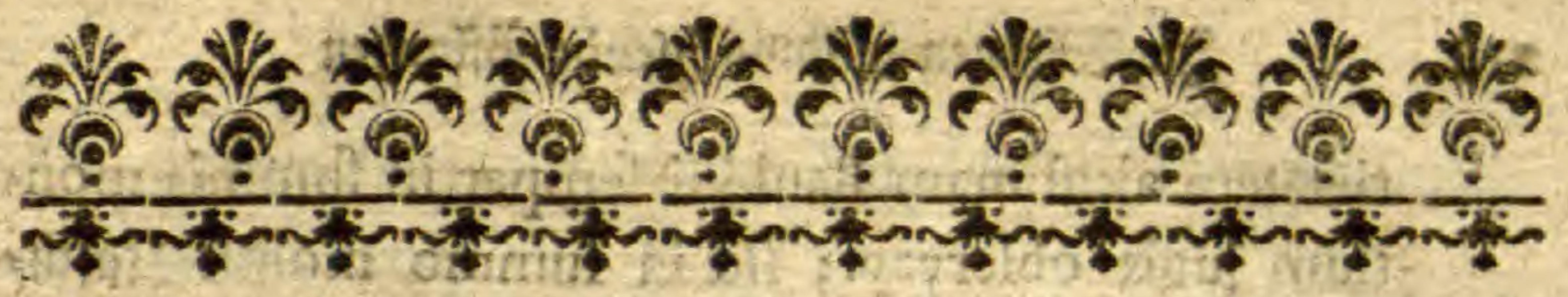

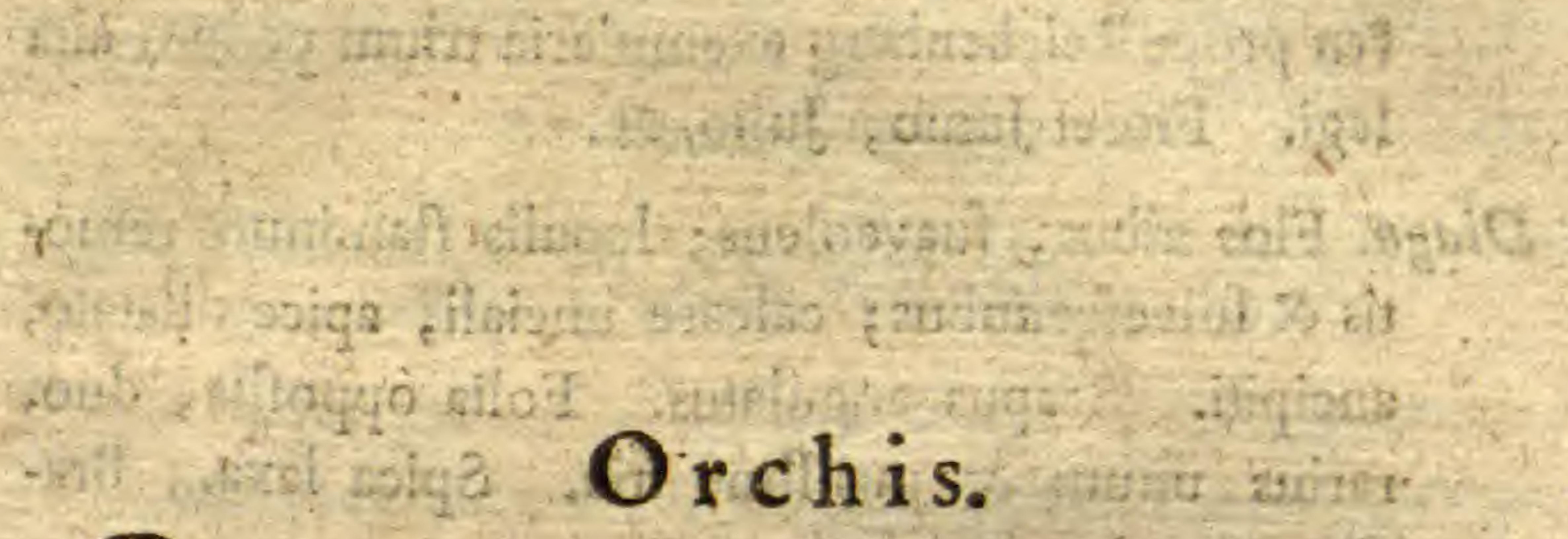

Corolla quinquepetala: Petala tria exteriora; duo interióra furfum conniventia. Nectario calcarato poftice prominente. Germen contortum.

A. Orchides. Calcare longiJlimo.
* Bulbis indivifis.

\section{Orchis bifolia.}

Orchis bulbis indivifis, nectarii labio lanceolato integerrimo, cornu longiffimo, petalis pateptibus, Linn. Syft. veget. p.808. Leers. Fl. Herb. n. 687. Leyff, Fl. Hall. n. 902 . Pollich, hift. palat, n. 84 r. Wildenow Fl. Berol. n. 42. Roth. Fl. germ. P, 375. Scop. Fl. carn. n. 1 102. Oeder Fl. dan. t. 235. Cranz. ftirp. auft. p. 304 . Gunn. Fl. norv. n. 32 . Blackw. herb. t. 588 . Matthus. Fl. files, n. 655 .

Orchis radicibus oblongis, labello lineari. Hall. hift, helv. n. 1285 .

Orchisalba bifolia minor, calcare oblongo. Bauh. pin. 83. \%. Orchis bifolia altiffima. Bauh. pin. 1. c.

Habitat in nemoribus, pratis, ficcioribus, fylvaticis, \& in montanis, Yrope Pragam copiofe in Stern. Va05 rieta. 
rietatem altiflimam Bauhini femper in fummis montium jugis obfervavi; fie in fummo montis $J_{0}(\mathrm{f})$. fen prope Reichenberg exemplaria trium pedum alta legi. Floret Junio, Julio. 4.

- Diagn. Flos albus, fuaveolens; loculis ftaminum remo. tis \& fulvefcentibus; calcare unciali, apice dilatato, ancipiti. Scapus angulatus, Folia oppofita, duo, rarius unum \& rarifficme tria. Spica laxa, Bractea germine longior.

Icon. Hall. 1. c. t. 35 , Oeder Fl, dan. t. 235 ,

\section{Orchis pyramidalis.}

Orchis bulbis indivifis, nectarii labio, bicorni trifido rquali integerrimo: cornu longo, petalis fublanceolatis. Linn. Syft. veget. p. 808 . Cranz, ftirp. auft. p. 506. Leyfl. Fl. Hall, n. 904. Rath, Fl. germ. p. 376, Jacq. Fl, ault, t, 226. Scop. Fl. carn. n. I ros.

Orchis radicibus fubrotundis, fpica denfa, calcare longifimo, labello bicorni, aqualiter tripartito. Hall. hift. helv. n. 1286.

Cynoforchis militaris montana, Spica rubente conglomerato. Bauh, pin, $8 \mathbf{r}$.

Habitat in montanis. Cìrca Reichenberg verfus Reinowitz, in montanis, udis Moldava non procul Slapp, in oer Slapper 2 ufi. Floret Majo, Ju. nio. 4.

Diagn. Flos parpureus, petala lateralia reflexa; Nectarium bicorne; Calcar longiffmum. Spica denfa, 
pyramidalis. Auriculz binæ ad bafin membranx ftaminiferx.

Icon. Hall. 1. c. t. 35 . Jacq. 1. c.

$$
\text { ** Bulbis palmatis. }
$$

\section{Orchis conopfea.}

Orchis bulbis palmatis, nectarii cornu fetaceo germinibus longiore: labio trifido, petalis duobus patentiffimis, Linn. fyft, veget. p. 8 ro. Gmel, Fl. Sib.

2. p. 22. Cranz. Stirp. auft. p. 507. Scop. Fl. carn. n. II21. Leers. Fl. Herb. n. 694. Leyff, Fl. Hall. n. 913 . Pollich Fl, palat. n. 850 . Willdenow. Fl. Berol. n. 47. Oeder Fl. dan. tab. 224. Orchis radicibus palmatis; calcare longiffimo; labello trifido, obtufo, unicolore. Hall, hift. helv. n. I287. Orchis palmata minor: calcaribus oblongis. Bauh. 85 . Habitat in pratis montanis, Sylveftribus ubique. Floret Junio, Julio. 24.

Diagn. Flores purpurei aut carnei. Petala exteriora patentia. Labium trifidum. Calcar longifimum. Bractea germine longior. Spica laxa elongata. Icon. Hall. 1. c. t, 29. Oeder l, c. Varietates: I.) Folitis anguftioribus linearibus. Orchis palmata anguftifolia minor. Bauh, J. c. 2.) Folis latioribus, fcapo fesquipedali. Orchis palmata pratenfis maxima. Bauh.1. c. 3.) Floribus albis, rariflume.

B. Orchides; calcare longinfculo.

* Bulbis indivifis. 
ya

\section{Orchis globofa.}

Orchis bulbis indivifis, nectarii labio refupinato trifido: media emarginata: cornu brevi, petalis apice fubulatis, Linh. Syft, veget. p. 808 . Leyff. Fl. Hall. n. 903. Scop. Fl. carn. n. I 106. Jacq. Fl. auft. t. 265 . Roth. Fl. germ. p. 376 .

Orchis radicibus fubrotundis; Spica denfiffima, petalis exterioribus ariftatis. Hall. hift. helv, n. $\mathbf{2} 272$.

Orchis Halleri. Cranz. Stirp. auft. p. 488.

Orchis flore globofo. Bauh. pin. $8 \mathrm{I}$.

Incolit prata montana; prope Reichenberg verfus Friedrichswalde, rara. Floret Junio, Julio. 24.

Diagn. Spica denfiflima. Petala apice dilatata, caudata.

Flores refupinati purpurafcentes, Calcar germine brevius.

Icon. Jacq. 1, c. Hall. 1. c, t. 27.

\section{Orchis coriophora.}

Orchis bulbis indivilis, nectarii labio trifido reflexo crenato: cornu brevi, petalis conniventibus. Linn. fyft. veget. 808. Leyf. Fl. Hall. n. 905. Pollich. hift. palat. n. 842. Jacq. Fl, auft, t. 122. Roth. Fl, germ. p. 376. Scop, Fl, carn, n. I ro7. Vill. Fl. Delph. II. p. 26.

Orchis radicibus fubrotundis, galea connivente, labello trifido reflexo. Hall. hift. helv. n. 1284.

Orchis cimicina. Cranz. firp. auftr. p. 498. Orchis flore parvo viridi purpureo, Rivin. hex, t. 20. Orchis odore hirci minor. Bauh. pin. 82. 
Habitat in pafcuis montanis fubhumidis; Floret Majo, Junio. 24.

Diugn. Flores viridi-purpurafcentes, hircini odoris; $\mathrm{Pe}$. tala ovalem galeam connivent. Calcar germine brevius. Bractea longitudine Floris.

Iton. Jac. I. c. Hall. I, c. t. 34 . Oeder FI, dan. t. 224. Variat Floribus fufco-rubris.

Orchis odore hirci minor, Spica purpurafcente. Bauh. pin. 82.

\section{Orchis Morio.}

Orchis bulbis indivifis, nectarii labio quadrifido crenula. to: cornu obtufo adfcendente, petalis obtufis conniventibus, Linn. Syft, veget. p. 808 , Leers. Fl. Herb. n. 688. Leyff. Fl. Hall. n. 906. Pollich. hift. palat. n. 843. Wildenow Fl. Berol. n. 43. Oeder Fl. dan. t. 253. Cranz. firp. auf. p. 499. Mattufeh, Fl. Silef. n. 657. Scop. Fl. carn. n. I 1 io, Roth. Fl. germ. p. 376 . Villars Fl, Delph. II. p. 27.

Orchis radicibus fubrotundis, galex petalis lineatis, labello trifido, crenato, medio fegmento emarginato. Hall. hilt, helv. n. 1282.

Orchis morio femina. Bauh. pin. 82.

Vulgatifima in pafcuis fylveftribus, montofisque pratis.

Floret fub finem Aprilis, Majo. 4.

Diagn. Flores purpurei. Spica rara. Galex petala coadunata. Labium trifidum, rubro-maculatum; fegmento medio cordato ferrato. Calcar obtufum, adfcendens!

Icon. 
Icon, Oeder. Fl. dan. I. c. Hall. I. c. t. 33 .

Variat I.) Floribus albis; ftriis viridibus pictis.

2.) - - carneis, lineis dilutius purpureis friatis.

\section{Orchis laxiflora.}

Orchis bulbis indivifis, petalis reflexis, nectarii labio trifido crenato, cornu germinibus longiore.

Orchis radicibus fubrotundis, petalis reflexis, nectario labio bilobo crenato, foliis enfiformibus. Villars. Fl. Delph. II. p. 2g. n. 7 .

Orchis laxiflora. La Mark. Fl. franc. III. 504 .

Orchis morio fémina procerior, majori flore. Vaill. Bot. paris. 150. tab. 3 1. f. $33 \cdot 34$.

Orchis morio femina calcare extuberante, bifariamque divifo. Seguier, ver. II, 125 .t. I5.

Habitat in pafcuis afperis montofis, nemoribusque lapidofis. Floret Majo. 4.

Diagn. Flores purpurafcentes; Labium pallide carneum nigro-purpureis punctis pietum, reflexum crenatum; fegmento medio obfolete emarginato. Calcar germine majus, bifidum. Petala reflexa, non connivent. Spica laxa, raraque. Bractex coloratx longitudine florum. Scapus angulatus. Folia enfiformia, erecta acuminata. Omnes partes majores, quam in Orchide Morio; cum qua conjunxerat Linnæuś. 


\section{Orchis paluftris. Jacq. coll. I. p. 75 .}

Orchis bulbis indivifis; nectarii labio trifido integro; cornu brevi obtufo; petalis erectis, interioribus conniventibus.

Orchis mafcula. Cranz. ftirp. auftr, p. 500.

Rariflimus hucusque Bohemix Civis. Duo folum exemplaria inventa; , unum in vliginofis, qua vix adiri - fine fubmerfionis periculo poffunt, montium Ifere majoris fluvii, fic dicto Sferwiefe; alterum mihi amicus mifit e Circulo Klattovienfi, ubi ad piscinas inter Thyphas invenit. Floret Iunio, Iulio.

Diagn. Flores purpurei, inodori. Labii trifidi laciniz lateralis rotundata, intermedia minima emarginata; Calçar obtufum germine paulo brevius. Petala obIongo - erecta. Bractea longitudine Germinis. Folia erectiufcula fublinearia acuta.

Icon. Iacq, icon. rar.

\section{Orchis mafcula.}

Orchis bulbis indivifis, nectarii labio quądrilobo crenulato; cornu obtufo, dorfalibus reflexis. Linn. fyst. veget, p. 890 . Leers. Fl. Herb. n. 689. Leyfs. Fl. Hal. n. 907. Pollich. hift. palat n. 844. Oeder Fl. dan. t, 4 7. Scop. Fl. carn. n. IIII. Roth, Fl. germ. p. 377. Villars FI. delph. II. p. 28.

Orchis radicibus fubrotundis, petalis lateralibus reflexis, labello trifido, fegmento medio longiori bifido. Hall. hift. helv. n. 1283.

Orchis morio mas, foliis maculatis. Bauh. pin. 82 . 
Habitat in pratis humidis fylvaticis; frequentius montanis. Floret Majo, Junio. 4.

Diagn. Flores purpurei, plurimi. Labium quadrilobun ex purpureo cerulefcit; et ad faucem maculis dilutioris coloris punctatum; fegmenta iateralia incurva, medium bifidun. Calcar obtufum, fubenar. ginatum. Bractea germine longior, colorata. $\mathrm{Pe}$ tila anceolata, exteriora tria reflexa. Tota planta pedalis. Folia plana acuta, maculata.

Icon. Oeder, 1. c. Hall, 1. c, t. 33. Iacq. icon. rar.

\section{Orchis ovalis.}

Orchis bulbis indivifis; nectarii labio trilobo, lacinia intermedia obfolete emarginata fubcrenulata; cornu longitudine germinis adfcendente obtufo; petalis dorfalibus reflexis.

An Orchis morio mas foliis feffilibus, non maculatis. Bauh. pin. 82?

Habitat in pratis fubalpinis circa Reichenberg bei ber f̧ofe flóge. Floret Junio. Rara. 4.

Diagn.Flores pallide purpurei labio immaculato. Spica Longa multiflora. Bractex latre germine paulo longiores non coloratx. Petala interiora conniventia exteriora undulato reflexa. Labii laciniæ duæ laterales obtufa fubtruncatæ, intermedia obfoleta emarginata, vix crenulata; aliquando denticulo prominente in medio predita. Folialata ovalia plana ob. tufa immaculata.

Icon. Tab. noftr. F, I. 


\section{I. Orchis uftulata.}

Orchis bulbis indivifis, nectarii labio quadrifido punctis Scabro: cornu obtufo, petalis diffinctis, Linn. fyft. veget. p. 809. Leers Fl. herb, n. 690. Pollich. hift. palat, U. 845. Oeder Fl. dan t. 103. Scop. Fl. carn. n. I I08. Roth. Fl. germ. p. 377. Villars Fl. delph. II. p. 31 .

Orchis amoena. Cranz. Airp. auft. p. 490.

Orchis radicibus fubrotundis, labello quadrifido, calcari breviflimo. Hail. hift. helv. n. 1273.

Cynoforchis militaris pratenfis humilior. Bauh. pin. $\delta 1$. Habitat in pratis nemorofis, fylvaticis vbique. Floret Majo, Junio. 4.

Diagn. Spica denfa. Petala diflincta conniventia atro. rubra. Labium media lacinia productiore, album, punctatum punctis fcabris, atro-rubris. Calcar breve, truncatum, incurvum albidum. Bractea ges: mine brevior.

16on. Hall, 1. c. t. 28 . Oeder. I. c.

\section{2. Orchis militaris.}

Orches bulbis indivifis, nectarii labio quinquefido punctis Scabro: cornu obtufo, petalis conlluentibus. Linn. fyft. veget, p. 809. Leyfs. Fl. Hall. n. 909. Pollich. hift. palat. n. 846 . Wildenow Fl. Berol. n. 44. Gunn. Fl. norv. n. 694. Mattufch. Fl. fil. n. 658. Cranz. ftirp. auftr. p. 50 r. Roth. Fl. germ. p. 377. Scop. Fl. carn, n. I I 12 . Villars Fl. Delph. II. p. 34 . Jacq. coliect. 2. p. 268 . 
Orchis radicibus fubrotundis, fpica conica, petalis conniventibus, nectarii labio trifido, lacinia media productiore bifida. Gouan. illuftr. 74 .

Orchis radicibus fubrotundis, fpica conica, labello quadrifido, brachiolis \& pectore peranguftis. Hall, hift. helv. n. 1277 .

Cynoforchis latifolia, hiante cucullo, major. Bauh. pin. 80.

Incolit prata fylvatica humida. In undis nemorofis Moldavx, ad Carlftein arcem in fylvis; in Subalpinis circa Friedland copiofe. Floret Majo, Junio, 4

Diagn. Flores purpureo-cinerei. Petala connata albida. Labium quinquefidum, maculatum, anthropomorphum. Calcar breve obtufiufculum, coloratum. Bractea germine brevior colorata.

Icon. Hall. 1. c. t. 28.

13. Orchis variegata. Jacq. collect. 2. p. 267. Orchis bulbis indivifis; nettarii labio quadrifido circum. ferrato, punctis afpero; cornu fubulato erectiufculo; petalis omnibus conniventibus.

Orchis radicibus fubrotundis, fpica breviffina; labello breviter quadrifido, circumferrato, punctato. Hall. hift, helv. n. 1275 .

Orchis militaris pratenfis elatior, floribus variegatis. Seguier, ver. 2. p. 123 t. 15. F. 3 .

Orchis militaris minor. Rupp. Fl. jen. p. 295. tab, 6. Orchis tridentata. Scop. Fl. carn, n. I I 09. Orchis fimia. Vill, Fl. Delph. II. p. 33 . 
Cynoforchis militaris pratenfis elatior, floribus variegatis, Bauh, pin. 81 .

Incolit prata montana. In undis fylvaticis Moldave non procul Nalfchowitz vulgo dictis ßasifd)er $\mathfrak{B u c f o =}$ wina, etiarn in fubalpinis non procul Friedland. Floret Majo, Junio, Julio. 24.

Diagn. Flores pallide purpureo-carnei, Spica brevis itas denfa fubrotunda. Petala coadunata lineata. Labium adfperfum punctis purpureis, laciniis ad apicem ferratis; lateralibus oblongis, intermediis brevioribus cum denticulo inter utramque. Calcar germine paulo brevius.

Icon. Hall. 1. c.t. 30 . Rupp. 1. c.

\section{Orchis Columnæ.}

Orchis bulbis indivifis, nectarii labio quinquefido; laciniis anguftis linearibus, intermedia brevior; cornu incurvo breviffimo; petalis confluentibus.

Orchis tephrofanthos. Villars Fl, delph. II. p. 32. Orchis Zoophora Cercopithecum exprimens Oreades. Column. ecphr. I. p. 319 . Fig. 320.

Orchis flore Simiam referens, Bauh. pin. 82.

Incolit prata \& pafcua fubhumida montofa. In fubalpinis circa Friedland. Floret Junia, Julio. 24

Diagn. Flores cucullo purpureo \& labio albo punctis creberrimis rubris variegato. Spica denfa elongata. Petala bafi connara in cucullum conniventia. Labium quinquefidum elongatum; lacinix anguftx lineares, truncatx; intermedia brevior acuminata. Bractea gerınine brevior colorata. .

Icon. Column. 1. c. bona.

$$
\mathrm{P}=\mathrm{x} \text {. Ot. }
$$




\section{Orchis fufca.}

Orchis bulbis indivifis, nectarii labio quadrifido: laciniis oblongis, cornu brevi, petalis confluentibus. Linn. fyft. veget, p. 809 . Jacq.Fl, auf, t. 307 , Roth.

Fl. germ. p. 377 .

Orchis radicibus fubrotundis, fpica longa, labello qiradrifido, brachiolis anguftis, crufculis Iatis, ferratis.

\section{niv Hall. hift. helv. n. 1276 .}

Cynoforchis militaris major. Bauh. pin. p. $8 \mathbf{r}$. Crefcit in fylvis montofis; circa arcem Karlftein copiafe. Floret Majo, Junio.

Diagn. Caulis unum \& dimidium pedem fere altus. Folia latiflima. Spica laxa palmaris. Flores magni fpeciofi purpurei. Petala omnia conniventia, faturatiore colore, flriata; labium quadrifidum magnum ex albo dilute purpureum, maculis fcabris faturatioris coloris adfperfum.

Icon. Jacq. 1. c. Hall. 1. c. tab. 3 I.

\section{Orchis pallens.}

Orchis bulbis indivifis, nectarii labio trifido integerrimo; cornu obtufo mediocri, petalis patentibus. Linn. fyft. veget. p. 809. Leyfs, Fl. Hall, n: 9 Io. Jacq. Fl. auftr. t. 45 . Villars. Fl. Delph. H. p. 30. Roth. Fl. germ. p. 377 .

Orchis radicibus fubrotundis, petalis galea lineatis, label. lo trifido, integerrimo. Hall. hift. helv. n. i281. Orchis pannonica VH. Clus. hiff, 1. p. 269. 
Habitat in nemoribus \& fylvis montofis fubhumidis. In undis fylveftribus Moldava ultra Rỏnigsfal. Floret Majo, Junio. 4.

Diagn. Flores pallide flavi. Labium trifidum integrum immaculatum; lacinia intermedia cordata obfolete emarginata. Cornu breve adfcendens. Petala diftincla patentia. Spica laxa.

Icon. Jacq. l. c. Hall, 1. c. t. 30.

\section{* Bulbis palmatis.}

\section{Orchis latifolia.}

Orchis bulbis fubpalmatis rectis, nectarii cornu conico: 57 labio trilobo lateralibus reflexo, bracteis flore longioribus. Linn. fyft. veget. p. 810. Leers. Fl. Herb, n. 69x. Leyfs. FI. Hall. n. 911 . Pollich. hift. palat. n. 847. Wildenow. Fl. Berol. n. 45 . Gmel. Fl. lib. I. p. 24. Cranz. Atirp. aufr. p. 493, Mattufch. Fl. fil. n. 659. Roth. Fl, germ. p. 378 . Oeder Fl. dan. t. 266 . Villars Fl. delph. II. p. 35 • Orchis radicibus palmatis, caule fiftulofo bracteis maximis, labello trifido ferrato, medio fegmento obtufo. Hall. hift helv. n. 1279, tab. 32 .

Orchis palmata pratenfis latifolia longis calcaribus. Bauh. pin. 85.

Orchis comofa. Scop. Fl. carn. n. I 120.

In pratis humidis ubique. Floret Majo, Junio. 24.

Diagn. Flores purpurei aut rofei coloris? Petala duo lateralia patent, reliqua tria connivent. Labium triJobum, intermedio fegmento paulo productiore ve- 
nis purpurafcentibus pictum; Calcar conicum ob. tufum longitudine germinis. Folia lata immaculata. Bractea flore longior. Caulis filtulofus,

Icon. Oeder. 1. c. Hall. 1. c. t. 32.

Variat. 1.) Floribus albis.

2.) Foliis latioribus.

Orchis palmata paluftris latifolia. Bauh. pin. 86 :

3.) Foliis maculis fufcis pictis.

Orchis palmata pratenfis maculata. Bauh; pin. 85 .

\section{Orchis cruenta.}

Orchis bulbis palmatis, nectarii cornu germine breviore, labio indivifo fubcordato crenato, petalis dorfalibus patulis. Oeder. Fl. dan, t. 876 .

Non raro cum antecedente reperitur, prefertim in pratis vliginofis circa Zbirow et St. ßenignam. Floret Majo. 4.

Diagn. Flores purpurei, Spica denfa. Petala exteriora patula, interiora conniventia. Labium indivifum crenulatum dilutioribus venis percurfum, punctis aliquando pictum, Calcar germine brevius; Braetea longitudine germinis, colorata. Folia ple. rumque ex rufo aut ferrugineo maculata.

Ieon. Oeder. 1. c.

\section{Orchis incarnata.}

Orchis bulbis palmatis, nectarii cornu conico: labio obfcure trilobo ferrato, petalis dorfalibus reflexis. Linn. 
Linn. fyft. veget. p. 810 . Roth. Fl. germ. p. 378 . Villars Fl. Delph. II. p. 36 .

Orchis radicibus palmatis, bracteis coloratis, labello circumferrato, trilobato, lobo medio emarginato. Hall. hift. helv. n. 1280.

Orchis latifolia. Scop. Fl. carn. n, III8.

Habisat in montofis fylveftribus. Circa arcem Carlftein. Floret Majo. 4.

Diagn. Flores purpurei. Spica pauciflora laxa. Petala tria erecta, duo lateralia reflexa. Labium trilobum crenulatum, lobo medio non emarginato. Calcar longitudine germinis conicum rectum obtufum. Bractea lanceolata colorata, flore paulo longior.

\section{Orchis fambucina.}

Orchis bulbis fubpalmatis erectis, nectarii cornu conico, labio ovato fubtrilobo, bracters longitudine florum. Linn. fyft. veget. p. 810 . Leers Fi, Herb. n. 692. Leyff. Fl. Hal. n. 91 2. Pollich. hift. palat. n. 849. Wildenow. Fl. Berol. n. 46. Roth. Fl. germ. p. 378. Scop. Fl. carn. n. I I18. var. 2. Gunn. Fl. norv, n, 426. Jacq. Fl, auftr, t, ros. Mattufch. Fl. Siles. n, 660. Villars, Fl.Delph, H. p. 36. cum anteçedente conjungit.

Orchis. Hall. hift, helv, n, 1280 . var. $\beta$.

Orchis palmata, Sambuci odore. Bauh. pin. 86 .

Habitat in fylvis, nemoribusque montofis. Circa St. Ivanum \& arcem Carlftein vulgaris. Floret Majo, Junio. 24.

$$
P_{4} \quad \text { Diagn. }
$$


Diagu. Flores ochroleuci, odori. Petala tria in ćuculs lum conniventia, duo lateralia expanfa alaruin infar. Labium vix lobatumi crenulatum, lateribus reflexum, medio emarginatuin, punctis purpureis pictum. Calcar incurvum dependens emarginatum. Bractea longitudine floris.

Icop. Jacq. 1. c.

\section{Orchis maculata.}

Orchis bulbis palmatis patentibus, nectarii cornu germinibus breviore: labio plano, petalis dorfalibus erectis. Linn, fyft. veget. p. 8 Io. Leers. Fl, herb. n. 692. Leyff. Fl. Hall, n. 912 , Roth. Fl, germ. p. 378. Wildenow Fl. Berol, n, 46. Pollich, Fl. palat, n. 849. Gmel. Fl. Sib. I. p. 23. Cranz. firp. aufr. p. 492. Mattufch, Fl. Siles. n. 661 . Scop. Fl. carn. n. I119. Villars Fl. Delph. II. p. 37.

Orchis radicibus palmatis, caule folido, labello trifido, ferrato, medio fegmento acuminato. Hall, hiff. helv, n. 1278.

Orchis palmata pratenfis maculata, Bauh, pin. 85 .

Frequens in pratis pinguibus fubhumidis; copiofiffine in fubalpinis circa Reichenberg. Floret Majo, Junio \& Julio. 4.

Diagn. Flores inconfantis coloris pierumque purpurei.

Spica taxa. Petala tria exteriora erecta, duo interiora conniventia. Labium planum, trilobum lineis et maculis variegatum; fegmento medio angufliore acuminato. Calcar obtufum, incurvulum, 
Bractea flore brevior, Caulis folidus varix altitudinis. Folia maculata.

Icon. Hall. 1, c. tab. 32 .

Variat. 1.) Floribus atro purpureis.

2.) - _- carneis non variegatis.

3.) - - albis inaculis variegatis.

4.) _- albis non variegatis.

5.) - - ochroleucis rariflime.

6.) Foliis non maculatis.

\section{Orchis longebracteata.}

Orchis bulbis palmatis patentibus; nectarii cornu germi. nibus breviore: labio profunde trilobo; petaiis te flexis; bracteis longiflimis.

Habitat in pratis fubalpinis Sudetorum \& Montium Iferz majores Fluvii, Floret Julio. 4.

Diagn. Caufis ad duos \& dimidium pedem altus. Folia inferiora ovata, obtufa, reliqua ovalia acuminata, raro maculis minimis ferrugineis adfperfa. Spica petalis fere multiflora. Flores e carneo purpurafcentes. Petala tria eriguntur, duo lateralia reflectuntur. Labium trifidun integrum variegatum; Laciniz ląterales lineares, media latior \& profundius emarginata, vt bifida appareat. Calcar rectiufculum germine brevius. Bractex lanceolatæacute germine duplo longiores virides.

Icon. Tab. noftr. Fig. 2.

\section{Orchis comofa.}

Orchis bulbis palmatis; fpica conglobata; nectarii labio trifido crenulato; cornu conico longitudine germinum; bracteis floribus longioribus. 
Nafcitur in pratis montanis fylvaticis; prafertim locis umbrofis. Ad Nalfchowitz in monte Drbaforo et ad St. Benignam. Floret Majo. 4.

Diagn. Flores carnei. Spica denffifima globofa pauciflora, Petala conniventia, Labium profunde trifidum planum immaculatum; fegmentis crenulatis, medio latiore non emarginato. Calcar rectum obtufum germen adxquat. Bractex flore longiores fubletacex comofam denfx fpicæ faciem conciliant. Folia lanceolata longa plana obtufa, maculis confluentibus transverfim picta.

Icon. Tab. noftr. F. 3.

\section{Orchis odoratiffima.}

Orchis bulbis palmatis nectarii cornu recurvo breviore; labio trilobo, foliis linearibus. Linn. fyft. veget. p. 8 ro. Leers. Fl. Herb. n. 693 . Roth. Fl. germ. p. 378. Gunn. Fl. norv. n. 696. Jacq. Fl. auftr. t. 264. Villars Fl. Delph. II. p. 38.

Orchis radicibus palmatis, labello obtufe trifido, concolore, calcare germine breviori. Hall. hift. helv. n. 1274 .

Orchis palmata anguftifolia minor odoratiflima. Bauh. pin. 86.

Habitat in pafcuis ficcis altioribus; nec non pratis apricis arenofis, non raro cum Orch. conopfea. Floret Junio, Julio.

Diagn. Flores purpurei, fragrantes. Petala dorfalia expanfa alarum inftar, reliqua conniventia. Labium xquale 
xquale trifidum; fegmento medio latiore acuto, Calcar breve recurvum. Bractere flore breviores, coloratz. Folia linearia, fulcata.

Icon. Jacq. l. c. Hall. 1. c. tab. 2 .

\section{*** Bulbis fafciculatis. \\ 25. Orchis abortiva.}

Orchis bulbis fafciculatis filiformibus, nectarii labio ovato integerrimo, caule aphyllo. Linn. fyft, veget. p. 379. Roth. Fl. germ. p. 379. Leers Fl. Herb. n. 695. Leyfl. Fl. Hal. n. 914. Jacq. Fl, auftr, tab., 193. Gunn. Fl. norv. n. 695. Villars Fl. Delph. II. p. 40.

Orchis abortiva violacea. Bauh. pin. 86 . Serapias abortiva. Scop. Fl. carn. n. I 130. Epipactis aphylla, calcare longo. labello ovato lanceo. lato, Hal. hift. helv. n. 1288. t. 36.

Habitat in montibus umbrofis; prefertim lapidofis. $\mathrm{R}_{2}$ riffime ad St. Ivanum. In illis montibus ad limites

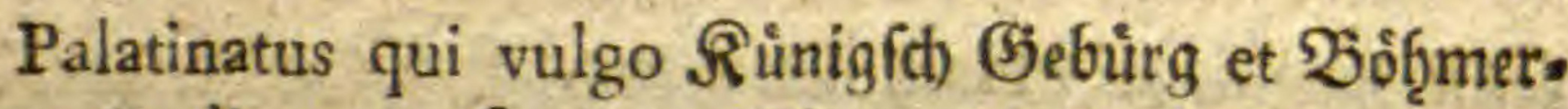
walo dicuntur frepius. Floret Majo, Junio. 24.

Diagn. Flores violacei. Labium fimplex lanceolatum indivifum. Calcar convergens, germine xquale. Caulis aphyllus, Squamis vaginatus. Icon. Jacq, 1. c. Hall, 1. c. t. 36 .

C. Calcare brevilfmo. Satyrix. Linn: 26. Orchis Hircina.

Orchis bulbis indivifis, foliis lanceolatis, nectarii labio trifido: intermedia lineari elongata obliqua pramorfa 
morfa. Scop. Fl. carn. n. I r13. Cranz, Atirp-auftr. p. 484 .

Orchis radicibus fubrotundis, labello longifimo, tripare tito, plicato. Hall. hift, helv. n. 1268.

Orchis barbata, odore hirci, breviore lationeque folio. Bauh. pin. 82.

Satyrium hircinum. Linn. fyn, veget, p. 8 Ir. Roth. - Fl. germ. p.379. Leyff. Fl. Hall. n. 915 . Pols lich. hift palat. n. 85 I. Jacq. Fl. auftr. t. 367 . Villars Fl. delph, II. p. 41. Mattufch. Enum, n. 861.

Habitat in montanis umbrofis. In undis fylveftribus Moldavæ rarius; circa St. Benignam rariffime; in fylva Bohemica verfus Palatinatum frequentius. Floret Majo, Junio. 4

Diagn. Flores albidi, hircofi, Spica longa, Labium trifidum: fegmento medio longiflimo lineari obliquo præmorfo fubbifido, lateralibus brevifimis fubulatis integerrimis. Calcar minime bifidum.

Icon. Jacq. 1. c. Hall. 1. c. t. 25.

\section{Orchis anthropophora.}

Orchis bulbis fubrotundis, feapo foliofo, nectarii labio lineari tripartito; medio elóngato bifido; cornu brevifimo.

Orchis radicibus fubrotundis, fpica longa, flore inermi, labello perangufto quadrifido. Hall. hift. helv. n. 1264 .

Orchis flore nudi hominis effigiem reprefentans, femina. Bauh. pith. 82 . 
Ophrys anthropophiora Linn. fyft. veget. Villars FI.

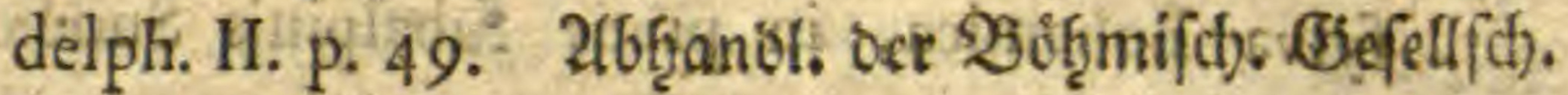
1790. Є. $66, n, 107$.

Orchis Anthropophora Orcades. Colum ecphr. I. ip. 320.

Ineolit prata fylvatica fubhemida. in in undis:Moldava

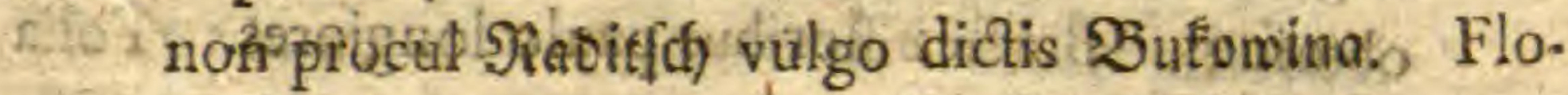
ret Majo, Junio. 4

Diagn. Splce longa, rara, Flores multi, purperafcentes graveolentes. Petala omnia connivent. Labium lineare quadrifidum longum; calear brevifimum obtufum. Bractere gêrnine brevioreslis Germagy

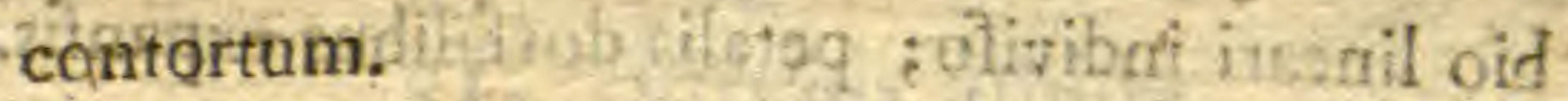

Icon. Hallili cit. 23. Planta noftra in omnibus fuis ofar

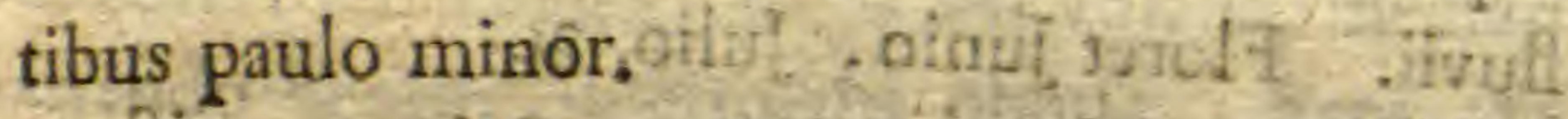

6rai boalis

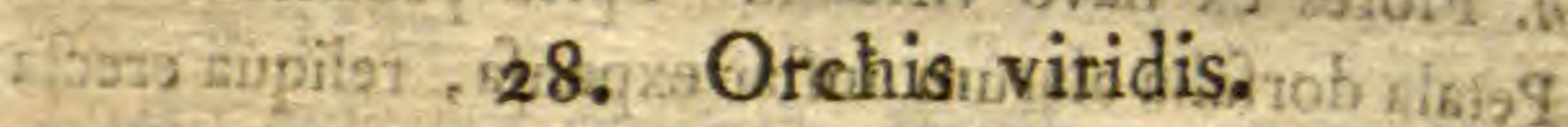

Orchis bulbis palmatis follis bblongis obtufis, hectarii labio linearitrifido! intermedia obfoleta. Ourata. flirp. aufr.-p. 49 r. Scop, Fl. carn. nl, I122. Allion. Fl. pedem. n. 1846 .

Orchis radicibus palmatis, galea connivertite, labello trifulco, caleare breviffmo: Hafl? hift. helv. ni 3269 . Orchis palinata, flore galericulato dilute vindi. Toefet.

Fl. prufs. I92. tab. 59 .

Orchis palnata, flore viridi. Bauli. pin. 86.

Satyrium vifade. Linn. fyft. veget. p. 8 rr. Pollich. hiff, pa.

lat. n. 852. Roth. Fl. germ. p. 379 Ginel. Fl. Sib. I. p. 21. Oeder Fl dan, t. 77. Villars Fl. Delph. II. p. 4r. Matthufch, Enum. A. 862 i,

Crefcit 
Crefcit in montanis pratis ficcis; circa St. Benignam; in (1) fylva Bohemica, in pratis fubalpinis Sudetorum. Floret Junio. 4

Diagn. Flores virefcentes. Petala conniventia. Labium planum inflexum trifidum; fegmentis lateralibus anguftioribus; medio minimo. Calcar breviflumum obtufum. Bractex floribus paulo longiores. Folia oblonga obtufa.

Icon. Oeder. Fl. dan. t, 77. Loeffel. 1.c. Hall, I. c. tab, $2 \sigma_{0}$ 29. Orchis ferruginea.

Orchistalbis palmatis, foliis ovatis obtufis; nectarii labio lineari indivifo; petalis dorfalibus expanfis. Incolit prata fubalpina uliginofa montium Ileræ majoris fluvii. Floret Junio, Julio, 24

Diagn. Flores ex flavo viridant. Spica pauciflora laxa. Petala dorfalia alarun inftar expanfa, reliqua erecta in galeam. Labium fimplex lineare indivifum, apice tribus denticulis crenatum, \& macula ferruginea pictum. Calcar breviffimum obtufum. Bractea longitudine florum. Folia ovata obtufa aliquando rotundata, macula ferruginea colorata. Tota planta digitalis, non vltra.

Icon. Tab. noftr. Fig, 4 .

\section{Orchis nigra.}

Orchis bulbis palmatis, foliis linearibus, nectarii labio refupinato indivifo. Allion. Fl. pedem. n. 1845 . Scop. Fl, carn. n. I 123.

Orchis miniata, Cranz. Atirp. auftr, p. 487. 
Orchis radicibus palmatis, fpica denfifima, flore refupinato, calcare breviflimo. Hall. hift. helv. n. I $27 \mathrm{x}$. Orchis palmata anguftifolia alpina, nigro flore. Bauh. pin. 86.

Satyrium nigrum. Linn. fyft. veget. p. 8 I r. Jacq. Fl. auftr. t. 368 . Villars FI. delph. II. p. 43.

Habitat in montibus Sudetorum. Floret Julio. 4.

Diagn. Flores atro-rubentes odoratiffimi inverfi. Spica denfa. Petala patentia, Labiun indivifum antice carinatum crenulatum, petalis paulo longior. Calcar vix lineam longum.

Icon. Jacq. 1, c. Hall. 1. c. tab, 27.

\section{$3^{\text {r. }}$ Orchis albida.}

Orchis bulbis fafciculatis, foliis lanceolatis, nectarii labio trifido acuto: intermedia obtufa, Scop. Fl. carn. n, 1 I 24.

Orchis radicibus confertis, teretibus, calcare breviffimo, labello trifido. Hall, hift, helv, n, 1270.

Orchis alpina. Cranz ftirp, auftr. p. 486.

Satyrium albidum. Linn. fyf, veget. p. 8 I2. Roth, Fl. germ. p. 370. Mattufch, Enum. n. 863. Villars Fl. delph. II. p. 42. Oeder Fl, dan, t. II5. Habitat in pratis fubalpinis Sudetorum; in pratis ficcis montanis circa Elbogen urbem, inque fylva Bolie. mica. Floret Junio. 4

Diagn. Flores albidi, parvi, leviter odorati. Labium trifidum; fegmentis acuminatis; medio majore. Petala erectiufcula, exteriora pallide viridia, interiora fubflava, Calcar breve album.

Icon. Oeder 1, c, Hall. I. c. t, 26 , 


\section{Orchis aphylla.}

Orchis bulbis compreflis dentatis, caule vaginato, nectarii labio refupinato indivifo.

Satyrium Epipogium. Linn, fyft, veget, p, 812 . Roth.

Fl. germ. p. 380 . Jacq. Fl. auftr. tab. 84 . Villars

Fl, delph. II. p. 44. tab. I. Weber Fl, goett. p. 23.

Epipogium. Gmel. Fl, Sib, 1, p. 12, tab. 2. f. 2.

Epipactis caule aphyllo, flore fupinato: labello ovato-

lanceolato, calcare ovato turgido. Hall. hift. helv.

n. 1289 .

Rariffima hucusque Rolremix planta ; detecta in montibus R'ünigfd)es (Jebuirg verfus Ralatinatum; locis lapido. fis, umbrofis, ut vix radix integra fine lrefione efodi poffit. Floret Julio. 24

Diagn. Spica rara. Flores inverfi. Petala patentia \& reflexa flava. Labium indivifum crenulatum \& fuperius in utraque parte appendice ovata ornatum, purpureum. Calcar breve turgidum maculatum. Scapus aphyllus, folum Squamis vaginantibus inftructus.

Icon. Jacq. 1. c. Gmel. 1. c. 
SEls

\section{Epipactis.}

Corolla quinque petala: Petalis duobus exterioribus, tribus interioribus conniventibus; Neätario non cal. carato. Germen oblongum non tortum.

A. Neitarium petalis longius dependens. Ophrydes Linn. * Bulbis ramojis.

\section{Epipactis nidus avis.}

Epipactis bulbis fibrofo fafciculatis, caule vaginato aphylIn, nectarii labio bifido.

Epipactis aphylla, flore inermi, labello bicorni. Hall. hift, helv, n. 1290.

Ophrys nidus avis. Linn, fyft, veget, p. 818. Leers Flor. Herb, n. 696. Roth. Fl. germ. p. 380. Leyff. Fl, Hall. n. 916 . Pollich, hift, palat. n. 853. Wildenow. Fl, Berol, n. 49. Scop. Fl. carn. n. I131. Mattufch, Fl. filef, n. 662. Oeder Fl, dan, t. 18r. Villars Fl, delph, II. p. 4 i.

Orchis abortiva fufea. Bauh. pin. 86.

Frequens in fylvis montanis umbrofis. Circa St. Ivanum et Carlftein vuigatis, Floret Majo, Junio. 4.

Diagn. Radices fafciculata fibris teretibus craffiusculis. Scapus aphyllus fquamofus. Petala conniventia in galeam; Labium deorfun flectitur et in duo crura finditur. Bractex germen vix adxquant. Tota planta eft fucculenta et bruna.

Icon. Oeder, L, c, Hall, l, c, tab. 37 . 


\section{Epipactis Corallorhiza.}

Epipactis bulbis ramofis flexuofis, caule vaginato aphyl. lo, nectarii labio trifido.

Corallorhiza. Hall, hift, helv. n, I301. Gunn, Fl, norv. 2. t. 6. f. 3. Gmel, Fl. Sib. I. p. 26.

Epipactis aphylla radice coralloide. Cranz, ftirp, auft. p. 464 .

Corallorhiza Neotia. Scop. Fl, carn. n. I 134 .

Ophrys Corallorhiza. Linn, fyft, veget, p: 8 r2. Roth. Fl. germ. p. 380 . Oeder Fl, dan. t. 45 I, Villars Fl. Delph. II. P. 45.

Orobanche radice coralloide. Bauh. pin. 88 .

Habitat in fylvis montefis. Circa St. Benignam, St. Ivanum, arcem Carlftein \&c. Floret Majo. 24.

Diagn. Scapus fquamis vaginantibus. Petala connivent. Labium trifidum. Bractea germine longior. Flores fecundi. Stamina quatuor. Tota planta albi$\mathrm{da}$, carnofa, fragilis.

Icon. Oeder I. c. Gunner I. c. Hall. 1.c. t. 44.

\section{Epipactis fpiralis.}

Epipactis bulbis aggregatis oblongis, caule fubfoliofo, floribus fpirali-fecundis, nectarii labio indivifo crenulato.

Epipactis bulbis cylindricis, fpica fpirali, labello crenato, Hall, hitt. helv. n. 1294.

Serapias fpiralis. Scop. Fl, carn. n. II25. Ophrys fpiralis. Linn. fyft, veget. p. 812. Roth. Fl. germ. p. 38r. Pollich. hift. palat, n. 854. Leyff. Fl. 
Fl. Hall. n. 917. Wildenow. Fl, Berol. n. 50. Weber Fl. Goettıng.p. 23. Villars Fl. Delph, II. p. 46. Oeder Fl, dan. t. 387 .

Triorchis alba odorata minor. Bauh, pin. 84.

Habitat in pafcuis gramineis montium. In fylva Bohemica, \& in fubalpinis Sudetorum. Floret Julio, Augufto. 2.

Diagn, Radices oblongx. Flores fpica fecunda fpiralf, intus albi. Petala interiora tria coadunata. Labium fubroturndum ciliato-crenulatum. Bractex floribus longiores.

Icon. Hall, 1. c. tab, 38 . Oeder. 1. c.

\section{Epipactis-ovata.}

Epipactis bullo fo fibrofo, caule bifolio, foliis ovatis, necta. rii ĺabio bifido.

Epipaztis foliis binis ovatis, labello bifido. Hall, hif. helv. n. $129 \mathrm{I}$.

Ophrys ovata, Linn. fyft, veget, p. 813.. Roth. Fl. germ. p. 381. Pollich, hift, palat. n, 855: Scop. Fl. carn. n.j1i32. Leers Fl. Herb. n. 697. Leyfs. Fl. Hall. n, 918. Wildenow. Fl Berol. $\therefore$ n. $5 \mathrm{I}$. Oeder. Fl, dan. t, 137: Villars Fl, delph, II, p. 47

Ophrys bifolia. Bauh, pin. 87 .

Habitat in pratis pinguibus, et pafcuis nemorofis humidis. Copiofe fub monte Jafchken ad Pagum Hannichen. Floret Majo, Junio. 4:

$$
\text { Q. Diags, }
$$


Diagn. Folia in caule duo oppofita ovata integerrima. Labium bifidum elongatum lineare. Spica longa floribus ex virido-flavicantibus.

Icon. Oeder 1. c. Hall. 1. c. t. 37 .

Varietatem in monte Jafchken vidi foliis ternis.

\section{Ophrys trifolia. Bauh. pin. 87. 5. Epipactis cordata.}

Epipaltis bulbo fibrofo, caule bifolio, foliis cordatis.

Epipactis foliis binis, cordatis, labello bifido, poftice bidentato.

Ophrys, cordata. Linn, fyft, veget, p. 8I3. Roth. Fl. germ. p. 381. Scop. Fl, carn. n.1133. Gunn.Fl. norv. 2. t. 3.f. 6. Gmel. Fl. Sib. I. p. 25. Weber Fl. Goetting. p. 24. Villars FI. Delph. II. p. 47. Jacq. collect, II. P. 265.

Ophrys minima. Baub. pin. 87.

Habitat in pinetis montanis humentibus; in Sylva Bohemica ad Planam copiofe; \& in monte Jafchken ad Reichenberg. Floret Junio, Julio. 4.

Diagn. Planta debilis gracilis, digitalis. Folia in caule bina oppofita, cordata. Labellum bifidum bafi utrinque dente notatum. Flores pauci e virido. rubelli.

Icon. Gunn, 1, c. Hall, L. c. t. 22. 


\section{* Bulbis rotundis.}

\section{Epipactis paludofa.}

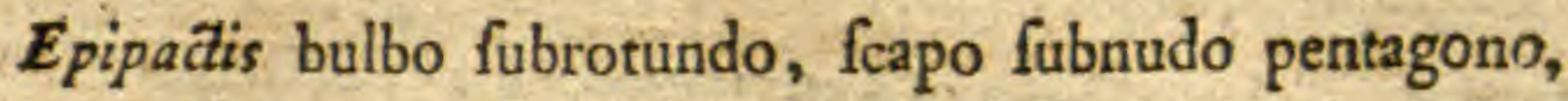
foliis apice fcabris, nectarii labio integro.

Ophrys paludofa. Linn, fyft, veget. p. 813. Rôth. FI. germ. p. 38 r. Pollich. hift. palat. n. 856 . Wildenow. Fl. Berol, p. 5 2. Gunn, Fl, norv, n. 965 . Habitat in paludibus. ad pifcinas inter Thypas \& Arundines in Circulo Pilfnenfi ad Planam; rarius. Floret Julio, Augufto. 24.

Diagn. Flores ex virido-flavefcentes. Petala lateralia duo exteriora reflexo-erecta, duo interiora lateralia, recurva; fupremum rectum. Labium reflexum integerrimum.

\section{Epipactis monophylla.}

Epipaçis bulbo rotundo; fcapó nudo, folio ovato, ne. ctarii labio integro.

Epipactis folio unico, amplexicauli, f́ica prolixa multiflora. Hall. hift. helv. n. 1290.

Ophrys monophyllos. Linn. fyft. veget, p. $8 \mathbf{3} 3$.

Ophrys monophyllos bulbofa. Loefel Fl. pruff, 180. tab. 57 .

Habitat in paludibus turfofis fylvaticis, Rariffume ad Salinas Aushovvitz. Floret Junio, Julio.

Diagn. Flores minuti virides multi in fpica elongata. Petalum fupremum multo latius reliquis. Labium Q3 inte- 
integerrimum lingureforme. Bractex minimæ. Fo. lium unicum ovato-lanceolatum, ad bafin vagina caulem amplectitur.

Icon. Hall, 1, c, t, 36, Loefs. 1. c,

Variat Foliis binis et fpica rara pauciflora.

\section{Epipactis Monorchis.}

Epipactis bulbo globofo, fcapo nudo, nectarii labio tri. fido cruciato.

Ophrys menarchis, Linn. fyft. veget. p. $8 \mathbf{1}_{4}$. Pollich. hif, palat. n, 857. Weber Fl, Goetting. p. 24 . Oeder Fl, dan. t. 102. Roth, Fl. germ. p. 382. Villars Fl, delph, II. p. 48 . Gunn. Fl. norv. n. 644.

Orchis bulba unico, fubrotundo, labello cruciformi. Hall. hift. helv, n, 1262 .

Orchis monorchis. Cranz, firp. auftr. p. 478. Scop. Fl, carn. n, II 16.

- Orchis coleo unico feu Monorchis flofculis pallide viri. dibus, Loefel. Fl. pruff, I84, tab. $6 \pi$.

Orchis odorata mofchata f, monorchis. Bauh. pin. 84 . Monorchis, Rupp. Fl, gen. 42 I, t. 2.

Incolit prata uliginofa montana. In Sylva Bohernica, ad Aushowitz prope Salinas; et in illis pratis fylvaticis non procul à Rónigswarṭ̨. Floret Junio, Julio, 4 . 
Diagn. Flores luteo-virentes, fuaveolentes. Petala patula. Labium trifidum; fegmentis lateralibus transverfis. Folia radicalia duo, ovato-Ianceolata. Bulbus unicus globofus.

Icon. Oeder Fl. dan, tab, 102. Hall, 1, c, tab, 22.

\section{Epipactis alpina.}

Epipaçtis bulbis ovatis, fcapo nudo, foliis fubulatis, nectarii labio indivifo obtufo utrinque unidentato.

Ophrys alpina, Linn, fyft, veget. p. 814 . Oeder FI, dan, tab. 4 52. Villars Fl, delph, II. P. 48. Gunn. Fl. norv. n. 1098.

Orchis radicibus fubrotundis, labello ovato, utrinque denticulo notato. Hall. hif. helv, $\mathrm{n}_{1} 126_{3}$.

Orchis graminea. Cranz ftirp. auftr. p. 480.

Orchis alpina. Scop. Fl. carn. n. 1117 .

Chamzorchis alpina, folio gramineo. Bauh. pin. 81.

Habitat in Sudetis, locis gramineis; raro aut bet weifen

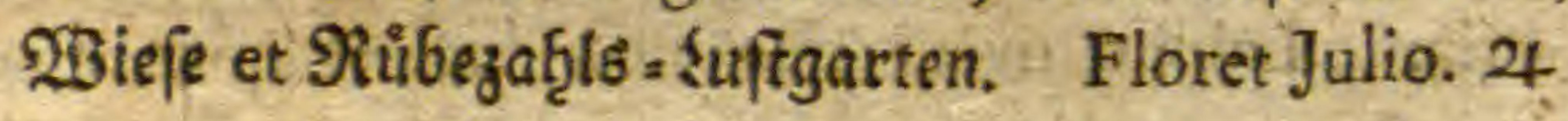

Diagn. Bulbi duo fubrotundi fupra radicati. Folia radicalia filiformia, graminea. Spica pauciflora. $\mathrm{Pe}-$ tala omnia in galeam connivent. Labium integrum linguxforme ad faucem duabus plicis feu denticulis. notatum. Scapus aphyllus. Vaginx duo e radice folia et fcapum includunt. Flores flavo-virentes.

$$
\text { Q4 ro. Ep:- }
$$




\section{Epipactis myodes}

Epipactis bulbis fubrotundis, fcapo foliofo, nectarii labio oblongo quadripartito: lacinis duabus mediis elongatis lanceolatis.

Ophrys myodes. Linn. fyft, veget. p. 813. Roth. Fl. germ. p. 382. Gunn. Fl. norv. n. 967. tab. 5. fig. I. Mattufch. Fl. Sil. enùm, n. 867 .

Ophrys infectifera. Linn. fyft. Reich. Vol. 4. p. 26. Villars. Fl. delph. II. p. 49.

Orchis radicibus fubrotundis, labello fericeo bifulco, brachiolis brevibus fubulatis. Hall. hift. helv, n. 1265 . Orchis mufcaria. Scop. Fl. carn. n. III4.

Orchis mufciflora. Schrank. FI. Bavar. n. 75.

Orchis mufcx corpus referens minor, galea et alis herbio dis. Bauh. pin, 83.

Habitat locis herbidis montium; in Sudetis ad eflbgrunb, et Mábelwiefe raro. Floret Junio, Julio. 4

Diagn. Petala tria exteriora latiora, interiora duo linea. ria. Labii convexi nec non bafi et apice dilatati, pectus maculam cerulefcentem habet, fupra quam brachia porrigit attenuata, deflexa et acutiufcula, Spica rara vix floribus.quinque conftat.

Icon. Hall. J. c. tab. 24. Gunn. I. c. 


\section{1. Epipactis arachnites.}

Epipatis bulbis fubrotundis, fcapo foliofo, nectarii 12. bio lato emarginato appendiculato.

Ophrys arachnites, Linn. fyft. veget. p. 813. Roth. Fl. germ. p. 382 .

Orchis arachnites. Seop. Fl. carn. n. II 15.

Orchis fuciflora. Schrank, Fl. Bavar, n, 74.

Orchis radicibus fubrotundis, labello holofericeo enarginato, appendiculato, Hall. hilt. helv, n. 1266.

Orchis araneam referens. Bauh, pin. 84 .

Ophrys infectifera. Pollich. hift palat, n. 858 .

Habitat in pafcuis herbidis depreflis ad radices montium. Im Runigfhen Bebuirg. Floret Majo, Junio. 4

Diagn. Petala patentia; tria exteriosa latiora, longiora, duo interiora breviora anguftiora. Labium integrum emarginatum, fere trilobum Spica rara pauciflora. Caulis foliatus.

Icon. Hall. 1, c. tab. 24 .

B. Noclarium longitudine petalorum. Serapias. Linn. 12. Epipactis repens.

Epipactis bulbis fibrofis, foliis ovatis radicalibus, floribus fecundis.

Epipactis foliis petiolatis, ovato-lanceolatis, floribus te. trapetalis hirfutis. Hall. hift. helv. n. 1295 .

Satyrium repens. Linn. fyft. veget. p. 812. Roth. Fl. germ. p. 380. Wildenow. Fl. Berolin. n. 48. Oeder FI. dan. t. 812 . Jacq. Fl. auft. t. 369. Gunn. Fl. norv, n. 32 I. tab, 6, fig, I.

Q5 Pfeudo 
Pfeudo Orchis. Baub. pin 84.

Habitat in montanis pinetis. Circa Thermas Corolinas. Floret Junio, Julio, 24

Diagn. Flores fecundi; Petala tria pubefcentia conglutio nata, Labiuin ovato-oblongum. Calcar nullum; ejus loco tuberculum, Folia petiolata ovata, Ra. dix repens.

Icon. Jacq. 1.c. Oeder. 1.c. Hall. 1, c.t. 22 .

13. Epipactis latifolia.

Epipactis bulbis fibrofis, foliis ovatis amplexicaulibus, floribus pendulis.

Epipactis folirs amplexicaulibus, ovato-laniceolatis, label-t lo lanceolato. Hall. hift. helv. n. I 297.

Epipactis Helleborine, Cranz. Hirp. auftr. p. 467. tab. 1. fig. 6. c.

Serapias latifolia, Linn. fyft, veget, p. 8 I 4 . Leers. Fl. Herb, n. 698. Leyfl. Fl. Halens, n. 920. Pollich. hift, palat. n. 859. Wildenow. Fl, Berolin. n. 53 . Oeder. Fl. dan. t. 81 r. Roth. Fl. ge:m. p. -382 . Gunn. FI. norv. n. 970 . tab. 5. f. $3-6$. Villars. Fl. Delph, II. p. 50 . Mattufch, Fl. Sil, n. 664. Enum, n. 868 . Scop. Fl. carn. k. 1128 .

Helleborine latifolia montana. Bauh. pin. 186 .

Habitat vulgaris in fylvis montanis. Floret Julio, Angufto, 4.

Diagn. Folia amplexicaulia lata. Spica multiflora longa, laxa, Petala lata acuminata, extus fublirfuta; Labium cordiforme acuminatum. Flores penduli. Icon. Oeder 1, c, Gunn. 1, c. Hall.1. c, tab. 40. 


\section{Epipactis longifolia.}

Epipactis bulbis fibrofis, foliis enfiformibus feffilibus, floribus pendulis.-

Epipactis foliis enfiformibuš, caulinis, floribus pendulis, labello obtufo, oris plicatis, Hall. hift. helv. n. 1296.

Epipatis paluftris, Scop. Fl. carn. n. 1129. Cranz. ftirp. auftr. p. 462, t, I, f. 5. Villars Fl. Delph. II. p. 5 I.

Serapias longifolia. Linn. fyft. veget, p. 815. Roth. Fl. germ. p. 382. Leers Fl. Herb. n, 6gg. Leyff. Fl. Hal. n. 921 . Pollich. hift, palat, n. 860 . Mattufch. Fl. Silef, ni. 665 . Enum, n. 869.

Helleborine angufifolia paluftris $f$. pratenfis. Bauh, pin. 87.

Habitat in fylvis umbrofis montofis, in pratis fylvarum vdis. In Undis Moldava ad Zaftoborz. Circa St. Benignam. Floret Julio, Augufto. 24.

Diagñ. Flores penduli majores, quam in precedenti, ex virido-purpurafcentes. Labium obtufum integrum, petalis paulo longius, album, glicatum. Folia amplexicaulia, enfiformia.

Icon. Hall. 1. c. t. 39.

\section{Epipactis enfifolia.}

Epipactis bulbis fibrofis, foliis enfiformibus diftichis, bracteis minutiflimis, floribus erectis; nectarii labio obtufo petalis breviore, 


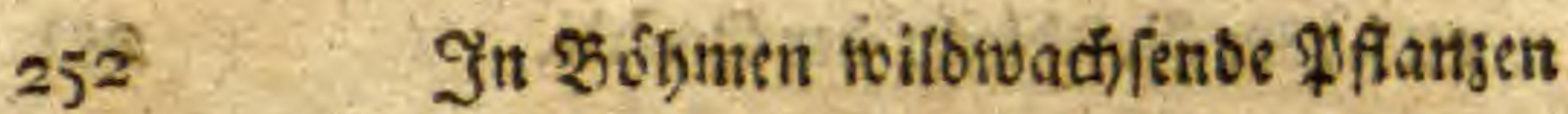

Epipactis caule paucifloro, lineis obtufi labelli levibus. Hall. hift, helv. n. 1298 , t. 4 I.

Epipactis alba. Cranz. ftirp. auftr. p. 460.

Serapias enfifolia. Linn. fyft, veget, p. 815. Roth. FI. germ. P. 383 .

Serapias nivea. Villars Fl. Delph. II. p. 52.

Serapias grandiflora. Linn. fyft. Reich. 4. p. 32. Scop.

Il. carn. n, I 127 . Pollich. hift. palat, n. 86 r. Oeder Fl. dan. t. 506.

Helleborine flore albo. Damafonium montanum latifolium. Bauh. pin. 187.

Habitat in montofis fylvis. Circa Zbirow et St. Benignam vulgaris. Floret Julio, Augufto.

Diagn. Flores magni albi erecti. Petala oblonga apicibus rubellis, Labium petalis brevius acutiufculum plicatum. Capfula hexagonxe erectro. Folia lanceolato-enfiformia. Bractex breviffimx.

Icon. Oed. I. c. Hall. I, c.

\section{Epipactis lancifolia.}

Epipactis bulbis fibrofis, foliis ovato-lanceolatis, bracteis longitudine capfula, floribus erectis, nectarii labio obtufo petalis breviore.

Serapias lancifolia. Linn. fyft. veget, p. 815. Roth. Fl. germ. p. 383.

Habitat in fylvis montofis umbrofis. In fylva Bohenica; in fubalpinis cirea Friedland. \&c. Floret Junio, Julio. 
Diagn. Flores erecti pauci ex albido-carnei. Petala oblonga obtufa, Labium obtufum fubemarginatum petalis brevius. Capfula erectx. Bractex longitudine capfula. Folia ovato lanceolata, acuminata.

\section{Epipactis rubra.}

Epipactis bulbis fibrofis, foliis enfiformibus, floribus erectis: nectarii labio acuto.

Epipactis caule paucifloro, lineis acuti labelli undulatis, Hall. hift. helv. n. 1299, t. 42.

Epipačtis purpurea, Cranz ftirp. auftr. p. 457. Serapias rubra, Linn. fylt, veget, p. 816. Roth. Fl. germ, p. 383. Leers Fl. Herb. n, 700. Leyfs. Fl. Hall, n. 924. Pollich, hift, palat. n. 862. Weber Fl. Goetting. p. 24. Wildenow. Fl. Berol. n. 55 . Villars Fl. Delph. II. p. 53. Oeder Fl, dan. t. 345 . Serapias longifolia. Scop. Fl. carn, n. I I 26.

Helleborine montana anguftifolia purpurafcens. Bauh. pin. 187.

Helleborine Flore carneo. Bauh. pin, 1. c.

Habitat in pratis montanis udis. Copiofiflime circa Reichenberg et Friedland. Floret Junio, Julio. 4

Diagn. Flores purpurei magni, erecti. Petala lanceolata acuminata, extus lanuginofa. Labium longius acutum lineis undulatis. Fructus erecti. Bractex lon. gitudine germinum. Folia conduplicata, bifariam verfa, 


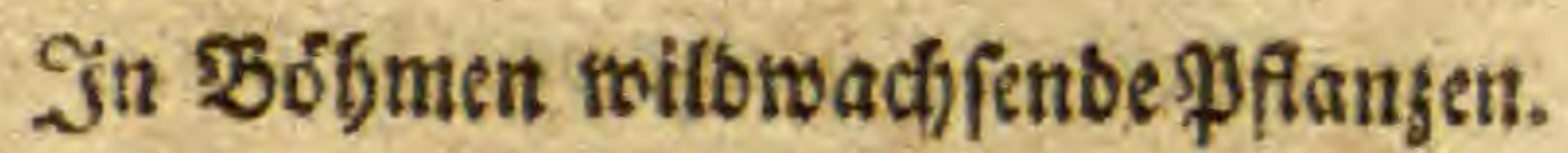

verfa, fenfim in acumen attenuata. Caulis non taro tortus.

Icon. Oeder 1, c. t. 42 .

Variat Floribus albis et carneis. -

Orchides omnes exhibeo, quod in iis a Linnzo ve. riffime fpecies expungantur, et auctoritas funmi viri, qua merito maxima eft, etiam peritos homines eo abducat, ut eas plantas inter varietates ablegent, qux vere diftinctr funt fpecies. Hall, in pref, ad hift. helv. T. II, p. XXII.

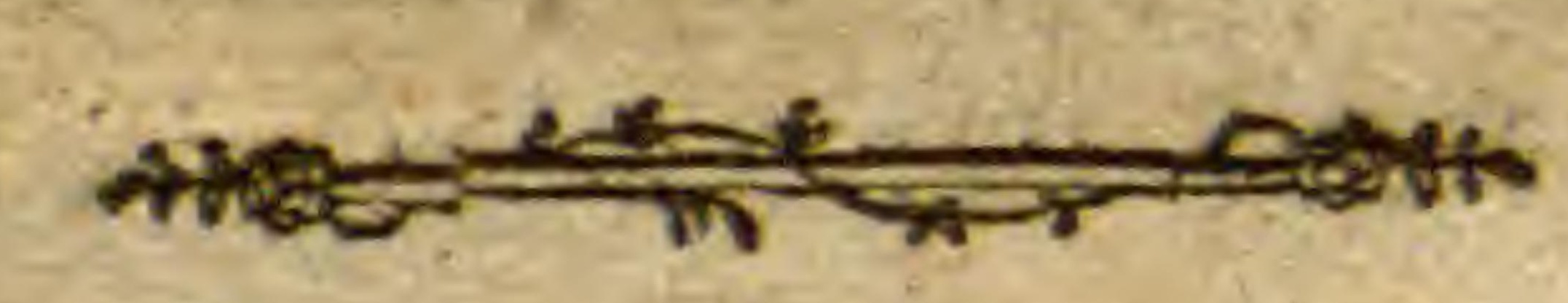




\section{XVI.}

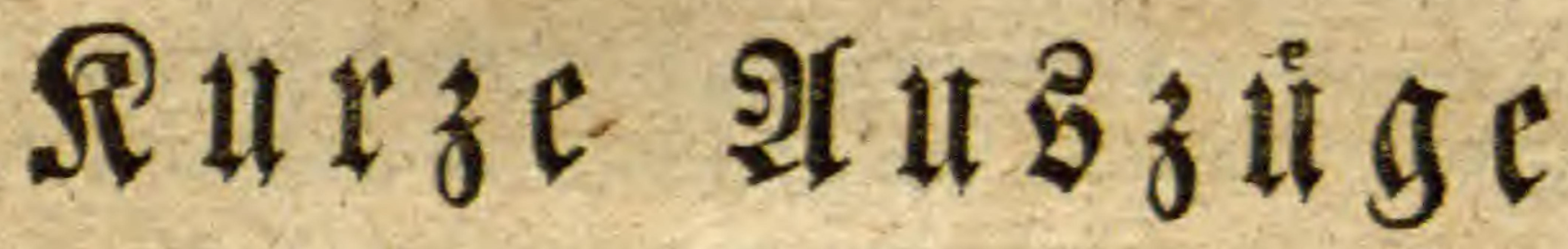
un श a d ridbten ตแริ ฐtiefen an Den Seraugeber. 


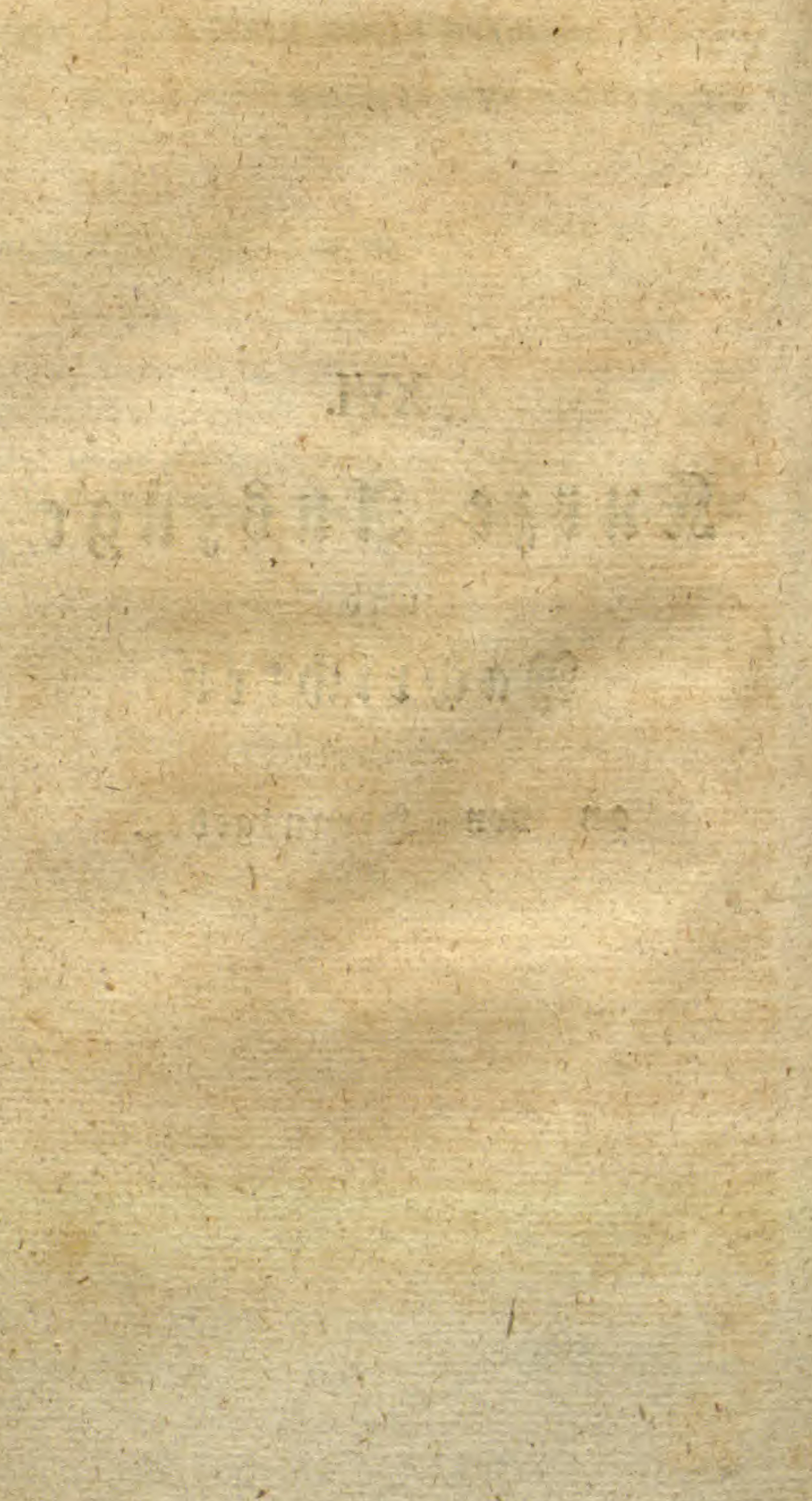




\section{I.}

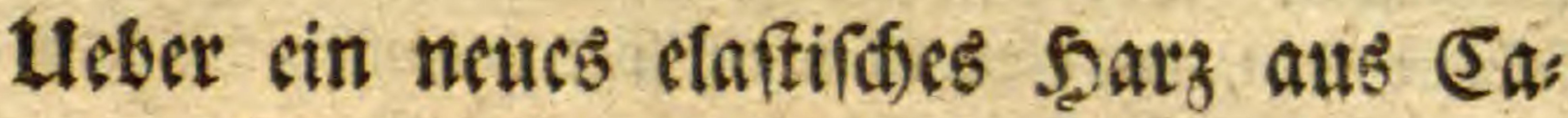
yenne, bom Serrn de la Borde in ஒaris.

9) uffer bem elaftifitien f̧arte, fo unter bem গamen bes Eaoutchoue aus Cayenne, uno bemjenigen bes 20 d. ne, fo aus Madagafcat ju uns gebradt)t wirt, uno in ganj Europa befannt ift, bat man ein neues, ebenfalls in Capenne entbeft, meid)es von cben ben (Figenfdhaften ift, als bie erroab̨hnten benten, ob es fid) gleich von ithnen in mandem unterfheibet. Der $\mathcal{E}_{\text {aft }}$ witb aus einer (Jat. tung von Mimofa gewonnen, welhke einen májigen Baaum mad)t. Jah babe blog einige troctne 3weige vor mir, bie

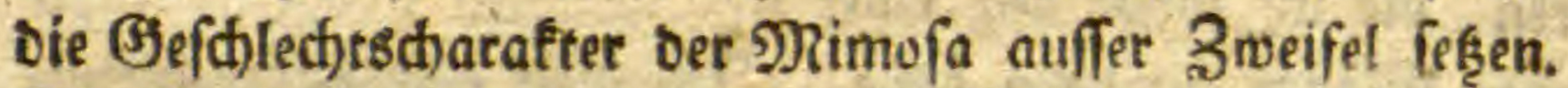
Die 3reige babon b̧aben in ib̧ren $2 B$ infeln fleine fumpfe Infäkęe, bie bie Etelle von Etad)eln vertreten, uno fino meiffens orey an ber వaḩl, bie gefieberten Blätter b̧aben

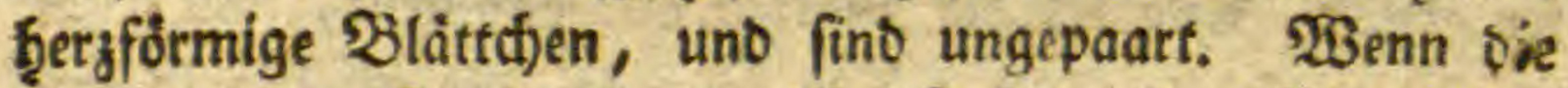

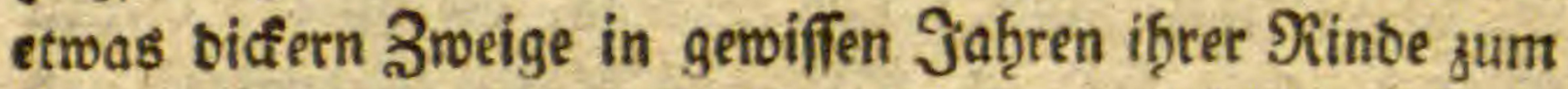

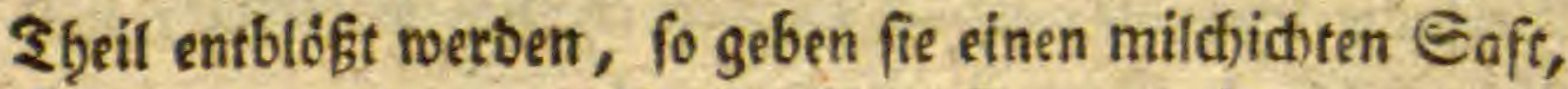
ber nur langfam unb ben grofier Connenwárme gerinnt. Tan fann if̧n bequem famlen, un'o in verfdtloffenen (S) faffen Jab̨re lang aufberwab̧ren, of̧ne baßz er getinht. Er brennt in fouter of̧ne merflichen (Serud), uno bins

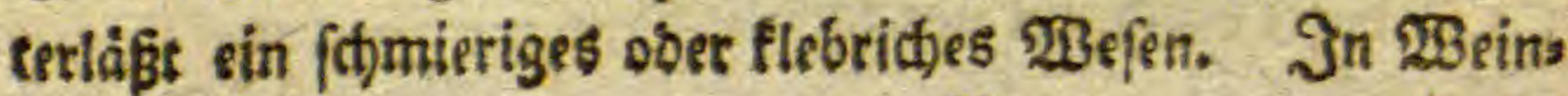




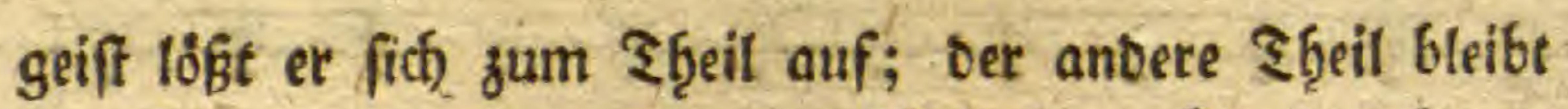
am Boben als eine geronnene Gaallerte. In langfamer Wiårme, ober an ber Conne, wirb es nach uno nad) flûf: fig, uno befommt bie Sonfiffenz uno Elaftitität, mie bas Caoutd)oue. Das elaftifde Şarz babon ift gologelb wie Der Bernffein, uno nimimt nur erft fpát eine unourdffichtige braune farbe an. *)

\section{II.}

Ueber Die $\mathfrak{A}$ flofing Des Eifens in luftlerem ख3affer, von $\mathfrak{D}$. Noris in Rondon.

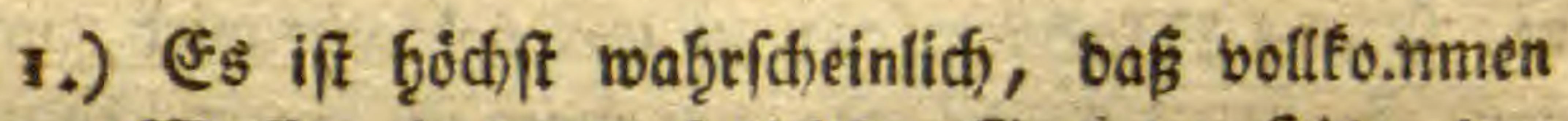

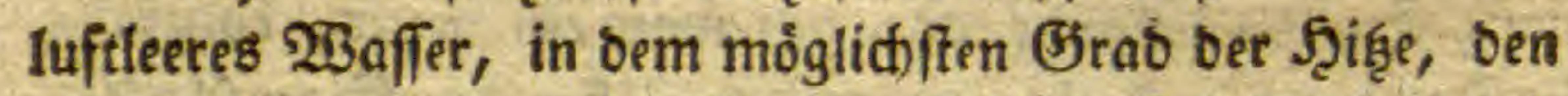
es annef̧men fann, fein (Eifen auflơfe. İh) mact)te eini. ge $\mathfrak{B e r}$ utude, wovon ith nur folgenbe anfüferen will. In

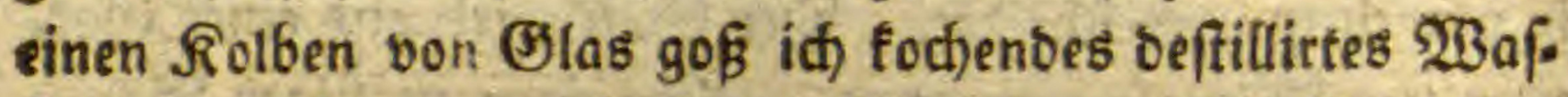
fer; in biefen legte idf) einige feb̧r bùnne feine Eifenplat. ten, bie ich zubor auf einer febr genauen uno empfintli= den $\mathfrak{B a a g e ~ g e r o o g e n ~ b q a b e . ~ J a t h ~ b i e l t ~ e i n e ~ g a n g e ~ S t u n e ~}$

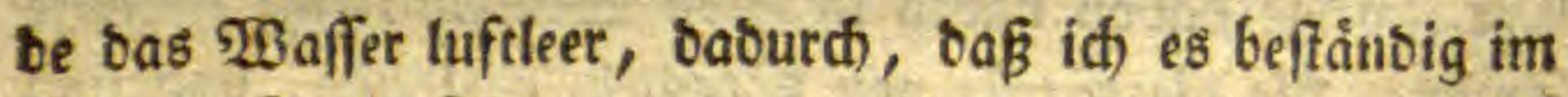

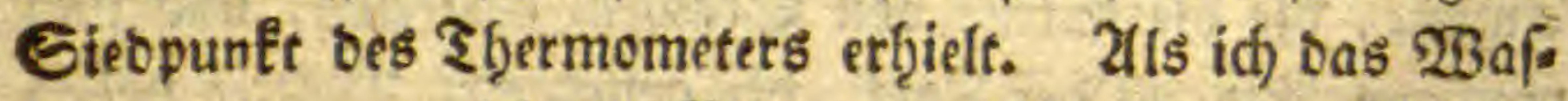
fer abgok, rog ich bie Platten auf bas neue, uno felbft

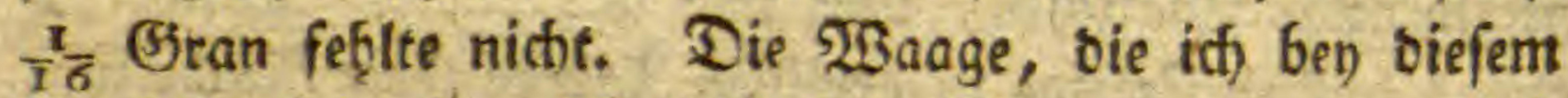
Berfuche braudfite, ift aflhier bon 2(bams verfertigt, uns Biebe felbft $\frac{1}{1 \sigma}$ Gran 2(usfd)lag.

গie. :

-) Der Şeraus̉geber bat ben flúfigen @aft biefę netren elas ftichen Scarzes erbalten, uno findert eร volltommen mit

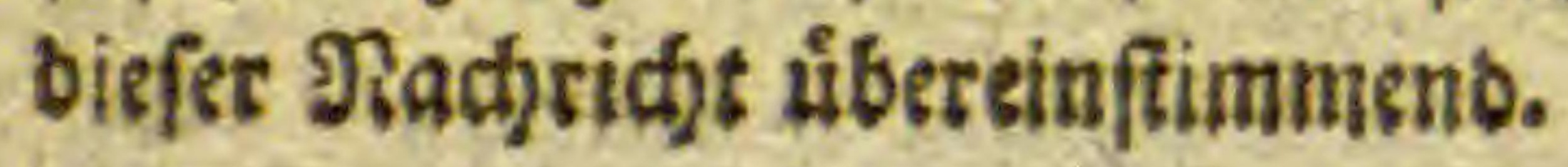


Niemano wiro bृoffentlich baran jweifeln, baf fo. dentes beftillirtes $\mathfrak{W a f f e r}$, menigftens fo lange es fiebenb geb̨alten wirb, volleommen luftleer fen)?

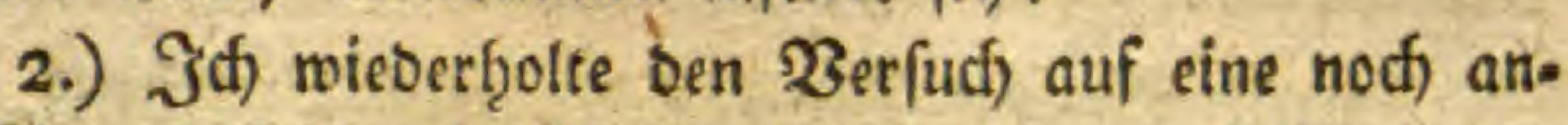

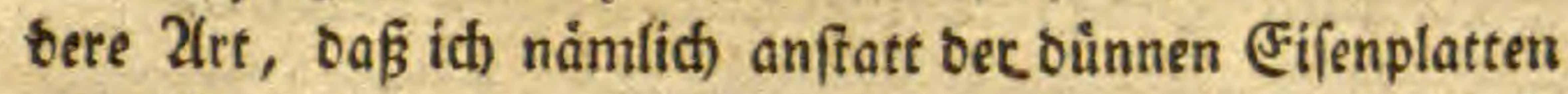
ober $\mathfrak{B}$ leche, feine, burch) ben Ragnet gereinigte feil(pa:-

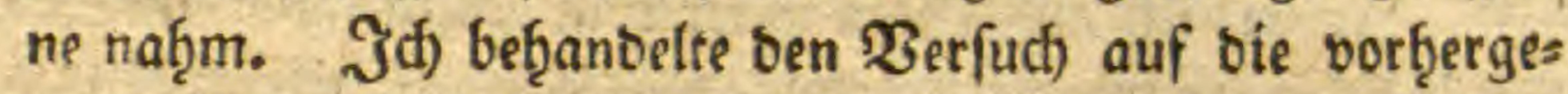
hende 2(re. 2(Is id) bas Rochen bes $\mathfrak{B}$ affers nad) einer Stunde einftellte, feigte id) bas übrige burch) zo̊fdpappier, welcfies juvor fitjon gewogen roar. Das Eifen, fo auf bem Papier fieng, warb gewogen, uno es zeigte fich ein 2lbgang von $1 \frac{5}{5}$ (Jran. IC) Dampfte alfo bas ourd)gelau. fene $\mathfrak{B} a f f e r$ bis jur Trofne im Dampfbao $a b$, fano meinen Berluft von Eifen sanz am Geftalt, benn es waro vom Nagnet angezogen. Diefes ift ein Bemeis, baß es nidit aufgetöbt, fonbern blos fus. fpentirt im $\mathfrak{W}$ affer qewefen, weil es im erftern Jalle falf: artig, uno feines Strennbaren beraubt, b̧ätte erfdeinen múffen. *)

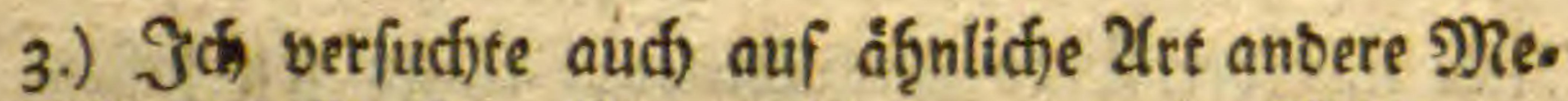
talle, nåmlid, Rupfer, Sinn, Blen, uno eine Mifd)ung bon benben leztern Metalten, mit meld)er man gewodb̨nlí() bie fupfernen (B)efáfle auszinnt. $\mathfrak{B}$ on Rupfer unb Binn waro gar fein 2 bgang, von $\mathfrak{B l e l}$ uno ber Mifchung jum 2(usjinnen, etroas fefgr unbetråd)tliches.

$$
\Re_{2}
$$

III. racb,

*) Ueber biefen legten Berfuch lieffen fich wobl einige wid)s tige Einnenoungen madien; oer ร̧r. $\mathfrak{B}$. aber bat in

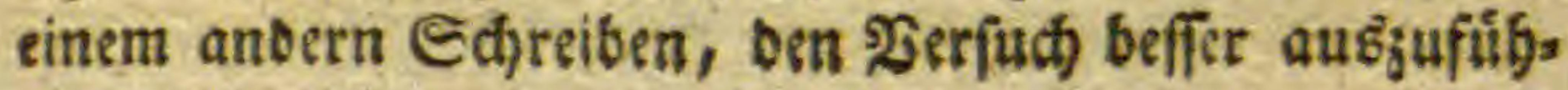
ren veriprochen.

ม. จ. รุ. 


\section{III.}

Tadjridt von Stcatitervftaffen aus Shina, von Scern Diageflan aut Sonoon.

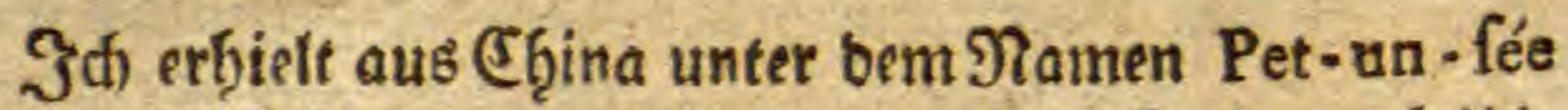
verfd)tebene Etrinarten, einige waren blos Steinmark (Lithomarga, ) anbere rothe ober veridfiebentlid)e in bas weis uno graue fallente feloipatfje, enolich gelbgrùne Serpentine uno Dpb̧iten, uno zulezt wab̧re bৃarte verfteinerte Epeffeine (Steatite, Pierre de lard.) Unter biefen mar eine 2(rt, bie in bas afthgraue fiel, uno zwifd)en weld)er verfdiebene Schid)ten zu fégen waren, bie aus einer vete bärteten weigen Eroe zu beftehen fatien, uno bie viel we: niger J̨årte batte, als ber Speffein felbft. Da id) biefe Eteinart, um fie in bem Innern ju feţen, ber Duere nad) burd)idoneiben ließ $\bar{\beta}$, fo waren bie meiften ber oben benann. ten Edjiciten nur mit lofer Eroe ausgefúltt, zwifhen weldher verfdiebene fleine Rrvffallen waren, bie theils lofe mit ber Erbe berausfielen, theils feft fasen. Eie waren fefgr bart, wie bie Steinart felbft, unb von eben Der Farbe, ganz unourchfiahtig, bon ber Broßjęe ber Şanf: fỏrngen. Eie b̧at 10 Flảđjen, worunter 4 groje gleid): fom bie Găule, uno 6 tleinere bie Enofpízen machten. Die feffifizenteen, waren an ib̨ren groffen flächen befeftigt. Gomobgl bie Eroe, als bie Rinftatlen uno bie gange Etein. art, geben bey ber demifhen Unterfudung Bitterfalgerbe. 


\section{IV.}

Don cinet neten Sternforalle aนs set Dit: fer, von feerrn Sd)ulz in Samburg.

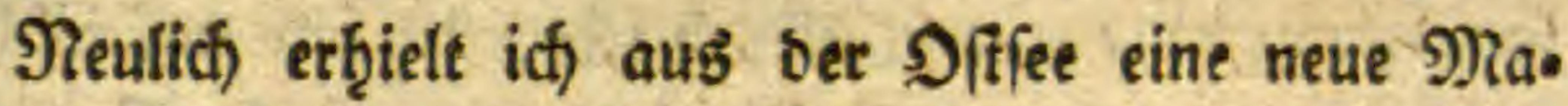
orepora, bie id noch nirgenos befdrieben finbe. $\Im$ gृt åufferes, feģe ḩartes (Sechảus ift biolet, uno gleidyt, nach

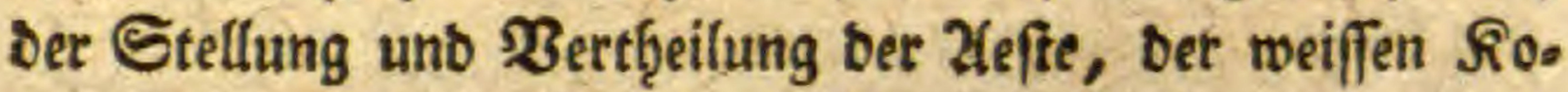

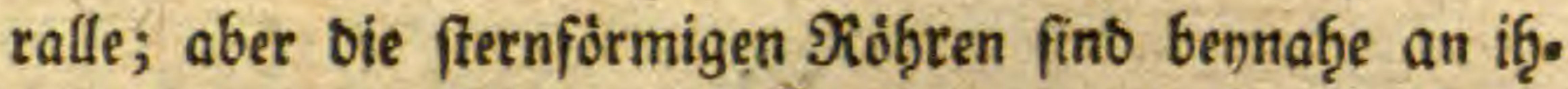

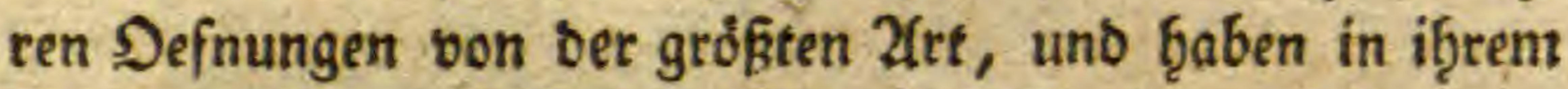
Durd)meffer eine sinie. Die fternförmigen Defnungen fino felten und fparfam an bem Etamme vertbeilt. W

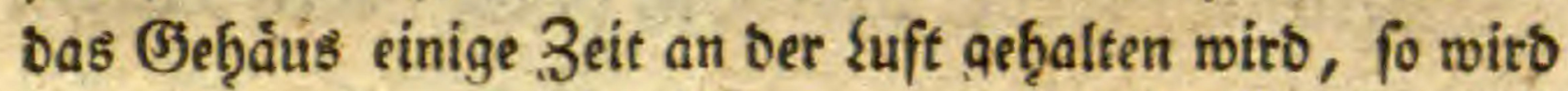

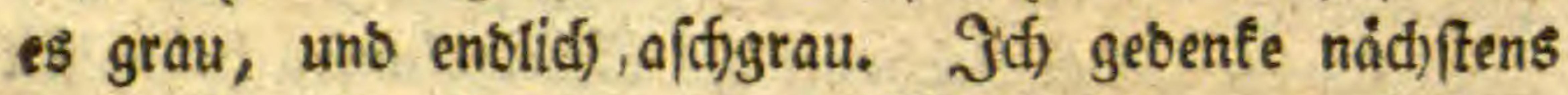
eime nóbere Befd)reibung unb 2(6bitbung bavon ju liefern.

\section{V.}

Leber die Elcktrizitåt verfátedener Saborle, von Ebendemfelben.

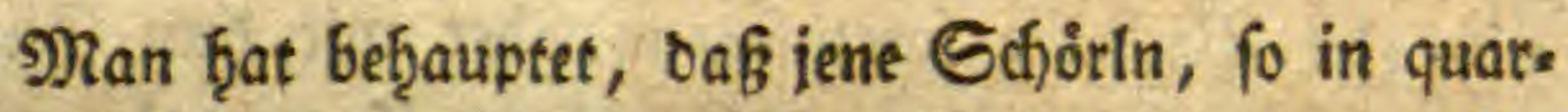
zigten Gebirgsarten eingemengt gefunben werben, eine glatte Dberflàd)e bुaben unb unourchifichtig finb, niemals Durd) Errwàrmung eine Spur von Eleféttigitàt gáben; abet id) habe bas Begentheil gefunben, benn eine Menge biez fer 2frten geben einen beträctllidien (Grab berfelben, wenn man fie, nadbem fie aus if̧rer Steinart ḩerausgenom= men worben, in einen Tiegel legt, fie mit reiner affije f(chid)tweife bebecft, unb fie, nactibem ber Siegel verfálof. fen, einigenal wechfelsweife langfam burdigltühet, uno

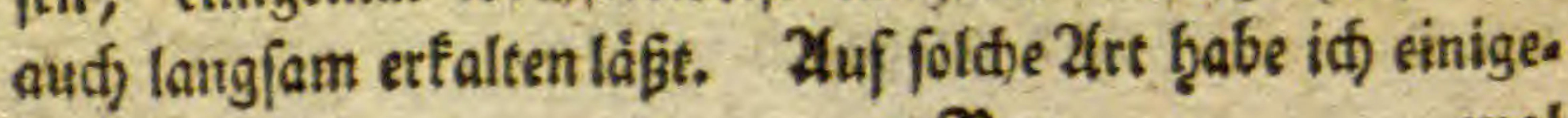


mal mir eine ziemliche 2 fnzahl elefirifher Surmaline ver. fdaft. Ein braunrotbeer b̧albourchfid)tiger Sdort aus bem fotlefiffthen Ricfengebirge, fo in einer Battung von

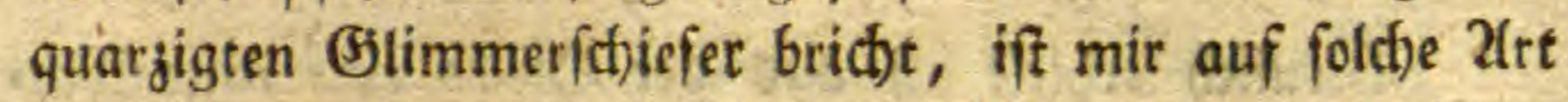

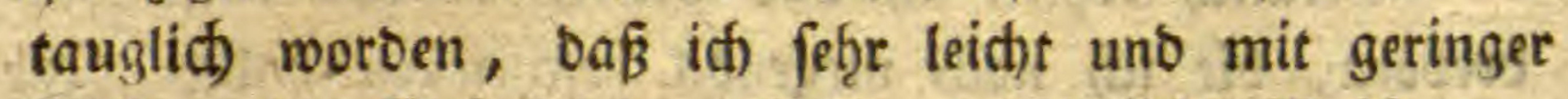

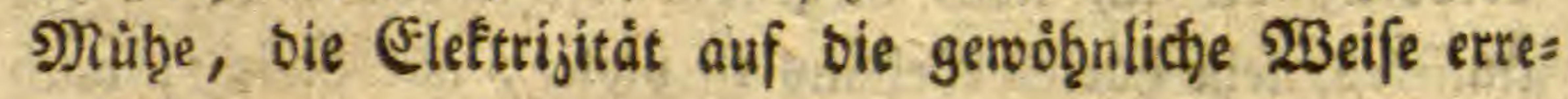
gen fann.

\section{VI.}

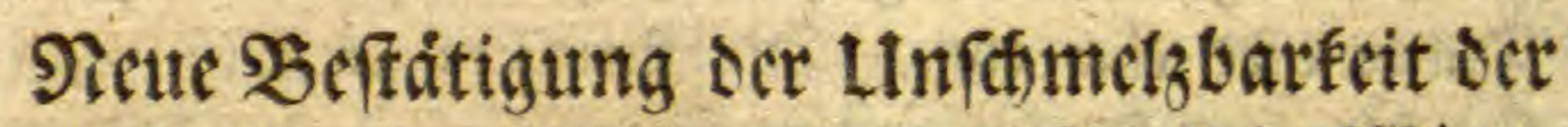
Glimmererde, ven 5 n. v. S $\rightarrow$ in $23 i e n$.

Einige biefige siebb̧aber ber Ect)eibefunft, ḩaben feit einiger 3eit verfuct)t, foroht bas Wafferblen, als aud) sie reine (3limmererbe vor fid allein, auf alle moglicte

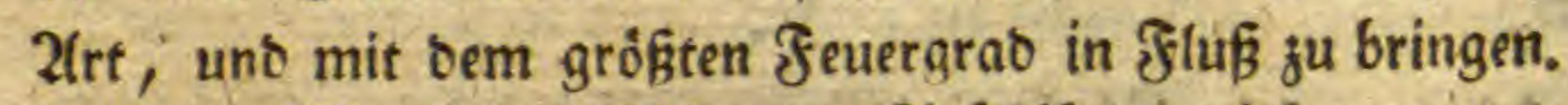
2fuf bas 2Bafferblen fohien ber 2rfenif ju' wirfen, weni es wie bie Platina beb̧anbelt wurbe. Man gebentt bier. über bie Berfudfe fortgufezen; aber mit bem Blimmer war nichts ausjurid)ten. In einem feurergrab, no bie

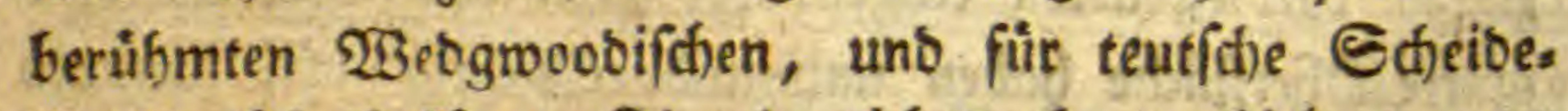
füftler fef̧r foftbaren ₹iegel, nicf)t meb̨r ausbielten, war siffe (Erbe nod) immer unberànbert, uno batte nid)ts am (B)

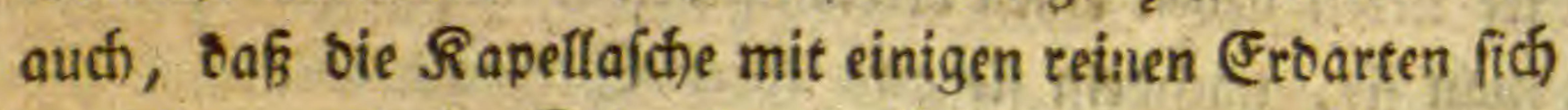
vereinigt, uno in Edomelgung übergebet; uno einen me.

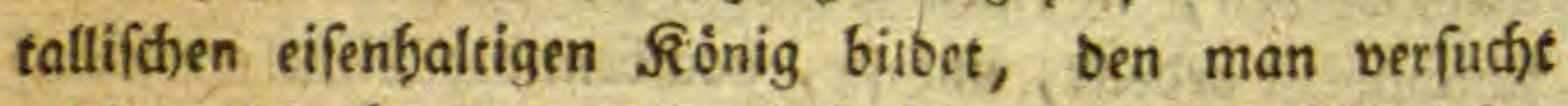
wirb zu glauben, aus ber einfad)en, in fich unfdomeljba. ren Erţart erḩalten z̆ ḩaben. 


\section{VII.}

Nadjrift von cincm neuen Mittel, dic ana: tomiftyen $23 a c h$ spráparaten Dautrhaf: ter zu madjen, von Stn. D. Guattani in Sion.

Unferer Seit war es aufbehalten, Figuren von $\mathfrak{B}$ adis zu erfinben, um ganze menfdhlid)e Rorper, ober bod) ge: wiffe Theile berfelben, Daburch vorzuffellen uno abjubils

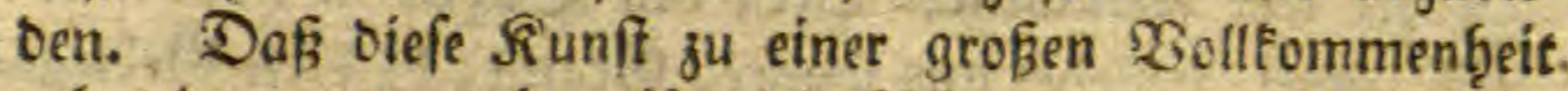
gebracht worben, berweifen Die fdoonen anatomifhen Prá. paraten, welche zu Zologna uno Sloren3 vel fertigt mer= Den, uno bie bie Senunderung afler Renner erregt haben. Bis jejt byat man aber bie traurige (Erfahtrung gemad)t, Daß̧ Diefe fuinftlicte 2(rbeiten, nad) einigen Jahren in Der farbe fich ánbern, uno auch bas 2 Bachs nichet mebre feine jåbe $\mathfrak{B}$ iegfamfeit, meldjes den Bufammenthang fichert, unb es bauerḩaft macht, behalte. Die Be. figer biefer fobonen Eeltenbeiten, feben baber oft bie Fats be verbleichen, bas $23 a d i s$ befómmt eine Eprobe uno

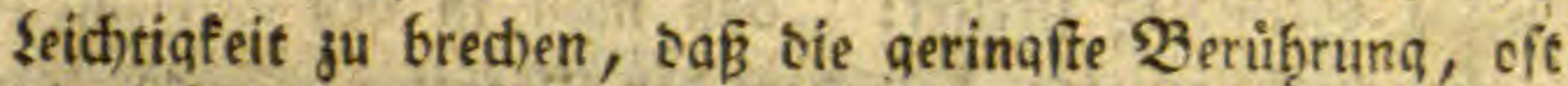
bie felbft eigene Edwere, Etricten abfallen uno jertrum: mern mac)t. Ein biefiger $\mathfrak{A r}_{\mathrm{j}} \mathrm{t}$, ber in Florenz, unter Fontana's 2uffititt, fiton bor vielen Jab̨ren Diefe Sunft geteffrt, bat ein Mittel stfunten, weiches biefen beisen Ulebein vorbengen foll, uno zum Beweife fielit er feine be: reits vor 23 İofren verfertigte Prajparate auf, welde ven beiben Bebrectien fren fint. Das genaue Werfabren ta. bey wirb er felbft befannt machen; vorláufig weíf man nur, Daß er feiner $\mathfrak{W}$ ad)sfompofition etwas von einem weiffen hatuitlidien Taplota, oder feinem Bergól benmifot, wel. (thes nidjt fo leid)t getinnbar, uno immer, feine Zäbigfeit beḩîlt.

$\Re_{4}$ XVII. Ueber 


\section{XVII. \\ Ueber \\ Den Grant fẩ in शieber= Ungarn}

bom

\section{Capitaine Stouze,} stósigt. Epanifden Dberauffebet ber Đergwerte.

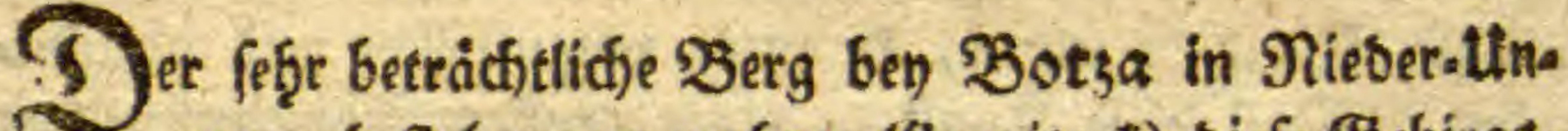
gatn, beftehet aus wab̨ren (Branit; *) biefe Bebirgss art ift mit einer großjen Menge bon (Sängen burd/f(d)nitten, weld)e man bergmànnifd belegt ḩat. Diefe groffe ఇenge

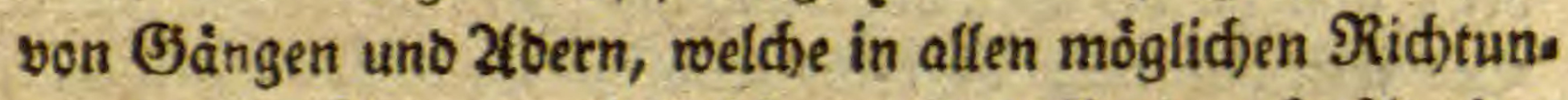
gen biefen $\mathfrak{B}$ erg ourd)frreidjen, fino für ben foríchenben Bergmann ảufferft merfwuiroig; theils weil biefe Bănge metalffüb̨rent, unb of̧ngeaditet iø̣rem verffitiebenen Gtrei.

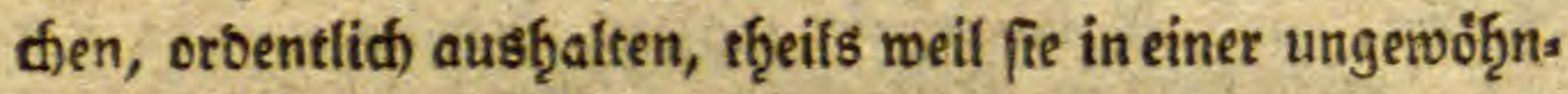
fichen Bebirgsart vorfommen; gegen welche ber angenoms

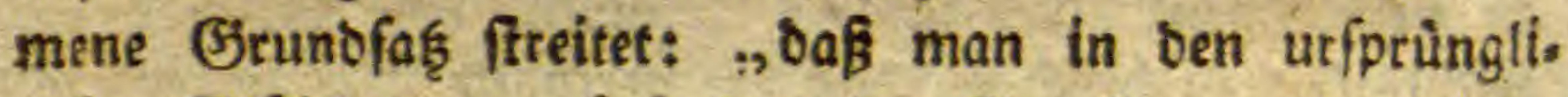
, dhen Giebirgsarten, befonbers ben Graniten uno granitars "tigen (Sefteinen, ben Dorphirarten, uno bem uranfángli. "d)en ఇalffiein feine Erzte (Minéraux) auffucten folle." Es ift befannt, baßz aud, biefe sef̧re von víelen berúţmiten शaturforfhern angenommen worben. Id habe bie Un. vidftigleit biefer Mennung in einer eigenen 166 b̧andlun be. (ftitten, weld)e iđ bereits bot einigen Jaģren burd) Şerrn

monge

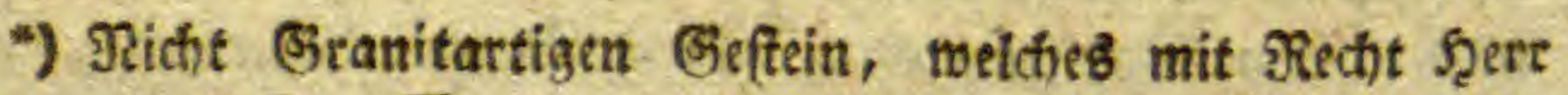
von Gaufurre unteridheibet, wic aus ber folgenden ba! fofreibung erbellen wirb. 
Monge an ben f̧errn f̧erzog von Riochefaucault ge.

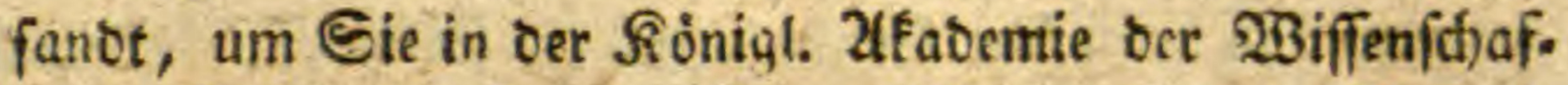
ten zu Paris vorlefen zu laffen. Meforere rebenbe Beweife fann ic) in meiner Mrineralien = Sammlung felbft aufwei. fen, welche idf) in Steiermarf uno Rärnten gefammlet, ba. von id) näc)ftens eine $\mathfrak{B}$ efdreibung ber $\mathfrak{B}$ elt vor 2lugen

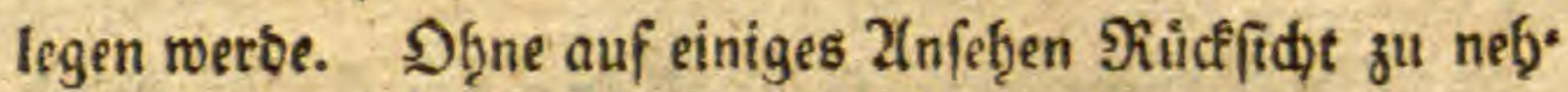
men, ift es nòtḩig, Diefes $\mathfrak{B}$ orurtb̧eil ju beftreiten, ba es in bie Bergbaufunbe von widtigem Einflus ift.

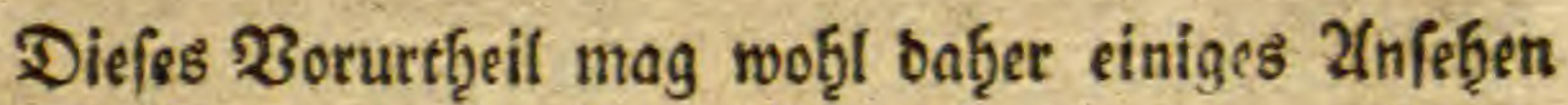
erb̧alten haben, weil man fidh nid) barein zu finben wuß̧te, zu erfláren: ob bie verergten शetafle zu ber Beit, als unfere Frofugel ifte enticheibenben $\mathfrak{B}$ eránberungen er: Iitten, fdjon exiffirt ḩaben? unb unter biefer Borausfef̧ung: wo fie eigentlid) enthalten waren, als bie ungebilbete Maffe ib̨re erffe 'Bilbung erb̨ielt? bas was burd) fpatere, weniger allgemeine Utmfeferungen gefd́abe, bon reldjen wir bie Epuren íber bie ganze Erbe zerftreut finben, getzore nidht bief̧er. Gebe fenpothefe, weldhe man immer er fintet, Diefes zu erflaren, hat feine Edfwierigfeiten, unb alles was fid) mit einigem (5rab von Sicherb̨eit bef̧aupten' lábt, ift: baß́ jene Rráfte uno Utmftànbe, melḑe ben urfprünglichen Sebirgen ib̨re $\mathfrak{b i l}$ bung uno georbnete $\mathfrak{B}$ eftanbtheile gege. ben, von jenen feb̨r unterfófieben fino (rwie es bie Folgen bes wei(en) Durds) weldse bie fpatern Gebirge, befonbers bie Flozgebirge gebilbet worben. Zflles baher, was ein ver= nimftiger $\mathfrak{B}$ ergmann baraus benufen fann, if : baß wenn er einen Erjtgang (filon de miner.) in einer (Sebirgsart bon fpaterer Billoung finbet, uno biefe Gebitgsart einer urats 
uranfänglictjen aufliegt, er fid) feine \$̧ofnung mad)t, bies fen (Ja) in benfeiben fortftreid)eno ju finoen, uno baţer einen eben fo Eoftbaren als unfrud)tbaren $\mathfrak{B a u}$ aufgiebe. J(c) barf nid)t exinnern, oaf foldbe, bie (Jewerke zu (5runo rid)tenben Unternef̧mungen, eben nid)t zu felten vorfoms men.

Die Şauptgänge, fo zu ß̧oza ben Granit burd).

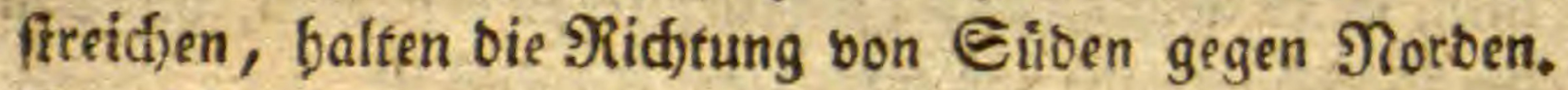
(Es giebt aber aud) einige, bie biefe rect)twinflict)t ourd). (d) neiben.

Swel) ber feauptgänge neigen fid) gegen einanber in

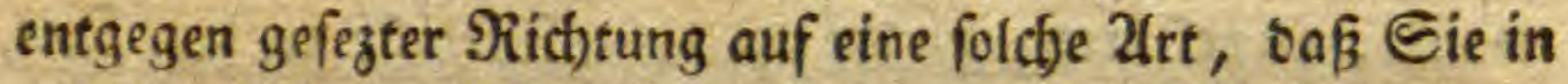
gróferer ₹eufe fich jufammenfdhaaren uno ausfdineiten. Raum wito es notḩmentig fenn, zu exinnetn, Daß man in bem (Granit weber sager nod) Bånfe antrift.

Zlte Berf(d)iebenbieiten, in weld)e fid) aflenfalls ber B̧iefige Branit einţ̧eilen ließ̄, beftę̧en aus folgenden:

1) Branit aus vielem 2uarg uno Jelofpath befteţeno, mit nur feffr menig Stlimmer. Der Felofpnth iff Der ḩert= fd)ende Theil. Diefe ift oie gewoonḩliche (Sebirgsart.

2) Eine 2 dbänberung bes Granits, befteţens aus Felofpatí, (5)limmer, uno fo menig Puary, baß man bie fleinen zerftreuten einzelnen Rörngen nur mit Můḩe entoeft. Der fatroarze (5limmer uno oer Jelofpath fino in gleidjen ₹Ģeilen bem (St)ein nach eingemifd). WBas aber befonbers an biefer Zbart, iff, oẩ ber Felofpath an vielen Gtúden im Brutche matt, unb bem Steatit ober Specffein (Steatite, Pierre ollaire, Pierre de lard) gleicht. Diefes (d)einet viels 
leid)t etwann bon einígen fef̧r zarten eingemiff)ten હૈlim. mertţeilchen ţerzufommen.

3) Eine 2tbainberung biefes Granits ift: two oer Jelofpath in (einer Miffjung fid) nod) mef̧r einem oerben Epecfftein, wie ber vorḩergeb̧enoe, náb̨ert, uno ber ḩerr. fhenoe ₹beil ift.

4) Broffe Raffen von §uar, oftmals mit talfidften (glimmerigten) uno thonigten F̧̧eilen gemifdt)t. 2(us bie= fer Bergart eigentlid), beftehen die (Erjtgänge uno abern, welche, nadjoem fie gewonnen, gepocjt unb zu Edlid)

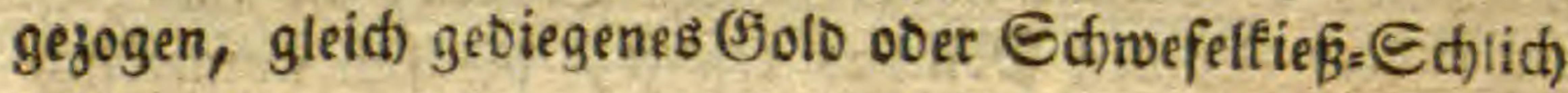
geben, aus reld)em man forohl (Bold als aud Silber etḩält.

In Nonat 2uguft bes Jaf̧res 1784 , ḩatte mais 1040. Sentner biefer Sangart gerwonnetl, aus meld)er man, nactberm es zu (d)lich) gezogen, blos burd) bas 2(malga= miren, zwen soth 7 2uentc)en gebiegenes (5olo abfonberte, uno 3 I Sentner Rieffichlich madte, roobon mieber jecer Bentner obgngefäbre zu gleiden Sţeilen jreen Quentchen Bolb und Eilber gab. 2fus biefem folgr, oafi jeber 3entner

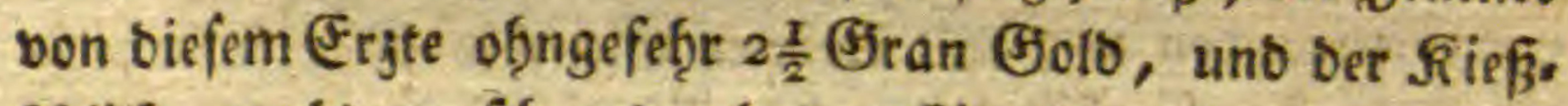
fhlich), nadjoem fition ourd) bas 2/malgamiren bas (5olb abgefonbert, noch) I Quentchen biefes edlen Metalfes uno ob̨naefeb̨r $\frac{3}{4}$ Gran aus bem Dentner beffelben berergt entḩalte. 


\section{Saddtrag.}

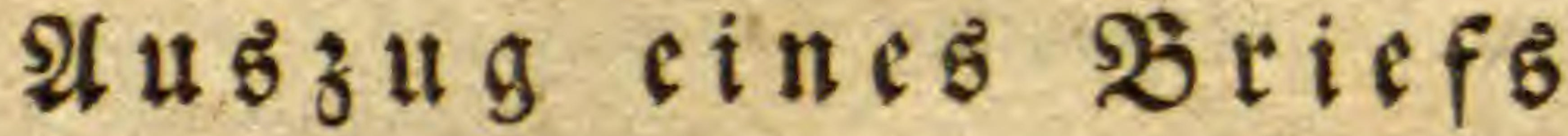

bon

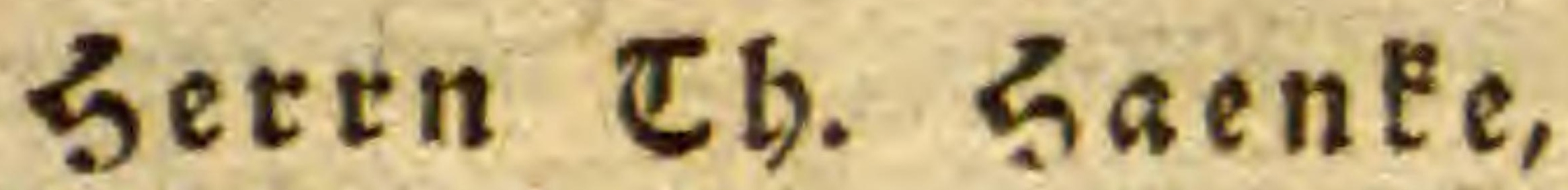

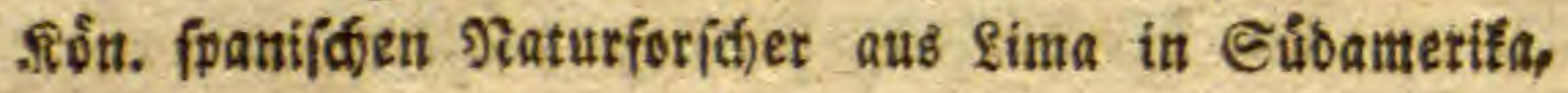

$$
\text { boin } 5 \text {. Junius } 1790 .
$$

(mitgetbeilt burd) Şertn Ş०fratb) v. Botn.)

Fich verlief im februar 1790 Suenos.2(ires, unb burd)wanberte nun mit fotneflen Echritten jene aus= gevef̨nte, Dem 24uge umúberfeţbare Ebbenen, bie man hiet unter bem Tamen Pompas fennet, Die fich unmerflićn von bem Lfer bes Mlatoftroms, bis an Den fub ber Cordilleras des Andes erbeben, uno bie nur alljuoft, burd) freifente Jorben milter Jnoianer, für Den Fieifenben fo

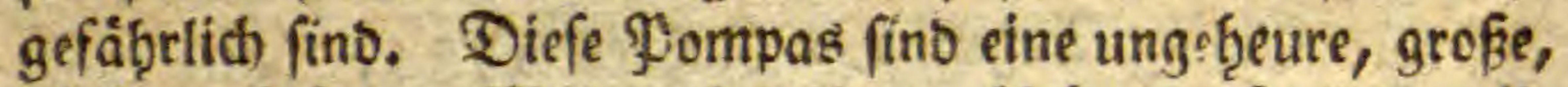
allein unbeboute $\mathfrak{B} e l t$, bie mit unjåh̨lbaren Şorben mil

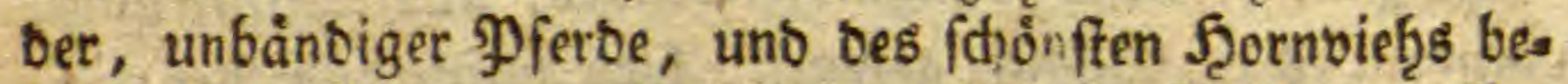

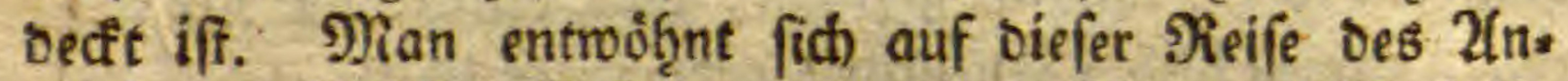
blicts menfchlicher (Seftalten, uno man if unenolich) froh, niemanten ju erblicfen, ba Sebensgefab̧r mit bem 2fr. blice verbunben ift. $2(\mathrm{~m}$ 17. N) beceutente Etabt Menooza, fthon im 2ngefictite ber biim: melanffeigenben unt mit emigem (Fis uno $S_{d}$ nee bebect. ten Rette ber Eorbilleras. Da Zlipenreifen uno bie Flore De: Alpen von jeber immer meine Sieblingsneiqungen ma. ren, fo bereitete ich) mid) mun mit aflem (Ernfte, uno mit voller (E) bie man unter ber Sonne fennt. \$enige )enfdien oủrften oem fyimmel fo nabe fommen, uno bie reine se.

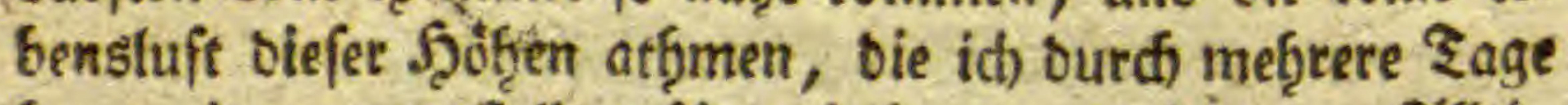
bey meinen angeftellten Unterfuchungen atb̧mete. Z(tlein balo, balo b̧ätte bey ber saft unvermeibliçer ungemäđ). Titbfeis. 


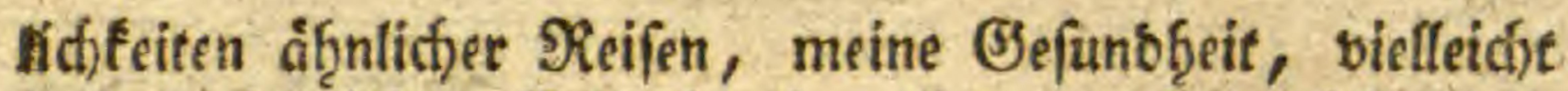
aud) mein seben Edjifforuch) gelitten, b̧àtte nicht auch bier, ben ven fchauberb̨aften abnrünoen, jener woblthá. tige Echu(ggeift ůber miđh gervacht, Der mir im Eturm, im Ediffbrud)e, uno unter J̧orben morbenter Jnsianer, ùberall fo allgegenwairtig war, allein ber Sofn meiner $\mathfrak{B} e=$ múf̧ungen ift eine reid)liche uno gefegrete Sammlung vor: Pflanzen, Die, wos if̨r aufferliches 2nfeben betrift, in einem ganj andern Planeten ergeugt ju fenn focinen, uns bie bas (J)epraige bes Eonberbaren uno ber Brófe ibjer Seburtsftátte verrathen. Şabe ich) bas (\$lúcf, einft wies Det Europa zu fehen, fo wirb Die befannte flora Der $21=$ pen, burch) mich) eine ganz anbere (Jeffalt betommen. Nachbem id) mitten zroifhen Stonee unb (Fis bie biefige

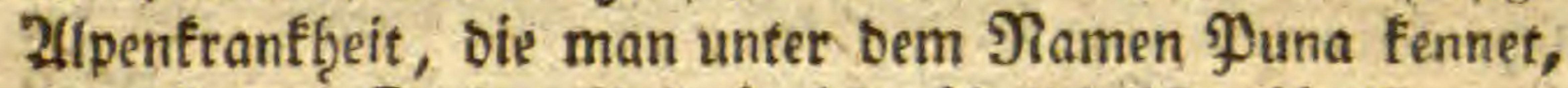

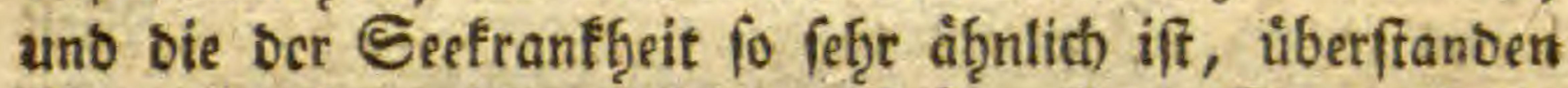
batte, erreichte id) enolid) am fiebenzef̧nten Sage wieber

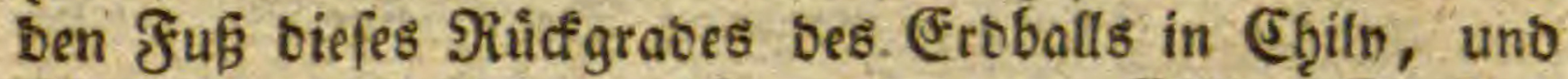

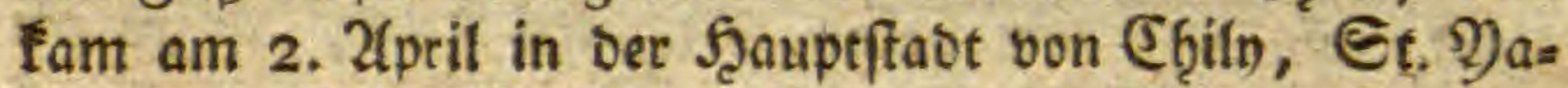
go, an. Diefer ₹ag war für mich ein ₹ag ber freube; Denn unbermutbet traf ich) Gier ben Commenbanten unferer

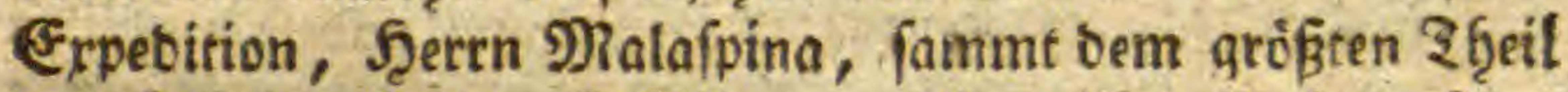
ber Dffiziere beiber Ediffe an, bie mid) alle inş̧efamt mit rùb̨renber ₹̧̧eilnébmunz aufnaf̧men, ba fie idjon von meb̨rereen Geiten bie Sufälle erfab̨ren batten, bie midh fo lange von if̧nen trennten. Nach) einem 2ufenthalte von wenigen Sagen, berlieffen wir nun alfe guten Nuths ${ } t$. 2) ago, uno begaben uns in ben J̧afen Nalparaifo, wo

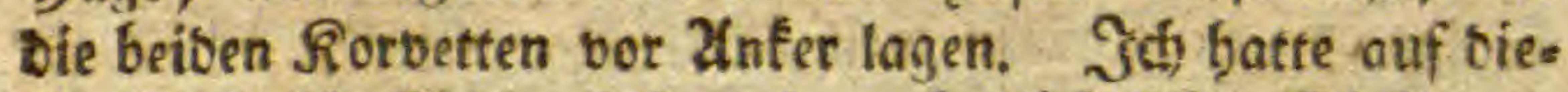

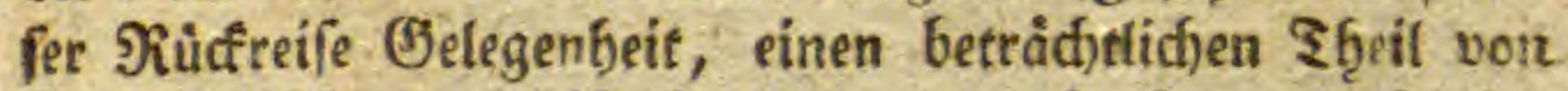
Ehily zu fefen, genoís eine ber angenebmften uno frucht: barften Эुrovinjen bes füblichen 2(merifa's; Die Echoingeif, Unffoulo ber Sitten, uno originelle (S)afffrenheit ber Ein:

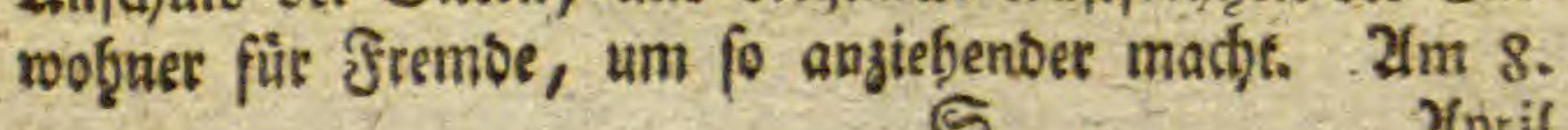

aprit 
2(pril bejog id jum erftenmal bie enge 230 hinung in bem Ectiffe Defcubierta, auf bem i(t) nun mit gơttli(t)em $\mathfrak{B}$ en)

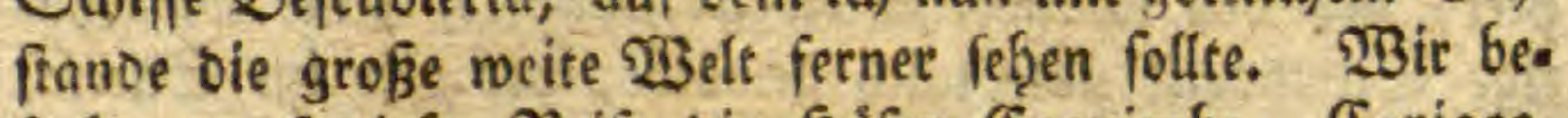

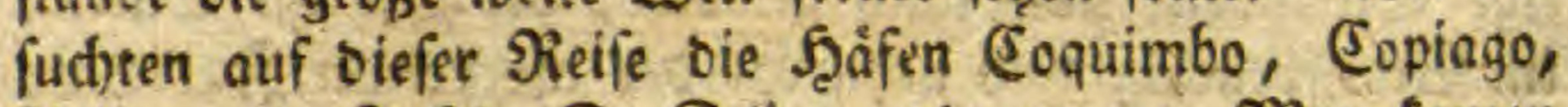
Zriḩa, Die Jnfeln Et. Felir, uno am 2r. Man famen wir in Eallao vor Anfer. Wir gebenten hier in sima einige Nionate juzubringen, um unfere gefammelten $\mathfrak{B}_{e 0}$ badtungen ju oronen. Unfer 2lufenţ̨alt ift in einem fethe reijenden Sanob̧aule jwifhen Callao uno Sima, bon wo aus wir nach) allen Eeiten unfere Etreiferenen für die Bereiderung ber פacurgef(f)idhte machen. Rurz nach unferer 2anfunft batten wir bas (Slůcf, bem prachtwollen

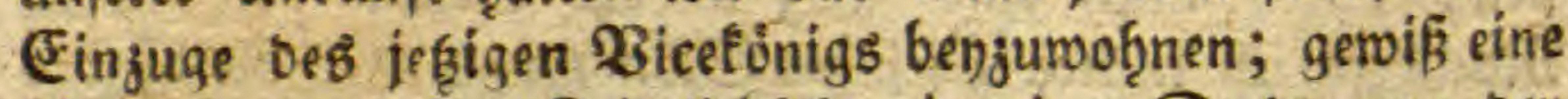
fehr felyenswuroige Jeierlidffeit, in einer Etaot, wo ber \{urus meb̨r, als in irgeno einem anbern Şgeile ber $\mathfrak{B e l t}$ zu Şaure iff. Dod)! wetche B'lủcffeligkeit ift's, unter Dem tropifd)en Silima ju wobnnen! Der hiefige $\mathfrak{B}$ inter be= ginnt nun, unb mir baben fo warme ₹age, als es bie Eommertage in Spanien fino. 2alles grunt, bluthte, uno trågt fruid)te jugleid); ber thátige Eonnenffrabl erb̧ơhet mit fiebenfacher Rraft bie Begetation, uno bie Nilbe bes Filima's entwicfelt vor ber Beit oie Fáthiafeiten bes

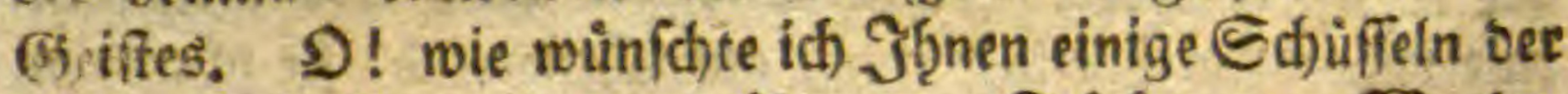
fd)madfhafteften, immerwåbrenben Früd)te Der ßBenbe: freife, von benen id) nur vorzugsweife oie Chirimoya (Anona chirinoya-L.), bas Meifterftúd ber Natur aus

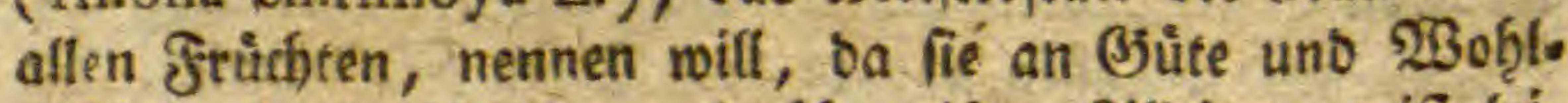
gefthmad alle tibrigen weit übertrift. Zfllein, es if leis ber! cin lecter 2 ưnfí). 


\section{Inntyaft.}

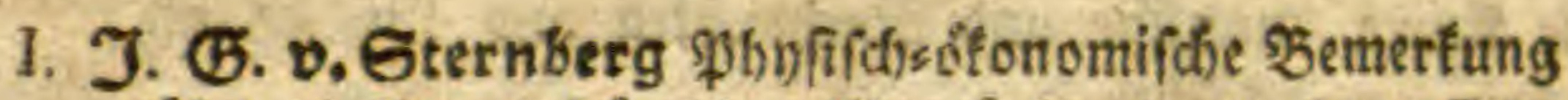

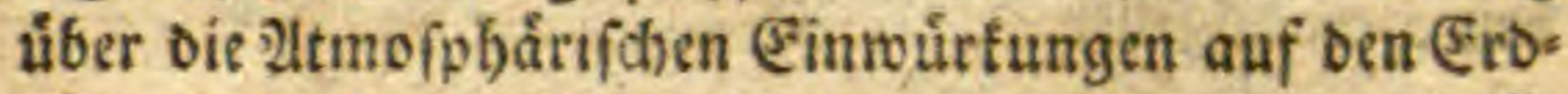
fórper, in Betrad)t ber fiultur s . Eeite I

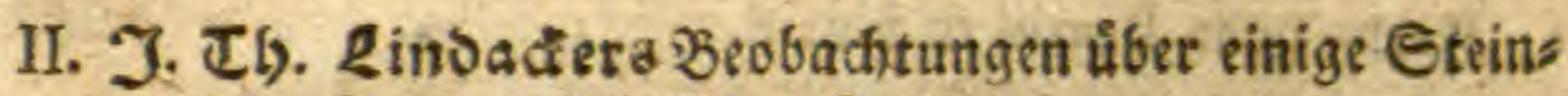
foblen-Ragen DeB \$ilfner STreifeß

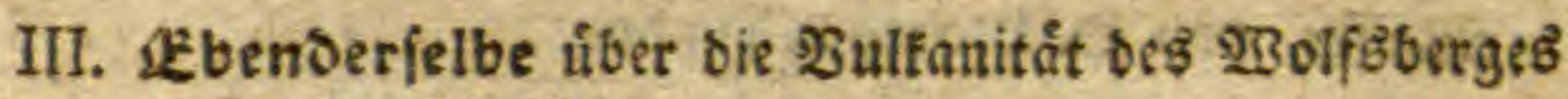
im \$ilfuer Rreif s.

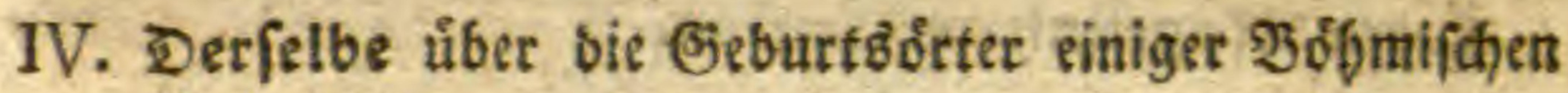

1. Raljebane 4

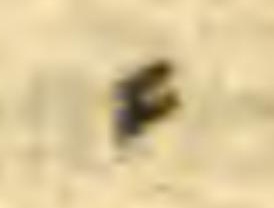

V. Deffelben befdreibung einer nod) nidht betannten Sífermuid

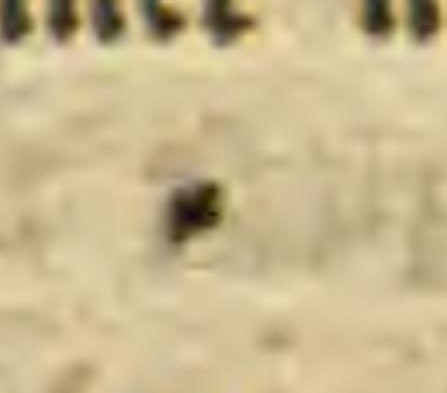

VI. Delfelbein Raturgefffid)té ber \$lautỏpfidften (En): Dechise

3

,

(I) 2

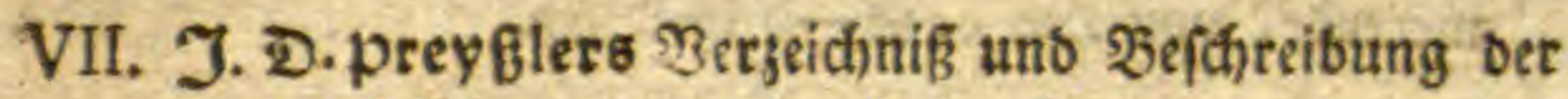
minbet befannten und in Eammlungen nicht aujsas bemabrenoen Infeften. NRit 2tbbiloungen.

Erfte Eammlung.

VIII. 3ronte Eammlung

IX. Dritte Eammlung a

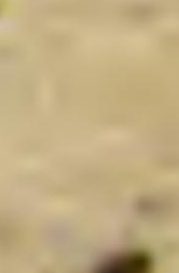

3

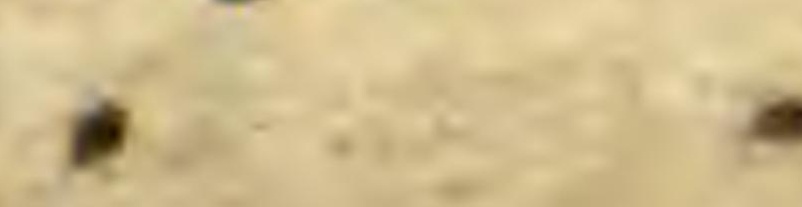

3.

-

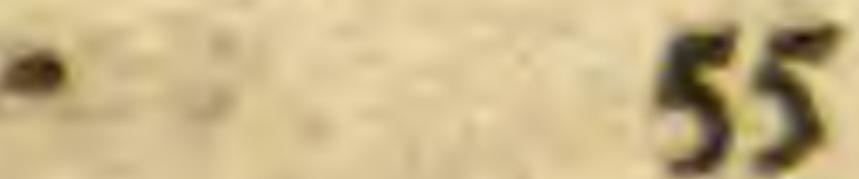

$-17 / 83$

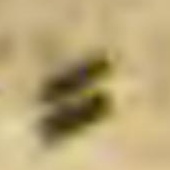

II

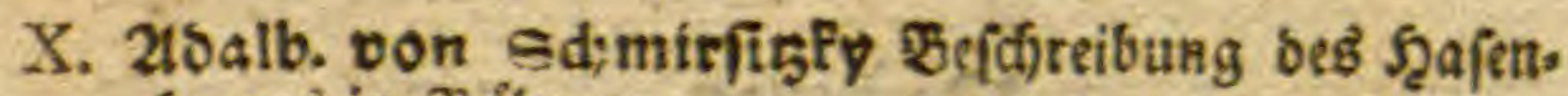
berges in 300 bmen

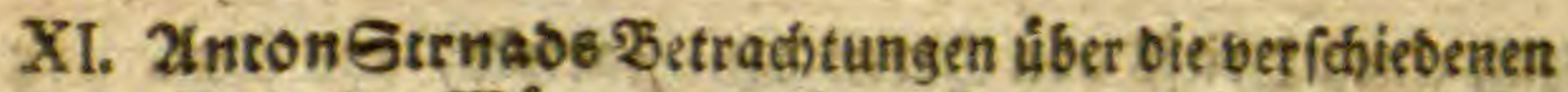

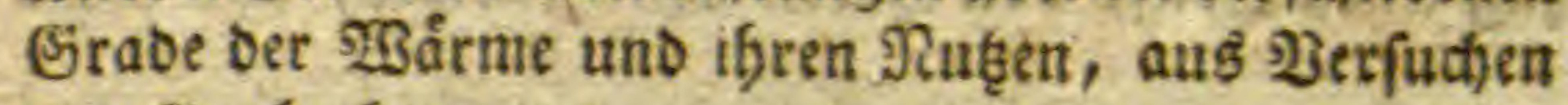
uno beobadtungen

XII. Gr. von Etertuberg über Die Itnrichtigfeit ber (Fus Diometrif(d)en 2 erfuclje

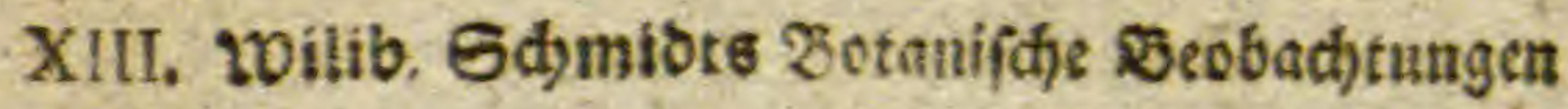




\section{Innbale.}

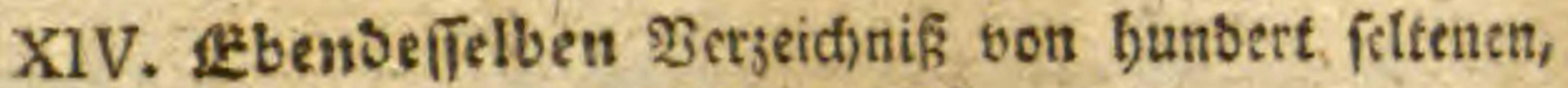
in \$obbmen wilowad) fenden Pflanjen

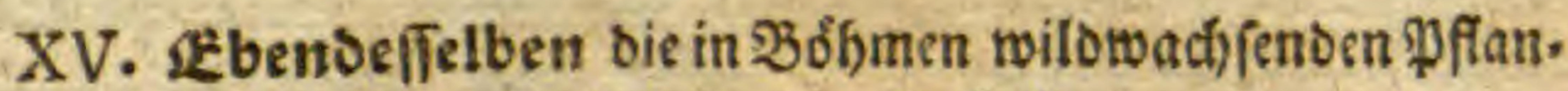
jen aแถ bem Gef́chled)t Der Drdfis.

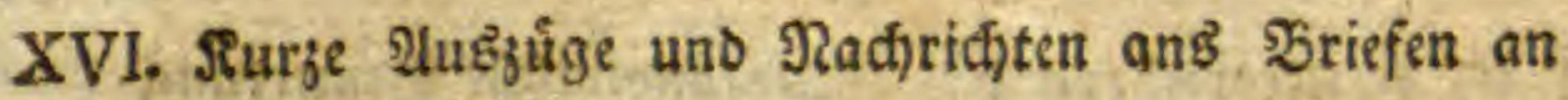
Den Serausgeber

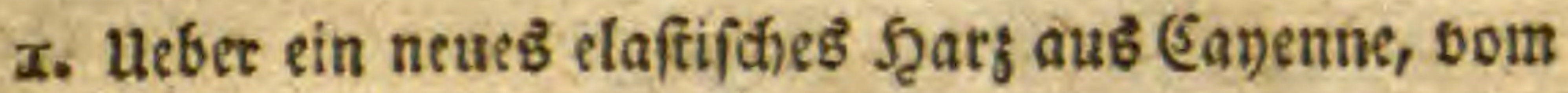

Şerrn De la Borde in झaris.

e 2. Ueber Die 2luflófung DeB Eifens in luftleerem

ISaffer, von D. mosis in Eonbon.

3. Nad)ridht von Etentittrnffallen auछ (E)ina, von

Şerrn viagellan aus bonbon.

4. Von einer neuen Eternforalle aus ber Dffice, von f̧errn Gdul; in Şamburg.

TR 5. Leber bie Eleftrijitåt verfchiebener Echơrle, von ZEendempelben

6. Neue beftåtigung ber Unichmel;barteit ber Glim: mererbe, bon f̧n. $\mathfrak{b}, \mathrm{S} \rightarrow$ in $2 B i e n$.

7. Nachridht von einem neten Nittel, bie anatomi,

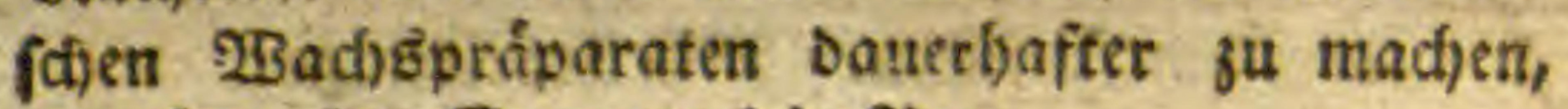
bon Sृrn. D. Guattani in Fiom.

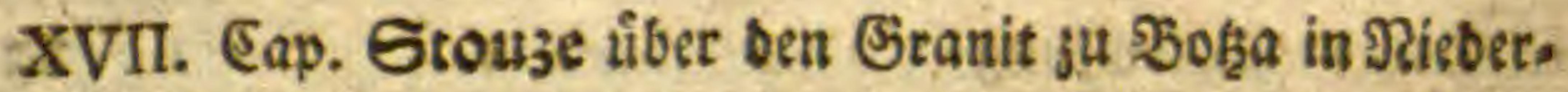

ungarn.

\section{Eif . Tracbteng.}

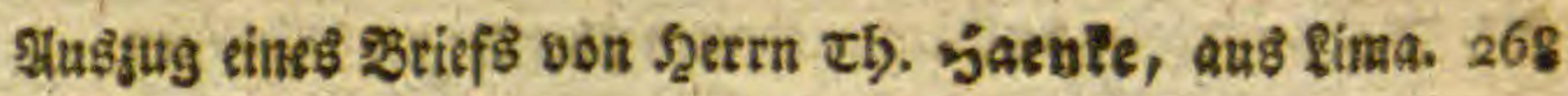




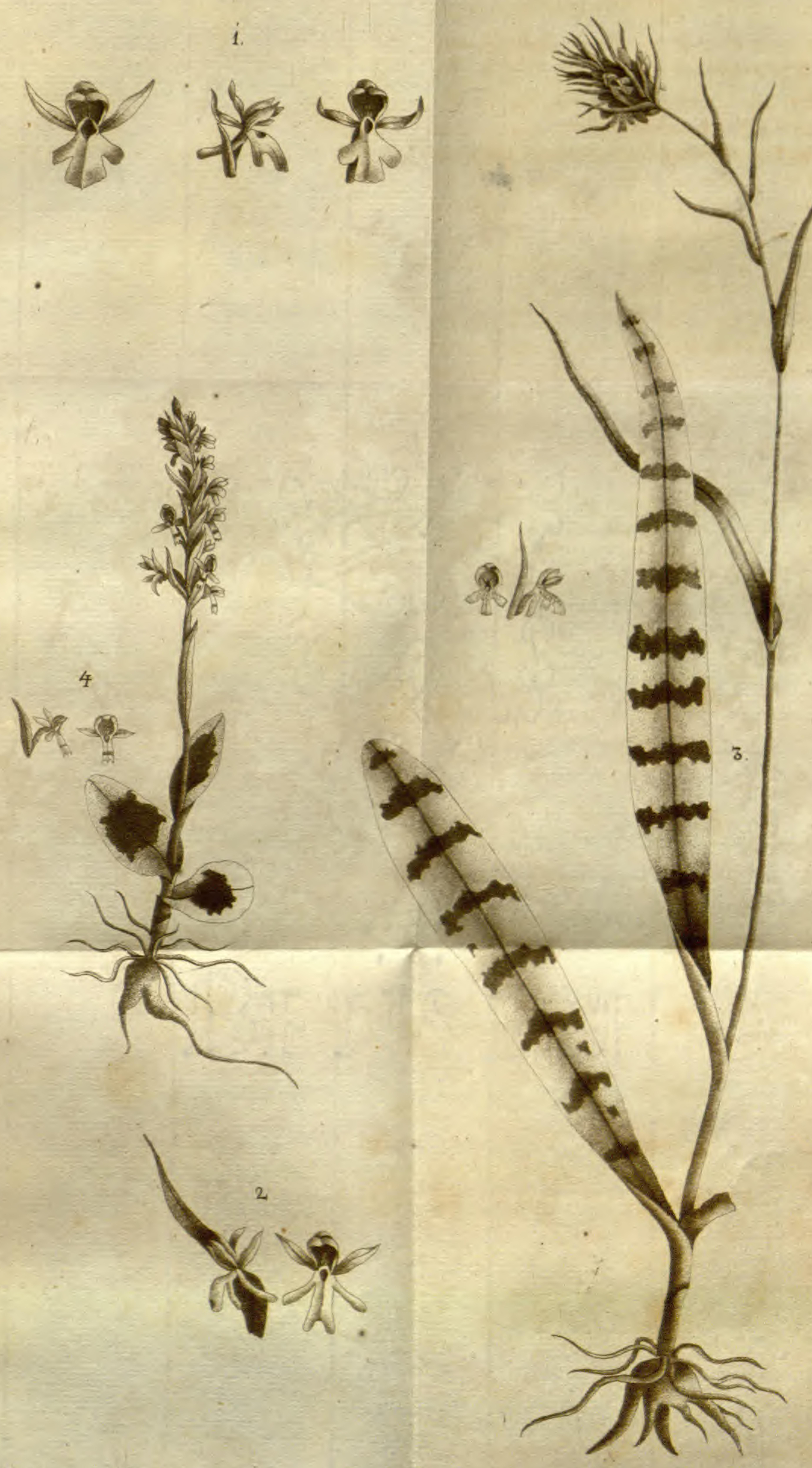



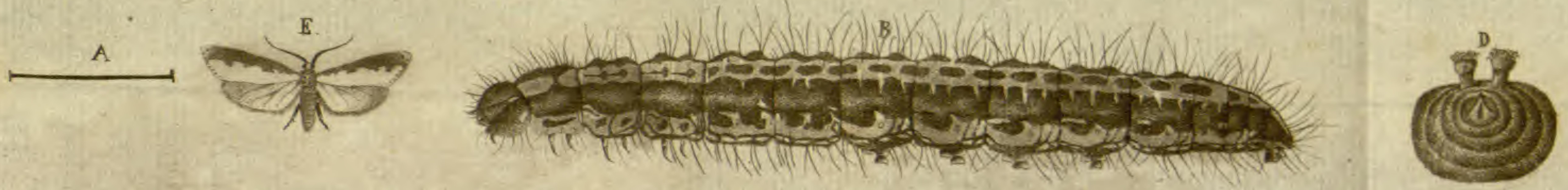

i
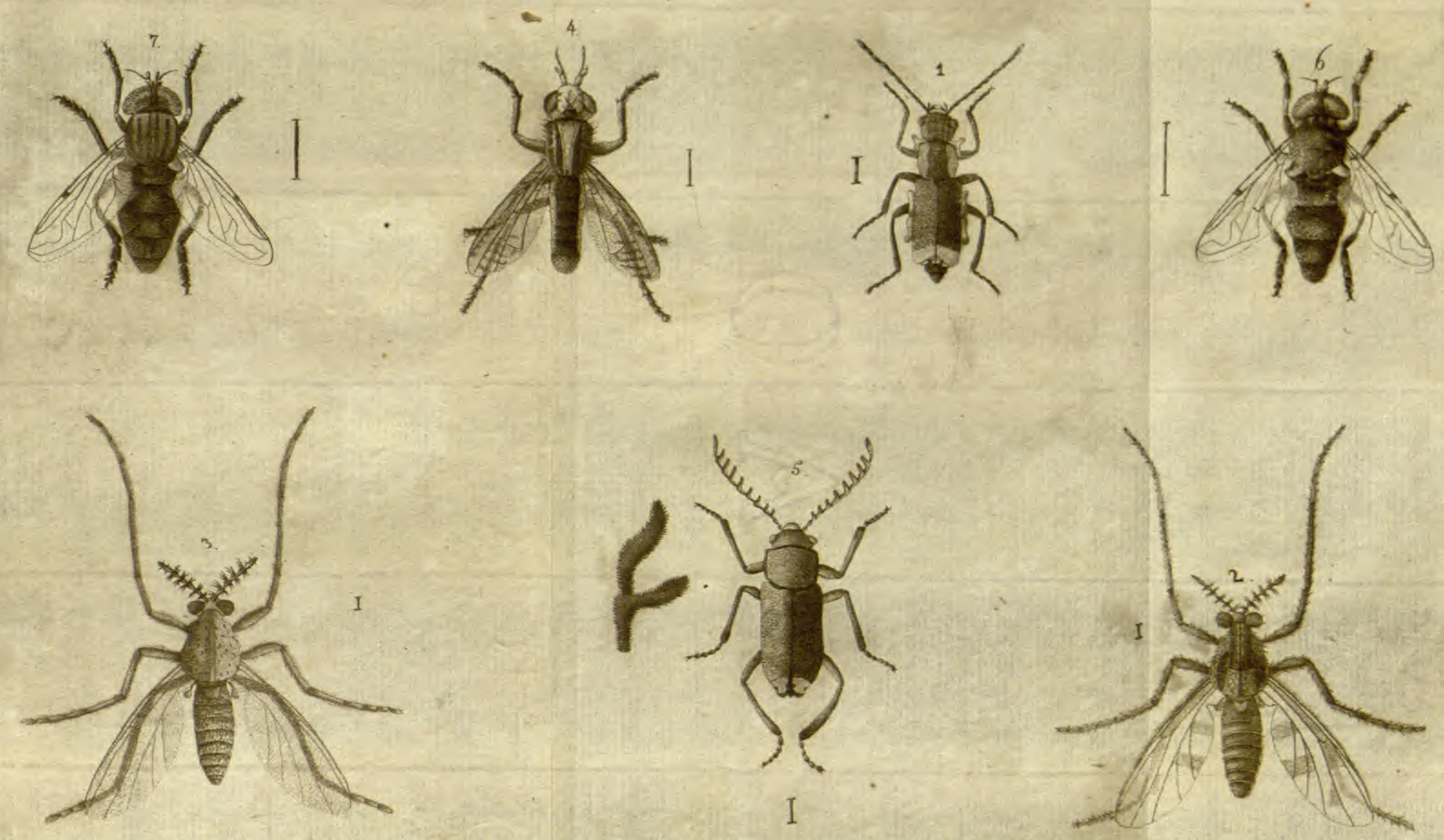


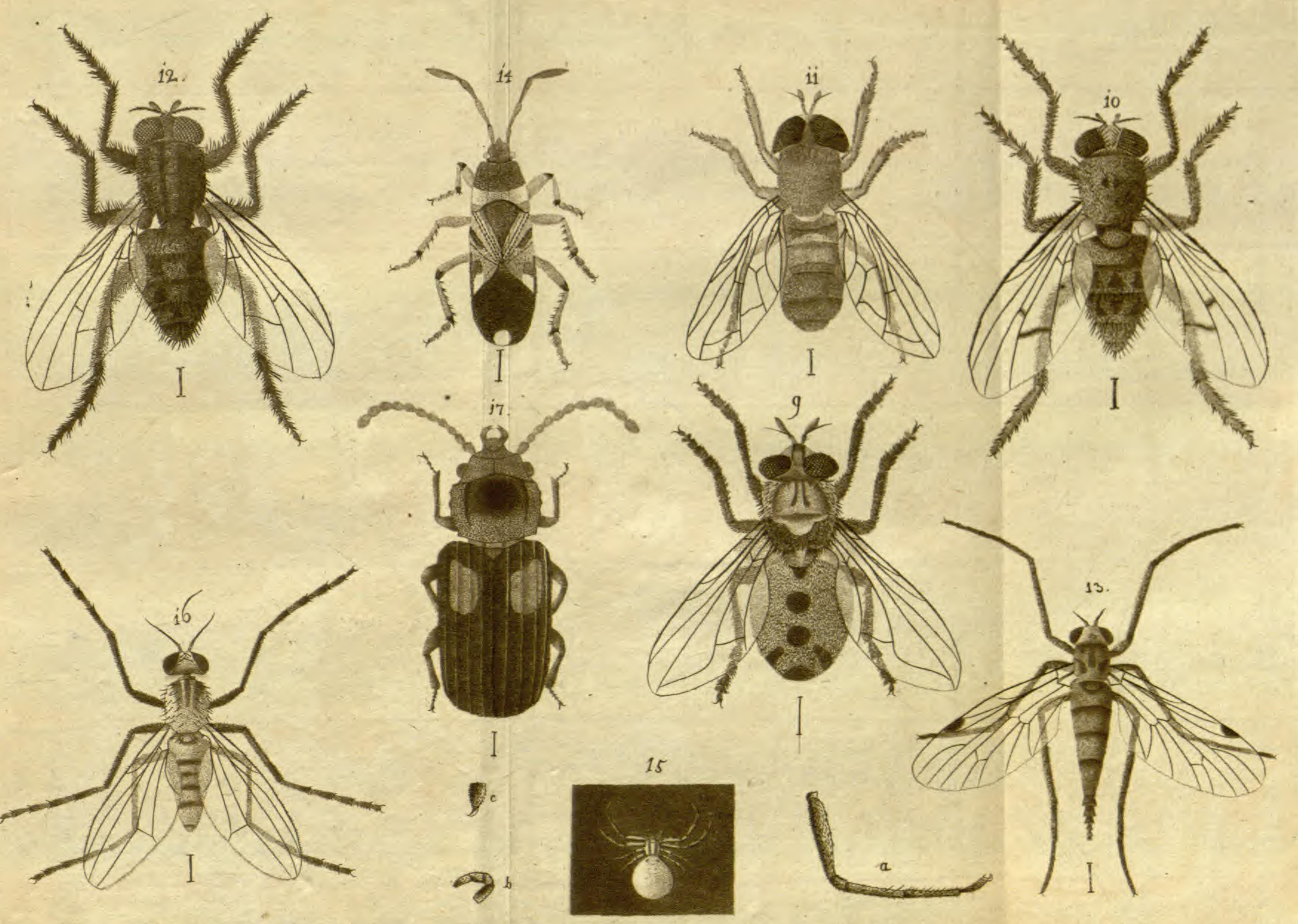




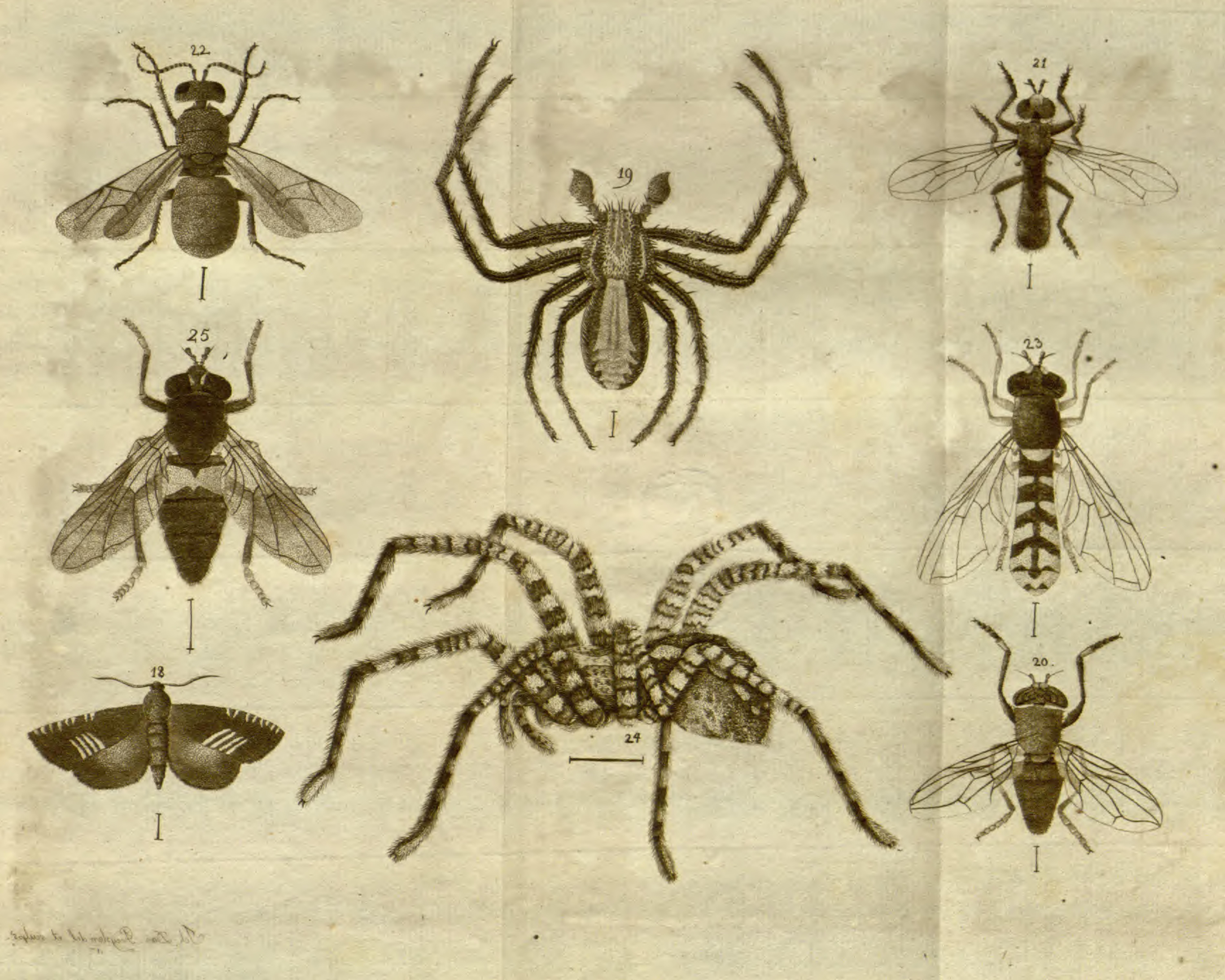

